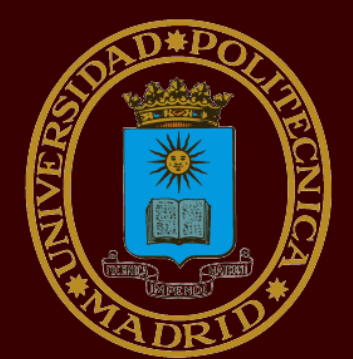

UNIVERSIDAD POLITÉCNICA DE MADRID

ESCUELA TÉCNICA SUPERIOR DE EDIFICACIÓN

\title{
DESARROLLO DE CONGLOMERADOS CON LA INCORPORACIÓN DE CENIZAS VOLANTES PROCEDENTES DE LA INCINERACIÓN DE RESIDUOS SÓLIDOS URBANOS
}

ESCUELA TÉCNICA SUPERIOR DE EDIFICACIÓN DEPARTAMENTO DE TECNOLOGÍA DE LA EDIFICACIÓN

TESIS DOCTORAL

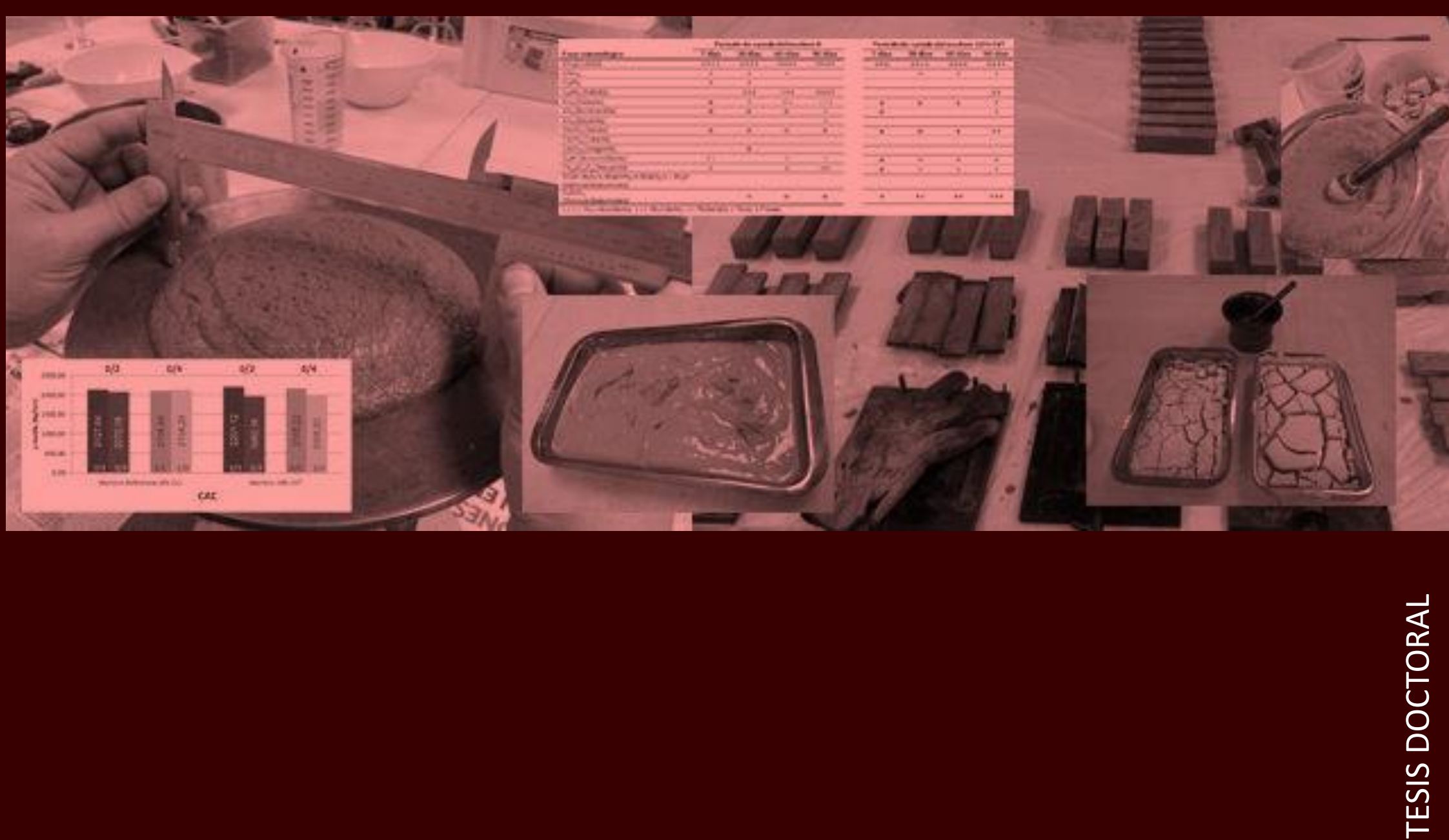

ÓSCAR LÓPEZ ZALDÍVAR ARQUITECTO

2015 

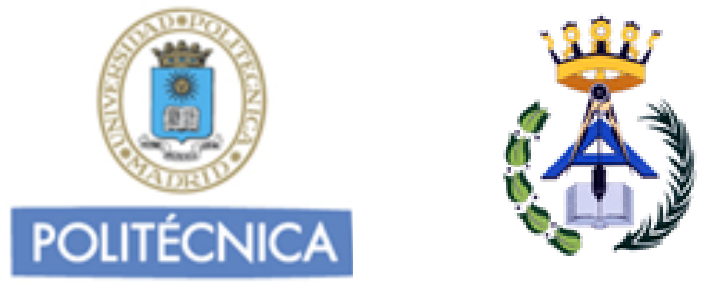

DEPARTAMENTO DE TECNOLOGÍA DE LA EDIFICACIÓN Escuela Técnica Superior de Edificación

\title{
DESARROLLO DE CONGLOMERADOS CON LA INCORPORACIÓN DE CENIZAS VOLANTES PROCEDENTES DE LA INCINERACIÓN DE RESIDUOS SÓLIDOS URBANOS
}

\section{TESIS DOCTORAL}

\author{
Autor \\ Óscar López Zaldívar \\ Arquitecto
}

\author{
Directores \\ D. Francisco Fernández Martínez
}

Doctor en Ciencias Químicas. Catedrático de Universidad.

D. Pablo Luis Mayor Lobo

Doctor Arquitecto. Profesor Titular de Universidad. 



\section{ÍNDICE}

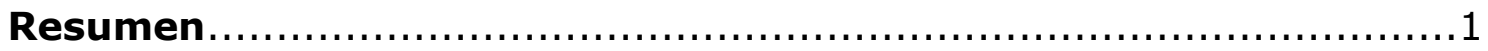

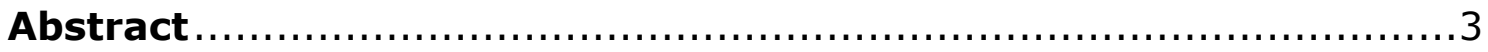

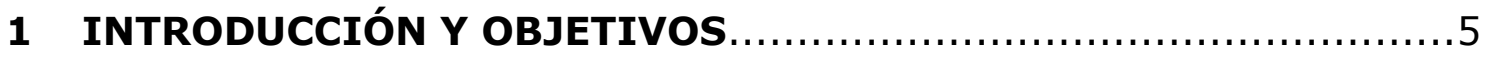

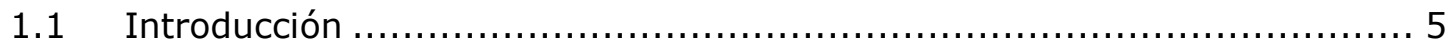

1.2 Incineración y transformación del paisaje urbano ..........................10

1.3 Áreas de utilización de las cenizas volantes procedentes de la incineración

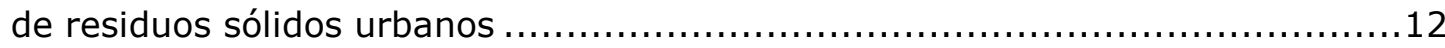

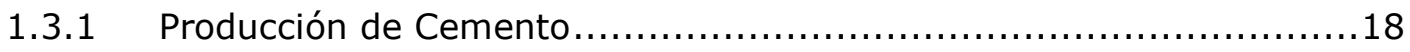

1.3.1.1 Clinker de cemento tradicional ..................................... 19

1.3.1.2 Clinker de cementos sulfoaluminosos ...............................21

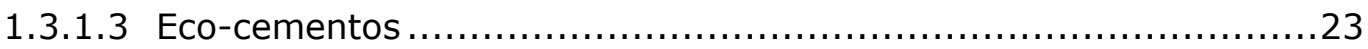

1.3.2 Hormigones y Morteros................................................. 25

1.3.2.1 CV de RSU como sustituto del cemento en hormigones y morteros. 26

1.3.2.2 CV de RSU como sustituto del árido en hormigones y morteros.....32

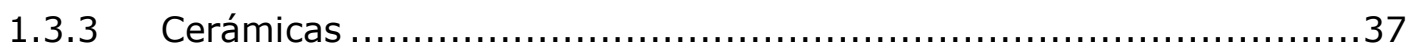

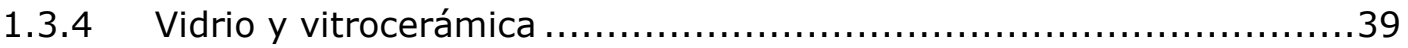

1.3.5 Modificación del terreno: Geotecnia..................................43

1.3.5.1 Firmes de rodadura. ................................................ 43

1.3.5.2 Relleno de terrenos y taludes..................................... 46

1.3.6 Tratamiento y recuperación de terrenos. ...........................47

1.3.7 Utilización de cenizas volantes en otros aspectos.....................51

1.3.7.1 Agentes estabilizadores en el tratamiento de desechos. ..............51

1.3.7.2 Agentes estabilizadores en el tratamiento y preparación de lodos. .52

1.3.7.3 Materiales adsorbentes. ........................................... 53 
1.3.7.4 Producción de Zeolita ...............................................55

1.4 Solidificación frente a Inertización. ..........................................58

1.4.1 Sistemas basados en cementos Portland ordinarios (OPC) .............60

1.4.2 Sistemas basados en cementos de aluminato de calcio (CAC) .........61

1.4.3 Sistemas basados en cementos de sulfoaluminato de calcio (CSA)...63

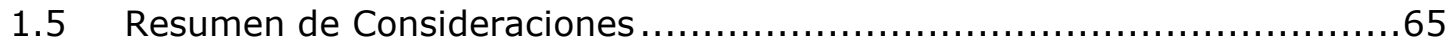

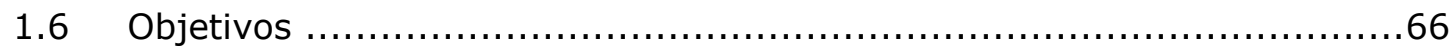

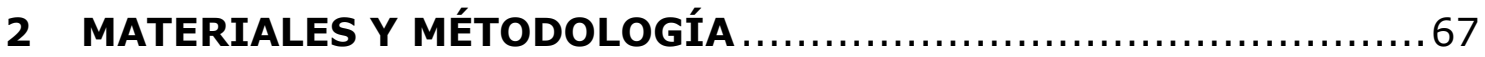

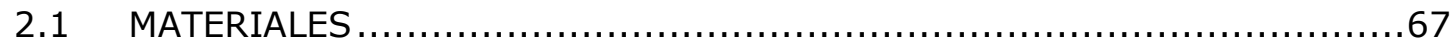

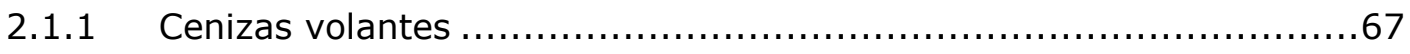

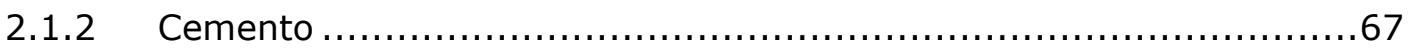

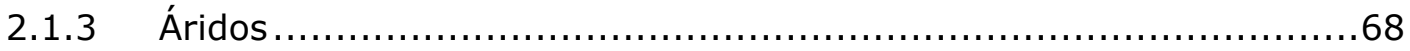

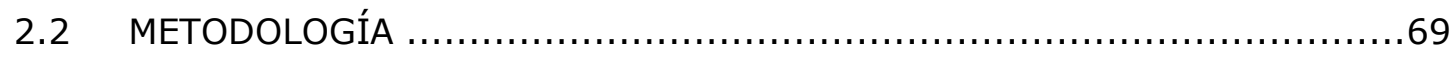

2.2.1 Caracterización de las cenizas volantes de RSU .......................72

2.2.1.1 Espectrofotometría de Emisión Óptica con fuente de Plasma de

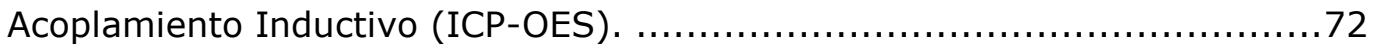

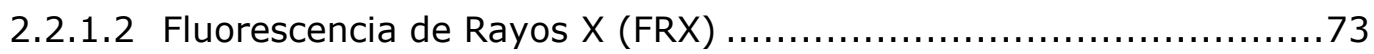

2.2.1.3 Difracción por Rayos X (DRX) ….................................73

2.2.1.4 Calorimetría Diferencial de Barrido y Termo-Gravimetría (DSC-TGA)

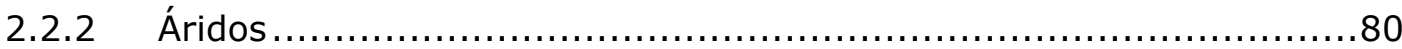

2.2.2.1 Determinación de la humedad del árido ............................... 80

2.2.2.2 Determinación de la distribución granulométrica del árido empleado mediante el método del tamizado............................................. 81

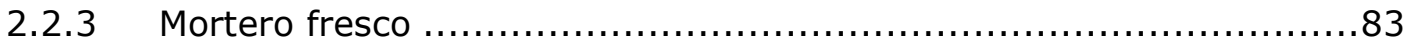

2.2.3.1 Determinación de la consistencia del mortero fresco por la mesa de sacudidas (UNE EN 1015-3:2000)

2.2.3.2 Determinación del periodo de trabajabilidad de los morteros ensayados (UNE EN 1015-9:1999 y UNE EN 1015-9:2000-A1) 
2.2.4.1 Determinación de la estabilidad dimensional de los morteros para albañilería endurecidos.

2.2.4.2 Determinación de la densidad aparente en seco del mortero endurecido (UNE EN 1015-10)

2.2.4.3 Determinación de la resistencia a la carbonatación (UNE EN 13295:2004)

2.2.4.4 Cálculo de la porosidad y de la distribución del tamaño de poros. Porosimetría por inyección de mercurio 100

2.2.4.5 Determinación de la resistencia a flexión y a compresión del mortero endurecido (UNE-EN 1015-11) 102

2.2.4.6 Determinación del lixiviado de iones de $\mathrm{Zn}, \mathrm{Cd}, \mathrm{Pb}$ y $\mathrm{Cu}$ mediante voltamperometría de redisolución anódica. 105

3 RESULTADOS Y DISCUSIÓN 107

3.1 Análisis y estudio de las cenizas volantes de RSU 107

3.1.1 Composición química de las cenizas volantes de RSU . 107

3.1.2 Proceso de inertización de las cenizas volantes de RSU 110

3.1.2.1 Búsqueda de los posibles reactivos a utilizar en el proceso de inertización. 110

3.1.2.2 Determinación de la cantidad de $\mathrm{NaHCO}_{3}$ utilizada en el proceso de inertización 116

3.1.2.3 Proceso de inertización y valorización de las cenizas volantes de RSU

3.1.2.4 Difracción de Rayos X. Análisis de CV y CVT 120

3.1.2.5 Calorimetría Diferencial de Barrido y Termo-Gravimetría (DSC-TGA). Análisis de CV y CVT 123

3.2 Análisis y estudio de los áridos ......................................... 126

3.2.1 Determinación de la humedad del árido 127

3.2.2 Determinación de la distribución granulométrica del árido empleado mediante el método del tamizado. 
3.3 Análisis y estudio de los morteros 130

3.3.1 Determinación de la consistencia del mortero fresco por la mesa de sacudidas (UNE EN 1015-3:2000)

3.3.1.1 Relación agua/cemento según la consistencia del mortero fresco para morteros CEM-I (UNE EN 1015-3:2000) 130

3.3.1.2 Determinación de la relación agua/cemento según la consistencia del mortero fresco para morteros CEM-II A/P (UNE EN 1015-3:2000) ......131

3.3.1.3 Determinación de la relación agua/cemento según la consistencia del mortero fresco para morteros CAC (UNE EN 1015-3:2000). 133

3.3.1.4 Determinación de la relación agua/cemento según la consistencia del mortero fresco para morteros CSA (UNE EN 1015-3:2000) 134

3.3.2 Determinación del periodo de trabajabilidad de los morteros ensayados 137

3.3.3 Estabilidad dimensional 139

3.3.3.1 Estabilidad dimensional de los morteros elaborados con CEM-I (UNE EN 83831:2010 EX) 140

3.3.3.1.1 Variación de la longitud (morteros CEM-I) ..................... 140

3.3.3.1.2 Variación de la masa (morteros CEM-I) 143

3.3.3.2 Estabilidad dimensional de los morteros elaborados con CEM-II A/P (UNE EN 83831:2010 EX) .................................................... 146

3.3.3.2.1 Variación de la longitud (morteros CEM-II A/P) .................. 146

3.3.3.2.2 Variación de la masa (morteros CEM-II A/P) ..................... 150

3.3.3.3 Estabilidad dimensional de los morteros elaborados con CAC (UNE

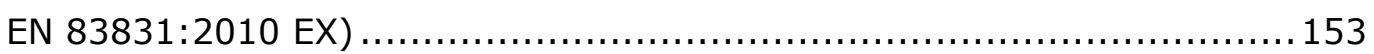

3.3.3.3.1 Variación de la longitud (morteros CAC) ....................... 153

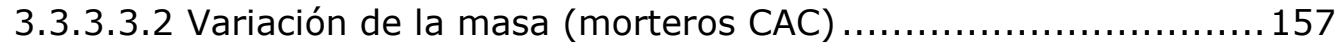

3.3.3.4 Estabilidad dimensional de los morteros elaborados con CSA (UNE

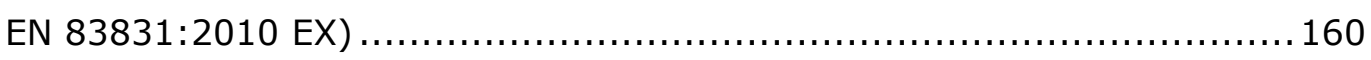

3.3.3.4.1 Variación de la longitud (morteros CSA) ........................ 160

3.3.3.4.2 Variación de la masa (morteros CSA) ............................. 163 
3.3.4 Densidad aparente en seco del mortero endurecido (UNE EN 1015-10)

3.3.4.1 Densidad aparente en seco de los morteros de CEM-I .............. 170

3.3.4.2 Densidad aparente en seco de los morteros de CEM-II A/P ........173

3.3.4.3 Densidad aparente en seco de los morteros de CAC ..................176

3.3.4.4 Densidad aparente en seco de los morteros de CSA ................ 180

3.3.5 Determinación de la resistencia a la carbonatación (EN 13295:2004)

3.3.5.1 Profundidad de carbonatación de morteros CEM-I $\ldots \ldots \ldots \ldots \ldots \ldots \ldots 186$

3.3.5.2 Profundidad de carbonatación de morteros CEM-II A/P ............ 187

3.3.5.3 Profundidad de carbonatación de los morteros con CAC ............187

3.3.5.4 Profundidad de carbonatación de los morteros con CSA ............. 189

3.3.6 Porosidad y distribución del tamaño de poros en morteros CAC...... 198

3.3.7 Determinación de la resistencia a flexión y a compresión del mortero endurecido (UNE-EN 1015-11) ................................................ 204

3.3.7.1 Resistencias mecánicas de los morteros de cemento CEM-I. ......205

3.3.7.1.1 Tensión de rotura a flexión: .........................................205

3.3.7.1.2 Tensión de rotura a compresión .................................206

3.3.7.2 Resistencias mecánicas de los morteros de cemento CEM-II A/P . 208

3.3.7.2.1 Tensión de rotura a flexión ................................... 208

3.3.7.2.2 Tensión de rotura a compresión .....................................209

3.3.7.3 Resistencias mecánicas de los morteros de cemento CAC ..........211

3.3.7.3.1 Tensión de rotura a flexión ................................. 211

3.3.7.3.2 Tensión de rotura a compresión ...............................212

3.3.7.4 Resistencias mecánicas de los morteros de cemento CSA ...........215

3.3.7.4.1 Tensión de rotura a flexión ................................... 215

3.3.7.4.2 Tensión de rotura a compresión ............................. 215

3.3.8 Calorimetría Diferencial de Barrido y Termo-Gravimetría (DSC-TGA).

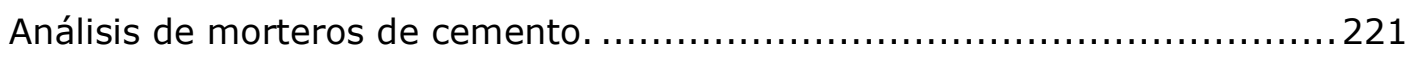




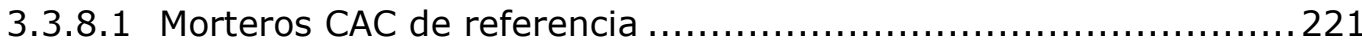

3.3.8.2 Morteros CAC con cenizas volantes...................................223

3.3.9 Difracción de Rayos X. Análisis de morteros de cemento CAC........227

3.3.10 Ensayos de lixiviado de morteros CAC ..............................236

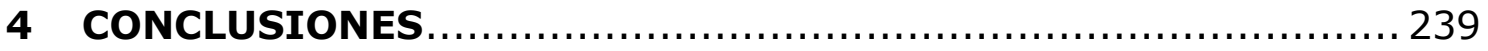

5 FUTURAS LÍNEAS DE INVESTIGACIÓN .............................. 243

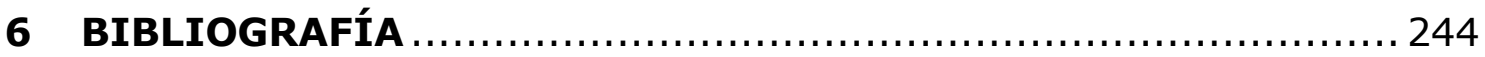




\section{ÍNDICE DE TABLAS}

Tabla 1. Análisis temporal de contenidos (Enero/Mayo) de las cenizas volantes de residuos sólidos urbanos recibidas en el laboratorio. Las cenizas volantes de RSU proceden de la planta de tratamiento integral de residuos de Mataró, Barcelona (España)

Tabla 2. Aplicaciones para las cenizas volantes de RSU (Lam Ch.H.K., 2010) 16

Tabla 3. Potenciales usos de las cenizas volantes de RSU (Ferreira et al., 2003)

Tabla 4. Compuestos principales de las cenizas volantes de RSU originales y lavadas (\%) (Gao, X. et al., 2008) 28

Tabla 5. Niveles deseables para los principales micronutrientes en el tejido de las plantas (Ferreira et al., 2003) 50

Tabla 6. Propiedades adsorbentes de determinados materiales (Ferreira et al., 2003). 56

Tabla 7. Análisis químico por Fluorescencia de Rayos $X$ de los cementos utilizados en la elaboración de los morteros. .68

Tabla 8. Valor del escurrimiento del mortero según UNE EN 1015-2:1998. .86

Tabla 9. Valores medios de CO, presión atmosférica y humedad relativa para los meses de abril, mayo y junio de 2012. (Fuentes: (CO) Área de Gobierno de Medio Ambiente y Movilidad. Dirección General de Sostenibilidad y Planificación de la Movilidad. Servicio de Protección de la Atmósfera. (P. Atm. y HR) AEMET). 96 
Tabla 10. Resumen de Valores de Temperaturas máximas y mínimas a lo largo del periodo de tiempo comprendido entre el $26 \mathrm{de}$ abril y el 25 de junio de 2012. (Fuente: AEMET)

Tabla 11. Análisis químico por ICP-OES de las cenizas de RSU originales (CV) y de las cenizas tratadas mediante el proceso de inertización (CVT) 108

Tabla 12. Análisis químico por Fluorescencia de Rayos $X$ de las cenizas de RSU originales (CV) y de las cenizas tratadas mediante el proceso de

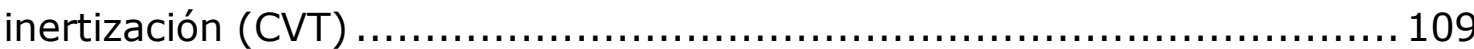

Tabla 13. Productos de solubilidad bibliográficos para iones de metales pesados, $P_{s}$ 110

Tabla 14. Solubilidad calculada de los precipitados, $\mathrm{S}$ ( $\mathrm{mol} / \mathrm{L}$ ) 112

Tabla 15. Solubilidad de los cationes de metales pesados en $\mathrm{mg} / \mathrm{L}$. $\mathrm{pH}=7$ y $25^{\circ} \mathrm{C}$. 113

Tabla 16. Resultados del análisis ICP-OES y Cromatografía iónica del agua de lavado del tratamiento con $\mathrm{NaHCO}_{3}$ de las cenizas volantes de RSU ... 115

Tabla 17. Principales componentes de las CV de RSU detectadas por DRX 122

Tabla 18. Peso húmedo y desecado, y contenido en humedad de los áridos utilizados en la elaboración de los morteros.

Tabla 19. Determinación de la granulometría del árido $0 / 2$ utilizado en los morteros. Método del tamizado (UNE EN 993-1) 128

Tabla 20. Determinación de la granulometría del árido 0/4 utilizado en los morteros. Método del tamizado (UNE EN 993-1). 129

Tabla 21. Valores de escurrimiento de los morteros CEM-I ensayados según UNE EN 1015:3-2000. (Rango del diámetro de la galleta de mortero en la mesa de sacudidas $=175 \pm 10 \mathrm{~mm}$ ) 130 
Tabla 22. Valores de escurrimiento de los morteros CEM-II A/P ensayados según UNE EN 1015:3-2000. (Rango del diámetro de la galleta de mortero en la mesa de sacudidas $=175 \pm 10 \mathrm{~mm}$ )

Tabla 23. Valores de escurrimiento de los morteros CAC ensayados según UNE EN 1015:3-2000. (Rango del diámetro de la galleta de mortero en la mesa de sacudidas $=175 \pm 10 \mathrm{~mm}$ )

Tabla 24. Valores de escurrimiento de los morteros CSA ensayados según UNE EN 1015:3-2000. (Rango del diámetro de la galleta de mortero en la mesa de sacudidas $=175 \pm 10 \mathrm{~mm}$ )

Tabla 25. Porcentajes de aumento de agua en la elaboración de los morteros con la incorporación de CVT con respecto a los morteros de referencia.

Tabla 26. Periodo de trabajabilidad (en minutos) de los morteros ensayados.

Tabla 27. Estabilidad dimensional de las probetas de mortero de CEM-I con árido 0/2 (Longitud inicial, variación de longitud a 7, 14 y 28 días y variación de la longitud específica) (R) mortero de referencia. (CVT) mortero con la incorporación de cenizas volantes inertizadas, en una proporción igual a un $10 \%$ en peso del árido utilizado. ... 141

Tabla 28. Estabilidad dimensional de las probetas de mortero de CEM-I con árido 0/4 (Longitud inicial, variación de longitud a 7, 14 y 28 días y variación de la longitud específica). (R) mortero de referencia. (CVT) mortero con la incorporación de cenizas volantes inertizadas, en una proporción igual a un $10 \%$ en peso del árido utilizado.

Tabla 29. Estabilidad dimensional de las probetas de mortero de CEM-I con árido 0/2 (Masa inicial, variación de masa a 7, 14 y 28 días y variación de la masa específica). (R) mortero de referencia. (CVT) mortero con la incorporación de cenizas volantes inertizadas, en una proporción igual a un $10 \%$ en peso del árido utilizado. 
Tabla 30. Estabilidad dimensional de las probetas de mortero de CEM-I con árido 0/4 (Masa inicial, variación de masa a 7, 14 y 28 días y variación de la masa específica). (R) mortero de referencia. (CVT) mortero con la incorporación de cenizas volantes inertizadas, en una proporción igual a un $10 \%$ en peso del árido utilizado.

Tabla 31. Estabilidad dimensional de las probetas de mortero de CEM-II A/P con árido 0/2 (Longitud inicial, variación de longitud a 7, 14 y 28 días y variación de la longitud específica). (R) mortero de referencia. (CVT) mortero con la incorporación de cenizas volantes inertizadas en una proporción de un $10 \%$ en peso de los áridos. 148

Tabla 32. Estabilidad dimensional de las probetas de mortero de CEM-II A/P con árido 0/4 (Longitud inicial, variación de longitud a 7, 14 y 28 días y variación de la longitud específica). (R) mortero de referencia. (CVT) mortero con la incorporación de cenizas volantes inertizadas en una proporción de un $10 \%$ en peso de los áridos.

Tabla 33. Estabilidad dimensional de las probetas de mortero de CEM-II $\mathrm{A} / \mathrm{P}$ con árido $0 / 2$ (Masa inicial, variación de masa a 7, 14 y 28 días y variación de la masa específica). (R) mortero de referencia. (CVT) mortero con la incorporación de cenizas volantes inertizadas en una proporción de un $10 \%$ en peso de los áridos. 151

Tabla 34. Estabilidad dimensional de las probetas de mortero de CEM-II A/P con árido 0/4 (Masa inicial, variación de masa a 7, 14 y 28 días y variación de la masa específica). (R) mortero de referencia. (CVT) mortero con la incorporación de cenizas volantes inertizadas en una proporción de un $10 \%$ en peso de los áridos. 152

Tabla 35. Estabilidad dimensional de las probetas de mortero de CAC con árido 0/2 (Masa inicial, variación de masa a 7, 14 y 28 días y variación de la masa específica). (R) mortero de referencia. (CVT) mortero con la incorporación de cenizas volantes inertizadas en una proporción de un 10\% en peso de los áridos. 155 
Tabla 36. Estabilidad dimensional de las probetas de mortero de CAC con árido 0/4 (Masa inicial, variación de masa a 7, 14 y 28 días y variación de la masa específica). (R) mortero de referencia. (CVT) mortero con la incorporación de cenizas volantes inertizadas en una proporción de un $10 \%$ en peso de los áridos. 156

Tabla 37. Estabilidad dimensional de las probetas de mortero de CAC con árido 0/2 (Masa inicial, variación de masa a 7, 14 y 28 días y variación de la masa específica). (R) mortero de referencia. (CVT) mortero con la incorporación de cenizas volantes inertizadas en una proporción de un 10\% en peso de los áridos. 158

Tabla 38. Estabilidad dimensional de las probetas de mortero de CAC con árido 0/4 (Masa inicial, variación de masa a 7, 14 y 28 días y variación de la masa específica). (R) mortero de referencia. (CVT) mortero con la incorporación de cenizas volantes inertizadas en una proporción de un 10\% en peso de los áridos.

Tabla 39. Estabilidad dimensional de las probetas de mortero de CSA con árido 0/2 (Masa inicial, variación de masa a 7, 14 y 28 días y variación de la masa específica). (R) mortero de referencia. (CVT) mortero con la incorporación de cenizas volantes inertizadas en una proporción de un $10 \%$ en peso de los áridos. 161

Tabla 40. Estabilidad dimensional de las probetas de mortero de CSA con árido 0/4 (Masa inicial, variación de masa a 7, 14 y 28 días y variación de la masa específica). (R) mortero de referencia. (CVT) mortero con la incorporación de cenizas volantes inertizadas en una proporción de un 10\% en peso de los áridos.

Tabla 41. Estabilidad dimensional de las probetas de mortero de CSA con árido 0/2 (Masa inicial, variación de masa a 7, 14 y 28 días y variación de la masa específica). (R) mortero de referencia. (CVT) mortero con la incorporación de cenizas volantes inertizadas en una proporción de un 10\% en peso de los áridos. 164 
Tabla 42. Estabilidad dimensional de las probetas de mortero de CSA con árido 0/4 (Masa inicial, variación de masa a 7, 14 y 28 días y variación de la masa específica). (R) mortero de referencia. (CVT) mortero con la incorporación de cenizas volantes inertizadas en una proporción de un $10 \%$ en peso de los áridos. 165

Tabla 43. Densidad media aparente en seco del mortero de CEM-I endurecido con tamaño del árido 0/2. Valores analíticos de cálculo de cada una de las tres probetas analizadas en cada dosificación. ( $R$ ) Morteros de referencia. (CVT) Morteros con la incorporación de cenizas volantes inertizadas en una proporción de un $10 \%$ en peso de los áridos. 171

Tabla 44. Densidad media aparente en seco del mortero de CEM-I endurecido con tamaño del árido 0/4. Valores analíticos de cálculo de cada una de las tres probetas analizadas en cada dosificación. ( $R$ ) Morteros de referencia. (CVT) Morteros con la incorporación de cenizas volantes inertizadas en una proporción de un $10 \%$ en peso de los áridos. 172

Tabla 45. Densidad media aparente en seco del mortero endurecido de CEM-II A/P con tamaño del árido $0 / 2$. Valores analíticos de cálculo de cada una de las tres probetas analizadas en cada dosificación. (R) Morteros de referencia. (CVT) Morteros con la incorporación de cenizas volantes inertizadas en una proporción de un $10 \%$ en peso de los áridos. 174

Tabla 46. Densidad media aparente en seco del mortero endurecido de CEM-II A/P con tamaño del árido 0/4. Valores analíticos de cálculo de cada una de las tres probetas analizadas en cada dosificación. (R) Morteros de referencia. (CVT) Morteros con la incorporación de cenizas volantes inertizadas en una proporción de un $10 \%$ en peso de los áridos. 175

Tabla 47. Densidad media aparente en seco del mortero endurecido de CAC con tamaño del árido 0/2. Valores analíticos de cálculo de cada una de las tres probetas analizadas en cada dosificación. ( $R$ ) Morteros de referencia. (CVT) Morteros con la incorporación de cenizas volantes inertizadas en una proporción de un $10 \%$ en peso de los áridos. ............178 
Tabla 48. Densidad media aparente en seco del mortero endurecido de CAC con tamaño del árido 0/4. Valores analíticos de cálculo de cada una de las tres probetas analizadas en cada dosificación. ( $R$ ) Morteros de referencia. (CVT) Morteros con la incorporación de cenizas volantes inertizadas en una proporción de un $10 \%$ en peso de los áridos. 179

Tabla 49. Densidad media aparente en seco del mortero endurecido de CSA con tamaño del árido 0/2. Valores analíticos de cálculo de cada una de las tres probetas analizadas en cada dosificación. ( $R$ ) Morteros de referencia. (CVT) Morteros con la incorporación de cenizas volantes inertizadas en una proporción de un $10 \%$ en peso de los áridos. 182

Tabla 50. Densidad media aparente en seco del mortero endurecido de CSA con tamaño del árido 0/4. Valores analíticos de cálculo de cada una de las tres probetas analizadas en cada dosificación. ( $R$ ) Morteros de referencia. (CVT) Morteros con la incorporación de cenizas volantes inertizadas en una proporción de un $10 \%$ en peso de los áridos.

Tabla 51. Profundidad de carbonatación $(P C)$ y Superficie carbonatada $(S C)$ de los morteros ensayados con diámetro de árido 0/2. (R) Morteros de referencia (CVT) Morteros con la incorporación de cenizas volantes inertizadas en una proporción de un $10 \%$ en peso de los áridos. 185

Tabla 52. Profundidad de carbonatación $(P C)$ y Superficie carbonatada $(S C)$ de los morteros ensayados con diámetro de árido $0 / 4$. (R) Morteros de referencia (CVT) Morteros con la incorporación de cenizas volantes inertizadas en una proporción de un $10 \%$ en peso de los áridos. 186

Tabla 53. Resumen de los datos de intrusión de la porosimetría de mercurio sobre las probetas de mortero CAC $\cdot 1 / 1 \cdot 0 / 4$. 198

Tabla 54. Distribución de volumen intruido por tamaños de poro para morteros de CAC $1 / 1 \cdot 0 / 4$ 202

Tabla 55. Valores de resistencia mecánica a 7, 28, 60 y 90 días, en $\mathrm{N} / \mathrm{mm} 2$, obtenidos de la rotura de las probetas de mortero elaboradas con 
CEM-I. Valores medios de tensión de rotura a flexión y a compresión. En rojo, porcentaje comparativo de pérdida de resistencias entre morteros de referencia $(\mathrm{R} \cdot 0 \%)$ y morteros con la incorporación de cenizas volantes inertizadas (CVT·10\%). Entre paréntesis, desviación estándar de los valores de resistencia mecánica.

Tabla 56. Valores de resistencia mecánica a 7, 28, 60 y 90 días, en $\mathrm{N} / \mathrm{mm} 2$, obtenidos de la rotura de las probetas de mortero elaboradas con CEM-II-A/P. Valores medios de tensión de rotura a flexión y a compresión. En rojo, porcentaje comparativo de pérdida de resistencias entre morteros de referencia $(\mathrm{R} \cdot 0 \%)$ y morteros con la incorporación de cenizas volantes inertizadas (CVT·10\%). Entre paréntesis, desviación estándar de los valores de resistencia mecánica......................................................... 210

Tabla 57. Valores de resistencia mecánica a 7, 28, 60 y 90 días, en $\mathrm{N} / \mathrm{mm} 2$, obtenidos de la rotura de las probetas de mortero elaboradas con CAC. Valores medios de tensión de rotura a flexión y a compresión. En verde, porcentaje comparativo de ganancia de resistencias entre morteros de referencia (R.0\%) y morteros con la incorporación de cenizas volantes inertizadas (CVT-10\%). En rojo, pérdida de resistencias. Entre paréntesis, desviación estándar de los valores de resistencia mecánica...................214

Tabla 58. Valores de resistencia mecánica a $7,28,60$ y 90 días, en $\mathrm{N} / \mathrm{mm} 2$, obtenidos de la rotura de las probetas de mortero elaboradas con CSA. Valores medios de tensión de rotura a flexión y a compresión. En verde, porcentaje comparativo de ganancia de resistencias entre morteros de referencia (R.0\%) y morteros con la incorporación de cenizas volantes inertizadas (CVT-10\%). En rojo, pérdida de resistencias. Entre paréntesis, desviación estándar de los valores de resistencia mecánica...................218

Tabla 59. Intervalos de temperaturas para hidratos de cemento CAC (Bushnell-Watson, Sharp 1992) ............................................... 222

Tabla 60. Composición semicuantitativa de la fase (analizada por DRX) de

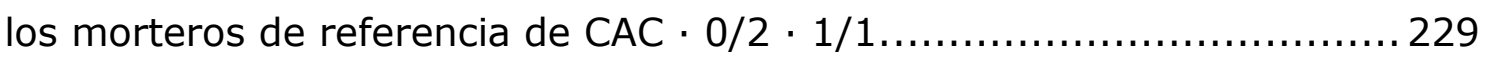


Tabla 61. Composición semicuantitativa de la fase (analizada por DRX) de los morteros CAC $\cdot 0 / 2 \cdot 1 / 1$ con la incorporación de un 10\% de CVT..... 229

Tabla 62. Composición semicuantitativa de la fase (analizada por DRX) de

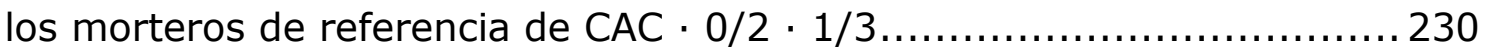

Tabla 63. Composición semicuantitativa de la fase (analizada por DRX) de los morteros CAC $\cdot 0 / 2 \cdot 1 / 3$ con la incorporación de un $10 \%$ de CVT..... 230

Tabla 64. Composición semicuantitativa de la fase (analizada por DRX) de

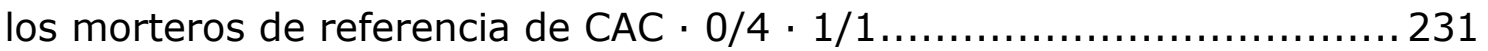

Tabla 65. Composición semicuantitativa de la fase (analizada por DRX) de los morteros CAC $\cdot 0 / 4 \cdot 1 / 1$ con la incorporación de un 10\% de CVT..... 231

Tabla 66. Composición semicuantitativa de la fase (analizada por DRX) de

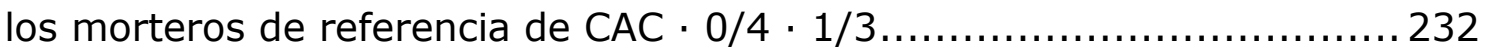

Tabla 67. Composición semicuantitativa de la fase (analizada por DRX) de los morteros CAC $\cdot 0 / 4 \cdot 1 / 3$ con la incorporación de un $10 \%$ de CVT. .... 232

Tabla 68. Valores de lixiviación en $\mathrm{ng} / \mathrm{L}$ de los morteros de CAC analizados. (R) Morteros de referencia. (CVT) Morteros con cenizas volantes inertizadas en forma de carbonatos. 238 


\section{ÍNDICE DE ILUSTRACIONES}

Ilustración 1. Sellado e identificación de probetas de mortero destinadas a su análisis DRX, DSC-TGA y lixiviado. .75

Ilustración 2. Preparación de los semiprismas de mortero de $4 \times 4 \times 4 \mathrm{~cm}^{3}$ para su utilización en los ensayos de DRX, DSC-TGA y lixiviado. .75

Ilustración 3. Machacado manual de las probetas de mortero. Obtención de la facción fina inferior a $63 \mu \mathrm{m}$. .76

Ilustración 4. Conservación e identificación de muestras para su utilización

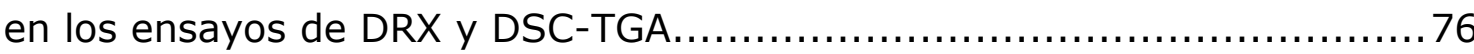

Ilustración 5. Preparación de las muestras sobre la bandeja de análisis del difractómetro 76

Ilustración 6. Difractómetro Siemens D-5000 del Laboratorio de Química

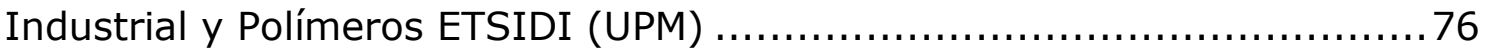

Ilustración 7. Analizador Termogravimétrico y Calorímetro Diferencial de Barrido (SDT-Q600) ubicado en el Laboratorio de Química Industrial y Polímeros de la Escuela Técnica Superior de Ingeniería y Diseño Industrial de la UPM. .78

Ilustración 8. Preparación de muestras para análisis DSC-TGA. 78

Ilustración 9. Comparación de muestras en los brazos del analizador TG. .78

Ilustración 10. Desecado de los áridos utilizados en la elaboración de los diversos morteros analizados. ( $115^{\circ} \mathrm{C}$ y $24 \mathrm{~h}$ )

Ilustración 11. Distribución granulométrica del árido. Proceso de lavado. 
Ilustración 12. Distribución granulométrica del árido. Proceso de tamizado.

Ilustración 13. Determinación de la consistencia del mortero fresco. Molde sobre la mesa de sacudidas según UNE EN 1015-3:2000. .85

Ilustración 14. Determinación de la consistencia del mortero fresco. Medición de la galleta de mortero según UNE EN 1015-3:2000. .85

Ilustración 15. Sonda de penetración y molde de ensayo del periodo de trabajabilidad.

Ilustración 16. Determinación de la estabilidad dimensional. Almacenamiento en cámara húmeda a una temperatura constante de $20^{\circ} \mathrm{C}$ $\pm 2{ }^{\circ} \mathrm{C}$ y una humedad relativa del $65 \% \pm 5 \%$ 90

Ilustración 17. Estabilidad dimensional. Medida de las variaciones de longitud. 92

Ilustración 18. Estabilidad dimensional. Medida de las variaciones de masa.... 92

Ilustración 19. Determinación del volumen de la probeta en el laboratorio mediante pesada hidrostática. 94

Ilustración 20. Gráfica de datos de temperaturas para el periodo de tiempo comprendido entre el 26de abril y el 25 de junio de 2012 para la estación meteorológica de Madrid, Cuatro Vientos. (Fuente: AEMET) ........97

Ilustración 21. Profundidad de carbonatación. Superficie fucsia: área de mortero no carbonatada. Línea verde: medición de las superficies carbonatadas y no carbonatadas mediante el procesamiento de la fotografía

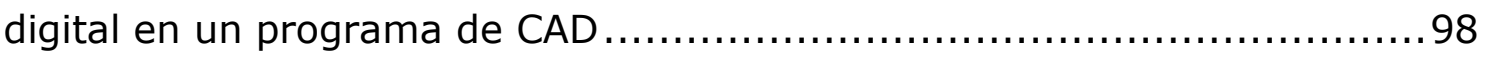

Ilustración 22. Profundidad de carbonatación. Procedimiento analítico de cálculo. Sc: Área carbonatada de la probeta. Pc: Profundidad de carbonatación 98 
Ilustración 23. Determinación de la resistencia a la carbonatación. Aplicación de fenolftaleína sobre mortero de CAC

Ilustración 24. Determinación de la resistencia a la carbonatación. Procesado de fotografía digital. Grado de saturación al 100\% 99

Ilustración 25. Preparación de moldes por cuadruplicado para la determinación de las resistencias a flexión y a compresión. Morteros de CEM-I. Probetas de referencia P1 a P12 y probetas con CVT P31T a P42T.

Ilustración 26. Determinación de la resistencia a flexión del mortero endurecido. Probetas P4, P55, P56, P57, P76, P77, P78, P262, P263, P264, P283 y P284. 104

Ilustración 27. Determinación de la resistencia a compresión del mortero endurecido. Probeta P200. 104

Ilustración 28. Voltamperímetro de redisolución anódica situado en el laboratorio de Química Industrial y Polímero de la ETSIDI - UPM 106

Ilustración 29. Determinación de la cantidad de $\mathrm{NaHCO}_{3}$, incorporación y agitado manual por medios mecánicos para el lavado de las CV de RSU . 117

Ilustración 30. Proceso de recuperación de las CV de RSU inertizadas. Filtrado mediante embudo Büchner, matraz kitasato y bomba de vacío. . 118

Ilustración 31. Proceso de recuperación de las CV de RSU inertizadas. Pasta final obtenida tras el filtrado. 118

Ilustración 32. Proceso de recuperación de las CV de RSU inertizadas. Pasta en bandejas previa a su desecación en estufa. 119

Ilustración 33. Proceso de recuperación de las CV de RSU inertizadas. Obtención de una torta quebradiza tras su desecación en estufa a $\left(75^{\circ} \mathrm{C}\right.$ y 24h) 
Ilustración 34. Proceso de recuperación de las CV de RSU inertizadas. Molienda manual y tamizado $(63 \mu \mathrm{m})$ de la torta de CVT. 119

Ilustración 35. Difractograma de las cenizas volantes de RSU originales.

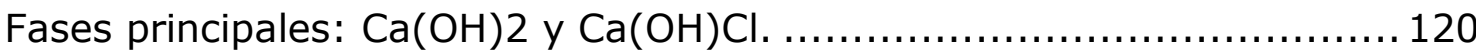

Ilustración 36. Difractograma de las cenizas volantes de RSU inertizadas (CVT). Fase mayoritaria: $\mathrm{CaCO} 3$

Ilustración 37. Curvas DSC-TGA de las muestras de cenizas volantes de RSU originales 124

Ilustración 38. Curvas DSC-TGA de las muestras de cenizas volantes inertizadas. 125

Ilustración 39. Relación óptima agua/cemento para los morteros elaborados con CEM-I. Consistencia del mortero para un valor de escurrimiento $175 \pm 10$ mm según EN 1015-3:2000. 131

Ilustración 40. Relación óptima agua/cemento para los morteros elaborados con CEM-II A/P. Consistencia del mortero para un valor de escurrimiento $175 \pm 10$ mm según EN 1015-3:2000. 132

Ilustración 41. Relación óptima agua/cemento para los morteros elaborados con CAC. Consistencia del mortero para un valor de escurrimiento $175 \pm 10$ mm según EN 1015-3:2000. 134

Ilustración 42. Relación óptima agua/cemento para los morteros elaborados con CSA. Consistencia del mortero para un valor de escurrimiento $175 \pm 10$ mm según EN 1015-3:2000. 135

Ilustración 43. Normalización de resultados de la variación de la longitud específica o deformación $(\varepsilon)$, a 7, 14 y 28 días de cada una de las dosificaciones ensayadas. Los valores mostrados corresponden al cociente entre las distintas longitudes de los morteros con la incorporación de CVT, en cada una de las edades, y los valores de referencia de los morteros sin adiciones, a esas mismas edades.... 168 
Ilustración 44. Normalización de resultados de la variación de la masa específica $(m)$ a 7, 14 y 28 días de cada una de las dosificaciones ensayadas. Los valores mostrados corresponden al cociente entre las distintas masas específicas de los morteros con la incorporación de CVT, en cada una de las edades, y los valores de referencia de los morteros sin adiciones, a esas mismas edades....

Ilustración 45. Densidad media aparente en seco, en $\mathrm{kg} / \mathrm{m}^{3}$, de los morteros de CEM-I (EN 1015-10:2000). Diámetros de árido 0/2 y 0/4.

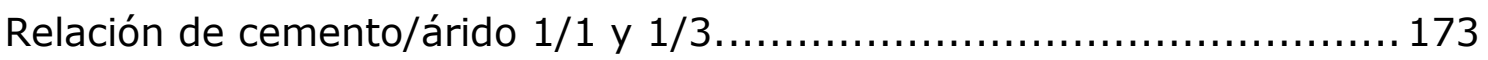

Ilustración 46. Densidad media aparente en seco, en $\mathrm{kg} / \mathrm{m}^{3}$, de los morteros de CEM-II A/P (EN 1015-10:2000). Diámetros de árido 0/2 y 0/4.

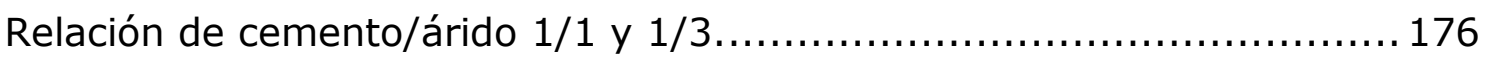

Ilustración 47. Densidad media aparente en seco, en $\mathrm{kg} / \mathrm{m}^{3}$, de los morteros de CAC (EN 1015-10:2000). Diámetros de árido 0/2 y 0/4.

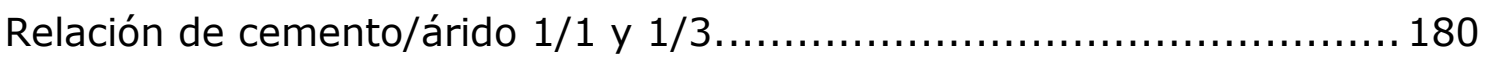

Ilustración 48. Densidad media aparente en seco, en $\mathrm{kg} / \mathrm{m}^{3}$, de los morteros de CSA (EN 1015-10:2000). Diámetros de árido 0/2 y 0/4.

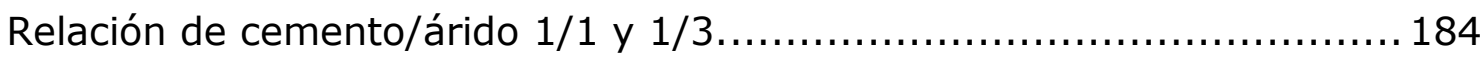

Ilustración 49. Determinación de la profundidad de carbonatación. Morteros de CEM-I, tamaño del árido 0/2 y dosificación cemento/árido 1/1. (Izda): Probeta P19. Mortero de referencia. (Dcha): Probeta P24T. Mortero con la incorporación de cenizas volantes inertizadas en una proporción de un $10 \%$ en peso de los áridos. 190

Ilustración 50. Determinación de la profundidad de carbonatación. Morteros de CEM-I, tamaño del árido 0/2 y dosificación cemento/árido 1/3. (Izda): Probeta P50. Mortero de referencia. (Dcha): Probeta P72T. Mortero con la incorporación de cenizas volantes inertizadas, en una proporción de un $10 \%$ en peso de los áridos. 190 
Ilustración 51. Determinación de la profundidad de carbonatación. Morteros de CEM-I, tamaño del árido 0/4 y dosificación cemento/árido 1/1. (Izda): Probeta P91. Mortero de referencia. (Dcha): Probeta P114T. Mortero con la incorporación de cenizas volantes inertizadas, en una proporción de un $10 \%$ en peso de los áridos.

Ilustración 52. Determinación de la profundidad de carbonatación. Morteros de CEM-I, tamaño del árido 0/4 y dosificación cemento/árido 1/3. (Izda): Probeta P133. Mortero de referencia. (Dcha): Probeta P155T. Mortero con la incorporación de cenizas volantes inertizadas, en una proporción de un $10 \%$ en peso de los áridos.

Ilustración 53. Determinación de la profundidad de carbonatación. Morteros de CEM-II A/P, tamaño del árido $0 / 2$ y dosificación cemento/árido 1/1. (Izda): Probeta P175. Mortero de referencia. (Dcha): Probeta P197T. Mortero con la incorporación de cenizas volantes inertizadas, en una proporción de un $10 \%$ en peso de los áridos.

Ilustración 54. Determinación de la profundidad de carbonatación. Morteros de CEM-II A/P, tamaño del árido 0/2 y dosificación cemento/árido 1/3. (Izda): Probeta P219. Mortero de referencia. (Dcha): Probeta P240T. Mortero con la incorporación de cenizas volantes inertizadas, en una proporción de un $10 \%$ en peso de los áridos.

Ilustración 55. Determinación de la profundidad de carbonatación. Morteros de CEM-II A/P, tamaño del árido 0/4 y dosificación cemento/árido 1/1. (Izda): Probeta P261. Mortero de referencia. (Dcha): Probeta P282T. Mortero con la incorporación de cenizas volantes inertizadas, en una proporción de un $10 \%$ en peso de los áridos.

Ilustración 56. Determinación de la profundidad de carbonatación. Morteros de CEM-II A/P, tamaño del árido 0/4 y dosificación cemento/árido 1/3. (Izda): Probeta P301. Mortero de referencia. (Dcha): Probeta P322T. Mortero con la incorporación de cenizas volantes inertizadas, en una proporción de un $10 \%$ en peso de los áridos. 193 
Ilustración 57. Determinación de la profundidad de carbonatación. Morteros de CAC, tamaño del árido 0/2 y dosificación cemento/árido 1/1. (Izda): Probeta P345. Mortero de referencia. (Dcha): Probeta P366T. Mortero con la incorporación de cenizas volantes inertizadas, en una proporción de un $10 \%$ en peso de los áridos.

Ilustración 58. Determinación de la profundidad de carbonatación. Morteros de CAC, tamaño del árido 0/2 y dosificación cemento/árido 1/3. (Izda): Probeta P385. Mortero de referencia. (Dcha): Probeta P407T. Mortero con la incorporación de cenizas volantes inertizadas, en una proporción de un $10 \%$ en peso de los áridos.

Ilustración 59. Determinación de la profundidad de carbonatación. Morteros de CAC, tamaño del árido 0/4 y dosificación cemento/árido 1/1. (Izda): Probeta P428. Mortero de referencia. (Dcha): Probeta P449T. Mortero con la incorporación de cenizas volantes inertizadas, en una proporción de un $10 \%$ en peso de los áridos.

Ilustración 60. Determinación de la profundidad de carbonatación. Morteros de CAC, tamaño del árido 0/4 y dosificación cemento/árido 1/3. (Izda): Probeta P470. Mortero de referencia. (Dcha): Probeta P492T. Mortero con la incorporación de cenizas volantes inertizadas, en una proporción de un $10 \%$ en peso de los áridos.

Ilustración 61. Determinación de la profundidad de carbonatación. Morteros de CSA, tamaño del árido 0/2 y dosificación cemento/árido 1/1. (Izda): Probeta P512. Mortero de referencia. (Dcha): Probeta P533T. Mortero con la incorporación de cenizas volantes inertizadas, en una proporción de un $10 \%$ en peso de los áridos. 196

Ilustración 62. Determinación de la profundidad de carbonatación. Morteros de CSA, tamaño del árido 0/2 y dosificación cemento/árido 1/3. (Izda): Probeta P599. Mortero de referencia. (Dcha): Probeta P574T. Mortero con la incorporación de cenizas volantes inertizadas, en una proporción de un $10 \%$ en peso de los áridos. 196 
Ilustración 63. Determinación de la profundidad de carbonatación. Morteros de CSA, tamaño del árido 0/4 y dosificación cemento/árido 1/1. (Izda): Probeta P595. Mortero de referencia. (Dcha): Probeta P616T. Mortero con la incorporación de cenizas volantes inertizadas, en una proporción de un $10 \%$ en peso de los áridos.

Ilustración 64. Determinación de la profundidad de carbonatación. Morteros de CSA, tamaño del árido 0/4 y dosificación cemento/árido 1/3. (Izda): Probeta P639. Mortero de referencia. (Dcha): Probeta P660T. Mortero con la incorporación de cenizas volantes inertizadas, en una proporción de un $10 \%$ en peso de los áridos.

Ilustración 65. Curvas de intrusión acumulada de mercurio frente al tamaño de poro. 202

Ilustración 66. Curvas de diámetro de tamaño de poro frente al logaritmo de intrusión diferencial. 203

Ilustración 67. Normalización de los valores de rotura a flexión, a 7, 28, 60 y 90 días, de cada uno de las dosificaciones ensayadas. Los valores mostrados corresponden al cociente entre las distintas tensiones de rotura a flexión de los morteros con la incorporación de CVT, en cada una de las edades, y los valores de referencia de los morteros sin adiciones, a esas mismas edades.

Ilustración 68. Normalización de los valores de rotura a compresión, a 7, 28,60 y 90 días, de cada uno de las dosificaciones ensayadas. Los valores mostrados corresponden al cociente entre las distintas tensiones de rotura a compresión de los morteros con la incorporación de CVT, en cada una de las edades, y los valores de referencia de los morteros sin adiciones, a esas mismas edades. 220

Ilustración 69. Termogramas del mortero de referencia de CAC $\cdot 1 / 1$. 0/4, a 7 días (parte superior), 28, 60 y 90. 225 
Ilustración 70. Termogramas del mortero de CAC $\cdot 1 / 1 \cdot 0 / 4$ con la incorporación de CVT , a 7 días (parte superior), 28, 60 y 90. 226

Ilustración 71. Difractogramas de los morteros CAC·0/4·1/1 con CVT a 7, 28, 60 y 90 días. Reflexiones más intensas de M: Monocarbonato C: Calcita 228

Ilustración 72. Ensayo de lixiviación de probetas monolíticas (NF P X31211). Mortero de cemento CAC de referencia (izda.). Mortero de CAC con cenizas volantes inertizadas (dcha.) 237 


\section{LISTADO DE ABREVIATURAS}

CAC Cemento de Aluminato de Calcio

CEM-I Cemento Portland Tipo I

CEM-II A/P Cemento Portland Tipo II con Adiciones Puzolánicas

CSA Cemento de Sulfoaluminato de Calcio

C-S-H Silicato Cálcico Hidratado

CV Cenizas Volantes

CVT Cenizas Volantes Tratadas (inertizadas)

DRX Difracción de Rayos $X$

DSC-TGA Calorimetría Diferencial de Barrido y Termo-gravimetría

FRX $\quad$ Fluorescencia de Rayos X

ICP-OES Espectrofotometría de Emisión Óptica con fuente de Plasma de Acoplamiento Inductivo

OPC Cemento Portland Ordinario

R Mortero de Referencia

RSU Residuos Sólidos Urbanos

RTP Residuo Tóxico y Peligroso 



\section{RESUMEN}

Esta tesis presenta los resultados de la investigación realizada sobre la inertización de cenizas volantes procedentes de residuos sólidos urbanos y su posterior encapsulación en distintas matrices de mortero.

Durante el proceso de inertización, se ha logrado la inertización de éste residuo tóxico y peligroso (RTP) y también su valorización como subproducto. De esta forma se dispone de nueva "materia prima" a bajo coste y la eliminación de un residuo tóxico y peligroso con la consiguiente conservación de recursos naturales alternativos.

La caracterización química de las cenizas analizadas refleja que éstas presentan altas concentraciones de cloruros, $\mathrm{Zn}$ y $\mathrm{Pb}$. Durante la investigación se ha desarrollado un proceso de inertización de las cenizas volantes con bicarbonato sódico $\left(\mathrm{NaHCO}_{3}\right)$ que reduce en un $99 \%$ el contenido en cloruros y mantiene el $\mathrm{pH}$ en valores óptimos para que la concentración de los metales pesados en el lixiviado sea mínima debido a su estabilización en forma de carbonatos insolubles.

Se han elaborado morteros con cuatro tipos distintos de cementos (CEM-I, CEM-II, CAC y CSA) incorporando cenizas volantes inertizadas en una proporción igual a un $10 \%$ en peso del árido utilizado. Los morteros ensayados abarcan distintas dosificaciones tanto en la utilización de áridos con distintos diámetros (0/2 y 0/4), como en la relación cemento/árido (1/1 y $1 / 3)$.

Se han obtenido las propiedades físicas y mecánicas de estos morteros mediante ensayos de Trabajabilidad, Estabilidad Dimensional, Carbonatación, Porosidad y Resistencias Mecánicas.

De igual forma, se presentan resultados de ensayos de lixiviación de $\mathrm{Zn}, \mathrm{Pb}, \mathrm{Cu}$ y $\mathrm{Cd}$, sobre probetas monolíticas de los morteros con los mejores comportamientos físico/mecánicos, donde se ha analizado el 
contenido en iones de dichos metales pesados lixiviados mediante determinación voltamperométrica de redisolución anódica

Se concluye que todos los morteros ensayados son técnicamente aceptables, siendo los más favorables los elaborados con Cemento de Sulfoaluminato de Calcio (CSA) y con Cemento de Aluminato de Calcio (CAC). En este último caso, se mejoran las resistencias a compresión de los morteros de referencia en más de un $48 \%$, y las resistencias a flexión en más de un $67 \%$. De igual forma, los ensayos de lixiviado revelan la completa encapsulación de los iones de Zn y la mitigación en el lixiviado de los iones de $\mathrm{Pb}$.

Ambos morteros podrían ser perfectamente validos en actuaciones en las que se necesitase un producto de fraguado rápido, altas resistencias iniciales y compensación de las retracciones con una elevada estabilidad dimensional. En base a esto, el material podría ser utilizado como mortero de reparación en viales y pavimentos que requiriesen altas prestaciones, tales como: soleras industriales, pistas de aterrizaje, aparcamientos, etc. 0 bien, para la confección de elementos prefabricados sin armaduras estructurales, dada su elevada resistencia a flexión. 


\section{ABSTRACT}

This dissertation presents the results of a research on inerting fly ash from urban solid waste and its subsequent encapsulation in mortar matrixes. The inerting of this hazardous toxic waste, as well as its valorization as a by-product has been achieved. In this way, a new "raw material" is available through a simple process and the toxic and hazardous waste is eliminated, and consequently, conservation of alternative natural resources is strengthened.

Chemical analysis of the ashes analyzed shows high concentrations of soluble chlorides, $\mathrm{Zn}$ and $\mathrm{Pb}$. An inerting process of fly ash with sodium bicarbonate $\left(\mathrm{NaHCO}_{3}\right)$ has been developed which reduces $99 \%$ the content of chlorides and maintains $\mathrm{pH}$ at optimal values, so that the concentration of heavy metals in the leachate is minimum, due to its stabilization in the form of insoluble carbonates.

Mortars with four different types of cements (CEM-I, CEM-II, CAC and CSA) have been developed by the addition of inertized fly ash in the form of carbonates, in the proportion of $10 \%$ in weight of the aggregates used.

The samples tested include different proportions in the use of aggregates with different sizes ( $0 / 2$ and $0 / 4)$, and in the cement/aggregate ratio (1/1 and 1/3). Physical/mechanical properties of these mortars have been studied through workability, dimensional stability, carbonation, porosity and mechanic strength tests.

Leaching tests of $\mathrm{Zn}, \mathrm{Pb}, \mathrm{Cu}$ and $\mathrm{Cd}$ ions are also being performed on monolithic samples of the best behavioral mortars. The content in leachated heavy metal ions is being analyzed through stripping voltammetry determination.

Conclusions drawn are that the tested CAC and CSA cement mortars present much better behavior than those of CEM-I and CEM-II cement. The results are especially remarkable for the CAC cement mortars, improving 
reference mortars compression strengths in more than $48 \%$, and also bending strengths in more than $67 \%$.

Leaching tests confirm that the encapsulation of $\mathrm{Zn}$ and $\mathrm{Pb}$ is achieved and leachate of both ions is mitigated within the mortar matrixes.

For the above stated reasons, it might be concluded that mortars made with calcium aluminate cements or calcium sulfoaluminate with the incorporation of treated fly ash, may be perfectly valid for uses in which a fast-curing product, with high initial strength and drying shrinkage compensation with a high dimensional stability is required. Based on this, the material could be used as repair mortar for structures, roads and industrial pavements requiring high performance, such as: industrial floorings, landing tracks, parking lots, etc. Alternatively, it could also be used in the manufacture of prefabricated elements without structural reinforcement, given its high bending strength. 


\section{INTRODUCCIÓN Y OBJETIVOS}

\subsection{INTRODUCCIÓN}

La gestión de los residuos urbanos a través de las plantas incineradoras ubicadas en las cercanías de nuestras ciudades está cobrando cada vez mayor importancia desde el momento en el que, a pesar de la crisis económica que nos afecta, en las últimas décadas ha experimentado un constante incremento la cantidad de basuras generada ${ }^{1}$. A todo esto, hay que unirle la creciente preocupación de la sociedad por los problemas medioambientales y los efectos potencialmente perjudiciales que generan las políticas de reciclado y reutilización que, de un tiempo a esta parte, se han convertido en una clara alternativa a los métodos tradicionales de eliminación de residuos.

De ésta manera, la incineración es uno de los procesos térmicos que pueden utilizarse para el tratamiento de los residuos sólidos urbanos, con la intención de disminuir su cantidad y, a su vez, aprovechar la energía que contiene. Como ya ha sido comentado, causa cierta preocupación las posibles emisiones atmosféricas, especialmente dioxinas y furanos, así como las escorias y los distintos tipos de cenizas formadas en el proceso de combustión.

La heterogeneidad de los materiales tratados y los diversos niveles de emisión impuestos por la normativa vigente han obligado a desarrollar y adaptar unas tecnologías especiales para cada proceso. Los aspectos socioeconómicos implican elevadas inversiones económicas y, por regla general, una fuerte oposición popular.

\footnotetext{
${ }^{1}$ La producción de residuos urbanos de la ciudad de Madrid ascendió en el año 2010 a 1.470.461 toneladas, lo que supone la generación de 4.029 toneladas de desechos diarias, lo cual supone una tasa anual de $447,8 \mathrm{Kg}$ por habitante. Si consideramos la tasa de producción por habitante y día ésta asciende a $1,23 \mathrm{Kg}$, lo que implica un descenso de la misma desde el año 2007 del 12,38\%. (Fuente: Memoria de Actividades del año 2010. Dirección General del Parque Tecnológico de Valdemingómez)
} 
En la actualidad, la incineración debe tratarse como uno más de los procesos existentes para la gestión integrada de los residuos sólidos urbanos. En todos estos procedimientos debe procederse de antemano a la reducción de la generación de residuos, a la recuperación de los materiales reciclables y finalmente, al tratamiento y eliminación de los residuos inevitables y no reciclables.

El aumento de la producción de residuos sólidos urbanos hace previsible un crecimiento progresivo de incineradoras en los países avanzados, con el consiguiente aumento de la producción de cenizas de fondo y cenizas volantes, residuos que, en caso de no aprovecharse deberán ser sometidos a tratamientos que eviten posteriores problemas medioambientales. A raíz de esto, surge el problema del tratamiento de los diversos tipos de cenizas generadas en los procesos de incineración, y su posible reutilización en distintos usos beneficiosos para la sociedad.

En las plantas incineradoras de residuos sólidos urbanos son ampliamente utilizados dos procesos de incineración dependiendo del tipo de combustible:

- Las que utilizan como combustible residuos sólidos urbanos a los que previamente les han sido separados metales ferrosos y vidrios mediante un proceso de clasificación. En este caso, los desperdicios resultantes son desmenuzados e incinerados y el calor producido es recuperado para la producción de electricidad, al tratarse de residuos con un mayor poder calorífico.

- Las que se basan en un proceso de quema en masa de la totalidad de residuos tal y como son recibidos en la planta sin que exista ningún tipo de separación de materiales o machaqueo.

Durante el proceso de incineración, la mayor parte de los residuos sólidos son transformados, tanto física, como químicamente. El resultado de la combustión son dos tipos distintos de cenizas: de hogar y volantes; las cuales pueden ser consideradas como un subproducto $y$, por tanto, ser 
utilizadas en determinadas aplicaciones, algunas de las cuales serán estudiadas con posterioridad.

Aunque el objetivo es, en ambos métodos, el de obtener energía y reducir el volumen de los residuos, la incineración de los mismos no se debe plantear como la solución definitiva a la gestión de los residuos sólidos urbanos ya que, durante en estos procesos de combustión se generan grandes cantidades de cenizas de hogar y de cenizas volantes que hay que almacenar con posterioridad en vertederos.

Las cenizas de hogar se recogen en la base de las cámaras de combustión donde actúan los quemadores y pueden ser consideradas como un tipo de escorias. La fracción más fina de las cenizas tras la incineración se mezcla con los gases de la combustión en los sistemas de filtrado y control de los extractores los cuales están elaborados con CaO como absorbente. Son los denominados filtros de mangas de la mayoría de los equipos de combustión. Estos finos granulados sólidos se denominan cenizas volantes y son las causantes de la mayor parte de los problemas medioambientales durante todo el proceso de incineración (Jin et al., 2011).

El subproducto generado en el proceso de calcinación constituye entre un $1 \%$ y un $30 \%$ del peso húmedo del total de los residuos sólidos urbanos incinerados, mientras que, a su vez, constituyen entre un 5 y un $15 \%$ del volumen húmedo de los mismos. Las cenizas forman un conjunto muy heterogéneo, puesto que todas estas cifras varían dependiendo de factores tan dispares como pueden ser: el sistema de incineración utilizado, del país en donde se encuentre la planta incineradora, la naturaleza de los residuos e incluso, de la estación climatológica en la que se realice la combustión.

Se calcula que en el proceso de incineración de residuos sólidos urbanos, un $75 \%$ del producto que se genera son gases de combustión, mientras que el $25 \%$ restante es remanente sólido de la misma. De éste último porcentaje, las cenizas de fondo constituyen aproximadamente entre el $75 \%$ y el $80 \%$ (Al-Rawas et al., 2005) de las que la mayor fracción 
(aproximadamente el 90\%) son cenizas depositas en la rejilla del horno al finalizar los distintos ciclos de combustión. Su apariencia física es parecida a una arena silícea grisácea con algo de gravilla y que además presenta porciones de materia orgánica que no ha podido ser incinerada y fragmentos de metal. El torrente de cenizas de fondo está compuesto en su mayor parte por vidrio, cerámica, metales tanto férricos como no-férricos y minerales.

El porcentaje restante correspondería a cenizas volantes (Hjelmar, 1996; Sabbas et al., 2003), partículas sólidas muy finas que se originan en los sistemas de incineración de combustibles sólidos (carbón, residuos sólidos urbanos, madera, etc.) y que son arrastradas junto a los gases de proceso, separándose de los mismos en los dispositivos de eliminación de partículas previstos (filtros, precipitadores electrostáticos, etc.). Se caracterizan por su poco peso y consecuentemente con una distribución granulométrica fina (1-1000 $\mu \mathrm{m}$, con más de la mitad por debajo de $65 \mu \mathrm{m})$ (Ribeiro et al., 2008). En particular las cenizas volantes recibidas en el laboratorio para desarrollar esta investigación presentan un contenido en metales pesados, cloruros, sulfuros y pH bastante homogéneo a lo largo del tiempo analizado: Enero-Mayo de 2010 (tabla 1).

Estas partículas contienen cantidades elevadas de metales pesados, los cuales tienen la posibilidad de poder ser lavadas $\mathrm{y}$, por lo tanto, de contaminar acuíferos con la consiguiente acción negativa sobre plantas, animales y personas. Además, también contienen otras sustancias de alta toxicidad como dioxinas, furanos e hidrocarburos policíclicos saturados (PAHs), lo cual multiplica el problema contaminante. Estos aspectos sobre la toxicidad de las cenizas volantes hacen de su gestión uno de los objetivos más importantes relacionados con la incineración de los residuos sólidos urbanos. En ciertas ocasiones, las cenizas volantes y las de hogar se gestionan mezcladas, formando un residuo denominado cenizas combinadas. Esta práctica es más frecuente en países como Japón y Estados Unidos. 
Tabla 1. Análisis temporal de contenidos (Enero/Mayo) de las cenizas volantes de residuos sólidos urbanos recibidas en el laboratorio. Las cenizas volantes de RSU proceden de la planta de tratamiento integral de residuos de Mataró, Barcelona (España)

\begin{tabular}{|c|c|c|c|c|c|c|c|c|c|c|}
\hline \multirow{3}{*}{ Fecha } & \multirow{3}{*}{$\begin{array}{c}\text { Sobre } \\
\text { residuo }\end{array}$} & \multicolumn{9}{|c|}{ Sobre Lixiviado EN 12457-4 } \\
\hline & & \multirow{2}{*}{$\begin{array}{l}\mathrm{pH} \\
\text { final }\end{array}$} & $\mathrm{Cd}$ & $\mathrm{Cu}$ & $\mathrm{Cr}$ & $\mathrm{Ni}$ & $\mathrm{Pb}$ & $\mathrm{Zn}$ & Cloruros & Sulfatos \\
\hline & & & \multicolumn{8}{|c|}{ (mg/Kg) s.m.s. } \\
\hline 04/01/2010 & 99.8 & 12.2 & $<2.5$ & $<2.5$ & 8.6 & $<2.5$ & 21.8 & 40.4 & 115500 & 13060 \\
\hline $12 / 01 / 2010$ & 99.4 & 12.1 & $<2.5$ & $<2.5$ & 3 & $<2.5$ & 47.3 & 31.2 & 111860 & 20190 \\
\hline $19 / 01 / 2010$ & 99.5 & 12.2 & $<2.5$ & $<2.5$ & 3 & $<2.5$ & 43.3 & 50 & 137610 & 11650 \\
\hline $25 / 01 / 2010$ & 99.6 & 12.2 & $<2.5$ & $<2.5$ & 3.3 & $<2.5$ & 34.8 & 60 & 125050 & 14620 \\
\hline $01 / 02 / 2010$ & 99.6 & 12.3 & $<2.5$ & $<2.5$ & $<2.5$ & $<2.5$ & 42.5 & 39.5 & 117630 & 13850 \\
\hline $08 / 02 / 2010$ & 99.4 & 12.3 & $<2.5$ & $<2.5$ & $<2.5$ & $<2.5$ & 88.7 & 39.1 & 129430 & 14810 \\
\hline $15 / 02 / 2010$ & 99.8 & 12.2 & $<2.5$ & $<2.5$ & $<2.5$ & $<2.5$ & 16.2 & 67.1 & 112430 & 10950 \\
\hline $22 / 02 / 2010$ & 99.7 & 12.3 & $<2.5$ & $<2.5$ & $<2.5$ & $<2.5$ & 34.6 & 23.1 & 113250 & 14490 \\
\hline $01 / 03 / 2010$ & 99.8 & 12.5 & $<2.5$ & $<2.5$ & $<2.5$ & $<2.5$ & 28.7 & 62.5 & 100410 & 9100 \\
\hline 08/03/2010 & 99.9 & 12.2 & $<2.5$ & $<2.5$ & 2.8 & $<2.5$ & 40.2 & 42.5 & 91300 & 12780 \\
\hline $15 / 03 / 2010$ & 99.8 & 12.2 & $<2.5$ & $<2.5$ & $<2.5$ & $<2.5$ & 33.9 & 54.1 & 96080 & 11850 \\
\hline $22 / 03 / 2010$ & 99.3 & 12.2 & $<2.5$ & $<2.5$ & 3.7 & $<2.5$ & 13.7 & 30.9 & 95450 & 13710 \\
\hline $30 / 03 / 2010$ & 99.9 & 12.1 & $<2.5$ & $<2.5$ & 3.2 & $<2.5$ & 69.3 & 39.6 & 126480 & 11400 \\
\hline $06 / 04 / 2010$ & 99.4 & 12.2 & $<2.5$ & $<2.5$ & 3.2 & $<2.5$ & 64.1 & 43.5 & 128600 & 13620 \\
\hline $12 / 04 / 2010$ & 99.7 & 12.3 & $<2.5$ & $<2.5$ & $<2.5$ & $<2.5$ & 57.9 & 68.2 & 114710 & 10970 \\
\hline $19 / 04 / 2010$ & 99.6 & 12.1 & $<1.0$ & $<2.5$ & $<2.5$ & $<2.5$ & 42.8 & 61.1 & 100270 & 14520 \\
\hline $26 / 04 / 2010$ & 99.5 & 12.1 & $<1.0$ & $<2.5$ & $<2.5$ & $<2.5$ & 25 & 41.5 & 100970 & 13190 \\
\hline 03/05/2010 & 99.5 & 12.2 & $<1.0$ & $<2.5$ & 4.8 & $<2.5$ & 60.8 & 63.4 & 117050 & 13170 \\
\hline $10 / 05 / 2010$ & 100 & 12.1 & $<1.0$ & $<2.5$ & 2.5 & $<2.5$ & 49 & 53.1 & 98490 & 10400 \\
\hline $17 / 05 / 2010$ & 99.6 & 12.2 & $<1.0$ & $<2.5$ & 3.3 & $<2.5$ & 28.1 & 38.8 & 111110 & 13020 \\
\hline $24 / 05 / 2010$ & 99.7 & 11.9 & $<1.0$ & $<2.5$ & $<2.5$ & $<2.5$ & 30 & 45.9 & 106690 & 13850 \\
\hline $31 / 05 / 2010$ & 99.8 & 12.0 & $<1.0$ & $<2.5$ & $<2.5$ & $<2.5$ & 72 & 48.5 & 122460 & 13920 \\
\hline
\end{tabular}




\subsection{INCINERACIÓN Y TRANSFORMACIÓN DEL PAISAJE URBANO}

Por todo lo dicho, queda claro que el desarrollo urbano impulsa el incremento de los residuos sólidos urbanos ${ }^{2}$ (RSU), con el consiguiente problema implícito de la recogida, el transporte y su almacenamiento. En la actualidad, la incineración se presenta como el mejor método posible para gestionarlos (Lam, 2010; Ferreira et al., 2003). Pero la incineración de los RSU produce cenizas que deben gestionarse, todo ello sobre la base de que estos productos están incluidos en la Lista de Europea de Residuos dentro del Capítulo 19 "Residuos de las instalaciones para el tratamiento de residuos, de las plantas externas de tratamientos de aguas residuales y de la preparación de agua para el consumo humano y de agua para uso industrial", con el código 190113 "Cenizas volantes que tienen sustancias peligrosas, y están caracterizadas como residuos peligrosos" (European Commission 2008).

La puesta en práctica de la actual ${ }^{3}$ y de la futura legislación medioambiental ${ }^{4}$, junto con el desarrollo tecnológico experimentado en los últimos tiempos, prevé mejorar la gestión de los centros de procesamiento

\footnotetext{
2 El Plan Nacional Integrado de Residuos 2007-2015 del Ministerio de Medio Ambiente, estima que durante el año 2004 en España se generaron un total de $22.732 .142 \mathrm{t}$ de residuos sólidos urbanos. Si se mantiene la tendencia del periodo 1995-2004, se podría inferir que este tipo de residuos sufre un aumento anual de en torno a un 3,5\%. Si bien es cierto que en los últimos años se presenta un crecimiento relativamente moderado e incluso ligeramente decreciente en los años 2007, 2009 y 2010 respecto a años anteriores, consecuencia directa de la crisis económica a nivel global.
}

3 El Real decreto 653/2003 sobre incineración de residuos, la Directiva 2000/76/CE y la Directiva 2006/12/CE del Parlamento Europeo y del Consejo de 5 de abril de 2006 sobre residuos son las normativas principales que forman el sistema legislativo que rige las plantas incineradoras. En ellas se establece que los Estados miembros de la UE deberán tomar las medidas adecuadas para fomentar:

- La prevención y/o reducción de la producción de residuos y de su nocividad.

- La valorización de los residuos mediante procesos de reciclado o recuperación, dándole un nuevo uso, o bien cualquier otra acción destinada a obtener materias primas secundarias.

- La utilización de los residuos como fuente de energía.

${ }^{4}$ En 2014 se fijaron los nuevos objetivos de prevención a nivel europeo que serán de obligado cumplimiento en el 2020, en lo relativo a la fijación de los metales pesados en las escorias como sales estables. Las cenizas, que podrían contenerlos, se depositan en rellenos especiales para ellas, o se vitrifican vía tecnología plasma. 
de RSU, minimizando emisiones contaminantes para reducir su impacto ambiental. Recientes investigaciones, analizan la implantación de estas mejoras restringidas a la recogida y tratamiento de residuos orgánicos y aguas residuales (Iacovidou et al., 2012; Mata-Alvarez et al., 2011).

Battistoni et al., (2007) propone integrar la gestión municipal de RSU dentro de pequeñas ciudades y áreas descentralizadas. Esta actuación integrada sobre la totalidad de los RSU produce un ahorro tanto en su transporte, como en la gestión de los mismos, así como una optimización del consumo de la energía generada y unos nuevos subproductos de bajo coste.

Las nuevas técnicas de tratamiento de residuos sólidos urbanos se establecen como un elemento transformador del paisaje urbano, implicando a arquitectos y urbanistas en la modificación de la organización social. De igual forma, se promueve una nueva manera de relación de los habitantes de enclaves urbanos con este nuevo entorno, como lo hacen con la red general de saneamiento o la de abastecimiento de agua o electricidad. De esta manera, el propio día a día es el generador de recursos o subproductos, consiguiendo el compromiso de que cada barrio 0 asentamiento de nueva creación se autoabastezca y consuma sus propios recursos autogenerados.

La implantación de sistemas de trituración de basuras en nuevos enclaves urbanos, al margen o en combinación con la recogida selectiva de residuos, favorece su recogida directa y su canalización a plantas procesadoras de menor tamaño que las actuales, con mejor encaje social y estético en el paisaje urbano. Una vez allí, los residuos serían clasificados, depurados, secados, y preparados para su incineración.

De esta forma, mediante la instalación de sistemas de recuperación de energía del proceso de combustión, como pueden ser los generadores de ciclo combinado de producción de gas, valorizarían energéticamente los procesos de descomposición de los residuos, obteniendo combustibles para la generación de energía eléctrica o vapor, para su uso tanto en calefacción, 
como en refrigeración. Estos beneficios redundarían directamente en los habitantes de la zona ofreciendo mejores oportunidades en términos de economía, un aumento en el rendimiento energético $y$, sobre todo, una reducción del impacto ambiental.

\section{3 ÁREAS DE UTILIZACIÓN DE LAS CENIZAS VOLANTES PROCEDENTES DE LA INCINERACIÓN DE RESIDUOS SÓLIDOS URBANOS}

Las cenizas volantes de RSU son una pequeña parte del problema, pero no por ello la menos importante, ya que son las que plantean los mayores problemas medioambientales. Durante el proceso de incineración, la fracción más fina de las cenizas se mezcla con los gases de la combustión y dan lugar a un producto granular que contiene grandes cantidades de metales pesados fácilmente lixiviables, así como otras sustancias tóxicas (dioxinas, furanos, PAHs, etc.). Las cenizas volantes deben ser inertizadas, estabilizadas o encapsuladas con el objetivo de reducir su impacto medioambiental, y posteriormente valorizadas. Con el objeto de aumentar la retención de las mismas, los gases de combustión y partículas finas se hacen pasar por un lecho adsorbente de cal.

En la caracterización de las cenizas volantes de RSU, destacan una serie de compuestos como la portlandita $\mathrm{Ca}(\mathrm{OH})_{2}$, que sugiere su incorporación a cementos ecoeficientes (Kai et al., 2012; Isaia, 2000), o bien como materia prima secundaria en la confección de morteros (Aubert et al., 2006 y 2007), en hormigones y otros productos de la construcción (Ferreira et al., 2003; Mangialardi, 2001), como ya se ha implementado con la utilización de escorias molidas de la combustión de altos hornos (Ampadu, 2001) o de conglomerantes alternativos (Juenger et al., 2011). Por el contrario, presentan un elevado contenido en cloruros, provenientes de la combustión de residuos de policloruro de vinilo, PVC, que impide la utilización de mallazos de refuerzo en estos morteros, por su efecto altamente corrosivo. 
Por regla general, la utilización de las cenizas, ya sea por separado o mezclada con escoria, está prohibida en toda Europa y el material resultante ha de ser eliminado como desecho químico. La composición química y la alta superficie específica de las cenizas representan riesgos considerables de contaminación sobre todo a los suelos y aguas subterráneas anexos a sus áreas de aplicación.

Hasta la fecha, su utilización es sólo aceptable en determinadas áreas como puede ser en la construcción de carreteras dentro formando parte de las mezclas bituminosas. De esta forma, los riesgos de lixiviación se ven reducidos por la completa encapsulación de la ceniza en el aglomerado. Aun así, se han de tomar unas medidas protectoras mínimas con la intención de controlar posibles contaminaciones. Éstas varían desde guardar unas distancias mínimas con respecto a pozos de agua potable o ríos, hasta la encapsulación totalmente estanca, con un filtro de arena-bentonita de los terraplenes ejecutados con escorias. Como se observa, los aspectos medioambientales de la utilización de este tipo de residuos están casi exclusivamente relacionados con su comportamiento a la lixiviación, aunque la mayoría de países europeos también limitan las concentraciones totales de sustancias dañinas en las escorias y cenizas.

En la mayoría de países de nuestro entorno y en el nuestro, la opción principal para la gestión de las cenizas volantes de RSU es su almacenamiento en vertederos. Queda claro que no debe ser la solución definitiva, ya que ésta deberá ir en la dirección del reciclado y reutilización de estos subproductos (Ferreira et al., 2003). Las cenizas volantes pueden ser aprovechadas como materias primas, ya que son ricas en elementos como metales y sales. De esta forma, cada una de las aplicaciones potenciales de las cenizas volantes de RSU presenta tres ventajas principales:

1a) Pueden ser aprovechadas para conseguir una materia prima de manera asequible.

2a) Su utilización implica la conservación de los recursos naturales. 
3a) De igual forma, su uso posibilita la eliminación de residuos potencialmente peligrosos.

Estas ventajas no son nuevas ya que se han tenido en cuenta en la gestión de otro tipo de residuos, como por ejemplo los de las centrales térmicas de combustibles sólidos (carbón, hulla, etc.), o escorias siderúrgicas. Sin embargo, las cenizas volantes no han podido ser aprovechadas hasta ahora dado que la incineración no había sido tenida en cuenta como un proceso válido para solucionar el problema del desorbitado aumento de RSU en nuestras ciudades y la, cada vez mayor, escasez de espacio en nuestros vertederos.

De acuerdo a Ferreira et al., 2003, hay tres factores principales que se deben considerar relevantes para evaluar si es o no adecuado el uso de cenizas volantes de RSU para unas determinadas aplicaciones.

1a) El primer factor, relacionado con la idoneidad en el proceso de aplicación de las cenizas volantes, depende de las características físicas y químicas de las cenizas, tales como el tamaño de las distintas partículas y su composición química. En algunos casos, ésto puede suponer una limitación en lo relativo a determinados usos. Pero siempre habrá que tener en cuenta que estas características podrán ser ajustadas mediante técnicas adecuadas para poder cumplir con los requerimientos exigidos.

2a) El segundo factor está relacionado con el comportamiento técnico. Incluso en el caso de que las cenizas volantes puedan ser procesadas para ser utilizadas con facilidad, si el producto final no presenta un buen comportamiento técnico, éste no será de utilidad.

3a) Por último, el tercer factor que se deberá de tener en cuenta es el del impacto ambiental. La totalidad de los componentes tóxicos de las cenizas volantes no desaparecen mediante los tratamientos iniciales de valorización. Los riesgos a los que se puede exponer el medioambiente 
cercano a cada posible utilización deben ser cuidadosamente sopesados para no crear nuevas fuentes de contaminación.

Varios autores han intentado acotar las posibilidades de uso de las cenizas volantes de RSU. Entre ellos, Lam (2010) realiza una clasificación de utilización de todo tipo de cenizas provinientes de RSU de acuerdo al porcentaje de éstas utilizado en cada experimento (tabla 2). Así, las cenizas volantes son un subgrupo que, a su vez, se divide en siete categorías generales: Producción de cemento y hormigón; Firmes de rodadura; Vidrio, vitrocerámica y cerámica; Agricultura; Agentes estabilizadores; Adsorbentes y Producción de zeolita.

Si bien, Ferreira et al. (2003) en un primer momento resume los usos eficientes de las cenizas volantes de RSU en tres grandes bloques: Construcción, Agricultura y Aplicaciones múltiples; con posterioridad, matiza esta división según nueve potenciales aplicaciones de las cenizas volantes (tabla 3): Materiales de construcción, Agricultura, Geotecnia y un último apartado de aplicaciones múltiples. Esta clasificación, por su objetividad y precisión se ha venido manteniendo a lo largo de los últimos años (Siddique, 2010), y con base en esto, será utilizada para establecer las investigaciones más recientes sobre la materia. 
Tabla 2. Aplicaciones para las cenizas volantes de RSU (Lam Ch.H.K., 2010)

\begin{tabular}{|c|c|c|}
\hline Tipo de cenizas & Aplicación & Composición (\%) \\
\hline Hogar & Árido para hormigón & Hasta un $50 \%$ \\
\hline Hogar & Árido para hormigón & $\begin{array}{c}\text { Reemplazando hasta un } \\
15 \% \text { del cemento }\end{array}$ \\
\hline Hogar & Base para firmes de rodadura & \\
\hline Hogar & Adsorbente en tintes & \\
\hline Hogar & Hormigón & \\
\hline Combinadas & Clinker de cemento & Hasta un $50 \%$ \\
\hline Combinadas & Clinker de cemento & $44 \%$ \\
\hline Combinadas & Clinker de cemento & $15 \%$ \\
\hline Combinadas & Clinker de cemento & $\begin{array}{c}1,75 \% \text { de volantes y } \\
3,5 \% \text { de hogar }\end{array}$ \\
\hline Combinadas & Árido para hormigón & \\
\hline Volantes & Hormigón & $50 \%$ \\
\hline Volantes & Eco-cementos & $50 \%$ \\
\hline Volantes & Baldosas cerámicas & \\
\hline Volantes & $\begin{array}{c}\text { Aglutinante para la } \\
\text { estabilización de lodos }\end{array}$ & $45 \%$ \\
\hline Volantes & Cerámica vitrificada & $\begin{array}{c}\text { 75\% Cenizas volantes, } \\
20 \% \mathrm{SiO}_{2}, 5 \% \mathrm{MgO}\end{array}$ \\
\hline Volantes & $\begin{array}{l}\text { Cerámica vitrificada (Bajas } \\
\text { temperaturas de fusión) }\end{array}$ & \\
\hline Volantes & Clinker de cemento & $\begin{array}{l}\text { Reemplazo de hasta un } \\
30 \% \text { de materias primas }\end{array}$ \\
\hline Volantes & Cementos mixtos & Hasta un $45 \%$ \\
\hline
\end{tabular}


Tabla 3. Potenciales usos de las cenizas volantes de RSU (Ferreira et al., 2003).

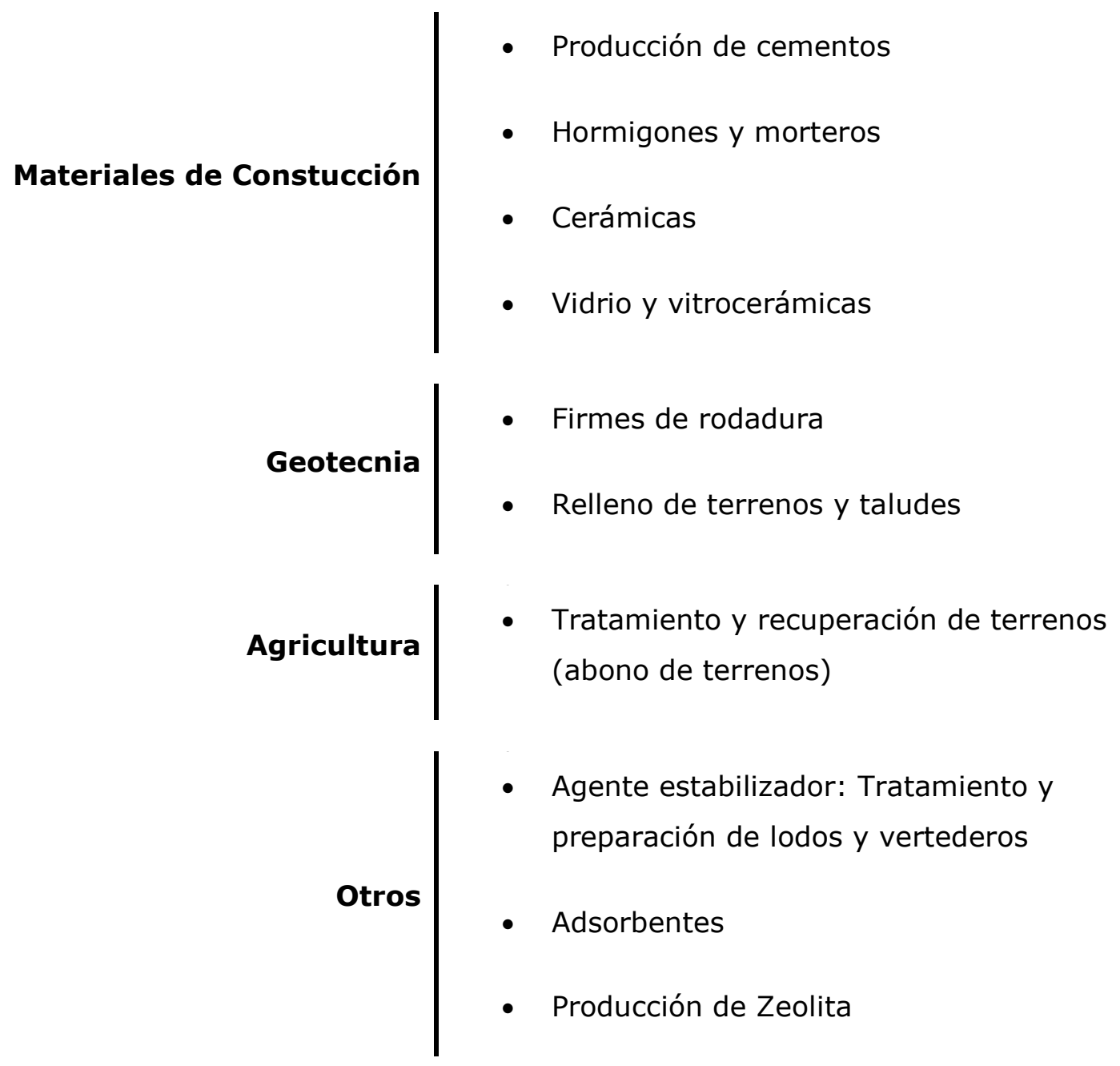

Una de las principales posibilidades para conseguir la reutilización de las cenizas volantes provenientes de la combustión de los residuos sólidos urbanos es su utilización como un subproducto de ciertos materiales de construcción. Como ya se ha reflejado en el gráfico adjunto, las distintas opciones son: Producción de cementos, hormigones y morteros, cerámicas y vidrio y vitrocerámicas. Por su relevancia, se investiga a continuación sobre los diversos estudios que se han venido realizando recientemente en cada campo. 


\subsubsection{PRODUCCIÓN DE CEMENTO}

Se denomina cemento a un conglomerante formado a partir de una mezcla de caliza y arcilla calcinadas y posteriormente molidas, que tiene la propiedad de endurecer al contacto con el agua.

El tipo de cemento más utilizado como aglomerante para la preparación del hormigón es el cemento Portland, producto que se obtiene por la pulverización del clinker portland con la adición de una o más formas de sulfato de calcio. Se fabrica a partir de ciertas calizas $\left(\mathrm{CaCO}_{3}-\right.$ Carbonato Cálcico) mezcladas con arcillas y otros materiales con contenido en aluminio y sílice. La mezcla obtenida posteriormente es calentada en hornos giratorios a una temperaturas entre $1540^{\circ}$ y $1600^{\circ}$. El producto resultante es denominado "clinker" y consiste en un polvo muy fino compuesto en distintas proporciones por silicato tricálcico $\left(\mathrm{C}_{3} \mathrm{~S}\right.$ ó $\left.3 \mathrm{CaO} \cdot \mathrm{SiO}_{2}\right)$, aluminato tricálcico $\left(\mathrm{C}_{3} \mathrm{~A}\right.$ ó $\left.3 \mathrm{CaO} \cdot \mathrm{Al}_{2} \mathrm{O}_{3}\right)$ y silicato dicálcico $\left(\mathrm{C}_{2} \mathrm{~S}\right.$ ó $\left.2 \mathrm{CaO} \cdot \mathrm{SiO}_{2}\right)$, además de ciertas proporciones de magnesio y componentes férricos. En ocasiones se puede añadir ciertas cantidades de yeso para ralentizar el proceso de endurecimiento.

En lo referente a las cenizas volantes, y dado que éstas contienen entre un $24 \%$ y un $27 \%$ de cal (Alba et al., 1997) y ciertas cantidades de silicatos y aluminosilicatos (Mangialardi et al., 1999), podrían ser utilizadas para la producción de polvo de cemento.

La producción de cemento es una actividad industrial que consume grandes cantidades de materias primas y energía y, a su vez, produce unas grandes emisiones de $\mathrm{CO}_{2}$, las cuales contribuyen en gran medida a la producción de gases de efecto invernadero y, por lo tanto, al calentamiento global. Gran parte de la energía utilizada lo es en la descomposición del carbonato cálcico $\left(\mathrm{CaCO}_{3}\right)$ en cal $(\mathrm{CaO})$. Se puede decir que por cada tonelada de cemento que se produce, se emite la misma cantidad de $\mathrm{CO}_{2}$ a la atmósfera. De esta forma, si las cenizas volantes fueran utilizadas como una fuente de obtención de cal, se podría conseguir una reducción de dichas emisiones de $\mathrm{CO}_{2}$ y, por lo tanto, contribuir a la reducción del calentamiento 
global. No obstante, existen en la actualidad diversas investigaciones (Wang et al., 2010) que demuestran que la reactividad de las cenizas volantes de RSU es baja, produciendose un cemento con tiempos de fraguado retardados respecto a los tiempos de fraguado de los cementos comunes, lo que da lugar también a una mayor producción de ettringita durante el proceso de hidratación que no tiene por qué ser perjudicial para las resitencias finales del cemento endurecido (Shi et al., 2009).

\subsubsection{Clinker de cemento tradicional}

En la actualidad, gran parte de las investigaciones realizadas con cenizas volantes de RSU están centradas en su reutilización como un nuevo recurso natural, especialmente en la preparación de productos a base de cementos. Existen tres grandes aplicaciones en este tipo de materiales (Shi et al., 2009): Como materia prima en la producción del clinker de cemento; como adición a cementos y hormigónes; y como árido de para las mezclas de cementos. Estos dos últimos apartados serán estudiados en el siguiente punto: Hormigones y morteros.

A nivel de laboratorio se han llevado a cabo estudios encaminadosa la sinterización de clinker de cemento Portland ordinario. (Saikia et al., 2007) evaluaron las propiedades de un clinker de cemento formado con una fracción del $44 \%$ en peso de cenizas volantes de $\mathrm{RSU}$, mezcladas con $\mathrm{CaCO}_{3}$ y pequeñas cantidades de óxidos de silicio y hierro. La dosis de carbonato cálcico en ningún momento superó el 50\%, mucho menor que el $70 \%$ requerido en la confección industrial de clinker de cemento tradicional. Esta reducción del $20 \%$ en $\mathrm{CaCO}_{3}$ puede ser de gran utilidad a la hora de reducir las emisiones de $\mathrm{CO}_{2}$ a la atmosfera ligadas a la producción de cemento. Esta investigación utiliza las cenizas volantes sin ningún tipo de tratamiento previo, aunque consideran la opción de realizar un lavado previo con la intención de reducir el contenido en cloruros desde un $15 \%$ hasta el $1 \%$, lo cual presentaría grandes beneficios a la hora de superar el problema generado por el exceso de cloruros en los hornos de producción. Sin 
embargo, estos ensayos no llegan a investigar mas profundamente en la calidad del producto resutante, ni a discutir sus posibles aplicaciones.

Aprovechando el alto contenido en metales pesados y sales, Pan et al. (2008), valoraron la posibilidad de reutilizar cenizas de hogar y volantes de RSU como materia prima en la producción de cemento Portland. Las cenizas en un primer momento fueron tratadas en una mezcla de agua y ácido con la intención de reducir o eliminar el contenido en cloruros, lo cual provocaría graves problemas de corrosión en los hornos de preparación del clinker de cemento. Según su investigación, los niveles aceptables de cloruros serían hasta un $1,75 \%$, en el caso de cenizas volantes, y de hasta un 3,50\% en las cenizas de hogar. La conclusión fue que la producción de este tipo de cemento sería una alternativa perfectamente viable para la gestión de las cenizas procedentes de la incineración de RSU. De la misma forma, se evidencia en sus estudios que la adición de cualquiera de los dos tipos de cenizas no afectaría a las resistencias a compresión de los productos derivados del clinker de cemento según lo establecido en la $\mathrm{CNS}^{5}$ para los cementos Portland tipo II, salvo en lo relativo a los tiempos de fraguado los cuales se verían ligeramente prolongados posiblemente por algún tipo de sobre-cocción durante el proceso de sinterización.

En la misma dirección, también estudiaron la influencia que el uso de cenizas volantes de RSU como materia prima en la confección del clinker de cemento podrian tener sobre la resistencia mecánica, las propiedades físicas y la seguridad medioambiental de sus uso. De igual forma, llegaron a la conclusión de que existía muy poca diferencia en cuanto a las propiedades de este clinker de cemento con respecto al tradicional. En concreto, se ensayaron muestras en las cuales se habían utilizado cenizas volantes de RSU en la confección de un clinker de cemento y se compararon con otras de referencia. Tanto la estabilidad del producto definitivo, sus necesidades de hidratación para conseguir una consistencia normal, como los tiempos de fraguado o su resistencia a flexión, eran equiparables a los de las muestras de referencia, a excepción de un mínimo descenso de la resistencia a

\footnotetext{
${ }^{5}$ Sistema Chino de Normalización
} 
compresión entre el tercer y el vigesimo octavo dia de fraguado. En cuanto a los requisitos medioambientales, se llegó a la conclusión de que una sustitución de materias primas por un 4,62\% de cenizas volantes implicaba alcanzar unos patrones de calidad medioambiental de clase III en lo relativo al contenido de metales pesados en el agua superficial, aunque sólo en edades tempranas (agua de lixiviado entre 0 y 3 dias, y 3 a 7 días). Para etapas más tardías, entre 7 y 28, y 28 y 60 dias, sólo se alcanzaba al clase II.

\subsubsection{Clinker de cementos sulfoaluminosos}

Una aplicación particular de este tipo de cenizas volantes podría ser su utilización con cementos de baja energía, también llamados cementos de sulfoaluminato de calcio $\left(4 \mathrm{CaO} \cdot 3 \mathrm{Al}_{2} \mathrm{O}_{3} \cdot \mathrm{SO}_{3}\right)$. Éstos son cementos especiales que pueden ser sinterizados a bajas temperaturas y además presentan altas resistencias con un rápido endurecimiento. Las cenizas volantes pueden ser utilizadas en este tipo de cementos como fuente tanto de aluminio, para la formación de los sulfoaluminatos de calcio, como sílice para la formación del silicato de calcio. La aplicación de otro tipo de residuos industriales en la fabricación de este tipo de cementos de baja energía ya sean cenizas volantes del carbón, escorias de altos hornos, finos de bauxita o fosfoyesos, ya ha sido objeto de varias investigaciones (Beretka et al., 1993).

Este tipo de cementos ha sido desarrollado con éxito en el laboratorio con la caracterización de sus propiedades físicas, químicas y sus posibles aplicaciones. El clínker se fabrica a temperaturas entre $1200^{\circ} \mathrm{C}$ y $1300^{\circ} \mathrm{C}$ durante 120 minutos, en laboratorio. Contiene iones de cloro en cantidades que rondan el $1 \%$ en peso, pero se hidrata con los otros componentes. Este tipo de sales deberán ser analizadas y estudiadas con rigor para evaluar los aspectos negativos relacionados con la corrosión de las armaduras. Hasta la fecha se ha podido constatar que sus resistencias mecánicas a compresión son bastante elevadas. Por el contrario, se incrementan las cantidades de metales pesados con lo que se debería establecer una serie de limitaciones para controlar su uso en la construcción. 
En la misma línea de investigación, Shi, H.S. et al., 2009, emplearon cenizas volantes de RSU como materia prima fundamental en la sinterización en el laboratorio de un clinker de cemento sulfoaluminoso. Mediante técnicas de escaneado microscópico de barrido se estudiaron los sistemas de sinterización, su comportamiento mecánico, así como, los procesos de hidratación y la microestructura del clinker. Los resultados mostraron que este tipo de clinker de cemento pude ser sinterizado de manera satisfactoria a temperaturas de entre $1200^{\circ} \mathrm{C}$ y $1300^{\circ} \mathrm{C}$ con unos tiempos de sinterización de entre 30 y 120 minutos, aunque teniendo en cuenta la fase de composite, el consumo de energía y el rendimiento mecánico, los mejores sistemas de sinterización fueron a 120 minutos. El contenido en iones de cloro $\left(\mathrm{Cl}^{-}\right)$del clinker desarrollado con cenizas volantes de RSU se encuentra en torno al 1,08\%. Es destacable que, la mayor parte de ellos, no pueden ser lixiviados en una solución acuosa, ya que la mayoría se encuentran entrelazados con los minerales del propio clinker y sus hidratos, sobre todo en la pasta de cemento endurecida durante el primer y el vigesimo octavo día de curado. Entre los productos de hidratación mencionados están: La ettringita, el gel de hidróxido de aluminio $\left(\mathrm{Al}(\mathrm{OH})_{3}\right)$ y el silicato cálcico hidratado $(\mathrm{C}-\mathrm{S}-\mathrm{H})$. Las resistencias a compresión del cemento sulfoaluminoso sinterizado a través de cenizas volantes de RSU, se mostraron muy elevadas en los primeros días de curado aunque se fueron suavizando en fases tardías.

Más recientemente, Wu et al. (2011), estudiaron la viabilidad de una sustitución parcial de las materias primas del clinker de cementos sulfoaluminosos por cenizas volantes de RSU. La producción de este clinker de laboratorio fue investigada mediante difracción de rayos-x (DRX), sometiendo a las diversas muestras a ensayos de resistencia a compresión y de libre expansión. La novedad en este caso es que se realizaron tres tipos distintos de ensayos de lixiviado con la intención de poder evaluar el impacto ambiental del producto generado. Los resultados mostraron que la sustitución de las cenizas volantes podría realizarse hasta en un 30\% de la combinación de materias primas. A lo largo de toda la experimentación, se 
determinó que para conseguir una buena calidad en el clinker de cemento sulfoaluminoso, tanto a nivel de composisión de fases, propiedades mecánicas y ahorro energético, se debian mantener unos niveles cercanos al 1,05 en el módulo de alcalinidad $\left(C_{m}\right)$, unas proporciones entre aluminio y azufre de 2,5 y entre aluminio y silicio de entre 2,0 y 3,0. Así mismo, la cocción de todos los componentes se tuvo que llevar hasta los $1250{ }^{\circ} \mathrm{C}$ durante 2 horas. De esta forma, se consiguieron altas resistencias a compresión, que coincidian con propiedades expansivas, en las etapas tempranas de los cementos sulfoaluminosos dependiendo del contenido en yeso de las materias primas. El estudio de los elementos tóxicos por el lixiviado de las fases de hidratación del sistema reveló que todos los elementos estudiados se encontraban fijados en los minerales del clinker o inmovilizados en los productos generados en los procesos de hidratación. A pesar de ser un estudio preliminar, representa un gran avance ya que de él se deduce que no existiría ningún tipo de amenaza directa al medioambiente en la utilización de cenizas volantes de RSU para la preparación de cementos sulfoaluminosos, si bien deja abiertas distintas líneas de investigación en lo referente al estudio de una posible toxicidad a largo plazo, así como a otros temas tan importantes como el mantenimiento de las propiedades mecánicas, tanto a corto, como a largo plazo, o la posible corrosión de los hornos de producción por el exceso de cloruros emitidos durante el proceso.

\subsubsection{Eco-cementos}

El uso de cenizas volantes en la producción de cementos puede suponer algún tipo de problemas técnicos. Su adición en hornos de cemento probablemente incrementaría las concentraciones de cloruros y metales pesados en el polvo de cemento. Las concentraciones de metales en el cemento deben estar sujetas a una serie de valores máximos por razones técnicas, mientras que el alto contenido en cloruros puede llevar a "ciclos", esto es una volatilización repetida en las zonas más calientes seguida de una condensación en las más frías. Estos ciclos pueden atascar rápidamente 
la batería de los intercambiadores de calor y provocar la inutilización de la planta de producción. Por lo tanto, en estos casos se debe proceder con mucha cautela para intentar evitar este tipo de problemas, bien llevando a cabo pre-tratamientos en las cenizas volantes para intentar eliminar los metales pesados y los cloruros, o bien controlando la cantidad de cenizas volantes añadidas al proceso de producción para no alcanzar los niveles perjudiciales.

De todo lo anterior se deduce que una línea de investigación posible será la de analizar y valorar un tratamiento previo de las cenizas volantes de RSU (Ferreira et al., 2008), tratando de limitar los contenidos en cloro y metales pesados antes de su incorporación a los hornos de fabricación del clínker de cemento. Debido a que estos residuos, contienen además de $\mathrm{Cl}$, elementos como $\mathrm{Ca}, \mathrm{Si}, \mathrm{Al}$, y $\mathrm{S}$, pueden ser empleados como materia prima para la fabricación de cementos especiales tipo Alinita (Goñi et al., 2011).

Mediante un tratamiento higrotermal se forman fases hidraúlicas precursoras de nuevos cemento belíticos que, además tienen la propiedad intrínseca de inmovilizar metales pesados tóxicos como el $\mathrm{Cd}, \mathrm{Pb}$ y $\mathrm{Zn}$. Este proceso de fabricación, vía hidrotermal, presenta importantes ventajas tales como el empleo de material prima residual y una reducción de las emisiones de $\mathrm{CO}_{2}$, y una importante reducción de la energía del proceso $\left(800^{\circ} \mathrm{C}\right.$ vs $1450^{\circ} \mathrm{C}$ ) con una práctica eliminación del proceso de molturación. A la vista de los resultados, se puede decir que este residuo, presenta una aplicación potencial para la obtención de la fase alinita a una temperatura de $1100^{\circ} \mathrm{C}$, lo que permite desarrollar cementos más ecoeficientes que los cementos Pórtland (que se obtienen por encima de los $1400^{\circ} \mathrm{C}$ ) con importantes aplicaciones

En base a esta línea de trabajo, (Wu et al., 2012) realizan la producción de cementos de Alinita con cenizas volantes de RSU, haciendo posible la sustitución parcial de materias primas básicas por el mismo porcentaje en peso de dichas cenizas. Los resultados fueron positivos siempre que el porcentaje de sustitución no fuera superior al 30\% en peso y, sobre todo, que la cantidad total de óxido de magnesio estuviera situada 
en torno al 1,4\%. En el proceso, obtuvieron un clinker de cemento buena calidad mediante la cocción de la mezcla a $1200^{\circ} \mathrm{C}$ durante dos horas. Durante los experimentos llevados a cabo, se probó la adición de yesos al clinker de cemento con la intención de mejorar los resultados mecánicos.

Los cementos de Alinita sinterizados presentaban mejores resultados a compresión en edades tempranas, siendo las muestras con un 5\% de yeso las óptimas en este aspecto. Por el contrario, la introducción de yeso en la mezcla, incrementaba ligeramente el agua de amasado necesaria y reducía los tiempos de fraguado. Finalmente, certificaron que no existiría ningún problema medioambiental dado que los análisis de lixiviación de metales pesados como: $\mathrm{Cr}, \mathrm{Pb}, \mathrm{Cd}, \mathrm{Zn}, \mathrm{Ni}$ y $\mathrm{Cu}$, quedaron atrapados en el Clinker y fijados a los productos de hidratación.

\subsubsection{HORMIGONES Y MORTEROS}

Al añadir agua a un cemento se produce una compleja serie de procesos simultáneos de hidratación a distintas temperaturas. Los productos formados durante estos procesos cristalizan y forman estructuras tridimensionales que enlazan a todas las sustancias presentes en el proceso y forman una masa firme y endurecida. Las reacciones que tienen lugar son la base para los procesos de estabilización/solidificación de aplicación a nivel mundial para el tratamiento de residuos peligrosos.

La estructura tridimensional formada en la hidratación de este tipo de compuestos también puede incluir pequeñas partículas de un diámetro inferior a $150 \mu \mathrm{m}$. Ya que las cenizas volantes procedentes de la combustión de los residuos sólidos urbanos tienen un grano de partícula muy pequeño podrían rellenar estos espacios y quedar encapsuladas en el interior de la matriz que forman hormigones y morteros.

Aunque la estabilización/solidificación es una técnica aplicada al tratamiento de residuos, podría ser reorientada para su reutilización. Las cenizas volantes pueden ser potencialmente usadas tanto como sustitutas del cemento usado en hormigones y morteros, como de los finos. En esta 
investigación se estudiará su uso como remplazo de un porcentaje del árido utilizado en la ejecución de diversos morteros de cemento.

\subsubsection{Cenizas volantes como sustituto del cemento en hormigones y morteros.}

En lo relativo al uso de las cenizas volantes como sustitutivo de parte del cemento usado en hormigones y cementos es de resaltar que éstas poseen ciertas características puzolánicas. Esto posibilita que las cenizas puedan ser usadas como remplazo parcial de parte del cemento en la ejecución de estas mezclas, algo parecido a lo que en la actualidad ocurre con el uso de las cenizas volantes provenientes de la combustión del carbón, las cual son ampliamente aceptadas como parte de la mezcla cementosa (Lin et al., 2003).

Las diversas normativas existentes regulan los requerimientos químicos y físicos de las cenizas volantes del carbón y las puzolanas naturales utilizadas en como parte de los hormigones provenientes de cementos Portland. Hamernik y Frantz (1991) investigaron distintos tipos de cenizas volantes de la combustión de residuos sólidos urbanos y llegaron a la conclusión de que eran similares a las puzolanas de clase $\mathrm{C}$, tal y como estas son definidas en las Normas ASTM. Pero también identificaron que cada tipo de ceniza volante no alcanzaba a cumplir con al menos un criterio de dicha Norma. Por ejemplo, las cenizas de combustibles derivados de residuos poseen altos valores de pérdidas de incandescencia y partículas muy gruesas, mientras que las cenizas de incineradoras presentan altos contenidos de óxido de azufre (VI) $\left(\mathrm{SO}_{3}\right)$ y estaban por debajo de los límites requeridos por las puzolanas clase $\mathrm{C}$ en lo requerido a los óxidos de silíceo, hierro y aluminio.

Aunque el propósito de esta Norma es la protección de la construcción ante una baja calidad y su deterioro, su aplicación estricta puede acarrear restricciones innecesarias en lo relativo a la utilización de nuevos materiales. En vez de especificar unos requerimientos determinados para 
cada material, Swamy (1994) propuso un enfoque centrado en su rendimiento, lo que permitiría la utilización de una amplia variedad de materiales sustitutivos sin comprometer sus requerimientos cualitativos.

Una de las propiedades fundamentales de cualquier hormigón o mortero es su resistencia a compresión. Hamernik y Frantz (1991) estudiaron el efecto de la resistencia a compresión derivado de la sustitución de cemento por cenizas volantes de residuos sólidos urbanos. Mientras que para niveles de sustitución del $45 \%$ en cenizas de combustibles derivadas de residuos se obtuvieron hormigones con resistencias a compresión asimilables a las del hormigón de referencia (sin cenizas), para sustituciones del $15 \%$ los resultados relativos a compresión fueron superiores al hormigón de control. Por el contrario, las cenizas de incineradora no se comportaron muy bien, dando resultados de resistencias a compresión mucho menores a los hormigones de control.

De cualquier forma, los niveles aceptables de sustitución son fuertemente dependientes de las características de las cenizas volantes, principalmente por su actividad puzolánica. En este aspecto, Zhang et al. (2006) investigaron la utilización de cenizas de incineración y su combinación. Los resultados probaron que este tipo de cenizas estaban compuestas principalmente por minerales arcillosos que podrían ser utilizados como parte activa de las mezclas de cementos. La actividad hidraúlica de las cenizas de incineradora es similar a la de las cenizas volantes con contenidos bajos en calcio, siempre y cuando estemos trabajando con una fracción de cenizas de incineradora en peso inferior al $20 \%$ del total de la mezcla. Por el contrario, las resistencias a compresión disminuyen si esta cantidad alcanza el 30\%, aunque con la adición de escorias de alto horno existe una pequeña mejora.

Si bien las resistencias obtenidas en la mayoría de los estudios realizados son acordes a las de los productos utilizados como referencia, el problema del lixiviado de partículas tóxicas se presenta como la asignatura pendiente en este tipo de actuaciones. Gao et al. (2008) acometieron una investigación en base a la viabilidad del uso de cenizas volantes de RSU 
como sustituto parcial del cemento. Collivignarelli y Sorlini (2002) investigaron en la misma línea de trabajo pero como añadido inerte en morteros. Para la preparación de las muestras, y con la intención de reducir los contenidos en cloro de las cenizas volantes, se sometieron a éstas a un proceso de lavado en unas proporciones sólido-líquido de 1/5 durante 30 minutos para, posteriormente, secar la solución mediante un filtro-prensa de placas y reducir el contenido en agua en un $20 \%$. El pH de la solución se ajustó a 6.0-10.5 mediante la adición de ácido para evitar el lixiviado de metales pesados. Durante este proceso, se lixiviaron pequeñas cantidades de metales pesados (con valores de $\mathrm{pH}$ de $8,8 \pm 0,3$ ), mientras que las sales solubles como cloruros y sulfatos de sodio, potasio y calcio desaparecieron en su mayoria en el agua del lavado.

Tabla 4. Compuestos principales de las cenizas volantes de RSU originales y lavadas (\%) (Gao, X. et al., 2008)

$\begin{array}{lllllllllllllll}\mathrm{Al}_{2} \mathrm{O}_{3} & \mathrm{SiO}_{2} & \mathrm{CaO} & \mathrm{Fe}_{2} \mathrm{O}_{3} & \mathrm{Na}_{2} \mathrm{O} & \mathrm{K}_{2} \mathrm{O} & \mathrm{MgO} & \mathrm{Cl} & \mathrm{F} & \mathrm{P}_{2} \mathrm{O}_{5} & \mathrm{SO}_{3} & \mathrm{SnO}_{2} & \mathrm{TiO}_{2} & \mathrm{ZnO}^{2}\end{array}$

\begin{tabular}{|c|c|c|c|c|c|c|c|c|c|c|c|c|c|c|}
\hline $\begin{array}{c}\text { CV } \\
\text { Original }\end{array}$ & 6,97 & 19,81 & 23,63 & 4,00 & 6,68 & 6,23 & 3,78 & 10,16 & 1,83 & 2,54 & 8,74 & 1,02 & 1,21 & 2,79 \\
\hline $\begin{array}{c}\mathrm{CV} \\
\text { Lavada }\end{array}$ & 9,82 & 28,46 & 26,78 & 5,33 & 1,56 & 2,09 & 5,35 & 1,28 & 1,79 & 3,59 & 6,63 & 1,28 & 1,60 & 3,65 \\
\hline
\end{tabular}

A su vez, durante esta transformación aparecieron nuevas especies minerales que mostraron el buen comportamiento de las cenizas lavadas. Tras el proceso de lavado, el contenido en cloro se redujo hasta $1,28 \%$, mientras que el resto de componentes químicos de las cenizas volantes lavadas (tabla 4) se presentaba muy parecido a los de las cenizas de clase C de la incineración del carbón y, por lo tanto, podrían ser incorporadas a los morteros de cemento como sustituto parcial del cemento (Huang, 2003).

En este punto de la investigación, las cenizas volantes lavadas se mezclaron con los clinkers de cemento en proporciones de 10\%, 20\% y $30 \%$ para la elaboración de distintos morteros en algunos de los cuales 
además, se incorporó entre un 0,25\% y un 0,50\%, en peso, de un tipo de agente quelante ${ }^{6}$ ditiocarbámico con la intención de estabilizar la presencia de metales pesados. Tanto los morteros al 10 y al $20 \%$ de contenido en cenizas volantes, presentaron resistencias aceptables, considerando éste último como el límite máximo de sustitución. La novedad dentro de esta investigación se encuentra en la realización de dos tipos de ensayos de lixiviado:

10) Por un lado se efectuó un ensayo TCLP a 7 y 180 días de muestras machacadas de morteros endurecidos en las cuales, la concentración de metales pesados en el lixiviado de las muestras sin quelatos eran mucho mayores que en las de los morteros de referencia (sin cenizas volantes). En estos mismos morteros, la cantidad de metales pesados descendió gracias a la adición del agente quelante e, incluso, el tiempo de curado también se mostró como un elemento influyente en la concentración de metales pesados ya que a mayor tiempo de curado se obtenian menores valores en el lixiviado.

20) También se realizaron ensayos de lixiviación a 180 días de muestras monolíticas de mortero consolidado. En estos casos, los morteros con cenizas volantes de RSU lavadas presentan una lixiviación de metales pesados más elevada que los morteros de referencia. Sin embargo, éstos se ven drásticamente reducidos al mínimo en el caso de la utilización del agente quelante. En este ensayo, el lixiviado del cloro se incrementó a largo plazo, con los consiguientes problemas de corrosión de armaduras que esto podría causar en una hipotética utilización. Por este motivo, en posteriores estudios se deberían acometer ensayos que intentaran reducir el contenido del $0,1 \%$ en cloro de las cenizas volantes de RSU.

\footnotetext{
${ }^{6}$ Antagonistas de los metales pesados. Son sustancias que forman complejos con iones de metales pesados. Una de las aplicaciones de los quelantes es evitar la toxicidad de los metales pesados para los seres vivos. Los quelantes se diseñan para competir con los metales por los grupos reactivos fisiológicos, evitando o revertiendo así sus efectos tóxicos.
} 
Otro resultado destacado fue que el elevado tiempo de fraguado del hormigón derivado de la adición de las cenizas puede ser resuelto mediante la inclusión de diversos acelerantes del fraguado. Mangialardi et al. (1999) propusieron otra forma de reducir el tiempo de fraguado de este tipo de hormigones ejecutados con cenizas volantes mediante un pre-lavado de las cenizas volantes con la intención de eliminar, de manera parcial, partículas solubles como sulfatos, cloruros álcalis y metales pesados, que son las responsables de retrasar el fraguado.

McCarthy y Dhir (2005) también realizaron investigaciones sobre el uso de cenizas volantes descalcificadas (denominadas "cenizas de gran volumen"), utilizandolas en un porcentaje superior al del 30\% comunmente aceptado para componentes distintos al clinker de cemento en la ejecución de hormigones. Los resultados demostraron que la utilización de hasta un $45 \%$ en masa de estas cenizas, combinadas con un cemento Portland tipo I, reportaba rangos de resistencias parecidos a los generados por los hormigones de referencia ( $\sin$ cenizas volantes), aunque las durezas tempranas, algo que resulta crítico en determinadas construcciones, se veian mermadas de manera muy importante al ser comparadas con esos mismos hormigones de referencia o incluso, con hormigones tratados con un menor porcentaje de cenizas volantes. Por este motivo, se decidió la repetición de los distintos experimentos pero empleando, en esta ocasión, cementos Portland tipo II de rápido endurecimiento y Portland tipo III de clinker de baja energía, con la intención de poder subsanar las disminuciones iniciales de resistencia, en base a que estos hormigones se aprovechan de las propiedades de absorción de agua de las cenizas volantes $y$, por lo tanto requieren un mínimo incremento en la cantidad total de cemento de la que les corresponderían en el caso de cementos sin adición de cenizas. A su vez, también se practicaron ensayos sobre el hormigón fresco (disminución de la trabajabilidad de la mezcla y exudado y perdida de humedad); de comportamiento mecánico (evolución de las distintas resistencias, modulos de elasticidas, retracción y fracturas); y durabilidad (absorción de agua, permeabilidad, tasas de carbonatación y difusión de 
cloruros). Los resultados obtenidos en el laboratorio indicaron que, en la mayoría de los casos, se obtenian similares o incluso mejores prestaciones con la utilización de cenizas de gran volumen en comparación con las ofrecidas por los hormigones ejecutados con cementos Portland tradicionales. Tan sólo se veian afectados los índices de carbonatación en los casos de hormigónes diseñados para bajas resistencias.

Además de la resistencia de hormigones y morteros y sus tiempos de fraguado, existen otro tipo de propiedades afectadas por el uso de cenizas volantes tales como el aire ocluido, resistencia a la helada, deshielo y resistencia al descascarillado de las superficies. Los resultados ofrecidos por Triano y Franz (1992) indican que, dependiendo del tipo de ceniza volante utilizada (de combustibles derivados de residuos o de incineradora) y de las condiciones aplicadas durante la incineración, estas propiedades pueden ser mejoradas o empeoradas. Por ejemplo, la incorporación de un determinado tipo de ceniza volante incrementa la resistencia a los procesos de hielo y deshielo en comparación con los hormigones de control, mientras que la utilización del otro tipo de cenizas la disminuye. Otra importante característica técnica es la posible reacción entre los álcalis y las cenizas de RSU. De acuerdo a lo expuesto por Rashid y Frantz (1992), el aluminio presente en las cenizas volantes puede reaccionar con los álcalis del cemento y producir eflorescencias que pueden derivar en la dilatación y rotura del producto. Este tipo de reacciones alkali-cenizas deberán ser tenidas en cuenta en cualquier tipo de potencial aplicación de las cenizas como sustituto del cemento.

Más recientemente, Lee et al. (2010 y 2011), tuvieron en cuenta todas estas directrices y consiguieron la elaboración de un producto granulado proveniente del machaqueo de cenizas volantes de residuos y de cenizas de hogar. A este polvo se le añadieron arenas de fundición, también llamadas de moldeo, con la intención de ajustar la basicidad de la mezcla a 1.1. Tras mezclar de nuevo, se formó una masa granular que fue fundida hasta formar una pasta, la cual fue de nuevo machacada hasta valores de partícula cercanos a $38 \mu \mathrm{m}$. En este punto, el producto obtenido fue 
mezclado en porcentajes del $10 \%, 20 \%, 30 \%$ y $40 \%$ en peso con el cemento utilizado para realizar los morteros. Los ensayos de lixiviación dieron, en todos los casos, resultados por debajo de lo establecido por la normativa. Así mismo, el comportamiento mecánico fue gradualmente en ascenso. Al tercer día era de la misma magnitud que el de los morteros de referencia $y$, a partir del séptimo, superior en todos los casos. Siendo la muestra con una sustitución de cemento del 30\% la que desarrolló mejor rendimiento con ganancias de resistencia cercanas al $48 \%$. Las conclusiones dieron la razón a los objetivos establecidos, ya que los análisis de termogravimetría de los productos establecieron que las pastas obtenidas se comportaba como un material puzolánico que reaccionaba con el $\mathrm{Ca}(\mathrm{OH})_{2}$ para formar silicato de calcio hidratado, el cual sería el encargado de rellenar los poros del mortero y conferir así las propiedades mecánicas mejoradas.

\subsubsection{Cenizas volantes de RSU como sustituto del árido en hormigones y morteros.}

La arena es utilizada como árido en las mezclas de hormigón y morteros. Aunque la utilización de cenizas volantes de RSU combinadas (cenizas de fondo y volantes) como árido ya ha sido estudiada (Rashid et al., 1992), su utilización como un mero sustituto de la arena no ha sido muy prometedora ya que el diámetro de las cenizas volantes es mucho menor que el de las distintas arenas utilizadas en la ejecución de hormigones y morteros. Pero si es cierto que podría ser utilizado para ser añadido a la fracción más fina de la arena, con lo que su utilización estaría más dirigida a la ejecución de hormigones aligerados como sustitutos de los áridos comerciales disponibles en la actualidad. Los hormigones aligerados tienen una menor densidad que los tradicionales, pero presentan el problema de tener una menor resistencia a compresión.

En el lado positivo, poseen unos mejores rendimientos en cuanto a su comportamiento como aislantes térmicos y acústicos, lo cual les hace apropiados para su aplicación como hormigones no estructurales con fines 
aislantes. También podría ser usado en aplicaciones estructurales siempre y cuando sus características técnicas tales como resistencia a compresión, densidad y niveles de absorción de agua, sean las adecuadas.

Dentro de este apartado, se está investigando la posible sinterización de las cenizas volantes de RSU para generar áridos ligeros y su posterior uso en la fabricación de hormigones ligeros o cualquier otro tipo de material de construcción que pueda emplear este tipo de áridos sintéticos ligeros, tales como bloques, losas para cubiertas, elementos de relleno, prefabricados, morteros decorativos, etc (Chen et al., 2010).

Los procesos de sinterización de las cenizas de RSU han sido estudiados por Mangialardi (2001, 2003 y 2004), mediante la modificación de la composición química de las cenizas a través de lavados preliminares de las mismas con agua y en cuatro etapas. El estudio se practicó sobre muestras cilindricas compactas de $15 \mathrm{~mm}$ de diametro y $20 \mathrm{~mm}$ de altura con la intención mejorar las características mecánicas y químicas de las cenizas. Sobre estos ejemplares que contenian cenizas tanto tratadas, como no tratadas, se ejercieron distintas presiones de compactación, así como, procesos de sinterización a distintas temperaturas y duración. De estos ensayos se concluyó que este lavado preliminar mejoraba notablemente las características tanto mecánicas, como químicas, de todas y cada una de las cenizas sinterizadas estudiadas. Siendo el mejor de los resultados el obtenido en las muestras compactadas a $28 \mathrm{~N} / \mathrm{mm}_{2}$ que habian sufrido procesos de sinterización a $1140^{\circ} \mathrm{C}$ durante 1 hora.

Los efectos del tamaño de las partículas también fueron objeto de estudio por Wang et al. (2002), los cuales practicaron diversas sinterizaciones (desde $400^{\circ} \mathrm{C}$ a $1000^{\circ} \mathrm{C}$ ), con diversas duraciones (desde 60 minutos a 4 horas) para estudiar el comportamiento de una serie de cenizas volantes de RSU fraccionadas y divididas en seis tamaños diferentes. En los ensayos se constató que la resistencia a compresión de las muestra sinterizadas disminuía de acuerdo con el tamaño de las partículas. Así mismo, la temperatura de sinterización afectaba a esta resistencia. De esta forma, las cenizas incineradas a $800^{\circ} \mathrm{C}$ durante menos 
de una hora, presentaban unas resistencias mayores de $68,5 \mathrm{MPa}$, lo que las situa dentro de unos límites aceptables para su utilización como materiales de construcción. En cuanto al tema de residuos tóxicos, los contenidos de cadmio y plomo en las muestras sinterizadas a $400^{\circ} \mathrm{C}-600^{\circ} \mathrm{C}$ mostraban una tendencia a disminuir inversamente proporcional al tamaño de los granos. De igual forma, en la sinterización a $800^{\circ} \mathrm{C}-1000^{\circ} \mathrm{C}$ los niveles de estos metales se mantenian proporcionalmente bajos sin que en este caso su contenido se viera afectado por el tamaño de las partículas. Por el contrario, la sinterización a estas temperaturas mostraba un mayor contenido en cromo, incluso mayor que el estudiado en las muestras sin tratar, debido a que los compuestos a base de cromo fueron convertidos en formas más solubles o de mejor extracción tras la sinterización. Igualmente, el contenido en cromo muestra una tendencia a disminuir inversamente proporcional al tamaño del grano.

En torno a este tema existe numerosa bibliografía (Mangialardi et al, 1999; Biernacki et al., 2008) orientada en gran parte a estudiar la mineralogía, tamaño de las partículas y propiedades del producto a sinterizar en bruto, y después de producida ésta. Se investigan y describen las resistencias mecánicas, cristalinidad, densidad, retracción lineal, absorción de agua y microestructura del producto resultante. Además se está comenzando a investigar otros parámetros como las presiones de compactación, molienda, tiempos y temperaturas de sinterización (Pomi et al., 2004), aunque el éxito de la snterización depende en gran manera de la composición química de las cenizas volantes.

Estas investigaciones precedentes tienen en cuenta la modificación de las cenizas volantes y su sinterización para su uso como áridos. Estudios más recientes (De Casa et al., 2007), se centran en la obtención directa de una materia prima para su utilización como componente de productos de construcción secundarios. Así, realizan ensayos sobre distintas mezclas de cenizas de hogar con cenizas volantes recogidas de los sitemas de control de polución. De todos los análisis concluyen que el mejor porcentaje de uso como árido en la formulación de pastas de cemento es del 10\%. La mezcla 
granular ensayada, presenta un comportamiento medioambiental satisfactorio, considerando que los valores de lixiviado estudiados estaban por debajo de los límites de la legislación relativa a la valorización de materiales de desecho. Los ensayos se realizaron sobre probetas de hormigón si bien, las muestras que ofrecieron mejores resultados mecánicos, mostraron cierta tendencia a la abrasión. De igual forma, la resistencia a la abrasión fue considerada demasiado baja para poder utilizar estos materiales como sub-base de rodaduras. Por el contrario, sus especificaciones son perfectas para su uso en muros de contención o taludes, ya que las propiedades mecánicas en este tipo de trabajos no son tan restrictivas. En este punto, se ensayó también la posibilidad de mezclar con determinadas cantidades de cenizas de hogar con el fin de mejorar las resistencias mecánicas.

Como en este último caso, en la mayoría de estas investigaciones se realiza el proceso de sinterización a partir de las cenizas volantes de RSU tal y como estas son recibidas en el laboratorio, sin ningún tipo de tratamiento previo. El proceso de densificación ocurre de manera simultanea al de la volatización del carbono residual, esto es, en forma de dioxido de carbono $\left(\mathrm{CO}_{2}\right)$, lo que necesita una capacidad de ajuste de las variables del proceso muy elevada para intentar alcanzar las máximas resistencias o las mayores densidades posibles. En las investigaciones consultadas, existe una relación lineal entre la resistencia a tracción indirecta de las muestras cilindricas sinterizadas y la densidad alcanzada en el proceso (De Casa et al., 2004).

Desde el punto de vista medioambiental, la evaluación de la liberación de elementos contaminantes en la utilización de cenizas volantes de RSU en hormigones y morteros, podría ser llevada a cabo mediante ensayos de lixiviado a corto y largo plazo, con la intención de asimilar el uso de los productos a su ciclo de vida (Yu et al., 2005). Existen multitud de ensayos muy dispares que pueden ser realizados para intentar evaluar el impacto ambiental de los residuos de la incineración sobre suelos y aguas subterráneas (van der Sloot et al., 2001; van der Sloot, 2002). 
Barna et al. (2000), presentan una metodología para modelar la liberación de residuos a largo plazo de un embalse de agua para la lucha contra el fuego cuyo fondo fue construido con una mezcla de cenizas volantes, conglomerantes hidráulicos y agua. Aunque el escenario no puede ser considerado una obra muy habitual, la metodología desarrollada puede ser extrapolada en otro tipo de aplicaciones parecidas. Triano y Franz (1992) evaluaron el comportamiento de lixiviación del hormigón que contenía hasta un $15 \%$ de cenizas volantes, y notificaron pequeñas cantidades de metales pesados en el lixiviado, muy por debajo de lo especificado en el procedimiento de toxicidad EPTOX ${ }^{7}$ (Applewhite-Ramsey et al., 1993).

El uso de cenizas volantes en este tipo de construcciones no es susceptible de crear problemas medioambientales, ya que el lixiviado de metales pesados no será importante debido que los hormigones aligerados serán utilizados a resguardo de la intemperie en estructuras internas. Aun así, el problema medioambiental radicará en la finalización de su periodo de vida, ya que habrá que tener en cuenta su procedencia y tratarlos, no como a los actuales RCDs, si no como a un nuevo tipo de residuos de construcción con un determinado contenido en metales pesados.

En cualquiera de los casos expuestos habrá que tener en cuenta dentro del ámbito normativo español, lo establecido por la Instrucción de Hormigón Estructural (EHE-08), la cual en su Capítulo VI, artículos 30 y 30.1, establece las características y limitaciones del uso de este tipo de adiciones en hormigones con fines estructurales. La limitación más importante es la que establece un valor inferior al $0,1 \%$ en el contenido de iones $\mathrm{Cl}^{-}$. Por lo tanto, queda abierta una nueva línea de investigación encaminada al tratamiento y preparación de estas cenizas volantes y su adecuación a esta Instrucción: "Las cenizas volantes no podrán contener elementos perjudiciales en cantidades tales que puedan afectar a la durabilidad del hormigón o mortero y causar fenómenos de corrosión de las armaduras.

\footnotetext{
7 "Extraction Procedure Toxicity"
} 
Además deberán cumplir las siguientes especificaciones de acuerdo con la Norma UNE EN 450-1". Es decir, en esta aplicación el contenido de óxido de calcio libre está limitado a un máximo del 1\%, lo cual las hace inviables sin un tratamiento previo (ya se ha visto con anterioridad que los contenidos de CaO están entre un $20 \%$ y un $30 \%$ ).

De esta forma, si nos centramos en los hormigones o morteros no reglados por la EHE-08, podremos ampliar las aplicaciones de las cenizas volantes de RSU a diversos productos de la construcción basados en el cemento como conglomerante. Así, conseguiremos utilizar la capacidad del cemento como fijador de las partículas tóxicas presentes en las cenizas, como los metales pesados, y anular la posible contaminación por lixiviación. Para ello se tendrán que iniciar diferentes investigaciones en este sentido realizando análisis de lixiviado con diferentes dosificaciones.

\subsubsection{CERÁMICAS}

De la amplia gama de productos cerámicos, entre los cuales se encuentra la alfarería y la porcelana, serán objeto de análisis sólo y exclusivamente los relacionados con la producción de materiales cerámicos para la construcción y, dentro de estos, lo serán aquellos con mayor posibilidad de absorción de cantidades importantes de cenizas volantes de RSU y con riesgos de contaminación menores. Nos referimos a los productos de cerámica porosa como es el caso de todo tipo de ladrillos, bovedillas, tejas, losas, losetas, piezas de gres y adoquines cerámicos para pavimentación.

La cerámica proviene de materiales terrosos maleables como la arcilla, que se consiguen endurecer mediante la acción de altas temperaturas. Aparte de las arcillas que confieren al producto cohesión y plasticidad, la pasta de cerámica también incluye otros tipos de materiales inertes que proporcionan al conjunto una estabilidad estructural para poder conservar la forma dada durante la cocción y su secado. El cuarzo, compuesto de dióxido de silicio (también llamado sílice, $\mathrm{SiO}_{2}$ ), es el más frecuente de estos 
materiales inertes y se suele encontrar en forma de arena o esquistos. La sílice se suele utilizar en el esmaltado o vitrificado de los materiales cerámicos en combinación con otra serie de agentes rigidizadores y fundentes. Cuando se aplica una capa de esmalte a un cuerpo cerámico y posteriormente se cuece, los componentes del esmalte se funden y obtienen su aspecto vítreo.

Las arcillas tienen una gran capacidad de retención de metales pesados en su estructura cristalina mineralógica una vez producida la sinterización. Si a esta capacidad de fijación le unimos que, una vez combinadas con la sílice, incrementan notablemente su capacidad de vinculación estable con los elementos presentes en las cenizas volantes de RSU que aportan óxidos y aluminosilicatos, se produce una contribución especial a la vitrificación interna, y también superficial, que confiere una protección a los productos cerámicos en donde son aplicadas y, además, se favorece su impermeabilidad.

De acuerdo a lo mencionado con anterioridad, la industria cerámica es una gran consumidora de materias primas naturales con base silícea. Esto la convierte en un potencial consumidor de cenizas volantes de RSU. Es más, al tratarse éstas de un polvo de escasa entidad (CEDEX, 2007), podrán ser fácilmente incorporadas a las pastas cerámicas casi sin necesidad de ningún tratamiento previo. Contra su utilización sin embargo, y de igual forma que en los casos anteriores, está el hecho de que las cenizas volantes de RSU tienen una gran cantidad de óxido de hierro y de diferentes metales, lo cual puede afectar de manera negativa a las propiedades del producto cerámico resultante (Queralt et al., 1997). No obstante, la industria cerámica siempre ha utilizado óxidos de metales pesados como plomo, cromo o cobalto durante su proceso industrial (Rokhvarger et al., 2009), con lo cual el problema planteado puede ser fácilmente solucionado mediante una elección razonada de la cantidad de cenizas volantes de RSU añadidas a los procesos.

La inclusión de este tipo de cenizas en baldosas cerámicas ha sido ya estudiada mediante la adición de un 50\% de cenizas de incineración, lo cual 
ha presentado aceptables resultados en cuanto a la durabilidad del producto obteniéndose unos módulos de rotura de $76,20 \mathrm{~kg} / \mathrm{cm}^{2}$, lo cual es incluso superior a los $12,24 \mathrm{~kg} / \mathrm{cm}^{2}$ exigidos por la Norma JIS para suelos de baldosas. Los valores del coeficiente de absorción están dentro de la normalidad para este tipo de pavimentos cerámicos. Así mismo, los ensayos de lixiviación muestran valores mínimos para los metales pesados y elementos orgánicos estudiados. De acuerdo a estos ensayos, los pavimentos de baldosas cerámicas podrán ser utilizados tanto al exterior como al interior, así como en el chapado de muros exteriores.

En conexión directa con esto, el estudio completo realizado por Haiying et al. (2007) incorpora análisis de lixiviados. Los mayores riesgos de toxicidad detectados se refieren a elementos químicos como mercurio, zinc, plomo y cadmio, los cuales quedan reducidos sustancialmente tras la sinterización y el proceso de vitrificación, quedando libres cantidades muy pequeñas en fases solubles. En este caso, las temperaturas de cocción deben determinarse con precisión para obtener un control adecuado de los lixiviados. De esta forma, los autores de esta investigación concluyen que la utilización de cenizas volantes de RSU en la fabricación de productos cerámicos vidriados es un modo muy efectivo de poder estabilizar los mencionados metales pesados.

\subsubsection{VIDRIO Y VITROCERÁMICA}

Otra posible aplicación para las cenizas volantes de RSU es intentar convertirlas en una sustancia de tipo vidrioso mediante su fusión a temperaturas por encima de los $1300^{\circ} \mathrm{C}$. Este proceso se denomina comúnmente vitrificación y es una de las posibles opciones para el tratamiento de las cenizas volantes de RSU. A lo largo del proceso de vitrificado, las altas temperaturas se encargan de destruir los componentes orgánicos de las cenizas como las dioxinas, con unas tasas de eficiencia de entorno al 99,9\% (Abe et al., 1996; Elliot et al., 1993), mientras que los metales pesados, o son encapsulados dentro de la matriz silícea, o son 
separados del producto final por evaporación o precipitación diferencial (Boccaccini et al., 1999).

Park y Heo (2002) desarrollaron una investigación mediante la que reutilizaban vidrios confeccionados a partir de cenizas volantes de RSU para su posterior uso como productos vitrocerámicos para materiales de construcción. Los vidrios originales fueron realizados mediante la vitrificación de cenizas volantes de RSU con la adición de dioxido de silicio $\left(\mathrm{SiO}_{2}\right)$, óxido de magnesio ( $\left.\mathrm{MgO}\right)$ y dióxido de titanio $\left(\mathrm{TiO}_{2}\right)$. Con posterioridad, el vidrio fue tratado termicamente mediante un proceso de ceramización. En un primer momento sufrió un proceso de nuclearización a $720^{\circ} \mathrm{C}$ durante 90 minutos $\mathrm{y}$, posteriormente, una fase de crecimiento cristalino a $870^{\circ} \mathrm{C}$ durante 10 horas. La vitrocerámica formada mostró buenas resistencias mecánicas, con unas durezas de hasta 6,73 $\mathrm{MPa}$, una tenacidad a la fractura de 1,86 MPa.m ${ }^{1 / 2}$ y una resistencia a flexión de 127 $\mathrm{MPa}$. Los compuestos vitrocerámicos desarrollados, en los que el uso de cenizas volantes de RSU alcanzan valores de hasta un 75\%, muestran una excelente resistencia al lixiviado de iones de metales pesados en agua. La cantidad de estos iones lixiviados después de 18 horas y a $23^{\circ} \mathrm{C}$ está muy por debajo de las regulaciones internacionales con unas proporciones de $\mathrm{Cd}^{2+}$ menores a 0,04 ppm, de $\mathrm{Cr}^{3+}$ menores a 0,004 ppm, de $\mathrm{Cu}^{2+}$ por debajo de 0,003 ppm y de $\mathrm{Pb}^{2+}$ inferiores a 0,15 ppm.

En la actualidad, existen varias compañías a lo largo de todo el mundo que han implementado la tecnología de vitrificado con adición de cenizas volantes de RSU, especialmente en Japón y China (Haiying et al., 2007), o de plantas de centrales térmicas de carbón (Myung, 2004). En este caso, el proceso implica la fusión de las cenizas volantes a temperaturas elevadas $\left(1500^{\circ} \mathrm{C}-1600{ }^{\circ} \mathrm{C}\right)$, a continuación se mezclan con otros materiales $\mathrm{TiO}_{2}$ y $\mathrm{CaO}$ para que actuen como agentes nucleantes con la intención de producir un tipo de vidrio que, cuando se trata termicamente a menor temperatura, nuclea fases cristalinas que dan al composite final las propiedades apropiadas para un material vitrocerámico. 
Por el contrario, uno de los mayores inconvenientes del uso de la vitrificación es su alto coste debido a que se trata de un proceso con un alto uso energético. Las temperaturas para conseguir la vitrificación $\left(1300^{\circ} \mathrm{C}\right.$ ) son algo más elevadas que las de cocción de cerámicas porosas ( $920^{\circ} \mathrm{C}-$ $980^{\circ} \mathrm{C}$ ) lo cual hace que el proceso tenga un mayor consumo energético y económico.

Para reducir estos costes de procesado, Boccaccini et al. (1999) sugieren la transformación de las cenizas de RSU en materiales vitrocerámicos ya que éstos son productos con mejores propiedades y un mayor precio en el mercado lo cual supondría una clara recuperación de la inversión. Los productos vitrocerámicos convencionales se forman provocando la cristalización de ciertos vidrios bajo tratamientos controlados de calor (Paul et al., 1990). Los materiales vitrocerámicos presentan mayores resistencias mecánicas además de propiedades aislantes a la electricidad, por lo que su habitual ámbito de utilización es la industria aeronáutica o transformadores eléctricos de alto rendimiento.

Los productos vitrocerámicos derivados de cenizas volantes de RSU pueden ser obtenidos mediante la aplicación controlada de una determinada temperatura en las etapas de enfriado (Boccaccini et al., 1997). El producto resultante presenta mejores características tanto mecánicas, como técnicas en relación al original. Entre estas mejoras están: una mayor dureza, mejor trabajabilidad, mayor resistencia a la fractura y una mayor resistencia a choques térmicos. De lo dicho se deduce que las posibles aplicaciones de estos productos serán: solados de instalaciones industriales; revestimientos interiores o exteriores de paramentos; y, la producción de componentes de maquinaria industrial. Hasta la fecha este tipo de usos no ha sido investigado.

En esta línea de investigación, Yang et al. (2009) continuaron los trabajos desarrollado por Boccaccinni en el uso de aditivos con la intención de aminorar la temperatura de fusión de los residuos y, por lo tanto, reducir los costes de producción de los productos vitroderámicos derivados de la vitrificación de RSU. En el desarrollo de su investigación se redujeron 
significativamente dichas temperaturas de fusión desde los $1500^{\circ} \mathrm{C}$ hasta los $1200^{\circ} \mathrm{C}$, lo cual fue logrado mediante la combinación de cenizas volantes de RSU con polvo de arena de sílice y escorias de hierro ricas en oxido de férrico $\left(\mathrm{Fe}_{2} \mathrm{O}_{3}\right)$ y óxido de calcio $(\mathrm{CaO})$.

Desde el punto de vista medioambiental, hasta la fecha se han realizado numerosos estudios para comprobar la lixiviación y posible toxicidad de la vitrificación de las cenizas volantes (Haugsten et al., 2000; Elliot et al., 1993; Van der Sloot et al., 1996 y Boccaccini et al., 1997). Como era esperado, las cenizas volantes vitrificadas se convierten en un producto mucho menos lixiviante que el original, lo cual avala este tipo de tratamientos como posible uso de las mismas.

Park y Heo (2002) crearon compuestos vitrocerámicos alcanzando valores de hasta un $75 \%$ de cenizas volantes de RSU que muestraron excelentes resistencias al lixiviado de iones de metales pesados en agua. La cantidad de estos iones lixiviados está muy por debajo de las regulaciones internacionales. La estabilidad química probada por los procedimientos de lixiviados tóxicos (TCLP) establecieron que los iones de los metales pesados formaban enlaces quimicos muy estables en estas estructuras vitrocerámicas.

A pesar de que la mayoría de cenizas volantes vitrificadas superan los ensayos de lixiviado y toxicidad, existen una serie de ensayos con cultivos en vivo que reflejan su potencial toxicidad (Boccaccini et al., 1997). Haugsten y Gustavson (2000) se encargaron de comparar los resultados de una serie de ensayos de lixiviado realizados con cenizas volantes vitrificadas poniéndolas en comparación con normativas de diferentes países. Los resultados indicaron que este tipo de tratamientos satisfacen los mínimos establecidos por las normas alemanas, francesas, austriacas, suizas y americanas en lo relativo a materiales inertes e, incluso, a la holandesa en lo relacionado con materiales de construcción, con la única excepción de los valores de antimonio los cuales estaban por encima de los exigidos. 
En este sentido, Yang et al. (2009) demostraron la viabilidad, en lo que al lixiviado de metales pesados se refiere, de la reutilización de cenizas volantes de RSU en la producción de productos vitrocerámicos a una baja temperatura de fusión. De hecho, el comportamiento de lixiviación de estos productos fue menor que el obtenido del ensayo de otros realizados sobre una matriz cementosa de referencia, elaborados usando el mismo tipo de residuos.

\subsubsection{MODIFICACIÓN DEL TERRENO: GEOTECNIA.}

\subsubsection{Firmes de rodadura.}

Se trata de elementos estratificados con una estructura formada por múltiples capas: una capa superficial bituminosa o asfáltica, una capa media (con una capa base y varias sub-bases) y un último nivel en contacto con el terreno, que es la explanada.

La capa base es la que se encuentra inmediatamente por debajo de la superficie portante con una función de soporte estructural al conjunto. Está formada por una serie de materiales granulares (fragmentos de materiales pétreos de machaqueo o escorias) que deben ser estabilizados mediante la utilización de productos cementosos (cementos, puzolanas naturales, etc.). Entre ésta y la capa inferior, suelen existir una serie de estratos denominados sub-bases que proporcionan estabilidad a la capa base y que están ejecutados con el mismo tipo de materiales que la anterior pero de menor calidad.

Una posible aplicación de las cenizas volantes de RSU dentro de los firmes de rodadura es servir como sustituto de la arena o del cemento utilizado en la capa base 0 en las sub-bases. Los aspectos medioambientales relacionados con este tipo de utilización son los derivados de una posible contaminación de los estratos de suelo subyacentes debido al lixiviado producido por el agua de la lluvia. 
La viabilidad de este tipo de utilización ha sido estudiada por la Organización Holandesa para la Investigación en Ciencia Aplicada (Mulder et al., 1996). El producto obtenido después de una serie de prelavados seguidos de una cementación de las cenizas, cumple con la normativa holandesa para materiales de construcción. Aunque la investigación se centra en aspectos medioambientales también se incluye un apartado relacionado con sus posibles costes en el cual se demuestra que este tipo de tratamientos es más económico que los procesos de eliminación de las cenizas como material tóxico. Sin embargo, el informe no incluye ningún tipo de referencia al comportamiento técnico de los productos desarrollados por lo que no se asegura su adecuación como firme de rodadura.

En otro tipo de estudios, la utilización de cenizas volantes provenientes de la combustión del carbón (Mulder et al., 1996) y las cenizas de fondo de los hornos en la combustión de RSU (Rogbeck et al., 1996) como materias primas colaborantes en la ejecución de firmes de rodadura, sí que ha sido definida. Aunque la investigación de Xue et al. (2009) es la que avala sin ninguna duda la mejora en las propiedades de las mezclas asfálticas que contienen cenizas volantes de RSU, incluso para las capas de rodadura de pavimentos tipo Marshall y lo denominados superpavimentos ${ }^{8}$. En su estudio, se define la posibilidad de utilizar estas cenizas volantes para reemplazar parcialmente fracciones finas de áridos o de filler mineral en aglomerados asfálticos. Así, se disminuye el consumo de recursos naturales y se produce una reutilización de unos residuos valorizados.

Además de las cenizas volantes, también se experimentó el uso de escorias granuladas para sustituir de manera parcial fracciones correspondientes de áridos gruesos. En total se llegaron a analizar mezclas con más de un $90 \%$ en peso correspondientes a residuos sólidos. Se llevaron a cabo comparativas de probetas realizadas con la sustitución del árido con otras con áridos naturales, y se ensayaron para definir estabilidad Marshall, sensibilidad al agua, módulo dinámico, leyes de fatiga y formación

\footnotetext{
${ }^{8}$ Del inglés SUPERPAVE o "Superior Performing Asphalt Pavements": Pavimentos de asfalto con un rendimiento superior (Trad. del autor)
} 
de roderas. Todos los ensayos efectuados demostraron la mejora de las propiedades de las mezclas para superpavimentos con sustitución parcial de fracciones de áridos, filler y finos por granulados sólidos procedentes de RSU, frente a las propiedades de las mezclas convencionales con áridos de procedencia natural, incluso por encima de los pavimentos Marshall. La investigación se completó con un análisis de lixiviación comparado entre el mismo tipo de probetas aplicando sobre ellas el ensayo TCLP para la obtención de componentes tóxicos lixiviados.

Los resultados confirmaron que las mezclas asfálticas actúan, como estaba previsto (Mulder et al., 1996), como verdaderos agentes de estabilización y solidificación con la capacidad de fijar los metales pesados contenidos en las cenizas volantes de RSU, debido a la adherencia y estabilidad química que presenta la matriz asfáltica. Las concentraciones de la mayor parte de los metales pesados lixiviados de este tipo de asfaltos está dentro de los niveles establecidos por la EPA ${ }^{9}$. En comparación con las estabilizaciones y solidificaciones realizadas en productos cementosos, aquellas realizadas en esfaltos resultan mucho más efectivas para limitar y fijar la movilidad de los metales pesados dentro de sus matrices. Sin embargo, la capacidad de acumulación de metales lixiviados se incrementa proporcionalmente al tiempo dedicado al lixiviado $\mathrm{y}$, por el contrario, disminuyen dependiendo del $\mathrm{pH}$ de la sustancia lixiviante. La relación de metales pesados obtenidos a través del proceso de lixiviado TCLP tienen una correlación directa con su concentración inicial en los residuos originales, salvo en el caso de las concentraciones de niquel ( $\mathrm{Ni}$ ). En este caso, existian unos niveles moderadamente bajos de $\mathrm{Ni}$ que, tras la realización de los diversos ensayos, se transformaron en una tasa relativamente elevada dentro de la matriz asfáltica final. Lo cual nos lleva a afirmar que este tipo de productos asfálticos no esta capacitado para estabilizar y solidificar de manera eficaz el $\mathrm{Ni}$ contenido en las cenizas volantes de RSU.

\footnotetext{
9 "Environmental Protection Agency": Agencia de Protección Ambiental de los Estados Unidos
} 
Otro posible campo de aplicación de las cenizas volantes de RSU dentro del apartado de firmes de rodadura, puede ser la utilización de pavimentos de hormigón/mortero, no solo para las capas inferiores, sino también en el diseño y construcción de firmes rígidos. De esta forma, la incorporación de nano arcillas y cenizas volantes posibilitará la ejecución de hormigones autocompactantes, con técnicas de encofrado deslizante, para desarrollar acabados superficiales lisos mediante la utilización de un gran volumen de cenizas volantes de RSU. El comportamiento medioambiental de este tipo de residuos con estas aplicaciones ha sido ampliamente investigado.

\subsubsection{Relleno de terrenos y taludes}

Este tipo de construcciones están formadas por tierra y materiales pétreos y son utilizados para la contención de terrenos. Cuando los terrenos en cuestión no presentan unas determinadas propiedades geotécnicas es una práctica muy común el estabilizarlos con cal y cemento. Esta práctica reduce la compresibilidad del terreno e incrementa la resistencia al esfuerzo cortante por lo que mejora las propiedades técnicas de los suelos.

Una posible aplicación de las cenizas volantes de RSU dentro de este campo de actuación será como sustitución de la cal o el cemento utilizado, aprovechando las características puzolánicas de este tipo de cenizas. La densidad media de las cenizas volantes de RSU es menor que las de otros productos de relleno utilizados en la ejecución de taludes: Los valores usuales de densidad de estas cenizas son entre 1,7 y 2,4 (Tay, 1991), mientras que para la arena tradicional es 2,65. En el caso de terrenos blandos y fácilmente comprimibles existiría una ventaja en la utilización de las cenizas volantes de RSU ya que el peso propio del material se vería reducido con lo que los asentamientos diferenciales serían menores.

El principal problema que presenta el uso de cenizas volantes de RSU en la modificación de terrenos es la posibilidad de una hipotética contaminación del terreno y los acuíferos anexos a las zonas de su aplicación. 
Goh y Tay (1993) compararon los lixiviados procedentes de cenizas volantes y de aquellos en los que las cenizas habían sido estabilizadas con cal y cemento. Reflejaron que, como era previsible, los segundos tenían unos valores de lixiviado mucho menores. Sin embargo, limitaron su estudio a las cenizas volantes y no lo ampliaron a suelos afectados por ellas, lo cual hubiera proporcionado mucha más información del comportamiento de lixiviación de taludes y rellenos ejecutados con éstas. De nuevo, tratamientos mediante prelavados de las cenizas podría ser un aspecto a tener en cuenta de acuerdo a lo ensayado por Mulder et al. (1996) respecto a los firmes de rodadura.

\subsubsection{TRATAMIENTO Y RECUPERACIÓN DE TERRENOS.}

La aplicación de fertilizantes con la intención de enriquecer los suelos de cultivo es una práctica habitual. Las plantas requieren más de una docena de componentes químicos para su cultivo. Nitrógeno, fósforo y potasio son los tres elementos principales que se encargan de suministrar los fertilizantes, mientras que boro, cobre y manganeso son también necesarios aunque en una menor cantidad.

Las cenizas volantes de RSU son ricas en dos de los tres nutrientes principales mencionados: fosforo y potasio (ya que el nitrógeno se pierde durante el proceso de combustión). Esto significa que estas cenizas tienen un uso potencial como sustituto de fertilizantes dentro de la agricultura. Este uso fue estudiado por Rosen et al. (1994), el cual descubrió que las plantas cultivadas en suelos abonados con cenizas volantes de RSU eran entre un $50 \%$ y un $100 \%$ más grandes que las que lo hacían en suelos sin este tipo de abono. Incluso eran mayores que cultivos realizados en suelos abonados con sólo fertilizantes de potasio o de fósforo.

Aparte de este poder fertilizante, las cenizas volantes de RSU pueden ser utilizadas como agente calcificante. La cal (óxido de calcio) es a menudo añadida a los terrenos con la intención de reducir su acidez. Las cenizas volantes de RSU presenta unos valores muy elevados de $\mathrm{pH}$ y, por lo tanto, 
pueden reducir fácilmente la acidez de determinados terrenos (Rosen et al., 1994).

La cantidad de cenizas aplicadas sobre estos suelos es uno de los puntos clave, ya que un exceso en su cantidad supondría una inclusión innecesaria de nutrientes (a la vez que elementos contaminantes). Los valores estudiados hasta el momento hablan de cifras en torno al $5 \%$ y el $40 \%$. Rosen et al. (1994) propone la aplicación de unas tasas que dependen de la disponibilidad de nutrientes dentro de las cenizas y de las recomendaciones de los fertilizantes de uso común dependiendo del cultivo en cuestión.

Desde el punto de vista medioambiental, este tipo de usos tanto como fertilizante, como abono de terrenos, es una materia bastante controvertida. Hace que surjan preguntas sobre el tema de la toxicidad de estos componentes que hay que tratar de forma cautelosa y más cuando los vegetales forman la base de la cadena alimenticia para el ser humano. Especialmente importante es el contenido en metales pesados y sales de las cenizas volantes.

\section{a) Metales pesados:}

En lo referente a este tipo de metales, es conveniente establecer una diferencia entre la concentración de metales en un suelo y su disponibilidad en él. De hecho, sólo una pequeña fracción del total contenido en un suelo está disponible para la absorción por las plantas, y ésta depende de unas determinadas interacciones entre la planta, el suelo y los elementos químicos. Por ejemplo, el césped común absorbe preferencialmente potasio por encima de magnesio, mientras que legumbres como la alfalfa, tienen una gran capacidad de absorción de magnesio (Ferreira et al., 1999).

El principal factor que afecta a la movilidad de los metales pesados es el $\mathrm{pH}$. La disponibilidad de fósforo puede resultar un problema en suelos muy ácidos o muy alcalino calcáreos, ya que las formas insolubles de éste metal (de ahí su inmovilidad) son las predominantes 
en este tipo de suelos. Otro factor que afecta a la movilidad de los metales dentro de los suelos es el contenido en cloruros. Los cloruros son uno de los componentes frecuentemente encontrado en las cenizas volantes de RSU y son capaces de complicar los enlaces químicos ciertos metales aunque favoreciendo su movilidad.

Unas cantidades excesivas de elementos disponibles en un suelo implica su acumulación en los tejidos de las plantas en él cultivadas. Algunos de estos elementos como el boro, cobre, molibdeno o zinc son considerados como nutrientes esenciales $y$, en determinadas cantidades, pueden incluso mejorar el crecimiento de la planta. Sin embargo, por encima de ciertos niveles se pueden transformar componentes fitotóxicos ${ }^{10}$. Los niveles aceptables de estos elementos dentro de los tejidos de las plantas quedan reflejados en la tabla adjunta.

Diversas investigaciones realizadas en plantas cultivadas sobre suelos abonados con cenizas volantes de RSU muestran una seria acumulación en los tejidos de las plantas de zinc, cadmio y plomo (Giordano et al., 1983) y molibdeno, boro y cobre (Rosen et al., 1994), la mayoría de los cuales se encontraba por encima de los niveles aceptables. Resulta llamativo que en estas investigaciones no hubo ningún interés en intentar adaptar la cantidad de cenizas utilizadas dependiendo de los nutrientes requeridos por cada especie. Un aspecto interesante que debe ser mencionado es que, a pesar de haber superado los niveles definidos en la tabla 5 , en ningún caso se vio afectado el crecimiento de las plantas lo cual podría significar que se trata de unos niveles ciertamente conservadores o generalistas.

\footnotetext{
${ }^{10}$ Sustancias que matan o inhiben el crecimiento de las plantas, o que causan un efecto adverso sobre ellas. Definición dada por la Asociación Española de Toxicología. Glosario de términos toxicológicos. Versión española ampliada por M. Repetto y P. Sanz. Sevilla: AET; 1995. (AET)
} 
Tabla 5. Niveles deseables para los principales micronutrientes en el tejido de las plantas (Ferreira et al., 2003)

\begin{tabular}{ccc}
\hline Micronutriente & Rango deseable $(\mathrm{mg} / \mathrm{kg})$ & Alto riesgo de fitotoxicidad \\
\hline Hierro & $40-250$ & Suelos anaeróbicos ácidos \\
\hline Manganeso & $16-45$ & Suelos ácidos \\
\hline Aluminio & & Suelos ácidos con bajo \\
& & contenido en materia \\
\hline Cobre & $0,9-7$ & orgánica \\
\hline Zinc & $1-3,5$ & Suelos ácidos \\
\hline Boro & $0,4-1$ & Suelos $>20$ mg/kg \\
\hline Molibdeno & 0,15 & Suelos alcalinos \\
\hline
\end{tabular}

En cultivos destinados al consumo animal existe una preocupación añadida: Incluso en el caso de que la cantidad de metales pesados se encuentren dentro de unos niveles aceptables en lo relativo a la fitotoxicidad, esto no implicaría que no exista ninguna clase de riesgo para los animales que se alimentan de esos cultivos. Por ejemplo, el molibdeno es muy importante a la hora de la fijación del nitrógeno y tiene una influencia muy positiva en el crecimiento pero, por el contrario, unos niveles de concentración en los tejidos de los cultivos por encima de los 5 a $10 \mathrm{mg} / \mathrm{kg}$ puede causar un efecto denominado molibdenosis en los rumiantes que han pastado en esas plantaciones (Rosen et al., 1994). Por lo tanto esto limita el uso de cenizas provenientes de residuos con altos contenidos de molibdeno.

b) Salinidad:

La adición de cenizas volantes de RSU a los suelos destinados a cultivos con toda seguridad incrementará su contenido en sales debido, 
en gran parte, a los altos niveles de sales solubles que éstas presentan. Este hecho es relevante desde el momento en que puede provocar el denominado estrés salino a las plantaciones tratadas con estas cenizas.

La tolerancia a la sal de las plantas es variable dependiendo de la especie. Según esto, los cultivos pueden ser clasificados de tres formas distintas: tolerantes, moderadamente tolerantes y moderadamente sensibles. La disminución de la productividad de ciertos cultivos debido al incremento en la salinidad de los suelos ha sido ampliamente estudiada (Ferreira et al., 1999) al igual que la fitotoxicidad derivada de la salinidad de los campos (Giordano et al., 1983).

De lo analizado dentro del ámbito agrícola, se puede afirmar que existe un uso potencial de las cenizas volantes de RSU como fertilizante o agente calcáreo. Sin embargo, este uso no podrá ser a gran escala debido ha de circunscribirse a determinado tipo de cenizas las cuales realmente podrán ser aprovechadas. Su uso dependerá de los cultivos específicos y del entorno medioambiental del suelo, y su valoración deberá ser realizada caso por caso, haciendo especial énfasis en la concentración de metales pesados tanto en los tejidos de los vegetales, como en los acuíferos cercanos por el problema de la lixiviación de estos elementos.

\subsubsection{UTILIZACIÓN DE CENIZAS VOLANTES EN OTROS ASPECTOS.}

\subsubsection{Agentes estabilizadores en el tratamiento de desechos.}

Las cenizas volantes de RSU también han sido estudiadas con la intención de realizar coberturas provisionales de desechos. De esta forma, Lo et al. (2009) estudiaron la co-digestión de residuos sólidos urbanos mediante la adición de una determinada cantidad de cenizas volantes de RSU. En estas investigaciones se concluyó que la mejora en la tasa de producción de gases mediante la actividad de metano a través de los bioreactivos mejorados con cenizas volantes de RSU fue estimulada potencialmente mediante las concentraciones adecuadas de metales básicos 
y alcalinos en un entrono con pH casi neutro. Estos hechos indican que determinadas cantidades de cenizas volantes de RSU dispuestas junto a los residuos a la hora de la digestión de los mismos, facilitaba la actividad bacteriana y el propio rendimiento de la digestión de los residuos, así como la tasa de producción de gas metano. Así mismo, tanto las cantidades de metales pesados presentes, como la liberación de ciertos iones, como los cloruros, no tuvieron un impacto significativo en la digestión anaeróbica de los residuos.

1.3.7.2 Agentes estabilizadores en el tratamiento y preparación de lodos.

Los lodos originados a raíz del tratamiento de las aguas residuales contienen una gran cantidad de agua (más del $95 \%$ en peso) y necesitan ser desecados con la intención de reducir su volumen para reducir los costes de su retirada y eliminación. El filtrado es el método más extendido para conseguir su desecado. Sin embargo, los contenedores utilizados para estos procedimientos suelen contener pequeñas cantidades de aceite que dificultan las labores de desecado. Para solucionar este problema, los lodos pueden ser acondicionados mediante el uso de componentes auxiliares al filtrado.

El uso de cenizas volantes de RSU como un acondicionador químico ha sido investigado (Hwa et al., 1997) con el resultado de que estas cenizas ayudan al proceso de filtrado, ya que se encargan de disminuir tanto la resistencia específica del filtrado, como los tiempos de succión por capilaridad. Las cantidades de metales pesados en la sustancia filtrada aumentaron, pero los valores se encuentran dentro de los límites permitidos dentro de los máximos permitidos para la descarga de efluentes ${ }^{11}$. La dosificación de cenizas volantes de RSU usada en estas investigaciones fue de entre un $3 \%$ y un $4 \%$.

Con el mismo objetivo, también se ha investigado el uso potencial de cenizas volantes de RSU como agente encapsulador mediante sistemas de

\footnotetext{
${ }^{11}$ Líquidos para el tratamiento de residuos sólidos y lixiviados
} 
estabilización y solidificación, en el tratamiento de lodos con altos contenidos de metales pesados. Mezclas óptimas formadas por un $45 \%$ de cenizas volantes, $50 \%$ de lodos y $5 \%$ de cemento, proporcionan la estabilidad necesaria a la hora de su almacenamiento en vertedero. De esta forma, y mediante este co-almacenamiento, se puede minimizar y estabilizar eficazmente el volumen de metales pesados existentes en los vertederos de lodos. Así lo analizaron Qian et al. (2006). En su análisis, la mezcla de cenizas volantes de RSU junto con cemento Portland de uso corriente consigue inmovilizar tres tipos distintos de lodos industriales, a la vez que se estabilizan las cenizas volantes utilizadas durante el proceso. En sus ensayos demostraron que las matrices de lodos que portaban altos contenidos de metales pesados en combinación con cenizas volantes de RSU conseguian un alto poder de fijación de: $\mathrm{Zn}, \mathrm{Pb}, \mathrm{Cu}, \mathrm{Ni}$ y $\mathrm{Mn}$. Se demostró que las muestras ensayadas realizadas con cantidades de entre un 5 y un $15 \%$ en contenido de cemento eran perfectamente válidas para conseguir resistencias superiores a 0,3 $\mathrm{MPa}$, por otro lado mínimas requeridas para poder realizar el almacenamiento de estos lodos. Como ya ha sido reflejado anteriormente, se consiguió una mezcla óptima (45\% de cenizas volantes, $5 \%$ de cemento Portland y $50 \%$ de lodos industriales) en la cual se daban las condiciones perfectas para conseguir la solidificación y estabilización de los metales pesados en la matriz. Así mismo, el simple hecho de la adición de cenizas volantes de RSU a esta matriz, mejoraba la resistencia de la misma. Por otro lado, los productos principales de la hidratación de la nueva matriz solidificada y estabilizada son: etringita AFt $\left(\mathrm{Al}_{2} \mathrm{O}_{3}-\mathrm{FE}_{2} \mathrm{O}_{3}\right.$-Trisulfatos), sal de Friedel y $\mathrm{C}-\mathrm{S}-\mathrm{H}$, los cuales juegan un papel muy importante en la fijacion de los mencionados metales pesados (Chrysochou y Dermatas, 2006).

\subsubsection{Materiales adsorbentes.}

El uso de materiales adsorbentes, como por ejemplo el carbón activado, se ha generalizado de manera reciente concretamente en el tratamiento de aguas residuales. Sin embargo, se están investigando 
alternativas de menor precio a estos métodos. En un principio, las cenizas de hogar de RSU han sido empleadas con la intención de extraer tintes y metales pesados de aguas residuales (Shim et al., 2003; Gupta et al., 2005). Al igual que en el resto de posibles usos de las cenizas de RSU, una de las máximas preocupaciones a la hora de su utilización es el posible lixiviado de metales pesados debido a su alta toxicidad. El uso de cenizas volantes de RSU como adsorbente ha sido menos común que el de las cenizas de hogar debido, probablemente, al hecho de una mayor existencia de metales pesados en el lixiviado de este tipo de cenizas, lo cual reduciría la posibilidad de su uso. En contraste, las cenizas de hogar, raramente expulsan metales pesados tóxicos en los lixiviados realizados.

Existen varios estudios en la línea de investigación del uso de cenizas volantes como adsorbentes para distintos tipos de tintes: Ho, Y.S. et al, 1999, estudiaron la capacidad equilibrante de las cenizas volantes en los procesos de adsorción de tres tipos de tintes: Rojo de cromo, o-cresol y el p-nitrofenol; y determinaron del grado de adsorción inicial y la temperatura alzanzada en dicho proceso. En la misma dirección, Khare et al. (1987) estudiaron la adsorción del tinte azul victoria en los vertidos de las industrias textiles.

Las cenizas volantes tambien han sido estudiadas como adsorbentes de metales pesados. En todos estos estudios, una de las ventajas del uso de este tipo de cenizas es su habilidad neutralizadora, de tal forma que pueden ser utilizadas en el tratamiento de aguas residuales acidificadas por determinados vertidos industriales. Esto es debido al exceso de cal incorporado en el tratamiento de los gases de combustión generados por la incineración de residuos solidos urbanos, con la intención de eliminar tanto el ácido clorhídrico $(\mathrm{ClH})$ y el dióxido de azufre $\left(\mathrm{SiO}_{2}\right)$. A pesar de este característica estabilizante el $\mathrm{pH}$ final de las aguas tratadas va a depender en gran medida de la relación sólido-líquido usada.

En lo relativo al tratamiento de gases contaminantes de las instalaciones dedicadas a la combustión, es una práctica habitual el añadir cal hidratada en los conductos por los que circula el gas e incorporar 
adsorbentes con una alta superficie específica, como el carbón activo. Una posibilidad para tratar de reducir los costes de estos procesos es la utilización alterna de adsorbentes, como por ejemplo mezclas de cal con materiales con alto contenido en sílice como arcillas y cenizas volantes de la combustión del carbón (Garea et al., 1996) en los sistemas de desulfurización de gases y de limpieza de acidez de los mismos. Miyake et al. (2002) confirmaron que la capacidad de adsorción de un producto está relacionada con la cantidad de componentes cálcicos presentes en las cenizas del carbón y dependía de la superficie del grano y del volumen del poro. Estudiaron que el tratamiento de estas cenizas con una solución acuosa de hidróxido cálcico aumentaba la capacidad de adsorción. Sin que hasta la fecha se hayan realizado otras investigaciones al respecto, es muy probable que las cenizas volantes de RSU se comporten de manera parecida, más si cabe, desde el momento en que los flujos de los gases en las incineradores de residuos urbanos son tratados con cal.

\subsubsection{Producción de Zeolita}

Otro de los ejemplos es la zeolita (término que se refiere a un gran conjunto de minerales que comprenden silicatos alumínicos hidratados de metales alcalinos y alcalinotérreos) la cual es utilizada en procesos de intercambio de iones, como por ejemplo en la purificación del agua. Aunque la zeolita se presenta de manera natural en vetas y cavidades de ciertas rocas ígneas (especialmente el basalto), existen estudios sobre la síntesis de zeolitas artificiales derivadas de las cenizas de la combustión del carbón mediante un tratamiento hidrotérmico con hidróxido de sodio $(\mathrm{NaOH})$ (Queralt et al., 1997; Hollman et al., 1999; Lin et al., 1995).

La idea original de utilizar cenizas volantes de la combustión del carbón para sintetizar zeolitas artificiales está basada en el hecho de que ambos materiales tienen una composición térmica similar, concretamente en lo relativo al contenido en cristales de aluminosilicato con una elevada superficie específica (Queralt et al., 1997). Las cenizas volantes de RSU también poseen una alta superficie específica y elementos composicionales 
como el óxido de silicio $\left(\mathrm{SiO}_{2}\right)$ (tabla 6), los cuales tienen mucha importancia en la síntesis de la zeolita artificial aunque, en este caso, aparecen en menor cantidad que en las cenizas volantes del carbón.

Tabla 6. Propiedades adsorbentes de determinados materiales (Ferreira et al., 2003).

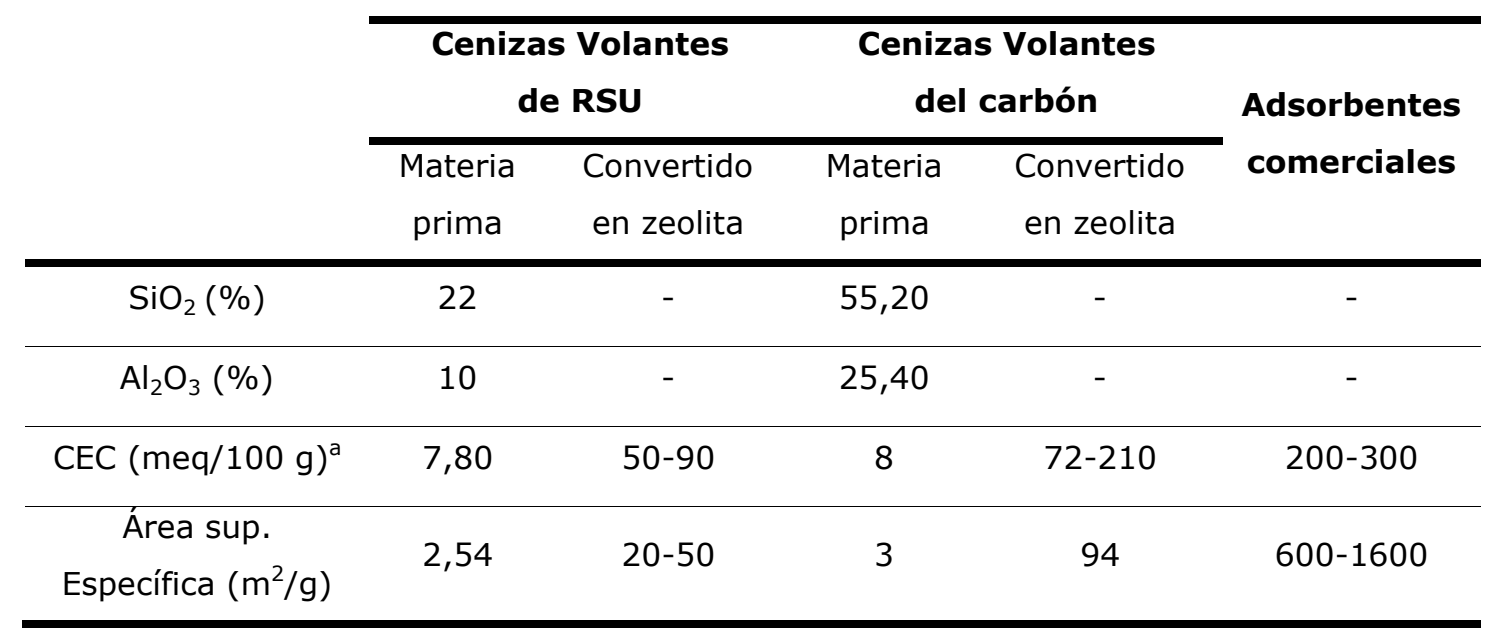

${ }^{\text {a }}$ Capacidad de intercambio de cationes

Yang et al. (1998) analizaron la obtención de materiales de características similares a la zeolita conseguidos a través de la síntesis de cenizas volantes de RSU mediante un proceso hidrotérmico alcalino muy parecido al utilizado para sintetizar las cenizas de la combustión del carbón. Determinaron que, aunque la calidad del producto zeolítico era inferior a la ofrecida por los adsorbentes comerciales, su utilización sería medioambientalmente segura de acuerdo a los procesos de extracción de toxicidad y lixiviado TCLP. A pesar de ello, los residuos generados durante el proceso de sintetizado contienen altos niveles de metales pesados como plomo y zinc, por lo que deberían ser tratados antes de su eliminación. Yang et al. (1999), de igual forma, estudiaron la síntesis de un tipo de tobermorita con sustitución del aluminio de cenizas volantes de RSU. La utilización de este producto para eliminar los cationes de cesio $\left(\mathrm{Cs}^{+}\right)$y amonio $\left(\mathrm{NH}_{4}{ }^{+}\right)$de las aguas residuales llevó a unos resultados de 0,40 $\mathrm{nmol} / \mathrm{g}$ eliminados para los primeros y de $0,35 \mathrm{nmol} / \mathrm{g}$ para los segundos. 
Aunque los resultados de estas investigaciones son preliminares, se puede decir que existe la posibilidad de convertir las cenizas volantes de RSU en materiales zeolíticos. Esta zeolita sintetizada puede tener aplicaciones industriales como producto adsorbente, como por ejemplo en la eliminación de determinados iones o moléculas de una solución. También podría ser utilizado en el tratamiento de aguas residuales para la eliminación de metales pesados del agua o bien para el mismo tratamiento de aguas en actividades ganaderas en este caso para la eliminación del amonio $\left(\mathrm{NH}_{4}\right)$.

La zeolita tanto sintética, como natural, ha sido utilizada ampliamente para aplicaciones medioambientales y procesos catalíticos. Al tener una composición química similar a las cenizas volantes procedentes de la combustión del carbón (óxido de silicio $\left(\mathrm{SiO}_{2}\right)$ y óxido de aluminio $\left(\mathrm{Al}_{2} \mathrm{O}_{3}\right)$ como componentes principales en un $70 \mathrm{u} 80 \%$ ), éstas han sido usadas comúnmente como materia prima para la síntesis de materiales de apariencia zeolítica (Lin et al., 1995; Murayama et al., 2002). En el caso de las cenizas volantes de RSU y, a pesar de tener unos contenidos de $\mathrm{SiO}_{2}$ y $\mathrm{Al}_{2} \mathrm{O}_{3}$ mucho menores (entre un 15 y un 30\%), existen diversos estudios que han logrado sintetizarlas mediante procesos hidrotermales y de fusión (Yang, 1998; Miyake, 2002). Tanto la superficie específica, como la capacidad de intercambio de cationes se demostraron ser mayores en la zeolita producida utilizando cenizas volantes como materia prima que en comparación con éstas. Aunque la capacidad de intercambio de cationes de la zeolita sintetizada $(90 \mathrm{meq} / 100 \mathrm{~g})$ es menor que la de la zeolita comercializada (200-300meq/100g), queda demostrada la viabilidad del uso cenizas volantes para la síntesis de zeolita. Sin embargo, una vez más, el problema medioambiental aparece al encontrarse en los líquidos residuales posteriores a la síntesis, altas concentraciones de metales pesados como $\mathrm{Pb}$ y $\mathrm{Zn}$, lo cual haría necesario una serie de tratamientos adicionales antes de su eliminación definitiva (Yang, 1998).

Hasta aquí queda demostrado que, en la mayoría de los usos posibles, existe una gran preocupación por el comportamiento medioambiental de los 
diferentes productos, sobre todo en lo relacionado con el lixiviado de metales pesados y toxinas que puedan contaminar suelos y acuíferos. En la mayoría de los casos es necesario un tratamiento previo de las cenizas, lo cual implica un encarecimiento de su uso pero, por el contrario, facilita su eliminación. De conseguir una utilización satisfactoria de este tipo de cenizas, se obtendrá una considerable reducción del volumen de residuos generados por nuestras ciudades, así como una alternativa de calidad a los depósitos en vertederos.

\subsection{SOLIDIFICACIÓN FRENTE A INERTIZACIÓN.}

Los procesos de solidificación e inertización de residuos contaminantes llevan implantados dentro del sector de la construcción desde hace más de 35 años (Macías et al., 1999; Anastasiadou et al., 2012), aunque ha sido recientemente cuando ha experimentado un creciente interés por parte de ingenieros, arquitectos y expertos medioambientales su utilización como un medio asequible y directo para el tratamiento y gestión de residuos tóxicos y peligrosos, en especial de aquellos que contienen, en mayor o menor medida, metales pesados (John, Zordan 2000).

Antes de proseguir, debemos dejar clara la diferencia existente entre dichos procedimientos. Si bien ambos coinciden en que el objetivo es que un determinado residuo tóxico se transforme en una sustancia no tóxica, en la mayoría de las ocasiones, quedan solapados por su acción directa en la transformación de los materiales, pero en la práctica son fases completamente distintas que conviene detallar:

- Un proceso de solidificación o inmovilización se debe entender como aquel en el que cualquier tipo de residuo (sólido, líquido, granulosa, pastoso, etc.) queda transformado en un nuevo material sólido pero con la característica de poseer un bajo grado de penetración o absorción. Dicha solidificación no pretende una interacción química entre ambos componentes: residuos y conglomerantes. Lo que se persigue como objetivo básico, es que exista una cohesión mecánica 
de los residuos dentro de la matriz monolítica y que ésta sea este conjunto sea menos permeable que el original.

- A diferencia de lo anterior, los procesos de inertización o estabilización intentan conseguir una minoración del peligro latente que cualquier sustancia tóxica posee, mediante la conversión de los elementos químicos que lo forman en otros de menor movilidad, toxicidad o capacidad de disolución. Por sus características, todo proceso de inertización conlleva un cambio de estado físico.

Debido a los problemas que genera la gestión de las cenizas volantes de RSU, los procesos combinados de solidificación/estabilización han sido muy utilizados como tratamiento previo antes de ser depositadas en vertederos especializados. En un porcentaje muy elevado de los casos, este es el fin del ciclo de vida de dichas cenizas (Yvon, Antenucci et al., 2006). Si bien como alternativa a este actividad, muchos autores han estudiado los procesos de solidificación/estabilización y su tecnología, mediante el uso de diversos tipos de conglomerantes hidráulicos, tales como: cementos Portland ordinarios, cales, cenizas volantes del carbón o escorias de alto horno (Morel, Clastres et al., 2001, Siddique 2010). O bien mediante su mezcla con otros productos como: resinas de poliéster (Fuoco, Ceccarini et al., 2005), fosfatos solubles (Sun, Zheng et al., 2011), sulfatos férricos (Sørensen, Stackpoole et al., 2001) o geopolímeros (Luna Galiano, Fernández Pereira et al., 2011, Jin, Huang et al., 2011).

Ya se ha mencionado la existencia de diversas tecnologías investigadas con el objeto de reducir o eliminar el componente tóxico de las cenizas volantes de RSU, siendo los métodos de estabilización/solidificación los más ampliamente utilizados $y$, en particular, aquellos que intentan aprovechar las características compactantes de los cementos, con la intención de atrapar en su matriz los metales pesados. 


\subsubsection{SISTEMAS BASADOS EN CEMENTOS PORTLAND ORDINARIOS (OPC)}

Los sistemas basados en cemento Portland han sido los más extendidos y fueron los primeros en ser utilizados en el campo de los residuos radioactivos a principios de 1950 . En ellos, el residuo, bien sea en forma líquida o sólida, se introduce en la mezcla cementante, produciéndose una pasta de consistencia fluida la cual será volcada en un molde o en un contenedor válido para un transporte seguro al almacén. La cementación de los residuos reduce el riesgo de un vertido o contaminación accidental en condiciones extremas.

Todos los cementos Portland, así como la cal, son representativos de una familia de materiales que tienen ventajas prácticas y conceptuales como matrices de inmovilización de residuos (Chan et al., 2000). Son materiales de construcción probados en situaciones reales a lo largo de muchos años y con una amplia historia de uso en distintas condiciones ambientales.

Las ventajas de estos sistemas son numerosas:

- Tecnología ampliamente probada y testada tanto en la industrialización del producto, como en su puesta en obra.

- Materias primas económicas y accesibles.

- Dada la férrea normalización existente en el sector de la construcción, las composiciones químicas son constantes.

- Son productos muy flexibles a la hora de incorporar subproductos que alteren la matriz sólida y que favorecen la inmovilización de los residuos.

- Excelente comportamiento medioambiental a largo plazo dados sus componentes no tóxico.

- Los procesos de hidratación favorecen la inmovilización tanto física como química. De la misma forma, la amplia bibliografía existente, 
favorece el conocimiento de sus reacciones de fraguado y endurecimiento en la fijación de metales pesados en su matriz sólida.

- Una consecuencia directa de esto último, son las múltiples modelizaciones existentes relativas a la lixiviación de residuos inmovilizados en matrices de cemento procedentes del campo de los residuos nucleares.

- Como consecuencia de los productos generados durante el fraguado, se genera un entorno altamente alcalino que impide cualquier tipo de actividad microbiológica.

Por el contrario, existen una serie de desventajas que, en ningún caso, pueden hacer desechar este producto como uno de los mejores medios para la inmovilización de residuos.

- Libera calor al endurecer

- Dependiendo de las adiciones utilizadas, puede reaccionar con metales pesados, produciendo gases tóxicos

- Una amplia gama de disolventes orgánicos e inorgánicos pueden inhibir y prevenir su fraguado

- En presencia de entornos ácidos o en disoluciones salinas pueden sufrir degradaciones.

\subsubsection{SISTEMAS BASADOS EN CEMENTOS DE ALUMINATO DE CALCIO (CAC)}

A día de hoy, las distintas investigaciones que se han venido realizando sobre el proceso de fijación de los diversos metales pesados en las matrices de morteros o pastas de cementos Portland ordinarios no han derivado en conclusiones cuantitativas, aunque si se ha podido definir cómo se articulan los sistemas de retención de dichos metales. Estos sistema dependen en 
gran manera de parámetros tales como la concentración de la sustancia aditivada, o del tipo de sustancia en sí.

De acuerdo a Chinchón Yepes y Sanjuán Barbudo, 2008, la posibilidad de definir claramente el sistema de fijación de los metales a los hidratos de los cementos Portland, cuenta con un problema de difícil solución: la portlandita. De hecho se trata del único compuesto cristalino que se produce en la hidratación de los silicatos dicálcicos y tricálcicos, y desaparece durante el proceso de carbonatación. Además, la otra fase mayoritaria, el C-S-H, tiene una estructura de compuesto amorfo.

Las ventajas introducidas en la utilización de los CAC en contraposición de las desarrolladas por los cementos Portland ordinarios son:

a) Los hidratos hexagonales $\mathrm{CAH}_{10}$ y $\mathrm{C}_{2} \mathrm{AH}_{8}$, son fases cristalinas. Debido a su carácter metaestable, durante el proceso de hidratación se convierten en hidratos cúbicos, también cristalinos, $\mathrm{CAH}_{6}$ (katoita) y $\mathrm{AL}(\mathrm{OH})_{3}$ (gibsita). Dicha transformación se denomina "proceso de conversión" de los CAC y lleva aparejada una disminución en el comportamiento mecánico de los productos confeccionados con este tipo de cementos. Al tratarse de fases cristalinas, existe la posibilidad de poder observar la incorporación de los metales incorporados a los hidratos originales mediante su estudio con aparatos de microscopía electrónica y difracción de rayos $X$.

b) Por otro lado, durante el proceso de hidratación de los compuestos derivados del cemento Portland el pH del conjunto se rebaja de 12.5 a 9 (independientemente de la cantidad de portlandita presente), en el caso de los cementos CAC, debido a sufrir procesos de carbonatación distintos, se asegura un $\mathrm{pH}$ de 11.5 debido sobre todo a la presencia de hidróxido de aluminio (gibsita). Este pH favorece la formación de determinados compuestos insolubles derivados de los componentes inorgánicos presentes. 
c) En el proceso de hidratación se generan fases cristalinas como los polimorfos del carbonato cálcico (vaterita, aragonito o calcita) o de hidróxido de aluminio (gibbsita, bayerita o nordstrandita), cuyos procesos de carbonatación podrían favorecer la sustitución de alguno de los metales presentes (Chinchón Yepes y Sanjuán Barbudo, 2008).

\subsubsection{SISTEMAS BASADOS EN CEMENTOS DE SULFOALUMINATO DE CALCIO (CSA)}

Se trata, sin duda alguna, de la más novedosa de las aplicaciones para la estabilización/solidificación en matrices de cemento. La combinación de este tipo de cementos con las cenizas volantes de RSU, a priori presenta cuatro hipótesis de trabajo muy interesantes.

- En primer lugar, la aparición de etringita en las fases tempranas tiene como consecuencia un rápido endurecimiento del producto, lo cual confiere a morteros y hormigones elaborados con este tipo de cementos una elevada resistencia inicial, así como una alta impermeabilidad y resistencias superiores a los cementos Portland ordinarios, tanto a la corrosión, como a la heladicidad (Péra y Ambroise, 2004; Glasser y Zhang, 2001).

- En segundo lugar, al estar combinándolo con un producto, como las cenizas volantes de RSU, cuya composición es rica en sulfuros y cloruros, éstos pueden reaccionar fácilmente con el sulfoaluminato de calcio presente en el cemento y generar productos principales en la hidratación del cemento como etringita y sales de Friedel, para formar una matriz conjunta (Auer et al., 1995; Suryavansh et al., 1996).

- En tercer lugar, la matriz estabilizadora de los productos derivados del cemento de Sulfoaluminato de calcio muestran excelentes comportamientos en el lixiviado de nitrato de zinz y de sulfato, así como en el de nitrato de plomo, cloruro de calcio y cloruro de cromo (Peysson et al., 2005). 
- Por último, la formación de esta matriz conjunta, mantendrá a las cenizas volantes de RSU estabilizadas dentro de un sistema con una baja alcalinidad que favorecerá la posibilidad de utilizar cualquier tipo de refuerzo a base de fibras de vidrio de los morteros estudiados.

La base de la utilización de este tipo de cementos radica en la formación de etringita. Estamos hablando de un sulfoaluminato de calcio hidratado que se forma durante las primeras etapas de hidratación del cemento Portland a partir de la reacción de la fase aluminato del clinker $(\mathrm{CaO})_{3} \mathrm{Al}_{2} \mathrm{O}_{3}$ con el yeso $\left(\mathrm{CaSO}_{4} \cdot 2 \mathrm{H}_{2} \mathrm{O}\right)$ empleado para retardar el fraguado. Además, la mayoría de los sulfatos del cemento normalmente se consume para formar etringita o monosulfoaluminato en un periodo de 24 horas (Klemm y Millar, 1997). La importancia del estudio de etringita reside en la influencia de esta fase en las propiedades reológicas del cemento.

Ha sido también objeto de estudio que las matrices de este tipo de cementos con etringita primaria, tiene mayores afinidades, no sólo con los cationes de los metales pesados, sino también con los oxianiones, la configuración de la estructura cristalina de etringita favorece la sustitución de especies atómicas en las posiciones cristalográficas ocupadas tanto por los cationes como por los aniones y además permite la movilidad de moléculas de agua e iones. De esta forma, las matrices de morteros elaborados con este tipo de cementos pueden inmovilizar de manera más eficaz la alta concentración de metales pesados tales como $\mathrm{Pb}$ y $\mathrm{Zn}$, de manera más efectiva de lo que pudieran hacer los cementos Portland ordinarios, incluso durante el primer día de hidratación (Qian et al., 2008). 


\subsection{RESUMEN DE CONSIDERACIONES}

De acuerdo a la bibliografía consultada, se presentan las siguientes consideraciones previas al inicio de la investigación:

- En la presente investigación, el área de utilización de las cenizas volantes de RSU se centra en el empleo de las mismas como "Material de Construcción", más concretamente en la elaboración de morteros tradicionales de albañilería, los cuales representan una manera muy segura de reutilizar estos materiales peligrosos.

- Con base en los resultados analizados previamente, se decide la aplicación de un proceso combinado de estabilización/solidificación como sistema adecuado para la gestión y el tratamiento de dicho residuo tóxico y peligroso.

- Partiendo de esos mismos argumentos, se ha elegido el cemento como conglomerante hidráulico de partida. En las investigaciones analizadas se destaca que la resistencia mecánica de los morteros ejecutados con cementos Portland ordinarios se veía claramente afectada en comparación con la de los morteros de referencia, por ello se ha dispuesto, además, la utilización de sistemas de encapsulación de nueva generación, como los de Cemento de Aluminato de Calcio y los de Cemento de Sulfoaluminato de Calcio, con la intención de que las rápidas resistencias iniciales contrarresten una hipotética disminución de las resistencias mecánicas.

- En la bibliografía consultada se incide de manera generalizada en la sustitución de parte del árido o del cemento tanto en morteros, como en hormigones si bien, y dada la granulometría del residuo en cuestión (más del $50 \%$ por debajo de $63 \mu$ ), en la investigación que aquí se presenta se decide su incorporación a los distintos morteros de cemento como "filler", asimilando un $10 \%$ en peso del árido y añadiéndolo a la mezcla como una nueva dosificación y no como una formulación tradicional de sustitución. La cantidad del $10 \%$ fue seleccionada 
tomando como base las investigaciones con resultados más positivos analizadas en la bibliografía.

- De igual forma, se ha considerado estudiar la incidencia del uso de dosificaciones distintas a las establecidas por la Norma Europea EN 1961 y su repercusión en los comportamientos físicos y mecánicos de los morteros resultantes. Para ello, se han confeccionado morteros ricos en cemento (relación cemento/árido 1/1) y morteros tradicionales de albañilería (relación cemento/árido 1/3).

- Esta investigación profundiza en la utilización de dos tipos de áridos con diámetros distintos, $0 / 2$ y 0/4, con la intención de analizar el impacto de la granulometría en los procesos de carbonatación de los distintos morteros.

\subsection{OBJETIVOS}

El objetivo principal de esta investigación es la eliminación de un residuo tóxico y peligroso formado por cenizas volantes procedentes de la incineración de residuos sólidos urbanos, mediante su encapsulación en diversas matrices de morteros de cemento, con la intención de mantener o mejorar las prestaciones constructivas de los mismos.

Como objetivo secundario, y tomando como base las distintas investigaciones analizadas sobre los efectos beneficiosos de la carbonatación en morteros de cemento, se pretende desarrollar un procedimiento eficiente de inertización del residuo, constituido mayoritariamente por portlandita, en otro material de tipo calizo -carbonato de calcio- para su incorporación a los distintos morteros. De esta forma se tiene la intención de conseguir una valorización del residuo original previa a su eliminación, con la consiguiente reducción del impacto medioambiental que ello implica. 


\section{MATERIALES Y MÉTODOLOGÍA}

\subsection{MATERIALES}

\subsubsection{CENIZAS VOLANTES}

Las cenizas volantes de RSU proceden de la planta de tratamiento integral de residuos de Mataró, Barcelona (España), la cual realiza el proceso de incineración en un horno de parrilla.

Aproximadamente $100 \mathrm{~kg}$ de cenizas volantes fueron recogidos durante el mes de enero del año 2010 y almacenados en barriles sellados para su posterior estudio en el laboratorio.

\subsubsection{CEMENTO}

Para la ejecución de los diversos morteros realizados durante la presente investigación, se utilizaron cuatro tipos distintos de cementos de uso corriente en obras de construcción e ingeniería civil en España. La Tabla 7 muestra la composición química de dichos cementos.

- Dos cementos Portland ordinarios, Tipo I 52,5 R (CEM-I) y Tipo II A/P 42,5 R (CEM-II), ambos procedentes de la fábrica que la compañía CEMEX ESPAÑA S.A.B. posee en Castillejo, Toledo (España).

- Cemento de Aluminato de Calcio (CAC) de la empresa Cementos Molins Industrial, S.A. con denominación comercial Electroland. Se trata de un cemento $100 \%$ clinker molturado sin adiciones, procedente de la planta de Sant Vicenç dels Horts, Barcelona, (España).

- Por último, se ha utilizado Cemento de Sulfoaluminato de Calcio (CSA) denominado ALIPRE. Es un clinker de sulfoaluminato-belita molido cuyos componentes principales son: Calcio, Sulfoaluminato, Belita y Sulfato de Calcio. Procede de la planta que el Grupo Italcementi posee en Arrigorriaga, Bilbao (España). 
Tabla 7. Análisis químico por Fluorescencia de Rayos X de los cementos utilizados en la elaboración de los morteros.

\begin{tabular}{|c|c|c|c|c|}
\hline & \multicolumn{4}{|c|}{ Composición química (\% peso) } \\
\hline & CEM I & CEM II (A/P) & CAC & CSA \\
\hline $\mathrm{SiO}_{2}$ & 19,40 & 21,69 & 4,42 & 8,90 \\
\hline $\mathrm{Al}_{2} \mathrm{O}_{3}$ & 5,04 & 5,85 & 38,65 & 31,47 \\
\hline $\mathrm{Fe}_{2} \mathrm{O}_{3}$ & 3,54 & 4,33 & 15,59 & 1,35 \\
\hline $\mathrm{CaO}$ & 61,38 & 52,69 & 38,14 & 39,70 \\
\hline $\mathrm{MgO}$ & 2,12 & 3,13 & 0,58 & 3,90 \\
\hline $\mathrm{SO}_{3}$ & 4,10 & 3,27 & 0,00 & 10,82 \\
\hline $\mathrm{K}_{2} \mathrm{O}$ & 1,04 & 1,04 & 0,13 & 0,37 \\
\hline $\mathrm{Na}_{2} \mathrm{O}$ & 0,14 & 0,52 & 0,00 & 0,73 \\
\hline $\mathrm{TiO}_{2}$ & 0,26 & 0,66 & 1,87 & 0,37 \\
\hline $\mathrm{P}_{2} \mathrm{O}_{5}$ & 0,19 & 0,35 & 0,10 & 0,11 \\
\hline $\mathrm{Mn}_{2} \mathrm{O}_{3}$ & 0,10 & 0,10 & 0,06 & 0,16 \\
\hline $\mathrm{Cr}_{2} \mathrm{O}_{3}$ & 0,01 & 0,01 & 0,06 & 0,06 \\
\hline SrO & 0,12 & 0,10 & 0,02 & 0,44 \\
\hline $\mathrm{BaO}$ & 0,03 & 0,04 & 0,02 & 0,06 \\
\hline $\mathrm{ZnO}$ & 0,01 & 0,02 & 0,02 & 0,08 \\
\hline P.F. & 2,51 & 6,19 & 0,34 & 1,47 \\
\hline
\end{tabular}

\subsection{3 ÁRIDOS}

El árido elegido es una arena silícea lavada de diámetros $0 / 2$ y 0/4, proveniente de la gravera de Sotopajares de San Martín de la Vega, Madrid (España). Ambos diámetros cumplen con la norma UNE-EN 13043:2003/AC:2004 de áridos para morteros y cuentan con el correspondiente certificado AIDICO de control de producción en fábrica. 


\subsection{METODOLOGÍA}

La metodología desarrollada a lo largo de la presente investigación se divide en dos fases:

- En una primera fase, se realizó el análisis y caracterización en el laboratorio, de las cenizas volantes de RSU. Dentro de este apartado, se realizó también el estudio de la legislación vigente y de los requisitos necesarios para conseguir la descatalogación de este residuo como peligroso.

De igual manera, se realizó el estudio de las cantidades de cenizas volantes de RSU que debían ser inertizadas, previo desarrollo de un sistema eficaz y viable de inertización, el cual estuvo apoyado constantemente en diversos ensayos y pruebas a nivel de laboratorio para conseguir un sistema prototipo de tratamiento.

Para la caracterización química de las cenizas volantes se realizaron los siguientes tipos de ensayos y análisis:

- Espectrometría de Emisión Óptica con Fuente de Plasma de Acoplamiento Inductivo (ICP-OES).

- Fluorescencia de Rayos X (FRX).

- Difracción por Rayos X (DRX).

- Calorimetría Diferencial de Barrido y Termo-gravimetría (DSC-TGA).

- En la segunda fase, se ejecutaron dos tipos distintos de probetas normalizadas de mortero. Un mortero de referencia, sin adiciones (R). Y un segundo mortero con la incorporando cenizas volantes lavadas $y$ tratadas para su inertización (CVT) en una proporción igual a un 10\% en peso del árido utilizado. Este porcentaje fue decidido como relación óptima, de acuerdo a los trabajos previos desarrollados en numerosas investigaciones (Cinquepalmi, Mangialardi et al., 2008, Ginés 2009, Lima, Ottosen et al., 2012, Rémond, Pimienta et al., 2002, Rémond, Bentz et al., 2002). 
Las muestras ensayadas abarcan, asimismo, distintas dosificaciones tanto en la utilización de áridos con distintos diámetros (0/2 y 0/4), como en la relación cemento/árido (1/1 y 1/3). De igual forma, este proceso experimental fue repetido con la utilización de los cuatro tipos distintos de cemento referidos (CEM-I, CEM-II, CAC y CSA).

De cada una de las dosificaciones de mortero previstas se han realizado las siguientes probetas:

- Dos series (mortero de referencia y mortero con CVT) de tres probetas, para la determinación de la estabilidad dimensional y densidad de mortero en seco.

- Dos series (mortero de referencia y mortero con CVT) de tres probetas, para los análisis de DRX, DSC-TGA y Voltamperometría de redisolución anódica.

- Dos series (mortero de referencia y mortero con CVT) de tres probetas, para los estudios de carbonatación.

- Ocho series (cuatro de mortero de referencia y otras cuatro de mortero con CVT) de tres probetas cada una, para la determinación de la resistencia a flexión y a compresión a 7, 28, 60 y 90 días.

A su vez, durante esta segunda fase se sometieron a los materiales, tanto de manera individualizada, como en conjunto -morteros- a los siguientes ensayos:

a) Áridos

- Determinación de la humedad

- Determinación de la distribución granulométrica mediante el método del tamizado. 
b) Mortero fresco

- Determinación de la consistencia del mortero fresco por la mesa de sacudidas (UNE EN 1015-3:2000) para la obtención de la relación agua/cemento.

- Determinación del periodo de trabajabilidad del mortero (UNE EN 1015-9:2000).

c) Mortero endurecido

- Determinación de la estabilidad dimensional de los morteros para albañilería endurecidos (UNE 83831:2012 EX).

- Determinación de la densidad aparente en seco del mortero endurecido (UNE EN 1015-10:2000).

- Determinación de la resistencia a la carbonatación (EN 13295:2004).

- Determinación de la porosidad y de la distribución del tamaño de poros.

- Determinación de la resistencia a flexión y a compresión del mortero endurecido (UNE EN 1015-11:2000).

- De igual forma, para las probetas de mortero de Cemento de Aluminato de Calcio CAC.1/1·0/4, se procedió a su análisis mediante Difracción por Rayos X (DRX), calorimetría Diferencial de Barrido y Termogravimetría (DSC-TGA), voltamperometría de redisolución anódica y porosimetría por intrusión de mercurio. 


\subsubsection{CARACTERIZACIÓN DE LAS CENIZAS VOLANTES DE RSU}

2.2.1.1 Espectrofotometría de Emisión Óptica con fuente de Plasma de Acoplamiento Inductivo (ICP-OES).

A través de una espectrofotometría de emisión con plasma de acoplamiento inductivo es posible determinar de forma cuantitativa la mayoría de los elementos de la tabla periódica a niveles de traza y ultratraza, partiendo de muestras en disolución acuosa.

La muestra líquida, se transporta por medio de una bomba hasta un sistema nebulizador donde es transformada en aerosol por medio de la acción de gas argón. Este aerosol es trasladado al área de ionización el cual es un plasma generado al someter un flujo de gas argón a la acción de un campo magnético oscilante inducido por una corriente de alta frecuencia, con temperaturas de hasta $8000^{\circ} \mathrm{K}$. En estas condiciones, los átomos presentes en la muestra son excitados a un nivel energético superior $y$, al volver a su estado fundamental, emiten radiaciones de una longitud de onda que es característica de cada elemento. Esta radiación pasa a través de un sistema óptico que separa la radiación según su longitud onda. A continuación un detector mide la intensidad de cada una de las radiaciones relacionando ésta con la concentración de cada elemento en la muestra.

De esta forma, las cenizas volantes originales sin inertizar y las cenizas volantes inertizadas fueron analizadas, previa digestión ácida, sobre la base de un estudio macroelemental mediante técnicas de Espectrofotometría de Emisión Óptica con fuente de Plasma de Acoplamiento Inductivo SPECTRO (modelo ICP-OES ARCOS), y de componentes elementales a través de Espectrometría de Masas con Plasma de Acoplamiento Inductivo VARIAN ICP-MS (modelo ULTRAMASS). En dichos análisis también se utilizó un Cromatógrafo iónico con detector conductimétrico (modelo DIONEX DX500).

Estos análisis fueron realizados durante el mes de junio del año 2012 por el equipo del Centro de Asistencia a la Investigación del Laboratorio de Análisis Geoquímico y Ambiental de la Facultad de Geológicas de la Universidad Complutense de Madrid. 


\subsubsection{Fluorescencia de Rayos X (FRX)}

La fluorescencia de rayos $X(F R X)$ es una técnica espectroscópica que se basa en el estudio de las emisiones de fluorescencia generadas después de la excitación de una muestra mediante una fuente de rayos $\mathrm{X}$.

La radiación incide sobre la muestra excitando los átomos presentes en ella. La energía absorbida por estos átomos, genera la producción de rayos $X$ secundarios, también denominada fluorescencia de rayos $X$. Esta radiación, convenientemente colimada, incide sobre un cristal analizador (con espaciado interatómico "d") que la difracta en un ángulo ( $\theta$ ) dependiente de su longitud de onda $(\lambda)$ por la ley de Bragg ( $\operatorname{sen} \theta=n \lambda / 2 d$ ). La existencia de un detector que puede moverse sobre un determinado rango de ángulos, mide el valor de la intensidad de radiación en uno determinado y por tanto para una longitud de onda específica, que es función lineal de la concentración del elemento en la muestra que produce tal radiación de fluorescencia. Estos rayos $X$ secundarios tienen una intensidad proporcional a la concentración de cada elemento de la muestra, por ello, al cuantificar esta radiación se determina la cantidad de cada elemento presente en dicha muestra.

Esta técnica se emplea normalmente cuando se quiere conocer con rapidez la composición elemental exacta de una sustancia, en este caso fue aplicada para la determinación cuantitativa de la composición en óxidos de los cuatro tipos de cementos utilizados en la investigación y de los dos tipos de cenizas: originales e inertizadas.

El equipo utilizado para llevar a cabo la fluorescencia de rayos $X$, fue el espectrómetro de fluorescencia de rayos $X$, de la marca Philips, PANalytical PW-2404, ubicado en el Laboratorio Central de Calidad de la empresa Lafarge Cementos S.A.U.

\subsubsection{Difracción por Rayos X (DRX)}

La técnica de Rayos X se basa en la interacción radiación-materia de la radiación obtenida mediante el bombardeo de electrones a un cátodo de cobre, produciéndose la radiación $\mathrm{K} \alpha$ del $\mathrm{Cu}$, que puede tener una longitud 
de onda comparable a los espaciados de las sustancias cristalinas. Después de filtrarse, los rayos $X$ se hacen incidir con una muestra de tamaño de partícula inferior a $50 \mu \mathrm{m}$ que está desorientada (método de polvo). Un sensor detecta los rayos $\mathrm{X}$ difractados, que cumplen la ley de Bragg, generando un diagrama donde se encuentran estas reflexiones producidas por los minerales presentes en la muestra a los distintos ángulos $2 \Theta$ de barrido.

Para determinar los componentes mayoritarios a nivel estructural de las cenizas volantes recibidas, se han sometido las muestras a un análisis por difracción de Rayos $X$ mediante el método de polvo. Los ensayos fueron realizados en el Difractómetro Siemens D-5000 ubicado en el Laboratorio de Química Industrial y Polímeros de la Escuela Técnica Superior de Ingeniería y Diseño Industrial de la Universidad Politécnica de Madrid (ilustración 4).

De igual forma, las cenizas volantes inertizadas han sido estudiadas mediante difracción de Rayos $X$ para determinar su cristalinidad y realizar una semicuantificación del grado de carbonatación alcanzado.

Por último, los morteros con mejor comportamiento físico/mecánico, fueron sometidos a idéntico análisis. Los minerales mayoritarios más comunes que se encuentran en los morteros proceden de las arenas: cuarzo $\left(\mathrm{SiO}_{2}\right)$, dolomita $\left(\mathrm{CaMg}\left(\mathrm{CO}_{3}\right)_{2}\right)$, feldespatos, etc. y de los conglomerantes: yeso $\left(\mathrm{CaSO}_{4} \cdot 2 \mathrm{H}_{2} \mathrm{O}\right)$, calcita $\left(\mathrm{Ca}\left(\mathrm{CO}_{3}\right)\right.$ procedente de la carbonatación del hidróxido de calcio $\left(\mathrm{Ca}\left(\mathrm{OH}_{2}\right)\right)$ de la cal apagada, del resultante del proceso de hidratación del cemento $y$, como base de esta investigación, de la inertización de las cenizas volantes en forma de carbonatos insolubles.

Los difractogramas de los morteros permiten identificar productos y compuestos procedentes de la hidratación del cemento del tipo de tobermoritas, etringita, monosulfoaluminato, etc. Además, la variedad de minerales minoritarios encontrada puede ser muy amplia: filosilicatos, anfíboles, micaesquistos, metacuarcitas, gneis, glauconita, óxidos de hierro (goethita y hematites), vaterita, etc. 
Para la preparación de las muestras, las probetas de los diversos morteros fueron inicialmente selladas en bolsas de polietileno, identificadas y conservadas en cámara húmeda a $20^{\circ} \mathrm{C}$ de temperatura y $95 \%$ de humedad relativa. Llegado el momento de la realización del ensayo fueron desembolsadas, divididas en semiprismas de $4 \times 4 \times 4 \mathrm{~cm}^{3}$ aproximadamente para su utilización en distintos ensayos, machacadas manualmente y tamizadas por el tamiz de $63 \mu \mathrm{m}$. Las muestras fueron conservadas en un recipiente plástico de cierre hermético para su posterior utilización en los ensayos de termogravimetría (DSC-TGA) (ilustraciones 1 a 6 ).

Los datos obtenidos fueron analizados con el software X'Pert Highscore Plus v2.2a (2.2.1). Los resultados cualitativos fueron comparados con ficheros de datos de difracción para sustancias puras y se identificaron elementos y compuestos mediante la Base de Datos Internacional JCPDS (Joint Committee on Powder Difraction Standards). Para el análisis semicuantitativo se estudiaron las áreas de los picos de la reflexión de mayor intensidad.

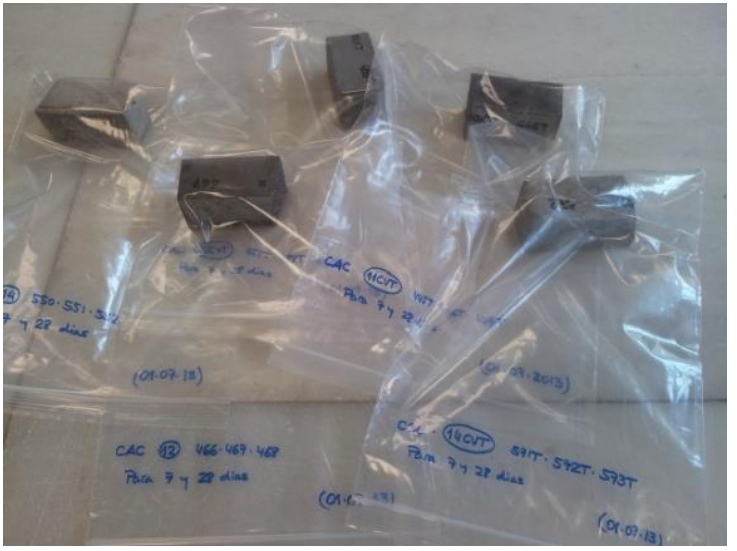

Ilustración 1. Sellado e identificación de probetas de mortero destinadas a su análisis DRX, DSC-TGA y lixiviado.

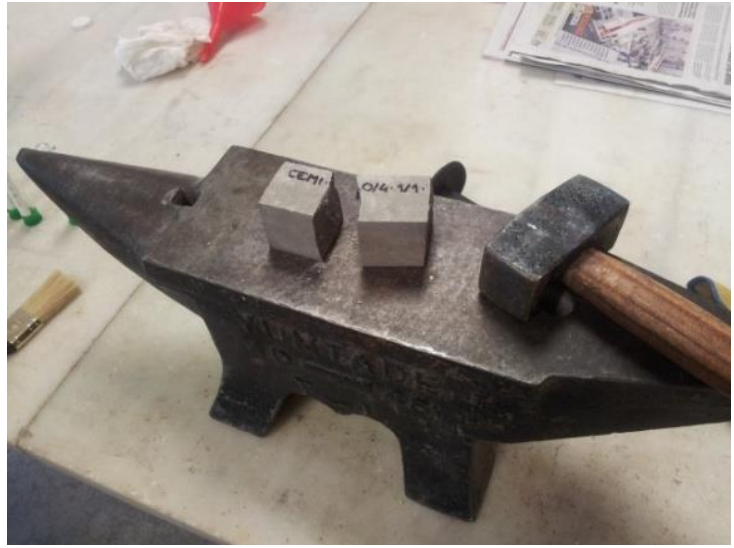

Ilustración 2. Preparación de los semiprismas de mortero de $4 \times 4 \times 4 \mathrm{~cm}^{3}$ para su utilización en los ensayos de DRX, DSCTGA y lixiviado. 


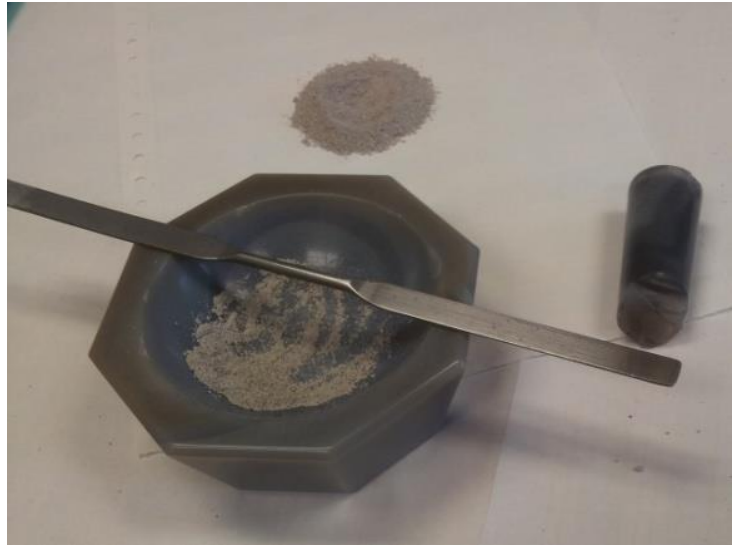

Ilustración 3. Machacado manual de las probetas de mortero. Obtención de la facción fina inferior a $63 \mu \mathrm{m}$

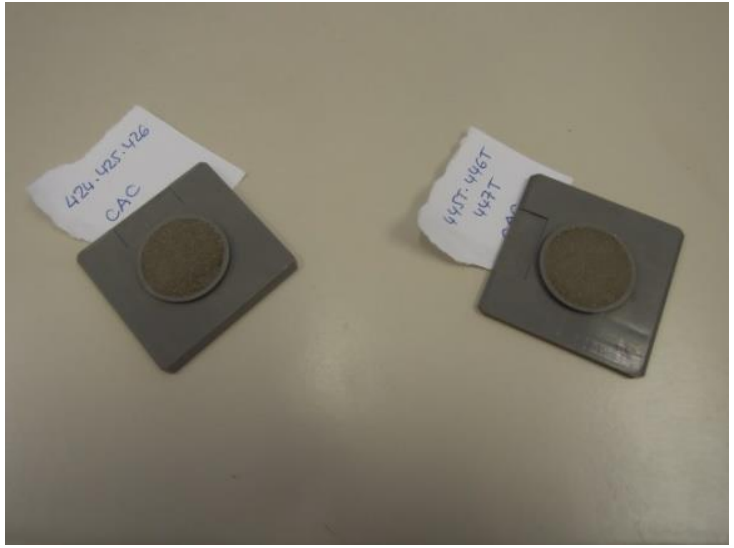

Ilustración 5. Preparación de las muestras sobre la bandeja de análisis del difractómetro.

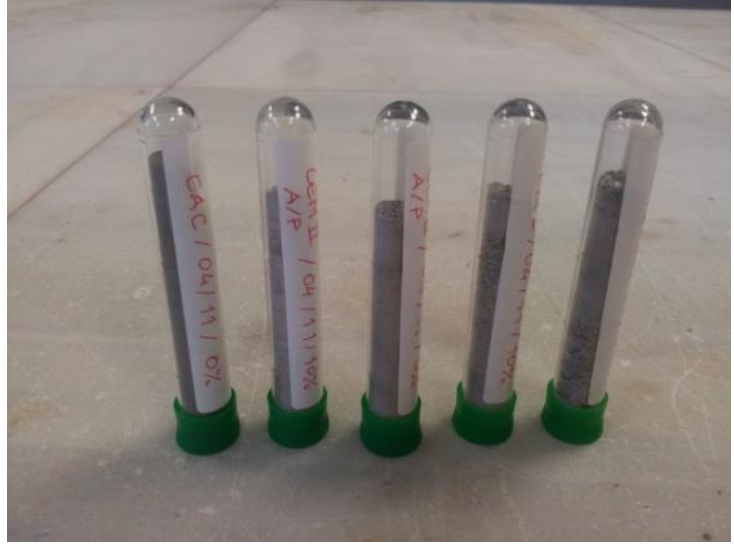

Ilustración 4. Conservación e identificación de muestras para su utilización en los ensayos de DRX y DSC-TGA.

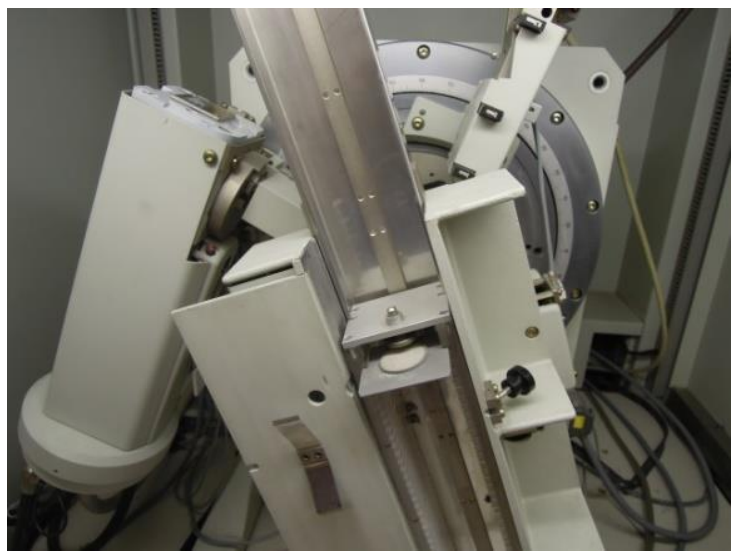

Ilustración 6. Difractómetro Siemens D5000 del Laboratorio de Química Industrial y Polímeros ETSIDI (UPM) 


\subsubsection{Calorimetría Diferencial de Barrido y Termo-Gravimetría (DSC-TGA)}

Tanto las cenizas de RSU originales, como las cenizas volantes inertizadas, fueron sometidas a un proceso de análisis termogravimétrico usando el Analizador Termogravimétrico y Calorímetro Diferencial de Barrido (SDT-Q600) ubicado en el Laboratorio de Química Industrial y Polímeros de la Escuela Técnica Superior de Ingeniería y Diseño Industrial de la UPM (ilustración 7).

El equipo térmico utilizado, es capaz de medir simultáneamente, el flujo de calor (DSC) y el cambio de peso (TGA) de una misma muestra desde la temperatura ambiente hasta $1000^{\circ} \mathrm{C}$. EL TGA tiene instalado una balanza con dos brazos con sensibilidad de 0.1 microgramos y el DSC mide el flujo de calor de una muestra en un crisol de platino en comparación con otro crisol sin muestra (previamente calibrado con una muestra estándar). Igualmente, tiene incorporado un horno con movimiento automatizado y un sistema de ingreso de gases de purga en dirección horizontal y regulada con un controlador digital de flujo másico (ilustraciones 8 y 9).

Los análisis de termogravimetría también han sido utilizados para realizar la caracterización de los morteros con mejores prestaciones técnicas de todos los estudiados. El análisis térmico diferencial da una idea de las transformaciones físico-químicas que tienen lugar dentro de los morteros analizados y las temperaturas a las que dichas transformaciones aparecen. El registro de datos obtenido indica si la sustancia es térmicamente activa al someter a las muestras a un aumento de temperatura desde $50^{\circ} \mathrm{C}$ hasta $1000^{\circ} \mathrm{C}$ y a una velocidad contante de $20^{\circ} \mathrm{C}$ por minuto. Los termogramas obtenidos reflejan la aparición de una serie de picos cuya posición depende fundamentalmente de la composición química y estructura cristalina del mismo, y cuya superficie está relacionada con la energía envuelta en la reacción que está ocurriendo.

El uso del termoanálisis junto a otras técnicas analíticas, como la difracción de rayos $X(D R X)$, constituye uno de los mejores mecanismos para poder realizar la identificación de morteros y revestimientos 
tradicionales, así como para obtener información adicional relevante sobre éstos.

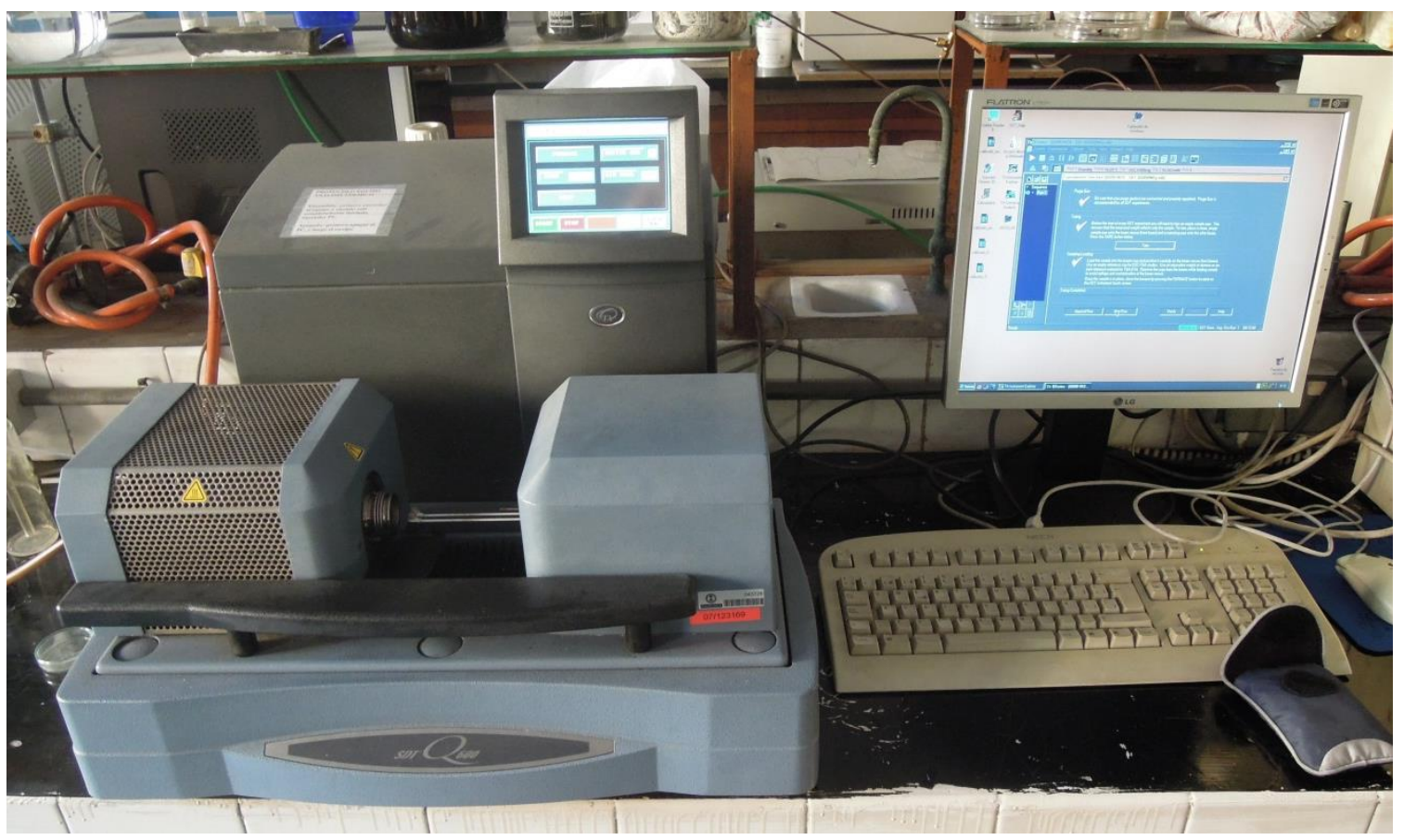

Ilustración 7. Analizador Termogravimétrico y Calorímetro Diferencial de Barrido (SDTQ600) ubicado en el Laboratorio de Química Industrial y Polímeros de la Escuela Técnica Superior de Ingeniería y Diseño Industrial de la UPM.

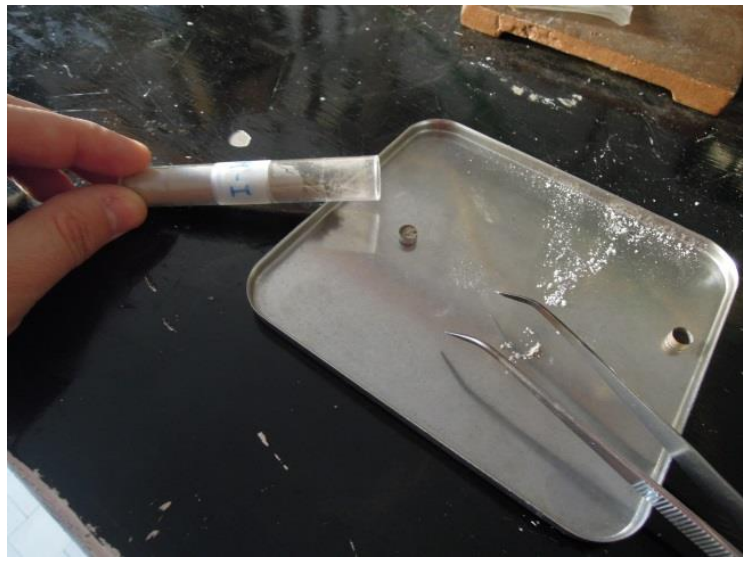

Ilustración 8. Preparación de muestras para análisis DSC-TGA.

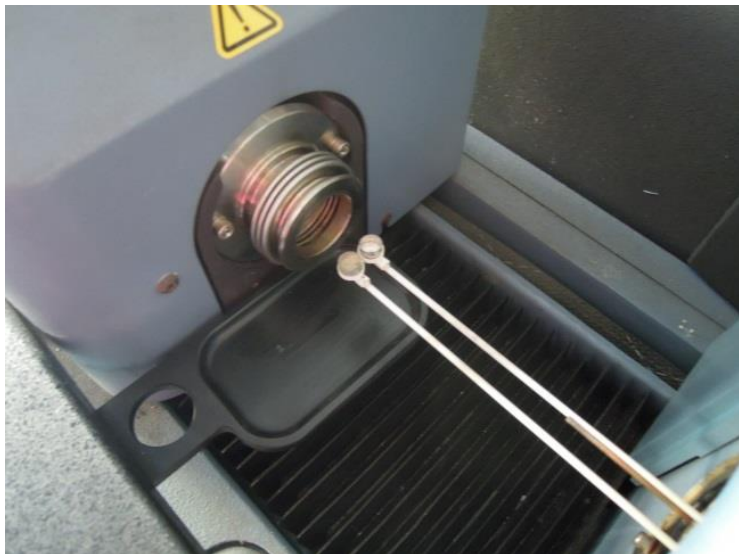

Ilustración 9. Comparación de muestras en los brazos del analizador TG. 
Para la preparación de las muestras, las probetas de los diversos morteros fueron inicialmente selladas en bolsas de polietileno, identificadas y conservadas en cámara húmeda a $20^{\circ} \mathrm{C}$ de temperatura y $95 \%$ de humedad relativa. Llegado el momento de la realización del ensayo fueron desembolsadas, divididas en semiprismas de $4 \times 4 \times 4 \mathrm{~cm}^{3}$ aproximadamente, machacadas manualmente y tamizadas por el tamiz de $63 \mu \mathrm{m}$ (ilustraciones 1 a 4$)$.

Los resultados de cada ensayo se reflejan en los distintos termogramas obtenidos mediante el software conectado al analizador TA Instruments Universal Analysis 2000 v.4.4A. Cada uno de los termogramas muestra tres gráficas, dependiendo del estado de carbonatación de la muestra analizada, siendo dichas gráficas la segunda derivada de la que se obtiene directamente del ensayo. Se utiliza este procedimiento con la intención de que los resultados sean más visibles y su análisis más intuitivo. De esta forma, los termogramas muestran:

- El porcentaje de pérdida de peso (línea verde).

- El flujo de calor, en W/g. (línea roja).

- La derivada del peso con relación a la temperatura, en $\% /{ }^{\circ} \mathrm{C}$, (línea azul).

En el caso del análisis térmico en morteros, la técnica resulta muy útil para identificar los distintos hidratos que pueden formarse en estos sistemas, especialmente en las edades tempranas de la hidratación, cuando están presentes las fases pobremente cristalinas. Las curvas presentadas muestran picos atribuibles a todos estos hidratos, aunque su superposición dificulta frecuentemente su interpretación, de ahí que sea imprescindible la utilización de técnicas como la difracción de rayos $X$ para facilitar los análisis.

A pesar de la valiosa información suministrada por los análisis químicos y la caracterización mediante técnicas de DRX y DCS-TGA de las cenizas volantes y de los morteros con ellas ejecutados, es importante 
destacar el hecho de su carácter complementario. Por eso se ha decidido completar y complementar los análisis realizados con datos procedentes de los estudios físico-mecánicos de todos los morteros estudiados, los cuales se detallarán en los próximos apartados.

\subsection{2 ÁRIDOS}

\subsubsection{Determinación de la humedad del árido}

Este ensayo tiene por finalidad, determinar el contenido de humedad de una muestra de árido. El contenido de humedad de un árido está formado por la suma de las aguas libre, capilar e higroscópica

El contenido de agua que presenta un árido representa, junto con la cantidad de aire, una de las características más importantes para explicar el comportamiento de éste (especialmente los de textura más fina) ante cambios de volumen o estabilidad dinámica.

El método de determinación de la humedad del árido en el laboratorio se ha obtenido por medio del secado al horno mediante una estufa cuya temperatura se ha graduado a $115 \pm 5^{\circ} \mathrm{C}$ durante 24 horas (ilustración 10 ).

De esta forma, la humedad de un árido es expresada en porcentaje entre el peso del agua existente en una determinada masa de arena y el peso de las partículas sólidas, o sea:

$$
\omega=\left[\frac{\left(m_{h}-m_{s}\right)}{m_{s}}\right] x 100
$$

dónde:

$m_{h}=$ masa húmeda de árido $(\mathrm{g})$.

$m_{s}=$ masa seca de árido $(\mathrm{g})$. 


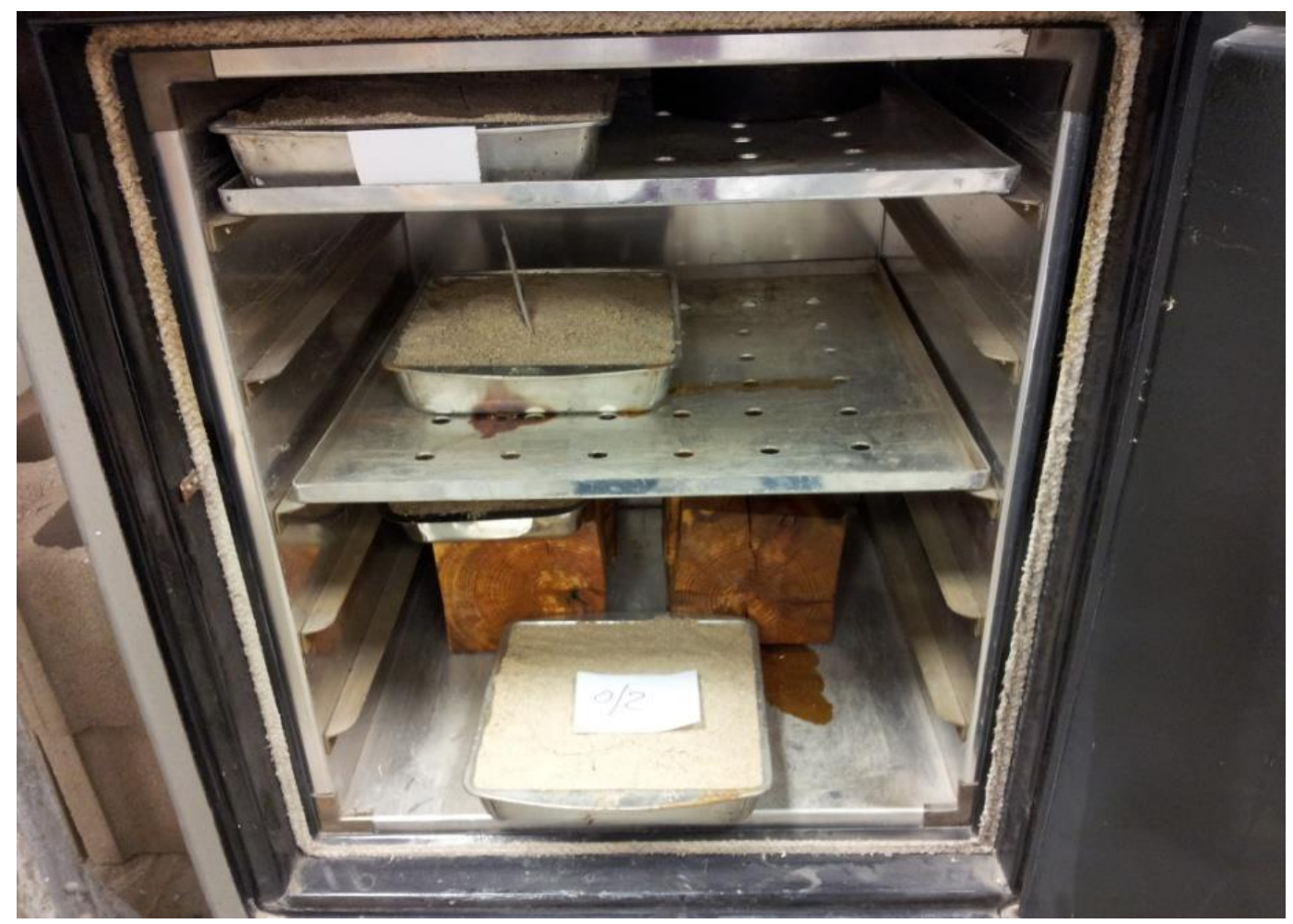

Ilustración 10. Desecado de los áridos utilizados en la elaboración de los diversos morteros analizados. (115 $\mathrm{C}$ y $24 \mathrm{~h}$ )

2.2.2.2 Determinación de la distribución granulométrica del árido empleado mediante el método del tamizado.

A través este ensayo se pretende dividir y separar, mediante la utilización de una serie de tamices normalizados, el árido empleado en la fabricación de los morteros objeto de esta tesis, en varias fracciones granulométricas de tamaño creciente. De acuerdo a la tabla 1 de la norma UNE EN 933-1:1997, al tratarse de dos áridos 0/2 y 0/4 la muestra mínima debe ser $200 \mathrm{~g}$. Para la realización del ensayo se han seleccionado $300 \mathrm{~g}$ de ambos áridos.

En un primer momento se ha procedido al lavado de la totalidad de la muestra para obtener la completa separación y suspensión de finos. Para ello se ha utilizado un tamiz de $63 \mu \mathrm{m}(0,063 \mathrm{~mm})$ el cual ha sido protegido con dos tamices de graduación superior ( 1 y $2 \mathrm{~mm}$ ). El proceso de lavado 
se ha continuado hasta que el agua que fluía por el tamiz de ensayo se ha considerado limpia y que no arrastraba finos. Una vez terminado el lavado (ilustración 11), los residuos retenidos por el tamiz de $63 \mu \mathrm{m}$ se han secado a una temperatura de $110^{\circ} \mathrm{C}$ hasta conseguir una masa constante.

Tras esto, se ha procedido al tamizado. Para ello se han seleccionado los siguientes tamices: $4,2,1,0,5,0,25,0,125$ y 0,063 mm de acuerdo con lo establecido en la Norma EN 933-2 y de los requisitos de las Normas ISO 3310-1 y 3310-2. Éstos se han colocado en la máquina tamizadora de arriba abajo, en orden decreciente de tamaños de abertura con un fondo y una tapa (ilustración 12). La tamizadora ha agitado el conjunto de tamices de manera mecánica durante 3 minutos tras lo cual se ha procedido al pesado del material retenido en todos y cada uno de los tamices, registrando sus masas con la denominación $\mathrm{R}_{\mathrm{i}}$.

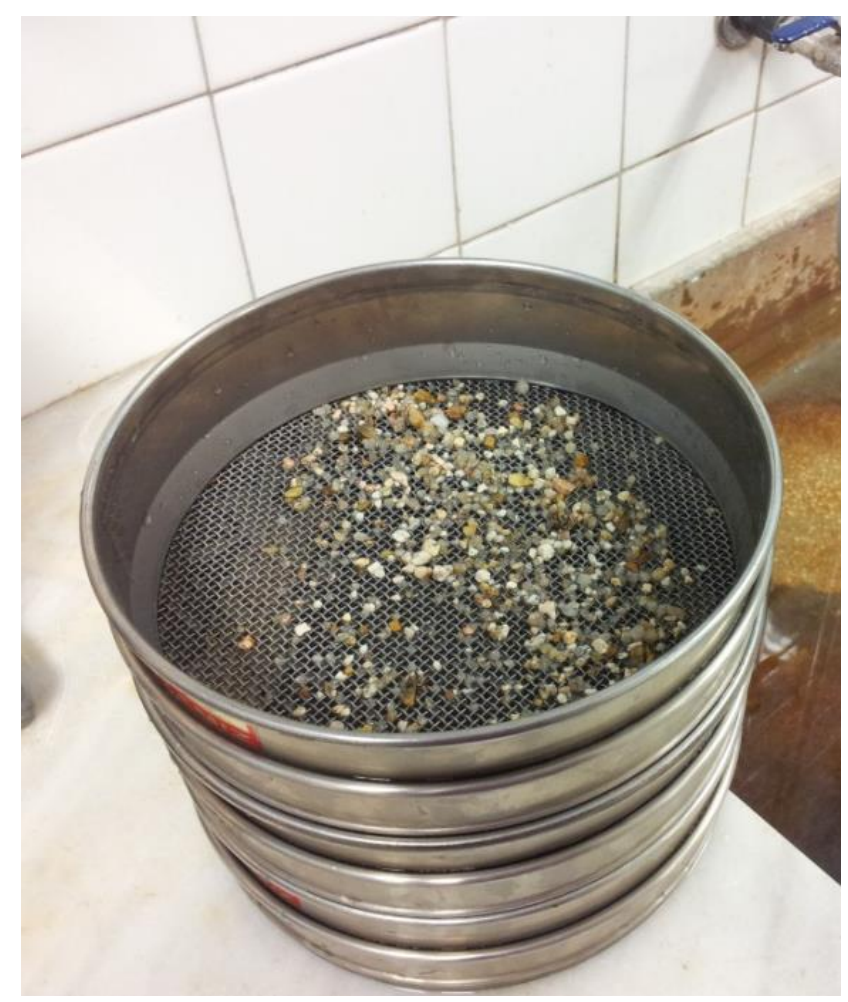

Ilustración 11. Distribución granulométrica del árido. Proceso de lavado.

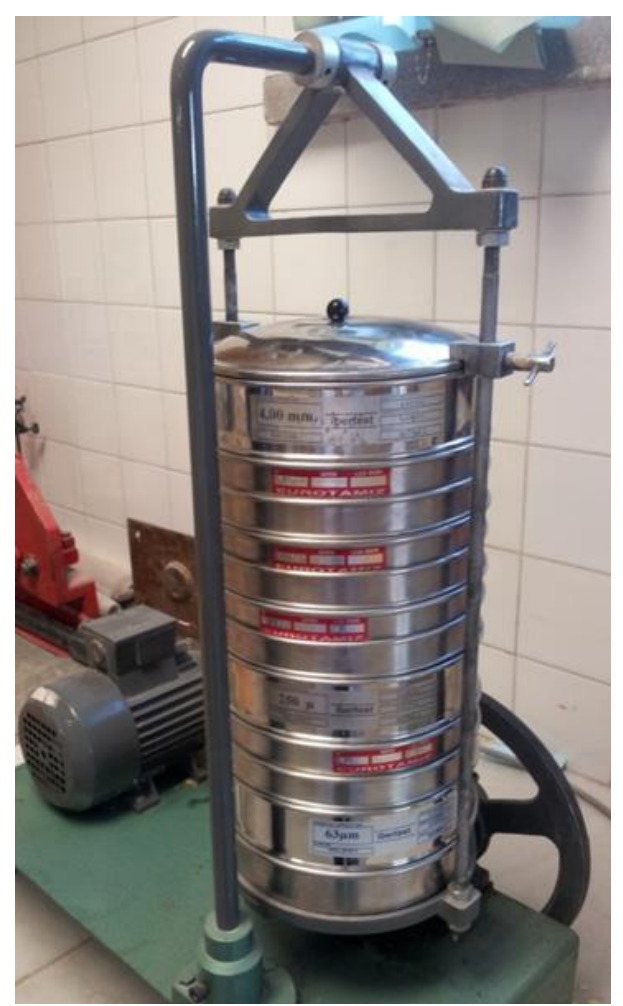
$\begin{array}{lll}\text { Ilustración } 12 . & \text { Distribución } \\ \text { granulométrica del árido. Proceso de }\end{array}$ tamizado. 


\subsubsection{MORTERO FRESCO}

Los morteros analizados fueron amasados en una amasadora planetaria IBERTEST normalizada. Las probetas de mortero de $4 \times 4 \times 16$ $\mathrm{cm}^{3}$, fueron preparadas en moldes de acero, desmoldadas a las 24 horas y curadas a $20^{\circ} \mathrm{C}$ sumergidas en agua según el método de ensayo establecido en la Norma Europea EN 196-1.

Dada la complejidad y heterogeneidad de las muestras a analizar, y para favorecer la comparación entre ellas, se estudió la relación agua/cemento de todos y cada uno de los morteros ensayados con el fin de mantener la trabajabilidad de los mismos. Se llevó la consistencia de todas las muestras a un valor de escurrimiento de $175 \pm 10 \mathrm{~mm}$, determinado por la mesa de sacudidas de acuerdo a lo establecido por la Norma EN 1015-3:2000 en lo relativo a morteros con densidades aparentes superiores a $1200 \mathrm{~kg} / \mathrm{m} 3$.

En las muestras de mortero fresco se determina, a su vez, el Periodo de Trabajabilidad en minutos, definido por la aplicación de la Norma Europea EN 1015-9:2000 para morteros de albañilería de uso corriente.

2.2.3.1 Determinación de la consistencia del mortero fresco por la mesa de sacudidas (UNE EN 1015-3:2000)

Esta norma europea especifica un método de ensayo para determinar, por medio del valor del escurrimiento, la consistencia de los morteros frescos amasados incluyendo en su ámbito de actuación los morteros de áridos normales y ligeros usados para la elaboración de las muestras estudiadas en esta investigación.

Mediante la aplicación de este ensayo se han llevado todos y cada uno de los morteros estudiados, a unos niveles de consistencia específicos para intentar mantener la trabajabilidad de las muestras, antes de proceder a evaluar las diversas propiedades de los mismos. De esta forma, se ha determinado la capacidad de retención de agua de los distintos morteros 
para poder evitar una rigidización excesiva de los mismos o una disgregación que imposibiliten su manejo a lo largo de los distintos ensayos.

La consistencia es un mecanismo indirecto de medición del nivel de agua necesario en el amasado de un mortero, que define la manejabilidad o trabajabilidad del mismo. Los valores así obtenidos estarán directamente relacionados con el comportamiento de un determinado mortero a la hora de su puesta en obra.

El valor del escurrimiento se determina midiendo el diámetro medio de una muestra de mortero fresco colocado, con ayuda de un molde troncocónico de latón, sobre el disco de una mesa de sacudidas, en donde se somete el mortero a un determinado número de sacudidas verticales, levantando la mesa de sacudidas y dejándola caer libremente desde una altura determinada.

El ensayo fue realizado en el Laboratorio de Materiales de Construcción de la ETSEM. Antes de comenzar cada una de las tomas de muestra de los distintos morteros, se limpió detenidamente el disco de la mesa de sacudidas, así como la superficie interior y los bordes del molde de latón, con ayuda de un paño húmedo. Con posterioridad se procedió a lubrificar ligeramente las superficies en contacto con la pasta de mortero.

Para iniciar el ensayo, el molde de latón fue situado en el centro del disco de la mesa de sacudidas; se introdujo en el molde la pasta de mortero en dos tongadas, compactando cada una de ellas con diez golpes de pisón de sección circular, asegurando un llenado uniforme del molde. Una vez lleno, se eliminó el exceso de mortero con la regla metálica para enrasar, se limpia y seca la superficie libre del disco procediendo con la eliminación del agua que pueda quedar alrededor del borde inferior del molde (ilustración 13).

Tras 15 segundos, se levantó verticalmente el molde con cuidado de no moverlo y se ejercieron 15 sacudidas a la mesa con una frecuencia de una sacudida por segundo, con lo que la pasta de mortero se extendió sobre la superficie del disco. 


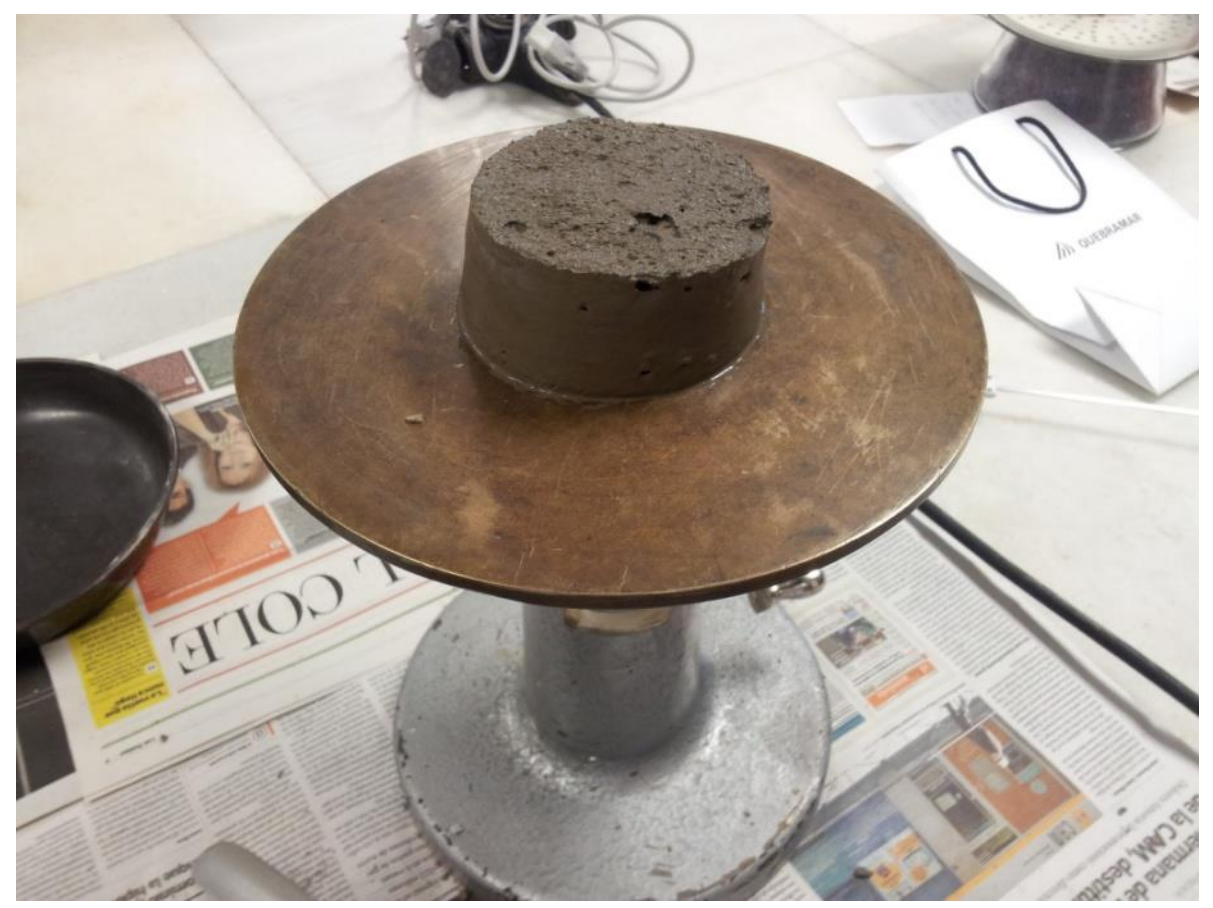

Ilustración 13. Determinación de la consistencia del mortero fresco. Molde sobre la mesa de sacudidas según UNE EN 1015-3:2000.

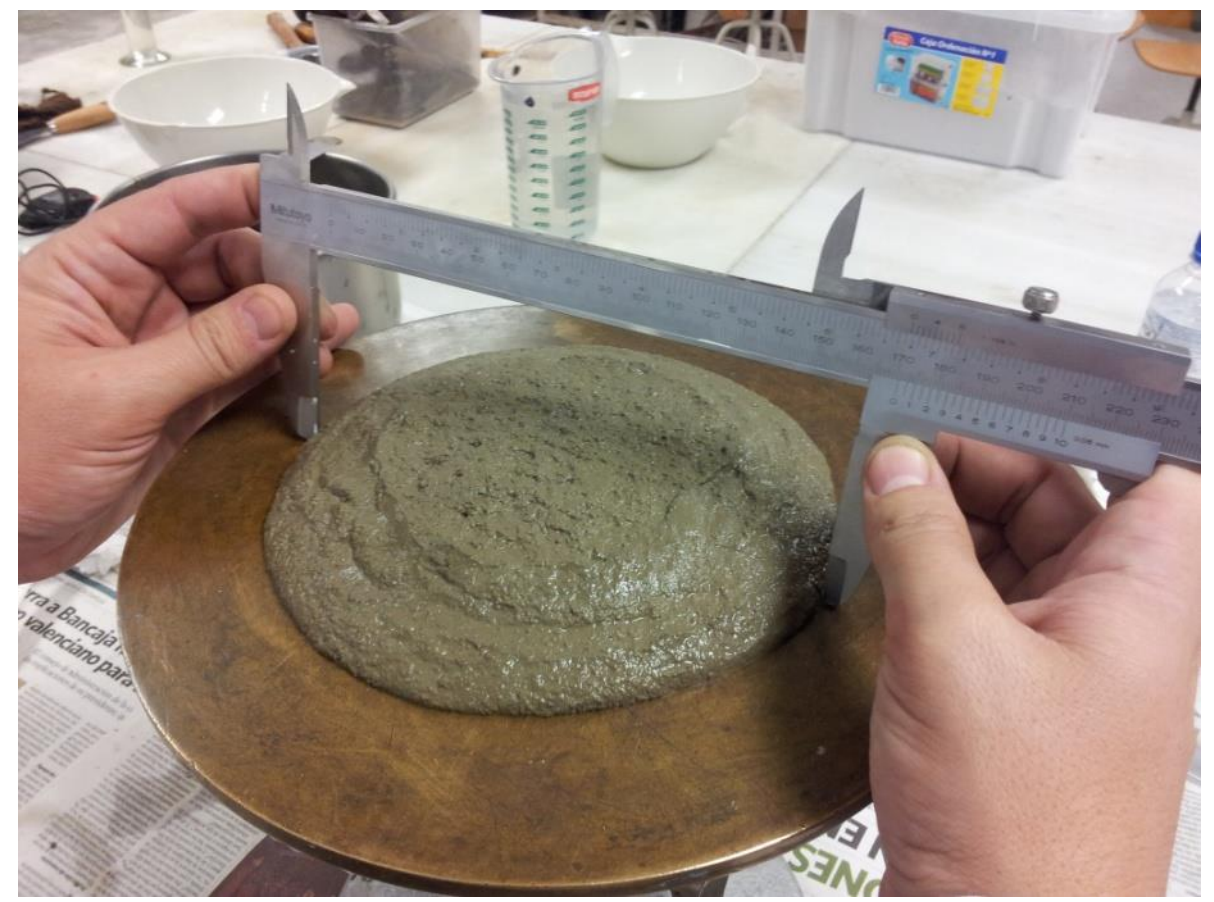

Ilustración 14. Determinación de la consistencia del mortero fresco. Medición de la galleta de mortero según UNE EN 1015-3:2000. 
Inmediatamente después, con la ayuda de un calibre, el diámetro del mortero fue medido, realizando dos medidas en dos direcciones perpendiculares entre sí (ilustración 14).

La toma de datos se realizó en milímetros, con una exactitud de $1 \mathrm{~mm}$, calculando el valor medio de las dos medidas. Este valor medio corresponde con el valor del escurrimiento de la muestra ensayada puesto que en todos los casos ensayados, los valores individuales de cada medida de escurrimiento difirieron de su valor medio en menos de un $10 \%$.

El proceso se realizó en repetidas ocasiones hasta conseguir unos valores de escurrimiento acordes a los definidos por la Norma Europea EN 1015-2: 1998 (tabla 8).

Tabla 8. Valor del escurrimiento del mortero según UNE EN 1015-2:1998.

\begin{tabular}{cc}
\hline $\begin{array}{c}\text { Densidad aparente del mortero } \\
\text { fresco }\left(\mathbf{k g} / \mathbf{m}^{\mathbf{3}}\right)\end{array}$ & Valor del escurrimiento $(\mathbf{m m})$ \\
\hline$>1200$ & $175 \pm 10$ \\
\hline$>600 a \leq 1200$ & $160 \pm 10$ \\
\hline$>300 a \leq 600$ & $140 \pm 10$ \\
\hline$\leq 300$ & $120 \pm 10$ \\
\hline
\end{tabular}

Ha quedado definido en el apartado "Determinación de la densidad aparente del mortero fresco", que todos los morteros frescos ensayados en esta tesis tienen unas densidades aparentes muy superiores a $1200 \mathrm{~kg} / \mathrm{m}^{3}$, con lo que los diámetros del mortero extendido, una vez superados los 15 impactos de la mesa de sacudidas, deberán estar comprendidos entre los $165 \mathrm{~mm}$ y los $185 \mathrm{~mm}$ (de acuerdo a lo reflejado en la tabla 8), si se quiere conseguir un valor de escurrimiento adecuado $\mathrm{y}$, por lo tanto, una trabajabilidad o capacidad de manejo adecuada para los ensayos que se han de llevar a cabo. 
2.2.3.2 Determinación del periodo de trabajabilidad de los morteros ensayados (UNE EN 1015-9:1999 y UNE EN 1015-9:2000-A1)

El periodo de trabajabilidad de una muestra de mortero fresco, llevado inicialmente a un valor de escurrimiento definido, se determina midiendo el tiempo en minutos, a partir del cual alcanza un límite definido de rigidez o de trabajabilidad, durante un ensayo tipo definido. Para la realización de este ensayo se ha contado con una sonda de penetración (ilustración 15).

La muestra de mortero fresco utilizado en este ensayo tuvo un volumen de $1,5 \mathrm{l}$. Se obtuvo por preparación en el laboratorio a partir de los componentes secos y de agua.

Antes de realizar los ensayos, las muestras para ensayo mezcladas en el laboratorio se llevaron a valores de escurrimiento definidos, según lo especificado en 2.2.3.1 Determinación de la consistencia del mortero fresco por la mesa de sacudidas (UNE EN 1015-3:2000).

La duración del amasado se midió a partir del momento en el que todos los componentes fueron introducidos en la amasadora.

Antes de los ensayos, el mortero amasado fue agitado suavemente a mano, utilizando una paleta, durante $10 \mathrm{~s}$ con el fin de evitar cualquier falso fraguado, pero sin realizar un amasado adicional.

Con posterioridad, se procedió a llenar un molde cilíndrico de $75 \mathrm{~mm}$ de diámetro y $75 \mathrm{~mm}$ de altura con el mortero (amasado de acuerdo a EN 1015-2) en, aproximadamente, 10 tongadas. Tras cada adición de mortero se golpeó el mismo contra la mesa de trabajo cuatro veces. Una vez lleno, se enrasó la superficie para nivelar el mortero con la parte superior del molde.

Una vez hecho lo anterior, se situó el molde con el mortero sobre la balanza del aparato de determinación de la trabajabilidad, de tal forma que la superficie superior del mortero situada inmediatamente debajo de la sonda normalizada del aparato se situé a menos de $20 \mathrm{~mm}$ del borde del molde o del emplazamiento de cualquier penetración anterior. Tras esto, se 
taró el peso del molde con el mortero y mediante la palanca que acciona la sonda se penetra la masa de mortero hasta que la arandela testigo rozó la superficie del mortero. En este momento, se registró el valor indicado por la balanza, en kilogramos, y se corrigió en función de la masa del molde lleno, tras dividir por 3 dicho valor, para expresar la resistencia a la penetración en $\mathrm{N} / \mathrm{mm}^{2}$.

En condiciones normales, para morteros no retardados como los ensayados a lo largo de esta tesis, la resistencia a la penetración se determina cada 15 minutos, comenzando 30 minutos después del periodo de trabajabilidad declarado del mortero. En éste caso, al tratarse de morteros amasados en laboratorio con dosificaciones estudiadas para cumplir consistencias acordes a la norma UNE EN 1015-3:2000, se ha procedido a realizar penetraciones de tanteo a 60, 120 y 180 minutos hasta zonas temporales cercanas a los valores límite prescritos, a partir de las cuales se realizaron penetraciones cada 15 minutos.

El periodo de trabajabilidad, por tanto, se determinó tomando como tiempo cero el momento de la adición del agua a los componentes secos, y finalizando en el momento, redondeado al minuto más próximo, en el que se alcanzó una resistencia a la penetración de $0,5 \mathrm{~N} / \mathrm{mm}^{2}$. Dada la imposibilidad de hacer coincidir exactamente la penetración que delimitará el periodo de trabajabilidad, éste se determina por la interpolación de los valores individuales obtenidos, inmediatamente, por encima y por debajo de $0,5 \mathrm{~N} / \mathrm{mm}^{2}$.

De la interpolación de los resultados obtenidos inmediatamente por encima y por debajo a una resistencia de penetración de $0,5 \mathrm{~N} / \mathrm{mm}^{2}$, es decir: $0,516 \mathrm{~N} / \mathrm{mm}^{2}$ a 195 minutos y $0,371 \mathrm{~N} / \mathrm{mm}^{2}$ a 180 minutos; y de la aplicación de una regla de tres y redondeando al minuto más próximo, se deduce que el periodo de trabajabilidad del mortero CEMI.0/2.1/1·R, es de 193 minutos.

Para mayor precisión de los cálculos efectuados, se realizaron dos ensayos de cada dosificación. 

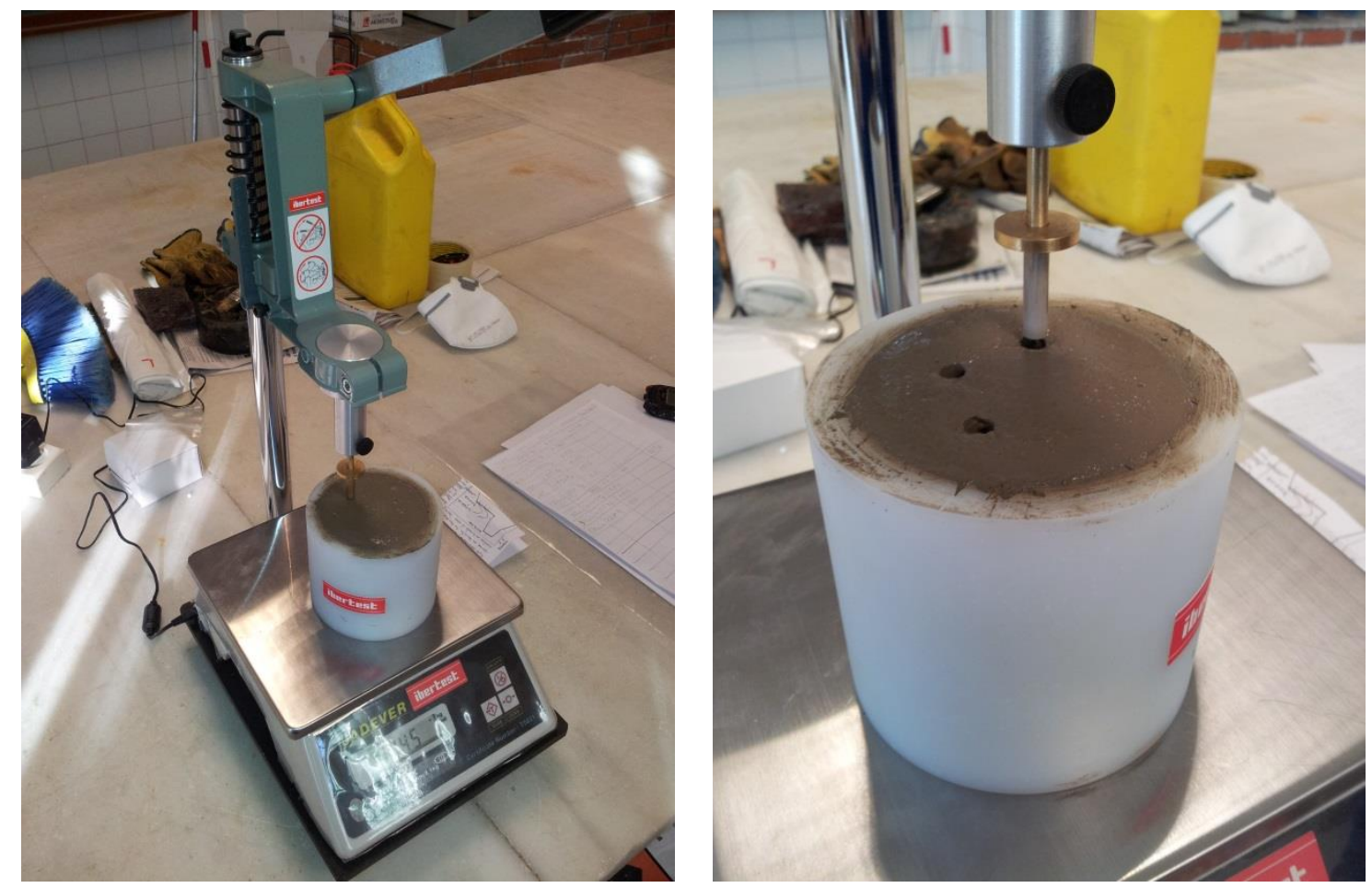

Ilustración 15. Sonda de penetración y molde de ensayo del periodo de trabajabilidad.

\subsubsection{MORTERO ENDURECIDO}

2.2.4.1 Determinación de la estabilidad dimensional de los morteros para albañilería endurecidos

Para la determinación de la variación de longitudes y masas se realizó una adaptación de la Norma Europea 83831:2012 EX. En ella se describe el método de ensayo para determinar la estabilidad dimensional es decir, los posibles movimientos de retracción o expansión debidos a cambios del contenido de humedad, tanto de los morteros para albañilería, como de los morteros para revoco y enlucido. En el ensayo realizado se mantuvieron los aspectos relativos a la determinación de la variación de la masa, si bien para la determinación de la variación de longitud, ésta se determinó a través de la toma directa de valores mediante un calibre. 
La retracción y la expansión, así como la masa, de un mortero endurecido se determinaron midiendo, en función del tiempo, la variación de longitud y de masa de las probetas prismáticas de mortero, conservadas, después de desmoldadas, en condiciones ambientales normalizadas.

Los morteros analizados fueron amasados en una amasadora planetaria IBERTEST normalizada. Se prepararon tres probetas de mortero de $4 \mathrm{~cm} \times 4 \mathrm{~cm} \times 16 \mathrm{~cm}$ en moldes de acero, desmoldadas a las 48 horas y curadas a $20^{\circ} \mathrm{C} \pm 2^{\circ} \mathrm{C}$ en cámara húmeda con una humedad relativa del $95 \% \pm 5 \%$, según el método de ensayo establecido en la Norma Europea UNE-EN 1015-11. A lo largo de la duración del ensayo, las probetas se conservan en condiciones de almacenamiento sobre una parrilla con bandas de sección triangular al aire a una temperatura de $20{ }^{\circ} \mathrm{C} \pm 2{ }^{\circ} \mathrm{C}$ y una humedad relativa del $65 \% \pm 5 \%$ separadas entre ellas, al menos $10 \mathrm{~mm}$, hasta la medida de la retracción o de la expansión (ilustración 16).

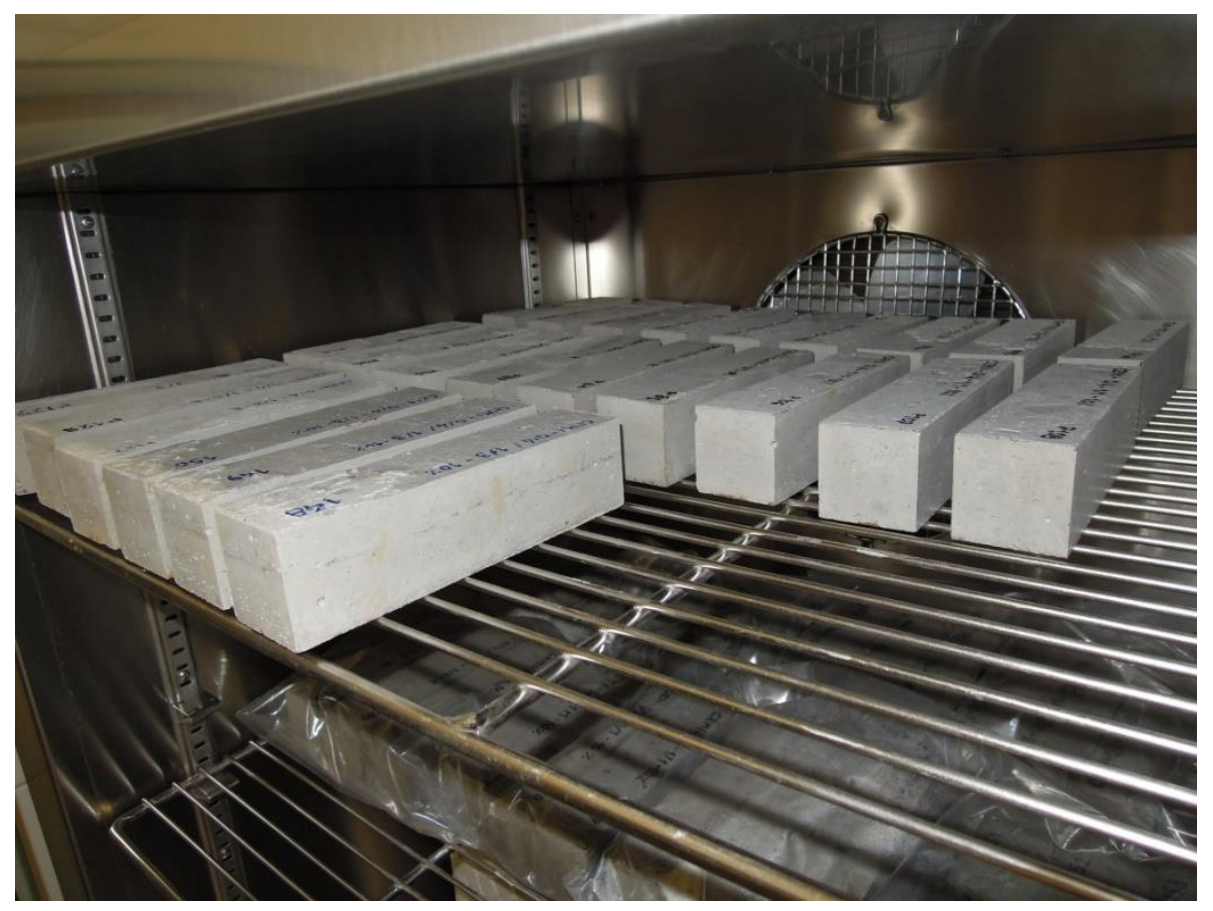

Ilustración 16. Determinación de la estabilidad dimensional. Almacenamiento en cámara húmeda a una temperatura constante de $20^{\circ} \mathrm{C} \pm 2{ }^{\circ} \mathrm{C}$ y una humedad relativa del $65 \% \pm$ $5 \%$. 
Tanto para el ensayo de retracción, como para el de expansión, una vez realizado el desmolde se mide la longitud de la probeta ( $L$ ) y se pesa (M). A continuación, se colocan las probetas en las condiciones de conservación definidas anteriormente hasta la próxima lectura.

Las distintas medidas se efectúan sobre las tres probetas preparadas para el ensayo a las siguientes edades:

a) inmediatamente después del desmolde (medida inicial de las variaciones),

b) a las edades de 7, 14 y 28 días después de la confección de las probetas.

1) Medida de las variación de la longitud

Las medidas de la variación de la longitud, se efectuaron con un calibre según el eje longitudinal de la probeta de ensayo mantenida en posición horizontal (ilustración 17).

2) Medida de la variación de masa (Norma Europea 83831:2012 EX)

Para determinar las medidas de la variación de masa, se pesó cada probeta de ensayo con una aproximación de $0,1 \mathrm{~g}$ cada vez que se efectuó una medida de longitud, con la intención de evitar mantener las probetas más de 30 minutos fuera de las condiciones ambientales en las cuales se han conservado (ilustración18).

\section{3) Cálculo y expresión de los resultados}

Las variaciones de la longitud específica $(\varepsilon)$, con una aproximación de $0,001 \%$ y, las variaciones de masa específica $(m)$, con una aproximación de $0,1 \%$, para cada probeta de ensayo y para cada edad especificada, se han calculado por medio de las siguientes expresiones:

$$
\begin{gathered}
\varepsilon=(\Delta L / L) \times 100 \% \\
m=(\Delta M / M) \times 100 \%
\end{gathered}
$$


Tanto el valor medio de la retracción, como el valor medio de expansión, se han calculado dividiendo por tres la suma de los valores de las variaciones de longitud individuales de las tres probetas para cada edad, con una aproximación de 0,001\%.

El valor medio de la variación de masa, se ha calculado dividiendo por tres la suma de los valores de las variaciones individuales de masa de las tres probetas para cada edad, con una aproximación de 0,01\%.

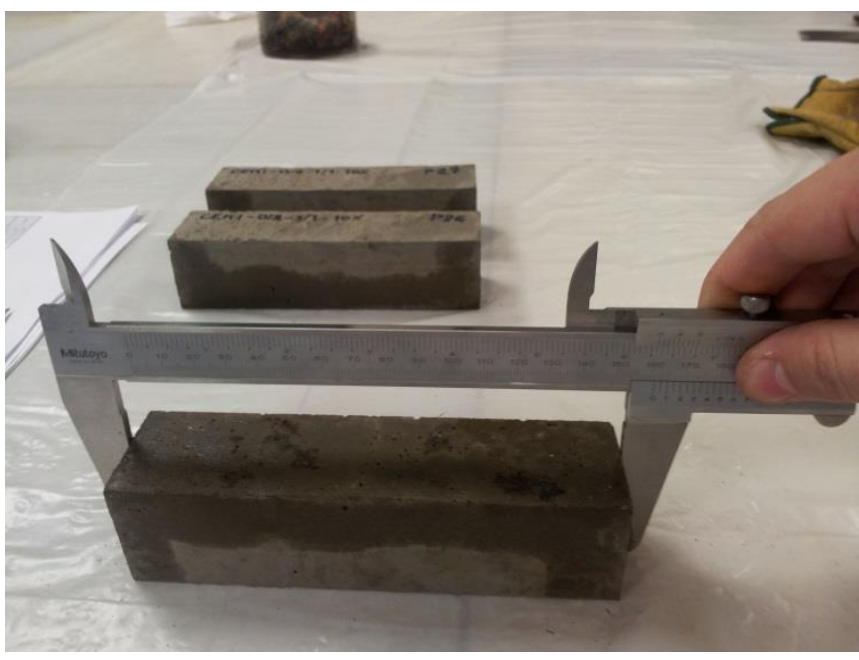

Ilustración 17. Estabilidad dimensional. Medida de las variaciones de longitud.

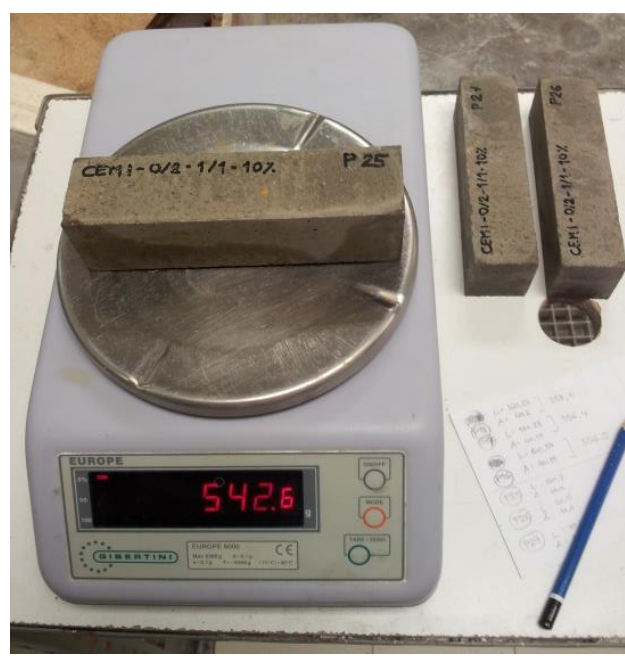

Ilustración $\quad \mathbf{1 8 .} \quad$ Estabilidad dimensional. Medida de las variaciones de masa.

2.2.4.2 Determinación de la densidad aparente en seco del mortero endurecido (UNE EN 1015-10)

Esta norma describe el método de ensayo para determinar la densidad aparente en seco de los morteros endurecidos y es de aplicación tanto a morteros ligeros, como a morteros para uso corriente y de juntas finas.

Los morteros analizados fueron amasados en una amasadora planetaria IBERTEST normalizada ubicada en el laboratorio de materiales de construcción de la ETSEM. 
Se prepararon tres probetas de mortero de $4 \times 4 \times 16 \mathrm{~cm}^{3}$ en moldes de acero, desmoldadas a las 48 horas y curadas a $20^{\circ} \mathrm{C} \pm 2{ }^{\circ} \mathrm{C}$ en cámara húmeda con una humedad relativa del $95 \% \pm 5 \%$, según el método de ensayo establecido en la Norma Europea UNE-EN 1015-11.

El procedimiento operatorio es el reseñado a continuación:

\section{1) Secado a masa constante:}

Las probetas se secan en estufa, a una temperatura de $70^{\circ} \mathrm{C} \pm 5^{\circ} \mathrm{C}$, hasta alcanzar una masa constante. Se considera que la probeta alcanza una masa constante cuando dos pesadas sucesivas, efectuadas a intervalos de 2 horas de secado, no difieren en más de 0,2\% de la masa de la probeta seca. La masa de la probeta, $m_{s, s e c}$, se anota en $\mathrm{kg}$, con una exactitud aproximada del $0,1 \%$.

2) Determinación del volumen de la probeta por desplazamiento volumétrico:

Con posterioridad, las probetas se sumergen en agua a $20^{\circ} \mathrm{C} \pm 2^{\circ} \mathrm{C}$ hasta que no se observe aumento de la masa aparente. Se considera que esta fase se alcanza cuando dos pesadas sucesivas, efectuadas en un intervalo de 15 minutos durante la inmersión, no difieren en más de 0,2\% en masa. La probeta húmeda se pesa después de haber eliminado el exceso de agua con un paño húmedo y se anota su masa, $m_{s, s a t}$ en $\mathrm{kg}$ con una exactitud aproximada del $0,1 \%$.

El volumen de la probeta se determina por pesada hidrostática. Una vez que el instrumento de pesado alcanza el equilibrio, se asegura que el estribo vacío está suspendido y que está completamente sumergido en el agua del recipiente. El estribo se sumerge hasta la misma profundidad en las que se efectúen las pesadas con la probeta. La probeta húmeda se coloca en el estribo. Se eliminan las burbujas de aire atrapadas en las caras de la probeta. Una vez que la probeta sumergida cesa en su oscilación de la 
balanza hidrostática, se pesa y se anota la masa de la probeta, $m_{s, i}$, en $\mathrm{kg}$ (ilustración 19).

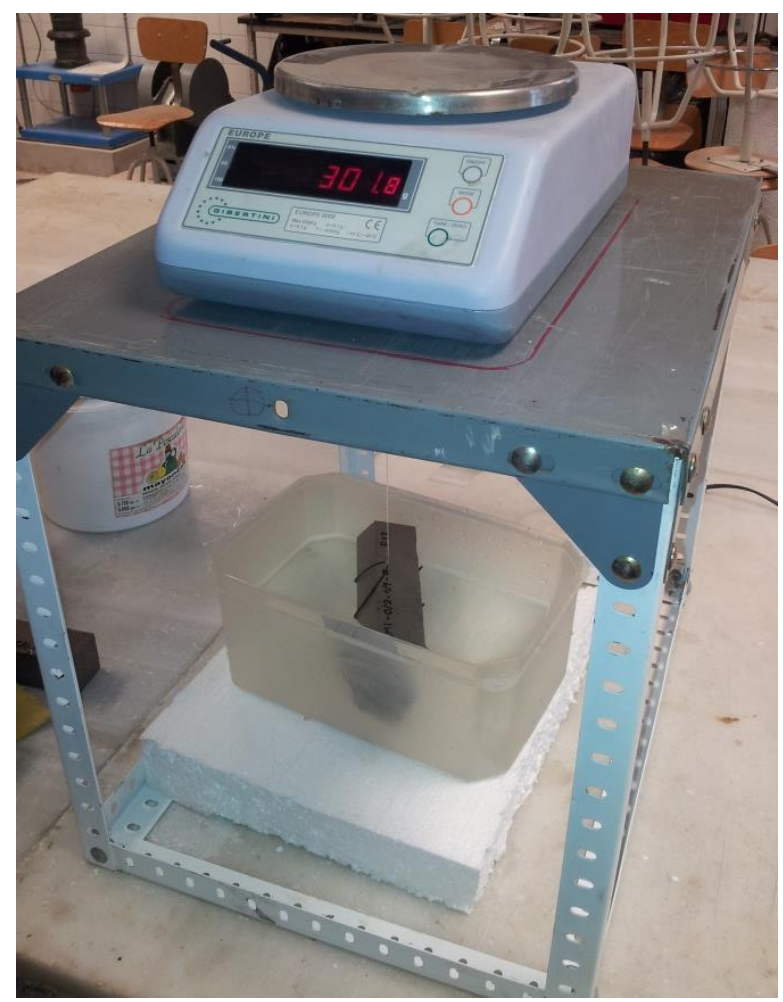

Ilustración 19. Determinación del volumen de la probeta en el laboratorio mediante pesada hidrostática.

El volumen de la probeta, en $\mathrm{m}^{3}$, se calcula por medio de la siguiente expresión:

$$
V s=\frac{m_{s, s a t}-m_{s, i}}{\rho_{w}}
$$

Siendo:

$m_{s, s e c}$ es la masa de la probeta del mortero endurecido secado en estufa, en kilogramos $(\mathrm{kg})$; 
$m_{s, s a t}$ es la masa de la probeta saturada del mortero endurecido, en kilogramos $(\mathrm{kg})$;

$m_{s, i}$ es la masa aparente de la probeta saturada del mortero endurecido sumergido en agua, en kilogramos $(\mathrm{kg})$;

$\rho_{W}$ es la densidad del agua, en kilogramos por metro cúbico $\left(\mathrm{kg} / \mathrm{m}^{3}\right)$;

$V_{S}$ es el volumen de la probeta de mortero endurecido, en metros cúbicos $\left(\mathrm{m}^{3}\right)$.

\section{3) Cálculo y expresión de los resultados}

La densidad aparente en seco de cada probeta de mortero se calcula dividiendo la masa de la probeta secada en estufa, $m_{s, s e c}$, en kilogramos, por el volumen de la probeta del mortero endurecido, $V_{s}$, en metros cúbicos.

El valor medio se calcula a partir de los valores individuales obtenidos para cada probeta de mortero, todos los valores se redondean, a $10 \mathrm{~kg} / \mathrm{m}^{3}$.

2.2.4.3 Determinación de la resistencia a la carbonatación (UNE EN 13295: 2004)

Esta norma europea describe un método de ensayo acelerado, llevado a cabo en el laboratorio, para medir la resistencia a la penetración del dióxido de carbono $\left(\mathrm{CO}_{2}\right)$ a través de pastas, morteros y hormigones para reparación en los que no se ha aplicado un sistema de revestimiento protector. El método se basa en la medición de la profundidad de carbonatación de una probeta situada en una atmosfera concentrada de dióxido de carbono durante un intervalo de tiempo determinado.

Se entiende por carbonatación de un mortero, a la reacción de los componentes alcalinos que se encuentran en las pastas de cemento, como por ejemplo el hidróxido de calcio, con el dióxido de carbono atmosférico, lo cual genera una disminución del valor del pH del mortero.

Mediante este ensayo se define la profundidad de este proceso de carbonatación, $d_{k}$, como la distancia media, medida en mm, a partir de la 
superficie del mortero, en la que el $\mathrm{CO}_{2}$ ha reducido la alcalinidad del cemento hidratado, hasta tal punto que una disolución indicadora de fenolftaleína permanece incolora.

La resistencia de los morteros frente a la carbonatación ha sido medida en el laboratorio de materiales de construcción de la ETSEM mediante un ensayo acelerado en el que las probetas han sido expuestas durante 60 días, a la acción atmosférica directa en la Ciudad Universitaria de Madrid entre los días 26 de abril y 25 de junio del año 2012. Los valores medios de $\mathrm{CO}$, presión atmosférica y humedad relativa correspondientes a los meses de abril, mayo y junio de 2012 se muestran en la tabla 9. De igual forma, las condiciones de temperatura durante este periodo de tiempo, referentes a la estación meteorológica más cercana a la zona de depósito de las probetas de mortero, son las reflejadas en la ilustración 20 y la tabla 10.

Tras la rotura de las distintas probetas mediante una prensa para conseguir dos superficies regulares y planas, se procedió a eliminar todo el polvo residual de las superficies fracturadas y a pulverizar sobre ellas una disolución de fenolftaleína al 1\%. Las áreas carbonatadas no cambian de color, mientras que las áreas con un $\mathrm{pH}$ superior a 9 adquieren un color fucsia brillante. Este cambio de color nos muestra la profundidad del frente de carbonatación.

Tabla 9. Valores medios de CO, presión atmosférica y humedad relativa para los meses de abril, mayo y junio de 2012. (Fuentes: (CO) Área de Gobierno de Medio Ambiente y Movilidad. Dirección General de Sostenibilidad y Planificación de la Movilidad. Servicio de Protección de la Atmósfera. (P. Atm. y HR) AEMET)

\begin{tabular}{cccc} 
& $\mathrm{CO}\left(\mathrm{mg} / \mathrm{m}^{3}\right)$ & $\begin{array}{c}\text { Presión atmosférica } \\
\text { media }(\mathrm{hPa})\end{array}$ & $\begin{array}{c}\text { Porcentaje medio de } \\
\text { humedad relativa }\end{array}$ \\
\hline Abril & 0.3 & 930.7 & 64 \\
\hline Mayo & 0.3 & 937.1 & 47 \\
\hline Junio & 0.2 & 937.1 & 35 \\
\hline
\end{tabular}




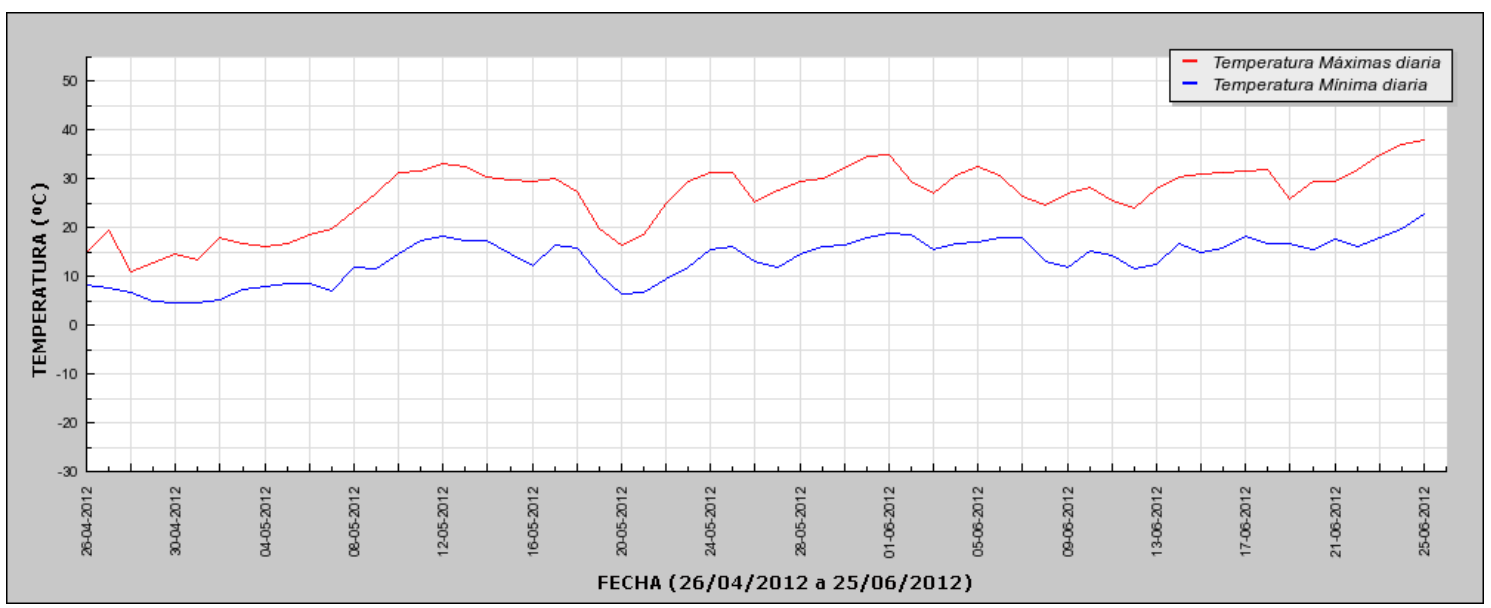

Ilustración 20. Gráfica de datos de temperaturas para el periodo de tiempo comprendido entre el 26de abril y el 25 de junio de 2012 para la estación meteorológica de Madrid, Cuatro Vientos. (Fuente: AEMET)

Tabla 10. Resumen de Valores de Temperaturas máximas y mínimas a lo largo del periodo de tiempo comprendido entre el 26de abril y el 25 de junio de 2012. (Fuente: AEMET)

\begin{tabular}{|c|c|c|}
\hline CARACTERISTICA / VALOR & $\mathrm{T}\left({ }^{\circ} \mathrm{C}\right)$ & FECHA \\
\hline Ta Máxima más alta Registrada: & 38 & $25-06-2012$ \\
\hline Ta Máxima más baja Registrada: & 11.1 & 28-04-2012 \\
\hline Ta Mínima más alta Registrada: & 22.8 & $25-06-2012$ \\
\hline Ta Mínima más baja Registrada: & 4.5 & 01-05-2012 \\
\hline $\begin{array}{l}\text { Mayor diferencia de temperaturas } \\
\text { en un mismo día (Tmax-Tmin): }\end{array}$ & 17.6 & $23-05-2012$ \\
\hline $\begin{array}{l}\text { Mayor ascenso de temperaturas } \\
\text { Máximas en } 24 \mathrm{~h} \text { : }\end{array}$ & 6.2 & $21-05-2012$ a $22-05-2012$ \\
\hline $\begin{array}{l}\text { Mayor ascenso de temperaturas } \\
\text { Mínimas en } 24 \text { h: }\end{array}$ & 5.1 & $07-05-2012$ a $08-05-2012$ \\
\hline $\begin{array}{l}\text { Mayor descenso de Temperaturas } \\
\text { máximas en } 24 \mathrm{~h} \text { : }\end{array}$ & 8.3 & $27-04-2012$ a $28-04-2012$ \\
\hline $\begin{array}{l}\text { Mayor descenso de Temperaturas } \\
\text { mínimas en } 24 \mathrm{~h} \text { : }\end{array}$ & 5.5 & $18-05-2012$ a $19-05-2012$ \\
\hline
\end{tabular}


Posteriormente, se tomó una fotografía digital (ilustración 21) mediante un macro, procurando captar la verdadera magnitud de la superficie tratada. Esta fotografía fue exportada a un programa de Diseño Asistido por Ordenador para dibujar una serie de polilíneas de acuerdo a los contornos de las distintas probetas (S) y a las superficies de carbonatación (Sc) (ilustración 22). Con el cálculo de ambas áreas, ha sido posible determinar el porcentaje de superficie carbonatada.

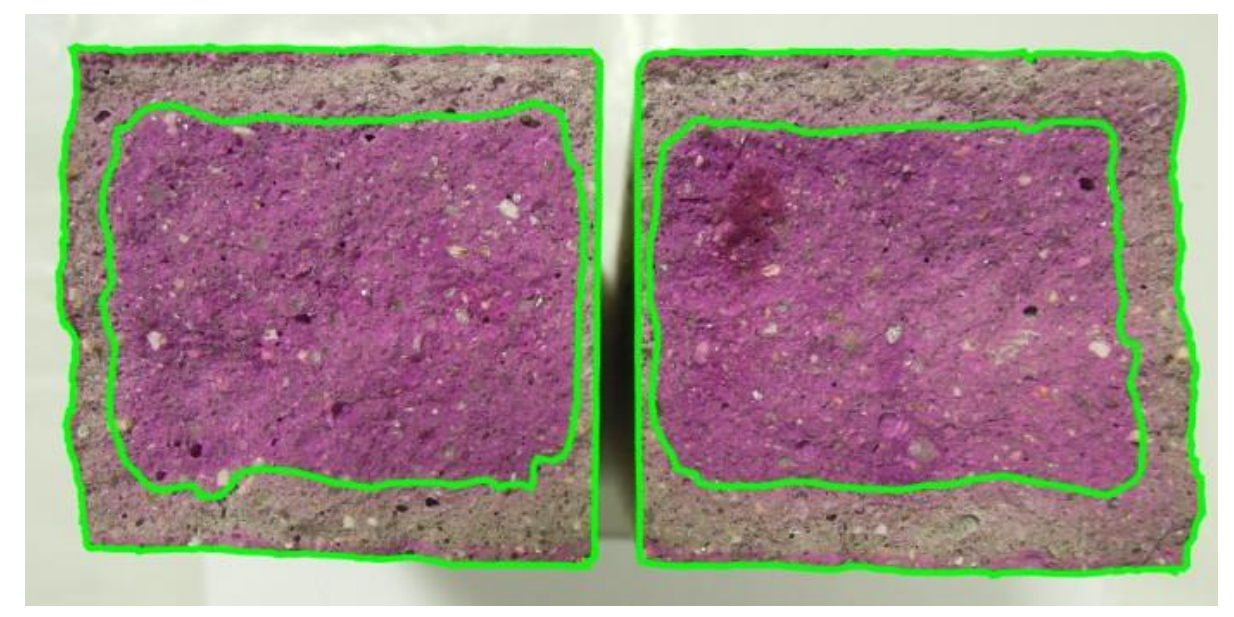

Ilustración 21. Profundidad de carbonatación. Superficie fucsia: área de mortero no carbonatada. Línea verde: medición de las superficies carbonatadas y no carbonatadas mediante el procesamiento de la fotografía digital en un programa de CAD
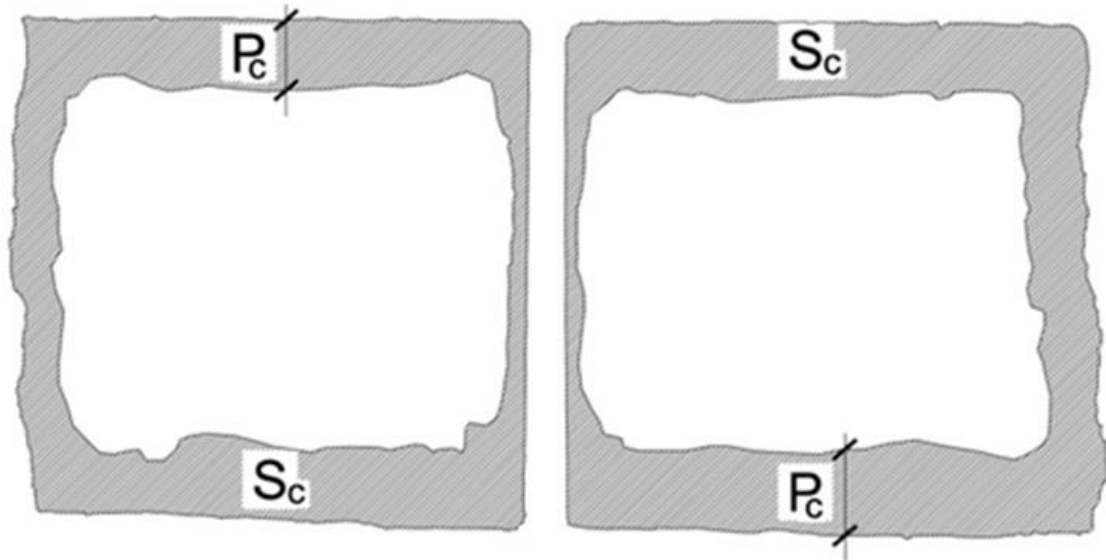

Ilustración 22. Profundidad de carbonatación. Procedimiento analítico de cálculo. Sc: Área carbonatada de la probeta. Pc: Profundidad de carbonatación 
En el caso de los morteros realizados con CAC, dado el color tan característico de este cemento (ilustración 23), ha sido necesario, además, procesar todas las fotografías digitales y elevar el grado de saturación de las mismas hasta el $100 \%$ para conseguir tener un contorno nítido y uniforme (ilustración 24).

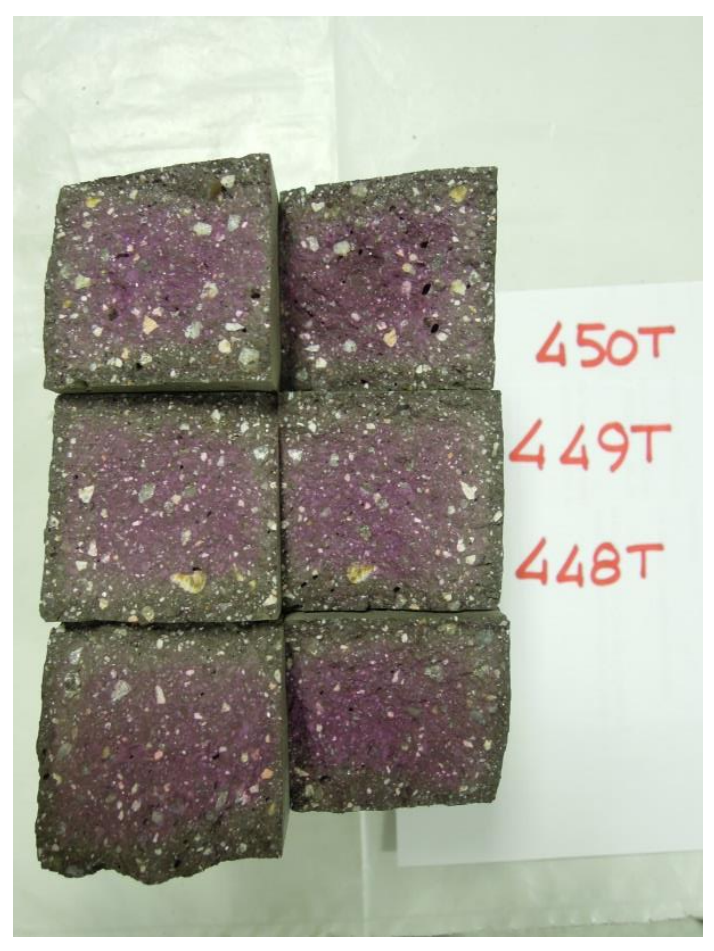

Ilustración 23. Determinación de la resistencia a la carbonatación. Aplicación de fenolftaleína sobre mortero de CAC.

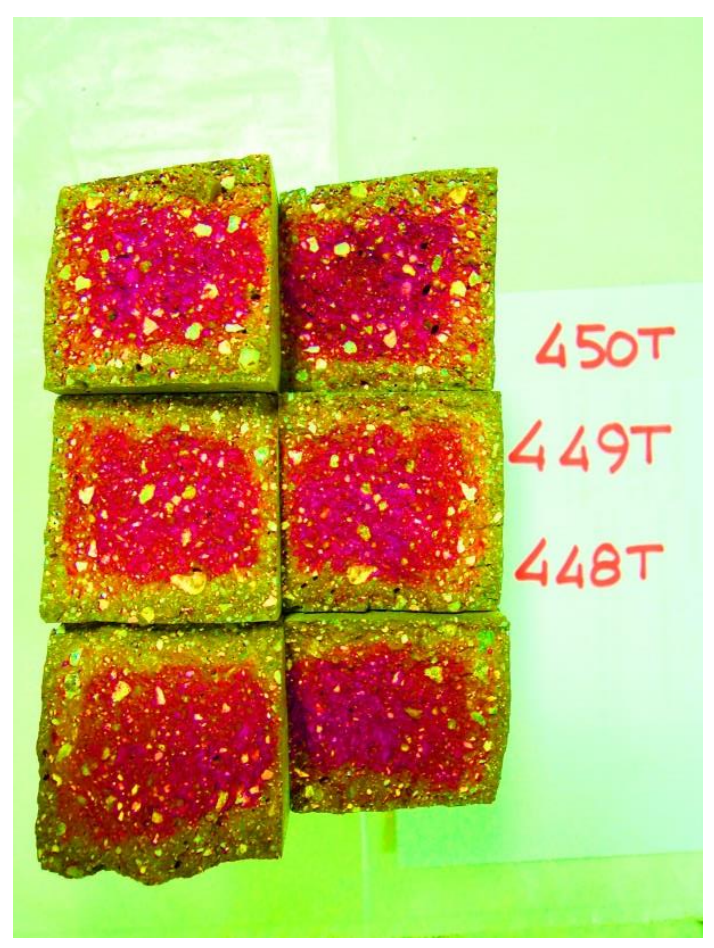

Ilustración 24. Determinación de la resistencia a la carbonatación. Procesado de fotografía digital. Grado de saturación al $100 \%$

De acuerdo a estas superficies, se ha calculado una profundidad de carbonatación media teórica (Pc). De esta forma, y teniendo en cuenta que uno de los lados de las probetas (el de apoyo en la base durante los 60 días a la intemperie) no ha sufrido ningún proceso de carbonatación directo, se ha estimado que el perímetro activo de carbonatación es de $120 \mathrm{~mm}$ lineales (correspondientes a las otras tres caras expuestas), por lo que:

$$
P c=\frac{S c\left(\mathrm{~mm}^{2}\right)}{120 \mathrm{~mm}}
$$


Siendo:

Pc: Profundidad de carbonatación media teórica.

Sc: Superficie de carbonatación, calculada aplicando el porcentaje de carbonatación dado por el programa de diseño asistido por ordenador, a una superficie de fractura teórica de $1600 \mathrm{~mm} 2$ (40 mm x $40 \mathrm{~mm}$ ).

2.2.4.4 Cálculo de la porosidad y de la distribución del tamaño de poros. Porosimetría por inyección de mercurio

El ensayo de intrusión de mercurio nos aporta información muy útil para caracterizar la estructura interna del material y los factores que la afectan. Se trata de una técnica indirecta para la caracterización del sistema poroso de cualquier material, fundamentado en la obtención de la distribución de la porosidad en función del tamaño aparente de acceso a los poros.

Esta técnica está basada en los fenómenos de capilaridad generados por los líquidos que no mojan a los sólidos con los que están en contacto. Así, un líquido como el mercurio que no penetra de forma natural en los conductos capilares de un material, precisa de una determinada presión $(p)$ para su introducción. Dicha presión es inversamente proporcional al radio (r) de los mismos:

$$
r=\frac{2 \sigma \cos \alpha}{p}
$$

donde " $\sigma$ " es la tensión superficial del mercurio y " $\alpha$ " el ángulo de contacto sólido/líquido.

El ensayo de porosimetría consiste en inyectar mercurio a presión y registrar el volumen de mercurio absorbido. En cada intervalo de presión definido, nos refleja el volumen de poros con un determinado intervalo de 
tamaño de acceso. Por tanto, permite obtener una distribución de los diferentes tamaños de poros presentes en el material, lo que da una evaluación de la microestructura del mismo. Previamente a la ejecución del ensayo de porosimetría por inyección de mercurio es necesario someter a las muestras a un proceso de liofilización o "freeze drying". Este mecanismo se basa en la congelación del material y su posterior reducción de la presión circundante y adición de bastante calor para permitir al agua congelada en el material que sublime directamente de la fase sólida a gas. Este proceso previo de secado es de gran utilidad en el estudio a realizar, ya que permite mantener la estructura del material intacta durante su secado, de manera que la porosimetría no se ve alterada.

En los ensayos de porosimetría por intrusión de mercurio se distinguen dos fases diferentes, la fase de intrusión y la fase de extrusión. Durante la fase de intrusión, se incrementa la presión de mercurio hasta un valor máximo (220 MPa) y se mide el volumen de mercurio entrado en la muestra. En la segunda fase, fase de extrusión, se disminuye la presión de mercurio aplicada de forma controlada y se mide el volumen de mercurio saliente de la muestra.

La fase de intrusión nos permite tener información sobre el volumen de vacíos interconectados (porosidad interconectada) y de su distribución por tamaño. Durante la segunda fase del ensayo, fase de salida o extrusión del mercurio, se mide el volumen de mercurio "saliente" frente al decremento de la presión. A lo largo de la fase de extrusión, se observan diversos efectos tales como: histéresis o conservación de propiedades en ausencia del estímulo que las ha generado y también remanencia del mercurio en el interior de la muestra. Estos fenómenos se deben por una parte la diferencia existente en el ángulo de mojado durante el proceso de entrada y de salida del mercurio, y en segundo lugar, por la existencia de poros con constricciones o poros "cuello de botella", que hacen las veces que caverna o cavidades donde el mercurio permanece almacenado.

Los ensayos se realizaron en un porosímetro de mercurio "Autopore IV 9500 1.05" ubicado en el Laboratorio de Petrofísica de la Facultad de 
Ciencias Geológicas de la Universidad Complutense de Madrid, el cual pertenece al Instituto de Geociencias IGEO (CSIC-UCM). Este equipo tiene la capacidad para medir diámetros de poro en un rango que va desde 0,003 a, aproximadamente, 1000 micrones.

2.2.4.5 Determinación de la resistencia a flexión y a compresión del mortero endurecido (UNE-EN 1015-11)

Para la realización de este ensayo se prepararon tres probetas prismáticas de $160 \mathrm{~mm} \times 40 \mathrm{~mm} \times 40 \mathrm{~mm}$ de cada uno de los morteros objeto de esta investigación. Por cada uno de los morteros, además, se elaboraron un mortero de referencia, y un mortero con la incorporación de cenizas volantes inertizadas en forma de carbonatos insolubles, en una proporción igual a un $10 \%$ en peso del árido utilizado.

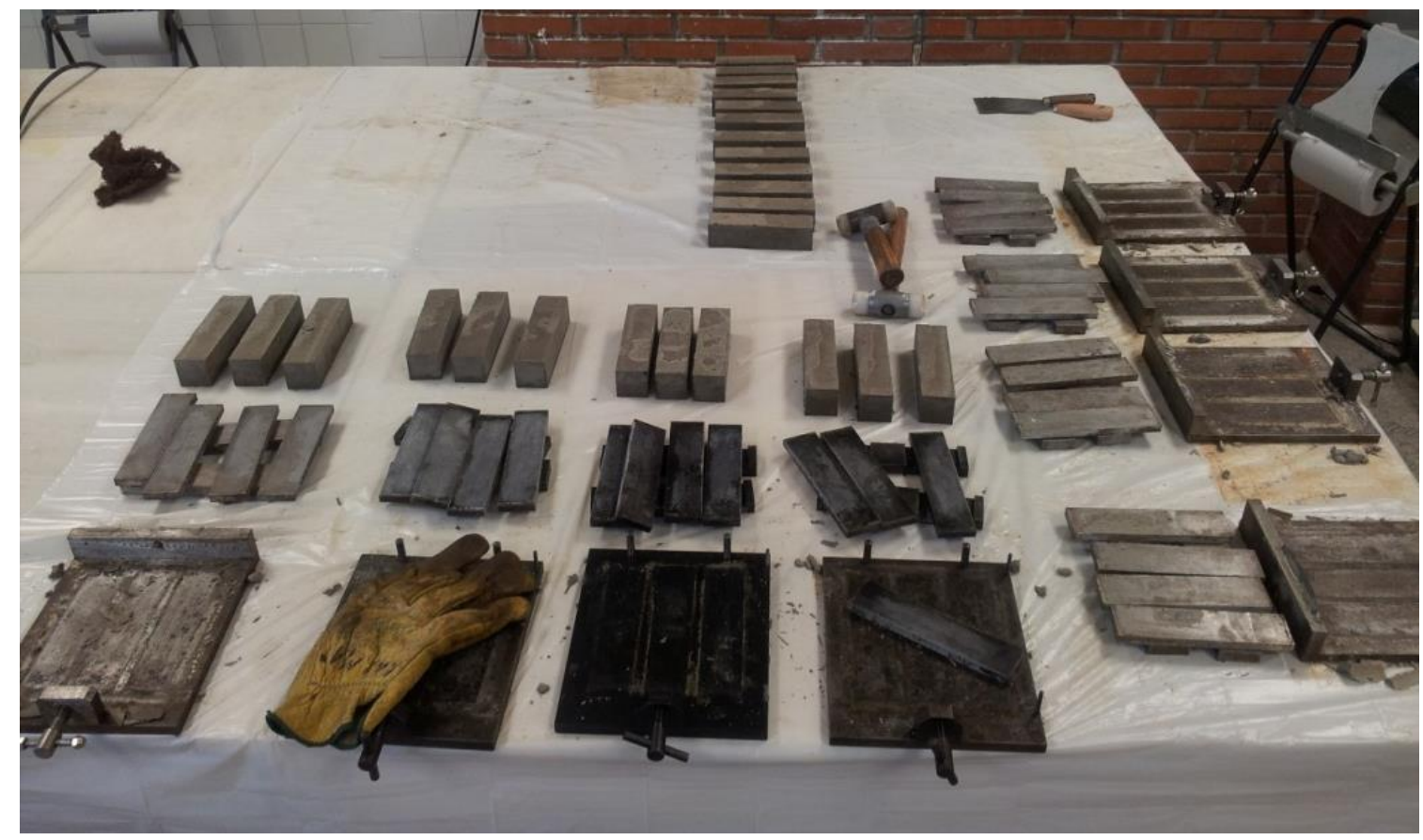

Ilustración 25. Preparación de moldes por cuadruplicado para la determinación de las resistencias a flexión y a compresión. Morteros de CEM-I. Probetas de referencia P1 a P12 y probetas con CVT P31T a P42T. 
El procedimiento descrito anteriormente, se realizó por cuadriplicado, con la intención de ensayar cada mortero a edades de 7, 28, 60 y 90 días (ilustración 25). Una vez desmoldadas las probetas, fueron conservadas en cámara húmeda a una temperatura media de $20^{\circ} \mathrm{C} \pm 2^{\circ} \mathrm{C}$ y a una humedad relativa de $95 \% \pm 5 \%$ hasta la fecha de su ensayo definitivo.

\section{1) Resistencia a flexión.}

La resistencia a flexión de los morteros se determinó aplicando una carga en tres puntos en cada uno de los prismas de mortero endurecido, hasta su rotura. Las superficies de contacto de los rodillos y las caras de la probeta se limpiaron con el fin de eliminar las partículas o cualquier otro material no adherido. Una de las caras de la probeta que ha estuvo en contacto con las paredes de los moldes durante el enmoldado fue colocada sobre los rodillos de apoyo (ilustración 26).

La aplicación de la carga se realizó sin aceleraciones bruscas y a una velocidad uniforme comprendida entre $10 \mathrm{~N} / \mathrm{s}$ y $50 \mathrm{~N} / \mathrm{s}$, de tal modo que la rotura se produjo en todos los casos entre $30 \mathrm{~s}$ y $90 \mathrm{~s}$. Una vez rota la probeta, se registró la carga máxima aplicada, en $\mathrm{N}$ y se conservaron las mitades de la probeta partida para su inmediata determinación de la resistencia a compresión.

- Expresión y cálculo de los resultados:

La resistencia a flexión, $f$, en $\mathrm{N} / \mathrm{mm}^{2}$ fue calculada por medio de la siguiente expresión:

$$
f=1,5 \frac{F l}{b d^{2}}
$$

Siendo:

$b$ y $d$ las dimensiones interiores del molde.

De todas las probetas ensayadas, se registró la resistencia a flexión, aproximadamente a $0,05 \mathrm{~N} / \mathrm{mm}^{2}$ con una aproximación de $0,1 \mathrm{~N} / \mathrm{mm}^{2}$ 


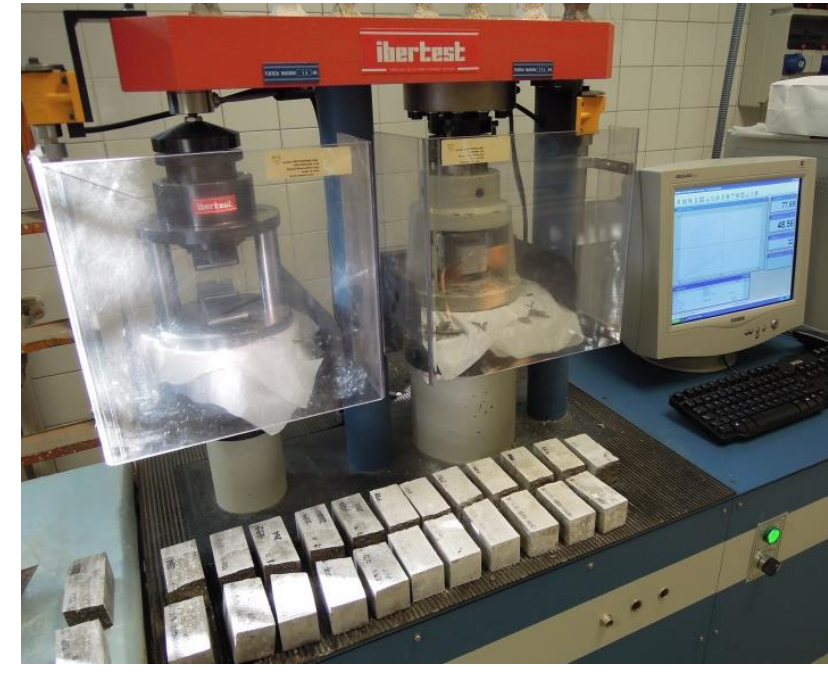

Ilustración 26. Determinación de la resistencia a flexión del mortero endurecido. Probetas P4, P55, P56, P57, P76, P77, P78, P262, P263, $\mathrm{P} 264, \mathrm{P} 283$ y $\mathrm{P} 284$.

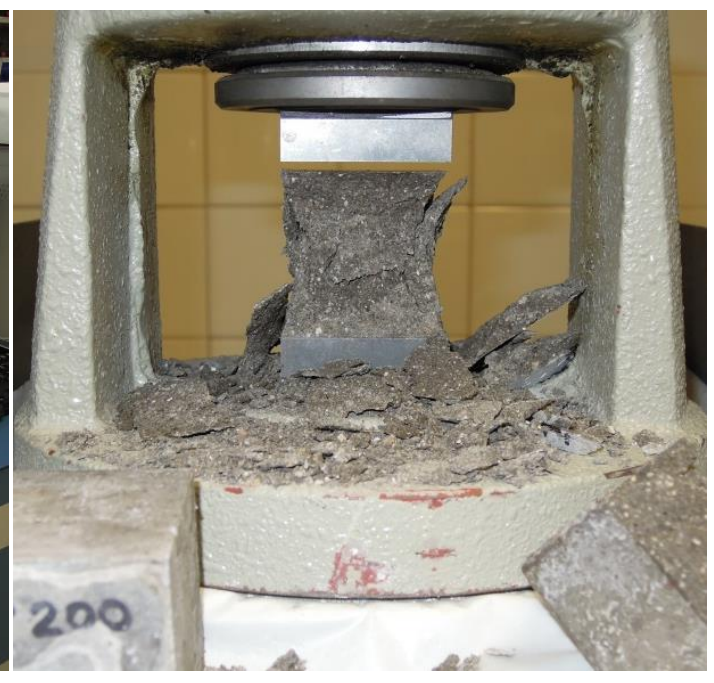

Ilustración 27. Determinación de la resistencia a compresión del mortero endurecido. Probeta P200.

\section{2) Resistencia a compresión.}

La resistencia a compresión del mortero fue calculada posteriormente en cada una de las seis mitades semiprismáticas resultantes del ensayo de la resistencia a flexión.

La probeta se alineó cuidadosamente, de tal modo que la carga fue aplicada en todo el ancho de las caras en contacto con los platos de la máquina. La aplicación de la carga se realizó sin aceleraciones y fue aumentan progresivamente a un ritmo comprendido entre $50 \mathrm{~N} / \mathrm{s}$ y $500 \mathrm{~N} / \mathrm{s}$ de tal modo que la rotura se produjo en todos los casos entre $30 \mathrm{~s}$ y $90 \mathrm{~s}$ después de empezar el ensayo (ilustración 27). Tras esto, se registraron los valores de las cargas máximas aplicadas, en $\mathrm{N}$.

- Expresión y cálculo de los resultados:

La resistencia a la compresión se calculó dividiendo la carga máxima soportada por la probeta entre su sección transversal. La resistencia de cada probeta fue anotada con una aproximación de 0,05 N/mm². Mientras 
que la media de los valores fue registrada con una aproximación de 0,1 $\mathrm{N} / \mathrm{mm}^{2}$.

2.2.4.6 Determinación del lixiviado de iones de $\mathrm{Zn}, \mathrm{Cd}, \mathrm{Pb}$ y $\mathrm{Cu}$ mediante voltamperometría de redisolución anódica.

Se trata de una técnica basada en la aplicación de un potencial constante lo suficientemente negativo como para poder depositar un metal sobre un electrodo formado por una gota colgante de mercurio donde el metal queda amalgamado (etapa de acumulación o electrodeposición). A esta fase, le sigue una etapa de determinación por aplicación de un barrido de potenciales en sentido positivo en el que se registra la altura/área de los picos de redisolución anódica (stripping) que ocurren a los diferentes potenciales de oxidación de cada uno de los metales amalgamados en la gota colgante de mercurio.

Mediante este análisis es posible determinar iones metálicos con una exactitud muy razonable, en un margen de concentraciones comprendido entre $10^{-6}$ y $10^{-9}$. En primer lugar se realiza la electodeposición, desde una solución agitada mecánicamente, imponiendo al electrodo un potencial que permite la reducción de los iones de $\mathrm{Zn}, \mathrm{Pb}, \mathrm{Cd}$ y $\mathrm{Cu}$. Durante esta etapa se deposita, por regla general, sólo una fracción del analito, por lo que se hace imprescindible controlar no solo el potencial del electrodo, sino el tamaño de la gota, el tiempo de electrólisis y la velocidad de agitación.

Una vez realizada la electrodeposición, se desconecta el agitador y, manteniendo el electrodo al mismo potencial, se espera durante unos 30 segundos, a que la disolución quede en reposo. Finalmente, los analitos depositados sobre la gota de mercurio pueden cuantificarse por cualquier procedimiento voltamperométrico. En este análisis se realizó un barrido anódico lineal, para lo cual el potencial del electrodo se hace variar linealmente hacia potenciales menos negativos, registrando la intensidad de la corriente. En este proceso, al alcanzarse el potencial correspondiente se produce la oxidación electroquímica de los diferentes analitos originando 
picos de redisolución, cuya intensidad es proporcional a la concentración del metal.

Los análisis de lixiviado se realizaron en un Voltamperímetro "Metrohm 747 VA Stand 746 VA Trace Analyzer" equipado con muestreador automático, que se encuentra en el laboratorio de Química Industrial y Polímeros de la Escuela Técnica Superior de Ingeniería y Diseño Industrial de la UPM (ilustración 28).

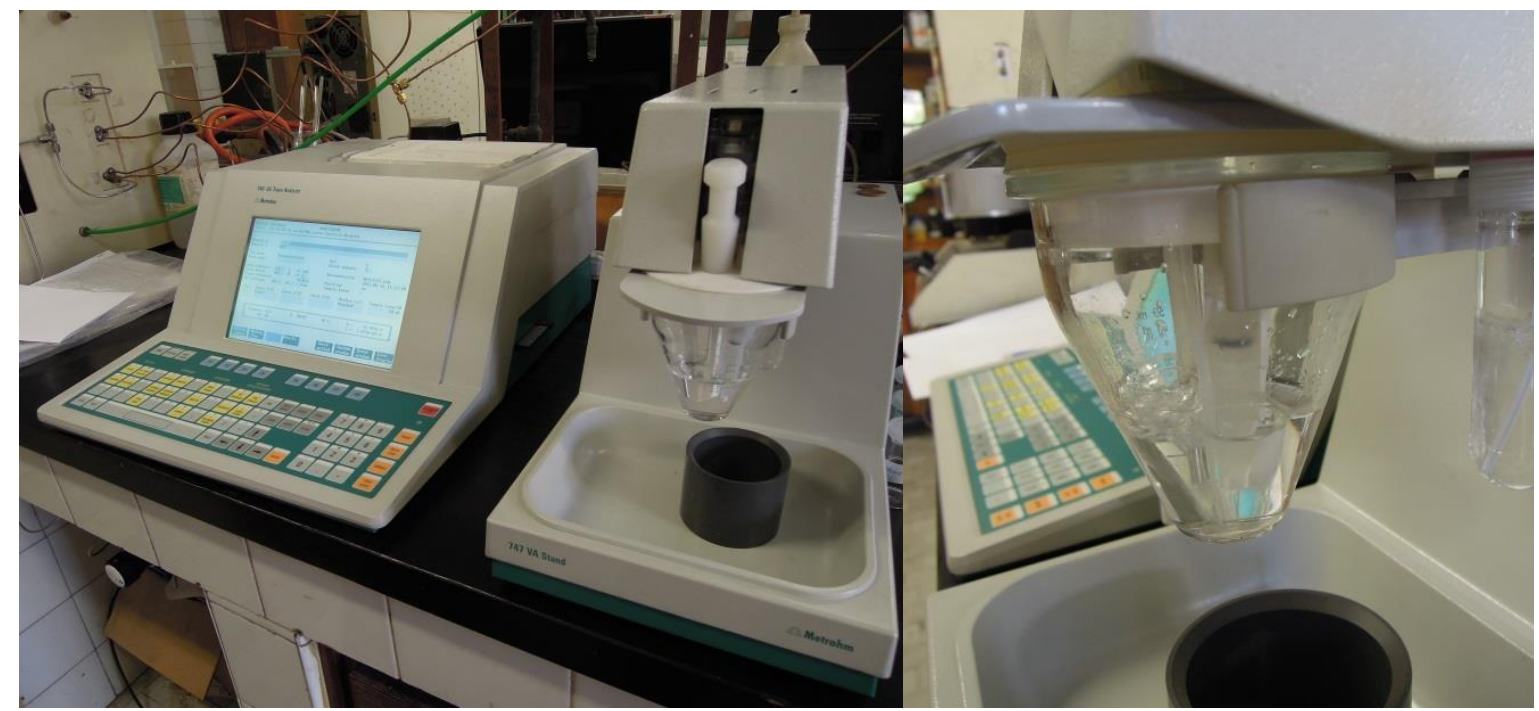

Ilustración 28. Voltamperímetro de redisolución anódica situado en el laboratorio de Química Industrial y Polímero de la ETSIDI - UPM 


\section{RESULTADOS Y DISCUSIÓN}

\subsection{ANÁLISIS Y ESTUDIO DE LAS CENIZAS VOLANTES DE RSU}

\subsubsection{COMPOSICIÓN QUÍMICA DE LAS CENIZAS VOLANTES DE RSU}

Con base en los datos mostrados en la tabla 11 , se puede afirmar que las cenizas volantes utilizadas durante los ensayos, superan los valores límite, al menos, en lo referente a $\mathrm{Zn}, \mathrm{Pb}$, cloruros y sulfatos, lo que hace que deban ser tratadas como residuos especiales (European Union 16 January, 2003; European Union 16 Julio, 1999), y requieran de un tratamiento previo a su uso como subproducto en cualquier material de construcción.

En efecto, en ellos destaca una cantidad de cloruros solubles extremadamente alta. El problema derivado de un exceso de ion $\mathrm{Cl}$ - en mezclas cementosas es, básicamente, el que se deriva de la corrosión.

Por un lado, la despasivación del ion cloruro genera corrosión por picadura que puede afectar de manera local a las posibles armaduras que pudieran existir (tanto las estructurales, como las destinadas a evitar fisuraciones superficiales) (Zornoza et al., 2008).

Por otro lado, existe una reacción del $\mathrm{Ca}(\mathrm{OH})_{2}$ (portlandita), para formar $\mathrm{Ca}(\mathrm{OH}) \mathrm{Cl}$ (hidroxicloruro cálcico). De esta forma, el $\mathrm{Ca}(\mathrm{OH})_{2}$ deja de reaccionar con la sílice y se produce un descenso en el $\mathrm{pH}$ del mortero. La consecuencia directa de esta disminución del pH es la destrucción del film protector pasivante que las barras de acero generan en contacto con las pasta de cemento y que sirve como barrera protectora contra los diversos agentes agresivos.

La combinación de ambas posibilidades (exceso de cloruros y disminución del $\mathrm{pH}$ de la matriz de mortero) puede generar una corrosión completa y uniforme con consecuencias muy peligrosas en los elementos estructurales. 
Tabla 11. Análisis químico por ICP-OES de las cenizas de RSU originales (CV) y de las cenizas tratadas mediante el proceso de inertización (CVT)

\begin{tabular}{|c|c|c|}
\hline \multicolumn{3}{|c|}{ Elementos primarios $(\mu \mathrm{g} / \mathrm{g})$} \\
\hline & CV & CVT \\
\hline $\mathbf{Z n}$ & $4492 \pm 232$ & $4065 \pm 210$ \\
\hline $\mathbf{P b}$ & $1026 \pm 51$ & $876 \pm 44$ \\
\hline Mn & $315 \pm 31$ & $530 \pm 30$ \\
\hline Sn & $351 \pm 18$ & $455 \pm 23$ \\
\hline $\mathbf{P}$ & $5005 \pm 310$ & $4900 \pm 300$ \\
\hline $\mathrm{Cr}$ & $242 \pm 24$ & $470 \pm 47$ \\
\hline $\mathbf{N i}$ & $93 \pm 9$ & $146 \pm 15$ \\
\hline $\mathrm{Cu}$ & $330 \pm 17$ & $266 \pm 13$ \\
\hline $\mathbf{B a}$ & $412 \pm 30$ & $806 \pm 60$ \\
\hline Sb & $372 \pm 19$ & $322 \pm 16$ \\
\hline Cd & $60 \pm 3$ & $52 \pm 3$ \\
\hline $\mathbf{S r}$ & $361 \pm 25$ & $349 \pm 24$ \\
\hline $\mathbf{W}$ & $8,2 \pm 0,8$ & $8,1 \pm 0,8$ \\
\hline $\mathbf{Z r}$ & $73 \pm 5$ & $114 \pm 8$ \\
\hline As & $<25$ & $<25$ \\
\hline Co & $9,2 \pm 0,9$ & $14 \pm 1$ \\
\hline Mo & $8,3 \pm 0,8$ & $9,4 \pm 0,9$ \\
\hline $\mathbf{B i}$ & $<5,0$ & $<5,0$ \\
\hline $\mathrm{Ce}$ & $18 \pm 1$ & $30 \pm 2$ \\
\hline $\mathbf{G a}$ & $<25$ & $<25$ \\
\hline $\mathbf{L a}$ & $10,4 \pm 0,5$ & $15,3 \pm 0,8$ \\
\hline Nd & $8,1 \pm 0,6$ & $11,9 \pm 0,8$ \\
\hline $\mathbf{N b}$ & $6,1 \pm 0,6$ & $8,9 \pm 0,9$ \\
\hline
\end{tabular}

\begin{tabular}{ccc}
\hline \multicolumn{3}{c}{ Elementos primarios (\%) } \\
\hline CV & CVT \\
\hline Cl $^{-}$solubles & $11 \pm 2$ & $0,12 \pm 0,02$ \\
\hline $\mathbf{C a}$ & $33 \pm 1$ & $28 \pm 1$ \\
\hline $\mathbf{S i}$ & $4,2 \pm 0,2$ & $7,7 \pm 0,4$ \\
\hline $\mathbf{S}$ & $1,38 \pm 0,08$ & $0,85 \pm 0,05$ \\
\hline $\mathbf{A l}$ & $2,23 \pm 0,20$ & $3,55 \pm 0,36$ \\
\hline $\mathbf{M g}$ & $0,94 \pm 0,09$ & $1,0 \pm 0,1$ \\
\hline $\mathbf{F e}$ & $0,79 \pm 0,05$ & $1,50 \pm 0,1$ \\
\hline $\mathbf{T i}$ & $0,40 \pm 0,01$ & $0,60 \pm 0,06$ \\
\hline $\mathbf{N a}$ & $0,84 \pm 0,04$ & $0,28 \pm 0,01$ \\
\hline $\mathbf{K}$ & $3,1 \pm 0,3$ & $0,65 \pm 0,15$ \\
\hline $\begin{array}{c}\text { Sulfatos } \\
\text { ( } \mathbf{m g} / \mathbf{L})\end{array}$ & $<2500$ & - \\
\hline
\end{tabular}


Tabla 12. Análisis químico por Fluorescencia de Rayos $X$ de las cenizas de RSU originales (CV) y de las cenizas tratadas mediante el proceso de inertización (CVT)

\begin{tabular}{|c|c|c|}
\hline & \multicolumn{2}{|c|}{ Composición química (\% peso) } \\
\hline & CV & CVT \\
\hline $\mathrm{SiO}_{2}$ & 12,01 & 13,54 \\
\hline $\mathbf{A l}_{2} \mathbf{O}_{3}$ & 6,10 & 7,03 \\
\hline $\mathrm{Fe}_{2} \mathrm{O}_{3}$ & 1,37 & 1,66 \\
\hline $\mathrm{CaO}$ & 37,14 & 43,71 \\
\hline MgO & 1,81 & 2,08 \\
\hline $\mathrm{SO}_{3}$ & 5,37 & 4,88 \\
\hline $\mathbf{K}_{\mathbf{2}} \mathbf{O}$ & 2,35 & 0,52 \\
\hline $\mathrm{Na}_{2} \mathrm{O}$ & 3,15 & 1,25 \\
\hline $\mathrm{TiO}_{2}$ & 1,32 & 1,43 \\
\hline $\mathbf{P}_{2} \mathbf{O}_{5}$ & 1,38 & 1,56 \\
\hline $\mathrm{Mn}_{2} \mathrm{O}_{3}$ & 0,05 & 0,06 \\
\hline $\mathrm{Cr}_{2} \mathrm{O}_{3}$ & 0,06 & 0,08 \\
\hline SrO & 0,04 & 0,04 \\
\hline BaO & 0,06 & 0,06 \\
\hline Zno & 0,53 & 0,70 \\
\hline P.F. & 15,48 & 21,41 \\
\hline
\end{tabular}




\subsubsection{PROCESO DE INERTIZACIÓN DE LAS CENIZAS VOLANTES DE RSU}

3.1.2.1 Búsqueda de los posibles reactivos a utilizar en el proceso de inertización.

Se ha llevado a cabo una búsqueda de los posibles reactivos a utilizar en la inertización de las cenizas volantes de RSU, teniendo en cuenta su contenido en metales pesados. Para ello se revisado en la bibliografía (tabla 13) los diferentes aniones que reaccionarían con los metales pesados presentes y que generarían un precipitado insoluble (Chang, 1990).

Tabla 13. Productos de solubilidad bibliográficos para iones de metales pesados, $P_{s}$.

\begin{tabular}{|c|c|c|c|c|c|c|}
\hline & $\mathrm{CO}_{3}{ }^{2-}$ & $\mathbf{S}^{2-}$ & $\mathrm{SO}_{4}{ }^{2-}$ & $\mathrm{C}_{2} \mathrm{O}_{4}{ }^{2-}$ & $\mathbf{O H}^{-}$ & $\mathrm{PO}_{4}{ }^{3-}$ \\
\hline \multirow{2}{*}{$\mathrm{Zn}^{2+}$} & $\mathrm{ZnCO}_{3}$ & $\mathrm{SZn}$ & --- & $\mathrm{ZnC}_{2} \mathrm{O}_{4} * 2 \mathrm{H}_{2} \mathrm{O}$ & $\mathrm{Zn}(\mathrm{OH})_{2}$ & $\mathrm{Zn}_{3}\left(\mathrm{PO}_{4}\right)_{2}$ \\
\hline & $1.19 \mathrm{E}-10$ & $2.93 \mathrm{E}-25$ & & $1.37 \mathrm{E}-09$ & $7.71 \mathrm{E}-17$ & $9.00 \mathrm{E}-33$ \\
\hline \multirow{2}{*}{$\mathbf{P b}^{2+}$} & $\mathrm{PbCO}_{3}$ & $\mathrm{PbS}$ & $\mathrm{PbSO}_{4}$ & $\mathrm{PbC}_{2} \mathrm{O}_{4}$ & $\mathrm{~Pb}(\mathrm{OH})_{2}$ & --- \\
\hline & $1.46 \mathrm{E}-13$ & $9.04 \mathrm{E}-29$ & $1.46 \mathrm{E}-13$ & $8.51 \mathrm{E}-10$ & $1.42 \mathrm{E}-20$ & \\
\hline \multirow{2}{*}{$\mathrm{Cu}^{2+}$} & $\mathrm{CuCO}_{3}$ & Cus & --- & $\mathrm{CuC}_{2} \mathrm{O}_{4}$ & $\mathrm{Cu}(\mathrm{OH})_{2}$ & $\mathrm{Cu}_{3}\left(\mathrm{PO}_{4}\right)_{2}$ \\
\hline & $1.40 \mathrm{E}-10$ & $1.27 \mathrm{E}-36$ & & $4.43 \mathrm{E}-17$ & $2.20 \mathrm{E}-20$ & $1.39 \mathrm{E}-37$ \\
\hline \multirow{2}{*}{$\mathbf{C d}^{2+}$} & $\mathrm{CdCO}_{3}$ & $\mathrm{CdS}$ & --- & $\mathrm{CdC}_{2} \mathrm{O}_{4} * 3 \mathrm{H}_{2} \mathrm{O}$ & $\mathrm{Cd}(\mathrm{OH})_{2}$ & $\mathrm{Cd}_{3}\left(\mathrm{PO}_{4}\right)_{2}$ \\
\hline & $6.18 \mathrm{E}-12$ & $1.40 \mathrm{E}-29$ & & $1.42 \mathrm{E}-08$ & $5.27 \mathrm{E}-15$ & $2.53 E-33$ \\
\hline \multirow{2}{*}{$\mathrm{Cr}^{2+}$} & & & & & $\mathrm{Cr}(\mathrm{OH})_{2}$ & \\
\hline & & & & & $2.00 \mathrm{E}-16$ & \\
\hline \multirow{2}{*}{$\mathrm{Cr}^{3+}$} & & & & & $\mathrm{Cr}(\mathrm{OH})_{3}$ & \\
\hline & & & & & $6.30 \mathrm{E}-31$ & \\
\hline \multirow{2}{*}{$\mathrm{Ni}^{2+}$} & $\mathrm{NiCO}_{3}$ & $\mathrm{NiS}$ & --- & --- & $\mathrm{Ni}(\mathrm{OH})_{2}$ & $\mathrm{Ni}_{3}\left(\mathrm{PO}_{4}\right)_{2}$ \\
\hline & $1.42 \mathrm{E}-07$ & $1.07 \mathrm{E}-21$ & & & $5.47 \mathrm{E}-16$ & $4.73 E-32$ \\
\hline
\end{tabular}

As

\begin{tabular}{|c|c|c|c|c|c|c|}
\hline \multirow{2}{*}{$\mathrm{Ca}^{2+}$} & $\mathrm{CaCO}_{3}$ & --- & $\mathrm{CaSO}_{4}$ & $\mathrm{CaC}_{2} \mathrm{O}_{4} * 2 \mathrm{H}_{2} \mathrm{O}$ & $\mathrm{Ca}(\mathrm{OH})_{2}$ & $\mathrm{Ca}\left(\mathrm{PO}_{4}\right)_{2}$ \\
\hline & 4.96E-09 & & $7.10 \mathrm{E}-05$ & 2.34E-09 & $4.68 \mathrm{E}-06$ & $2.07 \mathrm{E}-33$ \\
\hline
\end{tabular}


El dato más importante a tener en cuenta es el producto de solubilidad, definido por la constante de equilibrio a $25^{\circ} \mathrm{C}$ de la reacción de disolución del compuesto $\left(\mathrm{B}_{\mathrm{y}} \mathrm{C}_{\mathrm{x}}\right)$ :

$$
B_{y} \cdot C_{X(s)} \leftrightarrows y \cdot B^{x^{-}}(\text {aq. })+X \cdot C^{y+}(\text { aq. })
$$

Definido como:

$$
P_{S}=[B] y \cdot[C]^{x}=[y S]^{y} \cdot[x S]^{x}
$$

Donde S, representa la cantidad de precipitado que se ha de ser solubilizado.

A partir de estos datos, se ha calculado en primer lugar el valor de la solubilidad, S (tabla 14) y, a partir de éste, la solubilidad que presentaría el catión del metal pesado $(\mathrm{x} \cdot \mathrm{S})$ - $\mathrm{o}\left(\mathrm{x} \cdot \mathrm{C}^{\mathrm{y}}\right)$-, multiplicando la solubilidad obtenida, $\mathrm{S}$, por su coeficiente $\mathrm{x}$, de acuerdo a:

$$
S=\sqrt[x+y]{\frac{P_{S}}{\left(x^{x} y^{y}\right)}}
$$

Finalmente, con el único objetivo de utilizar los datos y poder compararlos con los establecidos por la legislación vigente (European Union 16 January, 2003; European Union 16 July, 1999), ha sido necesario transformar los resultados desde Mol/L a mg/L o ppm (tabla 15). 
Tabla 14. Solubilidad calculada de los precipitados, $S$ (mol/L)

\begin{tabular}{|c|c|c|c|c|c|c|}
\hline & $\mathrm{CO}_{3}{ }^{2-}$ & $\mathbf{S}^{2-}$ & $\mathrm{SO}_{4}{ }^{2-}$ & $\mathrm{C}_{2} \mathrm{O}_{4}{ }^{2-}$ & $\mathbf{O H}^{-}$ & $\mathrm{PO}_{4}{ }^{3-}$ \\
\hline \multirow{2}{*}{$\mathrm{Zn}^{2+}$} & $\mathrm{ZnCO}_{3}$ & SZn & --- & $\mathrm{ZnC}_{2} \mathrm{O}_{4} * 2 \mathrm{H}_{2} \mathrm{O}$ & $\mathrm{Zn}(\mathrm{OH})_{2}$ & $\mathrm{Zn}_{3}\left(\mathrm{PO}_{4}\right)_{2}$ \\
\hline & $1.190 \mathrm{E}-09$ & $5.41 \mathrm{E}-13$ & & $3.70 \mathrm{E}-05$ & $2.86 \mathrm{E}-06$ & $1.53 \mathrm{E}-07$ \\
\hline \multirow{2}{*}{$\mathbf{P b}^{2+}$} & $\mathrm{PbCO}_{3}$ & PbS Cus & $\mathrm{PbSO}_{4}$ & $\mathrm{PbC}_{2} \mathrm{O}_{4}$ & $\mathrm{~Pb}(\mathrm{OH})_{2}$ & --- \\
\hline & $3.821 \mathrm{E}-07$ & $9.508 \mathrm{E}-15$ & $1.82 \mathrm{E}-08$ & $2.92 \mathrm{E}-05$ & $1.53 \mathrm{E}-07$ & \\
\hline \multirow{2}{*}{$\mathrm{Cu}^{2+}$} & $\mathrm{CuCO}_{3}$ & Cus & --- & $\mathrm{CuC}_{2} \mathrm{O}_{4}$ & $\mathrm{Cu}(\mathrm{OH})_{2}$ & $\mathrm{Cu}_{3}\left(\mathrm{PO}_{4}\right)_{2}$ \\
\hline & $1.183 \mathrm{E}-05$ & $1.127 \mathrm{E}-18$ & & $6.66 \mathrm{E}-09$ & $1.77 \mathrm{E}-07$ & $1.67 \mathrm{E}-08$ \\
\hline \multirow{2}{*}{$\mathrm{Cd}^{2+}$} & $\mathrm{CdCO}_{3}$ & $\mathrm{CdS}$ & --- & $\mathrm{CdC}_{2} \mathrm{O}_{4} * 3 \mathrm{H}_{2} \mathrm{O}$ & $\mathrm{Cd}(\mathrm{OH})_{2}$ & $\mathrm{Cd}_{3}\left(\mathrm{PO}_{4}\right)_{2}$ \\
\hline & $2.486 \mathrm{E}-06$ & $3.742 \mathrm{E}-15$ & & $1.19 \mathrm{E}-04$ & $1.10 \mathrm{E}-05$ & $1.19 \mathrm{E}-07$ \\
\hline \multirow{2}{*}{$\mathrm{Cr}^{2+}$} & & & & & $\mathrm{Cr}(\mathrm{OH})_{2}$ & \\
\hline & --- & --- & --- & --- & $2.00 \mathrm{E}-16$ & --- \\
\hline \multirow{2}{*}{$\mathrm{Cr}^{3+}$} & & & & & $\mathrm{Cr}(\mathrm{OH})_{3}$ & \\
\hline & --- & --- & --- & --- & $6.30 \mathrm{E}-31$ & --- \\
\hline \multirow{2}{*}{$\mathrm{Ni}^{2+}$} & $\mathrm{NiCO}_{3}$ & $\mathrm{NiS}$ & --- & --- & $\mathrm{Ni}(\mathrm{OH})_{2}$ & $\mathrm{Ni}_{3}\left(\mathrm{PO}_{4}\right)_{2}$ \\
\hline & $3.768 \mathrm{E}-04$ & $3.271 \mathrm{E}-21$ & & & $5.15 \mathrm{E}-06$ & $2.13 E-07$ \\
\hline As & --- & --- & --- & --- & --- & --- \\
\hline \multirow{2}{*}{$\mathrm{Ca}^{2+}$} & $\mathrm{CaCO}_{3}$ & --- & $\mathrm{CaSO}_{4}$ & $\mathrm{CaC}_{2} \mathrm{O}_{4} * 2 \mathrm{H}_{2} \mathrm{O}$ & $\mathrm{Ca}(\mathrm{OH})_{2}$ & $\mathrm{Ca}\left(\mathrm{PO}_{4}\right)_{2}$ \\
\hline & $7.043 E-05$ & & 7.10E-05 & $4.84 \mathrm{E}-05$ & $1.05 \mathrm{E}-02$ & $1.14 \mathrm{E}-07$ \\
\hline
\end{tabular}

Los datos así obtenidos, serán orientativos ya que están calculados bajo unas determinadas condiciones de $\mathrm{pH}(7)$ y temperatura $\left(25^{\circ} \mathrm{C}\right)$. Para diferentes valores de $\mathrm{pH}$ sería necesario calcular la concentración del ion de ácido débil, el cual varía fuertemente con el $\mathrm{pH}$, y recalcular a partir de este nuevo dato la solubilidad del catión del metal pesado.

No obstante, estos cálculos previos han servido para poder determinar y decidir el tipo de reactivo a utilizar en la fijación o estabilización de los mismos. 
Tabla 15. Solubilidad de los cationes de metales pesados en $\mathrm{mg} / \mathrm{L}$. $\mathrm{pH}=7$ y $25^{\circ} \mathrm{C}$.

\begin{tabular}{|c|c|c|c|c|c|c|}
\hline & $\mathrm{CO}_{3}{ }^{2-}$ & $\mathbf{S}^{2-}$ & $\mathrm{SO}_{4}{ }^{2-}$ & $\mathrm{C}_{2} \mathrm{O}_{4}{ }^{2-}$ & $\mathbf{O H}^{-}$ & $\mathrm{PO}_{4}{ }^{3-}$ \\
\hline \multirow{2}{*}{$\mathrm{Zn}^{2+}$} & $\mathrm{ZnCO}_{3}$ & SZn & --- & $\mathrm{ZnC}_{2} \mathrm{O}_{4} * 2 \mathrm{H}_{2} \mathrm{O}$ & $\mathrm{Zn}(\mathrm{OH})_{2}$ & $\mathrm{Zn}_{3}\left(\mathrm{PO}_{4}\right)_{2}$ \\
\hline & 0.713 & 3.5395E-08 & Insoluble & 2.420 & 0.1753 & 0.00999252 \\
\hline \multirow{2}{*}{$\mathbf{P b}^{2+}$} & $\mathrm{PbCO}_{3}$ & PbS Cus & $\mathrm{PbSO}_{4}$ & $\mathrm{PbC}_{2} \mathrm{O}_{4}$ & $\mathrm{~Pb}(\mathrm{OH})_{2}$ & --- \\
\hline & 0.079 & 1.97E-09 & 0.00377104 & 6.044 & 0.03166 & Insoluble \\
\hline \multirow{2}{*}{$\mathrm{Cu}^{2+}$} & $\mathrm{CuCO}_{3}$ & Cus & --- & $\mathrm{CuC}_{2} \mathrm{O}_{4}$ & $\mathrm{Cu}(\mathrm{OH})_{2}$ & $\mathrm{Cu}_{3}\left(\mathrm{PO}_{4}\right)_{2}$ \\
\hline & 0.752 & $4.206 E-14$ & Insoluble & $4.23 \mathrm{E}-04$ & 0.01121 & 0.00105927 \\
\hline \multirow{2}{*}{$\mathrm{Cd}^{2+}$} & $\mathrm{CdCO}_{3}$ & CdS & --- & $\mathrm{CdC}_{2} \mathrm{O}_{4} * 3 \mathrm{H}_{2} \mathrm{O}$ & $\mathrm{Cd}(\mathrm{OH})_{2}$ & $\mathrm{Cd}_{3}\left(\mathrm{PO}_{4}\right)_{2}$ \\
\hline & 0.279 & $4.206 \mathrm{E}-10$ & Insoluble & 13.395 & 1.23232 & 0.01332748 \\
\hline \multirow{2}{*}{$\mathrm{Cr}^{2+}$} & & & & & $\mathrm{Cr}(\mathrm{OH})_{2}$ & \\
\hline & Insoluble & Insoluble & Insoluble & Insoluble & 0.19155 & Insoluble \\
\hline \multirow{2}{*}{$\mathrm{Cr}^{3+}$} & & & & & $\mathrm{Cr}(\mathrm{OH})_{3}$ & \\
\hline & Insoluble & Insoluble & Insoluble & Insoluble & $6.426 \mathrm{E}-44$ & Insoluble \\
\hline \multirow{2}{*}{$\mathrm{Ni}^{2+}$} & $\mathrm{NiCO}_{3}$ & $\mathrm{NiS}$ & --- & --- & $\mathrm{Ni}(\mathrm{OH})_{2}$ & $\mathrm{Ni}_{3}\left(\mathrm{PO}_{4}\right)_{2}$ \\
\hline & 22.117 & 1.9199E-06 & Insoluble & Insoluble & 0.30239 & 0.01249904 \\
\hline As & Insoluble & Insoluble & Insoluble & Insoluble & Insoluble & Insoluble \\
\hline \multirow{2}{*}{$\mathrm{Ca}^{2+}$} & $\mathrm{CaCO}_{3}$ & --- & $\mathrm{CaSO}_{4}$ & $\mathrm{CaC}_{2} \mathrm{O}_{4} * 2 \mathrm{H}_{2} \mathrm{O}$ & $\mathrm{Ca}(\mathrm{OH})_{2}$ & $\mathrm{Ca}\left(\mathrm{PO}_{4}\right)_{2}$ \\
\hline & 2.823 & Insoluble & 2.845538 & 1.938 & 422.313205 & 0.0045673 \\
\hline
\end{tabular}

De acuerdo a los datos de solubilidad catiónica de los precipitados de metales pesados de la tabla 15 , los valores más bajos se alcanzan para los sulfuros de los metales pesados. Sin embargo, esta solución resulta inviable, debido a la toxicidad de los mismos y a que, en medios ácidos, desprenderían sulfuro de hidrógeno el cual, además de poseer un olor nauseabundo, es tóxico e inflamable.

Debido a esto, y teniendo en cuenta la mayor toxicidad del $\mathrm{Cd}$ y su carácter teratogénico frente a otros metales pesados, se estima que el reactivo que mejor estabiliza éste ion es el anión carbonato. Si durante el proceso se mantiene una regulación óptima del $\mathrm{pH}$ por encima del 7 , se conseguirá que sea más insoluble aún. 
De ésta forma, teniendo en cuenta los resultados anteriormente descritos en los que se intenta estabilizar los metales pesados $\mathrm{y}$, al mismo tiempo eliminar por lavado parte de los cloruros de las cenizas volantes, se establece la utilización de $\mathrm{NaHCO}_{3}$ como un método viable de inertizado.

Una combinación adecuada de $\mathrm{NaHCO}_{3}$, ejercerá por un lado la función de tampón y mantendrá el pH en un valor óptimo para el cual el contenido en metales pesados en el lixiviado será mínimo. Por otro lado, la adición del ion $\mathrm{Na}+$ facilitará que, en el proceso de lavado de las cenizas volantes, se elimine una gran cantidad de cloruros en forma de cloruro sódico.

Efectivamente, del análisis de los datos recogidos en la tabla 16 relativos al agua de lavado de las cenizas volantes de RSU, se observa que mediante el tratamiento con $\mathrm{NaHCO}_{3}$ se consigue dos objetivos: Por un lado, los metales pesados existentes en las cenizas originales quedan transformados en carbonatos $\mathrm{y}$, por otro, el pH resultante es inferior a los valores en los que se solubilizarían los metales pesados por formación de aniones como el plumbito y zincato. De igual forma, el contenido en cloruros se ha visto drásticamente reducido en casi un $99 \%$.

Un beneficio de este proceso de lavado y tratamiento de las cenizas volantes de RSU es que, junto con el agua del lavado de éstas, se elimina casi la totalidad del $\mathrm{Cl}^{-}$original debido a la formación de un residuo soluble no contaminante como el $\mathrm{NaCl}$ (cloruro sódico o sal común).

Con la incorporación del bicarbonato sódico al lavado, por un lado se transforman todos los hidróxidos en carbonatos $y$, por otro lado, el $\mathrm{Na}^{+}$ aportado por éste, reacciona formando $\mathrm{NaCl}$, de ahí que se precisen varios lavados con agua corriente para poder arrastrar y eliminar el $\mathrm{NaCl}$ formado.

De acuerdo a los valores límite establecidos en la normativa europea sobre criterios y procedimientos para la aceptación de residuos en vertederos (European Union 16 January, 2003; European Union 16 July, 1999), el agua procedente del lavado e inertización de las cenizas volantes puede ser tratada como un residuo no peligroso. A pesar de estos 
resultados y debido al contenido en cloruros existente, se decidió realizar un total de tres lavados según lo definido en el capítulo 2.

Tabla 16. Resultados del análisis ICP-OES y Cromatografía iónica del agua de lavado del tratamiento con $\mathrm{NaHCO}_{3}$ de las cenizas volantes de RSU

\begin{tabular}{|c|c|}
\hline Parámetro & $\begin{array}{c}\text { Muestra } \\
(\mathrm{Na} 1.72 \text { y Cl } 2.6 \mathrm{~g} / \mathrm{L})\end{array}$ \\
\hline Al $\left(\mu \mathrm{g} \mathrm{ml}^{-1}\right)$ & $0.11 \pm 0.02$ \\
\hline As $\left(\mu g l^{-1}\right)$ & $<0.020$ \\
\hline $\mathrm{Ba}\left(\mu \mathrm{g} \mathrm{ml}^{-1}\right)$ & $0.098 \pm 0.010$ \\
\hline $\mathrm{Ca}\left(\mu \mathrm{g} \mathrm{ml}^{-1}\right)$ & $105 \pm 5$ \\
\hline $\mathrm{Cd}\left(\mu \mathrm{g} \mathrm{ml}^{-1}\right)$ & $<0.020$ \\
\hline Co $\left(\mu \mathrm{g} \mathrm{ml}^{-1}\right)$ & $<0.020$ \\
\hline $\operatorname{Cr}\left(\mu g \mathrm{ml}^{-1}\right)$ & $0.24 \pm 0.08$ \\
\hline $\mathrm{Cu}\left(\mu \mathrm{g} \mathrm{ml}^{-1}\right)$ & $<0.020$ \\
\hline $\mathrm{Fe}\left(\mu \mathrm{g} \mathrm{ml^{-1 } )}\right.$ & $<0.020$ \\
\hline$K\left(\mu g \mathrm{ml}^{-1}\right)$ & $620 \pm 60$ \\
\hline$M g\left(\mu \mathrm{gl}^{-1}\right)$ & $<0.020$ \\
\hline $\operatorname{Mn}\left(\mu \mathrm{g} \mathrm{ml}^{-1}\right)$ & $<0.010$ \\
\hline $\mathrm{Ni}\left(\mu \mathrm{g} \mathrm{ml}^{-1}\right)$ & $<0.020$ \\
\hline$P\left(\mu g^{~ m l^{-1}}\right)$ & $<0.020$ \\
\hline $\mathrm{Pb}\left(\mu \mathrm{g} \mathrm{ml}^{-1}\right)$ & $0.31 \pm 0.03$ \\
\hline$S\left(\mu g^{-1}\right)$ & $141 \pm 6$ \\
\hline Sb $\left(\mu \mathrm{g} \mathrm{ml}^{-1}\right)$ & $<0.020$ \\
\hline Si $\left(\mu \mathrm{g} \mathrm{ml}^{-1}\right)$ & $1.3 \pm 0.1$ \\
\hline Sn $\left(\mu \mathrm{g} \mathrm{ml}^{-1}\right)$ & $<0.050$ \\
\hline $\mathrm{Sr}\left(\mu \mathrm{g} \mathrm{ml}^{-1}\right)$ & $0.15 \pm 0.02$ \\
\hline $\mathrm{Ti}\left(\mu \mathrm{g} \mathrm{ml}^{-1}\right)$ & $10,4 \pm 0,5$ \\
\hline$W\left(\mu g \mathrm{ml}^{-1}\right)$ & $<0.010$ \\
\hline $\mathrm{Zn}\left(\mu \mathrm{g} \mathrm{ml}^{-1}\right)$ & $0.16 \pm 0.03$ \\
\hline $\mathrm{Zr}\left(\mu \mathrm{g} \mathrm{ml}^{-1}\right)$ & $<0.020$ \\
\hline $\mathrm{Cl}^{-}\left(\mu \mathrm{g} \mathrm{ml}^{-1}\right)$ & $2540 \pm 127$ \\
\hline pH (medio) & 11.67 \\
\hline
\end{tabular}


3.1.2.2 Determinación de la cantidad de $\mathrm{NaHCO}_{3}$ utilizada en el proceso de inertización

Con el objeto de eliminar la mayor parte del ion cloruro existente en las cenizas volantes, se ha tomado como referencia el número de equivalentes del mismo en las cenizas. De esta forma, se ha calculado el número de equivalentes de sodio necesario e intentar la eliminación completa del mismo.

De igual forma, el anión carbonato $\mathrm{CO}_{3}{ }^{2-}$, reaccionará con los iones de los metales pesados existentes, para formar carbonatos insolubles.

Para ello, se disuelve totalmente en ácido nítrico diluido una cantidad pesada y conocida de cenizas y se procede a la valoración, mediante una potenciometría argentométrica del ion cloruro liberado.

El número de equivalentes obtenido por unidad de masa, nos indicará también el número de equivalentes de $\mathrm{NaHCO}_{3}$ a utilizar por unidad de masa:

$127 \mathrm{mg} \mathrm{de} \mathrm{Cl}^{-} / \mathrm{gr}$ de muestra de CV

ó

\section{$3,24 \mathrm{Eq} / \mathrm{Kg} \mathrm{de} \mathrm{Cl}{ }^{-}$}

En base a esto, se procede a calcular la cantidad exacta de $\mathrm{NaHCO}_{3}$ necesaria, en base a su peso molecular $\left(\mathrm{P}_{\mathrm{m}} \mathrm{NaHCO}_{3}=84,01 \mathrm{~g} / \mathrm{mol}\right)$ :

$$
\frac{84,01 \mathrm{~g} / \mathrm{mol}}{1} \times 3,24 \frac{\mathrm{Eq} \cdot \mathrm{g}}{\mathrm{KgCl}}=272,19 \frac{\mathrm{gNaHCO} 3}{\mathrm{Kg} \mathrm{CV}}
$$

Se determina la necesidad de utilizar 272,19 g de bicarbonato sódico $\left(\mathrm{NaHCO}_{3}\right)$, por cada kilogramo de cenizas volantes de RSU que se quieran inertizar. 


\subsubsection{Proceso de inertización y valorización de las cenizas volantes de RSU}

El procedimiento de inertización comienza con el lavado de las cenizas originales, con una proporción de agua desionizada con respecto al peso de cenizas volantes, de 10:1.

A tal efecto se depositan $4 \mathrm{~kg}$ de cenizas volantes en $40 \mathrm{dm}^{3}$ de agua y se procede a incorporar la cantidad exacta de $\mathrm{NaHCO}_{3}$. De la aplicación de los cálculos obtenidos en el apartado anterior, se pesan 1088,80 g de $\mathrm{NaHCO}_{3}$ (en dos pesadas sucesivas de 544,40 g) que se añaden a la mezcla, para continuar con el agitado manual con medios mecánicos de la misma durante 30 minutos (ilustración 29).
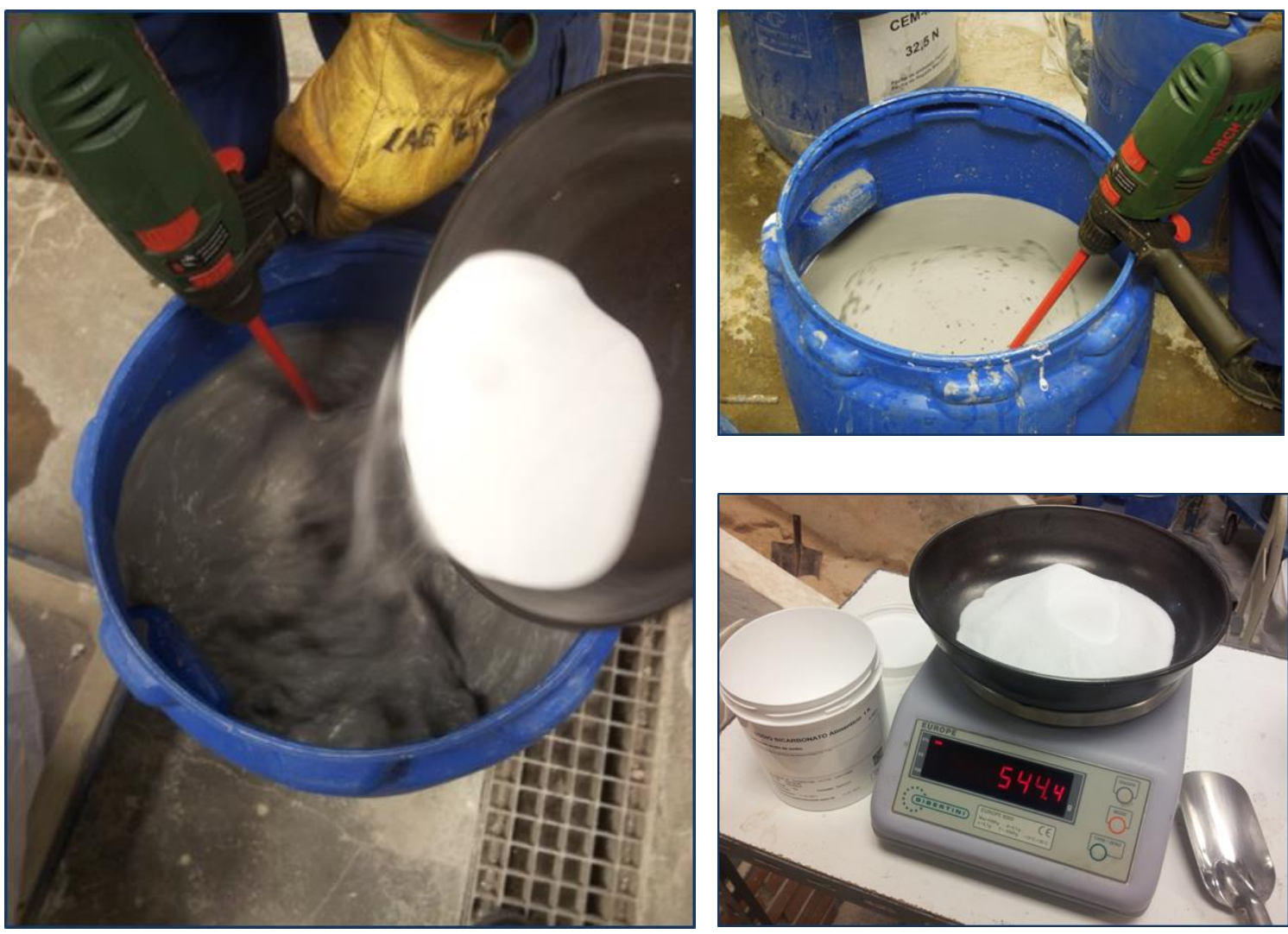

Ilustración 29. Determinación de la cantidad de $\mathrm{NaHCO}_{3}$, incorporación y agitado manual por medios mecánicos para el lavado de las CV de RSU 
A medida que se añadía la cantidad establecida de $\mathrm{NaHCO}_{3}$, se procedía a la medición del pH de la mezcla. El pH medio obtenido estuvo por encima de 10 , lo cual garantiza que los metales pesados no se redisuelven, al no tratarse de un pH ácido y que no se generen aniones plumbito o zincato, al no tratarse de un medio alcalino pero no lo suficiente para ello. Tras dejar reposar la mezcla durante 24 horas, se procede a retirar la parte líquida, compuesta en su mayor parte por Cloruro Sódico $(\mathrm{NaCl})$ disuelto en agua.

Se volvieron a lavar las cenizas volantes con agua desionizada, agitada por medios mecánicos durante 15 minutos y se comprobó que el pH medio era de 11,50 . Este procedimiento se realiza tres veces consecutivas (tres días), tras los que se inicia el proceso de recuperación de las cenizas volantes mediante un filtrado y lavado a través de un embudo Büchner de 2 $\mathrm{dm}^{3}$ de capacidad conectado a un matraz kitasato y a una bomba de vacío (ilustración 30).

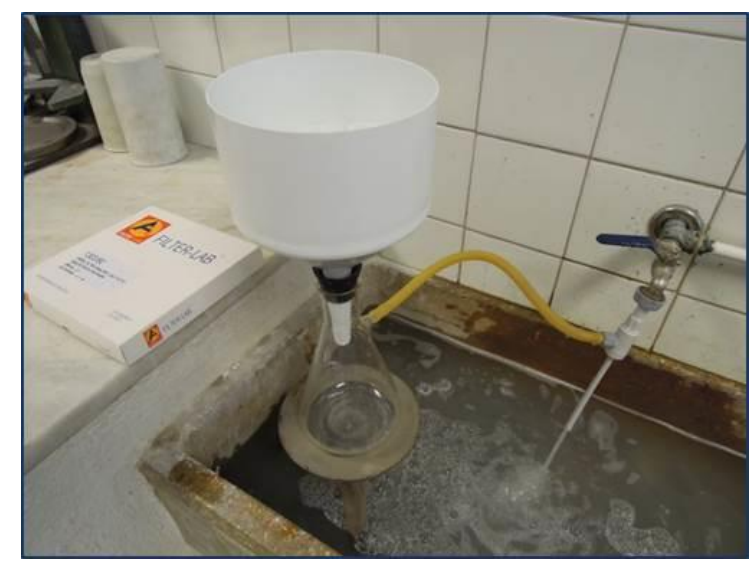

Ilustración 30. Proceso de recuperación de las CV de RSU inertizadas. Filtrado mediante embudo Büchner, matraz kitasato y bomba de vacío.

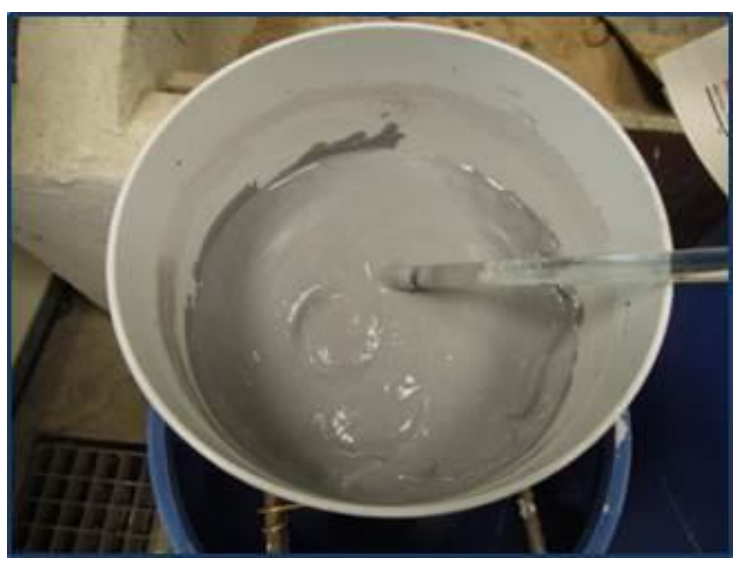

Ilustración 31. Proceso de recuperación de las CV de RSU inertizadas. Pasta final obtenida tras el filtrado.

En la ilustración 31 se puede apreciar una pasta gris oscura de cenizas volantes de RSU inertizadas, que para poder ser incorporada a la dosificación de los morteros deberá ser desecada y molida. 


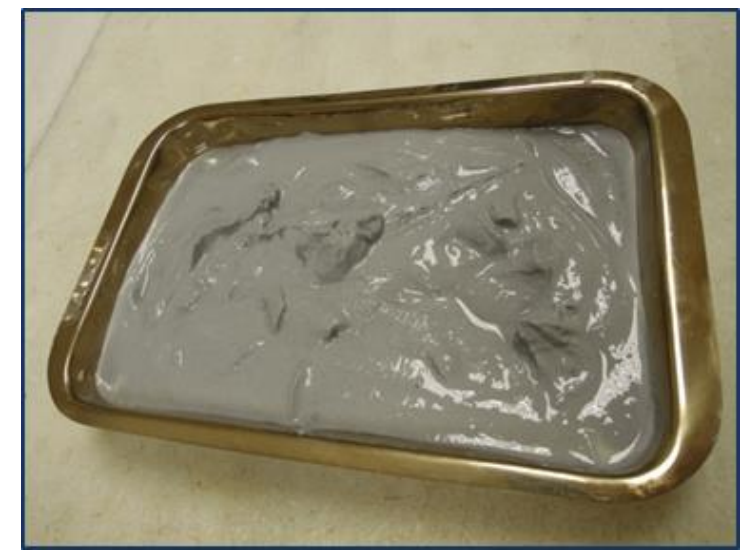

Ilustración 32. Proceso de recuperación de las CV de RSU inertizadas. Pasta en bandejas previa a su desecación en estufa.

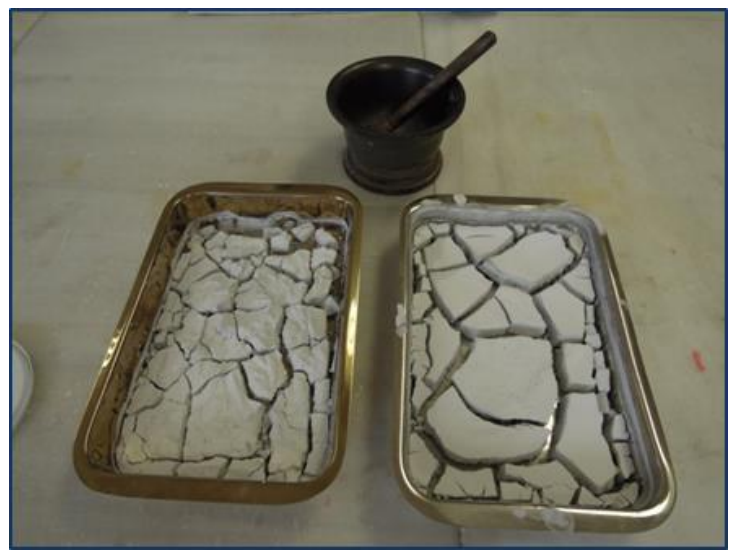

Ilustración 33. Proceso de recuperación de las CV de RSU inertizadas. Obtención de una torta quebradiza tras su desecación en estufa a $\left(75^{\circ} \mathrm{C}\right.$ y $\left.24 \mathrm{~h}\right)$

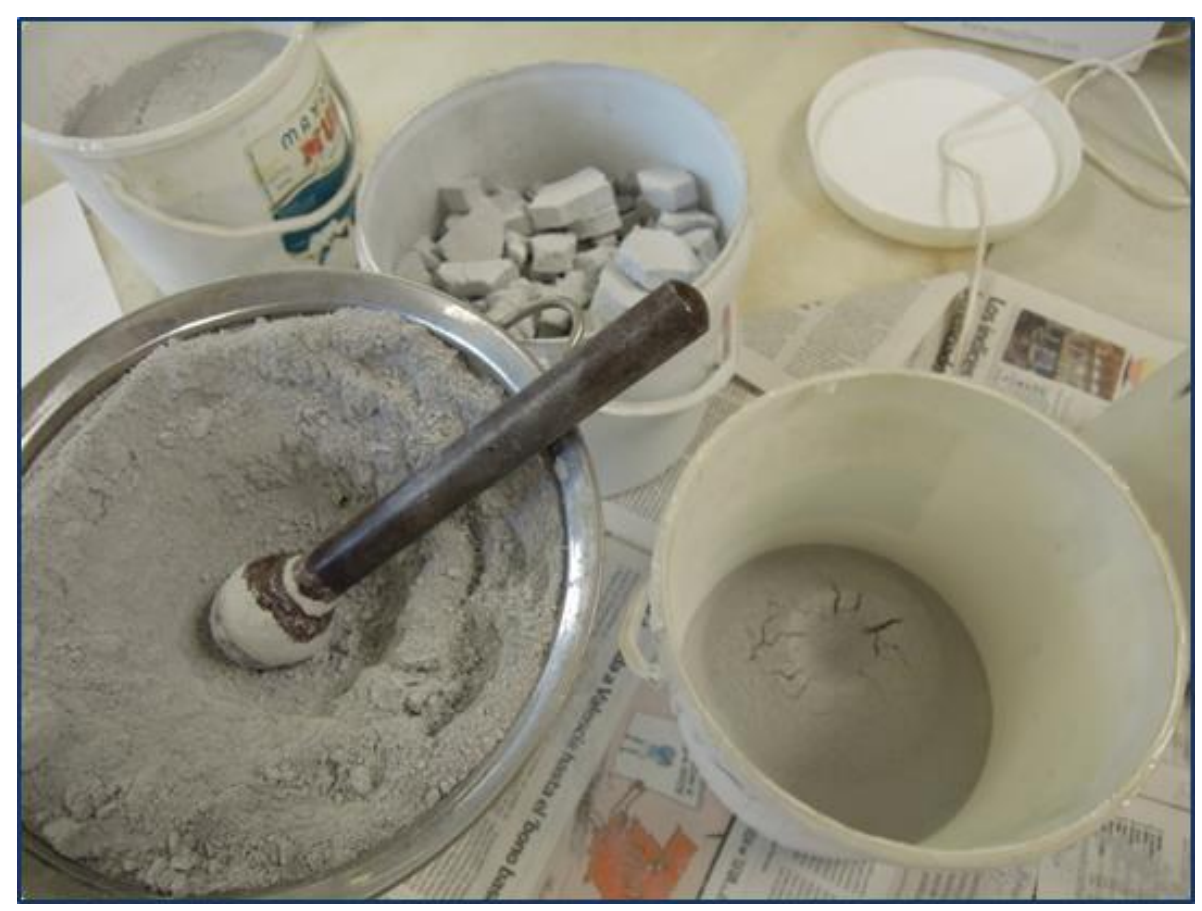

Ilustración 34. Proceso de recuperación de las CV de RSU inertizadas. Molienda manual y tamizado $(63 \mu \mathrm{m})$ de la torta de CVT.

Para su total recuperación, la pasta se depositó sobre una serie de bandejas (ilustración 32) y se procedió a su posterior secado en estufa durante un periodo de tiempo de 24 horas y a una temperatura de $75^{\circ} \mathrm{C}$. 
En la ilustración 33 se aprecia el resultado del secado. Se trata de una torta seca de material quebradizo que se muele, manual o mecánicamente, y se tamiza a través de un tamiz de $63 \mu \mathrm{m}$ para, de esta forma, obtener un polvo grisáceo fácilmente combinable con los áridos seleccionados para la ejecución de los morteros objeto de esta investigación (ilustración 34).

\subsubsection{Difracción de Rayos X. Análisis de CV y CVT}

Se ha registrado el diagrama de difracción de las CV en el intervalo de $2 \theta\left[5,00^{\circ}\right.$ a $\left.100,00^{\circ}\right]$, con un tamaño de paso de $\Delta(2 \theta)=0,04^{\circ}$ y un tiempo de contaje de 4 segundos por paso. Se utiliza la Ka del $\mathrm{Cu}=1.5418 \AA$. El resultado se muestra en la ilustración 35 .

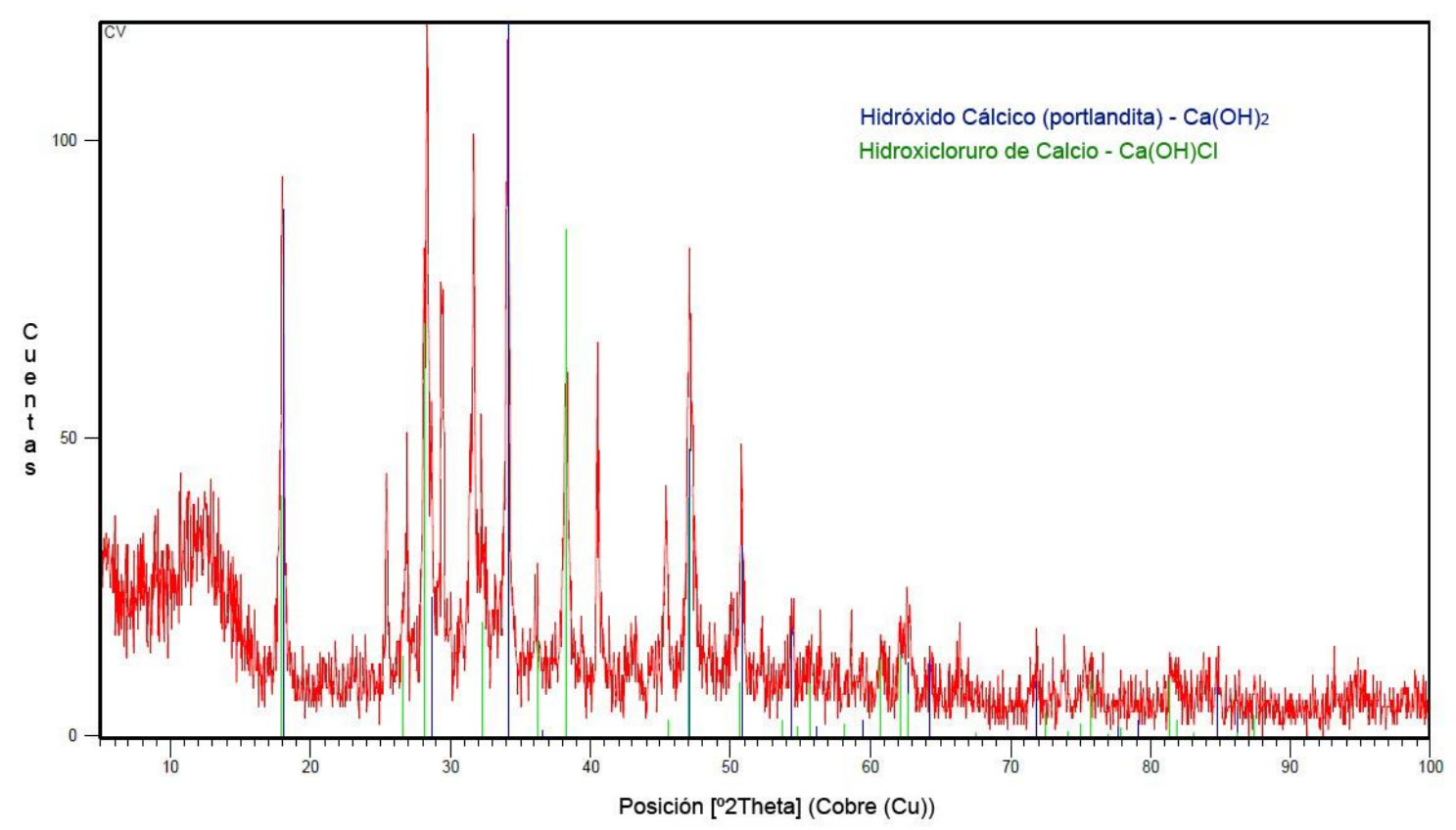

Ilustración 35. Difractograma de las cenizas volantes de RSU originales. Fases principales: $\mathrm{Ca}(\mathrm{OH}) 2$ y $\mathrm{Ca}(\mathrm{OH}) \mathrm{Cl}$.

Se trata de un difractograma con poca señal y mucho ruido, característico de un material de tamaño de partícula muy pequeña y/o altamente amorfo. Se han identificado mayoritariamente, al menos, dos fases principales: $\mathrm{Ca}(\mathrm{OH})_{2}$ y $\mathrm{Ca}(\mathrm{OH}) \mathrm{Cl}$. 
Los datos demuestran lo sucedido durante el proceso de combustión en las centrales incineradoras de RSU. En los filtros de recuperación de las cenizas volantes, se inyecta oxido cálcico - CaO- con la intención de neutralizar los gases ácidos producidos en la combustión. Éste reacciona con el agua procedente de la combustión de la materia orgánica para dar mayoritariamente $\mathrm{Ca}(\mathrm{OH})_{2}$ y $\mathrm{Ca}(\mathrm{OH}) \mathrm{Cl}$.

$$
\mathrm{CaO}+\mathrm{H}_{2} \mathrm{O} \rightarrow \mathrm{Ca}(\mathrm{OH})_{2}+\text { calor }
$$

La tabla 17 muestra los principales componentes cristalinos identificados mediante el estudio de DRX en las cenizas volantes de RSU. La cuantificación de los distintos compuestos se realiza en base a una estimación correspondiente a la altura de los distintos picos en el difractograma (ilustración 36). La simbología utilizada, "X", en la columna "cantidad" representa la altura relativa de los picos con respecto al resto de componentes. Los componentes más abundantes son: Hidróxido cálcico, hidroxicloruro de calcio, cloruro cálcico hidratado, tetracloruro de silicio y silvita. Estos componentes confirman el alto grado en cloruros supuesto a este tipo de sustancia. En menor medida aparecen: Óxidos de aluminio, plomo, silicio y sodio. También se aprecian trazas de halita y de otros componentes menores como: Calcita, óxidos de zinc, potasio, titanio y azufre.

Los resultados obtenidos confirman los obtenidos por otros investigadores en lo referente a los óxidos metálicos (Siddique, 2010), si bien, en estas mismas investigaciones, no se reflejan contenidos tan elevados tanto de hidróxido cálcico, como de cloruros, especialmente de hidroxicloruro de calcio. 
Tabla 17. Principales componentes de las CV de RSU detectadas por DRX

\begin{tabular}{|c|c|c|c|c|c|c|}
\hline \multirow{2}{*}{$\begin{array}{c}\text { Compuesto } \\
\text { Hidróxido Cálcico }\end{array}$} & \multicolumn{2}{|l|}{ Fórmula } & \multicolumn{4}{|c|}{ Cantidad } \\
\hline & $\mathrm{Ca}(\mathrm{OH})_{2}$ & + & + & + & + & + \\
\hline Hidroxicloruro de Calcio & $\mathrm{Ca}(\mathrm{OH}) \mathrm{Cl}$ & + & + & + & + & + \\
\hline Cloruro Cálcico Hidratado & $\mathrm{Ca}(\mathrm{ClO})_{2}+4 \mathrm{H} 2 \mathrm{O}$ & + & + & + & + & \\
\hline Tetracloruro de Silicio & $\mathrm{SiCl}_{4}$ & + & + & + & + & \\
\hline Sylvita & $\mathrm{KCl}$ & + & + & + & + & \\
\hline Óxido de Aluminio & $\mathrm{Al}_{2} \mathrm{O}_{3}$ & + & + & + & & \\
\hline Óxido de Plomo & $\mathrm{Pb}_{2} \mathrm{O}_{3}$ & + & + & & & \\
\hline Cuarzo & $\mathrm{SiO}_{2}$ & + & + & & & \\
\hline Óxido de Sodio & $\mathrm{Na}_{2} \mathrm{O}$ & + & + & & & \\
\hline Halita & $\mathrm{NaCl}$ & + & & & & \\
\hline
\end{tabular}

El diagrama de refracción de rayos $X$ de la ilustración 36, corresponde al estudio realizado sobre las cenizas volantes de RSU inertizadas. En él se confirman las previsiones ya que muestra un esquema mucho más uniforme en el cual predomina una única fase cristalina mayoritaria: Carbonato cálcico $\left(\mathrm{CaCO}_{3}\right)$ del tipo calcita.

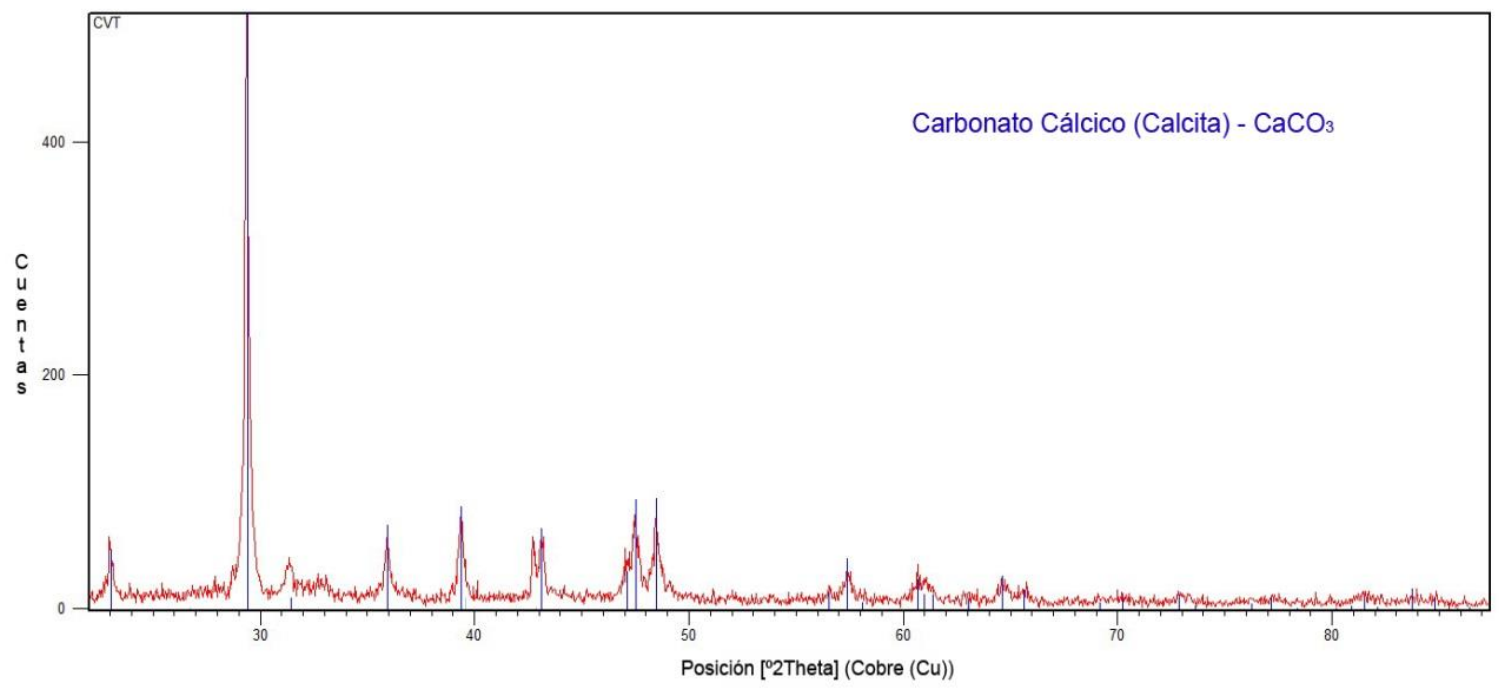

Ilustración 36. Difractograma de las cenizas volantes de RSU inertizadas (CVT). Fase mayoritaria: $\mathrm{CaCO} 3$. 
Los análisis DRX confirman que la incorporación de Bicarbonato Sódico $\left(\mathrm{NaHCO}_{3}\right)$, junto al lavado de las cenizas volantes, ha transformado las fases principales de las CV de RSU, Hidróxido Cálcico $\mathrm{Ca}(\mathrm{OH})_{2}$ e Hidroxicloruro de Calcio $\mathrm{Ca}(\mathrm{OH}) \mathrm{Cl}$, en carbonatos, principalmente Carbonato Cálcico $\left(\mathrm{CaCO}_{3}\right)$.

3.1.2.5 Calorimetría Diferencial de Barrido y Termo-Gravimetría (DSCTGA). Análisis de CV y CVT

La ilustración 37 muestra el termograma correspondiente a las cenizas volantes de RSU originales. Los datos obtenidos reflejan la aparición de una serie de picos cuya posición depende fundamentalmente de la composición química y estructura cristalina del mismo, y cuya superficie está relacionada con la energía envuelta en la reacción que está ocurriendo y el tipo de descomposición producida. Con el fin de determinar cada producto, se ha realizado una comparación bibliográfica con los rangos de temperaturas más comunes en la identificación de productos hidratados.

Dejando a un lado la deshidratación del agua estructural sufrida hasta $120^{\circ} \mathrm{C}$ de temperatura (Bakolas et al., 1998), la primera señal importante se produce entre $368,06^{\circ} \mathrm{C}$ y $501,21^{\circ} \mathrm{C}$, y es debida, principalmente, a la superposición de las descomposiciones del hidróxido cálcico $\left(\mathrm{Ca}(\mathrm{OH})_{2}\right)$ y del hidroxicloruro cálcico ( $\mathrm{CaClOH})$ (Rajammal et al., 2009; Sepulcre-Aguilar y Hernández-Olivares, 2010; Vedalakshmi et al., 2003).

La segunda señal, entre $596,62^{\circ} \mathrm{C}$ y $715,86^{\circ} \mathrm{C}$, es característica de acuerdo a la descarbonatación de diversos carbonatos y, en particular, con el carbonato cálcico (Sepulcre-Aguilar y Hernández-Olivares, 2010).

Por encima de los $828^{\circ} \mathrm{C}$ se produce una lenta descomposición de las fases de otros carbonatos bien cristalizadas (Gunasekaran y Anbalagan 2008). 


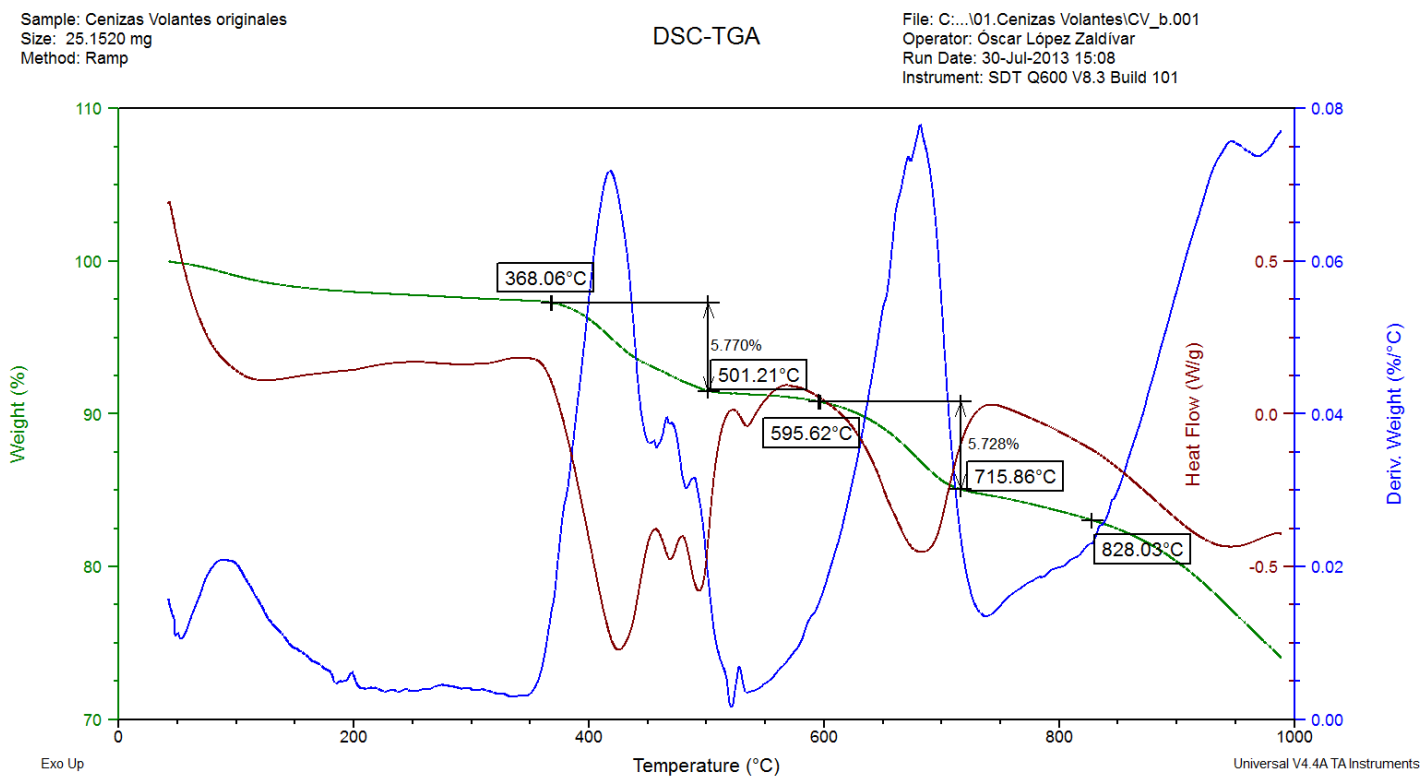

Ilustración 37. Curvas DSC-TGA de las muestras de cenizas volantes de RSU originales

La ilustración 38 corresponde al termograma de las cenizas volantes inertizadas. Hasta $100^{\circ} \mathrm{C}$ se observa la perdida de humedad residual del producto. A partir de $100^{\circ} \mathrm{C}$, se produce una pérdida de masa constante y de poca intensidad. Se puede considerar que se trata de una fase hidratada, por lo tanto, podemos inferir que la pérdida de masa en el tramo comprendido entre los $100^{\circ} \mathrm{C}$ y los $200^{\circ} \mathrm{C}$ se debe a la eliminación de moléculas de agua de constitución. En temperaturas superiores a los $636,78^{\circ} \mathrm{C}$ es cuando tiene lugar la primera pérdida de masa importante, que concluye entorno a los $804,63^{\circ} \mathrm{C}$, y corresponde a un $22,57 \%$ de la masa total. Esta es debida a la descomposición térmica del Carbonato Cálcico $\left(\mathrm{CaCO}_{3}\right)$ y su transformación en cal viva $(\mathrm{CaO})$ y $\mathrm{CO}_{2}$.

A partir del peso molecular del dióxido de carbono (44 uma) y la expresión de la reacción producida:

$$
\mathrm{CaCO}_{3} \rightarrow \mathrm{CaO}+\mathrm{CO}_{2} \uparrow
$$


La relación directa entre la pérdida de peso y el tamaño del pico explica y justifica las pérdidas de peso existentes, normalizadas a $100 \%$, y determina el porcentaje de carbonato cálcico presente en las cenizas volantes de RSU inertizadas:

$$
\% \mathrm{CaCO} 3=\left(\frac{22.57}{44}\right) \times 100=51.30 \%
$$

Por último, a partir de $804,63^{\circ} \mathrm{C}$ existe una segunda pérdida hasta cerca de los $900^{\circ} \mathrm{C}$ de mucha menor cuantía (3.214\%), correspondiente a otros tipos de carbonatos presentes en las cenizas inertizadas.

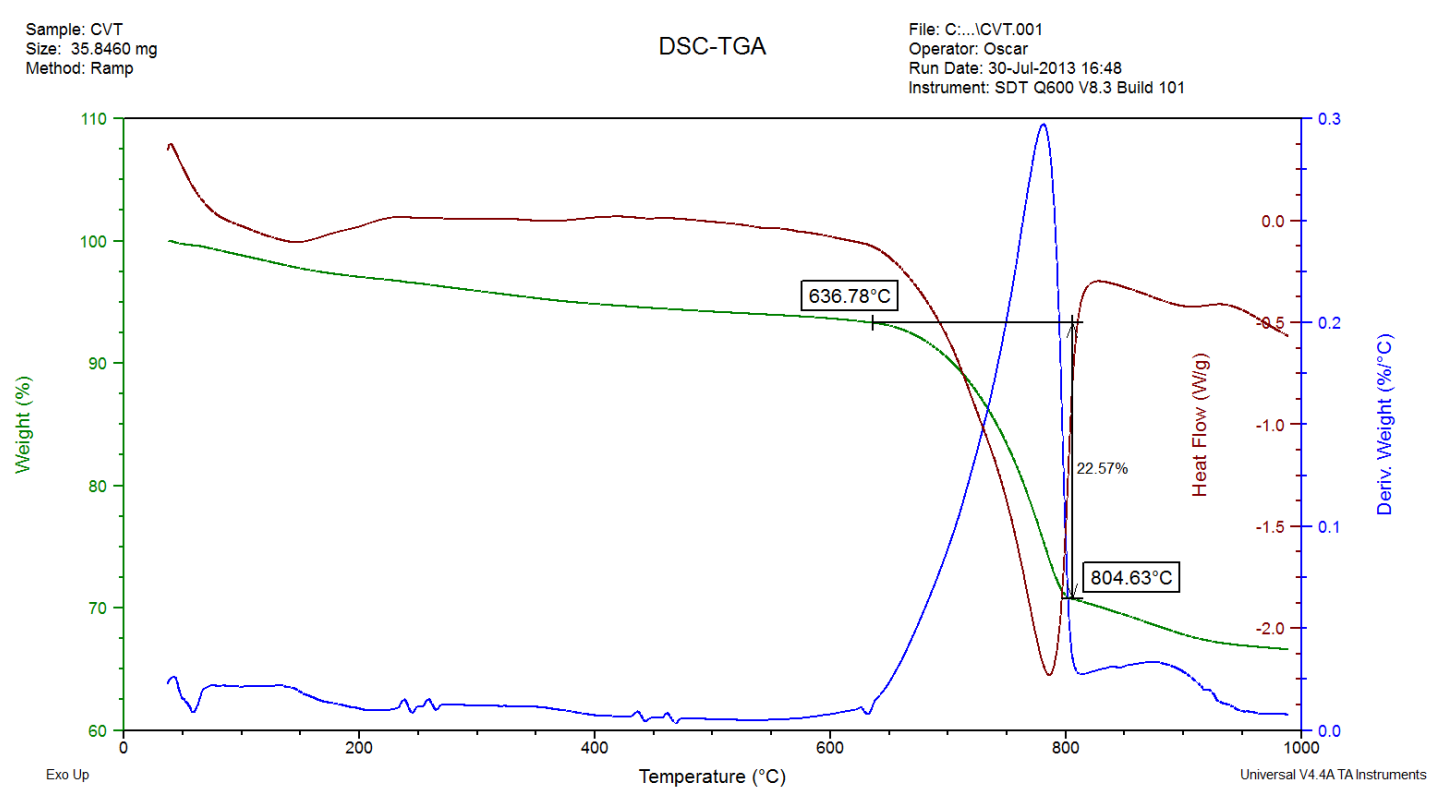

Ilustración 38. Curvas DSC-TGA de las muestras de cenizas volantes inertizadas. 


\subsection{ANÁLISIS Y ESTUDIO DE LOS ÁRIDOS}

Es ampliamente conocido en el ámbito de la construcción que la composición mineralógica de los áridos utilizados en la ejecución de morteros y hormigones tiene una influencia determinante en su ejecución (Delgado et al., 2006).

Este condicionante cobra aún mayor importancia en los productos derivados de los Cementos de Aluminato de Calcio. De hecho, en la "Guía para su empleo en elementos de estructura de ingeniería civil" editada por la empresa cementera "Lafarge Fondu International", en colaboración con el Laboratorio Central de "Ponts et Chaussées", dedican un solo apartado a la elección de los mejores áridos para su combinación en morteros y hormigones. En dicho apartado se prohíbe expresamente la elaboración de productos derivados del CAC, con áridos que puedan tener la posibilidad de liberar álcalis. Dentro de este grupo se hace referencia directa a: granitos alterados, esquistos y rocas con exceso de feldespato o mica. Por el contrario, recomienda la utilización de áridos calizos debido a su mejor comportamiento físico mecánico.

En base a los objetivos de la investigación realizada en esta Tesis, se decidió no utilizar este tipo de áridos calizos, con la intención de no alterar los resultados obtenidos en base al producto obtenido del lavado de las cenizas volantes (carbonato cálcico), y su posterior utilización en la elaboración de los morteros. A todo ello, ha de unirse que las arenas de procedencia caliza son de una calidad muy variable y que requieren más cantidad de agua de amasado que las silíceas.

También, desde el punto de vista de la durabilidad de los productos confeccionados en medios agresivos, es preferible la utilización de áridos de tipo silíceo (gravas y arenas de rio o de cantera) y los que provienen de machaqueo de rocas volcánicas o de calizas sólidas y densas. 


\subsubsection{DETERMINACIÓN DE LA HUMEDAD DEL ÁRIDO}

La tabla 18 muestra los valores de contenido de humedad (en \%) de los áridos $0 / 2$ y $0 / 4$ utilizados en la ejecución de los morteros analizados en esta tesis.

Tabla 18. Peso húmedo y desecado, y contenido en humedad de los áridos utilizados en la elaboración de los morteros.

\begin{tabular}{lccc}
\hline & Peso húmedo $(\boldsymbol{g})$ & Peso desecado $(\boldsymbol{g})$ & Contenido de humedad (\%) \\
\hline $\mathbf{0} / \mathbf{2}$ & 2640,00 & 2524,60 & 4,57 \\
& 2735,00 & 2605,60 & 4,97 \\
& 3125,00 & 2993,88 & 4,38 \\
& 3350,00 & 3215,70 & 4,18 \\
\hline \multirow{2}{*}{$\mathbf{0 / 4}$} & 3045,00 & 2903,90 & 4,86 \\
& 2865,00 & 2741,50 & 4,50 \\
& 3030,00 & 2902,30 & 4,40 \\
& 3050,00 & 2915,70 & 4,61 \\
\hline
\end{tabular}

3.2.2 DETERMINACIÓN DE LA DISTRIBUCIÓN GRANULOMÉTRICA DEL ÁRIDO EMPLEADO MEDIANTE EL MÉTODO DEL TAMIZADO.

De la aplicación de la fórmula:

$$
f=\frac{\left(M_{1}-M_{2}\right)+P}{M_{1}} \times 100
$$


Donde:

$M_{1}$ es la masa seca de la muestra de ensayo, en kilogramos.

$M_{2}$ es la masa seca del residuo retenido en el tamiz de $63 \mu \mathrm{m}(0,063$ $\mathrm{mm}$ ), en kilogramos.

$P$ es la masa del material tamizado que queda en la bandeja inferior, en kilogramos.

Se obtiene que el porcentaje de finos (f) correspondiente al diámetro 0/2 del árido utilizado que pasa por el tamiz de $63 \mu \mathrm{m}(0,063 \mathrm{~mm})$ es de un 97,67\%. De acuerdo a lo reflejado en la tabla 19 .

Tabla 19. Determinación de la granulometría del árido $0 / 2$ utilizado en los morteros. Método del tamizado (UNE EN 993-1)

Arena 0/2 - Masa seca total $300 \mathrm{~g}\left(M_{1}\right)$

\begin{tabular}{cccc}
\hline $\begin{array}{c}\text { Tamaño de apertura } \\
\text { del tamiz }(\mathrm{mm})\end{array}$ & $\begin{array}{c}\text { Masa del material } \\
\text { retenido } R_{i}(\mathrm{~g})\end{array}$ & $\begin{array}{c}\text { Porcentaje del } \\
\text { material retenido } \\
\left(R_{i} / M_{1}\right) \times 100\end{array}$ & $\begin{array}{c}\text { Porcentajes } \\
\text { acumulados }\end{array}$ \\
\hline 4 & $\mathbf{0 , 0 0}$ & 0,00 & $100-\Sigma\left(R_{i} / M_{1} \times 100\right)$ \\
\hline 2 & $\mathbf{3 , 7 0}$ & 1,23 & 100,00 \\
\hline 1 & $\mathbf{4 2 , 9 0}$ & 14,30 & 98,77 \\
\hline 0,5 & $\mathbf{8 1 , 1 0}$ & 27,03 & 84,47 \\
\hline 0,25 & $\mathbf{1 2 3 , 9 0}$ & 41,30 & 16,14 \\
\hline 0,125 & $\mathbf{3 7 , 8 0}$ & 12,60 & 3,54 \\
\hline 0,063 & $\mathbf{8 , 8 0}\left(M_{2}\right)$ & - & - \\
\hline
\end{tabular}

Material en la bandeja de fondo $P=\mathbf{1}, \mathbf{8 0} \mathrm{g}$

Porcentaje de finos que pasan por el tamiz de $0,063 \mathrm{~mm} . f=97,67 \%$ 
Con idéntico procedimiento, el porcentaje de finos ( $f$ ) correspondiente al diámetro 0/4 del árido utilizado que pasa por el tamiz de $63 \mu \mathrm{m}(0,063$ $\mathrm{mm}$ ) es de un 98,97\%. De acuerdo a lo reflejado en la tabla 20.

Tabla 20. Determinación de la granulometría del árido 0/4 utilizado en los morteros. Método del tamizado (UNE EN 993-1)

Arena 0/4 - Masa seca total $300 \mathrm{~g}\left(M_{1}\right)$

\begin{tabular}{cccc}
\hline $\begin{array}{c}\text { Tamaño de apertura } \\
\text { del tamiz }(\mathrm{mm})\end{array}$ & $\begin{array}{c}\text { Masa del material } \\
\text { retenido } R_{i}(\mathrm{~g})\end{array}$ & $\begin{array}{c}\text { Porcentaje del } \\
\text { material retenido } \\
\left(R_{i} / M_{1}\right) \times 100\end{array}$ & $\begin{array}{c}\text { Porcentajes } \\
\text { acumulados }\end{array}$ \\
\hline 4 & $\mathbf{9 , 5 0}$ & 3,17 & $100-\Sigma\left(R_{i} / M_{1} \times 100\right)$ \\
\hline 2 & $\mathbf{3 0 , 0 0}$ & 10,00 & 96,83 \\
\hline 1 & $\mathbf{4 8 , 7 0}$ & 16,23 & 86,83 \\
\hline 0,5 & $\mathbf{6 9 , 7 0}$ & 23,23 & 70,60 \\
\hline 0,25 & $\mathbf{1 0 4 , 8 0}$ & 34,93 & 12,44 \\
\hline 0,125 & $\mathbf{3 1 , 4 0}$ & 10,47 & 1,97 \\
\hline 0,063 & $\mathbf{4 , 5 0}\left(M_{2}\right)$ & - & - \\
\hline
\end{tabular}

Material en la bandeja de fondo $P=\mathbf{1}, \mathbf{4 0} \mathrm{g}$

Porcentaje de finos que pasan por el tamiz de $0,063 \mathrm{~mm} . f=98,97 \%$

Ambos ensayos muestran la homogeneidad del material elegido, lo cual presupone la no incidencia de las características del mismo en los resultados de los análisis realizados sobre los distintos morteros. 


\subsection{ANÁLISIS Y ESTUDIO DE LOS MORTEROS}

\subsubsection{DETERMINACIÓN DE LA CONSISTENCIA DEL MORTERO FRESCO POR} LA MESA DE SACUDIDAS (UNE EN 1015-3:2000)

3.3.1.1 Relación agua/cemento según la consistencia del mortero fresco para morteros CEM-I (UNE EN 1015-3:2000)

La tabla 21 presenta los valores experimentales de la aplicación de la norma UNE EN 1015:3-2000 sobre los morteros de CEM-I ensayados, para densidades superiores a $1200 \mathrm{~kg} / \mathrm{m}^{3}$. Los datos han sido obtenidos en el laboratorio tras sucesivas amasadas y con distintas combinaciones de agua y cemento. La consecución de valores de escurrimiento similares entre las diversas pastas, posibilita la comparación en igualdad de condiciones de los futuros resultados de los distintos morteros ensayados.

Asimismo, la ilustración 39 muestra los valores óptimos en la relación necesaria agua/cemento, para el cumplimiento de dicha norma en este tipo de morteros.

Tabla 21. Valores de escurrimiento de los morteros CEM-I ensayados según UNE EN 1015:3-2000. (Rango del diámetro de la galleta de mortero en la mesa de sacudidas = $175 \pm 10 \mathrm{~mm})$

\begin{tabular}{|c|c|c|c|c|c|c|c|c|c|}
\hline & & \multicolumn{8}{|c|}{ Morteros de CEM-I } \\
\hline & & \multicolumn{4}{|c|}{$1 / 1$} & \multicolumn{4}{|c|}{$1 / 3$} \\
\hline & & \multicolumn{2}{|c|}{$\mathbf{R}$} & \multicolumn{2}{|c|}{ CVT } & \multicolumn{2}{|c|}{$\mathbf{R}$} & \multicolumn{2}{|c|}{ CVT } \\
\hline \multirow{2}{*}{$0 / 2$} & Valor & 170.8 & 170.7 & 174.4 & 175.0 & 177.0 & 184.8 & 168.2 & 168.5 \\
\hline & Media & \multicolumn{2}{|c|}{170.75} & \multicolumn{2}{|c|}{174.68} & \multicolumn{2}{|c|}{180.90} & \multicolumn{2}{|c|}{168.83} \\
\hline \multirow{2}{*}{$0 / 4$} & Valor & 184.1 & 182.1 & 183.4 & 179.2 & 181.8 & 182.0 & 173.2 & 174.2 \\
\hline & Media & \multicolumn{2}{|c|}{183.10} & \multicolumn{2}{|c|}{181.28} & \multicolumn{2}{|c|}{181.90} & \multicolumn{2}{|c|}{173.70} \\
\hline
\end{tabular}




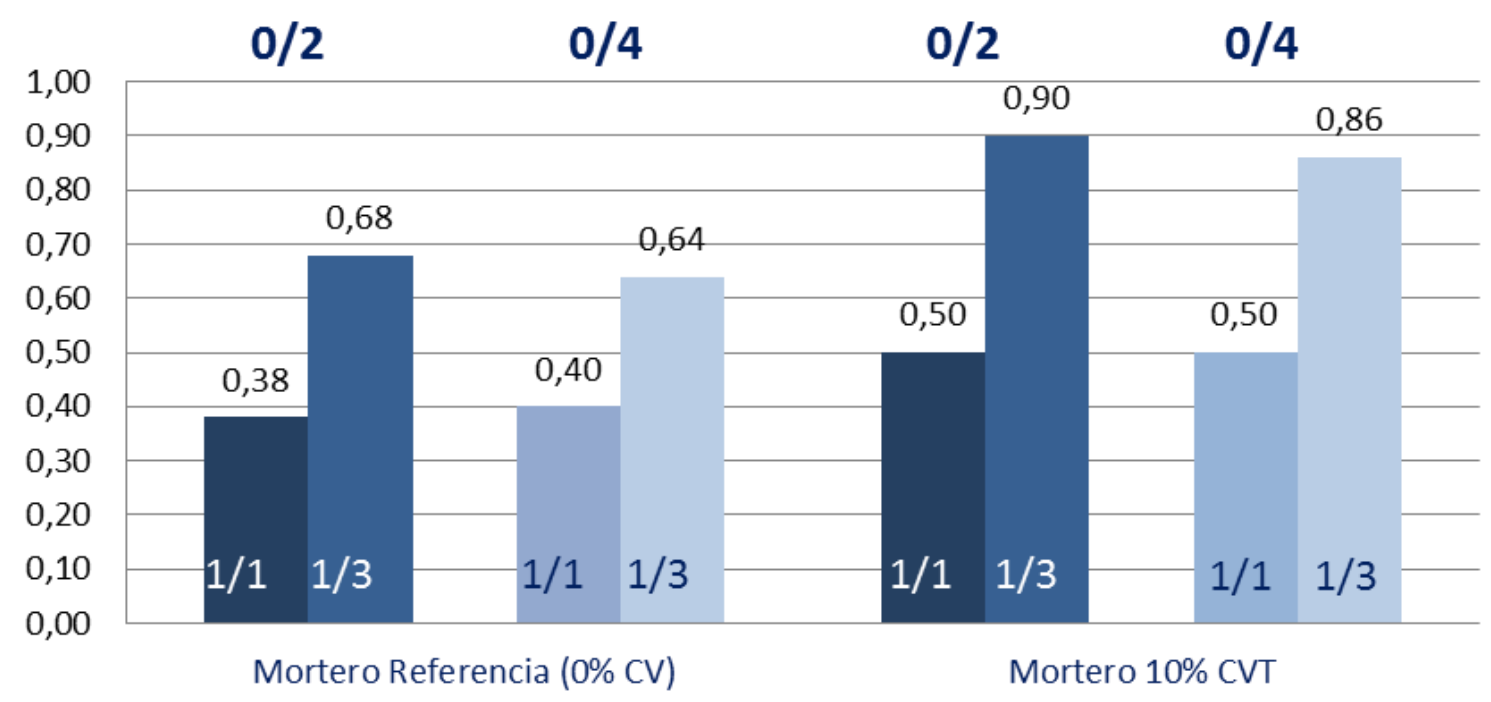

CEM I

Ilustración 39. Relación óptima agua/cemento para los morteros elaborados con CEM-I. Consistencia del mortero para un valor de escurrimiento $175 \pm 10$ mm según EN 1015$3: 2000$.

3.3.1.2 Determinación de la relación agua/cemento según la consistencia del mortero fresco para morteros CEM-II A/P (UNE EN 10153:2000)

La tabla 22 muestra los valores experimentales de la aplicación de la norma UNE EN 1015:3-2000 sobre los morteros de CEM-II A/P ensayados, para densidades superiores a $1200 \mathrm{Kg} / \mathrm{m}^{3}$. Los valores fueron alcanzados en el laboratorio tras sucesivas amasadas y con distintas combinaciones de agua y cemento. La obtención de valores de escurrimiento similares entre las diversas pastas, posibilita la comparación en igualdad de condiciones de los futuros resultados de los distintos morteros ensayados.

De igual forma, la ilustración 40 indica los valores óptimos en la relación necesaria agua/cemento, para el cumplimiento de dicha norma en este tipo de morteros. 
Tabla 22. Valores de escurrimiento de los morteros CEM-II A/P ensayados según UNE EN 1015:3-2000. (Rango del diámetro de la galleta de mortero en la mesa de sacudidas = $175 \pm 10 \mathrm{~mm})$

\begin{tabular}{|c|c|c|c|c|c|c|c|}
\hline \multicolumn{8}{|c|}{ Morteros de CEM-II A/P } \\
\hline \multicolumn{4}{|c|}{$1 / 1$} & \multicolumn{4}{|c|}{$1 / 3$} \\
\hline \multicolumn{2}{|c|}{$\mathbf{R}$} & \multicolumn{2}{|c|}{ CVT } & \multicolumn{2}{|c|}{$\mathbf{R}$} & \multicolumn{2}{|c|}{ CVT } \\
\hline 169.5 & 172.1 & 182.7 & 184.6 & 180.6 & 178.8 & 177.3 & 178.2 \\
\hline \multicolumn{2}{|c|}{170.80} & \multicolumn{2}{|c|}{179.10} & \multicolumn{2}{|c|}{180.90} & \multicolumn{2}{|c|}{177.75} \\
\hline 171.5 & 170.0 & 178.1 & 178.9 & 166.1 & 171.3 & 177.1 & 178.6 \\
\hline \multicolumn{2}{|c|}{170.75} & \multicolumn{2}{|c|}{178.50} & \multicolumn{2}{|c|}{168.70} & \multicolumn{2}{|c|}{177.85} \\
\hline
\end{tabular}

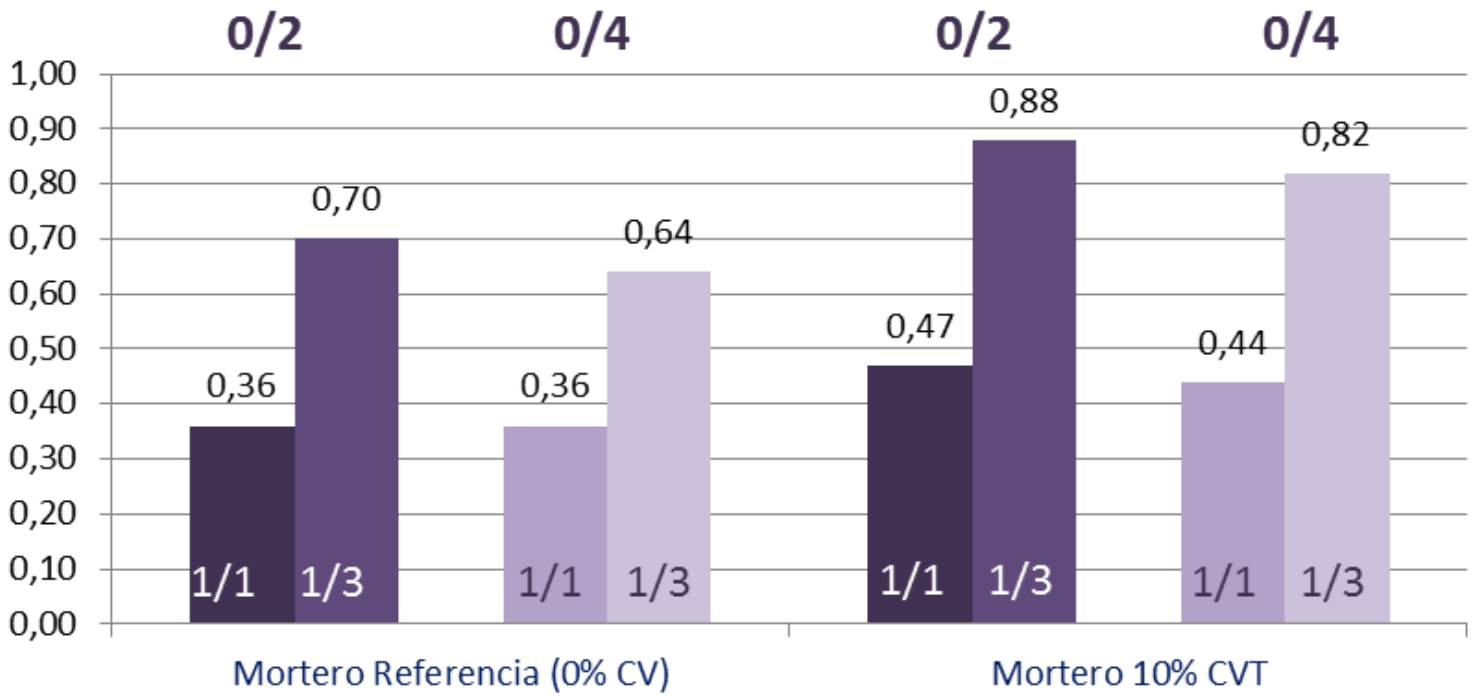

CEM II A/P

Ilustración 40. Relación óptima agua/cemento para los morteros elaborados con CEM-II A/P. Consistencia del mortero para un valor de escurrimiento $175 \pm 10 \mathrm{~mm}$ según EN 1015-3:2000. 
3.3.1.3 Determinación de la relación agua/cemento según la consistencia del mortero fresco para morteros CAC (UNE EN 1015-3:2000)

La tabla 23 ofrece los valores experimentales de la aplicación de la norma UNE EN 1015:3-2000 sobre los morteros de CAC ensayados, para densidades superiores a $1200 \mathrm{Kg} / \mathrm{m}^{3}$. Los resultados han sido logrados en el laboratorio tras sucesivas amasadas y con distintas combinaciones de agua y cemento. La obtención de valores de escurrimiento similares entre las diversas pastas, posibilita la comparación en igualdad de condiciones de los futuros resultados de los distintos morteros ensayados.

La ilustración 41 presenta los valores óptimos en la relación necesaria agua/cemento, para el cumplimiento de dicha norma en este tipo de morteros.

Tabla 23. Valores de escurrimiento de los morteros CAC ensayados según UNE EN 1015:32000. (Rango del diámetro de la galleta de mortero en la mesa de sacudidas $=175 \pm 10 \mathrm{~mm}$ )

\section{Morteros de CAC}

$1 / 1$

\begin{tabular}{llll}
\hline R & CVT & R & CVT
\end{tabular}

\begin{tabular}{|c|c|c|c|c|c|c|c|c|c|}
\hline \multirow{2}{*}{$0 / 2$} & Valor & 172.1 & 170.9 & 177.4 & 178.9 & 173.6 & 176.3 & 177.0 & 180.0 \\
\hline & Media & \multicolumn{2}{|c|}{171.50} & \multicolumn{2}{|c|}{178.15} & \multicolumn{2}{|c|}{174.90} & \multicolumn{2}{|c|}{178.50} \\
\hline \multirow{2}{*}{$0 / 4$} & Valor & 173.7 & 175.8 & 173.5 & 176.3 & 178.3 & 180.2 & 175.7 & 173.2 \\
\hline & Media & \multicolumn{2}{|c|}{174.75} & \multicolumn{2}{|c|}{174.90} & \multicolumn{2}{|c|}{179.25} & \multicolumn{2}{|c|}{174.45} \\
\hline
\end{tabular}




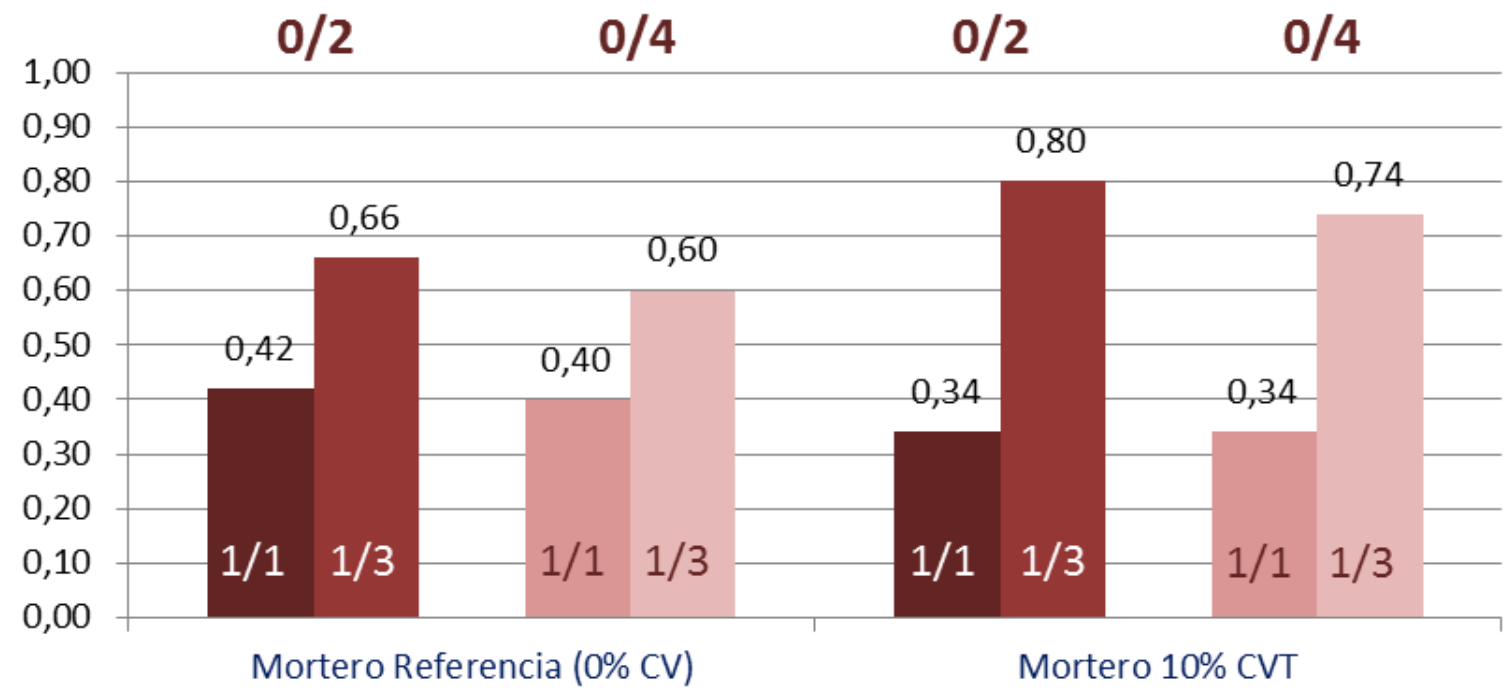

CAC

Ilustración 41. Relación óptima agua/cemento para los morteros elaborados con CAC. Consistencia del mortero para un valor de escurrimiento $175 \pm 10$ mm según EN 1015$3: 2000$.

3.3.1.4 Determinación de la relación agua/cemento según la consistencia del mortero fresco para morteros CSA (UNE EN 1015-3:2000)

La tabla 24 ofrece los valores experimentales de la aplicación de la norma UNE EN 1015:3-2000 sobre los morteros de CSA ensayados, para densidades superiores a $1200 \mathrm{Kg} / \mathrm{m}^{3}$. Los datos han sido recogidos en el laboratorio tras sucesivas amasadas y con distintas combinaciones de agua y cemento. La obtención de valores de escurrimiento similares entre las diversas pastas, posibilita la comparación en igualdad de condiciones de los futuros resultados de los distintos morteros ensayados.

Igualmente, la ilustración 42 presenta los valores óptimos en la relación necesaria agua/cemento, para el cumplimiento de dicha norma en este tipo de morteros. 
Tabla 24. Valores de escurrimiento de los morteros CSA ensayados según UNE EN 1015:32000. (Rango del diámetro de la galleta de mortero en la mesa de sacudidas $=175 \pm 10 \mathrm{~mm}$ )

\section{Morteros de CSA}

\begin{tabular}{|c|c|c|c|c|c|c|c|}
\hline \multicolumn{4}{|c|}{$1 / 1$} & \multicolumn{4}{|c|}{$1 / 3$} \\
\hline \multicolumn{2}{|c|}{$\mathbf{R}$} & \multicolumn{2}{|c|}{ CVT } & \multicolumn{2}{|c|}{$\mathbf{R}$} & \multicolumn{2}{|c|}{ CVT } \\
\hline 171.5 & 169.0 & 173.2 & 174.0 & 165.5 & 167.3 & 174.0 & 176.4 \\
\hline \multicolumn{2}{|c|}{170.30} & \multicolumn{2}{|c|}{173.60} & \multicolumn{2}{|c|}{166.38} & \multicolumn{2}{|c|}{175.20} \\
\hline 173.7 & 171.9 & 175.3 & 173.9 & 167.3 & 174.5 & 171.1 & 175.0 \\
\hline \multicolumn{2}{|c|}{172.80} & \multicolumn{2}{|c|}{174.60} & \multicolumn{2}{|c|}{170.90} & \multicolumn{2}{|c|}{173.05} \\
\hline
\end{tabular}

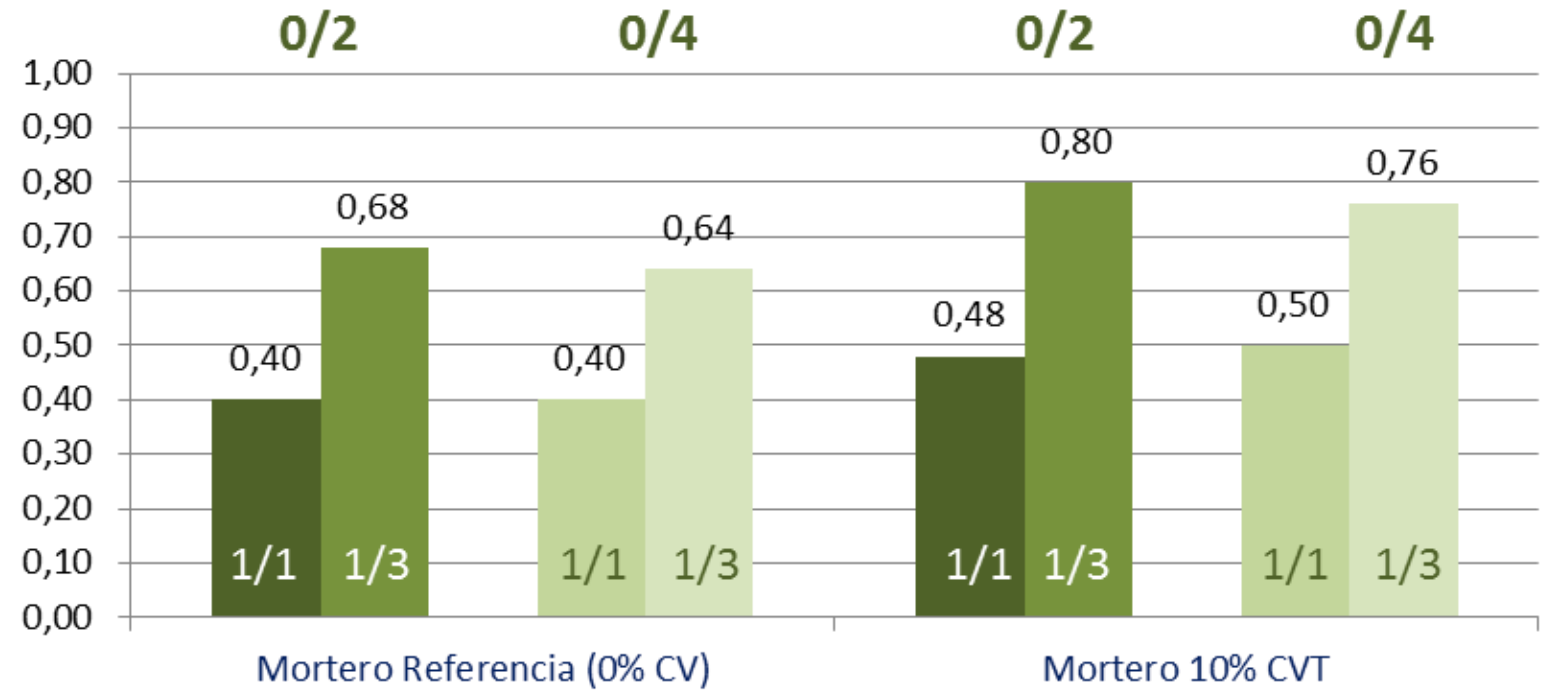

CSA

Ilustración 42. Relación óptima agua/cemento para los morteros elaborados con CSA. Consistencia del mortero para un valor de escurrimiento $175 \pm 10$ mm según EN 10153:2000. 
De acuerdo a los datos presentados, en todos los casos, salvo en los morteros de CAC con dosificaciones $1 / 1$ y para ambos diámetros de árido, la incorporación de las cenizas volantes inertizadas en forma de carbonatos (CVT) aumenta considerablemente el agua necesaria para mantener la trabajabilidad de la masa.

El significativo incremento de agua necesario para el amasado puede ser fácilmente explicado por la formación de las nuevas partículas de calcita $-\mathrm{CaCO}_{3}{ }^{-}$, las cuales originan un aumento de la superficie específica del árido utilizado (Aubert et al., 2006). Es indudable que el incremento en la demanda de agua de amasado de las distintas mezclas representa un condicionante negativo en los morteros, dado que una mayor relación agua/cemento reduce la resistencia a compresión de los productos finales (Mangialardi et al., 1999) y, de igual forma, podría suponer un inconveniente añadido a la hora de la encapsulación de las CV de RSU ya que favorecería el lixiviado de metales pesados (Coutand, 2011). De igual forma es sabido que esta relación agua/cemento, puede ser reducida o modificada mediante el uso de agentes superplastificantes de la construcción (Taylor, 1997).

Por el contrario, en la tabla 25 se puede observar que los morteros CAC dosificación $1 / 1$ requieren entre un $17.6 \%$ y un $23.5 \%$ menos de agua en su amasado de lo que necesitarían para cumplir los estándares de la norma los morteros sin ningún tipo de aditivo. Este comportamiento reológico diferenciado está directamente relacionado con la mayor reactividad química de los cementos de aluminato de calcio con respecto a la presentada por los cementos Portland y CSA y, como se verá más adelante, es uno de los factores que influirá en gran medida con el buen comportamiento físico/mecánico de los morteros CAC. Dada la reducida trabajabilidad que presentan estos morteros, se puede imputar el aumento de la resistencia a compresión al grado de absorción de agua que presentan las CVT durante el amasado. De acuerdo a los ensayos de (Rémond et al., 2002), las cenizas volantes de RSU pueden absorber hasta un $28 \%$ de su masa en agua, por lo que esta absorción de agua puede disminuir la 
relación efectiva real agua/cemento y, por lo tanto, producir un aumento de las resistencias. Por otro lado, la forma esférica de este tipo de cenizas, con un tamaño muy inferior a las partículas del cemento, mejoran y compensan la geometría angulosa e irregular de las partículas de cemento, contribuyendo de forma adicional a una disminución de la cantidad de agua precisada.

Tabla 25. Porcentajes de aumento de agua en la elaboración de los morteros con la incorporación de CVT con respecto a los morteros de referencia.

\begin{tabular}{cccc}
\cline { 2 - 4 } CEM-I & & $\mathbf{1 / 1}$ & $\mathbf{1 / 3}$ \\
\hline \multirow{2}{*}{ CEM-II A/P } & $\mathbf{0 / 2}$ & 31.6 & 32.4 \\
\cline { 2 - 4 } & $\mathbf{0 / 4}$ & 25.0 & 34.4 \\
\cline { 2 - 4 } & $\mathbf{0 / 2}$ & 30.6 & 25.7 \\
\hline \multirow{2}{*}{ CAC } & $\mathbf{0 / 4}$ & 22.2 & 28.1 \\
\cline { 2 - 4 } & $\mathbf{0 / 2}$ & -23.5 & 21.2 \\
\hline \multirow{2}{*}{ CSA } & $\mathbf{0 / 4}$ & -17.6 & 23.3 \\
\cline { 2 - 4 } & $\mathbf{0 / 2}$ & 20.0 & 17.6 \\
\hline
\end{tabular}

\subsubsection{DETERMINACIÓN DEL PERIODO DE TRABAJABILIDAD DE LOS MORTEROS ENSAYADOS}

En la tabla 26 se observa que los morteros confeccionados con cementos Portland ordinarios y con CVT en sus dosificaciones, poseen un incremento notable en sus tiempos de fraguado. Este efecto retardador de las CVT es, muy probablemente, causado por las cantidades de $\mathrm{P}, \mathrm{Zn}$ y $\mathrm{Pb}$ presentes en las cenizas. También el remanente de cloruros podría producir este efecto, si bien éstos también deberían mejorar los valores de las resistencias obtenidas y no es este el caso, como ya se verá más adelante. Los datos ofrecidos vienen a corroborar los resultados previos realizados 
sobre pastas de cemento y distintos tipos de morteros según los que, los tiempos de fraguado, se ven incrementados cuando la adición de cenizas volantes llega a valores de un $15 \%$ en peso (Siddique, 2010). Por otra parte, las partículas de calcita generan una mayor superficie aparente en los áridos utilizados y son comúnmente asociadas a mayores requerimientos de agua de amasado lo cual implica un aumento en los tiempos de curado de los morteros (Wesche, 1991). También es conocido que, dada su tendencia a absorber aire, el contenido de $\mathrm{CaCO}_{3}$ puede incrementar el contenido en aire de las mezclas de morteros lo que, una vez más, puede degenerar en una reducción de las resistencias a compresión de los mismos (Goh et al., 2003)

Por el contrario, en el resto de morteros con CVT ensayados (salvo en los CAC con granulometría 1/3) la adición de cenizas volantes inertizadas produce una marcada reducción del periodo de trabajabilidad. En este caso, la presencia de CVT actúa como un acelerador del fraguado en base a que los hidratos producidos podrían comportarse como partículas cristalinas que acelerarían la hidratación temprana del cemento y la cristalización de los diversos hidratos, modificando las propiedades del fraguado de los morteros (Fan et al., 1999). Por otro lado, la existencia de determinadas cantidades de $\mathrm{Zn}$ y $\mathrm{Pb}$ podría, a la inversa que ocurre en los morteros de cementos Portland, facilitar los procesos de hidratación y reducir los tiempos de fraguado en los cementos CSA (Wei et al., 2011).

A pesar de lo anteriormente analizado, la pérdida de trabajabilidad puede ser perfectamente compensada mediante la utilización de superplastificantes o mediante la adición de más cantidad de agua de amasado (Aubert et al., 2006). 
Tabla 26. Periodo de trabajabilidad (en minutos) de los morteros ensayados.

\begin{tabular}{ccccc}
\hline \multirow{2}{*}{ Cemento } & \multirow{2}{*}{$\begin{array}{c}\text { Tamaño del } \\
\text { árido }\end{array}$} & Dosificación & \multicolumn{3}{c}{ Mortero } \\
\cline { 3 - 5 } CEM I & $0 / 2 \cdot 0 / 4$ & $1 / 1$ & $193 \cdot 170$ & TFA \\
\cline { 3 - 5 } & \multirow{2}{*}{ CEM II } & $1 / 2$ & $248 \cdot 250$ & $205 \cdot 196$ \\
\hline \multirow{2}{*}{ CAC } & $0 / 2 \cdot 0$ & $1 / 1$ & $187 \cdot 165$ & $200 \cdot 320$ \\
\cline { 3 - 5 } & $0 / 2 \cdot 0 / 4$ & $1 / 3$ & $205 \cdot 225$ & $295 \cdot 345$ \\
\cline { 3 - 5 } & \multirow{2}{*}{ CSA } & $1 / 1$ & $151 \cdot 130$ & $<15$ \\
\hline \multirow{2}{*}{$0 / 2 \cdot 0 / 4$} & $1 / 3$ & $169 \cdot 155$ & $<22 \cdot 185$ \\
\cline { 3 - 5 } & & $1 / 3$ & $<15$ & $<15$ \\
\hline
\end{tabular}

\subsubsection{ESTABILIDAD DIMENSIONAL}

Se ha realizado un estudio de la Estabilidad Dimensional de todas las probetas de mortero ensayadas a lo largo de esta Tesis de acuerdo al ensayo EN 83831:2010 EX, el cual está caracterizado por el estudio de las longitudes y masas iniciales de las probetas de mortero y la variación específica de las mismas, en \% de deformación $(\varepsilon)$, a 7, 14 y 28 días.

A lo largo de los siguientes apartados se darán a conocer los datos obtenidos en los distintos ensayos. En primer lugar se hará referencia a las longitudes de las probetas $\left(L_{x}\right)$ y sus variaciones $(\Delta L)$, incluida la variación específica o deformación. A continuación, se desarrollarán los datos relativos a masas $\left(M_{x}\right)$, sus variaciones a lo largo del tiempo $(\Delta L)$ y su variación de masa específica $\left(\mathrm{m}_{\mathrm{x}}\right)$. 
3.3.3.1 Estabilidad dimensional de los morteros elaborados con CEM-I (UNE EN 83831:2010 EX)

\subsection{Variación de la longitud (morteros CEM-I)}

Las tablas 27 y 28 muestran los resultados de los morteros elaborados con cementos CEM-I relativos a longitudes iniciales ( $L$ ) en el desmoldado de las probetas, la variación de las longitudes $(\Delta \mathrm{L})$ a 7,14 y 28 días y la variación de las longitudes específicas o deformación $\left(\varepsilon_{\mathrm{x}}\right)$ a las mismas edades de fraguado. Los datos de estas tablas se refieren a morteros ejecutados con áridos de diámetro $0 / 2$ (tabla 27) y 0/4 (tabla 28), y abarcan tanto a morteros de referencia, (R), como a morteros con la incorporación de cenizas volantes inertizadas, en una proporción igual a un $10 \%$ en peso del árido utilizado en su dosificación (CVT).

En las dosificaciones $1 / 1$ y diámetros del árido $0 / 2$ y $0 / 4$, los porcentajes de deformación finales son similares, tanto en la comparación de los morteros de referencia, como con los que incorporan cenizas volantes inertizadas en su elaboración. Éstos últimos, muestran las mayores contracciones de todos los estudiados con este tipo de cementos ya que presentan la mayor variación específica de su longitud a 28 días, si bien es cierto que, la inclusión de CVT, consigue estabilizar las deformaciones a lo largo del tiempo dado que la curva obtenida es más constante, especialmente en el caso de áridos 0/2.

Para los morteros de CEM-I con una dosificación tradicional 1/3, los resultados son menos homogéneos (valores medios de los ensayos reflejados en las tablas 27 y 28 ). En el caso de morteros con áridos 0/2, los morteros de referencia no sufren casi deformación a lo largo del tiempo (máximo $-0.06 \%$ a 28 días), mientras que estos mismos morteros con la inclusión de CVT presentan una variación media de $-0.24 \%$, lo cual ofrece la mayor diferencia entre los morteros aditivados y sus referencias de todos los estudiados en CEM-I. 
Tabla 27. Estabilidad dimensional de las probetas de mortero de CEM-I con árido $0 / 2$ (Longitud inicial, variación de longitud a 7, 14 y 28 días y variación de la longitud específica) (R) mortero de referencia. (CVT) mortero con la incorporación de cenizas volantes inertizadas, en una proporción igual a un $10 \%$ en peso del árido utilizado.

\begin{tabular}{|c|c|c|c|c|c|c|c|c|}
\hline & & & \multicolumn{2}{|c|}{7 días } & \multicolumn{2}{|c|}{14 días } & \multicolumn{2}{|c|}{28 días } \\
\hline \multirow{2}{*}{\multicolumn{3}{|c|}{$\begin{array}{l}\text { Long. Inicial } \\
\text { L }(\mathrm{mm})\end{array}$}} & $\begin{array}{l}\text { Longitud } \\
\mathrm{L}_{7}(\mathrm{~mm})\end{array}$ & $\begin{array}{c}\text { Variación } \\
\text { de } \\
\text { longitud } \\
\Delta \mathrm{L}(\mathrm{mm})\end{array}$ & $\begin{array}{l}\text { Longitud } \\
\mathrm{L}_{14}(\mathrm{~mm})\end{array}$ & $\begin{array}{c}\text { Variación } \\
\text { de } \\
\text { longitud } \\
\Delta \mathrm{L}(\mathrm{mm})\end{array}$ & $\begin{array}{l}\text { Longitud } \\
\mathrm{L}_{28}(\mathrm{~mm})\end{array}$ & $\begin{array}{c}\text { Variación } \\
\text { de } \\
\text { longitud } \\
\Delta \mathrm{L}(\mathrm{mm})\end{array}$ \\
\hline & & & \multicolumn{2}{|c|}{$\begin{array}{l}\text { Var. long. especif. } \\
\varepsilon_{7}(\%) \text { deformación }\end{array}$} & \multicolumn{2}{|c|}{$\begin{array}{l}\text { Var. long. especif. } \\
\varepsilon_{14}(\%) \text { deformación }\end{array}$} & \multicolumn{2}{|c|}{$\begin{array}{l}\text { Var. long. especif. } \\
\varepsilon_{28}(\%) \text { deformación }\end{array}$} \\
\hline \multirow{12}{*}{ 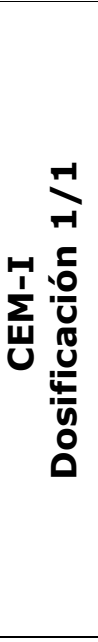 } & \multirow{6}{*}{$\boldsymbol{\alpha}$} & \multirow{2}{*}{160,50} & 160,10 & $-0,4$ & 160,15 & $-0,35$ & 160,05 & $-0,45$ \\
\hline & & & \multicolumn{2}{|c|}{$-0,25 \%$} & \multicolumn{2}{|c|}{$-0,22 \%$} & \multicolumn{2}{|c|}{$-0,28 \%$} \\
\hline & & \multirow{2}{*}{160,25} & 160,10 & $-0,15$ & 160,1 & $-0,15$ & 160 & $-0,25$ \\
\hline & & & \multicolumn{2}{|c|}{$-0,09 \%$} & \multicolumn{2}{|c|}{$-0,09 \%$} & \multicolumn{2}{|c|}{$-0,16 \%$} \\
\hline & & \multirow{2}{*}{160,25} & 160,05 & $-0,2$ & 160,1 & $-0,15$ & 160 & $-0,25$ \\
\hline & & & \multicolumn{2}{|c|}{$-0,12 \%$} & \multicolumn{2}{|c|}{$-0,09 \%$} & \multicolumn{2}{|c|}{$-0,16 \%$} \\
\hline & & \multirow{2}{*}{159,85} & 159,6 & $-0,25$ & 159,5 & $-0,35$ & 159,5 & $-0,35$ \\
\hline & & & \multicolumn{2}{|c|}{$-0,16 \%$} & \multicolumn{2}{|c|}{$-0,22 \%$} & \multicolumn{2}{|c|}{$-0,22 \%$} \\
\hline & & \multirow{2}{*}{160,00} & 159,65 & $-0,35$ & 159,5 & $-0,5$ & 159,45 & $-0,55$ \\
\hline & & & \multicolumn{2}{|c|}{$-0,22 \%$} & \multicolumn{2}{|c|}{$-0,31 \%$} & \multicolumn{2}{|c|}{$-0,34 \%$} \\
\hline & & \multirow{2}{*}{159,90} & 159,65 & $-0,25$ & 159,5 & $-0,4$ & 159,45 & $-0,45$ \\
\hline & & & \multicolumn{2}{|c|}{$-0,16 \%$} & & $5 \%$ & & $3 \%$ \\
\hline & & 16010 & 160,00 & $-0,1$ & 160 & $-0,1$ & 160 & $-0,1$ \\
\hline & & O & & $6 \%$ & & $5 \%$ & & $5 \%$ \\
\hline & $\boldsymbol{\alpha}$ & 16010 & 160,05 & $-0,05$ & 160 & $-0,1$ & 160 & $-0,1$ \\
\hline & 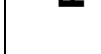 & 100,10 & & $3 \%$ & & $6 \%$ & & $5 \%$ \\
\hline$\vec{r}$ & & 16025 & 160,15 & $-0,1$ & 160,2 & $-0,05$ & 160,15 & $-0,1$ \\
\hline$\sum^{1} \frac{0}{4}$ & & S & & $6 \%$ & & $3 \%$ & & $5 \%$ \\
\hline Uు & & 15985 & 159,65 & $-0,2$ & 159,55 & $-0,3$ & 159,55 & $-0,3$ \\
\hline$\frac{4}{n}$ & & & & $3 \%$ & & $9 \%$ & & $\%$ \\
\hline ถ̊ & 5 & 15095 & 159,70 & $-0,25$ & 159,6 & $-0,35$ & 159,55 & $-0,4$ \\
\hline & 0 & & & $6 \%$ & & $2 \%$ & & $5 \%$ \\
\hline & & 16 & 159,7 & $-0,3$ & 159,55 & $-0,45$ & 159,55 & $-0,45$ \\
\hline & & 00 & & $9 \%$ & & $8 \%$ & & $3 \%$ \\
\hline
\end{tabular}


Tabla 28. Estabilidad dimensional de las probetas de mortero de CEM-I con árido 0/4 (Longitud inicial, variación de longitud a 7, 14 y 28 días y variación de la longitud específica). (R) mortero de referencia. (CVT) mortero con la incorporación de cenizas volantes inertizadas, en una proporción igual a un $10 \%$ en peso del árido utilizado.

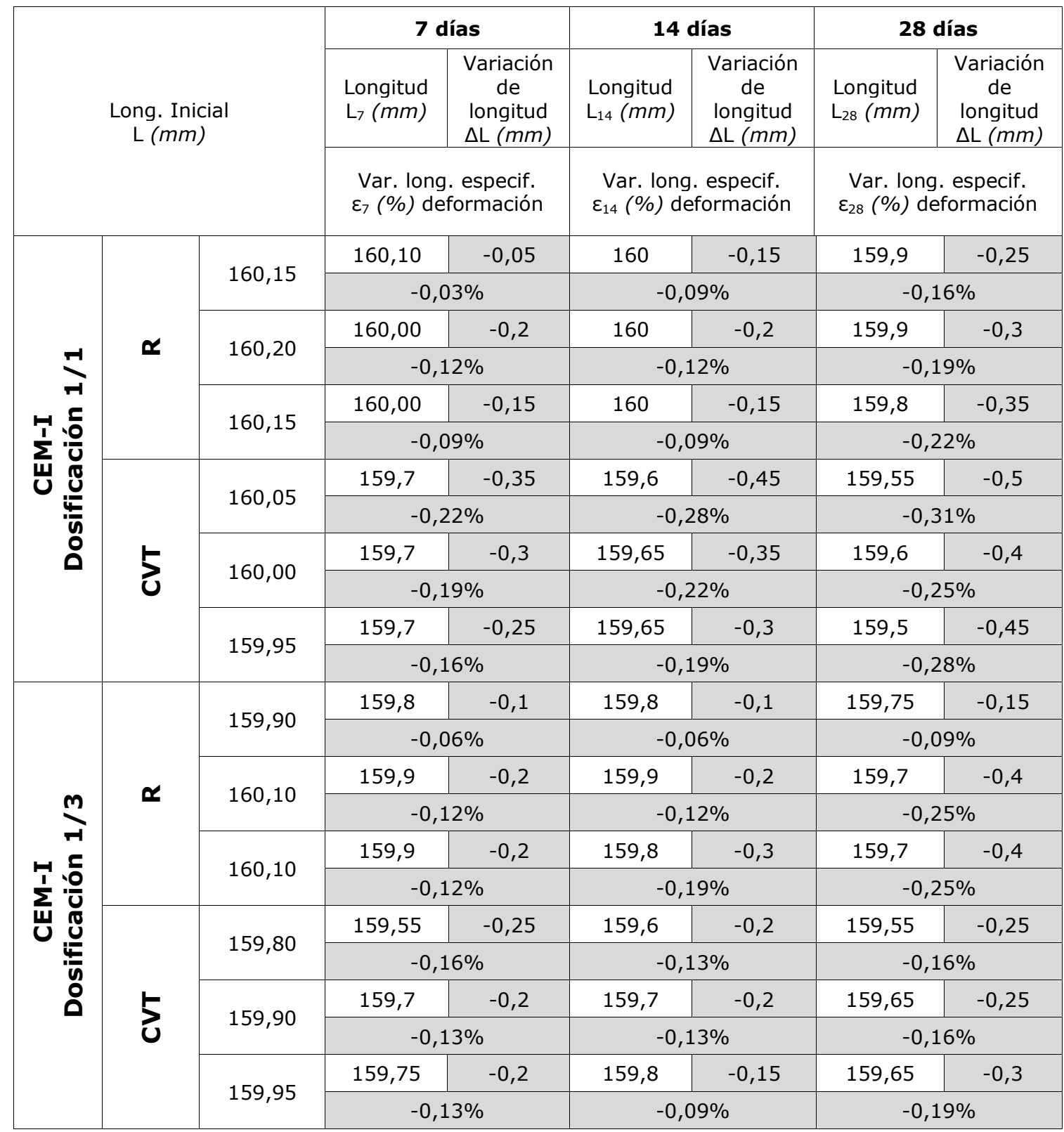




\subsection{Variación de la masa (morteros CEM-I)}

Las tablas 29 y 30 presentan los resultados de masas iniciales (M), variación de las masas a 7, 14 y 28 días $(\Delta M)$ y la variación de la masa específica $\left(m_{x}\right)$, de las probetas de mortero realizadas con CEM-I. Los datos de estas tablas se refieren a morteros ejecutados con áridos de diámetro 0/2 (tabla 29) y 0/4 (tabla 30), y abarcan tanto a morteros de referencia, $(\mathrm{R})$, como a morteros con la incorporación de cenizas volantes inertizadas en forma de carbonatos, en una proporción igual a un $10 \%$ en peso del árido utilizado (CVT).

Los valores medios de los resultados ofrecidos en dichas tablas muestran tendencias similares en todos los casos estudiados, aunque es singular el comportamiento de los morteros con dosificación $1 / 1$ y árido 0/2. En éstos, se revierte la conducta del resto de morteros y se evidencia que aquellos formulados con cenizas volantes de RSU inertizadas tienen una menor pérdida de masa a lo largo del tiempo que sus morteros de referencia.

Merece ser reseñado también que las mayores pérdidas de masa, $8,32 \%$ y $7.61 \%$, se producen en los morteros $1 / 3$ con CVT añadidas, a imitación de los morteros de referencia tradicionales, si bien en este último caso, los valores se reducen a la mitad. A mayor cantidad de finos, se produce una mayor movilización de moléculas de agua y, por lo tanto, una mayor retracción en los morteros. 
Tabla 29. Estabilidad dimensional de las probetas de mortero de CEM-I con árido 0/2 (Masa inicial, variación de masa a 7, 14 y 28 días y variación de la masa específica). (R) mortero de referencia. (CVT) mortero con la incorporación de cenizas volantes inertizadas, en una proporción igual a un $10 \%$ en peso del árido utilizado.

\begin{tabular}{|c|c|c|c|c|c|c|c|c|}
\hline \multirow{3}{*}{\multicolumn{3}{|c|}{ Masa inicial M (g) }} & \multicolumn{2}{|c|}{7 días } & \multicolumn{2}{|c|}{14 días } & \multicolumn{2}{|c|}{28 días } \\
\hline & & & $\begin{array}{c}\text { Masa M } \\
\text { (g) }\end{array}$ & $\begin{array}{c}\text { Variación } \\
\text { de masa } \\
\Delta \mathrm{M}(g)\end{array}$ & $\begin{array}{c}\text { Masa } \mathrm{M}_{1} \\
(\mathrm{~g})\end{array}$ & $\begin{array}{c}\text { Variación } \\
\text { de masa } \\
\Delta \mathrm{M}(g)\end{array}$ & $\begin{array}{c}\text { Masa } \mathrm{M}_{2} \\
(\mathrm{~g})\end{array}$ & $\begin{array}{c}\text { Variación } \\
\text { de masa } \\
\Delta \mathrm{M}(g)\end{array}$ \\
\hline & & & \multicolumn{2}{|c|}{$\begin{array}{c}\text { Variación masa } \\
\text { especifica } \\
\mathrm{m}_{7}(\%) \\
\end{array}$} & \multicolumn{2}{|c|}{$\begin{array}{c}\text { Variación masa } \\
\text { especifica } \\
\mathrm{m}_{14}(\%) \\
\end{array}$} & \multicolumn{2}{|c|}{$\begin{array}{c}\text { Variación masa } \\
\text { especifica } \\
\mathrm{m}_{28}(\%) \\
\end{array}$} \\
\hline \multirow{12}{*}{ 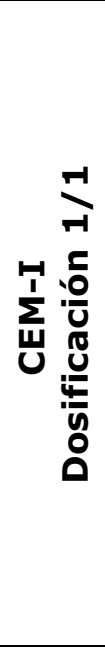 } & \multirow{6}{*}{$\alpha$} & \multirow{2}{*}{556,5} & 530,7 & $-25,8$ & 530,4 & $-26,1$ & 529,1 & $-27,4$ \\
\hline & & & \multicolumn{2}{|c|}{$-4,64 \%$} & \multicolumn{2}{|c|}{$-4,69 \%$} & \multicolumn{2}{|c|}{$-4,92 \%$} \\
\hline & & \multirow{2}{*}{556,4} & 530,6 & $-25,8$ & 530,3 & $-26,1$ & 529,0 & $-27,4$ \\
\hline & & & \multicolumn{2}{|c|}{$-4,64 \%$} & \multicolumn{2}{|c|}{$-4,69 \%$} & \multicolumn{2}{|c|}{$-4,92 \%$} \\
\hline & & \multirow{2}{*}{558,0} & 532,4 & $-25,6$ & 532,1 & $-25,9$ & 530,7 & $-27,3$ \\
\hline & & & \multicolumn{2}{|c|}{$-4,59 \%$} & \multicolumn{2}{|c|}{$-4,64 \%$} & \multicolumn{2}{|c|}{$-4,89 \%$} \\
\hline & & \multirow{2}{*}{525,3} & 509,9 & $-15,4$ & 507,8 & $-17,5$ & 505,9 & $-19,4$ \\
\hline & & & \multicolumn{2}{|c|}{$-2,93 \%$} & \multicolumn{2}{|c|}{$-3,33 \%$} & \multicolumn{2}{|c|}{$-3,69 \%$} \\
\hline & & \multirow{2}{*}{524,4} & 508,6 & $-15,8$ & 506,5 & $-17,9$ & 504,5 & $-19,9$ \\
\hline & & & \multicolumn{2}{|c|}{$-3,01 \%$} & \multicolumn{2}{|c|}{$-3,41 \%$} & \multicolumn{2}{|c|}{$-3,79 \%$} \\
\hline & & \multirow{2}{*}{524,8} & 509,3 & $-15,5$ & 507,2 & $-17,6$ & 504,9 & $-19,9$ \\
\hline & & & \multicolumn{2}{|c|}{$-2,95 \%$} & & $5 \%$ & & $9 \%$ \\
\hline & & 5121 & 515,0 & $-28,1$ & 512,7 & $-30,4$ & 511,8 & $-31,3$ \\
\hline & & גוסדת & & & & $0 \%$ & & $6 \%$ \\
\hline & 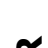 & & 514,7 & $-27,4$ & 512,5 & $-29,6$ & 511,6 & $-30,5$ \\
\hline & 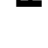 & $34<, 1$ & & & & $6 \%$ & & \\
\hline & & 5410 & 513,8 & $-28,1$ & 511,5 & $-30,4$ & 510,6 & $-31,3$ \\
\hline$\sum \frac{1}{2}$ & & כ, & & & & $1 \%$ & & $8 \%$ \\
\hline U & & 5217 & 485,1 & $-39,6$ & 482,4 & $-42,3$ & 480,9 & $-43,8$ \\
\hline$\frac{4}{n}$ & & 1, & & $5 \%$ & & $6 \%$ & & $5 \%$ \\
\hline ถ̊ & & 5 & 487,0 & $-39,3$ & 484,3 & -42 & 482,3 & -44 \\
\hline & 0 & J & & $7 \%$ & & $8 \%$ & & $6 \%$ \\
\hline & & 5 & 485,4 & $-38,2$ & 482,7 & $-40,9$ & 480,4 & $-43,2$ \\
\hline & & $\int<J, 0$ & & & & $1 \%$ & & $5 \%$ \\
\hline
\end{tabular}


Tabla 30. Estabilidad dimensional de las probetas de mortero de CEM-I con árido 0/4 (Masa inicial, variación de masa a 7,14 y 28 días y variación de la masa específica). (R) mortero de referencia. (CVT) mortero con la incorporación de cenizas volantes inertizadas, en una proporción igual a un $10 \%$ en peso del árido utilizado.

\begin{tabular}{|c|c|c|c|c|c|c|c|c|}
\hline \multirow{3}{*}{\multicolumn{3}{|c|}{ Masa inicial M $(g)$}} & \multicolumn{2}{|c|}{7 días } & \multicolumn{2}{|c|}{14 días } & \multicolumn{2}{|c|}{28 días } \\
\hline & & & $\begin{array}{c}\text { Masa } \mathrm{M}_{7} \\
\quad(g)\end{array}$ & $\begin{array}{c}\text { Variación } \\
\text { de masa } \\
\Delta \mathrm{M}(g)\end{array}$ & $\begin{array}{c}\text { Masa } M_{14} \\
\text { (g) }\end{array}$ & $\begin{array}{c}\text { Variación } \\
\text { de masa } \\
\Delta \mathrm{M}(g)\end{array}$ & $\begin{array}{c}\text { Masa } M_{28} \\
\text { (g) }\end{array}$ & $\begin{array}{c}\text { Variación } \\
\text { de masa } \\
\Delta \mathrm{M}(g)\end{array}$ \\
\hline & & & \multicolumn{2}{|c|}{$\begin{array}{c}\text { Variación masa } \\
\text { especifica } \\
\mathrm{m}_{7}(\%)\end{array}$} & \multicolumn{2}{|c|}{$\begin{array}{c}\text { Variación masa } \\
\text { especifica } \\
\mathrm{m}_{14}(\%)\end{array}$} & \multicolumn{2}{|c|}{$\begin{array}{c}\text { Variación masa } \\
\text { especifica } \\
\mathrm{m}_{28}(\%)\end{array}$} \\
\hline \multirow{12}{*}{ 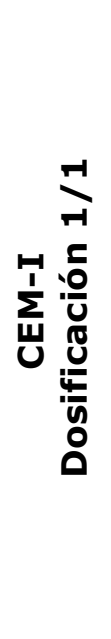 } & \multirow{6}{*}{$\boldsymbol{\simeq}$} & \multirow{2}{*}{554,6} & 543,1 & $-11,5$ & 542,6 & $-12,0$ & 540,8 & $-13,8$ \\
\hline & & & & & & & & \\
\hline & & \multirow{2}{*}{553,9} & 542,5 & $-11,4$ & 541,4 & $-12,5$ & 540,3 & $-13,6$ \\
\hline & & & \multicolumn{2}{|c|}{$-2,06 \%$} & \multicolumn{2}{|c|}{$-2,26 \%$} & \multicolumn{2}{|c|}{$-2,46 \%$} \\
\hline & & \multirow{2}{*}{555,3} & 544,1 & $-11,2$ & 542,6 & $-12,7$ & 542 & $-13,3$ \\
\hline & & & \multicolumn{2}{|c|}{$-2,02 \%$} & \multicolumn{2}{|c|}{$-2,29 \%$} & \multicolumn{2}{|c|}{$-2,40 \%$} \\
\hline & \multirow{6}{*}{5} & \multirow{2}{*}{531,3} & 514,3 & -17 & 512,3 & -19 & 510,3 & -21 \\
\hline & & & \multicolumn{2}{|c|}{$-3,20 \%$} & \multicolumn{2}{|c|}{$-3,58 \%$} & \multicolumn{2}{|c|}{$-3,95 \%$} \\
\hline & & \multirow{2}{*}{532,2} & 514,9 & $-17,3$ & 512,7 & $-19,5$ & 510,7 & $-21,5$ \\
\hline & & & \multicolumn{2}{|c|}{$-3,25 \%$} & \multicolumn{2}{|c|}{$-3,66 \%$} & \multicolumn{2}{|c|}{$-4,04 \%$} \\
\hline & & \multirow{2}{*}{531,3} & 514,4 & $-16,9$ & 512,0 & $-19,3$ & 510,0 & $-21,3$ \\
\hline & & & \multicolumn{2}{|c|}{$-3,18 \%$} & \multicolumn{2}{|c|}{$-3,63 \%$} & \multicolumn{2}{|c|}{$-4,01 \%$} \\
\hline & & & 535,6 & $-23,7$ & 534,3 & -25 & 533,3 & -26 \\
\hline & & בנכבנ & & & & & & \\
\hline & $\sim$ & 56 & 539,3 & $-23,4$ & 538,0 & $-24,7$ & 537 & $-25,7$ \\
\hline m & $\mathbf{L}$ & $50<, 1$ & & & & & & \\
\hline 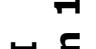 & & 5010 & 538,8 & $-23,0$ & 537,4 & $-24,4$ & 536,4 & $-25,4$ \\
\hline $\bar{\Sigma}: \overline{0}$ & & 301,8 & & & & & & \\
\hline U U & & & 491,3 & -36 & 488,9 & $-38,4$ & 487,2 & $-40,1$ \\
\hline$\frac{\hbar}{n}$ & & ב, & & & & & & \\
\hline 음 & 5 & 5270 & 491,9 & -36 & 489,5 & $-38,4$ & 487,8 & $-40,1$ \\
\hline & ú & J & & & & & & \\
\hline & & & 493,2 & -36 & 490,7 & $-38,5$ & 488,9 & $-40,3$ \\
\hline & & $J \angle J, 2$ & & & & & & \\
\hline
\end{tabular}


Como resumen a este apartado, se puede deducir que la inclusión de CVT en los morteros de CEM-I ensayados, disminuye la deformación media obtenida en aquellas pastas con más finos y de un mayor diámetro. Por el contrario, para reducir la retracción hay que elaborar morteros más ricos en cemento pero con áridos de menor diámetro.

3.3.3.2 Estabilidad dimensional de los morteros elaborados con CEM-II A/P (UNE EN 83831:2010 EX)

\subsection{Variación de la longitud (morteros CEM-II A/P)}

Las tablas 31 y 32 muestran los resultados de los morteros elaborados con cementos CEM-II A/P relativos a las longitudes iniciales en el desmoldado de las probetas $(L)$, la variación de las longitudes a 7,14 y 28 días $(\Delta \mathrm{L})$ y la variación de las longitudes específicas o deformación $\left(\varepsilon_{\mathrm{x}}\right)$ a las mismas edades de fraguado. Los datos de estas tablas se refieren a morteros ejecutados con áridos de diámetro 0/2 (tabla 31) y 0/4 (tabla 32), y abarcan tanto a morteros de referencia, (R), como a morteros con la incorporación de cenizas volantes inertizadas en forma de carbonatos, en una proporción igual a un 10\% en peso del árido utilizado (CVT).

El análisis de los datos revela que el comportamiento de los morteros CEM-II A/P en dosificación $0 / 2$ con incorporación de CVT es muy similar, obteniéndose valores de $0,19 \%$ y $0,20 \%$ para aquellos morteros elaborados con áridos de diámetro 0/2 y 0/4 respectivamente, obteniéndose un valor de retracción más cercano al de los morteros de referencia con los morteros de dosificación $1 / 1$.

Los morteros con áridos $0 / 4$ y cenizas volantes inertizadas añadidas, presentan unos valores de retracción finales casi idénticos a los de los morteros de referencia $(0,14 \%$ y $0,06 \%$ para las muestras con dosificaciones $1 / 1$ y $1 / 3$, respectivamente). De éstos, son especialmente reseñables los datos de los morteros con dosificación $1 / 1$, ya que no presentan grandes oscilaciones de retracción a lo largo de la vida del mortero y mejoran a los de referencia desde edades tempranas (14 días). 
A pesar de lo anteriormente reflejado, los mejores resultados de retracción a 28 días de todos los morteros elaborados con CEM-II A/P con la incorporación de cenizas volantes inertizadas en una proporción de un 10\% en peso de los áridos, los presentan las probetas realizadas con áridos $0 / 4$ y dosificación $1 / 1$. El valor final, $0,06 \%$, es el mismo que reflejan los morteros de referencia de esta dosificación.

En resumen, este tipo de morteros presentan menor deformación cuanto mayor es el diámetro del árido, correspondiendo el mejor dato al ejemplo en el que hay una mayor cantidad de áridos en la mezcla sin influir en el resultado final la existencia o no de CVT. 
Tabla 31. Estabilidad dimensional de las probetas de mortero de CEM-II A/P con árido 0/2 (Longitud inicial, variación de longitud a 7, 14 y 28 días y variación de la longitud específica). (R) mortero de referencia. (CVT) mortero con la incorporación de cenizas volantes inertizadas en una proporción de un $10 \%$ en peso de los áridos.

\begin{tabular}{|c|c|c|c|c|c|c|c|c|}
\hline \multirow{3}{*}{\multicolumn{3}{|c|}{\begin{tabular}{|c|} 
\\
Long. Inicial \\
$L(\mathrm{~mm})$
\end{tabular}}} & \multicolumn{2}{|c|}{7 días } & \multicolumn{2}{|c|}{14 días } & \multicolumn{2}{|c|}{28 días } \\
\hline & & & $\begin{array}{l}\text { Longitud } \\
\mathrm{L}_{7}(\mathrm{~mm})\end{array}$ & $\begin{array}{c}\text { Variación } \\
\text { de } \\
\text { longitud } \\
\Delta \mathrm{L}(\mathrm{mm})\end{array}$ & $\begin{array}{l}\text { Longitud } \\
\mathrm{L}_{14}(\mathrm{~mm})\end{array}$ & $\begin{array}{c}\text { Variación } \\
\text { de } \\
\text { longitud } \\
\Delta \mathrm{L}(\mathrm{mm})\end{array}$ & $\begin{array}{l}\text { Longitud } \\
\mathrm{L}_{28}(\mathrm{~mm})\end{array}$ & $\begin{array}{c}\text { Variación } \\
\text { de } \\
\text { longitud } \\
\Delta \mathrm{L}(\mathrm{mm})\end{array}$ \\
\hline & & & \multicolumn{2}{|c|}{$\begin{array}{l}\text { Var. long. especif. } \\
\varepsilon_{7}(\%) \text { deformación }\end{array}$} & \multicolumn{2}{|c|}{$\begin{array}{l}\text { Var. long. especif. } \\
\varepsilon_{14}(\%) \text { deformación }\end{array}$} & \multicolumn{2}{|c|}{$\begin{array}{l}\text { Var. long. especif. } \\
\varepsilon_{28}(\%) \text { deformación }\end{array}$} \\
\hline \multirow{12}{*}{ 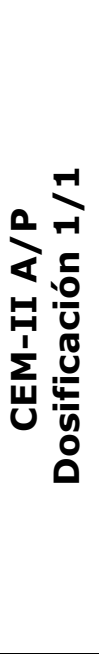 } & \multirow{6}{*}{$\alpha$} & \multirow{2}{*}{159,65} & 159,5 & $-0,15$ & 159,45 & $-0,2$ & 159,45 & $-0,2$ \\
\hline & & & \multicolumn{2}{|c|}{$-0,09 \%$} & \multicolumn{2}{|c|}{$-0,13 \%$} & \multicolumn{2}{|c|}{$-0,13 \%$} \\
\hline & & \multirow{2}{*}{159,55} & 159,4 & $-0,15$ & 159,4 & $-0,15$ & 159,4 & $-0,15$ \\
\hline & & & \multicolumn{2}{|c|}{$-0,09 \%$} & \multicolumn{2}{|c|}{$-0,09 \%$} & \multicolumn{2}{|c|}{$-0,09 \%$} \\
\hline & & \multirow{2}{*}{159,60} & 159,35 & $-0,25$ & 159,3 & $-0,3$ & 159,3 & $-0,3$ \\
\hline & & & \multicolumn{2}{|c|}{$-0,16 \%$} & \multicolumn{2}{|c|}{$-0,19 \%$} & \multicolumn{2}{|c|}{$-0,19 \%$} \\
\hline & \multirow{6}{*}{$\sum_{3}$} & \multirow{2}{*}{160,05} & 159,85 & $-0,2$ & 159,85 & $-0,2$ & 159,75 & $-0,3$ \\
\hline & & & \multicolumn{2}{|c|}{$-0,12 \%$} & \multicolumn{2}{|c|}{$-0,12 \%$} & \multicolumn{2}{|c|}{$-0,19 \%$} \\
\hline & & \multirow{2}{*}{160,10} & 159,80 & $-0,3$ & 159,90 & $-0,2$ & 159,8 & $-0,3$ \\
\hline & & & \multicolumn{2}{|c|}{$-0,19 \%$} & \multicolumn{2}{|c|}{$-0,12 \%$} & \multicolumn{2}{|c|}{$-0,19 \%$} \\
\hline & & \multirow{2}{*}{160,20} & 159,95 & $-0,25$ & 159,9 & $-0,3$ & 159,9 & $-0,3$ \\
\hline & & & & $\%$ & & $\%$ & & $9 \%$ \\
\hline & & 16 & 160,15 & $-0,1$ & 160,15 & $-0,1$ & 160,15 & $-0,1$ \\
\hline & & $100,1<0$ & & & & $5 \%$ & & $5 \%$ \\
\hline & $\boldsymbol{\alpha}$ & 16030 & 160,15 & $-0,15$ & 160,15 & $-0,15$ & 160,1 & $-0,2$ \\
\hline & 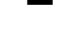 & טסו, & & & & $\%$ & & $2 \%$ \\
\hline$>a$ & & 16020 & 160,15 & $-0,05$ & 160,2 & 0 & 160,05 & $-0,15$ \\
\hline 봄 说 & & 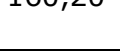 & & & & & & $9 \%$ \\
\hline$\sum 0$ & & 16 & 159,80 & $-0,20$ & 159,80 & $-0,2$ & 159,7 & $-0,3$ \\
\hline U & & & & $\%$ & & $2 \%$ & & $9 \%$ \\
\hline ด & 5 & 16010 & 159,80 & $-0,30$ & 159,80 & $-0,3$ & 159,7 & $-0,4$ \\
\hline & U & 100 & & $\%$ & & $\%$ & & $5 \%$ \\
\hline & & 160.15 & 159,95 & $-0,20$ & 159,90 & $-0,25$ & 159,9 & $-0,25$ \\
\hline & & (1) & & $\%$ & & $5 \%$ & & $5 \%$ \\
\hline
\end{tabular}


Tabla 32. Estabilidad dimensional de las probetas de mortero de CEM-II A/P con árido 0/4 (Longitud inicial, variación de longitud a 7, 14 y 28 días y variación de la longitud específica). (R) mortero de referencia. (CVT) mortero con la incorporación de cenizas volantes inertizadas en una proporción de un $10 \%$ en peso de los áridos.

\begin{tabular}{|c|c|c|c|c|c|c|c|c|}
\hline & & & \multicolumn{2}{|c|}{7 días } & \multicolumn{2}{|c|}{14 días } & \multicolumn{2}{|c|}{28 días } \\
\hline & \multirow{2}{*}{\multicolumn{2}{|c|}{$\begin{array}{l}\text { Long. Inicial } \\
\qquad \text { ( }(\mathrm{mm})\end{array}$}} & $\begin{array}{l}\text { Longitud } \\
\mathrm{L}_{7}(\mathrm{~mm})\end{array}$ & $\begin{array}{c}\text { Variación } \\
\text { de } \\
\text { longitud } \\
\Delta \mathrm{L}(\mathrm{mm})\end{array}$ & $\begin{array}{l}\text { Longitud } \\
\mathrm{L}_{14}(\mathrm{~mm})\end{array}$ & $\begin{array}{c}\text { Variación } \\
\text { de } \\
\text { longitud } \\
\Delta \mathrm{L}(\mathrm{mm})\end{array}$ & $\begin{array}{l}\text { Longitud } \\
\mathrm{L}_{28}(\mathrm{~mm})\end{array}$ & $\begin{array}{c}\text { Variación } \\
\text { de } \\
\text { longitud } \\
\Delta \mathrm{L}(\mathrm{mm})\end{array}$ \\
\hline & & & \multicolumn{2}{|c|}{$\begin{array}{l}\text { Var. long. especif. } \\
\varepsilon_{7}(\%) \text { deformación }\end{array}$} & \multicolumn{2}{|c|}{$\begin{array}{l}\text { Var. long. especif. } \\
\varepsilon_{14}(\%) \text { deformación }\end{array}$} & \multicolumn{2}{|c|}{$\begin{array}{l}\text { Var. long. especif. } \\
\varepsilon_{28}(\%) \text { deformación }\end{array}$} \\
\hline \multirow{12}{*}{ 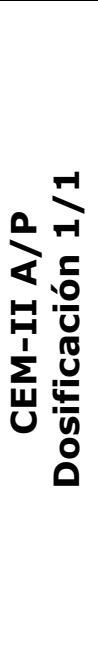 } & \multirow{6}{*}{$\propto$} & \multirow{2}{*}{159,65} & 159,4 & $-0,25$ & 159,45 & $-0,2$ & 159,5 & $-0,15$ \\
\hline & & & \multicolumn{2}{|c|}{$-0,16 \%$} & \multicolumn{2}{|c|}{$-0,13 \%$} & \multicolumn{2}{|c|}{$-0,09 \%$} \\
\hline & & \multirow{2}{*}{159,70} & 159,55 & $-0,15$ & 159,55 & $-0,15$ & 159,45 & $-0,25$ \\
\hline & & & \multicolumn{2}{|c|}{$-0,09 \%$} & \multicolumn{2}{|c|}{$-0,09 \%$} & \multicolumn{2}{|c|}{$-0,16 \%$} \\
\hline & & \multirow{2}{*}{159,80} & 159,65 & $-0,15$ & 159,5 & $-0,3$ & 159,5 & $-0,3$ \\
\hline & & & \multicolumn{2}{|c|}{$-0,09 \%$} & \multicolumn{2}{|c|}{$-0,19 \%$} & \multicolumn{2}{|c|}{$-0,19 \%$} \\
\hline & & \multirow{2}{*}{159,90} & 159,75 & $-0,15$ & 159,7 & $-0,2$ & 159,7 & $-0,2$ \\
\hline & & & \multicolumn{2}{|c|}{$-0,09 \%$} & \multicolumn{2}{|c|}{$-0,13 \%$} & \multicolumn{2}{|c|}{$-0,13 \%$} \\
\hline & $E$ & \multirow{2}{*}{160,00} & 159,8 & $-0,2$ & 159,8 & $-0,2$ & 159,75 & $-0,25$ \\
\hline & 0 & & \multicolumn{2}{|c|}{$-0,12 \%$} & \multicolumn{2}{|c|}{$-0,12 \%$} & \multicolumn{2}{|c|}{$-0,16 \%$} \\
\hline & & \multirow{2}{*}{160,10} & 159,9 & $-0,2$ & 159,9 & $-0,2$ & 159,9 & $-0,2$ \\
\hline & & & & & & $2 \%$ & & $2 \%$ \\
\hline & & 16000 & 159,9 & $-0,1$ & 159,8 & $-0,2$ & 159,9 & $-0,1$ \\
\hline & & (1) & & $\%$ & & $2 \%$ & & $5 \%$ \\
\hline & $\widetilde{N}$ & 150 م 15 & 160 & 0,1 & 159,8 & $-0,1$ & 159,85 & $-0,05$ \\
\hline & 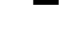 & טנונדע & & & & $6 \%$ & & $3 \%$ \\
\hline$\sum r$ & & & 159,9 & $-0,1$ & 159,85 & $-0,15$ & 159,85 & $-0,15$ \\
\hline 본 은 & & 100,00 & & & & $9 \%$ & & $9 \%$ \\
\hline$\sum \delta$ & & 15075 & 159,45 & $-0,3$ & 159,3 & $-0,45$ & 159,6 & $-0,15$ \\
\hline U " & & & & & & $8 \%$ & & $9 \%$ \\
\hline ถ̊ & $\rightarrow$ & 15065 & 159,45 & $-0,2$ & 159,7 & 0,05 & 159,65 & 0 \\
\hline & 0 & כט,בעد & & & & $3 \%$ & & \\
\hline & & $15 f_{0}$ & 159,5 & $-0,2$ & 159,4 & $-0,3$ & 159,55 & $-0,15$ \\
\hline & & טיונדעי & -0 & & & $9 \%$ & & $9 \%$ \\
\hline
\end{tabular}




\subsection{Variación de la masa (morteros CEM-II A/P)}

Las tablas 33 y 34 presentan los resultados de masas iniciales (M), variación de las masas a 7, 14 y 28 días $(\Delta M)$ y la variación de la masa específica $\left(\mathrm{m}_{\mathrm{x}}\right)$, de las probetas de mortero realizadas con CEM-II A/P. Los datos de estas tablas se refieren a morteros ejecutados con áridos de diámetro 0/2 (tabla 33) y 0/4 (tabla 34), y abarcan tanto a morteros de referencia, $(R)$, como a morteros con la incorporación de cenizas volantes inertizadas en forma de carbonatos, en una proporción de un $10 \%$ en peso de los áridos (CVT).

Los valores medios de los resultados ofrecidos en dichas tablas muestran tendencias muy similares en todos los ejemplos ensayados pero con resultados nítidos: La incorporación de CVT a la matriz de mortero produce mayores variaciones de la masa si se comparan con los morteros de referencia. Dentro de este comportamiento tan homogéneo, los mejores resultados se consiguen, tanto en cifras relativas, como en desviación con respecto a los morteros de referencia, en los morteros con dosificación 1/1 y diámetro del árido $0 / 4$, en los que el valor obtenido, $-4,48 \%$, no es sólo el mejor de los de todos los morteros CEM-II A/P con incorporación de CVT, sino que, éste, consigue la menor desviación, en torno a un 15\%, con relación a su mortero de referencia.

La variación de la masa específica en dosificaciones $1 / 1$ y $1 / 3$ presenta unos esquemas de comportamiento muy similares, aunque en la dosificación 1/3 los valores obtenidos son prácticamente el doble que los de $1 / 1$.

En resumen, los morteros CEM-II A/P con incorporación de CVT tienen una mejor estabilidad dimensional cuanto mayor es el diámetro del árido utilizado, considerándose que la dosificación $1 / 1$ es la que ofrece un comportamiento más homogéneo en cuanto a retracción y variación de masa, en comparación con las mismas prestaciones de los morteros de referencia. 
Tabla 33. Estabilidad dimensional de las probetas de mortero de CEM-II A/P con árido $0 / 2$ (Masa inicial, variación de masa a 7, 14 y 28 días y variación de la masa específica). (R) mortero de referencia. (CVT) mortero con la incorporación de cenizas volantes inertizadas en una proporción de un $10 \%$ en peso de los áridos.

\begin{tabular}{|c|c|c|c|c|c|c|c|c|}
\hline & & & \multicolumn{2}{|c|}{7 días } & \multicolumn{2}{|c|}{14 días } & \multicolumn{2}{|c|}{28 días } \\
\hline \multirow{2}{*}{\multicolumn{3}{|c|}{ Masa inicial M $(g)$}} & $\begin{array}{c}\text { Masa } M_{7} \\
(g)\end{array}$ & $\begin{array}{c}\text { Variación } \\
\text { de masa } \\
\Delta \mathrm{M}(g)\end{array}$ & $\begin{array}{c}\text { Masa } M_{14} \\
\text { (g) }\end{array}$ & $\begin{array}{c}\text { Variación } \\
\text { de masa } \\
\Delta \mathrm{M}(g)\end{array}$ & $\begin{array}{c}\text { Masa } M_{28} \\
\text { (g) }\end{array}$ & $\begin{array}{c}\text { Variación } \\
\text { de masa } \\
\Delta \mathrm{M}(\mathrm{g})\end{array}$ \\
\hline & & & \multicolumn{2}{|c|}{$\begin{array}{c}\text { Variación masa } \\
\text { especifica } \\
\mathrm{m}_{7}(\%)\end{array}$} & \multicolumn{2}{|c|}{$\begin{array}{c}\text { Variación masa } \\
\text { especifica } \\
\mathrm{m}_{14}(\%)\end{array}$} & \multicolumn{2}{|c|}{$\begin{array}{c}\text { Variación masa } \\
\text { especifica } \\
\mathrm{m}_{28}(\%)\end{array}$} \\
\hline \multirow{12}{*}{ 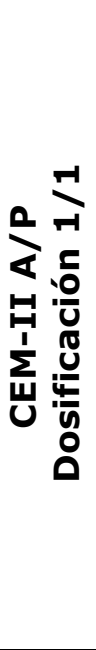 } & \multirow{6}{*}{$\boldsymbol{\alpha}$} & \multirow{2}{*}{558,5} & 540,4 & $-18,1$ & 538,6 & $-19,9$ & 537,2 & $-21,3$ \\
\hline & & & \multicolumn{2}{|c|}{$-3,24 \%$} & \multicolumn{2}{|c|}{$-3,56 \%$} & \multicolumn{2}{|c|}{$-3,81 \%$} \\
\hline & & \multirow{2}{*}{559,6} & 541 & $-18,6$ & 539,3 & $-20,3$ & 537,9 & $-21,7$ \\
\hline & & & \multicolumn{2}{|c|}{$-3,32 \%$} & \multicolumn{2}{|c|}{$-3,63 \%$} & \multicolumn{2}{|c|}{$-3,88 \%$} \\
\hline & & \multirow{2}{*}{564,0} & 546,3 & $-17,7$ & 544,5 & $-19,5$ & 543,3 & $-20,7$ \\
\hline & & & \multicolumn{2}{|c|}{$-3,14 \%$} & \multicolumn{2}{|c|}{$-3,46 \%$} & \multicolumn{2}{|c|}{$-3,67 \%$} \\
\hline & & \multirow{2}{*}{533,7} & 511,9 & $-21,8$ & 508,0 & $-25,7$ & 506,8 & $-26,9$ \\
\hline & & & \multicolumn{2}{|c|}{$-4,08 \%$} & \multicolumn{2}{|c|}{$-4,82 \%$} & \multicolumn{2}{|c|}{$-5,04 \%$} \\
\hline & & \multirow{2}{*}{533,5} & 511,1 & $-22,4$ & 507,5 & -26 & 506,4 & $-27,1$ \\
\hline & & & \multicolumn{2}{|c|}{$-4,20 \%$} & \multicolumn{2}{|c|}{$-4,87 \%$} & \multicolumn{2}{|c|}{$-5,08 \%$} \\
\hline & & \multirow{2}{*}{536,2} & 514,3 & $-21,9$ & 510,6 & $-25,6$ & 509,5 & $-26,7$ \\
\hline & & & \multicolumn{2}{|c|}{$-4,08 \%$} & & $7 \%$ & & $8 \%$ \\
\hline & & 5500 & 511,8 & $-39,1$ & 510 & $-40,9$ & 509,1 & $-41,8$ \\
\hline & & ע, & & $0 \%$ & & $2 \%$ & & $9 \%$ \\
\hline & $\boldsymbol{\alpha}$ & 5523 & 512,1 & $-40,2$ & 510,4 & $-41,9$ & 509,4 & $-42,9$ \\
\hline & 山 & $30<, 3$ & & $8 \%$ & & $9 \%$ & & $7 \%$ \\
\hline$\sum^{2}=$ & & 5517 & 512,6 & $-39,1$ & 510,7 & -41 & 509,9 & $-41,8$ \\
\hline 봅 웅 & & 'ונדנJ & & $9 \%$ & & $3 \%$ & & $8 \%$ \\
\hline$\sum$ & & 5287 & 485,7 & $-43,0$ & 477,8 & $-50,9$ & 477 & $-51,7$ \\
\hline 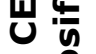 & & $\int<0,1$ & & $3 \%$ & & $3 \%$ & & $8 \%$ \\
\hline ถ̊ & & 5306 & 487,5 & $-43,1$ & 479,6 & -51 & 478,7 & $-51,9$ \\
\hline & & ט, & & $2 \%$ & & $1 \%$ & & $8 \%$ \\
\hline & & 5288 & 483,6 & $-45,2$ & 479,0 & $-49,8$ & 478,1 & $-50,7$ \\
\hline & & $3<0,0$ & & $5 \%$ & & $2 \%$ & & $9 \%$ \\
\hline
\end{tabular}


Tabla 34. Estabilidad dimensional de las probetas de mortero de CEM-II A/P con árido 0/4 (Masa inicial, variación de masa a 7, 14 y 28 días y variación de la masa específica). (R) mortero de referencia. (CVT) mortero con la incorporación de cenizas volantes inertizadas en una proporción de un $10 \%$ en peso de los áridos.

\begin{tabular}{|c|c|c|c|c|c|c|c|c|}
\hline \multirow{3}{*}{\multicolumn{3}{|c|}{ Masa inicial M $(g)$}} & \multicolumn{2}{|c|}{7 días } & \multicolumn{2}{|c|}{14 días } & \multicolumn{2}{|c|}{28 días } \\
\hline & & & $\begin{array}{c}\text { Masa M } \\
(g)\end{array}$ & $\begin{array}{c}\text { Variación } \\
\text { de masa } \\
\Delta \mathrm{M}(g)\end{array}$ & $\begin{array}{c}\text { Masa } M_{14} \\
\text { (g) }\end{array}$ & $\begin{array}{l}\text { Variación } \\
\text { de masa } \\
\Delta \mathrm{M}(g)\end{array}$ & $\begin{array}{c}\text { Masa } M_{28} \\
(g)\end{array}$ & $\begin{array}{c}\text { Variación } \\
\text { de masa } \\
\Delta \mathrm{M}(g)\end{array}$ \\
\hline & & & \multicolumn{2}{|c|}{$\begin{array}{c}\text { Variación masa } \\
\text { especifica } \\
\mathrm{m}_{7}(\%)\end{array}$} & \multicolumn{2}{|c|}{$\begin{array}{c}\text { Variación masa } \\
\text { especifica } \\
\mathrm{m}_{14}(\%)\end{array}$} & \multicolumn{2}{|c|}{$\begin{array}{c}\text { Variación masa } \\
\text { especifica } \\
\mathrm{m}_{28}(\%)\end{array}$} \\
\hline \multirow{12}{*}{ 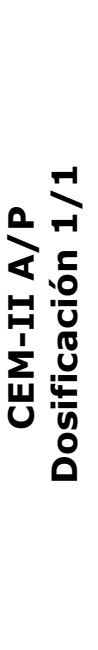 } & \multirow{6}{*}{$\boldsymbol{\alpha}$} & \multirow{2}{*}{564,5} & 545,8 & $-18,7$ & 544 & $-20,5$ & 542,7 & $-21,8$ \\
\hline & & & \multicolumn{2}{|c|}{$-3,31 \%$} & \multicolumn{2}{|c|}{$-3,63 \%$} & \multicolumn{2}{|c|}{$-3,86 \%$} \\
\hline & & \multirow{2}{*}{564,1} & 544,9 & $-19,2$ & 543,2 & $-20,9$ & 541,8 & $-22,3$ \\
\hline & & & \multicolumn{2}{|c|}{$-3,40 \%$} & \multicolumn{2}{|c|}{$-3,71 \%$} & \multicolumn{2}{|c|}{$-3,95 \%$} \\
\hline & & \multirow{2}{*}{568,1} & 549,4 & $-18,7$ & 547,6 & $-20,5$ & 546,3 & $-21,8$ \\
\hline & & & \multicolumn{2}{|c|}{$-3,29 \%$} & \multicolumn{2}{|c|}{$-3,61 \%$} & \multicolumn{2}{|c|}{$-3,84 \%$} \\
\hline & & \multirow{2}{*}{543,3} & 522,1 & $-21,2$ & 520,7 & $-22,6$ & 518,9 & $-24,4$ \\
\hline & & & \multicolumn{2}{|c|}{$-3,90 \%$} & \multicolumn{2}{|c|}{$-4,16 \%$} & \multicolumn{2}{|c|}{$-4,49 \%$} \\
\hline & & \multirow{2}{*}{545,4} & 524,2 & $-21,2$ & 522,8 & $-22,6$ & 520,9 & $-24,5$ \\
\hline & & & \multicolumn{2}{|c|}{$-3,89 \%$} & \multicolumn{2}{|c|}{$-4,14 \%$} & \multicolumn{2}{|c|}{$-4,49 \%$} \\
\hline & & \multirow{2}{*}{540,5} & 519,7 & $-20,8$ & 518,2 & $-22,3$ & 516,4 & $-24,1$ \\
\hline & & & \multicolumn{2}{|c|}{$-3,85 \%$} & & $3 \%$ & & $5 \%$ \\
\hline & & 5610 & 526,5 & $-34,5$ & 524,8 & $-36,2$ & 525,1 & $-35,9$ \\
\hline & & ( & & $5 \%$ & & $5 \%$ & & $\%$ \\
\hline & 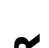 & 561 & 525,3 & $-36,1$ & 523,7 & $-37,7$ & 525,6 & $-35,8$ \\
\hline$m$ & 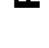 & 501,4 & & $3 \%$ & & $2 \%$ & & $3 \%$ \\
\hline 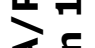 & & & 522,3 & $-34,9$ & 520,7 & $-36,5$ & 521,7 & $-35,5$ \\
\hline 분 은 & & 2, דנד & & & & $5 \%$ & & $7 \%$ \\
\hline$\sum \delta$ & & 5210 & 490,0 & $-44,8$ & 488,8 & -46 & 487,4 & $-47,4$ \\
\hline U & & & & $3 \%$ & & $\%$ & & $5 \%$ \\
\hline ถ̊ & $F$ & 5306 & 494,7 & $-44,9$ & 493,6 & -46 & 492,3 & $-47,3$ \\
\hline & & & & $2 \%$ & & $2 \%$ & -8, & $7 \%$ \\
\hline & & 5306 & 494,5 & $-44,1$ & 493,5 & $-45,1$ & 492,1 & $-46,5$ \\
\hline & & 538,0 & & $9 \%$ & & $7 \%$ & -8, & $3 \%$ \\
\hline
\end{tabular}


3.3.3.3 Estabilidad dimensional de los morteros elaborados con CAC (UNE EN 83831:2010 EX)

\subsection{Variación de la longitud (morteros CAC)}

Las tablas 35 y 36 muestran los resultados de los morteros elaborados con cementos CAC relativos a las longitudes iniciales en el desmoldado de las probetas $(L)$, la variación de las longitudes a 7,14 y 28 días $(\Delta L)$ y la variación de las longitudes específicas o deformación $\left(\varepsilon_{\mathrm{x}}\right)$, a las mismas edades de fraguado. Los datos de estas tablas se refieren a morteros ejecutados con áridos de diámetro $0 / 2$ (tabla 35) y 0/4 (tabla 36), y abarcan tanto a morteros de referencia, $(R)$, como a morteros la incorporación de cenizas volantes inertizadas en forma de carbonatos, en una proporción de un $10 \%$ en peso de los áridos (CVT).

El estudio de los resultados ofrece datos muy positivos en los análisis efectuados sobre las probetas con dosificaciones $1 / 1$ y diámetros de árido $0 / 2$. Las deformaciones finales en los morteros con adición de CVT son prácticamente nulas, ya que muestran valores de retracción de $-0,04 \%$, mejorando en un $25 \%$ a los de los morteros de referencia.

Los morteros con dosificación $1 / 3$ y tamaño del árido 0/4 también ofrecen buenos resultados finales $(-0,09 \%)$, si bien en este caso no consiguen mejorar los valores de referencia $(-0,07)$.

Mención aparte merecen los morteros con adición de CVT, dosificación $1 / 1$ y diámetro del árido 0/4. En ellos, se produce la única deformación por expansión sufrida en todos los morteros ensayados para la realización de esta investigación. La media de los datos muestra que las probetas de este tipo de morteros tienen un aumento de longitud de un 0,13\%. (Aubert et al., 2004), han demostrado que, al igual que la mayoría de residuos sólidos urbanos, las cenizas volantes contienen importantes cantidades de aluminio metálico que pueden influir en la expansión de productos basados en la hidratación del cemento. Esta deformación puede ser debida a la reacción del agua de amasado con el aluminio en las condiciones alcalinas derivadas del fraguado del mortero. Estos mismos problemas han sido estudiados 
previamente por diversos autores tanto en lo relacionado con cenizas de hogar (Pera et al., 1997; Quenee et al., 2000; Pecqueur et al., 2001), como con cenizas volantes de la incineración de residuos sólidos urbanos (Fernández, 2000; Morel et al., 2001; Guerrero et al., 2000; Chan et al., 2000).

Por otro lado, las cenizas volantes originales tienen una gran cantidad de sulfatos, lo cual podía ser un problema si son utilizadas en productos derivados del cemento. De hecho, este tipo de productos deben estar libres de sulfatos con la intención de prevenir formaciones retardadas de etringita lo cual podría producir expansividad en los morteros. En el presente caso, los valores de deformación son mínimos, y los análisis DRX de estos morteros revelan la no existencia de etringita retardada la cual conllevaría una importante degradación de la estructura interna que provocaría una elevada pérdida de las resistencias mecánicas del material algo que, como se verá en el apartado de resistencias mecánicas, no ocurre. 
Tabla 35. Estabilidad dimensional de las probetas de mortero de CAC con árido 0/2 (Masa inicial, variación de masa a 7, 14 y 28 días y variación de la masa específica). (R) mortero de referencia. (CVT) mortero con la incorporación de cenizas volantes inertizadas en una proporción de un $10 \%$ en peso de los áridos.

\begin{tabular}{|c|c|c|c|c|c|c|c|c|}
\hline \multirow{3}{*}{ 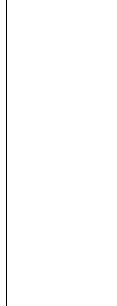 } & & & \multicolumn{2}{|c|}{7 días } & \multicolumn{2}{|c|}{14 días } & \multicolumn{2}{|c|}{28 días } \\
\hline & \multirow{2}{*}{\multicolumn{2}{|c|}{$\begin{array}{l}\text { Long. Inicial } \\
\text { L ( } \mathrm{mm})\end{array}$}} & $\begin{array}{l}\text { Longitud } \\
\mathrm{L}_{7}(\mathrm{~mm})\end{array}$ & $\begin{array}{c}\text { Variación } \\
\text { de } \\
\text { longitud } \\
\Delta \mathrm{L}(\mathrm{mm})\end{array}$ & $\begin{array}{l}\text { Longitud } \\
\mathrm{L}_{14}(\mathrm{~mm})\end{array}$ & $\begin{array}{l}\text { Variación } \\
\text { de } \\
\text { longitud } \\
\Delta \mathrm{L}(\mathrm{mm})\end{array}$ & $\begin{array}{l}\text { Longitud } \\
\mathrm{L}_{28}(\mathrm{~mm})\end{array}$ & $\begin{array}{l}\text { Variación } \\
\text { de longitud } \\
\Delta \mathrm{L}(\mathrm{mm})\end{array}$ \\
\hline & & & \multicolumn{2}{|c|}{$\begin{array}{l}\text { Var. long. especif. } \\
\varepsilon_{7}(\%) \text { deformación }\end{array}$} & \multicolumn{2}{|c|}{$\begin{array}{l}\text { Var. long. especif. } \\
\varepsilon_{14}(\%) \text { deformación }\end{array}$} & \multicolumn{2}{|c|}{$\begin{array}{l}\text { Var. long. especif. } \\
\varepsilon_{28}(\%) \text { deformación }\end{array}$} \\
\hline \multirow{12}{*}{ 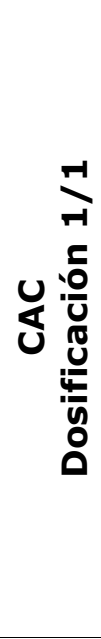 } & \multirow{6}{*}{$\propto$} & \multirow{2}{*}{159,55} & 159,60 & 0,05 & 159,45 & $-0,1$ & 159,45 & $-0,1$ \\
\hline & & & \multicolumn{2}{|c|}{$0,03 \%$} & \multicolumn{2}{|c|}{$-0,06 \%$} & \multicolumn{2}{|c|}{$-0,06 \%$} \\
\hline & & \multirow{2}{*}{159,60} & 159,50 & $-0,1$ & 159,5 & $-0,1$ & 159,5 & $-0,1$ \\
\hline & & & \multicolumn{2}{|c|}{$-0,06 \%$} & \multicolumn{2}{|c|}{$-0,06 \%$} & \multicolumn{2}{|c|}{$-0,06 \%$} \\
\hline & & \multirow{2}{*}{159,60} & 159,50 & $-0,1$ & 159,5 & $-0,1$ & 159,55 & $-0,05$ \\
\hline & & & \multicolumn{2}{|c|}{$-0,06 \%$} & \multicolumn{2}{|c|}{$-0,06 \%$} & \multicolumn{2}{|c|}{$-0,03 \%$} \\
\hline & \multirow{6}{*}{$\frac{5}{3}$} & \multirow{2}{*}{159,75} & 159,60 & $-0,15$ & 159,6 & $-0,15$ & 159,65 & $-0,1$ \\
\hline & & & \multicolumn{2}{|c|}{$-0,09 \%$} & \multicolumn{2}{|c|}{$-0,09 \%$} & \multicolumn{2}{|c|}{$-0,06 \%$} \\
\hline & & \multirow{2}{*}{159,80} & 159,60 & $-0,2$ & 159,5 & $-0,3$ & 159,7 & $-0,1$ \\
\hline & & & \multicolumn{2}{|c|}{$-0,13 \%$} & \multicolumn{2}{|c|}{$-0,19 \%$} & \multicolumn{2}{|c|}{$-0,06 \%$} \\
\hline & & 15005 & 159,70 & $-0,15$ & 159,65 & $-0,2$ & 159,85 & 0 \\
\hline & & כס,ענו & & & & & & $0 \%$ \\
\hline & & & 159,80 & $-0,1$ & 159,9 & 0 & 159,9 & 0 \\
\hline & & טכ,ענו & & & & & & $0 \%$ \\
\hline & $\widetilde{N}$ & 150 & 159,75 & $-0,2$ & 159,8 & $-0,15$ & 159,85 & $-0,1$ \\
\hline & $\mathbf{W}$ & 159,95 & & & & & & $6 \%$ \\
\hline$\vec{c}$ & & 15085 & 159,85 & 0 & 159,8 & $-0,05$ & 159,85 & 0 \\
\hline ט 은 & & 159,85 & & & & & & $0 \%$ \\
\hline 08 & & $10+2>$ & 159,40 & $-0,1$ & 159,4 & $-0,15$ & 159,4 & $-0,1$ \\
\hline$\frac{4}{n}$ & & & & & & & & $6 \%$ \\
\hline 요 & & $10+2$ & 159,40 & $-0,1$ & 159,45 & $-0,05$ & 159,3 & $-0,2$ \\
\hline & & טכנ, & & $5 \%$ & & & & $3 \%$ \\
\hline & & & 159,25 & $-0,15$ & 159,25 & $-0,15$ & 159,2 & $-0,2$ \\
\hline & & 159,40 & & & & & & $3 \%$ \\
\hline
\end{tabular}


Tabla 36. Estabilidad dimensional de las probetas de mortero de CAC con árido $0 / 4$ (Masa inicial, variación de masa a 7, 14 y 28 días y variación de la masa específica). (R) mortero de referencia. (CVT) mortero con la incorporación de cenizas volantes inertizadas en una proporción de un $10 \%$ en peso de los áridos.

\begin{tabular}{|c|c|c|c|c|c|c|c|c|}
\hline \multirow{3}{*}{ 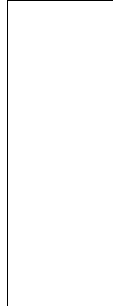 } & & & \multicolumn{2}{|c|}{7 días } & \multicolumn{2}{|c|}{14 días } & \multicolumn{2}{|c|}{28 días } \\
\hline & \multirow{2}{*}{\multicolumn{2}{|c|}{$\begin{array}{l}\text { Long. Inicial } \\
\quad \mathrm{L}(\mathrm{mm})\end{array}$}} & $\begin{array}{l}\text { Longitud } \\
\mathrm{L}_{7}(\mathrm{~mm})\end{array}$ & $\begin{array}{c}\text { Variación } \\
\text { de } \\
\text { longitud } \\
\Delta \mathrm{L}(\mathrm{mm})\end{array}$ & $\begin{array}{l}\text { Longitud } \\
\mathrm{L}_{14}(\mathrm{~mm})\end{array}$ & $\begin{array}{c}\text { Variación } \\
\text { de } \\
\text { longitud } \\
\Delta \mathrm{L}(\mathrm{mm})\end{array}$ & $\begin{array}{l}\text { Longitud } \\
\mathrm{L}_{28}(\mathrm{~mm})\end{array}$ & $\begin{array}{c}\text { Variación } \\
\text { de } \\
\text { longitud } \\
\Delta \mathrm{L}(\mathrm{mm})\end{array}$ \\
\hline & & & \multicolumn{2}{|c|}{$\begin{array}{l}\text { Var. long. especif. } \\
\varepsilon_{7}(\%) \text { deformación }\end{array}$} & \multicolumn{2}{|c|}{$\begin{array}{l}\text { Var. long. especif. } \\
\varepsilon_{14}(\%) \text { deformación }\end{array}$} & \multicolumn{2}{|c|}{$\begin{array}{l}\text { Var. long. especif. } \\
\varepsilon_{28}(\%) \text { deformación }\end{array}$} \\
\hline \multirow{12}{*}{ 궁 } & \multirow{6}{*}{$\boldsymbol{\alpha}$} & \multirow{2}{*}{159,95} & 159,90 & $-0,05$ & 159,9 & $-0,05$ & 159,9 & $-0,05$ \\
\hline & & & \multicolumn{2}{|c|}{$-0,03 \%$} & \multicolumn{2}{|c|}{$-0,03 \%$} & \multicolumn{2}{|c|}{$-0,03 \%$} \\
\hline & & \multirow{2}{*}{160,00} & 159,75 & $-0,25$ & 159,75 & $-0,25$ & 159,75 & $-0,25$ \\
\hline & & & \multicolumn{2}{|c|}{$-0,16 \%$} & \multicolumn{2}{|c|}{$-0,16 \%$} & \multicolumn{2}{|c|}{$-0,16 \%$} \\
\hline & & \multirow{2}{*}{159,80} & 159,70 & $-0,1$ & 159,7 & $-0,1$ & 159,65 & $-0,15$ \\
\hline & & & \multicolumn{2}{|c|}{$-0,06 \%$} & \multicolumn{2}{|c|}{$-0,06 \%$} & \multicolumn{2}{|c|}{$-0,09 \%$} \\
\hline & \multirow{6}{*}{5} & \multirow{2}{*}{159,50} & 159,70 & 0,2 & 159,65 & 0,15 & 159,75 & 0,25 \\
\hline & & & \multicolumn{2}{|c|}{$0,13 \%$} & \multicolumn{2}{|c|}{$0,09 \%$} & \multicolumn{2}{|c|}{$0,16 \%$} \\
\hline & & \multirow{2}{*}{159,55} & 159,60 & 0,05 & 159,55 & 0 & 159,75 & 0,2 \\
\hline & & & \multicolumn{2}{|c|}{$0,03 \%$} & \multicolumn{2}{|c|}{$0,00 \%$} & \multicolumn{2}{|c|}{$0,13 \%$} \\
\hline & & & 159,70 & 0,05 & 159,5 & $-0,15$ & 159,8 & 0,15 \\
\hline & & כט, נטגו & & & & $9 \%$ & & \\
\hline & & 16 & 160,15 & $-0,05$ & 160,1 & $-0,1$ & 160,1 & $-0,1$ \\
\hline & & & & $3 \%$ & & $5 \%$ & & $6 \%$ \\
\hline & 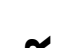 & 16 & 159,95 & $-0,15$ & 160,05 & $-0,05$ & 160 & $-0,1$ \\
\hline & 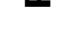 & 100,10 & & $9 \%$ & & $3 \%$ & & $5 \%$ \\
\hline & & & 160,05 & $-0,15$ & 160,05 & $-0,15$ & 160,05 & $-0,15$ \\
\hline 4 운 & & $100,<0$ & & $9 \%$ & & $9 \%$ & & $9 \%$ \\
\hline 08 & & 16 & 160 & $-0,05$ & 159,75 & $-0,3$ & 159,9 & $-0,15$ \\
\hline$\frac{4}{n}$ & & (100, & & $3 \%$ & & $9 \%$ & & $9 \%$ \\
\hline ถ̊ & 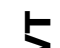 & 16000 & 159,8 & $-0,2$ & 159,75 & $-0,25$ & 159,85 & $-0,15$ \\
\hline & 0 & 100,00 & & $2 \%$ & & $5 \%$ & & $9 \%$ \\
\hline & & 1 & 159,9 & $-0,2$ & 159,9 & $-0,2$ & 159,95 & $-0,15$ \\
\hline & & 100,10 & & $2 \%$ & & $2 \%$ & & $9 \%$ \\
\hline
\end{tabular}




\subsection{Variación de la masa (morteros CAC)}

Las tabla 37 y 38 presentan los resultados de masas iniciales (M), variación de las masas a 7, 14 y 28 días $(\Delta M)$ y la variación de la masa específica $\left(m_{x}\right)$, de las probetas de mortero realizadas con CAC. Los datos de estas tablas se refieren a morteros ejecutados con áridos de diámetro 0/2 (tabla 37) y 0/4 (tabla 38), y abarcan tanto a morteros de referencia, $(R)$, como a morteros la incorporación de cenizas volantes inertizadas en forma de carbonatos, en una proporción de un $10 \%$ en peso de los áridos (CVT).

Los valores medios de los resultados ofrecidos en dichas tablas, en lo referente a la variación específica en porcentaje de las masas de los morteros CAC, muestran comportamientos análogos para los distintos tipos de diámetros del árido. Aquellos elaborados con CVT y con una dosificación 1/1 presentan menores retracciones que sus homólogos sin adición de cenizas volantes inertizadas.

Por el contrario, cuanta mayor cantidad de árido tienen los morteros (dosificación 1/3), peor estabilidad dimensional tienen aquellos con CVT en su formulación, empeorando ésta con los morteros con un tamaño de grano mayor.

Tanto en los datos de deformación, como en los de variación de la masa específica, destacan los resultados de los mortero elaborados con cenizas volantes inertizadas dosificación $1 / 1$ y con diámetro del árido $0 / 2$, ya que, en ambos casos, superan a los de los morteros de referencia. Estos morteros resultan ser los de mayor estabilidad dimensional de todos los estudiados. 
Tabla 37. Estabilidad dimensional de las probetas de mortero de CAC con árido 0/2 (Masa inicial, variación de masa a 7, 14 y 28 días y variación de la masa específica). (R) mortero de referencia. (CVT) mortero con la incorporación de cenizas volantes inertizadas en una proporción de un $10 \%$ en peso de los áridos.

\begin{tabular}{|c|c|c|c|c|c|c|c|c|}
\hline \multirow{3}{*}{\multicolumn{3}{|c|}{ Masa inicial M $(g)$}} & \multicolumn{2}{|c|}{7 días } & \multicolumn{2}{|c|}{14 días } & \multicolumn{2}{|c|}{28 días } \\
\hline & & & $\begin{array}{c}\text { Masa M } \\
(g)\end{array}$ & $\begin{array}{l}\text { Variación } \\
\text { de masa } \\
\Delta M(g)\end{array}$ & $\begin{array}{c}\text { Masa } M_{14} \\
(g)\end{array}$ & $\begin{array}{c}\text { Variación } \\
\text { de masa } \\
\Delta \mathrm{M}(\mathrm{g})\end{array}$ & $\begin{array}{c}\text { Masa } M_{28} \\
(g)\end{array}$ & $\begin{array}{c}\text { Variación } \\
\text { de masa } \\
\Delta \mathrm{M}(g)\end{array}$ \\
\hline & & & \multicolumn{2}{|c|}{$\begin{array}{c}\text { Variación masa } \\
\text { especifica } \\
\mathrm{m}_{7}(\%)\end{array}$} & \multicolumn{2}{|c|}{$\begin{array}{c}\text { Variación masa } \\
\text { especifica } \\
\mathrm{m}_{14}(\%)\end{array}$} & \multicolumn{2}{|c|}{$\begin{array}{c}\text { Variación masa } \\
\text { especifica } \\
\mathrm{m}_{28}(\%)\end{array}$} \\
\hline \multirow{12}{*}{ 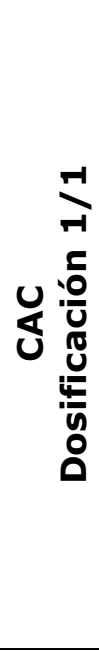 } & \multirow{6}{*}{$\alpha$} & \multirow{2}{*}{561,2} & 558,0 & $-3,2$ & 556,8 & $-4,4$ & 555,5 & $-5,7$ \\
\hline & & & \multicolumn{2}{|c|}{$-0,57 \%$} & \multicolumn{2}{|c|}{$-0,78 \%$} & \multicolumn{2}{|c|}{$-1,02 \%$} \\
\hline & & \multirow{2}{*}{562,6} & 559,2 & $-3,4$ & 557,9 & $-4,7$ & 556,6 & -6 \\
\hline & & & \multicolumn{2}{|c|}{$-0,60 \%$} & \multicolumn{2}{|c|}{$-0,84 \%$} & \multicolumn{2}{|c|}{$-1,07 \%$} \\
\hline & & \multirow{2}{*}{560,6} & 557,4 & $-3,2$ & 556,1 & $-4,5$ & 554,8 & $-5,8$ \\
\hline & & & \multicolumn{2}{|c|}{$-0,57 \%$} & \multicolumn{2}{|c|}{$-0,80 \%$} & \multicolumn{2}{|c|}{$-1,03 \%$} \\
\hline & & \multirow{2}{*}{582,2} & 581,1 & $-1,1$ & 580,7 & $-1,5$ & 580,5 & $-1,7$ \\
\hline & & & \multicolumn{2}{|c|}{$-0,19 \%$} & \multicolumn{2}{|c|}{$-0,26 \%$} & \multicolumn{2}{|c|}{$-0,29 \%$} \\
\hline & & \multirow{2}{*}{584,3} & 583,2 & $-1,1$ & 582,7 & $-1,6$ & 582,4 & $-1,9$ \\
\hline & & & \multicolumn{2}{|c|}{$-0,19 \%$} & \multicolumn{2}{|c|}{$-0,27 \%$} & \multicolumn{2}{|c|}{$-0,33 \%$} \\
\hline & & \multirow{2}{*}{583,1} & 582,1 & $-1,0$ & 581,6 & $-1,5$ & 581,3 & $-1,8$ \\
\hline & & & \multicolumn{2}{|c|}{$-0,17 \%$} & & & & \\
\hline & & 5611 & 554,2 & $-6,9$ & 551,8 & $-9,3$ & 548,9 & $-12,2$ \\
\hline & & 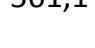 & & & & & & \\
\hline & $\sim$ & 5600 & 553,1 & $-6,9$ & 550,8 & $-9,2$ & 548,1 & $-11,9$ \\
\hline & 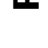 & 500,0 & & & & & & \\
\hline & & & 555,9 & $-6,8$ & 553,4 & $-9,3$ & 550,6 & $-12,1$ \\
\hline 눈 웁 & & $J 0<, 1$ & & & & & & \\
\hline 0 ర్ & & 5260 & 523,0 & $-13,4$ & 520,4 & -16 & 517,8 & $-18,6$ \\
\hline $\bar{n}$ & & & & & & & & \\
\hline ถ̊ & $F$ & 5260 & 523,4 & $-13,5$ & 520,8 & $-16,1$ & 517,9 & -19 \\
\hline & 7 & & & & & & & \\
\hline & & & 521,2 & $-13,8$ & 518,4 & $-16,6$ & 515,9 & $-19,1$ \\
\hline & & ט,כככ & & & & & & $7 \%$ \\
\hline
\end{tabular}


Tabla 38. Estabilidad dimensional de las probetas de mortero de CAC con árido 0/4 (Masa inicial, variación de masa a 7, 14 y 28 días y variación de la masa específica). (R) mortero de referencia. (CVT) mortero con la incorporación de cenizas volantes inertizadas en una proporción de un $10 \%$ en peso de los áridos.

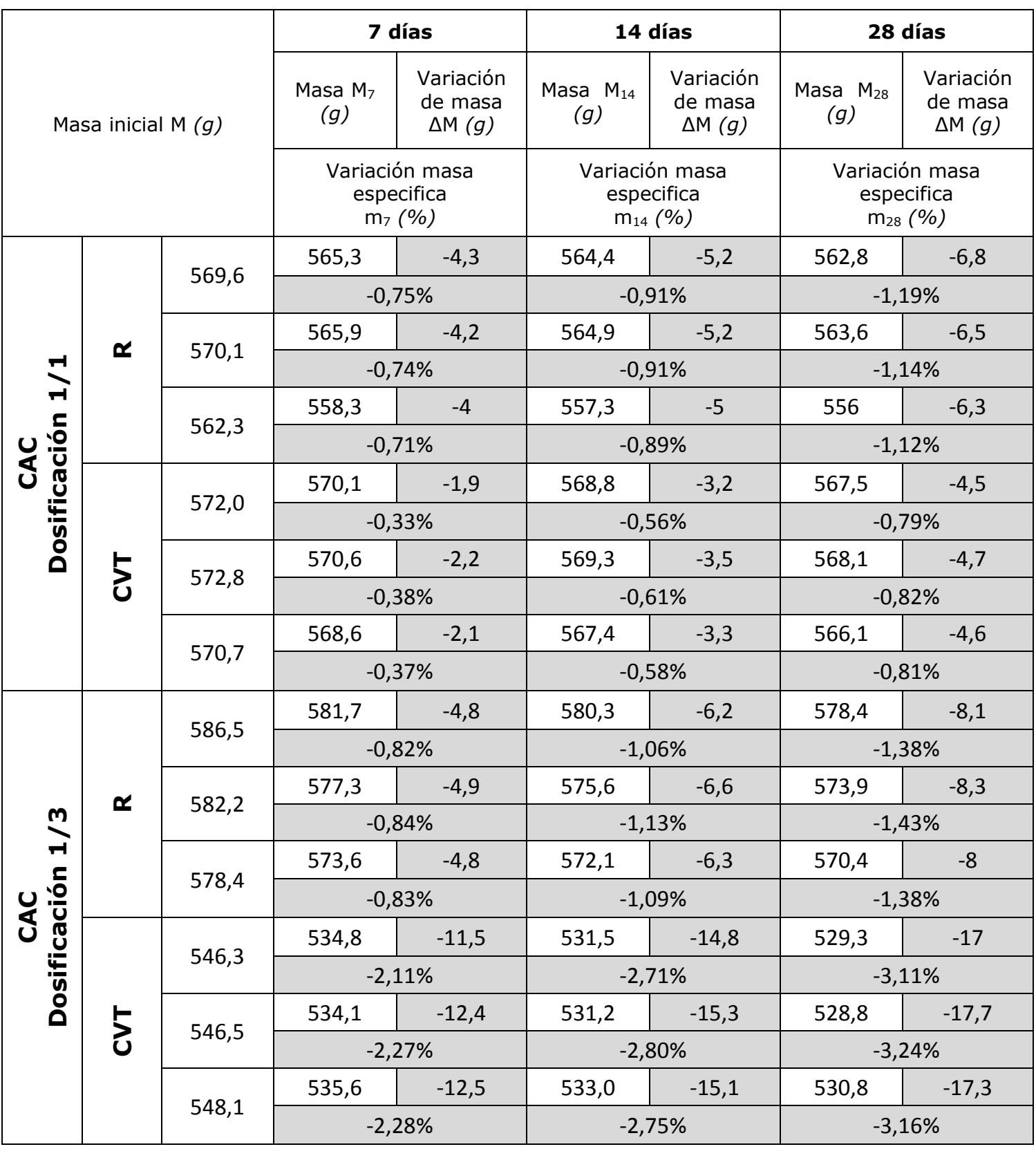


3.3.3.4 Estabilidad dimensional de los morteros elaborados con CSA (UNE EN 83831:2010 EX)

\subsection{Variación de la longitud (morteros CSA)}

Las tabla 39 y 40 muestran los resultados de los morteros elaborados con cementos CSA relativos a las longitudes iniciales en el desmoldado de las probetas $(L)$, la variación de las longitudes a 7,14 y 28 días $(\Delta L)$ y la variación de las longitudes específicas o deformación $\left(\varepsilon_{\mathrm{x}}\right)$, a las mismas edades de fraguado. Los datos de estas tablas se refieren a morteros ejecutados con áridos de diámetro $0 / 2$ (tabla 39) y 0/4 (tabla 40), y abarcan tanto a morteros de referencia, $(\mathrm{R})$, como a morteros la incorporación de cenizas volantes inertizadas en forma de carbonatos, en una proporción de un $10 \%$ en peso de los áridos (CVT).

El estudio de los resultados ofrece datos muy positivos en todos los análisis efectuados. Las retracciones de todos los morteros, tanto de referencia, como con CVT, presentan valores prácticamente nulos (el peor de ellos con CVT es de un -0,09\%).

En todos los caso ensayados, salvo para $1 / 3 \cdot 0 / 4$, los valores finales de deformación son mejores en los morteros con CVT. Siendo especialmente destacables los morteros $1 / 1 \cdot 0 / 2$ en los que las deformaciones a lo largo de la franja temporal de 7, 14 y 28 días fueron inferiores a las del mortero de referencia. A pesar de esto, el mejor valor obtenido de todos los estudiados corresponde a la dosificación $0 / 2 \cdot 1 / 3$ con un $-0,02 \%$.

El comportamiento de este tipo de morteros, concuerda con la bibliografía consultada según la que, por regla general, este tipo de cementos belíticos y sus compuestos presentan las menores retracciones en comparación con el resto de cementos Portland ordinarios (Guo et al., 2014). En conjunto, las mezclas analizadas, presentan los valores más estables, casi nulos, de todos los morteros estudiados. La adición de cenizas volantes inertizadas en forma de carbonatos mejora, salvo en el caso de tener más cantidad de árido y de mayor tamaño, los valores de retracción de las probetas estudiadas. 
Tabla 39. Estabilidad dimensional de las probetas de mortero de CSA con árido 0/2 (Masa inicial, variación de masa a 7, 14 y 28 días y variación de la masa específica). (R) mortero de referencia. (CVT) mortero con la incorporación de cenizas volantes inertizadas en una proporción de un $10 \%$ en peso de los áridos.

\begin{tabular}{|c|c|c|c|c|c|c|c|c|}
\hline \multirow{3}{*}{\multicolumn{3}{|c|}{$\begin{array}{c}\text { Long. Inicial } \\
\mathrm{L}(\mathrm{mm})\end{array}$}} & \multicolumn{2}{|c|}{7 días } & \multicolumn{2}{|c|}{14 días } & \multicolumn{2}{|c|}{28 días } \\
\hline & & & $\begin{array}{l}\text { Longitud } \\
\mathrm{L}_{7}(\mathrm{~mm})\end{array}$ & $\begin{array}{c}\text { Variación } \\
\text { de } \\
\text { longitud } \\
\Delta \mathrm{L}(\mathrm{mm})\end{array}$ & $\begin{array}{l}\text { Longitud } \\
\mathrm{L}_{14}(\mathrm{~mm})\end{array}$ & $\begin{array}{c}\text { Variación } \\
\text { de } \\
\text { longitud } \\
\Delta \mathrm{L}(\mathrm{mm})\end{array}$ & $\begin{array}{l}\text { Longitud } \\
\mathrm{L}_{28}(\mathrm{~mm})\end{array}$ & $\begin{array}{l}\text { Variación } \\
\text { de longitud } \\
\Delta \mathrm{L}(\mathrm{mm})\end{array}$ \\
\hline & & & \multicolumn{2}{|c|}{$\begin{array}{l}\text { Var. long. especif. } \\
\varepsilon_{7}(\%) \text { deformación }\end{array}$} & \multicolumn{2}{|c|}{$\begin{array}{l}\text { Var. long. especif. } \\
\varepsilon_{14}(\%) \text { deformación }\end{array}$} & \multicolumn{2}{|c|}{$\begin{array}{l}\text { Var. long. especif. } \\
\varepsilon_{28}(\%) \text { deformación }\end{array}$} \\
\hline \multirow{12}{*}{ 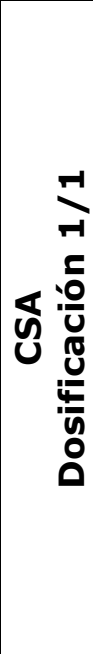 } & \multirow{6}{*}{$\boldsymbol{\alpha}$} & \multirow{2}{*}{160,25} & 160,20 & $-0,05$ & 160,1 & $-0,15$ & 160,05 & $-0,2$ \\
\hline & & & \multicolumn{2}{|c|}{$-0,03 \%$} & \multicolumn{2}{|c|}{$-0,09 \%$} & \multicolumn{2}{|c|}{$-0,12 \%$} \\
\hline & & \multirow{2}{*}{160,10} & 160,00 & $-0,1$ & 160 & $-0,1$ & 159,95 & $-0,15$ \\
\hline & & & \multicolumn{2}{|c|}{$-0,06 \%$} & \multicolumn{2}{|c|}{$-0,06 \%$} & \multicolumn{2}{|c|}{$-0,09 \%$} \\
\hline & & \multirow{2}{*}{160,10} & 159,95 & $-0,15$ & 160 & $-0,1$ & 159,9 & $-0,2$ \\
\hline & & & \multicolumn{2}{|c|}{$-0,09 \%$} & \multicolumn{2}{|c|}{$-0,06 \%$} & \multicolumn{2}{|c|}{$-0,12 \%$} \\
\hline & & \multirow{2}{*}{160,15} & 160,10 & $-0,05$ & 160,1 & $-0,05$ & 160,05 & $-0,1$ \\
\hline & & & \multicolumn{2}{|c|}{$-0,03 \%$} & \multicolumn{2}{|c|}{$-0,03 \%$} & \multicolumn{2}{|c|}{$-0,06 \%$} \\
\hline & E & \multirow{2}{*}{160,20} & 160,15 & $-0,05$ & 160,05 & $-0,15$ & 160,15 & $-0,05$ \\
\hline & & & \multicolumn{2}{|c|}{$-0,03 \%$} & \multicolumn{2}{|c|}{$-0,09 \%$} & \multicolumn{2}{|c|}{$-0,03 \%$} \\
\hline & & \multirow{2}{*}{160,20} & 160,15 & $-0,05$ & 160,1 & $-0,1$ & 160,15 & $-0,05$ \\
\hline & & & \multicolumn{2}{|c|}{$-0,03 \%$} & & $6 \%$ & & $3 \%$ \\
\hline & & 10 & 160,15 & $-0,05$ & 160,15 & $-0,05$ & 160 & $-0,2$ \\
\hline & & & & $3 \%$ & & $3 \%$ & & $2 \%$ \\
\hline & $\sim$ & 16015 & 160,20 & 0,05 & 160,1 & $-0,05$ & 160,1 & $-0,05$ \\
\hline & 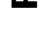 & כב, 100 & & & & $3 \%$ & & $3 \%$ \\
\hline & & & 160,25 & 0 & 160,2 & $-0,05$ & 160,2 & $-0,05$ \\
\hline & & & & & & $3 \%$ & & $3 \%$ \\
\hline 0 J & & 1 & 160,2 & $-0,05$ & 160,15 & $-0,1$ & 160,2 & $-0,05$ \\
\hline$\frac{4}{n}$ & & U, 100 & & $3 \%$ & & $6 \%$ & & $3 \%$ \\
\hline ถ̊ & E & 16 & 160,1 & $-0,05$ & 160,05 & $-0,1$ & 160,1 & $-0,05$ \\
\hline & 0 & כב, 100 & & $3 \%$ & & $6 \%$ & & $3 \%$ \\
\hline & & 1 & 160,1 & 0 & 160,00 & $-0,1$ & 160,1 & 0 \\
\hline & & 100,10 & & & & $6 \%$ & & $0 \%$ \\
\hline
\end{tabular}


Tabla 40. Estabilidad dimensional de las probetas de mortero de CSA con árido 0/4 (Masa inicial, variación de masa a 7, 14 y 28 días y variación de la masa específica). (R) mortero de referencia. (CVT) mortero con la incorporación de cenizas volantes inertizadas en una proporción de un $10 \%$ en peso de los áridos.

\begin{tabular}{|c|c|c|c|c|c|c|c|c|}
\hline \multirow{3}{*}{\multicolumn{3}{|c|}{$\begin{array}{l} \\
\text { Long. Inicial } \\
\mathrm{L}(\mathrm{mm})\end{array}$}} & \multicolumn{2}{|c|}{7 días } & \multicolumn{2}{|c|}{14 días } & \multicolumn{2}{|c|}{28 días } \\
\hline & & & $\begin{array}{l}\text { Longitud } \\
\mathrm{L}_{7}(\mathrm{~mm})\end{array}$ & $\begin{array}{l}\text { Variación } \\
\text { de longitud } \\
\Delta \mathrm{L}(\mathrm{mm})\end{array}$ & $\begin{array}{l}\text { Longitud } \\
\mathrm{L}_{14}(\mathrm{~mm})\end{array}$ & $\begin{array}{l}\text { Variación } \\
\text { de longitud } \\
\Delta \mathrm{L}(\mathrm{mm})\end{array}$ & $\begin{array}{l}\text { Longitud } \\
\mathrm{L}_{28}(\mathrm{~mm})\end{array}$ & $\begin{array}{l}\text { Variación } \\
\text { de longitud } \\
\Delta \mathrm{L}(\mathrm{mm})\end{array}$ \\
\hline & & & \multicolumn{2}{|c|}{$\begin{array}{l}\text { Var. long. especif. } \\
\varepsilon_{7}(\%) \text { deformación }\end{array}$} & \multicolumn{2}{|c|}{$\begin{array}{l}\text { Var. long. especif. } \\
\varepsilon_{14}(\%) \text { deformación }\end{array}$} & \multicolumn{2}{|c|}{$\begin{array}{l}\text { Var. long. especif. } \\
\varepsilon_{28}(\%) \text { deformación }\end{array}$} \\
\hline \multirow{12}{*}{ 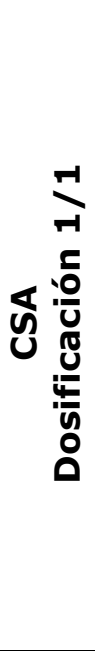 } & \multirow{6}{*}{$\boldsymbol{\alpha}$} & \multirow{2}{*}{159,90} & 159,8 & $-0,1$ & 159,75 & $-0,15$ & 159,7 & $-0,2$ \\
\hline & & & \multicolumn{2}{|c|}{$-0,06 \%$} & \multicolumn{2}{|c|}{$-0,09 \%$} & \multicolumn{2}{|c|}{$-0,13 \%$} \\
\hline & & \multirow{2}{*}{159,80} & 159,75 & $-0,05$ & 159,75 & $-0,05$ & 159,7 & $-0,1$ \\
\hline & & & \multicolumn{2}{|c|}{$-0,03 \%$} & \multicolumn{2}{|c|}{$-0,03 \%$} & \multicolumn{2}{|c|}{$-0,06 \%$} \\
\hline & & \multirow{2}{*}{159,90} & 159,8 & $-0,1$ & 159,7 & $-0,2$ & 159,75 & $-0,15$ \\
\hline & & & \multicolumn{2}{|c|}{$-0,06 \%$} & \multicolumn{2}{|c|}{$-0,13 \%$} & \multicolumn{2}{|c|}{$-0,09 \%$} \\
\hline & & \multirow{2}{*}{160,40} & 160,3 & $-0,1$ & 160,2 & $-0,2$ & 160,25 & $-0,15$ \\
\hline & & & \multicolumn{2}{|c|}{$-0,06 \%$} & \multicolumn{2}{|c|}{$-0,12 \%$} & \multicolumn{2}{|c|}{$-0,09 \%$} \\
\hline & & \multirow{2}{*}{160,45} & 160,25 & $-0,2$ & 160,3 & $-0,15$ & 160,3 & $-0,15$ \\
\hline & 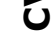 & & \multicolumn{2}{|c|}{$-0,12 \%$} & \multicolumn{2}{|c|}{$-0,09 \%$} & \multicolumn{2}{|c|}{$-0,09 \%$} \\
\hline & & \multirow{2}{*}{160,35} & 160,25 & $-0,1$ & 160,1 & $-0,25$ & 160,35 & 0 \\
\hline & & & \multicolumn{2}{|c|}{$-0,06 \%$} & & $6 \%$ & & $0 \%$ \\
\hline & & م? 160 & 160,2 & 0 & 160,15 & $-0,05$ & 160,1 & $-0,1$ \\
\hline & & & & $0 \%$ & & $3 \%$ & & $6 \%$ \\
\hline & $\sim$ & & 160,15 & 0,1 & 160 & $-0,05$ & 160 & $-0,05$ \\
\hline & 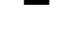 & כט, & & $6 \%$ & & $3 \%$ & & $3 \%$ \\
\hline 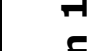 & & $160+2$ & 160 & $-0,15$ & 160 & $-0,15$ & 160,10 & $-0,05$ \\
\hline$<: \frac{0}{6}$ & & 100,10 & & D9\% & & $9 \%$ & & $3 \%$ \\
\hline 08 & & & 160,05 & $-0,15$ & 160,15 & $-0,05$ & 159,85 & $-0,35$ \\
\hline$\frac{4}{n}$ & & 100,20 & & 09\% & & $3 \%$ & & $2 \%$ \\
\hline 8 & & 1 & 160 & $-0,05$ & 160 & $-0,05$ & 160,00 & $-0,05$ \\
\hline & 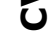 & כט, & & $3 \%$ & & $3 \%$ & & $3 \%$ \\
\hline & & & 160,1 & 0 & 160,05 & $-0,05$ & 160,05 & $-0,05$ \\
\hline & & 100,10 & & $0 \%$ & & $3 \%$ & & $3 \%$ \\
\hline
\end{tabular}




\subsection{Variación de la masa (morteros CSA)}

Las tablas 41 y 42 presentan los resultados de masas iniciales (M), variación de las masas a 7, 14 y 28 días $(\Delta M)$ y la variación de la masa específica $\left(m_{x}\right)$, de las probetas de mortero realizadas con CSA. Los datos de estas tablas se refieren a morteros ejecutados con áridos de diámetro 0/2 (tabla 41) y 0/4 (tabla 42), y abarcan tanto a morteros de referencia, $(\mathrm{R})$, como a morteros la incorporación de cenizas volantes inertizadas en forma de carbonatos, en una proporción de un $10 \%$ en peso de los áridos (CVT).

Los valores muestran comportamientos muy similares en todos los casos analizados. Aquellos morteros elaborados con CVT presentan mayores pérdidas de masa específica que sus homólogos sin adición de cenizas volantes inertizadas. Los peores datos, $-4.89 \%$ y $-4.06 \%$ para diámetros $0 / 2$ y $0 / 4$, respectivamente, se obtienen cuanta más cantidad de árido tiene el mortero en su dosificación (1/3). Si bien proporcionalmente, las menores variaciones con respecto a los morteros de referencia, también se obtienen con este tipo de mezcla. 
Tabla 41. Estabilidad dimensional de las probetas de mortero de CSA con árido $0 / 2$ (Masa inicial, variación de masa a 7, 14 y 28 días y variación de la masa específica). (R) mortero de referencia. (CVT) mortero con la incorporación de cenizas volantes inertizadas en una proporción de un $10 \%$ en peso de los áridos.

\begin{tabular}{|c|c|c|c|c|c|c|c|c|}
\hline \multirow{3}{*}{\multicolumn{3}{|c|}{ Masa inicial M $(g)$}} & \multicolumn{2}{|c|}{7 días } & \multicolumn{2}{|c|}{14 días } & \multicolumn{2}{|c|}{28 días } \\
\hline & & & $\begin{array}{c}\text { Masa M } \\
(g)\end{array}$ & $\begin{array}{c}\text { Variación } \\
\text { de masa } \\
\Delta \mathrm{M}(g)\end{array}$ & $\begin{array}{c}\text { Masa } M_{14} \\
(g)\end{array}$ & $\begin{array}{l}\text { Variación } \\
\text { de masa } \\
\Delta \mathrm{M}(g)\end{array}$ & $\begin{array}{c}\text { Masa M } \\
(g)\end{array}$ & $\begin{array}{c}\text { Variación } \\
\text { de masa } \\
\Delta \mathrm{M}(g)\end{array}$ \\
\hline & & & \multicolumn{2}{|c|}{$\begin{array}{c}\text { Variación masa } \\
\text { especifica } \\
\mathrm{m}_{7}(\%)\end{array}$} & \multicolumn{2}{|c|}{$\begin{array}{c}\text { Variación masa } \\
\text { especifica } \\
\mathrm{m}_{14}(\%)\end{array}$} & \multicolumn{2}{|c|}{$\begin{array}{c}\text { Variación masa } \\
\text { especifica } \\
\mathrm{m}_{28}(\%)\end{array}$} \\
\hline \multirow{12}{*}{ 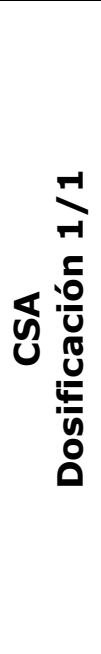 } & \multirow{6}{*}{$\boldsymbol{\alpha}$} & \multirow{2}{*}{532,9} & 529,8 & $-3,1$ & 530,5 & $-2,4$ & 530,2 & $-2,7$ \\
\hline & & & \multicolumn{2}{|c|}{$-0,58 \%$} & \multicolumn{2}{|c|}{$-0,45 \%$} & \multicolumn{2}{|c|}{$-0,51 \%$} \\
\hline & & \multirow{2}{*}{532,9} & 529,7 & $-3,2$ & 530,3 & $-2,6$ & 530 & $-2,9$ \\
\hline & & & \multicolumn{2}{|c|}{$-0,60 \%$} & \multicolumn{2}{|c|}{$-0,49 \%$} & \multicolumn{2}{|c|}{$-0,54 \%$} \\
\hline & & \multirow{2}{*}{534,8} & 531,6 & $-3,2$ & 532,1 & $-2,7$ & 531,8 & -3 \\
\hline & & & \multicolumn{2}{|c|}{$-0,60 \%$} & \multicolumn{2}{|c|}{$-0,50 \%$} & \multicolumn{2}{|c|}{$-0,56 \%$} \\
\hline & & \multirow{2}{*}{514,3} & 506,1 & $-8,2$ & 505,2 & $-9,1$ & 504,8 & $-9,5$ \\
\hline & & & \multicolumn{2}{|c|}{$-1,59 \%$} & \multicolumn{2}{|c|}{$-1,77 \%$} & \multicolumn{2}{|c|}{$-1,85 \%$} \\
\hline & & \multirow{2}{*}{517,6} & $509,0 €$ & $-8,6$ & 508,0 & $-9,6$ & 507,8 & $-9,8$ \\
\hline & & & \multicolumn{2}{|c|}{$-1,66 \%$} & \multicolumn{2}{|c|}{$-1,85 \%$} & \multicolumn{2}{|c|}{$-1,89 \%$} \\
\hline & & \multirow{2}{*}{515,5} & 507,3 & $-8,2$ & 506,4 & $-9,1$ & 506,1 & $-9,4$ \\
\hline & & & \multicolumn{2}{|c|}{$-1,59 \%$} & & $7 \%$ & & $2 \%$ \\
\hline & & & 530,6 & $-17,2$ & 529,8 & -18 & 529,4 & $-18,4$ \\
\hline & & נו, & & & & $9 \%$ & & $6 \%$ \\
\hline & $\sim$ & 5500 & 532,2 & $-17,8$ & 531,4 & $-18,6$ & 531,1 & $-18,9$ \\
\hline & 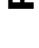 & ט, & & & & $8 \%$ & & $4 \%$ \\
\hline & & 510 & 533,0 & $-16,4$ & 532,3 & $-17,1$ & 531,8 & $-17,6$ \\
\hline :은 & & ד, & & & & $1 \%$ & & $0 \%$ \\
\hline ర & & 7 & 508,7 & -24 & 507,4 & $-25,3$ & 506,9 & $-25,8$ \\
\hline$\frac{4}{n}$ & & 1 & & & & $5 \%$ & & $4 \%$ \\
\hline : & 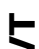 & ר? & 507,8 & $-24,4$ & 506,5 & $-25,7$ & 506,1 & $-26,1$ \\
\hline & u & 20, & & & & $3 \%$ & & $0 \%$ \\
\hline & & & 505,4 & $-24,7$ & 504,4 & $-25,7$ & 504 & $-26,1$ \\
\hline & & גונד & & & & $5 \%$ & & $2 \%$ \\
\hline
\end{tabular}


Tabla 42. Estabilidad dimensional de las probetas de mortero de CSA con árido 0/4 (Masa inicial, variación de masa a 7, 14 y 28 días y variación de la masa específica). (R) mortero de referencia. (CVT) mortero con la incorporación de cenizas volantes inertizadas en una proporción de un $10 \%$ en peso de los áridos.

\begin{tabular}{|c|c|c|c|c|c|c|c|c|}
\hline \multirow{2}{*}{\multicolumn{3}{|c|}{ Masa inicial M $(g)$}} & \multicolumn{2}{|c|}{7 días } & \multicolumn{2}{|c|}{14 días } & \multicolumn{2}{|c|}{28 días } \\
\hline & & & $\begin{array}{c}\text { Masa M } \\
(g)\end{array}$ & $\begin{array}{c}\text { Variación } \\
\text { de masa } \\
\Delta \mathrm{M}(\mathrm{g})\end{array}$ & $\begin{array}{c}\text { Masa } M_{1} \\
(g)\end{array}$ & $\begin{array}{c}\text { Variación } \\
\text { de masa } \\
\Delta \mathrm{M}(g)\end{array}$ & $\begin{array}{c}\text { Masa M } \\
(g)\end{array}$ & $\begin{array}{c}\text { Variación } \\
\text { de masa } \\
\Delta \mathrm{M}(g)\end{array}$ \\
\hline & & & \multicolumn{2}{|c|}{$\begin{array}{c}\text { Variación masa } \\
\text { especifica } \\
\mathrm{m}_{7}(\%)\end{array}$} & \multicolumn{2}{|c|}{$\begin{array}{c}\text { Variación masa } \\
\text { especifica } \\
\mathrm{m}_{14}(\%)\end{array}$} & \multicolumn{2}{|c|}{$\begin{array}{c}\text { Variación masa } \\
\text { especifica } \\
\mathrm{m}_{28}(\%)\end{array}$} \\
\hline \multirow{12}{*}{ 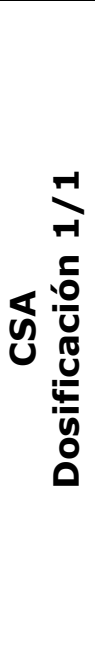 } & \multirow{6}{*}{$\boldsymbol{\alpha}$} & \multirow{2}{*}{539,0} & 534,1 & $-4,9$ & 533,5 & $-5,5$ & 533,7 & $-5,3$ \\
\hline & & & \multicolumn{2}{|c|}{$-0,91 \%$} & \multicolumn{2}{|c|}{$-1,02 \%$} & \multicolumn{2}{|c|}{$-0,98 \%$} \\
\hline & & \multirow{2}{*}{535,9} & 531,2 & $-4,7$ & 530,5 & $-5,4$ & 530,6 & $-5,3$ \\
\hline & & & \multicolumn{2}{|c|}{$-0,88 \%$} & \multicolumn{2}{|c|}{$-1,01 \%$} & \multicolumn{2}{|c|}{$-0,99 \%$} \\
\hline & & \multirow{2}{*}{534,8} & 530,3 & $-4,5$ & 529,5 & $-5,3$ & 529,7 & $-5,1$ \\
\hline & & & \multicolumn{2}{|c|}{$-0,84 \%$} & \multicolumn{2}{|c|}{$-0,99 \%$} & \multicolumn{2}{|c|}{$-0,95 \%$} \\
\hline & & \multirow{2}{*}{553,1} & 537,4 & $-15,7$ & 536,7 & $-16,4$ & 536,7 & $-16,4$ \\
\hline & & & \multicolumn{2}{|c|}{$-2,84 \%$} & \multicolumn{2}{|c|}{$-2,97 \%$} & \multicolumn{2}{|c|}{$-2,97 \%$} \\
\hline & & \multirow{2}{*}{554,0} & 538,8 & $-15,2$ & 538 & -16 & 538 & -16 \\
\hline & & & \multicolumn{2}{|c|}{$-2,74 \%$} & \multicolumn{2}{|c|}{$-2,89 \%$} & \multicolumn{2}{|c|}{$-2,89 \%$} \\
\hline & & \multirow{2}{*}{553,8} & 539,0 & $-14,8$ & 538,2 & $-15,6$ & 538,1 & $-15,7$ \\
\hline & & & \multicolumn{2}{|c|}{$-2,67 \%$} & & $2 \%$ & & $3 \%$ \\
\hline & & 5150 & 506,9 & $-8,9$ & 505,9 & $-9,9$ & 505,6 & $-10,2$ \\
\hline & & נ, & & & & $2 \%$ & & $8 \%$ \\
\hline & $\sim$ & 5140 & 505,7 & $-9,2$ & 504,7 & $-10,2$ & 504,5 & $-10,4$ \\
\hline & W & כודגנו & & & & $8 \%$ & & $2 \%$ \\
\hline $\bar{E}$ & & 5161 & 507,2 & $-8,9$ & 506,2 & $-9,9$ & 505,9 & $-10,2$ \\
\hline $4: \frac{0}{4}$ & & ג & & & & $2 \%$ & & $8 \%$ \\
\hline 08 & & גרכז & 517,6 & $-19,8$ & 516,3 & $-21,1$ & 515,8 & $-21,6$ \\
\hline$\frac{4}{n}$ & & דין ובנת & & & & $3 \%$ & & $2 \%$ \\
\hline : & $F$ & 5 & 515,9 & $-19,4$ & 514,2 & $-21,1$ & 513,6 & $-21,7$ \\
\hline & 0 & כ, נכנד & & & & $4 \%$ & & $5 \%$ \\
\hline & & & 517,4 & $-19,8$ & 515,8 & $-21,4$ & 515,2 & -22 \\
\hline & & 2, וכנד & & & & $8 \%$ & & $0 \%$ \\
\hline
\end{tabular}


A modo de comparativa entre los morteros analizados y con la intención de dar una explicación visual a cada uno de los comportamientos de estabilidad dimensional, se han desarrollado las gráficas de barras horizontales de longitudes y masas específicas como medida de normalización de los resultados (ilustraciones 43 y 44, respectivamente).

Los valores mostrados en dicha normalización corresponden al cociente ente las distintas longitudes y masas específicas de los morteros con la incorporación de CVT, (calculados como media de los valores reflejados en cada una de las tablas anteriores para cada una de las edades), y los valores de referencia de los mismos morteros sin adiciones, a esas mismas edades. De esta forma, se consigue determinar fácilmente qué morteros presentan mejores estabilidades dimensionales tanto a deformación, como a pérdida de masa, con relación a sus morteros de referencia, con el simple hecho de su cercanía, o alejamiento, a la línea de abcisas de valor 1 . Cada mortero está definido por una gama de colores característica CEM-I (azules), CEM-II (morados), CAC (granates) y CSA (verdes). De igual forma, mayor intensidad de color dentro de la misma gama implica mayor edad de los morteros.

De acuerdo a los valores reflejados en la ilustración 43, los mejores resultados en cuanto a deformación $(\varepsilon)$ para 28 días, se obtienen para los morteros elaborados con CSA $(0 / 2 \cdot 1 / 1$ y $1 / 3$ y $0 / 4 \cdot 1 / 1)$. Aunque también es significativa la estabilidad de los morteros CAC $(0 / 2 \cdot 1 / 1$ y $0 / 4 \cdot 1 / 1)$.

Igualmente, la ilustración 44 muestra la normalización de resultados elaborada para los valores de estabilidad de masa específica $(m)$ de los morteros ensayados. Al igual que ocurre con el apartado anterior, los valores óptimos se obtienen para los morteros de CAC y CSA (ambos en dosificaciones $0 / 4 \cdot 1 / 1)$, aunque también resultan positivos los morteros los morteros CSA $(0 / 4 \cdot 1 / 1)$ y CAC $(0 / 2 \cdot 1 / 1)$.

El análisis combinado de ambas ilustraciones refleja que los morteros CAC (0/4.1/1) y CSA $(0 / 4 \cdot 1 / 1)$, presentan los mejores valores de estabilidad dimensional de entre todos los analizados. De hecho, existen 
investigaciones que demuestran conductas análogas en cuanto a la estabilidades dimensionales entre los sistemas basados en cementos de aluminato de calcio y los basados en Sulfoaluminato de calcio (Bizzozero et al., 2011).

En CAC, este comportamiento diferenciado ha sido estudiado y analizado con base en la inclusión de determinadas cantidades de $\mathrm{CaCO}_{3}$ las cuales aceleraban la hidratación de la fase anhidra, mejorando la estabilidad dimensional de las muestras. De hecho, la incorporación de carbonato cálcico en pastas de CAC inhibe, o puede incluso hacer desaparecer, las reacciones de conversión de $\mathrm{CAH}_{10}$ y $\mathrm{C}_{2} \mathrm{AH}_{8}$. Este hecho está directamente relacionado con conductas más estables desde el punto de vista dimensional de las muestras analizadas (Luz y Pandolfelli, 2012).

Por el contrario, los peores valores se obtienen en ambos tipos de morteros Portland (siendo especialmente negativos los relativos a CEM-I). En este tipo de morteros, el alto contenido en cloruros y sulfatos de las cenizas volantes de RSU, pueden favorecer la formación de grandes cantidades de etringita y cloroaluminatos, los cuales movilizan gran cantidad de moléculas de agua. La formación temprana de cualquiera de estos hidratos podría explicar las contracciones de morteros que contuvieran cenizas volantes en fases tempranas. 


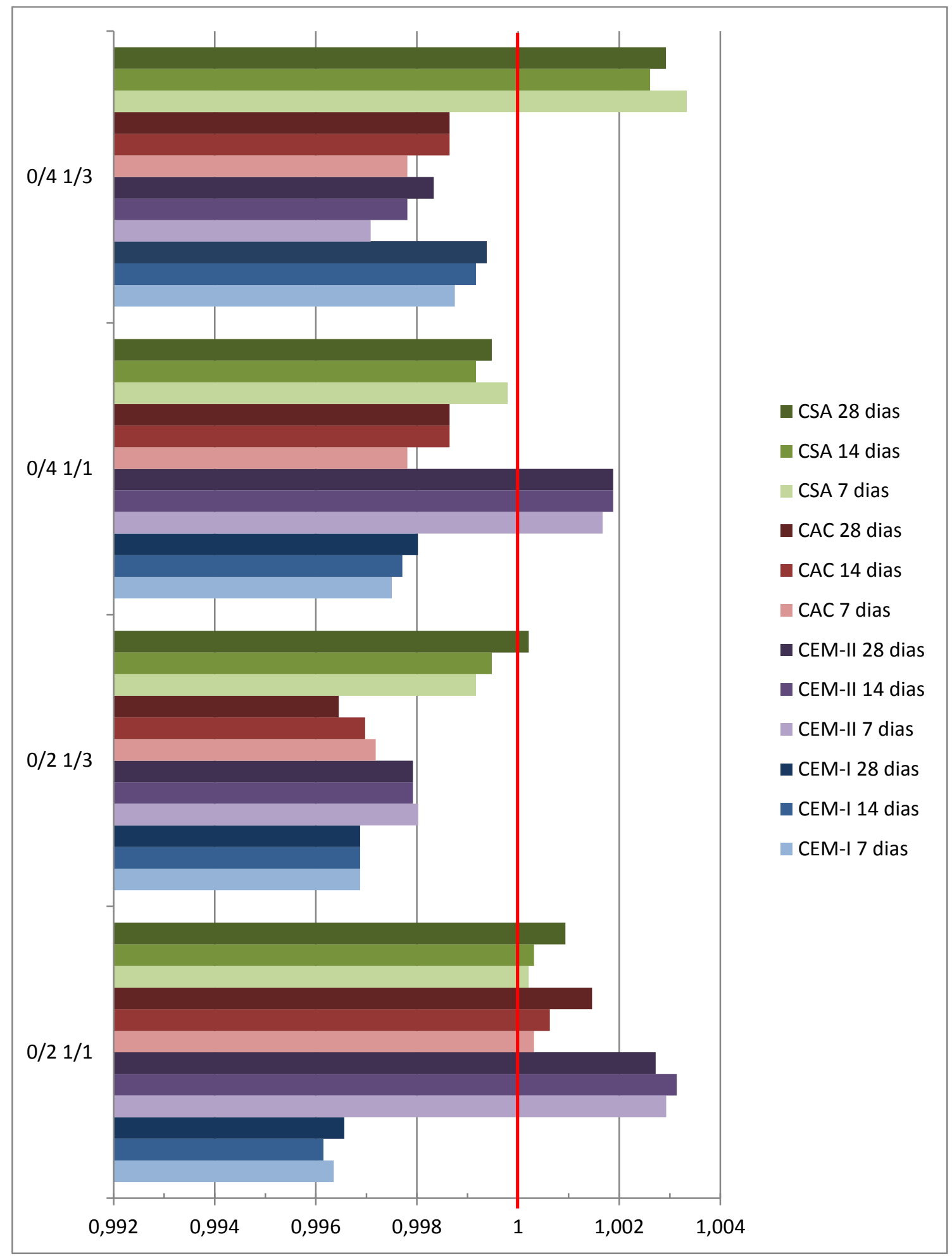

Ilustración 43. Normalización de resultados de la variación de la longitud específica o deformación $(\varepsilon)$, a 7, 14 y 28 días de cada una de las dosificaciones ensayadas. Los valores mostrados corresponden al cociente entre las distintas longitudes de los morteros con la incorporación de CVT, en cada una de las edades, y los valores de referencia de los morteros sin adiciones, a esas mismas edades. 


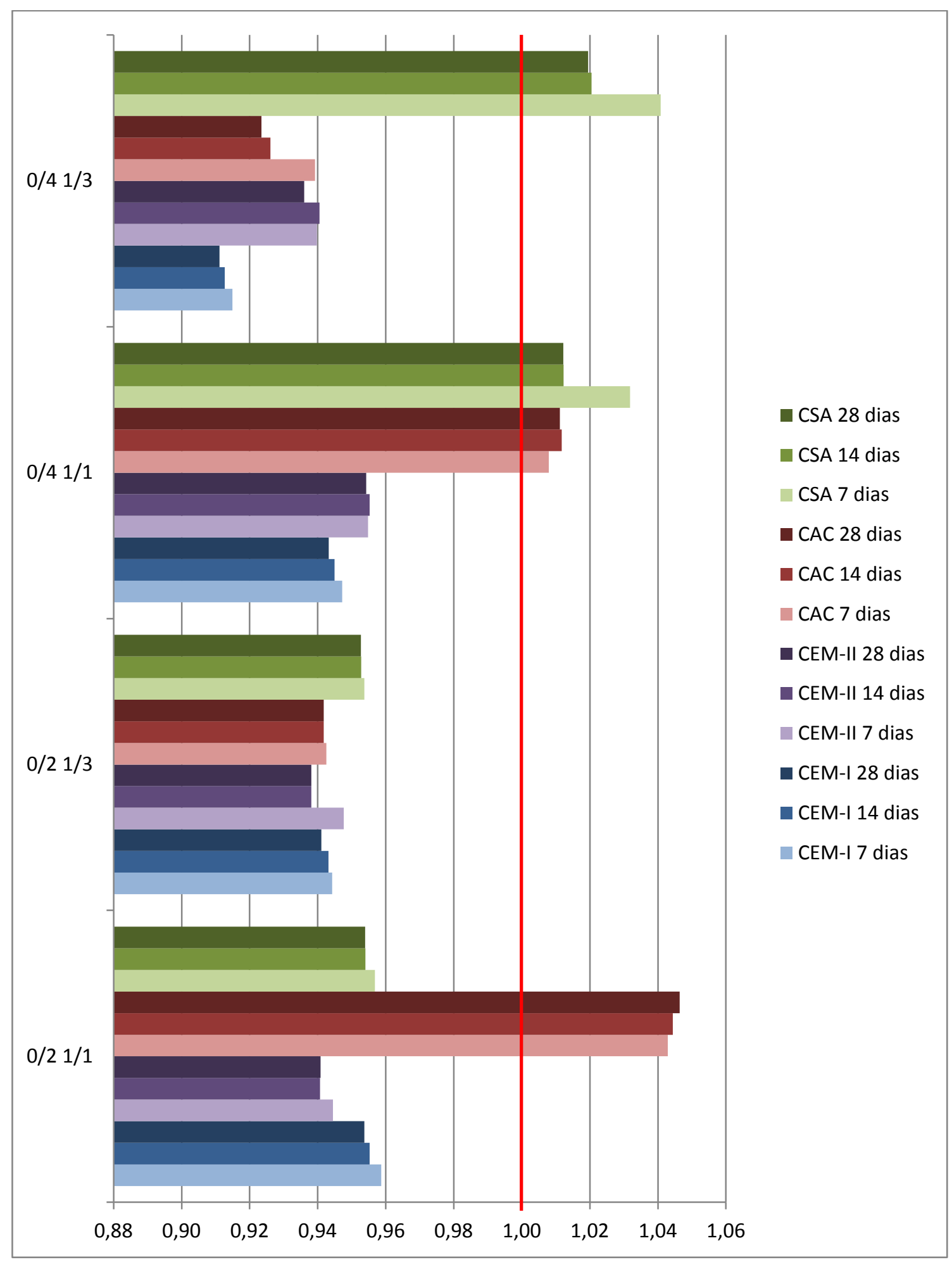

Ilustración 44. Normalización de resultados de la variación de la masa específica $(\mathrm{m})$ a 7 , 14 y 28 días de cada una de las dosificaciones ensayadas. Los valores mostrados corresponden al cociente entre las distintas masas específicas de los morteros con la incorporación de CVT, en cada una de las edades, y los valores de referencia de los morteros sin adiciones, a esas mismas edades. 


\subsubsection{DENSIDAD APARENTE EN SECO DEL MORTERO ENDURECIDO (UNE EN 1015-10)}

Como análisis complementario al de estabilidad dimensional, en los siguientes apartados se presentan los resultados referentes a la densidad del mortero en seco de todos los morteros analizados durante la investigación.

\subsubsection{Densidad aparente en seco de los morteros de CEM-I}

Las tablas 43 y 44 muestran los resultados analíticos obtenidos para el cálculo de la densidad media aparente en seco de los morteros elaborados con CEM-I tanto para morteros con tamaño de árido 0/2 (tabla 43), como para áridos 0/4 (tabla 44). Los datos fueron obtenidos de una serie de tres probetas elaboradas exclusivamente para tal fin.

La ilustración 45 presenta los valores medios de dichas densidades y su comparación entre los morteros de referencia ( $0 \% \mathrm{CVT}$ ) y los morteros con la incorporación de cenizas volantes inertizadas en forma de carbonatos (CVT), todas ellas elaboradas para cada una de las dosificaciones estudiadas.

Los resultados obtenidos son muy homogéneos. La incorporación de CVT a los morteros de CEM-I provoca una reducción de la densidad del mortero seco que varía entre un $9,31 \%$, en el caso de morteros con dosificación $1 / 3$ y tamaño de árido $0 / 2$, hasta un $18,68 \%$ para los de la misma dosificación pero con un árido de mayor diámetro (0/4).

De los datos se puede inferir que las densidades disminuyen con respecto a las muestras de referencia cuanto mayor es el tamaño del árido y cuanta más cantidad de finos se utilizan en su elaboración. Esto está claramente relacionado con los índices de agua requerida para el amasado de las mezclas. Los morteros con CVT en su formulación requerían mayor cantidad de agua, lo cual afecta negativamente a la porosidad de las matrices. Por otro lado, cuanto mayor es el diámetro de los áridos 
utilizados, mayor cantidad de espacios intersticiales presentarán los morteros, lo cual implica una menor densidad.

Tabla 43. Densidad media aparente en seco del mortero de CEM-I endurecido con tamaño del árido 0/2. Valores analíticos de cálculo de cada una de las tres probetas analizadas en cada dosificación. (R) Morteros de referencia. (CVT) Morteros con la incorporación de cenizas volantes inertizadas en una proporción de un $10 \%$ en peso de los áridos.

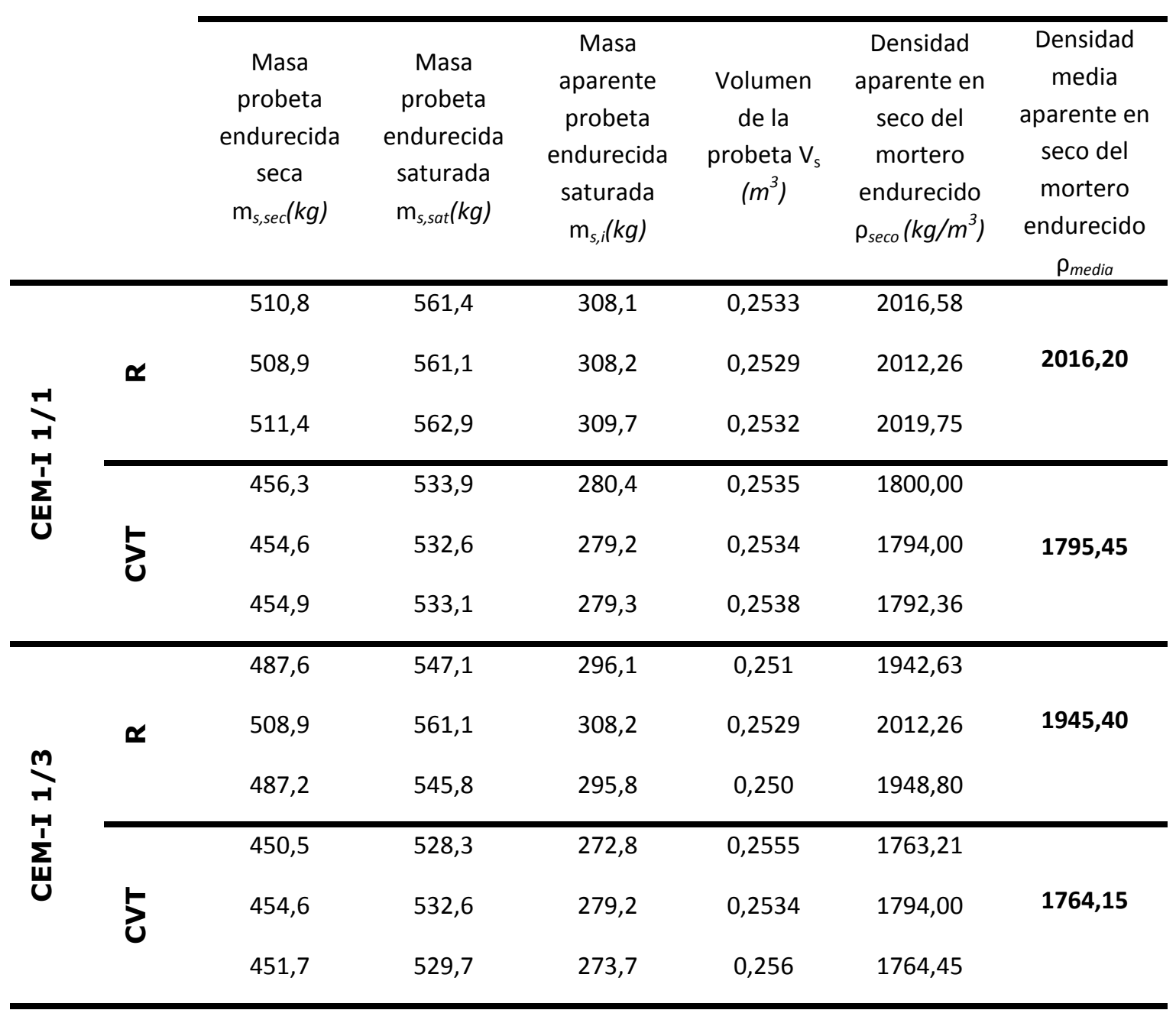


Tabla 44. Densidad media aparente en seco del mortero de CEM-I endurecido con tamaño del árido 0/4. Valores analíticos de cálculo de cada una de las tres probetas analizadas en cada dosificación. (R) Morteros de referencia. (CVT) Morteros con la incorporación de cenizas volantes inertizadas en una proporción de un $10 \%$ en peso de los áridos.

\begin{tabular}{|c|c|c|c|c|c|c|c|}
\hline & & $\begin{array}{c}\text { Masa } \\
\text { probeta } \\
\text { endurecida } \\
\text { seca } \\
\mathrm{m}_{s, \text { sec }}(\mathrm{kg})\end{array}$ & $\begin{array}{c}\text { Masa } \\
\text { probeta } \\
\text { endurecida } \\
\text { saturada } \\
\mathrm{m}_{s, \text { sat }}(\mathrm{kg})\end{array}$ & $\begin{array}{c}\text { Masa } \\
\text { aparente } \\
\text { probeta } \\
\text { endurecida } \\
\text { saturada } \\
\mathrm{m}_{s, i}(\mathrm{~kg})\end{array}$ & $\begin{array}{c}\text { Volumen } \\
\text { de la } \\
\text { probeta } \mathrm{V}_{\mathrm{s}} \\
\left(\mathrm{m}^{3}\right)\end{array}$ & $\begin{array}{c}\text { Densidad } \\
\text { aparente en } \\
\text { seco del } \\
\text { mortero } \\
\text { endurecido } \\
\rho_{\text {seco }}\left(\mathrm{kg} / \mathrm{m}^{3}\right)\end{array}$ & $\begin{array}{c}\text { Densidad } \\
\text { media } \\
\text { aparente en } \\
\text { seco del } \\
\text { mortero } \\
\text { endurecido } \\
\rho_{\text {media }}\end{array}$ \\
\hline \multirow{6}{*}{ 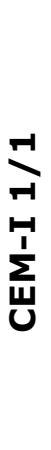 } & \multirow{3}{*}{$\boldsymbol{\alpha}$} & 503,6 & 561,6 & 306,5 & 0,2551 & 1974,13 & \multirow{3}{*}{1982,86} \\
\hline & & 508,9 & 561,1 & 308,2 & 0,2529 & 2012,26 & \\
\hline & & 504,5 & 560,9 & 306,6 & 0,2543 & 1983,88 & \\
\hline & & 475,10 & 568,00 & 284,50 & 0,2835 & 1675,84 & \multirow{3}{*}{1672,94} \\
\hline & & 454,6 & 532,6 & 279,2 & 0,2534 & 1794,00 & \\
\hline & & 474,40 & 569,00 & 284,60 & 0,2844 & 1668,07 & \\
\hline \multirow{6}{*}{ 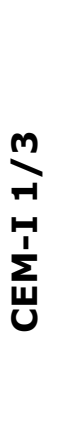 } & \multirow{3}{*}{$\boldsymbol{\alpha}$} & 505,9 & 562,7 & 310,2 & 0,2525 & 2003,56 & \multirow{3}{*}{2007,64} \\
\hline & & 508,9 & 561,1 & 308,2 & 0,2529 & 2012,26 & \\
\hline & & 509,1 & 566,2 & 312,7 & 0,2535 & 2008,28 & \\
\hline & & 459,6 & 559,7 & 278,2 & 0,2815 & 1632,68 & \multirow{3}{*}{1632,55} \\
\hline & & 454,6 & 532,6 & 279,2 & 0,2534 & 1794,00 & \\
\hline & & 460,5 & 560,2 & 278,5 & 0,2817 & 1634,72 & \\
\hline
\end{tabular}




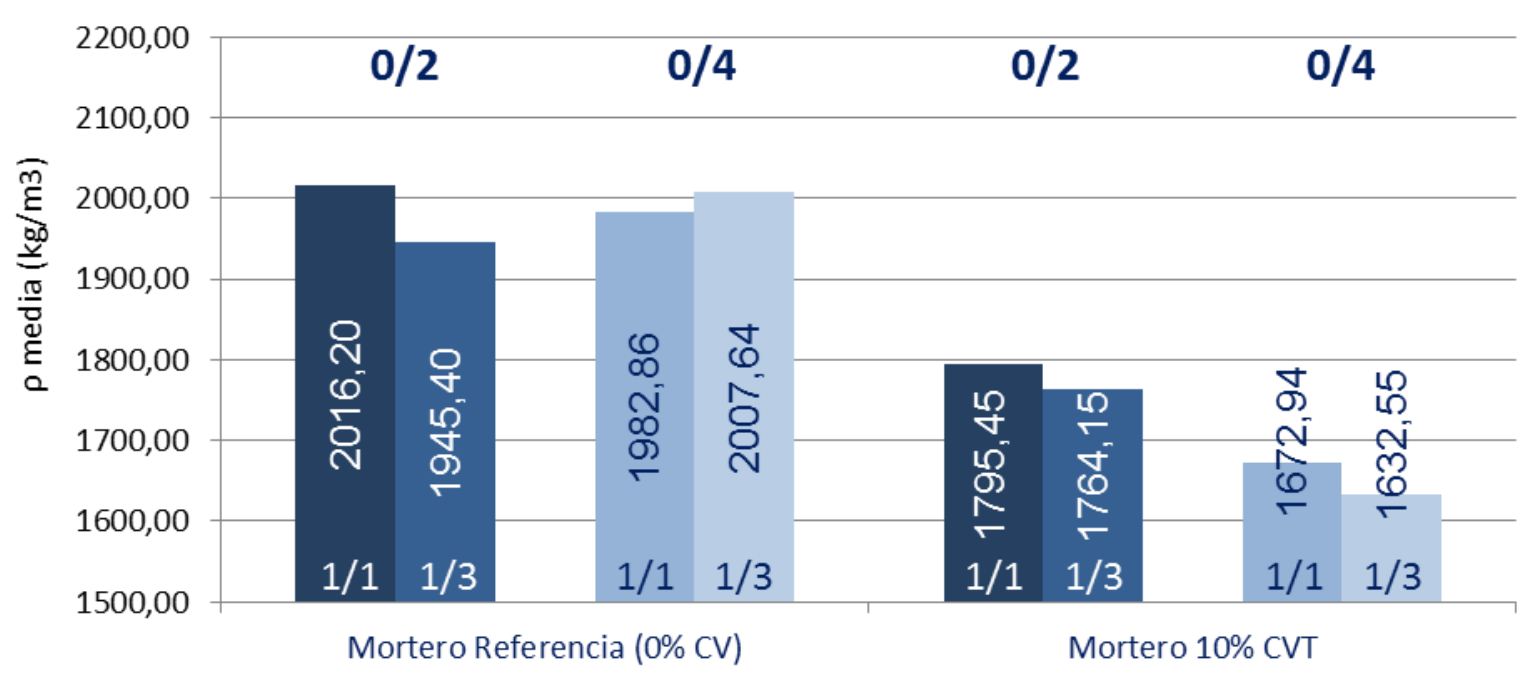

Ilustración 45. Densidad media aparente en seco, en $\mathrm{kg} / \mathrm{m}^{3}$, de los morteros de CEM-I (EN 1015-10:2000). Diámetros de árido 0/2 y 0/4. Relación de cemento/árido $1 / 1$ y 1/3.

\subsubsection{Densidad aparente en seco de los morteros de CEM-II A/P}

Las tablas 45 y 46 muestran los resultados analíticos obtenidos para el cálculo de la densidad media aparente en seco de los morteros elaborados con CEM-II A/P tanto para morteros con tamaño de árido 0/2 (tabla 45), como para áridos 0/4 (tabla 46). Los datos fueron obtenidos de una serie de tres probetas elaboradas exclusivamente para tal fin.

La ilustración 46 presenta los valores medios de dichas densidades y su comparación entre los morteros de referencia $(R)$ y los morteros con la incorporación de cenizas volantes inertizadas en forma de carbonatos, todas ellas elaboradas para cada una de las dosificaciones estudiadas.

De nuevo, los datos obtenidos son muy homogéneos y similares en su comportamiento a los obtenidos en los morteros elaborados con CEM-I. En este caso, no existe una relación clara en la reducción de densidades al incorporar CVT si bien, a diferencia de los que ocurría en los de CEM-I, los mejores resultados se obtienen cuando el tamaño de árido es mayor (0/4). En dosificaciones 1/1 la disminución en la densidad es de un 7,69\% frente al $8,97 \%$ obtenido en los morteros con menor diámetro de árido. De igual 
forma, en las dosificaciones $1 / 3$ se comporta mejor el mortero con el árido más grueso: 8,38\% de reducción de densidad, frente a un 10,55\%. Este tipo de cementos favorece el relleno de los espacios intersticiales entre partículas de mejor manera que los morteros de CEM-I.

Tabla 45. Densidad media aparente en seco del mortero endurecido de CEM-II A/P con tamaño del árido $0 / 2$. Valores analíticos de cálculo de cada una de las tres probetas analizadas en cada dosificación. (R) Morteros de referencia. (CVT) Morteros con la incorporación de cenizas volantes inertizadas en una proporción de un $10 \%$ en peso de los áridos.

\begin{tabular}{|c|c|c|c|c|c|}
\hline $\begin{array}{c}\text { Masa } \\
\text { probeta } \\
\text { endurecida } \\
\text { seca } \\
\mathrm{m}_{s, \text { sec }}(\mathrm{kg})\end{array}$ & $\begin{array}{c}\text { Masa } \\
\text { probeta } \\
\text { endurecida } \\
\text { saturada } \\
\mathrm{m}_{s, s a t}(k g)\end{array}$ & $\begin{array}{c}\text { Masa } \\
\text { aparente } \\
\text { probeta } \\
\text { endurecida } \\
\text { saturada } \\
\mathrm{m}_{s, i}(\mathrm{~kg})\end{array}$ & $\begin{array}{c}\text { Volumen } \\
\text { de la } \\
\text { probeta } V_{s} \\
\left(\mathrm{~m}^{3}\right)\end{array}$ & $\begin{array}{c}\text { Densidad } \\
\text { aparente en } \\
\text { seco del } \\
\text { mortero } \\
\text { endurecido } \\
\rho_{\text {seco }}\left(\mathrm{kg} / \mathrm{m}^{3}\right)\end{array}$ & $\begin{array}{c}\text { Densidad } \\
\text { media } \\
\text { aparente en } \\
\text { seco del } \\
\text { mortero } \\
\text { endurecido } \\
\rho_{\text {media }}\end{array}$ \\
\hline 501,7 & 564,6 & 310,3 & 0,2543 & 1972,87 & \\
\hline 502,3 & 565,2 & 310,9 & 0,2543 & 1975,23 & 1975,80 \\
\hline 506,9 & 570,0 & 313,9 & 0,2561 & 1979,30 & \\
\hline 461,5 & 543,1 & 286,8 & 0,2563 & 1800,62 & \\
\hline 460,9 & 543,0 & 286,4 & 0,2566 & 1796,18 & 1798,62 \\
\hline 463,8 & 545,5 & 287,7 & 0,2578 & 1799,07 & \\
\hline 491,2 & 552,4 & 303,2 & 0,2492 & 1971,11 & \\
\hline 491,4 & 553,2 & 303,7 & 0,2495 & 1969,54 & 1969,02 \\
\hline 491,8 & 553,4 & 303,3 & 0,2501 & 1966,41 & \\
\hline 451,7 & 533,4 & 277,3 & 0,2561 & 1763,76 & \\
\hline 452,4 & 535,1 & 278,1 & 0,257 & 1760,31 & 1761,21 \\
\hline 451,5 & 533,9 & 277,3 & 0,2566 & 1759,55 & \\
\hline
\end{tabular}


Tabla 46. Densidad media aparente en seco del mortero endurecido de CEM-II A/P con tamaño del árido 0/4. Valores analíticos de cálculo de cada una de las tres probetas analizadas en cada dosificación. (R) Morteros de referencia. (CVT) Morteros con la incorporación de cenizas volantes inertizadas en una proporción de un $10 \%$ en peso de los áridos.

\begin{tabular}{cccccc}
\hline $\begin{array}{c}\text { Masa } \\
\text { probeta } \\
\text { endurecida } \\
\text { seca } \\
\mathrm{m}_{s, \text { sec }}(\mathrm{kg})\end{array}$ & $\begin{array}{c}\text { Masa } \\
\text { probeta } \\
\text { endurecida } \\
\text { saturada } \\
\mathrm{m}_{\mathrm{s} \text { sat }}(\mathrm{kg})\end{array}$ & $\begin{array}{c}\text { Masa } \\
\text { aparente } \\
\text { probeta } \\
\text { endurecida } \\
\text { saturada } \\
\mathrm{m}_{\mathrm{s},}(\mathrm{kg})\end{array}$ & $\begin{array}{c}\text { Volumen } \\
\text { de la } \\
\text { probeta } \mathrm{V}_{\mathrm{s}} \\
\left(\mathrm{m}^{3}\right)\end{array}$ & $\begin{array}{c}\text { Densidad } \\
\text { aparente en } \\
\text { seco del } \\
\text { mortero } \\
\text { endurecido } \\
\rho_{\text {seco }}\left(\mathrm{kg} / \mathrm{m}^{3}\right)\end{array}$ & $\begin{array}{c}\text { Densidad } \\
\text { media } \\
\text { aparente en } \\
\text { seco del } \\
\text { mortero } \\
\text { endurecido } \\
\rho_{\text {media }}\end{array}$ \\
\hline 510,0 & 569,8 & 315,1 & 0,2547 & 2002,36 &
\end{tabular}

\begin{tabular}{|c|c|c|c|c|c|c|c|}
\hline \multirow{7}{*}{ 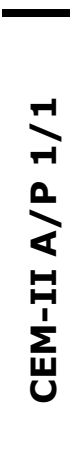 } & & & & & & & $\rho_{\text {media }}$ \\
\hline & \multirow{3}{*}{$\underline{\alpha}$} & 510,0 & 569,8 & 315,1 & 0,2547 & 2002,36 & \multirow{3}{*}{2006,53} \\
\hline & & 509,9 & 569,1 & 314,7 & 0,2544 & 2004,32 & \\
\hline & & 514,3 & 574,0 & 318,5 & 0,2555 & 2012,92 & \\
\hline & \multirow{3}{*}{5} & 476,7 & 551,8 & 294,5 & 0,2573 & 1852,70 & \multirow{3}{*}{1852,14} \\
\hline & & 477,4 & 553,3 & 295,6 & 0,2577 & 1852,54 & \\
\hline & & 473,9 & 548,1 & 292,1 & 0,256 & 1851,17 & \\
\hline \multirow{6}{*}{ 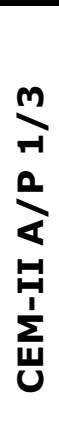 } & \multirow{3}{*}{$\boldsymbol{\alpha}$} & 505,0 & 565,0 & 310,5 & 0,2545 & 1984,28 & \multirow{3}{*}{1978,77} \\
\hline & & 503,7 & 564,8 & 309,5 & 0,2553 & 1972,97 & \\
\hline & & 500,9 & 561,0 & 307,9 & 0,2531 & 1979,06 & \\
\hline & \multirow{3}{*}{ Z } & 462,3 & 539,1 & 283,4 & 0,2557 & 1807,98 & \multirow{3}{*}{1812,87} \\
\hline & & 466,7 & 543,7 & 286,2 & 0,2575 & 1812,43 & \\
\hline & & 467,1 & 543,4 & 286,5 & 0,2569 & 1818,22 & \\
\hline
\end{tabular}




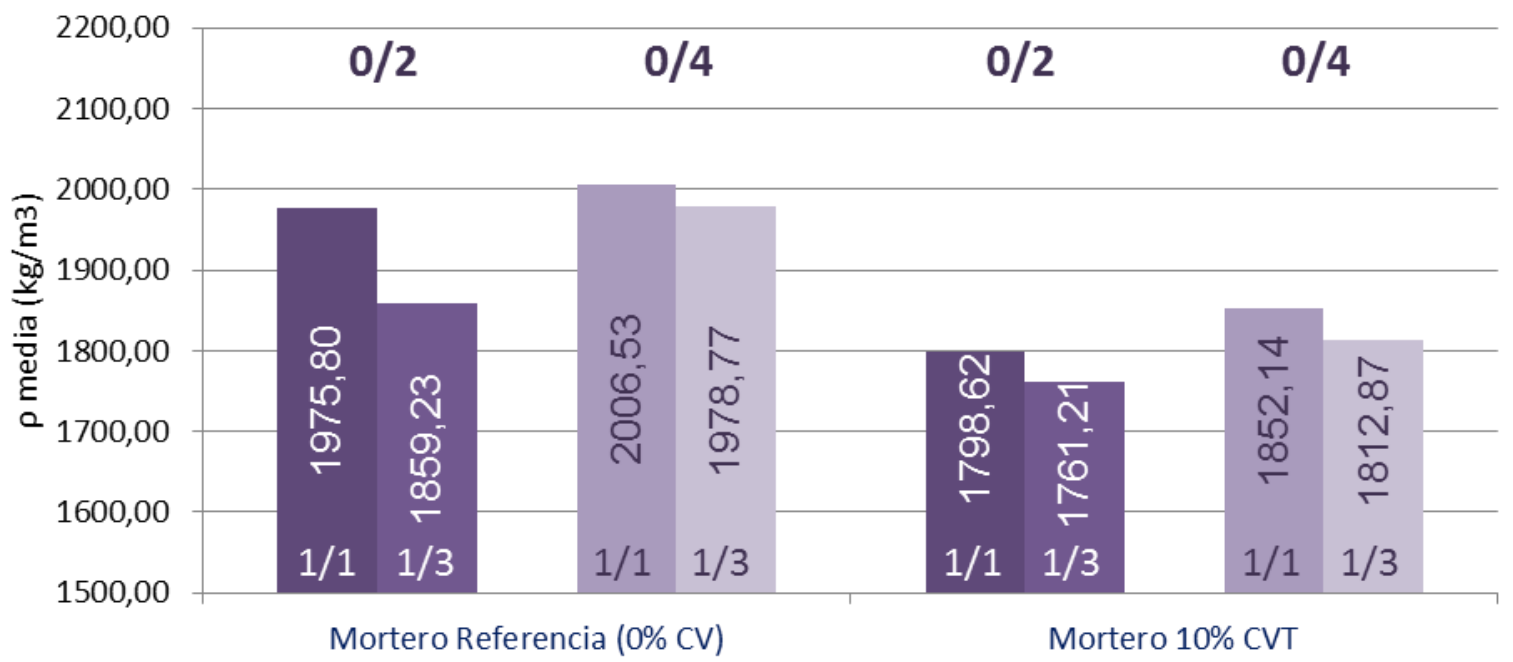

Ilustración 46. Densidad media aparente en seco, en $\mathrm{kg} / \mathrm{m}^{3}$, de los morteros de CEM-II A/P (EN 1015-10:2000). Diámetros de árido 0/2 y 0/4. Relación de cemento/árido 1/1 y 1/3.

\subsubsection{Densidad aparente en seco de los morteros de CAC}

Las tablas 47 y 48 muestran los resultados analíticos obtenidos para el cálculo de la densidad media aparente en seco de los morteros elaborados con CAC tanto para morteros con tamaño de árido 0/2 (tabla 47), como para áridos 0/4 (tabla 48). Los datos fueron obtenidos de una serie de tres probetas elaboradas exclusivamente para tal fin.

La ilustración 47 presenta los valores medios de dichas densidades y su comparación entre los morteros de referencia (R) y los morteros con la incorporación de cenizas volantes inertizadas en forma de carbonatos, todas ellas elaboradas para cada una de las dosificaciones estudiadas.

Los resultados obtenidos resultan dispares dependiendo de la dosificación de los morteros. En los morteros ricos (1/1), la adición de CVT implica una aumento de la densidad, mientras que en los morteros tradicionales (1/3) se produce el efecto contrario acorde a lo visto con anterioridad en los cementos Portland ( $\mathrm{I}$ y II A/P), pero con unas disminuciones de la densidad proporcionalmente mucho menores. Dependiendo del tamaño del árido se obtienen una reducción en la densidad con respecto al mortero de referencia del 5,31\%, en tamaños de árido de 
0/2, y del 5,96\%, para los 0/4. También influye el proceso de "conversión" característico de los cementos de aluminato de calcio. La conversión implica una reducción del volumen de hidratos durante el proceso de fraguado. Está reducción es debida a la pérdida del agua de cristalización ocurrida durante la transformación de los hidratos hexagonales a cúbicos (Garcés et al., 2012). En comparación con la estabilidad dimensional de las muestras, éstas permanecen prácticamente constantes, el proceso de conversión conlleva una reducción de la densidad y un incremento de la porosidad debido a la gran cantidad de poros generados en la evaporación del agua durante el fraguado.

Los datos relativos a los morteros $1 / 1$ presentan unos aumentos de las densidades de 3,45\% para áridos $0 / 2$ y de 2,77\% para los de 0/4. Estos datos están íntimamente relacionados con los del agua de amasado ya que, precisamente estos dos tipos de morteros son los que requieren de una menor cantidad de agua que las de sus respectivos morteros de referencia. Por contraposición a lo explicado en el párrafo anterior, en este caso se deduce la ausencia del proceso de conversión del CAC, lo cual implica un aumento de la densidad y un mejor comportamiento mecánico de las pastas así elaboradas. El proceso de carbonatación reduce significativamente la porosidad del material y, por lo tanto, incrementa su densidad (FernándezCarrasco et al., 2008), punto este que será comprobado en los sucesivos capítulos.

A lo anteriormente expuesto hay que añadir que, en el estudio de los difractogramas DRX relativos a estos morteros, no se apreció la formación de etringita, la cual está íntimamente relacionada con la posible interconexión entre poros aislados dentro de las matrices de cemento con el consiguiente aumento de la porosidad y reducción de la densidad (Bizzozero et al., 2014). 
Tabla 47. Densidad media aparente en seco del mortero endurecido de CAC con tamaño del árido 0/2. Valores analíticos de cálculo de cada una de las tres probetas analizadas en cada dosificación. (R) Morteros de referencia. (CVT) Morteros con la incorporación de cenizas volantes inertizadas en una proporción de un $10 \%$ en peso de los áridos.

\begin{tabular}{|c|c|c|c|c|c|c|c|}
\hline & & $\begin{array}{c}\text { Masa } \\
\text { probeta } \\
\text { endurecida } \\
\text { seca } \\
\mathrm{m}_{s, \text { sec }}(\mathrm{kg})\end{array}$ & $\begin{array}{c}\text { Masa } \\
\text { probeta } \\
\text { endurecida } \\
\text { saturada } \\
\mathrm{m}_{s, \text { sat }}(\mathrm{kg})\end{array}$ & $\begin{array}{c}\text { Masa } \\
\text { aparente } \\
\text { probeta } \\
\text { endurecida } \\
\text { saturada } \\
\mathrm{m}_{\mathrm{s}, \mathrm{l}}(\mathrm{kg})\end{array}$ & $\begin{array}{c}\text { Volumen } \\
\text { de la } \\
\text { probeta } V_{s} \\
\left(\mathrm{~m}^{3}\right)\end{array}$ & $\begin{array}{c}\text { Densidad } \\
\text { aparente en } \\
\text { seco del } \\
\text { mortero } \\
\text { endurecido } \\
\rho_{\text {seco }}\left(\mathrm{kg} / \mathrm{m}^{3}\right)\end{array}$ & $\begin{array}{c}\text { Densidad } \\
\text { media } \\
\text { aparente en } \\
\text { seco del } \\
\text { mortero } \\
\text { endurecido } \\
\rho_{\text {media }}\end{array}$ \\
\hline \multirow{6}{*}{$\begin{array}{l}-1 \\
\frac{1}{4} \\
0\end{array}$} & \multirow{3}{*}{$\boldsymbol{\alpha}$} & 537,20 & 582,10 & 330,00 & 0,2521 & 2130,90 & \multirow{3}{*}{2127,64} \\
\hline & & 539,40 & 585,50 & 332,10 & 0,2534 & 2128,65 & \\
\hline & & 537,00 & 582,70 & 329,80 & 0,2529 & 2123,37 & \\
\hline & \multirow{3}{*}{$\underset{v}{5}$} & 563,10 & 604,70 & 348,90 & 0,2558 & 2201,33 & \multirow{3}{*}{2201,12} \\
\hline & & 565,60 & 606,60 & 350,20 & 0,2564 & 2205,93 & \\
\hline & & 563,30 & 605,60 & 349,10 & 0,2565 & 2196,10 & \\
\hline \multirow{6}{*}{$\begin{array}{l}m \\
\dot{H} \\
0\end{array}$} & \multirow{3}{*}{$\propto$} & 524,60 & 576,00 & 322,50 & 0,2535 & 2069,43 & \multirow{3}{*}{2070,18} \\
\hline & & 524,10 & 574,80 & 321,80 & 0,2530 & 2071,54 & \\
\hline & & 526,50 & 578,00 & 323,60 & 0,2544 & 2069,58 & \\
\hline & & 494,90 & 551,30 & 299,80 & 0,2515 & 1967,79 & \multirow{3}{*}{1960,16} \\
\hline & & 494,50 & 551,70 & 299,70 & 0,2520 & 1962,30 & \\
\hline & & 491,50 & 551,20 & 299,20 & 0,2520 & 1950,40 & \\
\hline
\end{tabular}


Tabla 48. Densidad media aparente en seco del mortero endurecido de CAC con tamaño del árido 0/4. Valores analíticos de cálculo de cada una de las tres probetas analizadas en cada dosificación. (R) Morteros de referencia. (CVT) Morteros con la incorporación de cenizas volantes inertizadas en una proporción de un $10 \%$ en peso de los áridos.

\begin{tabular}{|c|c|c|c|c|c|c|c|}
\hline & & $\begin{array}{c}\text { Masa } \\
\text { probeta } \\
\text { endurecida } \\
\text { seca } \\
\mathrm{m}_{\mathrm{s}, \mathrm{sec}}(\mathrm{kg})\end{array}$ & $\begin{array}{c}\text { Masa } \\
\text { probeta } \\
\text { endurecida } \\
\text { saturada } \\
\mathrm{m}_{s, s a t}(\mathrm{~kg})\end{array}$ & $\begin{array}{c}\text { Masa } \\
\text { aparente } \\
\text { probeta } \\
\text { endurecida } \\
\text { saturada } \\
\mathrm{m}_{s, i}(\mathrm{~kg})\end{array}$ & $\begin{array}{c}\text { Volumen } \\
\text { de la } \\
\text { probeta } V_{\mathrm{s}} \\
\left(\mathrm{m}^{3}\right)\end{array}$ & $\begin{array}{c}\text { Densidad } \\
\text { aparente en } \\
\text { seco del } \\
\text { mortero } \\
\text { endurecido } \\
\rho_{\text {seco }}\left(\mathrm{kg} / \mathrm{m}^{3}\right)\end{array}$ & $\begin{array}{c}\text { Densidad } \\
\text { media } \\
\text { aparente en } \\
\text { seco del } \\
\text { mortero } \\
\text { endurecido } \\
\rho_{\text {media }}\end{array}$ \\
\hline \multirow{6}{*}{ 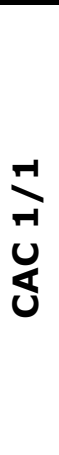 } & \multirow{3}{*}{$\boldsymbol{x}$} & 537,5 & 592,7 & 338,2 & 0,2545 & 2111,98 & \multirow{3}{*}{2106,84} \\
\hline & & 537,6 & 593,5 & 338,3 & 0,2552 & 2106,58 & \\
\hline & & 529,9 & 585,8 & 333,7 & 0,2521 & 2101,94 & \\
\hline & \multirow{3}{*}{5} & 549,4 & 594,2 & 340,3 & 0,2539 & 2163,84 & \multirow{3}{*}{2165,22} \\
\hline & & 549 & 594,3 & 341,6 & 0,2527 & 2172,54 & \\
\hline & & 546,3 & 592,6 & 339,6 & 0,253 & 2159,29 & \\
\hline \multirow{6}{*}{ 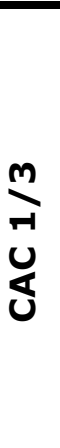 } & \multirow{6}{*}{5} & 554,4 & 601,5 & 342,3 & 0,2592 & 2138,89 & \multirow{3}{*}{2134,29} \\
\hline & & 550,1 & 597,5 & 339,5 & 0,258 & 2132,17 & \\
\hline & & 546,6 & 594 & 337,6 & 0,2564 & 2131,83 & \\
\hline & & 511,9 & 561,8 & 306,8 & 0,255 & 2007,45 & \multirow{3}{*}{2006,93} \\
\hline & & 511,2 & 562,1 & 307,3 & 0,2548 & 2006,28 & \\
\hline & & 512,2 & 563,7 & 308,5 & 0,2552 & 2007,05 & \\
\hline
\end{tabular}




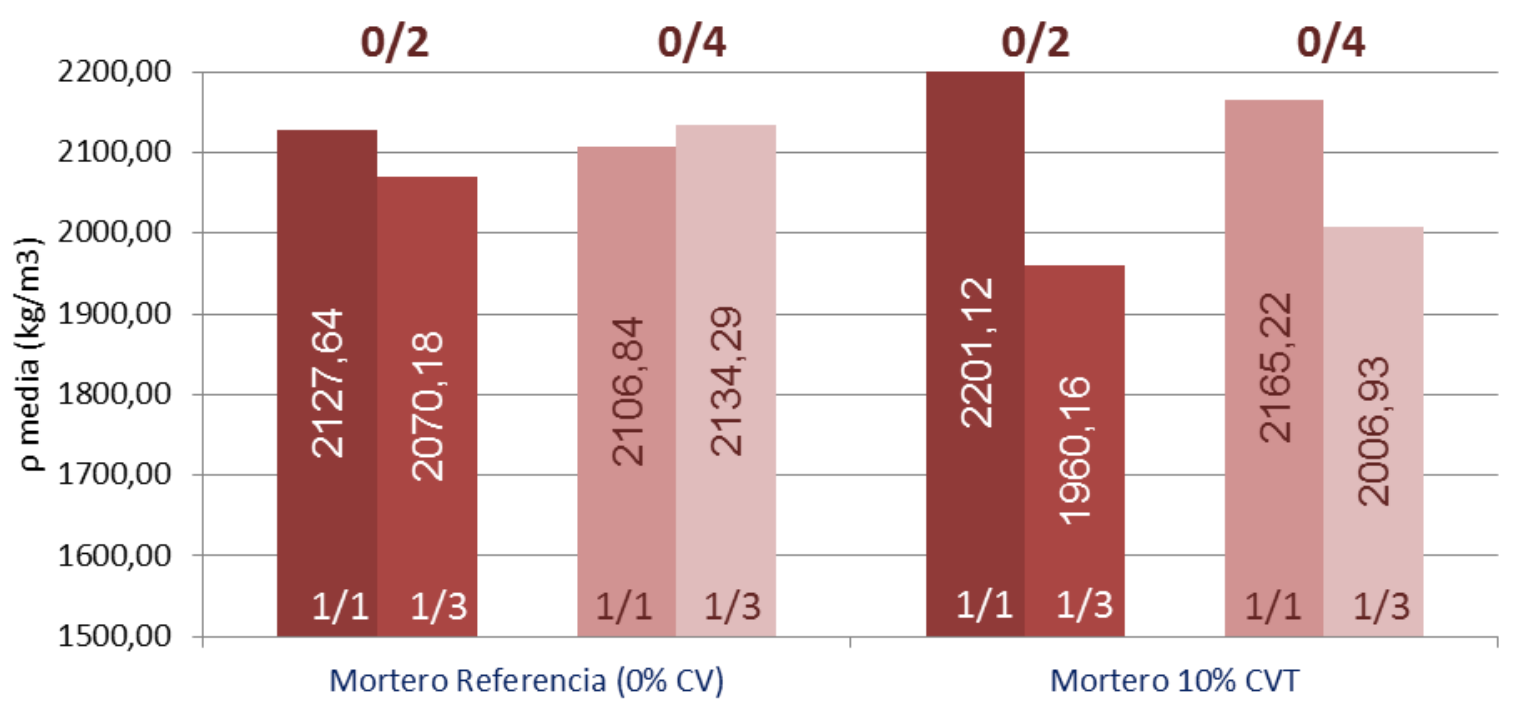

Ilustración 47. Densidad media aparente en seco, en $\mathrm{kg} / \mathrm{m}^{3}$, de los morteros de CAC (EN 1015-10:2000). Diámetros de árido 0/2 y 0/4. Relación de cemento/árido $1 / 1$ y 1/3.

\subsubsection{Densidad aparente en seco de los morteros de CSA}

Las tablas 49 y 50 muestran los resultados analíticos obtenidos para el cálculo de la densidad media aparente en seco de los morteros elaborados con CSA tanto para morteros con tamaño de árido 0/2 (tabla 49), como para áridos 0/4 (tabla 50). Los datos fueron obtenidos de una serie de tres probetas elaboradas exclusivamente para tal fin.

La ilustración 48 presenta los valores medios de dichas densidades y su comparación entre los morteros de referencia $(R)$ y los morteros con la incorporación de cenizas volantes inertizadas en forma de carbonatos, todas ellas elaboradas para cada una de las dosificaciones estudiadas.

Son especialmente positivos los resultados obtenidos en las dosificaciones con áridos de mayor tamaño (1/4). Al contrario de lo que pudiera intuirse, el aumento en el requerimiento de agua de amasado, no incide directamente en la porosidad del material ya que los resultados no difieren llamativamente si los comparamos con los morteros de referencia. En el caso de morteros con dosificación $1 / 3$, la diferencia con su mortero de referencia es de un $+0,67 \%$, mientras que en el caso de la dosificación $1 / 1$ esta diferencia es de sólo un $-0,03 \%$. Por lo tanto la inclusión de CVT en los 
morteros de CSA y dosificación 0/4 no afecta a la densidad de los mismos. Esto puede ser explicado por la rápida formación de cristales de etringita que desarrollan una microestructura de la matriz perfectamente definida, incluso durante las primeras 24 horas de hidratación (Irico et al., 2013).

Por el contrario, la disminución del tamaño del árido en la confección de los morteros produce una disminución en la densidad del mortero seco que va desde una reducción del $4,44 \%$ en el caso de dosificaciones $1 / 1$, a un $6,34 \%$ para las dosificaciones $1 / 3$. A mayor cantidad de áridos y cuanto más fino sea éste, mayor reducción de la densidad del mortero, la cual podría estar relacionada en este caso con la mayor cantidad de agua de amasado que requieren estos morteros, y con el efecto relleno que tienen las cenizas volantes de RSU.(García-Maté et al., 2013). 
Tabla 49. Densidad media aparente en seco del mortero endurecido de CSA con tamaño del árido 0/2. Valores analíticos de cálculo de cada una de las tres probetas analizadas en cada dosificación. (R) Morteros de referencia. (CVT) Morteros con la incorporación de cenizas volantes inertizadas en una proporción de un $10 \%$ en peso de los áridos.

\begin{tabular}{|c|c|c|c|c|c|c|c|}
\hline & & $\begin{array}{c}\text { Masa } \\
\text { probeta } \\
\text { endurecida } \\
\text { seca } \\
\mathrm{m}_{s, \text { sec }}(\mathrm{kg})\end{array}$ & $\begin{array}{c}\text { Masa } \\
\text { probeta } \\
\text { endurecida } \\
\text { saturada } \\
\mathrm{m}_{s, s a t}(\mathrm{~kg})\end{array}$ & $\begin{array}{c}\text { Masa } \\
\text { aparente } \\
\text { probeta } \\
\text { endurecida } \\
\text { saturada } \\
\mathrm{m}_{s, i}(\mathrm{~kg})\end{array}$ & $\begin{array}{c}\text { Volumen } \\
\text { de la } \\
\text { probeta } V_{s} \\
\left(\mathrm{~m}^{3}\right)\end{array}$ & $\begin{array}{c}\text { Densidad } \\
\text { aparente en } \\
\text { seco del } \\
\text { mortero } \\
\text { endurecido } \\
\rho_{\text {seco }}\left(\mathrm{kg} / \mathrm{m}^{3}\right)\end{array}$ & $\begin{array}{c}\text { Densidad } \\
\text { media } \\
\text { aparente en } \\
\text { seco del } \\
\text { mortero } \\
\text { endurecido } \\
\rho_{\text {media }}\end{array}$ \\
\hline \multirow{6}{*}{ 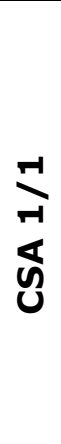 } & \multirow{6}{*}{$\boldsymbol{\alpha}$} & 506,0 & 562,3 & 305,8 & 0,2565 & 1972,71 & \multirow{3}{*}{1971,20} \\
\hline & & 504,4 & 562,4 & 305,4 & 0,257 & 1962,65 & \\
\hline & & 509,0 & 564,3 & 307,0 & 0,2573 & 1978,24 & \\
\hline & & 485,4 & 546,7 & 289,7 & 0,257 & 1888,72 & \multirow{3}{*}{1883,59} \\
\hline & & 486,6 & 550,4 & 291,8 & 0,2586 & 1881,67 & \\
\hline & & 484,2 & 548,3 & 290,8 & 0,2575 & 1880,39 & \\
\hline \multirow{6}{*}{ 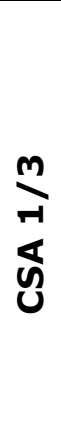 } & \multirow{3}{*}{$\alpha$} & 513,6 & 566,2 & 307,5 & 0,2587 & 1985,31 & \multirow{3}{*}{1990,09} \\
\hline & & 515,8 & 568,1 & 308,6 & 0,2595 & 1987,67 & \\
\hline & & 516,9 & 568 & 309,2 & 0,2588 & 1997,30 & \\
\hline & & 484,8 & 550,4 & 291,2 & 0,2592 & 1870,37 & \multirow{3}{*}{1863,94} \\
\hline & & 483,7 & 549,8 & 290,3 & 0,2595 & 1863,97 & \\
\hline & & 480,9 & 548,7 & 289,8 & 0,2589 & 1857,47 & \\
\hline
\end{tabular}


Tabla 50. Densidad media aparente en seco del mortero endurecido de CSA con tamaño del árido 0/4. Valores analíticos de cálculo de cada una de las tres probetas analizadas en cada dosificación. (R) Morteros de referencia. (CVT) Morteros con la incorporación de cenizas volantes inertizadas en una proporción de un $10 \%$ en peso de los áridos.

\begin{tabular}{|c|c|c|c|c|c|c|c|}
\hline & & $\begin{array}{c}\text { Masa } \\
\text { probeta } \\
\text { endurecida } \\
\text { seca } \\
\mathrm{m}_{s, s e c}(k g)\end{array}$ & $\begin{array}{c}\text { Masa } \\
\text { probeta } \\
\text { endurecida } \\
\text { saturada } \\
\mathrm{m}_{s, s a t}(\mathrm{~kg})\end{array}$ & $\begin{array}{c}\text { Masa } \\
\text { aparente } \\
\text { probeta } \\
\text { endurecida } \\
\text { saturada } \\
\mathrm{m}_{s, i}(\mathrm{~kg})\end{array}$ & $\begin{array}{c}\text { Volumen } \\
\text { de la } \\
\text { probeta } V_{\mathrm{s}} \\
\left(\mathrm{m}^{3}\right)\end{array}$ & $\begin{array}{c}\text { Densidad } \\
\text { aparente en } \\
\text { seco del } \\
\text { mortero } \\
\text { endurecido } \\
\rho_{\text {seco }}\left(\mathrm{kg} / \mathrm{m}^{3}\right)\end{array}$ & $\begin{array}{c}\text { Densidad } \\
\text { media } \\
\text { aparente en } \\
\text { seco del } \\
\text { mortero } \\
\text { endurecido } \\
\rho_{\text {media }}\end{array}$ \\
\hline \multirow{6}{*}{ 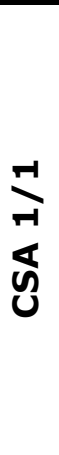 } & \multirow{3}{*}{$\boldsymbol{x}$} & 517,7 & 567,8 & 309,1 & 0,2587 & 2001,16 & \multirow{3}{*}{1999,61} \\
\hline & & 514,9 & 565,1 & 307,6 & 0,2575 & 1999,61 & \\
\hline & & 513,7 & 564,0 & 306,9 & 0,2571 & 1998,06 & \\
\hline & \multirow{3}{*}{5} & 518,9 & 572,6 & 313,7 & 0,2589 & 2004,25 & \multirow{3}{*}{1998,98} \\
\hline & & 519,5 & 572,9 & 313,2 & 0,2597 & 2000,39 & \\
\hline & & 518,2 & 573,7 & 313,6 & 0,2601 & 1992,31 & \\
\hline \multirow{6}{*}{$\begin{array}{l}m \\
\text { m } \\
\text { y }\end{array}$} & \multirow{3}{*}{$\boldsymbol{x}$} & 481,6 & 550,0 & 291,2 & 0,2588 & 1860,90 & \multirow{3}{*}{1852,60} \\
\hline & & 479,1 & 549,2 & 290,1 & 0,2591 & 1849,09 & \\
\hline & & 478,4 & 550,5 & 291,6 & 0,2589 & 1847,82 & \\
\hline & \multirow{3}{*}{$\frac{5}{3}$} & 483,6 & 557,8 & 298,4 & 0,2594 & 1864,30 & \multirow{3}{*}{1865,09} \\
\hline & & 481,6 & 554,4 & 296,3 & 0,2581 & 1865,94 & \\
\hline & & 483,6 & 556,6 & 297,3 & 0,2593 & 1865,02 & \\
\hline
\end{tabular}




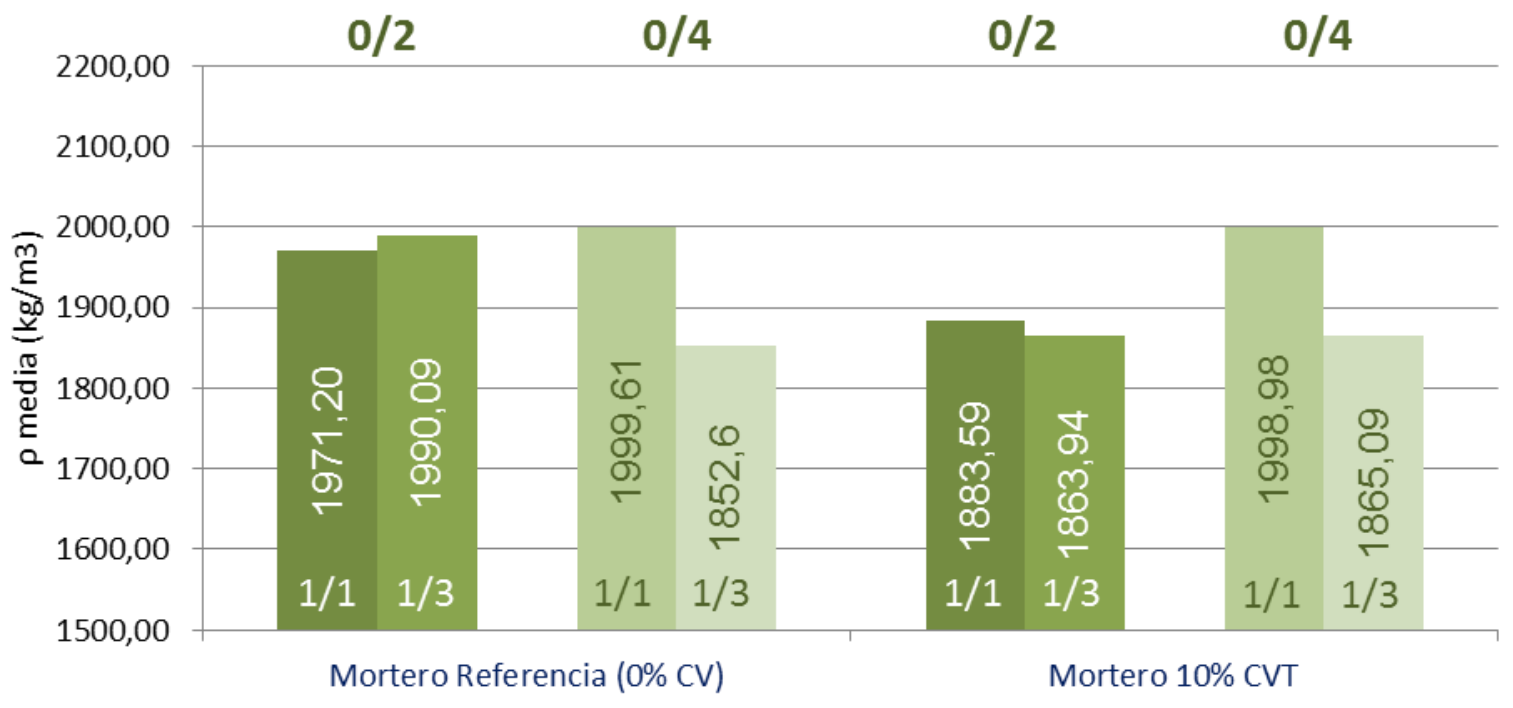

Ilustración 48. Densidad media aparente en seco, en $\mathrm{kg} / \mathrm{m}^{3}$, de los morteros de CSA (EN 1015-10:2000). Diámetros de árido 0/2 y 0/4. Relación de cemento/árido $1 / 1$ y 1/3.

\subsubsection{DETERMINACIÓN DE LA RESISTENCIA A LA CARBONATACIÓN (EN 13295:2004)}

Las tablas 51 y 52 muestran los valores medios tanto de profundidad de carbonatación $(\mathrm{Pc})$, como de superficie de carbonatación (Sc) de todos los morteros ensayados para tamaños de árido $0 / 2$ y 0/4, respectivamente, y con las diversas dosificaciones. Las ilustraciones 49 a 64 recogen fotografías de las probetas de mortero inmediatamente después de su rotura y recién aplicada la disolución de fenolftaleína al 1\%. En ellas, se presenta un ejemplo de cada una de las dosificaciones ensayadas en las que las áreas carbonatadas del mortero no cambian de color, mientras que aquellas con un pH mayor de 9 adquieren un color fucsia brillante.

Del análisis global de los valores en dichas tablas se desprende que la inclusión de cenizas volantes inertizadas en forma de carbonatos insolubles provoca una mayor velocidad de carbonatación en los morteros salvo aquellos elaborados con CAC y los de dosificación $1 / 1$ y diámetro de árido 0/4 de los morteros de CEM-I. Salvo para estos últimos, las velocidades de carbonatación de los morteros con mayor relación agua/cemento son 
superiores en todos los casos, a los de menor relación agua/cemento. Junto con la cantidad de agua de amasado, la microestructura de la pasta de cemento $\mathrm{y}$, en concreto, la composición del cemento que da lugar a esa microestructura, influyen de manera muy importante en el avance del frente de carbonatación.

Tabla 51. Profundidad de carbonatación $(P C)$ y Superficie carbonatada $(S C)$ de los morteros ensayados con diámetro de árido 0/2. (R) Morteros de referencia (CVT) Morteros con la incorporación de cenizas volantes inertizadas en una proporción de un $10 \%$ en peso de los áridos.

\begin{tabular}{|c|c|c|c|c|c|c|}
\hline \multirow{2}{*}{$\varnothing$ árido } & \multirow{2}{*}{$\begin{array}{l}\text { Tipo de } \\
\text { cemento }\end{array}$} & \multirow{2}{*}{$\begin{array}{c}\text { Dosificació } \\
n\end{array}$} & \multicolumn{2}{|c|}{$\mathrm{R}$} & \multicolumn{2}{|c|}{ CVT } \\
\hline & & & $S_{c}(\%)$ & $P_{c}(\mathrm{~mm})$ & $S_{c}(\%)$ & $P_{c}(\mathrm{~mm})$ \\
\hline \multirow{8}{*}{$0 / 2$} & \multirow{2}{*}{ CEM I } & $1 / 1$ & 7.59 & 1.012 & 10.83 & 1.445 \\
\hline & & $1 / 3$ & 16.65 & 2.220 & 19.97 & 2.662 \\
\hline & \multirow{2}{*}{ CEM II } & $1 / 1$ & 11.00 & 1.466 & 12.03 & 1.604 \\
\hline & & $1 / 3$ & 16.00 & 2.133 & 23.47 & 3.129 \\
\hline & \multirow{2}{*}{ CAC } & $1 / 1$ & 19.80 & 2.641 & 19.67 & 2.623 \\
\hline & & $1 / 3$ & 26.68 & 3.558 & 57.71 & 7.695 \\
\hline & \multirow{2}{*}{ CSA } & $1 / 1$ & 37.97 & 5.062 & 56.83 & 7.577 \\
\hline & & $1 / 3$ & 46.54 & 6.206 & 75.22 & 10.030 \\
\hline
\end{tabular}


Tabla 52. Profundidad de carbonatación $(P C)$ y Superficie carbonatada $(S c)$ de los morteros ensayados con diámetro de árido 0/4. (R) Morteros de referencia (CVT) Morteros con la incorporación de cenizas volantes inertizadas en una proporción de un $10 \%$ en peso de los áridos.

\begin{tabular}{|c|c|c|c|c|c|c|}
\hline \multirow{2}{*}{$\varnothing$ árido } & \multirow{2}{*}{$\begin{array}{l}\text { Tipo de } \\
\text { cemento }\end{array}$} & \multirow{2}{*}{$\begin{array}{c}\text { Dosificació } \\
n\end{array}$} & \multicolumn{2}{|c|}{$\mathrm{R}$} & \multicolumn{2}{|c|}{ CVT } \\
\hline & & & $S_{c}(\%)$ & $P_{c}(\mathrm{~mm})$ & $S_{c}(\%)$ & $P_{c}(\mathrm{~mm})$ \\
\hline \multirow{8}{*}{$0 / 4$} & \multirow{2}{*}{ CEM I } & $1 / 1$ & 11.53 & 1.537 & 10.00 & 1.333 \\
\hline & & $1 / 3$ & 13.31 & 1.75 & 17.38 & 2.318 \\
\hline & \multirow{2}{*}{ CEM II } & $1 / 1$ & 7.07 & 0.942 & 8.77 & 1.170 \\
\hline & & $1 / 3$ & 14.41 & 1.921 & 17.35 & 2.314 \\
\hline & \multirow{2}{*}{ CAC } & $1 / 1$ & 80.96 & 10.795 & 50.62 & 6.750 \\
\hline & & $1 / 3$ & 100 & $20 *$ & 93.10 & 12.414 \\
\hline & \multirow{2}{*}{ CSA } & $1 / 1$ & 3.08 & 0.410 & 15.36 & 2.048 \\
\hline & & $1 / 3$ & 16.59 & 1.212 & 99.57 & 13.276 \\
\hline
\end{tabular}

\subsubsection{Profundidad de carbonatación de morteros CEM-I}

En el caso de los morteros de CEM-I la mayor profundidad de carbonatación se obtiene para la dosificación $1 / 1$ y tamaño de árido 0/2, más de un $40 \%$ mayor que la del mismo mortero sin adiciones. Por el contrario, la menor, un $13,27 \%$ inferior a la conseguida en el mortero de referencia, es para la dosificación $1 / 1$ y con mayor tamaño de árido. En este caso, a menor cantidad de árido y cuanto mayor sea éste, se produce una menor porosidad del mortero posiblemente por la oclusión de los poros existentes por la fracción más fina de los áridos definida por las CVT.

Se puede observar en las ilustraciones 49 a 52 que, a mayor cantidad de árido en la mezcla, más rectilíneo y homogéneo es el frente de carbonatación. 


\subsubsection{Profundidad de carbonatación de morteros CEM-II A/P}

En el caso de este tipo de morteros, todas las probetas ensayadas arrojan mayores frentes de carbonatación y, por lo tanto, mayores superficies de carbonatación que los morteros de referencia. Los frentes de carbonatación más elevados corresponden a los morteros con CVT relación cemento/árido $1 / 3$ y tamaño del árido $0 / 2$, superando en un $46,69 \%$ al frente del mortero de referencia. En el caso de diámetros de fino 0/4, los valores se estabilizan y son mucho más parecidos, siendo de un $24,21 \%$ superior para dosificaciones $1 / 1$, y de un 20,46\% más para dosificaciones 1/3. De nuevo, el hecho de que un mortero tenga más cantidad de árido, dosificaciones $1 / 3$, sin importar el tamaño de éste, condiciona que el frente de carbonatación sea mucho más homogéneo ya que presenta un contorno de separación del área de carbonatación, con el de no carbonatación muy definido y de carácter lineal en paralelo al borde de la probeta (ilustraciones 53 a 56). En estas mismas dosificaciones, 1/3, la inclusión de CVT consigue un efecto beneficioso con relación a lo observado en los morteros de referencia. En las ilustraciones 54 y 56, se aprecia que en los morteros de referencia existen pequeñas zonas interiores con fisuras de carbonatación, posiblemente debido a la porosidad del material. En el caso de estos mismos morteros con la inclusión de CVT, no se aprecian estas carbonataciones interiores reflejando la existencia de un material con menor interrelación de poros. La carbonatación superficial consigue una disminución a una reducción de los poros abiertos, disminuyendo la permeabilidad del mortero.

\subsubsection{Profundidad de carbonatación de los morteros con CAC}

Los ensayos realizados sobre probetas de mortero elaborado con CAC y diámetros de árido 0/4, presentan resultados inversos a los obtenidos en el resto de morteros. En estos ejemplos, la inclusión de CVT en las mezclas disminuye los frentes de carbonatación de manera clara (ilustraciones 59 y 60). Es llamativo el comportamiento de los morteros CAC $1 / 3 \cdot 0 / 4$, en el 
que, en el mortero de referencia, se consigue una completa carbonatación de la superficie de rotura, lo cual estará íntimamente relacionado con las altas resistencias ofrecidas por este tipo de compuestos. En las dosificaciones $0 / 2$, el proceso de carbonatación se asemeja a lo sucedido con el resto de morteros, si bien es visible zonas de carbonatación parcial (ilustraciones 57 y 58), que presentan coloraciones mucho más tenues posiblemente por un descenso en el $\mathrm{pH}$ del mortero entre 8 y 9,5 , se trata de áreas de transición que deben considerarse carbonatadas.

Ya se ha visto con anterioridad que el proceso de carbonatación natural, unido a la inclusión de cenizas volantes inertizadas en forma de carbonatos insolubles, puede reducir significativamente la porosidad del mortero (Fernández-Carrasco et al., 2008)

Dado que la carbonatación es un proceso beneficioso tanto para hormigones, como para morteros, ya que la formación de carbonatos cristalinos favorece una mayor resistencia del hormigón y taponan la red de poros abiertos reduciendo la permeabilidad, no parece que en este tipo de morteros, se produzca el efecto contrario. Como veremos en el siguiente epígrafe sobre resistencias mecánicas, los morteros elaborados con CAC presentan las mejores prestaciones en cuanto a resistencia de todos los ensayados, si bien son los únicos a excepción de los morteros CEM-I de dosificación $1 / 1$ y tamaño de árido $0 / 4$, en los que se produce una disminución tanto del área, como del frente de carbonatación. Se puede inferir de estos datos que, si bien la carbonatación es un proceso beneficioso desde el punto de vista del rendimiento mecánico de los morteros, dicho grado de carbonatación no se encuentra en relación directa con la influencia que ésta pueda tener sobre los morteros elaborados con CVT. La influencia en las resistencias mecánicas finales habrá que buscarla en otros factores tales como la distribución del tamaño de los poros (Fernández-Carrasco, 2001). 


\subsubsection{Profundidad de carbonatación de los morteros con CSA}

A diferencia de lo esperado en relación con las pastas de cemento (Guo et al., 2014), los morteros de CSA no mejoran los valores de carbonatación de los morteros de CEM-I y CEM-II. Los datos obtenidos son ampliamente superiores a los de los morteros elaborados con cementos Portland ordinarios. Los compuestos de CSA se caracterizan por tener una distribución y un tamaño de poro muy similar a los cementos Portland ordinarios sin embargo, sus características de hidratación, así como su carácter expansivo, produce un significativo aumento de su porosidad, la cual va en aumento en función de la edad (Irico et al., 2013).

A pesar de esto, el análisis de la carbonatación de morteros ejecutados con CSA presenta una novedad con respecto al resto muestras analizadas. Las probetas con tamaño de árido $0 / 2$ ofrecen un borde perimetral de la probeta no carbonatado, que se hace más visible para la dosificación $1 / 1$ con la incorporación de cenizas volantes inertizadas (ilustración 61). Este proceso se repite con mayor cantidad de áridos en la mezcla, si bien en menor medida y más difuminado. De nuevo el núcleo presenta una casi total carbonatación, mientras que el anillo perimetral permanece inalterado. Este comportamiento puede estar directamente relacionado con la capacidad de las mezclas de cementos de sulfoaluminato de calcio de poder generar sistemas impermeables al agua (Guo et al., 2014), aunque también es sabido que este efecto impermeable con CSA está asociado con el volumen de los poros, con la distribución de éstos y con su interconexión (Singh et al., 2008).

En el caso de utilizar áridos más gruesos (ilustraciones 63 y 64), el comportamiento del frente de carbonatación se asemeja al ofrecido por los morteros de cemento Portland ordinario, salvo para la inclusión de CVT en los morteros CSA.1/3.0/4, en los que se produce una carbonatación casi total de la sección fracturada (ilustración 64). 


\section{CEM-I $\cdot 1 / 1 \cdot 0 / 2$}

$\mathrm{R}$

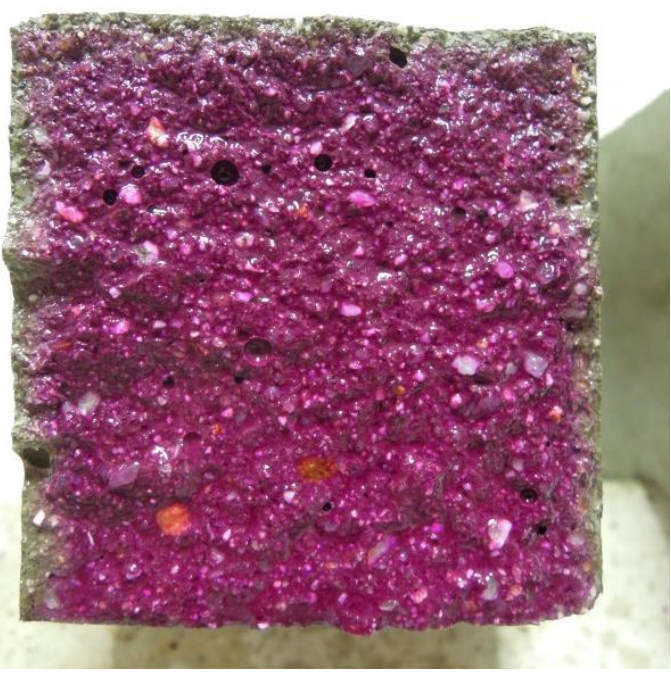

$10 \%$ CVT

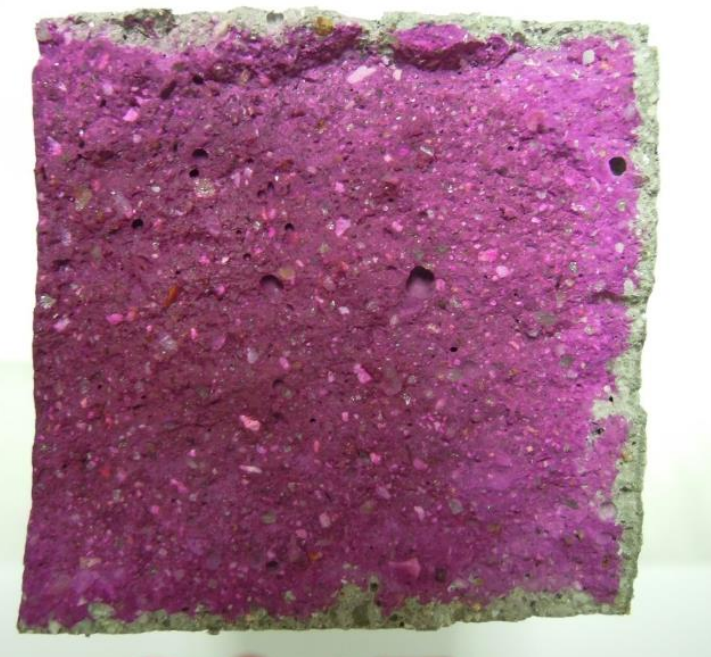

Ilustración 49. Determinación de la profundidad de carbonatación. Morteros de CEM-I, tamaño del árido 0/2 y dosificación cemento/árido 1/1. (Izda): Probeta P19. Mortero de referencia. (Dcha): Probeta P24T. Mortero con la incorporación de cenizas volantes inertizadas en una proporción de un $10 \%$ en peso de los áridos.

\section{CEM-I $\cdot 1 / 3 \cdot 0 / 2$}

$\mathrm{R}$

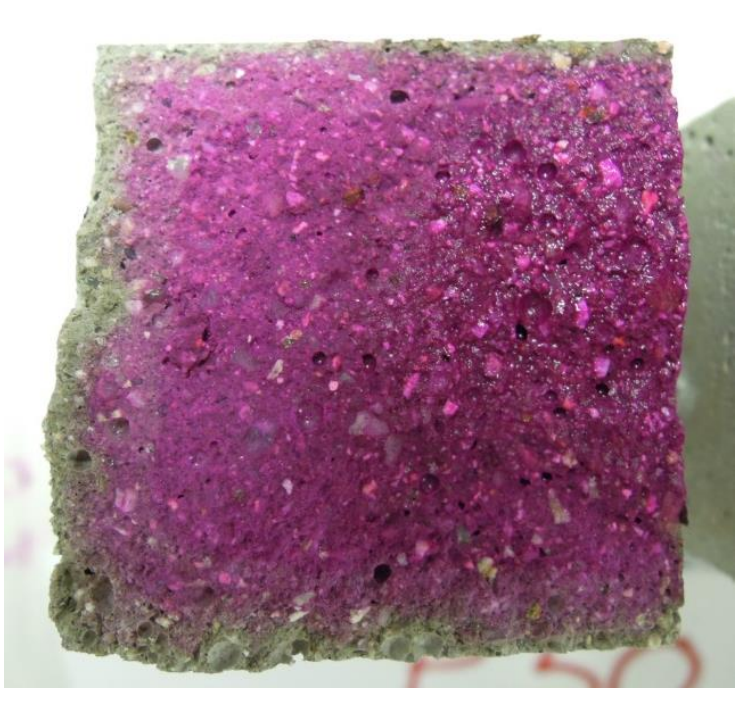

$10 \%$ CVT

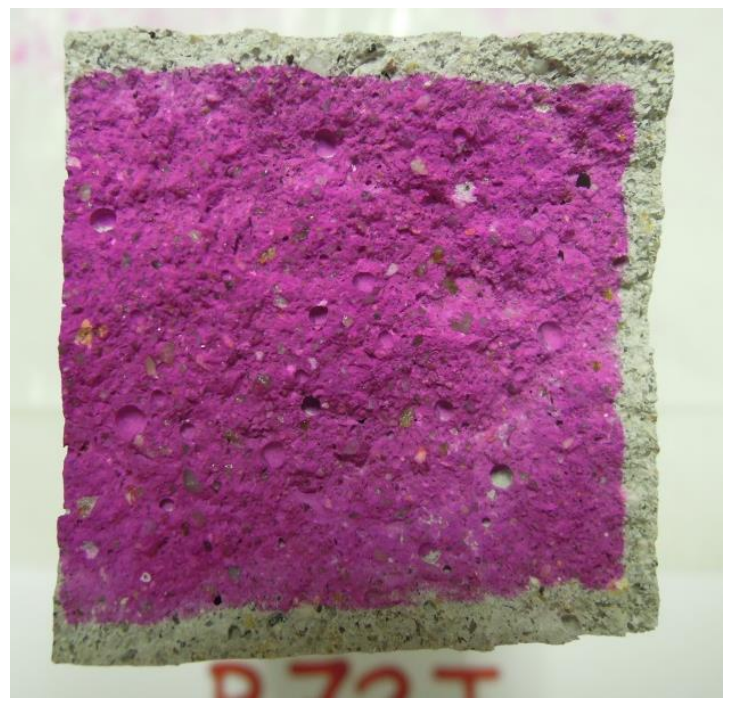

Ilustración 50. Determinación de la profundidad de carbonatación. Morteros de CEM-I, tamaño del árido 0/2 y dosificación cemento/árido 1/3. (Izda): Probeta P50. Mortero de referencia. (Dcha): Probeta P72T. Mortero con la incorporación de cenizas volantes inertizadas, en una proporción de un $10 \%$ en peso de los áridos. 


\section{CEM-I $\cdot 1 / 1 \cdot 0 / 4$}

$\mathrm{R}$

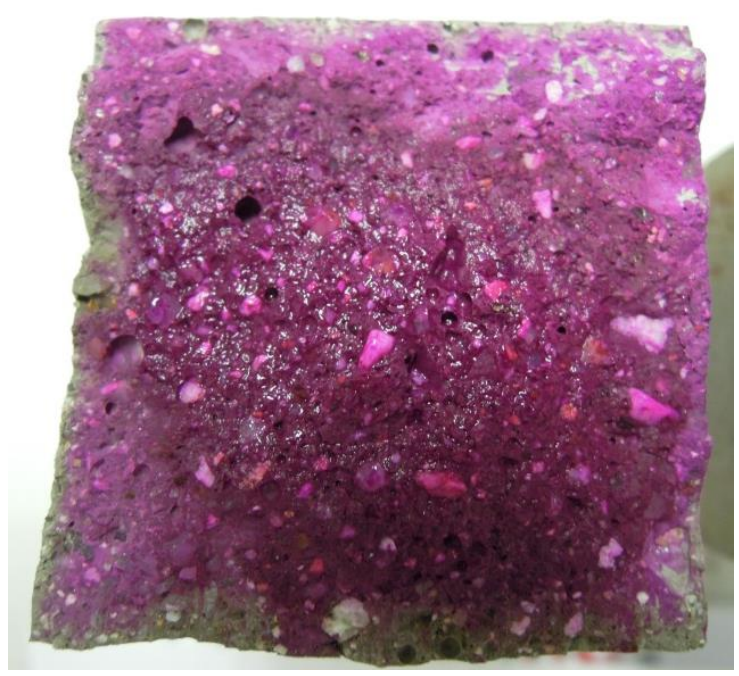

$10 \%$ CVT

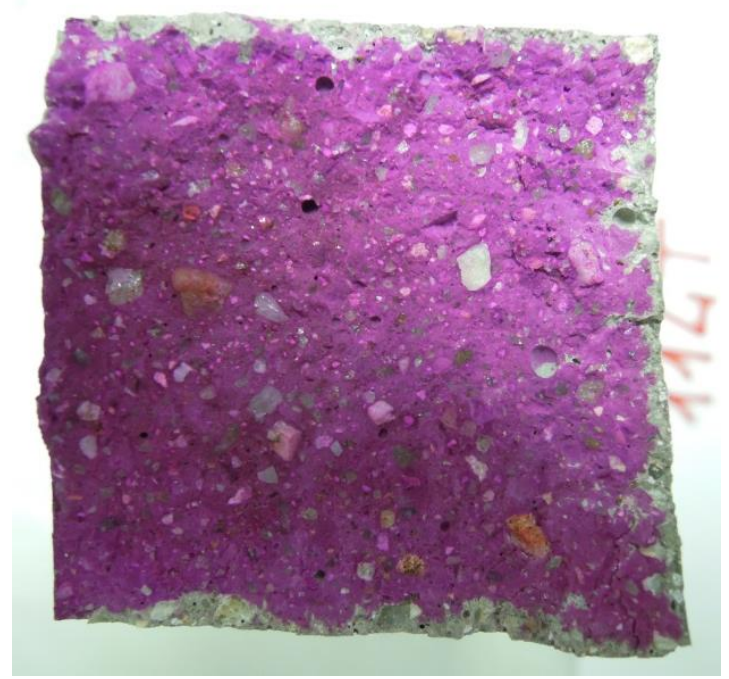

Ilustración 51. Determinación de la profundidad de carbonatación. Morteros de CEM-I, tamaño del árido 0/4 y dosificación cemento/árido 1/1. (Izda): Probeta P91. Mortero de referencia. (Dcha): Probeta P114T. Mortero con la incorporación de cenizas volantes inertizadas, en una proporción de un $10 \%$ en peso de los áridos.

\section{CEM-I $\cdot 1 / 3 \cdot 0 / 4$}

$\mathrm{R}$

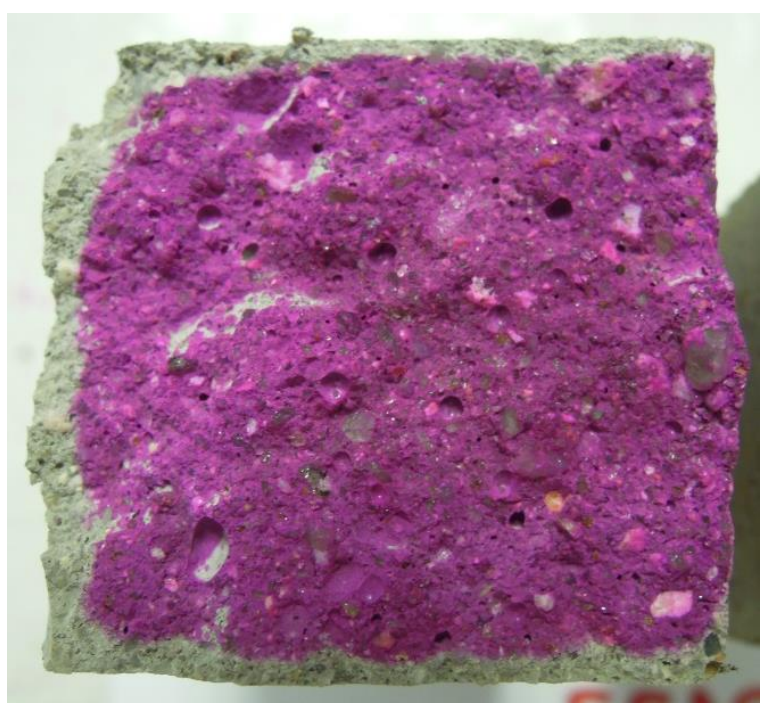

$10 \%$ CVT

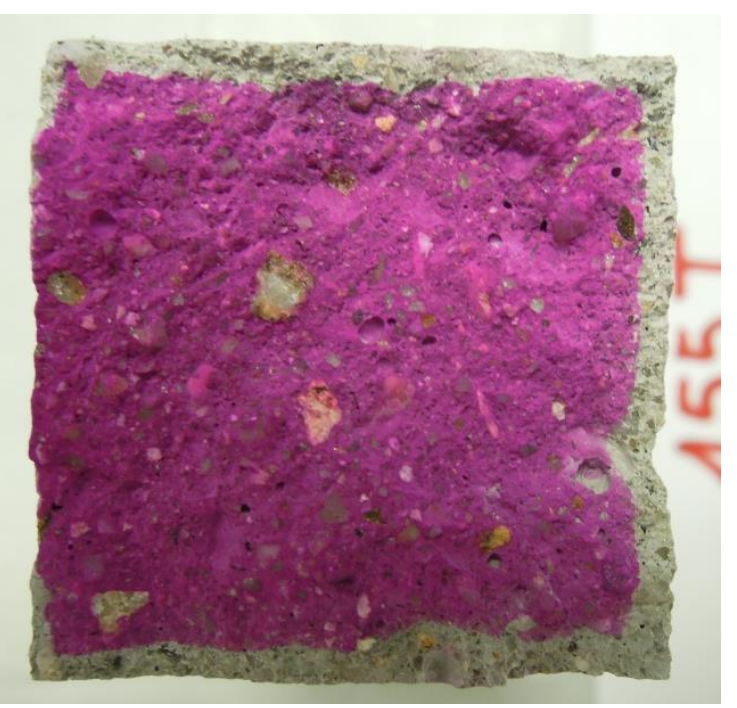

Ilustración 52. Determinación de la profundidad de carbonatación. Morteros de CEM-I, tamaño del árido 0/4 y dosificación cemento/árido 1/3. (Izda): Probeta P133. Mortero de referencia. (Dcha): Probeta P155T. Mortero con la incorporación de cenizas volantes inertizadas, en una proporción de un $10 \%$ en peso de los áridos. 
$\mathrm{R}$

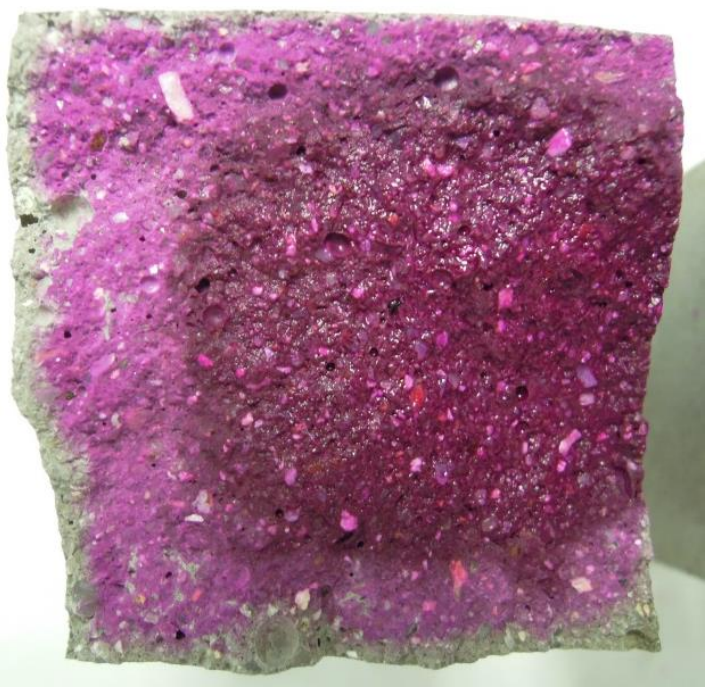

$10 \%$ CVT

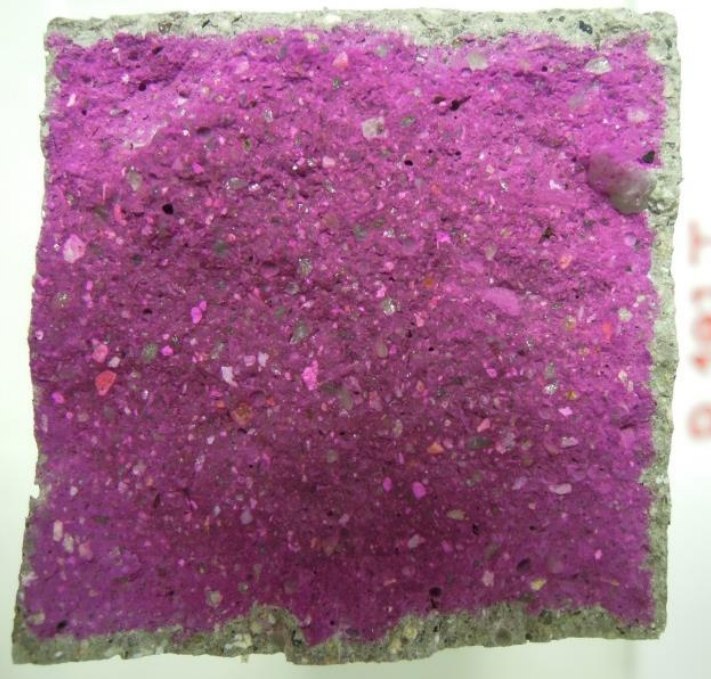

Ilustración 53. Determinación de la profundidad de carbonatación. Morteros de CEM-II A/P, tamaño del árido 0/2 y dosificación cemento/árido 1/1. (Izda): Probeta P175. Mortero de referencia. (Dcha): Probeta P197T. Mortero con la incorporación de cenizas volantes inertizadas, en una proporción de un $10 \%$ en peso de los áridos.

CEM-II A/P $\cdot 1 / 3 \cdot 0 / 2$

$\mathrm{R}$

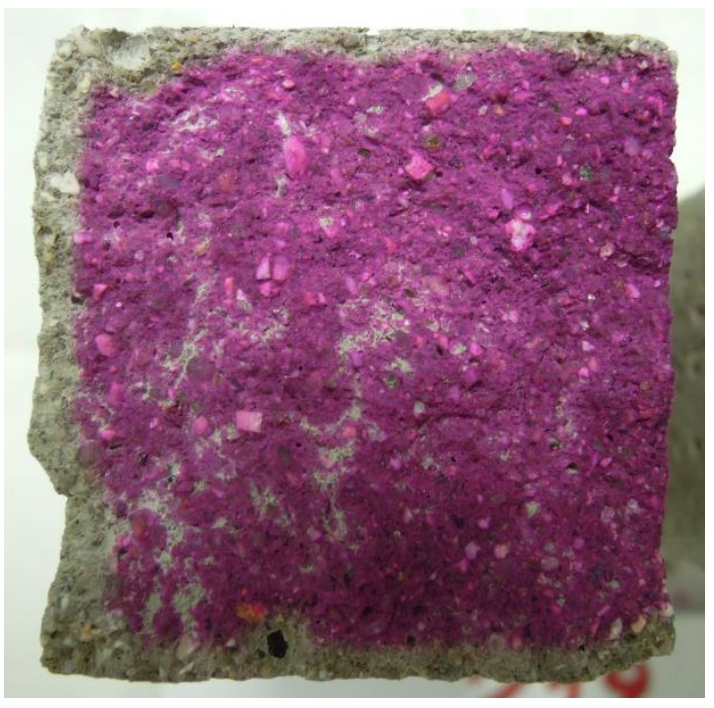

$10 \%$ CVT

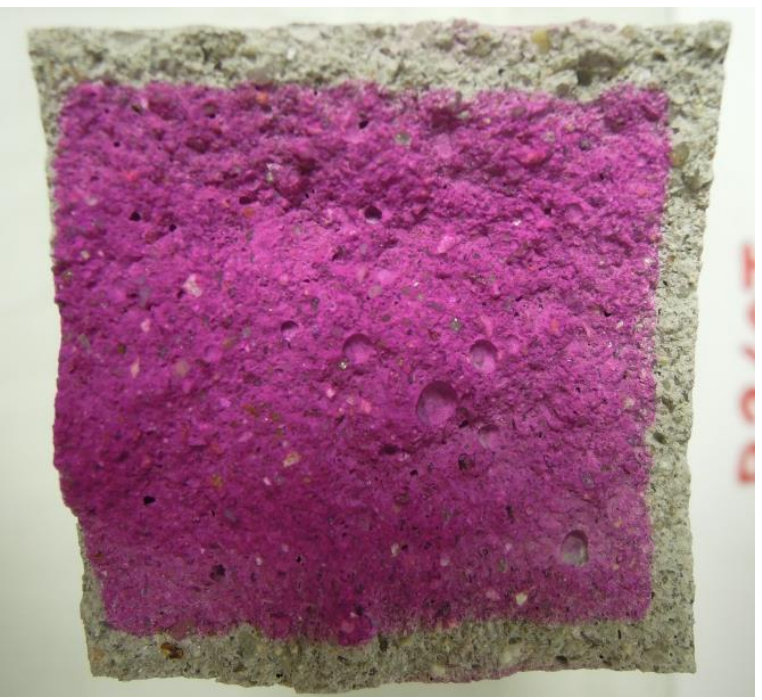

Ilustración 54. Determinación de la profundidad de carbonatación. Morteros de CEM-II A/P, tamaño del árido 0/2 y dosificación cemento/árido 1/3. (Izda): Probeta P219. Mortero de referencia. (Dcha): Probeta P240T. Mortero con la incorporación de cenizas volantes inertizadas, en una proporción de un $10 \%$ en peso de los áridos. 


\section{CEM-II A/P $\cdot 1 / 1 \cdot 0 / 4$}

$\mathrm{R}$

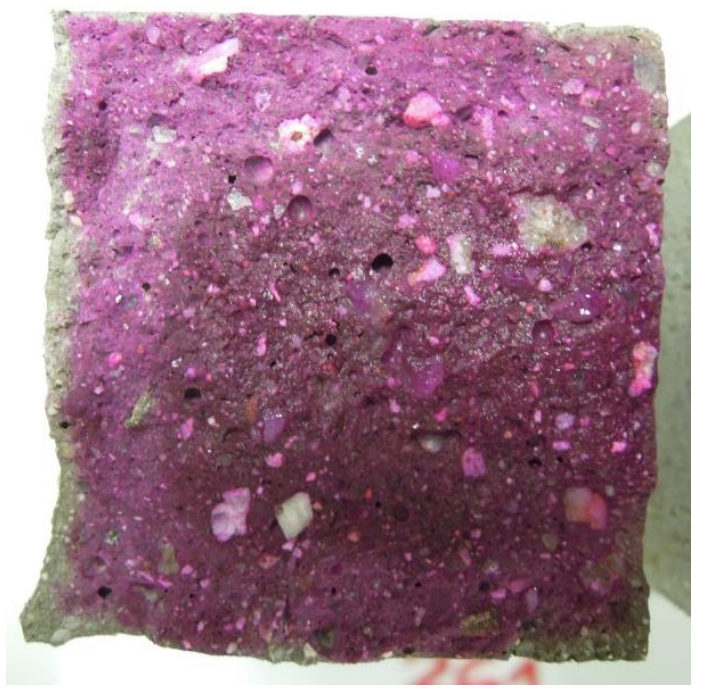

$10 \%$ CVT

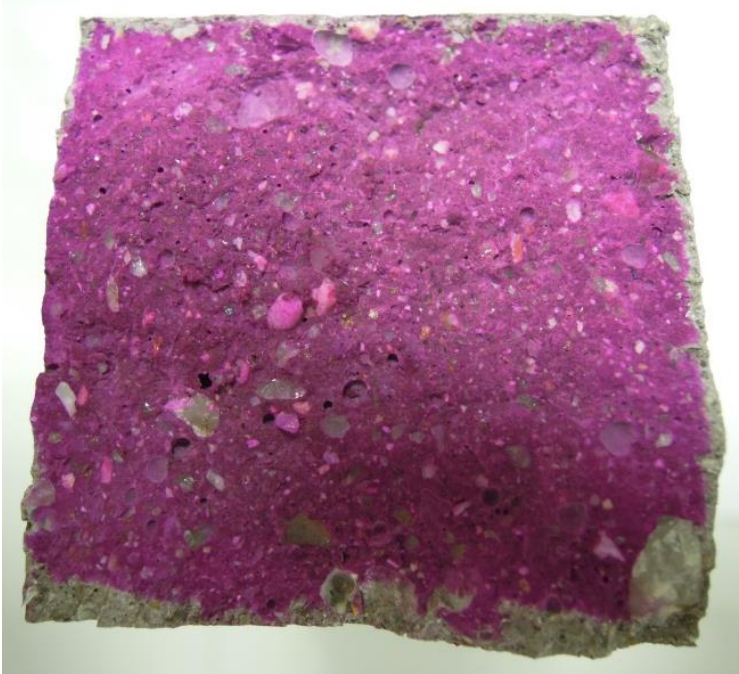

Ilustración 55. Determinación de la profundidad de carbonatación. Morteros de CEM-II A/P, tamaño del árido 0/4 y dosificación cemento/árido 1/1. (Izda): Probeta P261. Mortero de referencia. (Dcha): Probeta P282T. Mortero con la incorporación de cenizas volantes inertizadas, en una proporción de un $10 \%$ en peso de los áridos.

\section{CEM-II A/P $\cdot 1 / 3 \cdot 0 / 4$}

$\mathrm{R}$
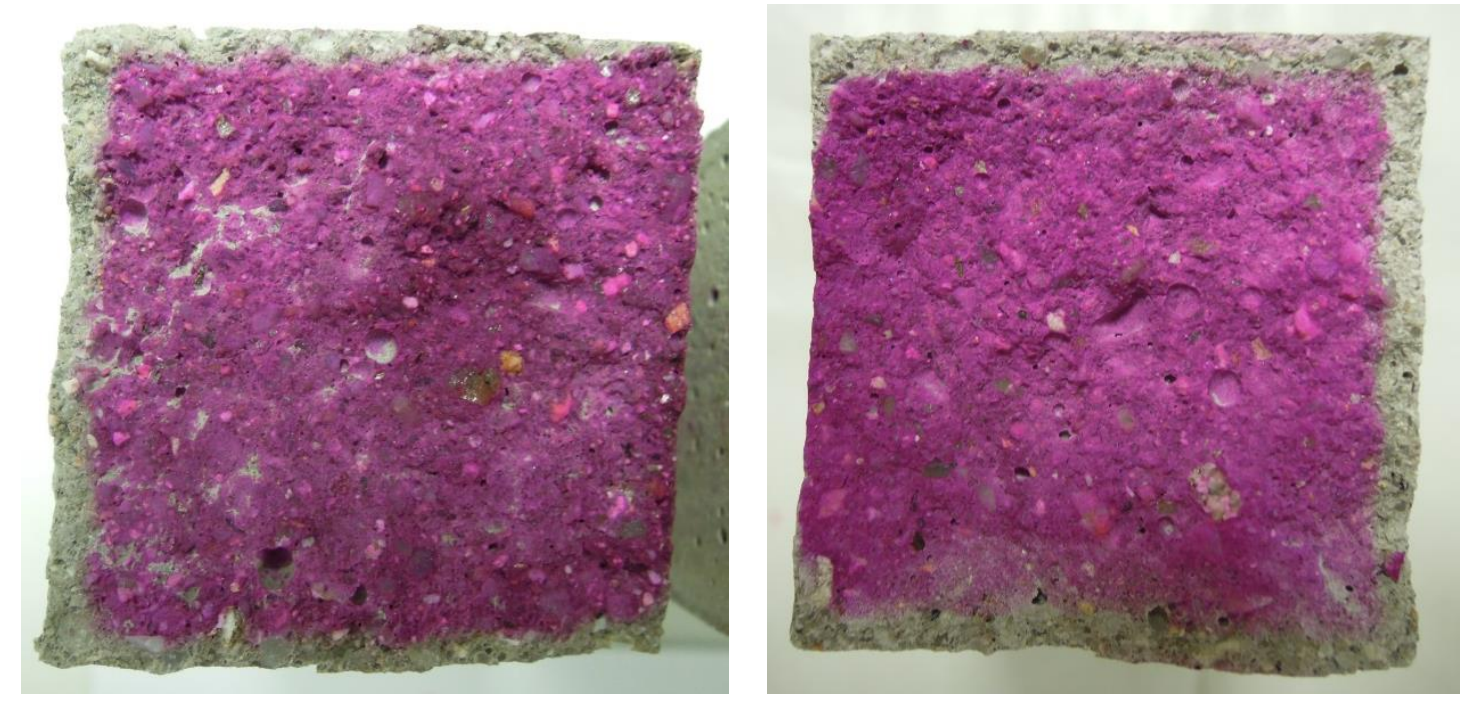

Ilustración 56. Determinación de la profundidad de carbonatación. Morteros de CEM-II A/P, tamaño del árido 0/4 y dosificación cemento/árido 1/3. (Izda): Probeta P301. Mortero de referencia. (Dcha): Probeta P322T. Mortero con la incorporación de cenizas volantes inertizadas, en una proporción de un $10 \%$ en peso de los áridos. 


\section{CAC $\cdot 1 / 1 \cdot 0 / 2$}

$\mathrm{R}$

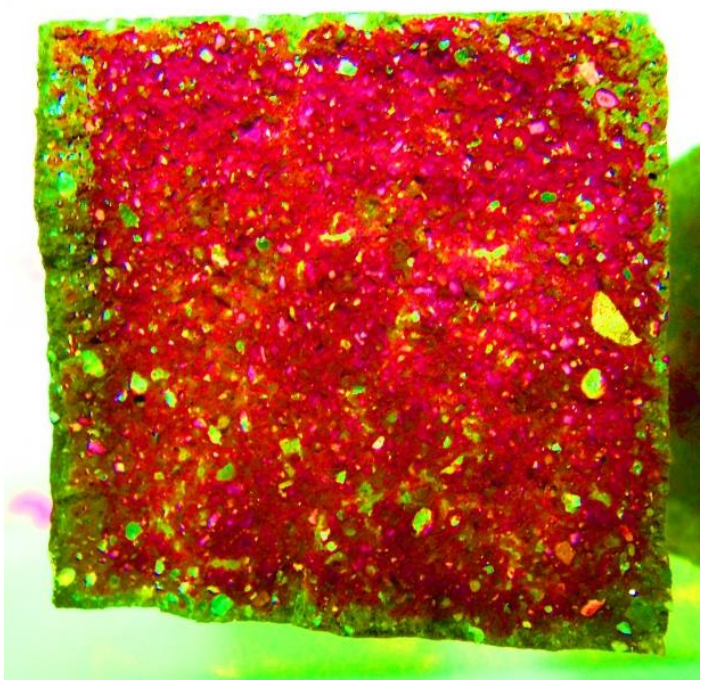

$10 \%$ CVT

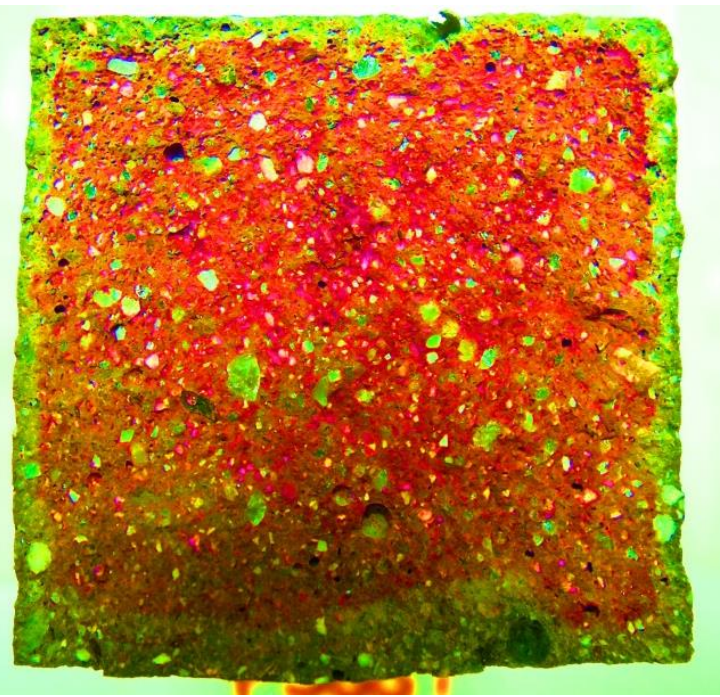

Ilustración 57. Determinación de la profundidad de carbonatación. Morteros de CAC, tamaño del árido 0/2 y dosificación cemento/árido 1/1. (Izda): Probeta P345. Mortero de referencia. (Dcha): Probeta P366T. Mortero con la incorporación de cenizas volantes inertizadas, en una proporción de un $10 \%$ en peso de los áridos.

\section{CAC $\cdot 1 / 3 \cdot 0 / 2$}

$\mathrm{R}$

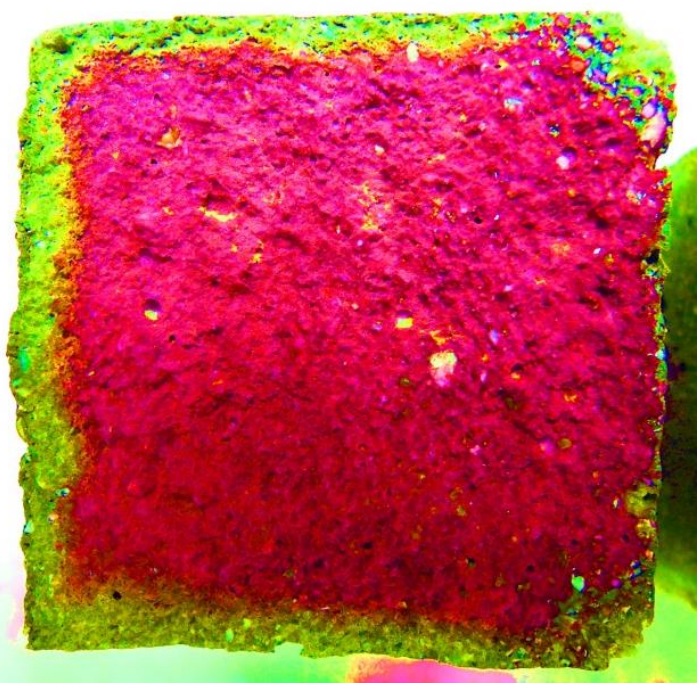

$10 \%$ CVT

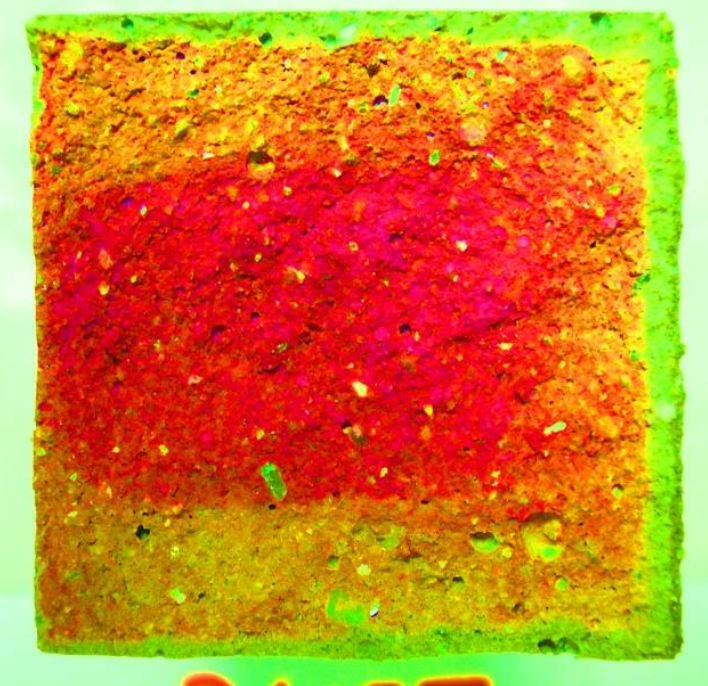

Ilustración 58. Determinación de la profundidad de carbonatación. Morteros de CAC, tamaño del árido 0/2 y dosificación cemento/árido 1/3. (Izda): Probeta P385. Mortero de referencia. (Dcha): Probeta P407T. Mortero con la incorporación de cenizas volantes inertizadas, en una proporción de un $10 \%$ en peso de los áridos. 


\section{CAC $\cdot 1 / 1 \cdot 0 / 4$}

$\mathrm{R}$

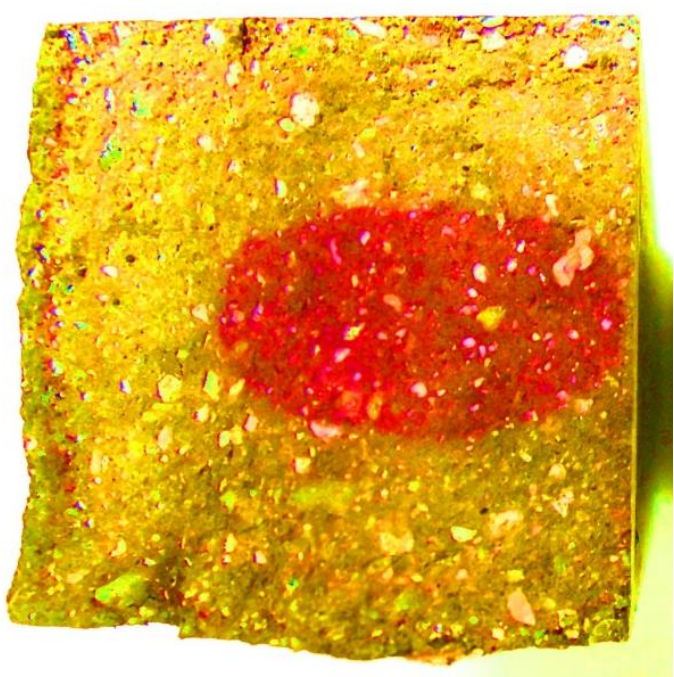

$10 \%$ CVT

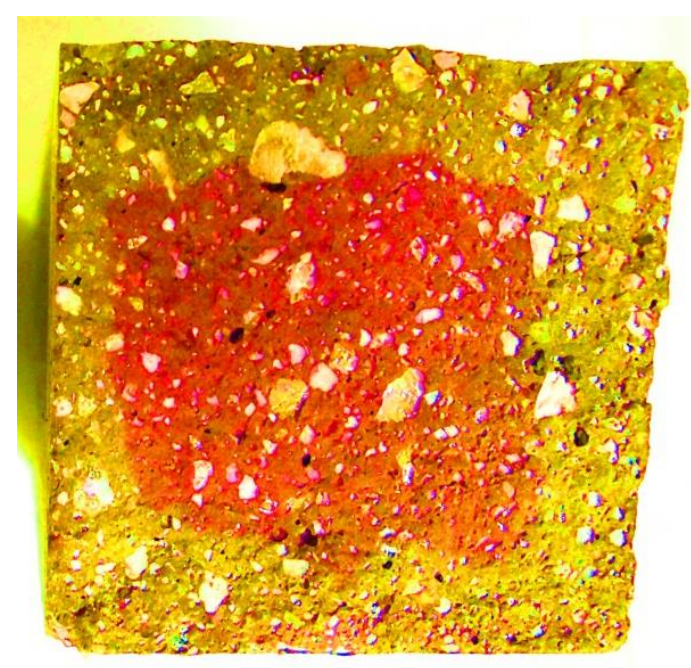

Ilustración 59. Determinación de la profundidad de carbonatación. Morteros de CAC, tamaño del árido 0/4 y dosificación cemento/árido 1/1. (Izda): Probeta P428. Mortero de referencia. (Dcha): Probeta P449T. Mortero con la incorporación de cenizas volantes inertizadas, en una proporción de un $10 \%$ en peso de los áridos.

\section{CAC $\cdot 1 / 3 \cdot 0 / 4$}

$\mathrm{R}$

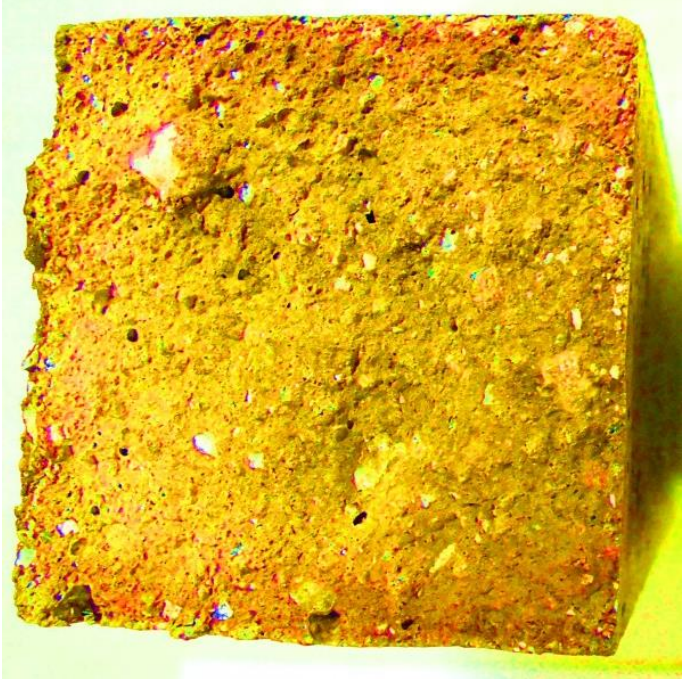

$10 \%$ CVT

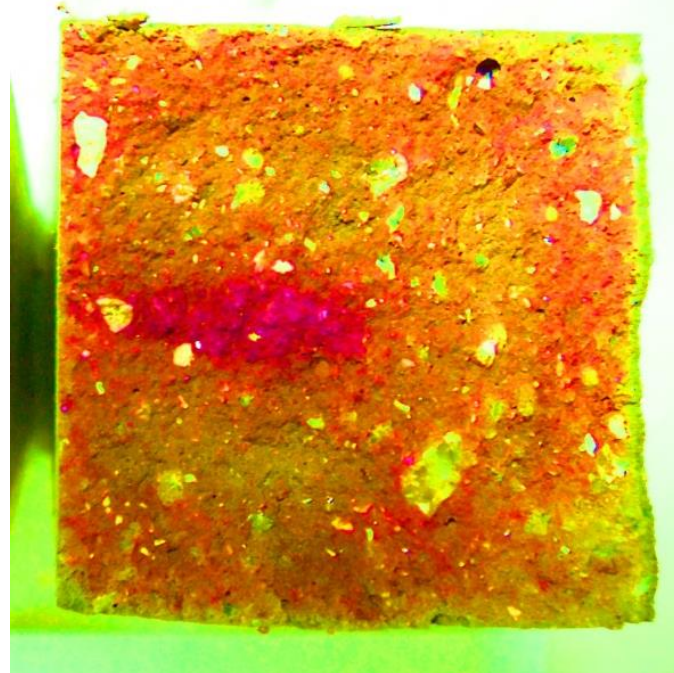

Ilustración 60. Determinación de la profundidad de carbonatación. Morteros de CAC, tamaño del árido 0/4 y dosificación cemento/árido 1/3. (Izda): Probeta P470. Mortero de referencia. (Dcha): Probeta P492T. Mortero con la incorporación de cenizas volantes inertizadas, en una proporción de un $10 \%$ en peso de los áridos. 


\section{$\operatorname{CSA} \cdot 1 / 1 \cdot 0 / 2$}

$\mathrm{R}$

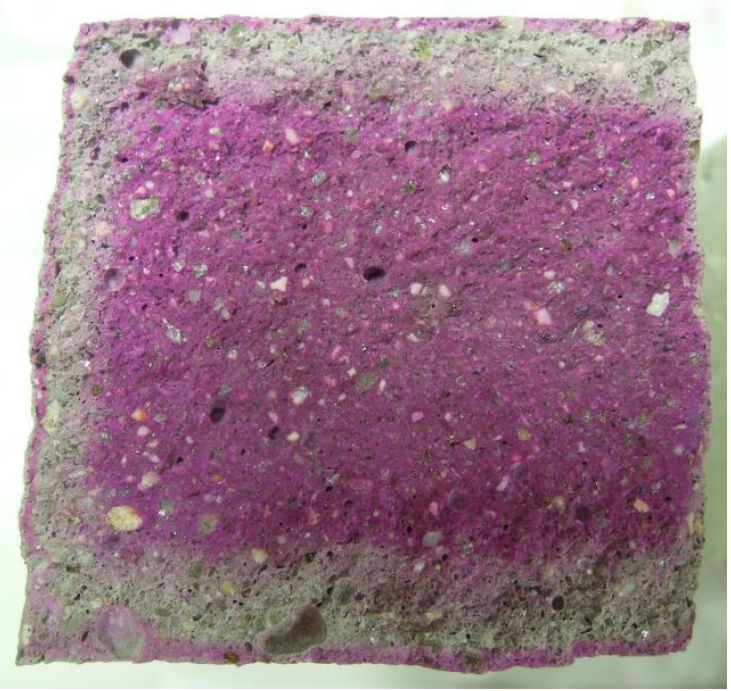

$10 \%$ CVT

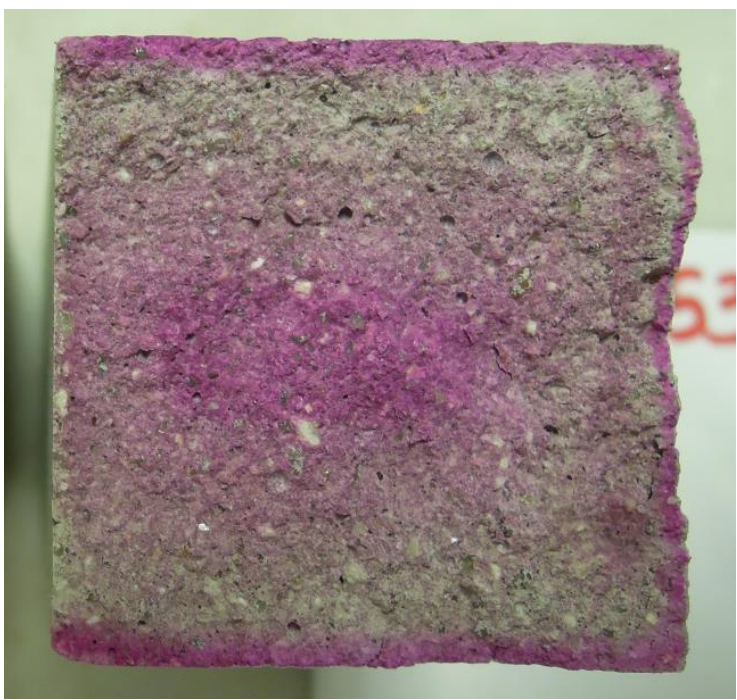

Ilustración 61. Determinación de la profundidad de carbonatación. Morteros de CSA, tamaño del árido 0/2 y dosificación cemento/árido 1/1. (Izda): Probeta P512. Mortero de referencia. (Dcha): Probeta P533T. Mortero con la incorporación de cenizas volantes inertizadas, en una proporción de un $10 \%$ en peso de los áridos.

\section{$\operatorname{CSA} \cdot 1 / 3 \cdot 0 / 2$}

$\mathrm{R}$

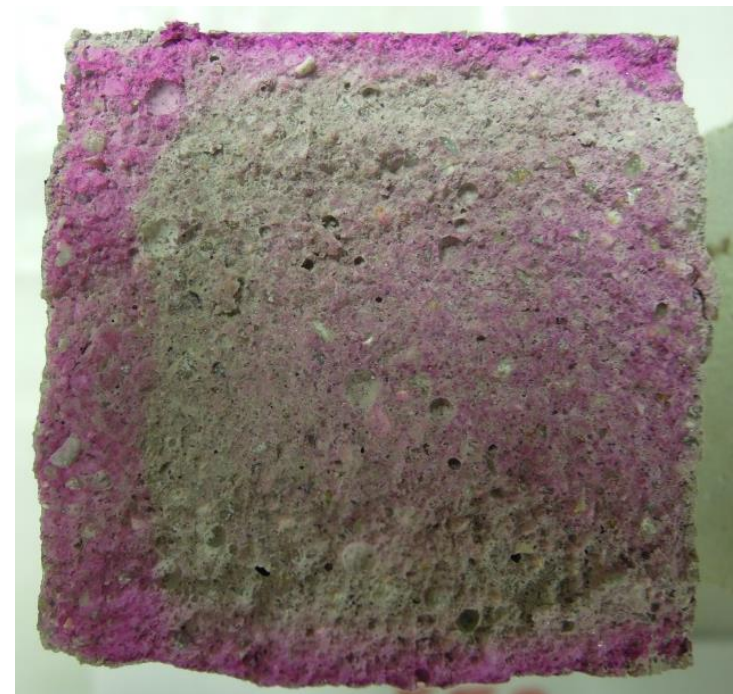

$10 \%$ CVT

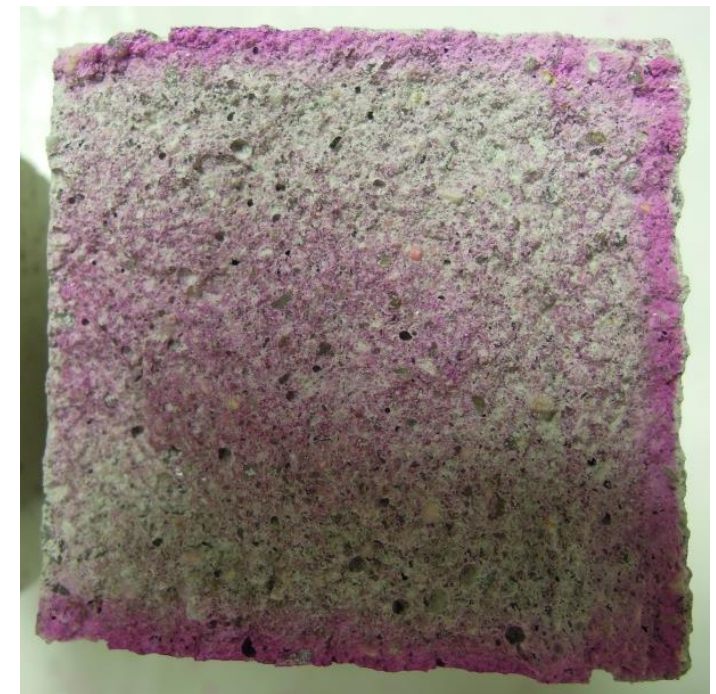

Ilustración 62. Determinación de la profundidad de carbonatación. Morteros de CSA, tamaño del árido 0/2 y dosificación cemento/árido 1/3. (Izda): Probeta P599. Mortero de referencia. (Dcha): Probeta P574T. Mortero con la incorporación de cenizas volantes inertizadas, en una proporción de un $10 \%$ en peso de los áridos. 


\section{$\operatorname{CSA} \cdot 1 / 1 \cdot 0 / 4$}

$\mathrm{R}$

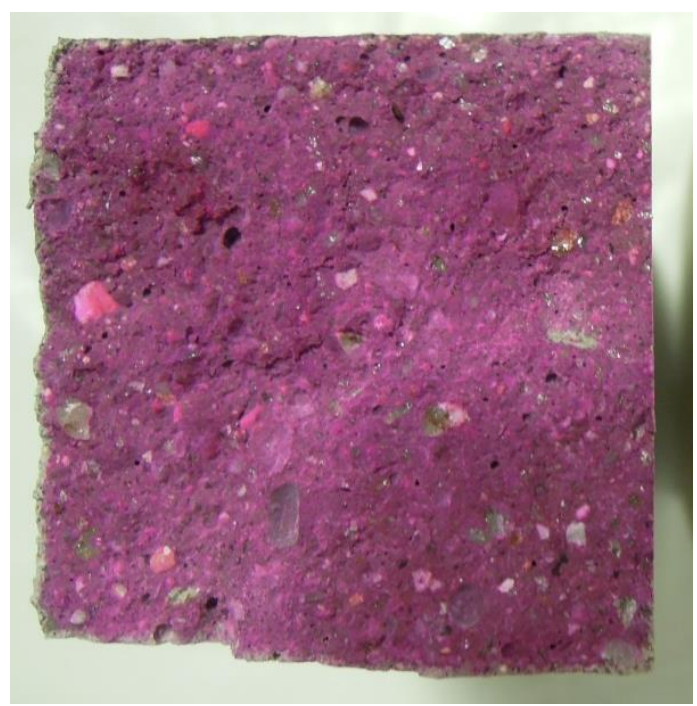

$10 \%$ CVT

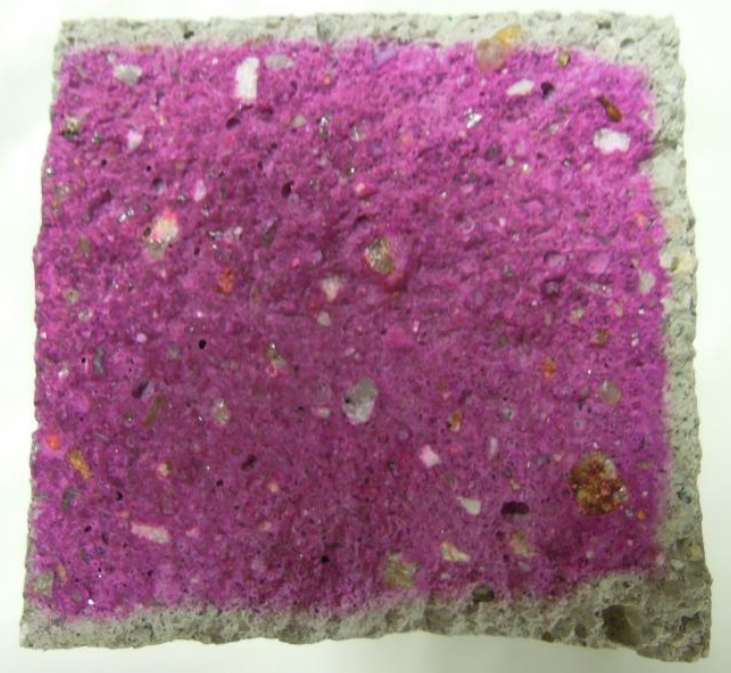

Ilustración 63. Determinación de la profundidad de carbonatación. Morteros de CSA, tamaño del árido 0/4 y dosificación cemento/árido 1/1. (Izda): Probeta P595. Mortero de referencia. (Dcha): Probeta P616T. Mortero con la incorporación de cenizas volantes inertizadas, en una proporción de un $10 \%$ en peso de los áridos.

\section{$\operatorname{CSA} \cdot 1 / 3 \cdot 0 / 4$}

$\mathrm{R}$

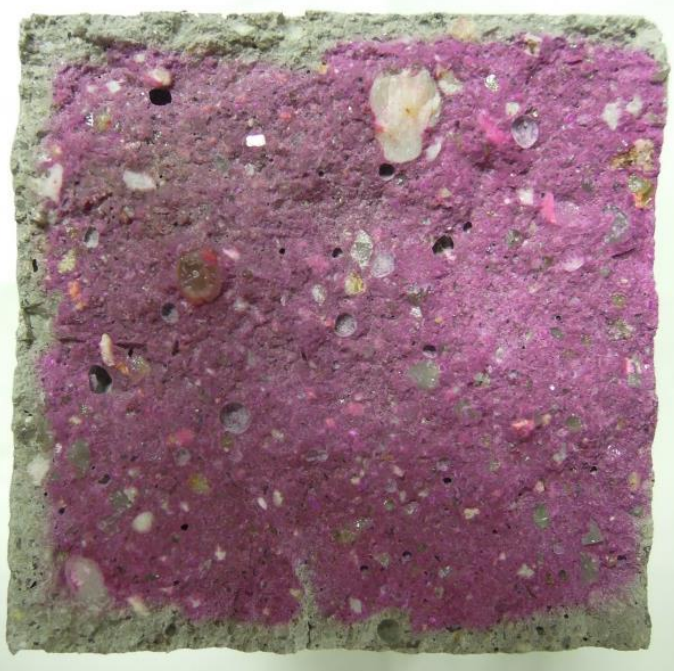

$10 \%$ CVT

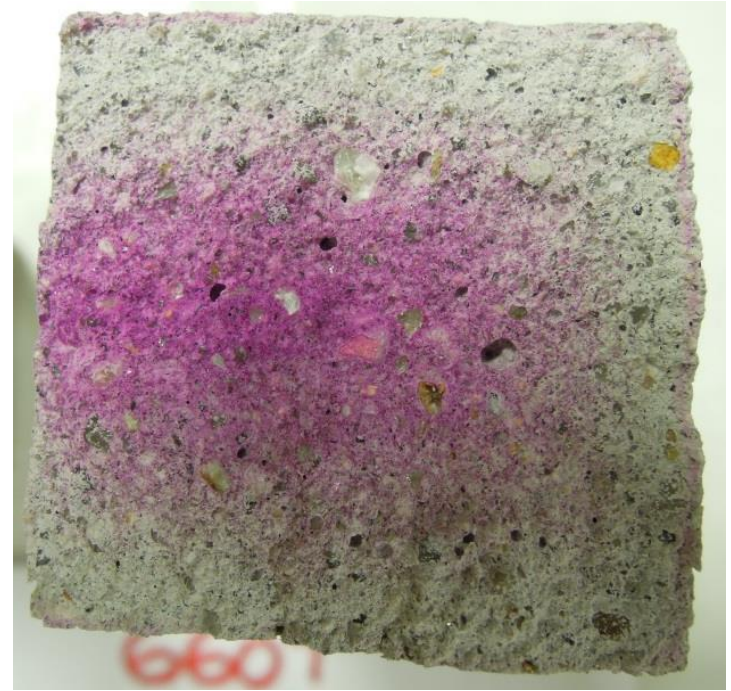

Ilustración 64. Determinación de la profundidad de carbonatación. Morteros de CSA, tamaño del árido 0/4 y dosificación cemento/árido 1/3. (Izda): Probeta P639. Mortero de referencia. (Dcha): Probeta P660T. Mortero con la incorporación de cenizas volantes inertizadas, en una proporción de un $10 \%$ en peso de los áridos. 


\subsubsection{POROSIDAD Y DISTRIBUCIÓN DEL TAMAÑO DE POROS EN MORTEROS CAC.}

De acuerdo al comportamiento claramente diferenciado de los morteros elaborados con cemento de aluminato de calcio en los ensayos de carbonatación, se decidió someter a las probetas de este tipo de cemento a un estudio de porosidad y distribución del tamaño de poros con la intención de ampliar dichos resultados y poder justificar su comportamiento.

La tabla 53 muestra un resumen de los datos obtenidos en la porosimetría por intrusión de mercurio. En ellos se aprecia que ambos morteros poseen características análogas salvo en lo relativo a la porosidad. Los morteros de CAC.1/1.0/4 con la incorporación de CVT son un 32,64\% menos porosos que los morteros CAC de referencia. De este hecho podemos inferir que el proceso de carbonatación aplicado, reduce significativamente la porosidad del material $y$, por lo tanto, justifica el incremento de su densidad.

Tabla 53. Resumen de los datos de intrusión de la porosimetría de mercurio sobre las probetas de mortero CAC $\cdot 1 / 1 \cdot 0 / 4$.

\begin{tabular}{ccc}
\cline { 2 - 3 } & Mortero de Referencia & Mortero con CVT \\
\hline Volumen intruido total & $0,0619 \mathrm{~mL} / \mathrm{g}$ & $0,5335 \mathrm{~mL} / \mathrm{g}$ \\
\hline Superficie específica & $3,834 \mathrm{~m}^{2} / \mathrm{g}$ & $3,522 \mathrm{~m}^{2} / \mathrm{g}$ \\
\hline $\begin{array}{c}\text { Mediana diámetro de poros } \\
\text { (Volumen) }\end{array}$ & $0,1583 \mu \mathrm{m}$ & $0,1209 \mu \mathrm{m}$ \\
\hline $\begin{array}{c}\text { Mediana diámetro de poros } \\
\text { (Área) }\end{array}$ & $0,0354 \mu \mathrm{m}$ & $0,0344 \mu \mathrm{m}$ \\
\hline $\begin{array}{c}\text { Diámetro de poro medio } \\
\text { (4V/A) }\end{array}$ & $0,0742 \mu \mathrm{m}$ & $0,0644 \mu \mathrm{m}$ \\
\hline Porosidad & $\mathbf{1 3 , 3 4 8 4 \%}$ & $\mathbf{8 , 9 9 0 7 \%}$ \\
\hline Volumen capilar empleado & $55 \%$ & $49 \%$ \\
\hline
\end{tabular}


Los datos de porosidad nos permiten establecer unas correspondencias analíticas con las tensiones de rotura a compresión para estas mismas dosificaciones (tabla 57). Los morteros de referencia tienen unas tensiones de rotura de $66,11 \mathrm{~N} / \mathrm{mm}^{2}$, mientras que para los morteros con incorporación de CVT la tensión es de 98,26 N/mm². De acuerdo a estos valores se puede suponer una línea de tendencia exponencial acorde a la expresión:

$$
\begin{gathered}
y=222,57 e^{-0,091 x} \\
R^{2}=1
\end{gathered}
$$

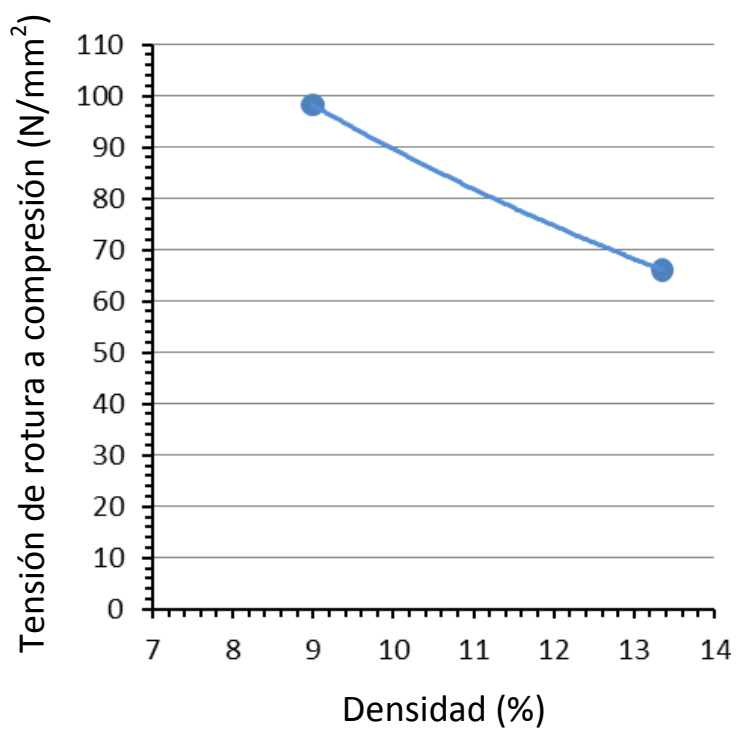

Dicha expresión explica la tendencia según la cual la reducción en la porosidad del material está en relación directa con la máxima capacidad resistente del mismo (Sugrañez et al., 2013).

De acuerdo a los datos de superficie específica de la tabla 53, se puede realizar una estimación del tamaño de partícula medio de cada uno de los morteros ensayados. Tomando como base de partida que las partículas tienen una forma esférica, y según los datos de densidad reflejados en la tabla 48 se puede deducir que:

$$
S_{e}=N \times S_{o}
$$

Donde: 
$S_{e}$, superficie específica del mortero endurecido $\left(\mathrm{m}^{2} / \mathrm{g}\right)($ tabla 48$)$

$N$, número de partículas por cada gramo de mortero.

$S_{o}$, superficie de las partículas. Suponiéndolas esféricas sería igual a: $S_{o}=4 \times \pi \times r^{2}$

De igual forma, para el cálculo del volumen por cada gramo de muestra de mortero:

$$
V_{g}=\frac{1}{\rho}
$$

Siendo la densidad del mortero $\rho=2,165 \mathrm{~g} / \mathrm{cm}^{3}$, el volumen así calculado será: $V=0,46 \mathrm{~cm}^{3}$.

Así, suponiendo las partículas esféricas, el volumen calculado para 1 gr de mortero será igual a:

$$
V_{g}=N \times \frac{4 \pi r^{2}}{3}
$$

Siendo $N$, el número de partículas existentes en cada gramo de mortero.

Para los valores de superficie específica de los morteros de referencia de la tabla $53, S_{e}=3,834 \mathrm{~m}^{2} / \mathrm{g}$, y de la sustitución en las ecuaciones (1) y (2) quedará:

$$
N \times r^{2}=\frac{3,834 \times 10^{4} \mathrm{~cm}^{2}}{4 \pi}
$$

Y,

$$
N \times r^{3}=\frac{3 \times 0,46 \mathrm{~cm}^{3}}{4 \pi}
$$


De donde:

$$
r=\frac{3 \times 0,46 \mathrm{~cm}^{3}}{3,834 \times 10^{4} \mathrm{~cm}^{2}} \quad r_{R}=3,59 \times 10^{-5} \mathrm{~cm}
$$

Si operamos de igual forma para los datos del mortero con inclusión de CVT, de acuerdo a su superficie específica: $S_{e}=3,522 \mathrm{~m}^{2} / \mathrm{g}$, obtendremos:

$$
r=\frac{3 \times 0,46 \mathrm{~cm}^{3}}{3,522 \times 10^{4} \mathrm{~cm}^{2}} \quad r_{C V T}=3,92 \times 10^{-5} \mathrm{~cm}
$$

Según los datos analizados, se puede estimar que el diámetro medio de las partículas de los morteros elaborados con CAC.1/1.0/4 y cenizas volantes inertizadas es de $7,84 \times 10^{-5} \mathrm{~cm}$, frente a los $7,18 \times 10^{-5} \mathrm{~cm}$ de los morteros de referencia. Los morteros con CVT tienen por tanto partículas de mayor tamaño, con menor superficie específica y porosidad que sus morteros de referencia.

La tabla 54 ofrece los valores de distribución del tamaño del poro para los morteros de CAC·1/1·0/4. De nuevo se trata de materiales muy homogéneos con características de poro similares, si bien el mortero con CVT en su dosificación posee una macroporosidad ligeramente superior al de referencia, con el consiguiente beneficio desde el punto de vista de la alterabilidad del material puesto que a menor tamaño de poro, mayores son las presiones de cristalización. Este hecho puede ser observado gráficamente en la curva de intrusión acumulada frente a tamaño de poro (ilustración 65). En ella, línea roja correspondiente al mortero con CVT, muestra una mayor cantidad de poros en la franja comprendida entre 0,5 
$\mu \mathrm{m}$ y $10 \mu \mathrm{m}$. Por el contrario, el acumulado de poros con diámetros inferiores a $0,5 \mu \mathrm{m}$ es superior en el mortero de referencia (línea azul).

Tabla 54. Distribución de volumen intruido por tamaños de poro para morteros de CAC $\cdot 1 / 1 \cdot 0 / 4$

\begin{tabular}{|c|c|c|}
\hline & Mortero de Referencia & Mortero con CVT \\
\hline Micro < 5 нm & $98,10 \%$ & $96,50 \%$ \\
\hline Macro > 5 $\mu \mathrm{m}$ & $1,90 \%$ & $3,50 \%$ \\
\hline$<0.01 \mu \mathrm{m}$ & $4,15 \%$ & $3,68 \%$ \\
\hline $0.01-0.1 \mu \mathrm{m}$ & $38,68 \%$ & $39.92 \%$ \\
\hline $0.1-1 \mu \mathrm{m}$ & $53,03 \%$ & $48,53 \%$ \\
\hline $1-10 \mu m$ & $3,06 \%$ & $6,47 \%$ \\
\hline $10-100 \mu m$ & $0,85 \%$ & $0,69 \%$ \\
\hline$>100 \mu \mathrm{m}$ & $0,23 \%$ & $0,71 \%$ \\
\hline
\end{tabular}

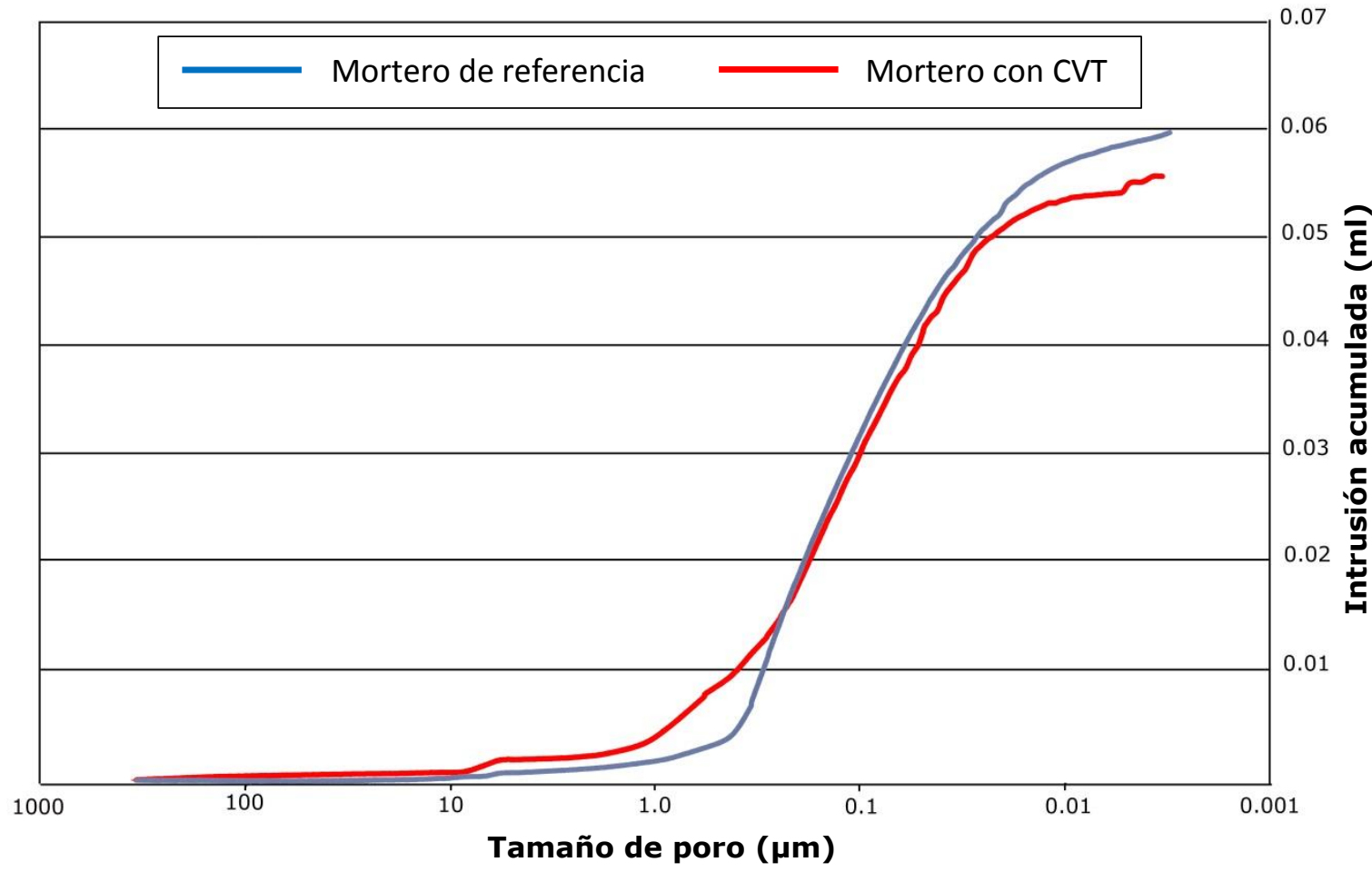

Ilustración 65. Curvas de intrusión acumulada de mercurio frente al tamaño de poro. 
De la observación de las curvas de tamaño de poro frente al logaritmo de intrusión diferencial (ilustración 66) se puede destacar que el mortero de referencia exhibe su máximo de distribución de poros a 0,32 $\mu \mathrm{m}$. Por el contrario, y siempre dentro de la distribución homogénea que presentan ambas curvas, el mortero con incorporación de CVT reduce la porosidad y el tamaño de poros con máximos a $0,18 \mu \mathrm{m}$.

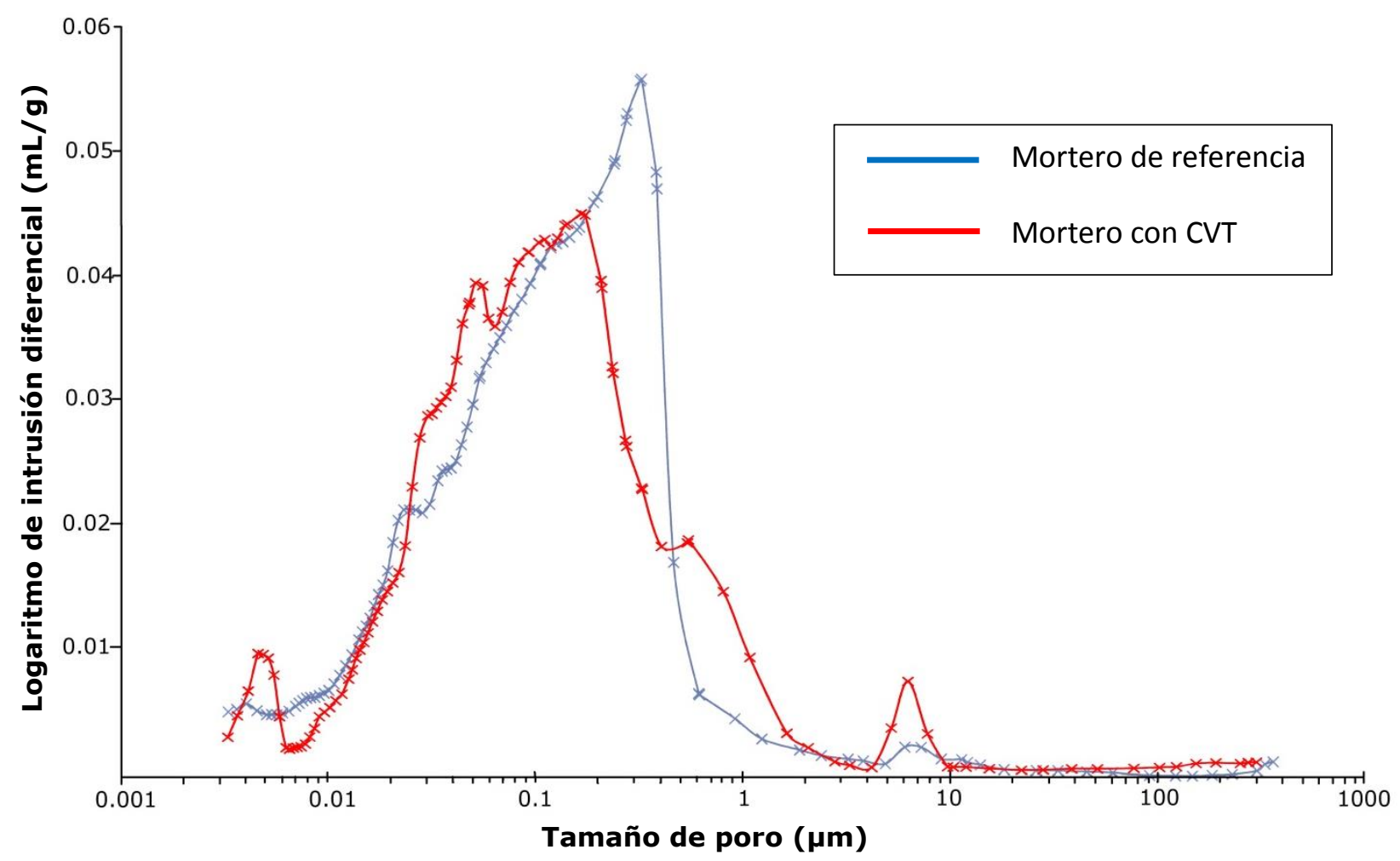

Ilustración 66. Curvas de diámetro de tamaño de poro frente al logaritmo de intrusión diferencial. 


\subsubsection{DETERMINACIÓN DE LA RESISTENCIA A FLEXIÓN Y A COMPRESIÓN DEL MORTERO ENDURECIDO (UNE-EN 1015-11)}

Las tablas 55 a 58 reúnen los valores, en $\mathrm{N} / \mathrm{mm} 2$, de resistencia mecánica, a edades de 7, 28, 60 y 90 días, obtenidos en la rotura a flexión y compresión de los morteros elaborados con los cementos CEM-I, CEM-II $A / P, C A C$ y CSA, respectivamente.

Para cada uno de los apartados temporales se ofrecen dos columnas de las cuales:

- La primera muestra los resultados analíticos del valor medio de la tensión de rotura a flexión de cada una de las tres probetas ensayadas.

- La segunda columna refleja los valores medios de tensión de rotura a compresión de los seis valores conseguidos tras el ensayo de rotura a flexión.

Con la intención de realizar una interpretación más precisa de los resultados obtenidos, a cada celda con valores de rotura se le ha incorporado en su parte inferior (entre paréntesis y sobre fondo gris) la desviación estándar de los distintos valores utilizados para el cálculo de las resistencias medias tanto de flexión, como de compresión.

A su vez, la información en las celdas relativas a datos de los morteros realizados con la incorporación de CVT, se ha ampliado incorporando el porcentaje de variación con respecto a los valores medios de los morteros de referencia (en rojo, si existe una disminución de los valores; y en verde, si la variación es positiva).

Al final de este epígrafe, se presentan las ilustraciones 67 y 68, las cuales tienen la finalidad de presentar en un solo gráfico una comparativa normalizada de cada una de las tensiones, flexión y compresión, respectivamente. Dicha normalización se ha conseguido dividiendo cada uno de los valores obtenidos para los morteros con la incorporación de CVT, 
entre los valores de referencia de esos mismos morteros. Todo ello para cada una de las edades estudiadas. De esta forma, valores muy por debajo del 1, muestran morteros en los que la incorporación de CVT perjudica seriamente las resistencias obtenidas. Aquellos cercanos al 1, definen morteros con comportamientos mecánicos similares a sus morteros de referencia. Por último, valores muy por encima del 1 determinan dosificaciones con la incorporación de CVT con prestaciones mecánicas muy superiores a las de los morteros de referencia.

\subsubsection{Resistencias mecánicas de los morteros de cemento CEM-I.}

\subsection{Tensión de rotura a flexión:}

Los datos presentados muestran una clara tendencia, la cual es similar a todas las dosificaciones ensayadas: La adición de cenizas volantes inertizadas reduce de manera considerable, en torno a una quinta parte, la resistencia a flexión de todas las probetas analizadas.

Los resultados son muy homogéneos, resultando menos desfavorables cuanta mayor cantidad de árido tiene la mezcla (1/3). De esta forma, la mejor dosificación se corresponde con la de los morteros CEM-I · 0/2 · $1 / 3$, en los que la pérdida de resistencia a flexión entre el mortero de referencia y el mismo mortero con un $10 \%$ de CVT, es de un $17,06 \%$ (tabla 55 ).

De igual forma, los mejores valores siempre se obtienen en los morteros con tamaño de árido menor. En tamaños de árido 0/2 las reducciones de la resistencia a flexión son de un 19,50\% y un 17,06\%, frente a un $22,60 \%$ y un $20,71 \%$ de las dosificaciones con diámetro 0/4 (tabla 55)

Los valores de tensión a flexión de las dosificaciones ensayadas con la incorporación de CVT son los que peores resultados presentan en relación a sus morteros de referencia. 


\subsection{Tensión de rotura a compresión}

Los valores obtenidos ofrecen un paralelismo absoluto a los resultados reflejados en la rotura a flexión. De nuevo, la incorporación de cenizas volantes inertizadas en los morteros reduce, en aproximadamente una quinta parte, las tensiones de rotura a compresión. Los valores de tensión a compresión de las dosificaciones ensayadas con la incorporación de CVT son los que peores resultados presentan en relación a sus morteros de referencia. Si bien en este caso, los valores más positivos, dentro de la pérdida de resistencia presentada, corresponden a los morteros ricos en cemento y, por lo tanto, con menor cantidad de áridos en su dosificación. Así, las menores mermas de resistencia son de un $19,71 \%$ y de un $18,95 \%$, ambos muy similares y correspondientes a las dosificaciones $1 / 1$. Por el contrario, el peor dato corresponde a los morteros CEM-I $\cdot 0 / 2 \cdot 1 / 3$ con un $25,44 \%$, lo que resulta en una pérdida de más de una cuarta parte de la tensión de rotura a compresión.

Las cantidades de portlandita presentes en las cenizas volantes de RSU originales no tiene ningún efecto en los morteros analizados ya que el tratamiento efectuado a través del lavado con bicarbonato sódico $\left(\mathrm{NaHCO}_{3}\right)$ produce una transformación de los hidróxidos en carbonatos, especialmente carbonato cálcico $\left(\mathrm{CaCO}_{3}\right)$, el cual es inerte.

Las pérdidas de resistencia mencionadas pueden ser explicadas con base en que las partículas de CVT utilizadas en la elaboración de los morteros pueden ser consideradas como puntos débiles dentro de la matriz del mortero. De igual manera, (Kessler et al. 1992) han demostrado que la reactividad de las mezclas de pastas de cemento y las cenizas volantes son especialmente débiles.

Por otro lado, esta reducción de las propiedades mecánicas es atribuible al alto grado de agua necesaria para su amasado (Lombardi et al., 1998), como así se ha manifestado en el apartado correspondiente. 
Tabla 55. Valores de resistencia mecánica a $7,28,60$ y 90 días, en $\mathrm{N} / \mathrm{mm} 2$, obtenidos de la rotura de las probetas de mortero elaboradas con CEM-I. Valores medios de tensión de rotura a flexión y a compresión. En rojo, porcentaje comparativo de pérdida de resistencias entre morteros de referencia (R.0\%) y morteros con la incorporación de cenizas volantes inertizadas (CVT·10\%). Entre paréntesis, desviación estándar de los valores de resistencia mecánica.

\begin{tabular}{|c|c|c|c|c|c|c|c|c|c|}
\hline \multirow{4}{*}{ 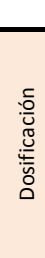 } & \multirow{4}{*}{$\begin{array}{l}5 \\
0 \\
0\end{array}$} & \multicolumn{2}{|c|}{7 días } & \multicolumn{2}{|c|}{28 días } & \multicolumn{2}{|c|}{60 días } & \multicolumn{2}{|c|}{90 días } \\
\hline & & \multicolumn{2}{|c|}{ Resistencia Mecánica $\left(\mathrm{N} / \mathrm{mm}^{2}\right)$} & \multicolumn{2}{|c|}{ Resistencia Mecánica (N/mm²) } & \multicolumn{2}{|c|}{ Resistencia Mecánica (N/mm²) } & \multicolumn{2}{|c|}{ Resistencia Mecánica (N/mm²) } \\
\hline & & \begin{tabular}{|c} 
Valor medio de \\
Tensión Rotura a \\
Flexión
\end{tabular} & $\begin{array}{l}\text { Valor medio de } \\
\text { Tensión de Rotura } \\
\text { a compresión }\end{array}$ & $\begin{array}{l}\text { Valor medio de } \\
\text { Tensión Rotura a } \\
\text { Flexión }\end{array}$ & $\begin{array}{l}\text { Valor medio de } \\
\text { Tensión de Rotura } \\
\text { a compresión }\end{array}$ & $\begin{array}{c}\text { Valor medio de } \\
\text { Tensión Rotura a } \\
\text { Flexión }\end{array}$ & $\begin{array}{l}\text { Valor medio de } \\
\text { Tensión de Rotura } \\
\text { a compresión }\end{array}$ & $\begin{array}{l}\text { Valor medio de } \\
\text { Tensión Rotura a } \\
\text { Flexión }\end{array}$ & $\begin{array}{l}\text { Valor medio de } \\
\text { Tensión de Rotura } \\
\text { a compresión }\end{array}$ \\
\hline & & \multicolumn{2}{|c|}{ EN 1015-11:2000 } & \multicolumn{2}{|c|}{ EN 1015-11:2000 } & \multicolumn{2}{|c|}{ EN 1015-11:2000 } & \multicolumn{2}{|c|}{ EN 1015-11:2000 } \\
\hline \multirow{5}{*}{ 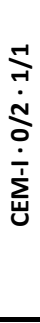 } & \multirow{2}{*}{$R(0 \%)$} & 10,35 & 69,46 & 9,15 & 81,92 & 11,24 & 87,74 & 10,91 & 86,46 \\
\hline & & $(0,38)$ & $(2,62)$ & $(0,77)$ & $(3,14)$ & $(0,22)$ & $(1,98)$ & $(0,27)$ & $(2,11)$ \\
\hline & \multirow{3}{*}{$\begin{array}{c}\mathrm{CVT} \\
10 \% \mathrm{~T}\end{array}$} & 8,91 & 54,45 & 8,86 & 62,23 & 8,35 & 67,77 & 8,78 & 69,42 \\
\hline & & $-13,90 \%$ & $-21,61 \%$ & $-3,18 \%$ & $-24,04 \%$ & $-25,64 \%$ & $-22,76 \%$ & $-19,50 \%$ & $-19,71 \%$ \\
\hline & & $(0,53)$ & $(0,67)$ & $(0,39)$ & $(1,96)$ & $(0,87)$ & $(1,00)$ & $(0,34)$ & $(0,95)$ \\
\hline \multirow{5}{*}{ 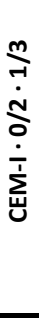 } & \multirow{2}{*}{$R(0 \%)$} & 6,29 & 31,72 & 7,86 & 39,08 & 8,09 & 41,49 & 8,80 & 44,35 \\
\hline & & $(0,41)$ & $(1,18)$ & $(0,47)$ & $(1,23)$ & $(0,20)$ & $(1,88)$ & $(0,30)$ & $(2,54)$ \\
\hline & \multirow{3}{*}{$\begin{array}{c}\mathrm{CVT} \\
10 \% \mathrm{~T}\end{array}$} & 5,26 & 24,42 & 5,77 & 29,43 & 6,63 & 31,31 & 7,30 & 33,07 \\
\hline & & $-16,47 \%$ & $-23,04 \%$ & $-26,54 \%$ & $-24,69 \%$ & $-18,07 \%$ & $-24,53 \%$ & $-17,06 \%$ & $-25,44 \%$ \\
\hline & & $(0,06)$ & $(0,13)$ & $(0,31)$ & $(0,51)$ & $(0,10)$ & $(0,67)$ & $(0,20)$ & $(0,22)$ \\
\hline \multirow{5}{*}{ 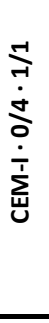 } & \multirow{2}{*}{$\mathrm{R}(0 \%)$} & 10,09 & 65,34 & 10,58 & 75,92 & 11,06 & 82,68 & 10,48 & 84,83 \\
\hline & & $(0,71)$ & $(0,69)$ & $(0,68)$ & $(3,72)$ & $(0,68)$ & $(2,81)$ & $(0,56)$ & $(2,41)$ \\
\hline & \multirow{3}{*}{$\begin{array}{c}\text { CVT } \\
10 \% T\end{array}$} & 8,61 & 54,52 & 8,47 & 60,43 & 8,59 & 66,14 & 8,11 & 68,76 \\
\hline & & $-17,18 \%$ & $-16,56 \%$ & $-19,94 \%$ & $-20,40 \%$ & $-22,35 \%$ & $-20,01 \%$ & $-22,60 \%$ & $-18,95 \%$ \\
\hline & & $(0,68)$ & $(0,65)$ & $(0,30)$ & $(2,47)$ & $(0,29)$ & $(1,78)$ & $(1,04)$ & $(1,24)$ \\
\hline \multirow{5}{*}{ 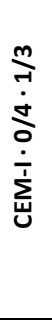 } & \multirow[t]{2}{*}{$R(0 \%)$} & 7,37 & 36,63 & 8,51 & 43,67 & 8,55 & 45,49 & 8,41 & 47,11 \\
\hline & & $(0,16)$ & $(0,98)$ & $(0,91)$ & $(0,91)$ & $(0,41)$ & $(2,56)$ & $(0,16)$ & $(1,52)$ \\
\hline & \multirow{3}{*}{$\begin{array}{c}\mathrm{CVT} \\
10 \% \mathrm{~T}\end{array}$} & 5,20 & 26,49 & 5,97 & 32,04 & 7,17 & 35,16 & 6,67 & 36,63 \\
\hline & & $-29,39 \%$ & $-27,68 \%$ & $-29,86 \%$ & $-26,63 \%$ & $-16,12 \%$ & $-22,72 \%$ & $-20,71 \%$ & $-22,24 \%$ \\
\hline & & $(0,14)$ & $(0,12)$ & $(0,25)$ & $(0,41)$ & $(0,37)$ & $(0,50)$ & $(0,09)$ & $(0,31)$ \\
\hline
\end{tabular}




\subsubsection{Resistencias mecánicas de los morteros de cemento CEM-II A/P}

La tabla 56 y las ilustraciones 67 y 68 , muestran los resultados de resistencia a compresión de los morteros de cemento CEM-II A/P y su comparativa con el resto de morteros analizados. Los datos son muy homogéneos y proporcionales a los reflejados para los morteros CEM-I y bastante cercanos en cuanto a las resistencias ofrecidas, si se tiene en cuenta que el tipo de cemento utilizado, CEM-II A/P, posee una resistencia inicial cercana a los 10MPa menor que el CEM-I.

\subsection{Tensión de rotura a flexión}

Al igual que sucede en los morteros elaborados con CEM-I, la incorporación de cenizas volantes inertizadas, produce una disminución en las tensiones de rotura a flexión, que se mantienen proporcionales a lo largo de la edad del mortero.

Los mejores datos, dentro de la merma de resistencia sufrida, se obtienen en aquellos morteros en donde, proporcionalmente, hay una mayor cantidad de áridos (1/3) y, dentro de éstos, el tamaño del árido influye de manera inversamente proporcional. Así, las menores reducciones son para los morteros CEM-II $\cdot 0 / 2 \cdot 1 / 3$ con sólo un $7,11 \%$ de disminución a 90 días, siendo el segundo mejor dato el correspondiente a la misma dosificación pero con un diámetro de árido mayor: CEM-II $\cdot 0 / 4 \cdot 1 / 3$, que presenta una minoración en las resistencias a flexión de un 11,05\%. Por el contrario, las mayores pérdidas de resistencia se obtienen en los morteros con mayor cantidad de cemento en su formulación, siendo el peor dato el ofrcido por el mortero CEM-II $\cdot 0 / 2 \cdot 1 / 1$ con una minoración de un 15,16\% con respecto a su mortero de referencia.

A pesar de ser un cemento con menores resistencias, los valores obtenidos a 90 días presentan mejores comportamientos con relación a los morteros de referencia que los obtenidos para los morteros confeccionados con CEM-I. 


\subsection{Tensión de rotura a compresión}

De nuevo, los morteros ejecutados con cenizas volantes tratadas (CVT) presentan unos descensos de tensión de rotura a compresión bastante pronunciados, si bien en este caso, no se observa una correspondencia directa que relacione cualquiera de las dosificaciones utilizadas o el tamaño del árido, con el porcentaje de reducción de la resistencia observado.

El mejor valor analizado, aunque dentro de la disminución de resistencias generalizada, es el relativo a los morteros CEM-II · 0/4 · 1/1 con un $11,10 \%$. Por el contrario, el peor de los datos registrados es de más del doble, 22,72\%, y corresponde a los morteros CEM-II · 0/2 · 1/1. De lo que se podría deducir el tamaño del árido es la principal causa de reducción de las resistencias. Sin embargo, en los valores analíticos de las dosificaciones tradicionales, $1 / 3$, el mejor dato es para el mortero CEM-II . $0 / 2 \cdot 1 / 3$ con un $17,27 \%$, frente a un $20,45 \%$ del CEM-II $\cdot 0 / 4 \cdot 1 / 3$. De todo lo anterior se podría inferir que, a igualdad de dosificación de árido, el diámetro del mismo repercute negativamente en la resistencia cuanto mayor es éste.

Dado el comportamiento equivalente entre este tipo de morteros y los elaborados con CEM-I, las causas relativas a la disminución de resistencias mecánicas son perfectamente extrapolables a las reflejadas para estos últimos.

Al igual que sucede en el comportamiento mecánico a flexión, los datos obtenidos a 90 días presentan valores ligeramente superiores a los obtenidos para los morteros elaborados con CEM-I. 
Tabla 56. Valores de resistencia mecánica a 7, 28, 60 y 90 días, en $\mathrm{N} / \mathrm{mm} 2$, obtenidos de la rotura de las probetas de mortero elaboradas con CEM-II-A/P. Valores medios de tensión de rotura a flexión y a compresión. En rojo, porcentaje comparativo de pérdida de resistencias entre morteros de referencia (R.0\%) y morteros con la incorporación de cenizas volantes inertizadas (CVT-10\%). Entre paréntesis, desviación estándar de los valores de resistencia mecánica.

\begin{tabular}{|c|c|c|c|c|c|c|c|c|c|}
\hline \multirow[b]{3}{*}{ 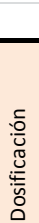 } & \multirow{4}{*}{$\begin{array}{l}5 \\
0 \\
0^{\circ}\end{array}$} & \multicolumn{2}{|c|}{7 días } & \multicolumn{2}{|c|}{28 días } & \multicolumn{2}{|c|}{60 días } & \multicolumn{2}{|c|}{90 días } \\
\hline & & \multicolumn{2}{|c|}{ Resistencia Mecánica $\left(\mathrm{N} / \mathrm{mm}^{2}\right)$} & \multicolumn{2}{|c|}{ Resistencia Mecánica (N/mm²) } & \multicolumn{2}{|c|}{ Resistencia Mecánica (N/mm²) } & \multicolumn{2}{|c|}{ Resistencia Mecánica (N/mm²) } \\
\hline & & \begin{tabular}{|c} 
Valor medio de \\
Tensión Rotura a \\
Flexión
\end{tabular} & $\begin{array}{l}\text { Valor medio de } \\
\text { Tensión de Rotura } \\
\text { a compresión }\end{array}$ & $\begin{array}{l}\text { Valor medio de } \\
\text { Tensión Rotura a } \\
\text { Flexión }\end{array}$ & \begin{tabular}{|c} 
Valor medio de \\
Tensión de Rotura \\
a compresión
\end{tabular} & $\begin{array}{l}\text { Valor medio de } \\
\text { Tensión Rotura a } \\
\text { Flexión }\end{array}$ & $\begin{array}{l}\text { Valor medio de } \\
\text { Tensión de Rotura } \\
\text { a compresión }\end{array}$ & $\begin{array}{l}\text { Valor medio de } \\
\text { Tensión Rotura a } \\
\text { Flexión }\end{array}$ & $\begin{array}{l}\text { Valor medio de } \\
\text { Tensión de Rotura } \\
\text { a compresión }\end{array}$ \\
\hline & & \multicolumn{2}{|c|}{ EN 1015-11:2000 } & \multicolumn{2}{|c|}{ EN 1015-11:2000 } & \multicolumn{2}{|c|}{ EN 1015-11:2000 } & \multicolumn{2}{|c|}{ EN1015-11:2000 } \\
\hline \multirow{5}{*}{ 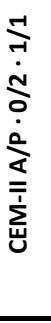 } & \multirow{2}{*}{$\mathrm{R}(0 \%)$} & 10,24 & 60,03 & 11,75 & 73,53 & 10,82 & 78,39 & 11,41 & 83,57 \\
\hline & & $(0,35)$ & $(1,03)$ & $(0,25)$ & $(3,97)$ & $(0,34)$ & $(5,90)$ & $(0,62)$ & $(2,25)$ \\
\hline & \multirow{3}{*}{$\begin{array}{c}\text { CVT } \\
10 \% \mathrm{~T}\end{array}$} & 7,74 & 40,35 & 8,95 & 55,94 & 9,64 & 59,40 & 9,68 & 64,58 \\
\hline & & $-24,41 \%$ & $-32,79 \%$ & $-23,87 \%$ & $-23,92 \%$ & $-10,92 \%$ & $-24,23 \%$ & $-15,16 \%$ & $-22,72 \%$ \\
\hline & & $(0,34)$ & $(0,36)$ & $(0,55)$ & $(1,08)$ & $(0,57)$ & $(1,20)$ & $(0,43)$ & $(1,89)$ \\
\hline \multirow{5}{*}{ 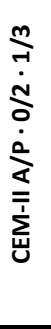 } & \multirow[t]{2}{*}{$R(0 \%)$} & 5,52 & 21,41 & 6,06 & 26,85 & 8,11 & 37,49 & 7,34 & 33,45 \\
\hline & & $(0,15)$ & $(1,22)$ & $(0,07)$ & $(1,99)$ & $(0,19)$ & $(1,30)$ & $(0,36)$ & $(1,72)$ \\
\hline & \multirow{3}{*}{$\begin{array}{l}\text { CVT } \\
10 \% \mathrm{~T}\end{array}$} & 4,40 & 17,51 & 5,23 & 22,77 & 5,87 & 26,96 & 6,82 & 27,67 \\
\hline & & $-20,23 \%$ & $-18,24 \%$ & $-13,75 \%$ & $-15,20 \%$ & $-27,65 \%$ & $-28,09 \%$ & $-7,11 \%$ & $-17,27 \%$ \\
\hline & & $(0,15)$ & $(0,32)$ & $(0,42)$ & $(0,35)$ & $(0,11)$ & $(0,51)$ & $(0,24)$ & $(0,18)$ \\
\hline \multirow{5}{*}{ 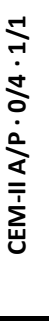 } & \multirow[t]{2}{*}{$\mathrm{R}(0 \%)$} & 9,84 & 59,95 & 11,44 & 68,49 & 11,39 & 76,99 & 10,68 & 78,73 \\
\hline & & $(0,57)$ & $(2,02)$ & $(0,57)$ & $(1,70)$ & $(0,34)$ & $(2,04)$ & $(0,95)$ & $(2,97)$ \\
\hline & \multirow{3}{*}{$\begin{array}{c}\text { CVT } \\
10 \% \mathrm{~T}\end{array}$} & 8,07 & 52,88 & 9,54 & 57,50 & 9,63 & 65,97 & 9,35 & 70,00 \\
\hline & & $-18,05 \%$ & $-11,79 \%$ & $-16,66 \%$ & $-16,05 \%$ & $-15,50 \%$ & $-14,31 \%$ & $-12,46 \%$ & $-11,10 \%$ \\
\hline & & $(0,83)$ & $(0,94)$ & $(0,68)$ & $(3,25)$ & $(0,22)$ & $(0,77)$ & $(0,44)$ & $(1,30)$ \\
\hline \multirow{5}{*}{ 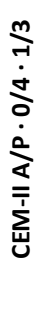 } & \multirow[t]{2}{*}{$\mathrm{R}(0 \%)$} & 5,75 & 25,47 & 7,55 & 34,24 & 7,85 & 38,81 & 7,87 & 40,32 \\
\hline & & $(0,17)$ & $(0,17)$ & $(0,29)$ & $(0,68)$ & $(0,07)$ & $(0,91)$ & $(0,65)$ & $(1,94)$ \\
\hline & \multirow{3}{*}{$\begin{array}{c}\text { CVT } \\
10 \% \mathrm{~T}\end{array}$} & 4,91 & 23,37 & 5,98 & 27,37 & 6,66 & 31,04 & 7,00 & 32,07 \\
\hline & & $-14,58 \%$ & $-8,24 \%$ & $-20,77 \%$ & $-20,09 \%$ & $-15,13 \%$ & $-20,01 \%$ & $-11,05 \%$ & $-20,45 \%$ \\
\hline & & $(0,23)$ & $(0,33)$ & $(0,32)$ & $(0,29)$ & $(0,09)$ & $(0,19)$ & $(0,49)$ & $(1,66)$ \\
\hline
\end{tabular}




\subsubsection{Resistencias mecánicas de los morteros de cemento CAC}

La tabla 57 y las ilustraciones 67 y 68 , ofrecen los datos de resistencias mecánicas obtenidos para los morteros elaborados con cemento CAC. El análisis de los mismos ofrece una clara conclusión: A 90 días de edad, todos los morteros de este tipo de cemento, independientemente de su dosificación, presentan valores por encima de los obtenidos en los morteros de referencia. Este comportamiento se extiende, salvo a edades tempranas, a lo largo de la línea temporal para los morteros de relación cemento/árido $1 / 1$. Siendo a partir de 60 días cuando se aprecia una mejora generalizada en la conducta de los morteros analizados, a excepción de los valores de resistencia a compresión de los morteros CAC. $0 / 2 \cdot 1 / 3$.

A diferencia de lo ocurrido con los morteros de CEM-I y CEM-II A/P, la inclusión de cenizas volantes de RSU inertizadas, no parece afectar a las resistencias mecánicas, sino todo lo contrario.

\subsection{Tensión de rotura a flexión}

Las tendencias en los valores obtenidos a lo largo de la vida de los distintos morteros ensayados, son prácticamente análogas si se comparan los datos de ambas tensiones mecánicas. Lo que denota un comportamiento muy similar en los morteros elaborados con CAC.

Las dosificaciones analizadas presentan unas mejoras en las tensiones de rotura a flexión, con respecto a los morteros de referencia, que van desde un $21,46 \%$, en los morteros CAC $\cdot 0 / 2 \cdot 1 / 1$, hasta un $67,02 \%$, en los morteros CAC $\cdot 0 / 4 \cdot 1 / 1$. En el resto de los casos, todos correspondientes a morteros con dosificaciones tradicionales de $1 / 3$, estos incrementos son cercanos al 30\%, 29.96\% para los morteros con áridos de diámetro 0/2; y $32,32 \%$ para los de $0 / 4$.

El mejor dato en valor absoluto de todas las tensiones de rotura a flexión analizadas, se obtiene para los morteros de CAC $\cdot 0 / 2 \cdot 1 / 1$ con CVT, 
$16,978 \mathrm{~N} / \mathrm{mm}^{2}$, siendo este dato, además, el mejor de entre todos los morteros ensayados para la realización de esta investigación. Estos datos resultarían especialmente favorables, si el fin último de este tipo de morteros son piezas prefabricadas sin armadura estructural que deben resistir su propia forma y tamaño.

\subsection{Tensión de rotura a compresión}

Es particularmente notable el comportamiento de los morteros con áridos de mayor tamaño, 0/4, y cenizas volantes inertizadas en su composición. En ellos se obtienen la mayor diferencia porcentual con respecto a los morteros de referencia. Las ganancias de resistencia van desde un $37,46 \%$, en los morteros CAC $\cdot 0 / 4 \cdot 1 / 3$, hasta un $48,62 \%$ en los CAC $\cdot 0 / 4 \cdot 1 / 1$. A pesar de esto, el mejor dato en valor absoluto de todas las tensiones de rotura a compresión analizadas, se obtiene para los morteros de CAC $\cdot 0 / 2 \cdot 1 / 1$ con CVT, $117,25 \mathrm{~N} / \mathrm{mm}^{2}$, siendo este dato, además, el mejor de entre todos los morteros ensayados para la realización de esta investigación, coincidiendo también con el mortero con mejor resistencia mecánica a flexión. Este mortero es, además, el único que presenta valores superiores a los de su mortero referencia a lo largo de los 90 días analizados. En el resto de morteros, salvo para CAC $\cdot 0 / 2 \cdot 1 / 3$, las mejoras comienzan a ser apreciables a partir de los 60 días.

El aumento de la resistencia a compresión no debería ser atribuible al potencial poder puzolánico de las cenizas tratadas ya que, como se ha comprobado, el tratamiento efectuado a través del lavado con bicarbonato sódico transforma el hidróxido cálcico mayoritariamente en productos inertes tales como el Carbonato Cálcico. Las reacciones puzolánicas, además, son muy lentas y su influencia resultaría evidente tras largos periodos de tiempo, normalmente entre 28 y 90 día, algo que, en este caso, no justificaría el comportamiento tan positivo de mezclas como las de CAC . $0 / 2 \cdot 1 / 1$, que adquieren resistencias muy elevadas a edades muy tempranas ( 7 días). Muchos autores centran el poder puzolánico de determinados materiales en su composición química, especialmente en los 
contenidos en $\mathrm{Al}_{2} \mathrm{O}_{3}$ y $\mathrm{SiO}_{2}$, presentes en gran medida en el cemento utilizado, sobre todo el primero de ellos.

Por otro lado, a pesar de haber reducido en casi un $99 \%$ el contenido en cloruros en las cenizas inertizadas, la presencia de ciertas cantidades de cloruros puede ser también la causa de un incremento en la resistencia. De hecho, los cloruros son conocidos por tener efectos acelerantes en el proceso de fraguado (Taylor, 1997).

Del análisis de los datos de la tabla 23 sobre las relaciones agua/cemento utilizadas en la elaboración de las muestras, y de su comparación con los resultados del periodo de trabajabilidad de la tabla 26, se deduce una trabajabilidad reducida de los morteros de cemento CAC con la incorporación de CVT. Esto podría provocar un aumento de la resistencia a compresión en base a la absorción de agua por parte de las cenizas volantes durante la preparación de la mezcla. Esta absorción de agua disminuye la relación efectiva de agua/cemento y puede provocar un aumento de la resistencia. 
Tabla 57. Valores de resistencia mecánica a 7, 28, 60 y 90 días, en $\mathrm{N} / \mathrm{mm} 2$, obtenidos de la rotura de las probetas de mortero elaboradas con CAC. Valores medios de tensión de rotura a flexión y a compresión. En verde, porcentaje comparativo de ganancia de resistencias entre morteros de referencia (R.0\%) y morteros con la incorporación de cenizas volantes inertizadas (CVT-10\%). En rojo, pérdida de resistencias. Entre paréntesis, desviación estándar de los valores de resistencia mecánica.

\begin{tabular}{|c|c|c|c|c|c|c|c|c|c|}
\hline \multirow[b]{3}{*}{ 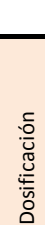 } & \multirow{4}{*}{$\begin{array}{l}5 \\
\text { d } \\
20\end{array}$} & \multicolumn{2}{|c|}{7 días } & \multicolumn{2}{|c|}{28 días } & \multicolumn{2}{|c|}{60 días } & \multicolumn{2}{|c|}{90 días } \\
\hline & & \multicolumn{2}{|c|}{ Resistencia Mecánica $\left(\mathrm{N} / \mathrm{mm}^{2}\right)$} & \multicolumn{2}{|c|}{ Resistencia Mecánica ( $\left.\mathrm{N} / \mathrm{mm}^{2}\right)$} & \multicolumn{2}{|c|}{ Resistencia Mecánica ( $\left.\mathrm{N} / \mathrm{mm}^{2}\right)$} & \multicolumn{2}{|c|}{ Resistencia Mecánica ( $\left.\mathrm{N} / \mathrm{mm}^{2}\right)$} \\
\hline & & $\begin{array}{l}\text { Valor medio de } \\
\text { Tensión Rotura a } \\
\text { Flexión }\end{array}$ & $\begin{array}{l}\text { Valor medio de } \\
\text { Tensión de Rotura } \\
\text { a compresión }\end{array}$ & $\begin{array}{l}\text { Valor medio de } \\
\text { Tensión Rotura a } \\
\text { Flexión }\end{array}$ & \begin{tabular}{|c} 
Valor medio de \\
Tensión de Rotura \\
a compresión
\end{tabular} & $\begin{array}{l}\text { Valor medio de } \\
\text { Tensión Rotura a } \\
\text { Flexión }\end{array}$ & $\begin{array}{l}\text { Valor medio de } \\
\text { Tensión de Rotura } \\
\text { a compresión }\end{array}$ & $\begin{array}{l}\text { Valor medio de } \\
\text { Tensión Rotura a } \\
\text { Flexión }\end{array}$ & $\begin{array}{l}\text { Valor medio de } \\
\text { Tensión de Rotura } \\
\text { a compresión }\end{array}$ \\
\hline & & \multicolumn{2}{|c|}{ EN 1015-11:2000 } & \multicolumn{2}{|c|}{ EN 1015-11:2000 } & \multicolumn{2}{|c|}{ EN 1015-11:2000 } & \multicolumn{2}{|c|}{ EN 1015-11:2000 } \\
\hline \multirow{5}{*}{ 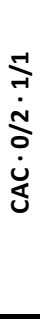 } & \multirow{2}{*}{$\mathrm{R}(0 \%)$} & 13,99 & 85,00 & 16,10 & 93,74 & 14,66 & 94,12 & 13,98 & 93,89 \\
\hline & & $(0,36)$ & $(2,41)$ & $(1,57)$ & $(6,40)$ & $(0,34)$ & $(6,82)$ & $(0,50)$ & $(3,83)$ \\
\hline & \multirow{3}{*}{$\begin{array}{c}\text { CVT } \\
10 \% \mathrm{~T}\end{array}$} & 13,36 & 91,02 & 16,16 & 103,55 & 16,64 & 107,79 & 16,98 & 117,75 \\
\hline & & $-4,49 \%$ & $7,08 \%$ & $0,41 \%$ & $10,46 \%$ & $13,49 \%$ & $14,52 \%$ & $21,46 \%$ & $25,42 \%$ \\
\hline & & $(1,00)$ & $(7,79)$ & $(1,08)$ & $(4,33)$ & $(0,39)$ & $(4,23)$ & $(1,17)$ & $(3,82)$ \\
\hline \multirow{5}{*}{ 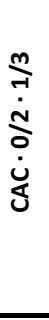 } & \multirow[t]{2}{*}{$\mathrm{R}(0 \%)$} & 6,79 & 58,52 & 6,48 & 58,27 & 6,85 & 51,93 & 6,72 & 44,87 \\
\hline & & $(0,28)$ & $(1,76)$ & $(0,27)$ & $(2,26)$ & $(0,23)$ & $(1,24)$ & $(0,25)$ & $(1,31)$ \\
\hline & \multirow{3}{*}{$\begin{array}{c}\text { CVT } \\
10 \% \mathrm{~T}\end{array}$} & 6,20 & 40,82 & 7,77 & 46,09 & 7,72 & 43,41 & 8,73 & 45,42 \\
\hline & & $-8,75 \%$ & $-30,25 \%$ & $19,86 \%$ & $-20,90 \%$ & $12,72 \%$ & $-16,40 \%$ & $29,96 \%$ & $1,21 \%$ \\
\hline & & $(0,23)$ & $(0,51)$ & $(0,08)$ & $(1,66)$ & $(0,47)$ & $(1,07)$ & $(0,44)$ & $(1,61)$ \\
\hline \multirow{5}{*}{ 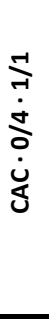 } & \multirow[t]{2}{*}{$R(0 \%)$} & 14,85 & 85,31 & 14,21 & 92,79 & 8,11 & 55,67 & 8,78 & 66,11 \\
\hline & & $(0,26)$ & $(4,01)$ & $(0,20)$ & $(3,56)$ & $(0,35)$ & $(2,61)$ & $(0,61)$ & $(3,25)$ \\
\hline & \multirow{3}{*}{$\begin{array}{c}\text { CVT } \\
10 \% \mathrm{~T}\end{array}$} & 15,27 & 83,64 & 15,46 & 96,72 & 17,60 & 108,46 & 14,66 & 98,26 \\
\hline & & $2,81 \%$ & $-1,96 \%$ & $8,78 \%$ & $4,24 \%$ & $116,90 \%$ & $94,82 \%$ & $67,02 \%$ & $48,62 \%$ \\
\hline & & $(1,60)$ & $(3,03)$ & $(0,96)$ & $(4,01)$ & $(0,50)$ & $(4,73)$ & $(0,83)$ & $(13,04)$ \\
\hline \multirow{5}{*}{ 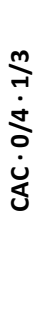 } & \multirow[t]{2}{*}{$R(0 \%)$} & 7,95 & 64,15 & 8,20 & 58,32 & 5,11 & 29,63 & 5,31 & 31,52 \\
\hline & & $(0,31)$ & $(2,00)$ & $(0,73)$ & $(1,63)$ & $(0,19)$ & $(3,04)$ & $(0,15)$ & $(1,32)$ \\
\hline & \multirow{3}{*}{$\begin{array}{c}\text { CVT } \\
10 \% \mathrm{~T}\end{array}$} & 6,57 & 42,15 & 7,06 & 43,43 & 7,28 & 43,37 & 7,03 & 43,32 \\
\hline & & $-17,27 \%$ & $-34,30 \%$ & $-13,93 \%$ & $-25,53 \%$ & $42,26 \%$ & $46,35 \%$ & $32,32 \%$ & $37,46 \%$ \\
\hline & & $(0,09)$ & $(0,66)$ & $(0,48)$ & $(1,46)$ & $(0,12)$ & $(0,97)$ & $(0,37)$ & $(1,41)$ \\
\hline
\end{tabular}




\subsubsection{Resistencias mecánicas de los morteros de cemento CSA}

\subsection{Tensión de rotura a flexión}

El análisis de los datos la tabla 58 y la comparativa de la ilustración 67, demuestra que los morteros de CSA formulados con CVT y con mayor cantidad de áridos en su composición, 1/3, tienen un mejor comportamiento a flexión a 90 días que sus homólogos con dosificaciones más ricas, $1 / 1$. Las tendencias mostradas son muy similares, a pesar de tratarse de morteros elaborados con áridos de distintos diámetros. Este tipo de morteros, junto con todos los CAC, son los únicos que mejoran los valores ofrecidos por los morteros de referencia.

Los valores obtenidos a 90 días pueden ser considerados como muy positivos por su semejanza a los de los morteros de referencia. Si bien el único mortero con CVT que supera a su mortero de referencia es el CSA . $0 / 2 \cdot 1 / 3$ en un $1,15 \%$, se puede considerar que el CSA $\cdot 0 / 4 \cdot 1 / 3$, mantiene el mismo comportamiento, ya que la pérdida de resistencia en igualdad de condiciones es sólo de un 1,37\%, correspondiente a una tensión media de rotura a flexión de 5,293 N/mm², frente a los 5,367 $\mathrm{n} / \mathrm{mm}^{2}$ de su referencia.

Por el contrario, la adición de CVT en los morteros de CSA con idéntica proporción de árido y cemento utilizado, perjudica notablemente las resistencias mecánicas a flexión. De esta forma, en las dosificaciones CSA . $1 / 1 \cdot 0 / 2$ y $0 / 4$, las pérdidas proporcionales de resistencia superan, en ambos casos, el $36 \%$.

\subsection{Tensión de rotura a compresión}

El comportamiento a compresión de los morteros elaborados con Cemento de Sulfoaluminato de Calcio se presenta en la tabla 58 y, al igual que sucede con los valores de flexión, los mejores resultados se obtienen en las dosificaciones tradicionales, 1/3. Mientras que los morteros de referencia muestran altas resistencias iniciales, pero con una paulatina pérdida de 
resistencia a 28 y a 60 días, las dos dosificaciones, $1 / 3$, confeccionadas con cenizas volantes inertizadas, invierten esta tendencia y se presentan con moderadas resistencias iniciales pero con una clara tendencia al alza, que se traduce en resistencias superiores a los morteros de referencia de un $8,01 \%$, en el caso de los morteros CSA $\cdot 0 / 2 \cdot 1 / 3$, y de un $11,89 \%$, para los CSA $\cdot 0 / 4 \cdot 1 / 3$. En estas matrices se comprueba que el exceso de agua necesario para su amasado no influye negativamente en las resistencias obtenidas. El proceso de hidratación favorece la porosidad y, por lo tanto, la carbonatación del mortero la cual afecta de manera positiva a la resistencia mecánica de los mismos. Por el contrario, los morteros con dosificaciones $1 / 1$, empeoran en relación directamente proporcional al tamaño del árido, siendo el peor dato un $12,60 \%$, correspondiente a la dosificación CSA $0 / 4 \cdot 1 / 1$.

A priori, los Cementos de Sulfoaluminato de Calcio presentan ciertos beneficios en comparación con los cementos Portland ordinarios (Péra, 2004). Al tratarse de un tipo de cemento con altas resistencias iniciales, su uso en combinación con las cenizas volantes de RSU favorecerá su estabilización/solidificación en la matriz de los morteros a estudiar.

Los datos analizados confirman los de investigaciones actuales (Guo et al., 2014) relativas a pastas de cemento de sulfoaluminato de calcio elaborado con cenizas volantes de RSU en los que, éstas, desarrollaban resistencias a compresión similares con respecto a las de las pastas de control. En estos mismos estudios, el exceso de ion cloruro remanente en las cenizas volantes de RSU era sintetizado dentro del clinker de cemento y estabilizado durante el proceso de hidratación. Esto permitía que los valores límite del lixiviado de metales pesados se mantuvieran dentro de los mínimos exigidos por la normativa vigente.

Ya ha sido analizado que las cenizas utilizadas son ricas en cloruros y sulfatos, los cuales podrán reaccionar fácilmente con el sulfoaluminato de calcio en su hidratación y aprovechar las nuevas fases de esta hidratación para encapsular los metales pesados (Klemm, 2002; Auer et al., 1995). Igualmente, el hecho de poseer azufre en su formulación inicial, facilitará la 
precipitación de los metales pesados contenidos en las CVT en forma de sulfatos.

En la comparativa con los resultados de CEM-I y CEM-II, los morteros de CSA con una dosificación tradicional, 1/3, independientemente del tamaño del árido, presentan, en valor absoluto, mejores datos que sus homólogos de CEM-II: $31,21 \mathrm{~N} / \mathrm{mm} 2$ frente a $27,67 \mathrm{n} / \mathrm{mm} 2$, en áridos $0 / 2$, y $36,74 \mathrm{~N} / \mathrm{mm} 2$ por $32,07 \mathrm{~N} / \mathrm{mm} 2$, en áridos $0 / 4$. Con respecto a las mismas dosificaciones de CEM-I, los morteros de CSA están muy poco por debajo en los morteros con árido 0/2: $31,21 \mathrm{~N} / \mathrm{mm} 2$ frente a 33,07 $\mathrm{N} / \mathrm{mm} 2$; y ligeramente por encima en los de árido $0 / 4: 36,74 \mathrm{~N} / \mathrm{mm} 2$ por $36,63 \mathrm{n} / \mathrm{mm} 2$ del CEM-I.

La incorporación de cenizas volantes inertizadas en este tipo de cementos belíticos resulta más favorable, desde el punto de vista de las resistencias mecánicas a compresión, que su utilización en cementos tradicionales con base de alita, con el consiguiente beneficio ambiental que ello conlleva. 
Tabla 58. Valores de resistencia mecánica a 7, 28, 60 y 90 días, en $\mathrm{N} / \mathrm{mm} 2$, obtenidos de la rotura de las probetas de mortero elaboradas con CSA. Valores medios de tensión de rotura a flexión y a compresión. En verde, porcentaje comparativo de ganancia de resistencias entre morteros de referencia (R.0\%) y morteros con la incorporación de cenizas volantes inertizadas (CVT-10\%). En rojo, pérdida de resistencias. Entre paréntesis, desviación estándar de los valores de resistencia mecánica.

\begin{tabular}{|c|c|c|c|c|c|c|c|c|c|}
\hline \multirow[b]{3}{*}{ 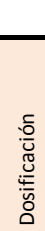 } & \multirow{4}{*}{$\begin{array}{l}5 \\
\text { S } \\
\text { do }\end{array}$} & \multicolumn{2}{|c|}{7 días } & \multicolumn{2}{|c|}{28 días } & \multicolumn{2}{|c|}{60 días } & \multicolumn{2}{|c|}{90 días } \\
\hline & & \multicolumn{2}{|c|}{ Resistencia Mecánica $\left(\mathrm{N} / \mathrm{mm}^{2}\right)$} & \multicolumn{2}{|c|}{ Resistencia Mecánica ( $\mathrm{N} / \mathrm{mm}^{2}$ ) } & \multicolumn{2}{|c|}{ Resistencia Mecánica ( $\left.\mathrm{N} / \mathrm{mm}^{2}\right)$} & \multicolumn{2}{|c|}{ Resistencia Mecánica (N/mm²) } \\
\hline & & $\begin{array}{l}\text { Valor medio de } \\
\text { Tensión Rotura a } \\
\text { Flexión }\end{array}$ & $\begin{array}{l}\text { Valor medio de } \\
\text { Tensión de Rotura } \\
\text { a compresión }\end{array}$ & $\begin{array}{l}\text { Valor medio de } \\
\text { Tensión Rotura a } \\
\text { Flexión }\end{array}$ & $\begin{array}{l}\text { Valor medio de } \\
\text { Tensión de Rotura } \\
\text { a compresión }\end{array}$ & $\begin{array}{l}\text { Valor medio de } \\
\text { Tensión Rotura a } \\
\text { Flexión }\end{array}$ & $\begin{array}{l}\text { Valor medio de } \\
\text { Tensión de Rotura } \\
\text { a compresión }\end{array}$ & $\begin{array}{l}\text { Valor medio de } \\
\text { Tensión Rotura a } \\
\text { Flexión }\end{array}$ & $\begin{array}{l}\text { Valor medio de } \\
\text { Tensión de Rotura } \\
\text { a compresión }\end{array}$ \\
\hline & & \multicolumn{2}{|c|}{ EN 1015-11:2000 } & \multicolumn{2}{|c|}{ EN 1015-11:2000 } & \multicolumn{2}{|c|}{ EN 1015-11:2000 } & \multicolumn{2}{|c|}{ EN 1015-11:2000 } \\
\hline \multirow{5}{*}{ 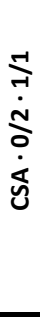 } & \multirow{2}{*}{$\mathrm{R}(0 \%)$} & 9,17 & 68,33 & 10,45 & 74,08 & 10,14 & 67,59 & 9,09 & 67,70 \\
\hline & & $(0,24)$ & $(1,73)$ & $(1,18)$ & $(2,10)$ & $(0,72)$ & $(3,77)$ & $(0,88)$ & $(3,08)$ \\
\hline & \multirow{3}{*}{$\begin{array}{c}\text { CVT } \\
10 \% \mathrm{~T}\end{array}$} & 6,15 & 58,20 & 8,52 & 64,17 & 7,49 & 66,96 & 5,73 & 64,40 \\
\hline & & $-32,94 \%$ & $-14,83 \%$ & $-18,48 \%$ & $-13,38 \%$ & $-26,18 \%$ & $-0,92 \%$ & $-36,96 \%$ & $-4,88 \%$ \\
\hline & & $(0,24)$ & $(1,37)$ & $(0,54)$ & $(2,00)$ & $(0,28)$ & $(3,16)$ & $(0,32)$ & $(1,56)$ \\
\hline \multirow{5}{*}{ 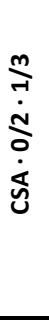 } & \multirow[t]{2}{*}{$R(0 \%)$} & 6,39 & 49,63 & 5,44 & 46,48 & 5,58 & 43,91 & 5,05 & 28,90 \\
\hline & & $(0,58)$ & $(3,29)$ & $(0,38)$ & $(3,87)$ & $(0,16)$ & $(2,07)$ & $(0,17)$ & $(1,54)$ \\
\hline & \multirow{3}{*}{$\begin{array}{c}\text { CVT } \\
10 \% \mathrm{~T}\end{array}$} & 4,63 & 28,60 & 4,55 & 32,37 & 4,54 & 35,43 & 5,10 & 31,21 \\
\hline & & $-27,44 \%$ & $-42,37 \%$ & $-16,34 \%$ & $-30,35 \%$ & $-18,59 \%$ & $-19,31 \%$ & $1,15 \%$ & $8,01 \%$ \\
\hline & & $(0,34)$ & $(0,39)$ & $(0,24)$ & $(1,31)$ & $(0,34)$ & $(0,71)$ & $(0,20)$ & $(0,95)$ \\
\hline \multirow{5}{*}{ 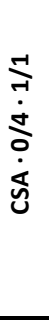 } & \multirow[t]{2}{*}{$R(0 \%)$} & 7,98 & 64,60 & 8,12 & 71,74 & 8,93 & 71,14 & 8,83 & 67,28 \\
\hline & & $(0,54)$ & $(3,08)$ & $(0,24)$ & $(1,44)$ & $(0,68)$ & $(3,46)$ & $(0,46)$ & $(2,67)$ \\
\hline & \multirow{3}{*}{$\begin{array}{c}\text { CVT } \\
10 \% T\end{array}$} & 6,92 & 52,07 & 7,27 & 55,27 & 6,28 & 51,35 & 5,60 & 58,80 \\
\hline & & $-13,28 \%$ & $-19,40 \%$ & $-10,40 \%$ & $-22,95 \%$ & $-29,67 \%$ & $-27,83 \%$ & $-36,58 \%$ & $-12,60 \%$ \\
\hline & & $(0,40)$ & $(1,07)$ & $(0,24)$ & $(1,07)$ & $(0,37)$ & $(0,91)$ & $(0,37)$ & $(2,64)$ \\
\hline \multirow{5}{*}{ 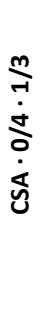 } & \multirow[t]{2}{*}{$R(0 \%)$} & 6,44 & 52,53 & 7,51 & 57,02 & 6,50 & 57,50 & 5,37 & 32,84 \\
\hline & & $(0,23)$ & $(3,21)$ & $(0,57)$ & $(2,32)$ & $(0,28)$ & $(2,03)$ & $(0,53)$ & $(1,25)$ \\
\hline & \multirow{3}{*}{$\begin{array}{l}\text { CVT } \\
10 \% T\end{array}$} & 5,48 & 28,48 & 5,05 & 33,92 & 4,71 & 37,01 & 5,29 & 36,74 \\
\hline & & $-14,91 \%$ & $-45,79 \%$ & $-32,77 \%$ & $-40,52 \%$ & $-27,56 \%$ & $-35,64 \%$ & $-1,37 \%$ & $11,89 \%$ \\
\hline & & $(0,18)$ & $(1,03)$ & $(0,24)$ & $(1,00)$ & $(0,04)$ & $(0,59)$ & $(0,22)$ & $(3,43)$ \\
\hline
\end{tabular}




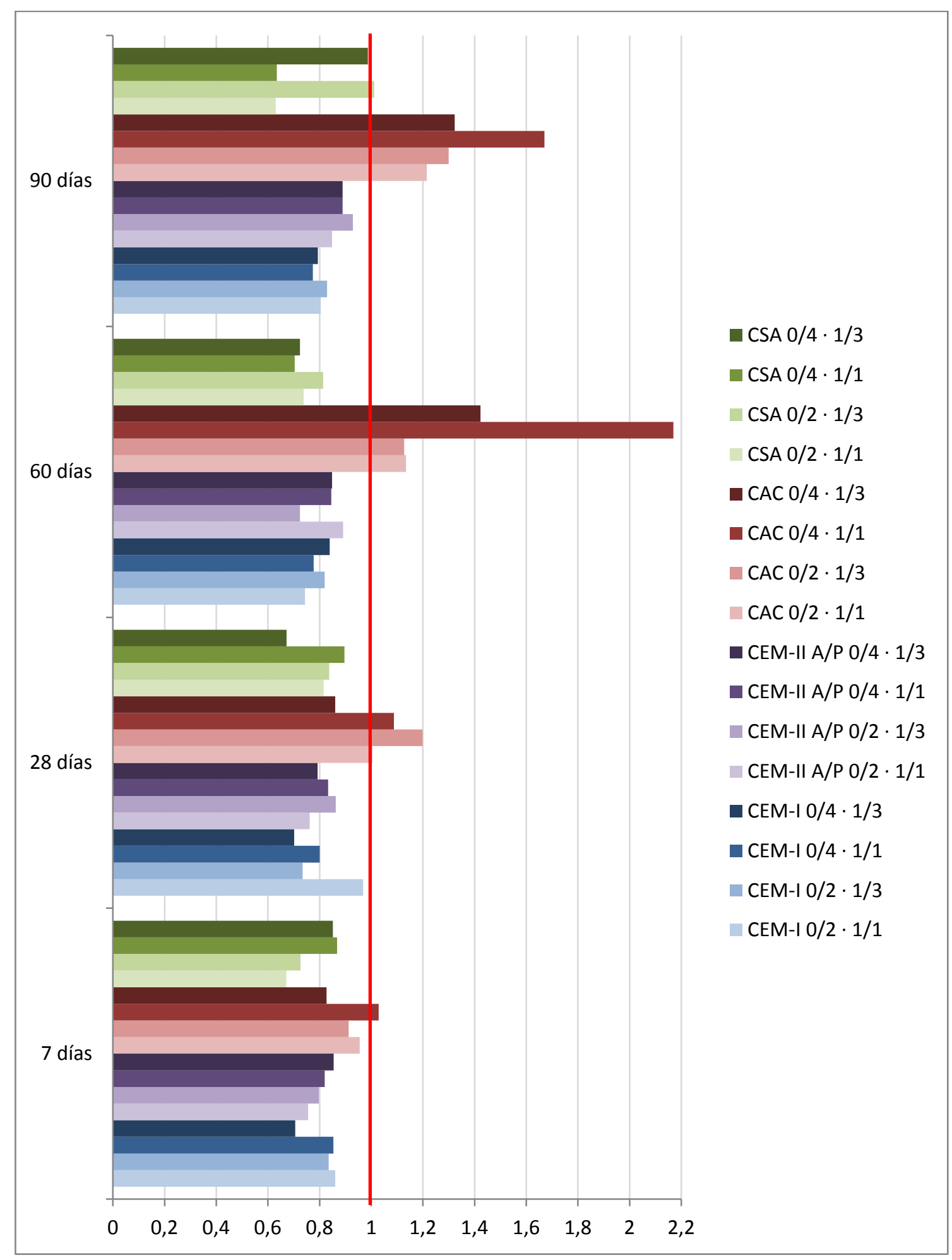

Ilustración 67. Normalización de los valores de rotura a flexión, a 7, 28, 60 y 90 días, de cada uno de las dosificaciones ensayadas. Los valores mostrados corresponden al cociente entre las distintas tensiones de rotura a flexión de los morteros con la incorporación de CVT, en cada una de las edades, y los valores de referencia de los morteros sin adiciones, a esas mismas edades. 


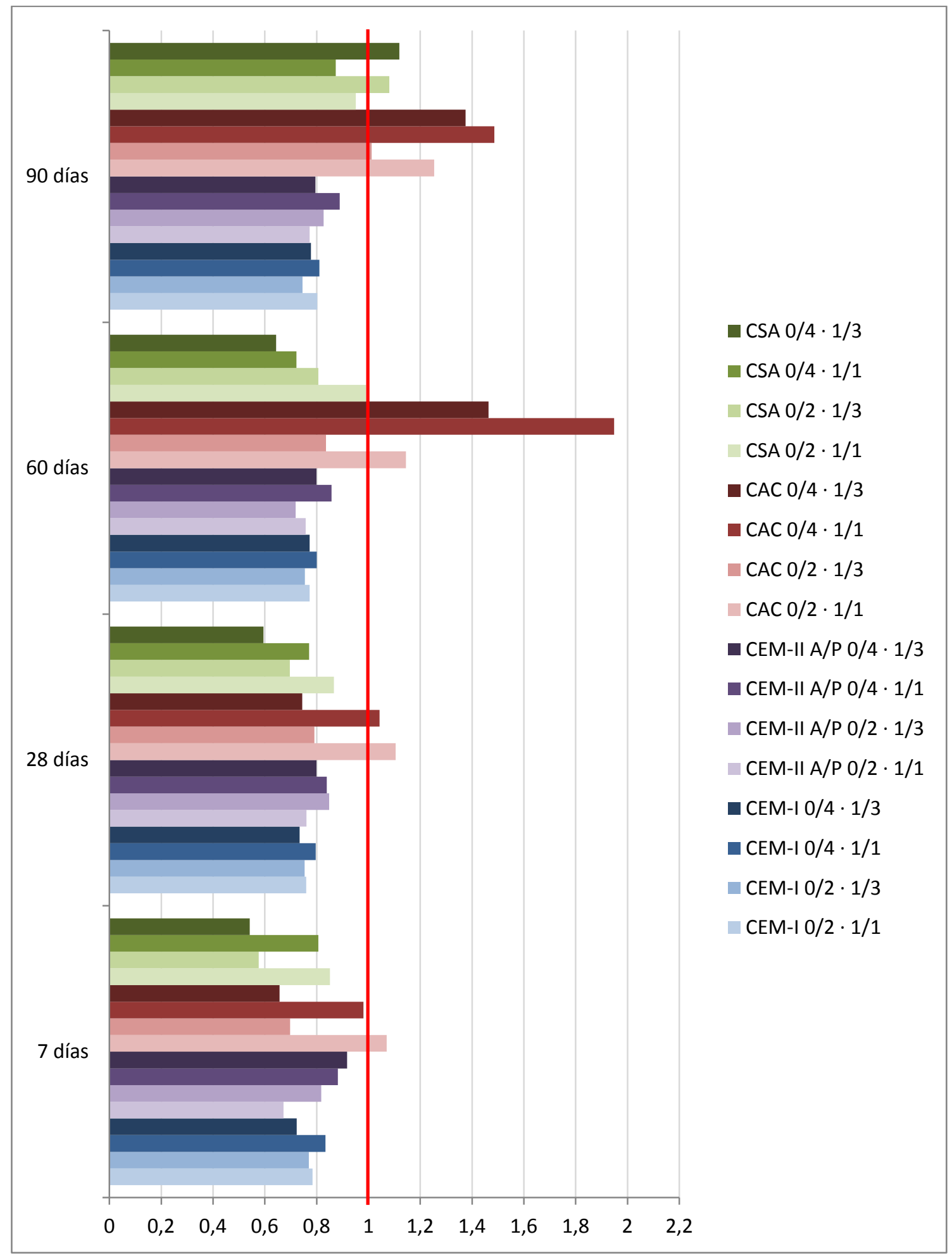

Ilustración 68. Normalización de los valores de rotura a compresión, a 7, 28, 60 y 90 días, de cada uno de las dosificaciones ensayadas. Los valores mostrados corresponden al cociente entre las distintas tensiones de rotura a compresión de los morteros con la incorporación de CVT, en cada una de las edades, y los valores de referencia de los morteros sin adiciones, a esas mismas edades. 


\subsubsection{CALORIMETRÍA DIFERENCIAL DE BARRIDO Y TERMO-GRAVIMETRÍA} (DSC-TGA). ANÁLISIS DE MORTEROS DE CEMENTO.

Aunque la presencia de los hidratos principales $C_{10} H_{10} C_{3} A H_{6}$ y $A_{3}$ pueden ser detectados por DRX, los picos no pueden ser utilizados para su análisis cuantitativo. Puede darse el caso de una orientación preferente con fases hexagonales como $\mathrm{CAH}_{10}$ y también puede que los hidratos no estén totalmente cristalizados, especialmente en las etapas iniciales de la hidratación. Existen algunas fases que son amorfas por naturaleza, las fases de gel, y la presencia de éstas no se detectará por DRX. Por lo tanto el uso de técnicas de análisis térmico es muy importante en el estudio de cementos, ya que proporciona información sobre las fases hidratadas presentes en las etapas iniciales de hidratación, cuando esto no es posible con la DRX (Ramachandran et al., 2002). No obstante, la comparación de la curva de análisis térmico con datos de una técnica complementaria (habitualmente DRX) permite una interpretación más clara.

\subsubsection{Morteros CAC de referencia}

Las técnicas de calorimetría diferencial de barrido han sido utilizadas para investigar el tipo de productos de hidratación presentes en los morteros de cemento de aluminato de calcio mediante la comparación con los intervalos de temperaturas para la deshidratación de los distintos hidratos del cemento CAC (tabla 59). La ilustración 69 presenta los termogramas a 7, 28, 60 y 90 días, respectivamente, del mortero de referencia $(R)$ de cemento de aluminato de calcio con una dosificación cemento/árido $1 / 1$ y tamaño del árido 0/4. Se ha elegido esta dosificación al ser la que mejor comportamiento mecánico presenta tanto a compresión, como a flexión, de todas las estudiadas.

La pauta mostrada en todos los diagramas es muy similar. Hasta los $100^{\circ} \mathrm{C}$ se observa una pérdida de peso que corresponde tanto a la eliminación de agua por evaporación, como a la deshidratación de los hidratos no estables. Entre $50^{\circ} \mathrm{C}$ y $240^{\circ} \mathrm{C}$, se produce una primera gran 
pérdida de masa con grandes velocidades, asociadas fundamentalmente a la descomposición de los hidratos estables, entre ellos el $\mathrm{CAH}_{10}$ y el $\mathrm{C}_{2} \mathrm{AH}_{8}$ (Ukrainczyk et al., 2007). Estos dos pasos de eliminación de agua constituyen una ventaja de los sistemas basados en aluminatos de calcio ya que ayudan a reducir la generación de vapor, en comparación con otros tipos de cementos, que tienden a liberar agua en un rango más estrecho de temperatura.

Tabla 59. Intervalos de temperaturas para hidratos de cemento CAC (Bushnell-Watson, Sharp 1992)

\begin{tabular}{cccccc}
\hline $\begin{array}{c}\text { Fase } \\
\text { hidratada }\end{array}$ & Gel & $\mathbf{C A H}_{\mathbf{1 0}}$ & $\mathbf{C}_{\mathbf{2}} \mathbf{A H}_{\mathbf{8}}$ & $\mathbf{A H}_{\mathbf{3}}$ & $\mathbf{C}_{\mathbf{3}} \mathbf{A H}_{\mathbf{6}}$ \\
\hline $\begin{array}{l}\text { Intervalo de } \\
\text { Temperatura }\end{array}$ & $60-130^{\circ} \mathrm{C}$ & $100-160^{\circ} \mathrm{C}$ & $140-200^{\circ} \mathrm{C}$ & $260-330^{\circ} \mathrm{C}$ & $290-350^{\circ} \mathrm{C}$ \\
\hline
\end{tabular}

En cada diagrama se aprecia un gran pico endotérmico relativamente fuerte a temperatura baja $\left(60^{\circ} \mathrm{C}\right.$ a $\left.120^{\circ} \mathrm{C}\right)$, atribuible la presencia de la fase de alúmina gel, $\mathrm{C}-\mathrm{A}-\mathrm{H}$, con algo de $\mathrm{CAH}_{10}$, salvo en el mortero a 90 días. Tanto la presencia de $\mathrm{CAH}_{10}$, como la ausencia de $\mathrm{C}_{2} \mathrm{AH}_{8}$, fueron verificadas a través de los análisis de difracción de Rayos $\mathrm{X}$.

La segunda dupla de picos endotérmicos, $\mathrm{AH}_{3}$, ente $260^{\circ} \mathrm{C}$ y $330^{\circ} \mathrm{C}$; y $\mathrm{C}_{3} \mathrm{AH}_{6}$, entre $290^{\circ} \mathrm{C}$ y $350^{\circ} \mathrm{C}$, crecen constantemente con la edad del mortero. El pico de gibsita va decreciendo en favor del de katoita, siendo muy elevada la presencia de estos hidratos cúbicos a 90 días, lo cual confirma el proceso de conversión.

Finalmente, entre $600^{\circ} \mathrm{C}$ y $800^{\circ} \mathrm{C}$, se aprecia una muy leve reacción endotérmica, visible más claramente en la gráfica a 7 días, correspondiente a la descomposición de carbonatos, especialmente carbonato cálcico (Sepulcre-Aguilar y Hernández-Olivares, 2010; Rajamma et al., 2009). 


\subsubsection{Morteros CAC con cenizas volantes}

La ilustración 70 muestra los termogramas a 7, 28, 60 y 90, respectivamente, de los morteros de CAC $\cdot 1 / 1 \cdot 0 / 4$ con la incorporación de cenizas volantes inertizadas, en una proporción de un $10 \%$ en peso de los áridos.

A diferencia de lo ocurrido en los morteros de referencia, en temperaturas bajas $\left(60^{\circ} \mathrm{C}\right.$ a $\left.120^{\circ} \mathrm{C}\right)$ existe un doble pico endotérmico de menor intensidad correspondiente a la fase de alúmina gel y a la de $\mathrm{CAH}_{10}$, esta última confirmada a través de los análisis de DRX. Este doble pico se presenta más nítido y menos intenso a medida que aumenta la edad del mortero. En torno a $150^{\circ} \mathrm{C}$ se observa la aparición de un pequeño "hombro", más nítido en los termográmas a 28 y 60 días, y de manera más solapada en los de 90 días, que podría ser característico de la aparición de $\mathrm{C}_{2} \mathrm{AH}_{8}$. Sin embargo, la presencia de este hidrato no ha sido verificada en los estudios de DRX. Esta nueva fase puede corresponder a la aparición de monocarboaluminato $\left(\mathrm{C}_{4} \mathrm{AcH}_{11}\right)$, característico en la bibliografía consultada sobre pastas de este tipo de cementos a las que se habría añadido $\mathrm{CaCO}_{3}$ a propósito para provocar su aparición dado que el aporte de carbonato cálcico, independientemente del tipo de adición propuesta, está íntimamente relacionado con un aumento de las capacidades mecánicas de los compuestos formados (Kuzel, 1996; Fentiman, 1985; Rivas-Mercury et al., 2003; Puertas et al., 1996).

Es de destacar que, a 7 y 28 días, el segundo doblete de picos endotérmicos, correspondiente a las temperaturas entre $260^{\circ} \mathrm{C}$ y $330^{\circ} \mathrm{C}$, aparece como un solo pico aislado. En la franja de $250^{\circ} \mathrm{C}$ aparece un fuerte pico endotérmico, normalmente acompañado de otros pequeño efectos endotérmicos alrededor $\left(250^{\circ} \mathrm{C}-300^{\circ} \mathrm{C}\right)$, característico de la aparición de gibsita $\left(\mathrm{AH}_{3}\right)$. La comparación de estos datos con los ofrecidos por la difracción de Rayos $X$, muestra que el pico principal de esta fase indica la presencia de más $\mathrm{AH}_{3}$ de la ofrecida por el difractograma DRX. Esto sugiere que en las etapas iniciales de hidratación se forman importantes cantidades 
de $\mathrm{AH}_{3}$ amorfo y también ciertas cantidades de $\mathrm{AH}_{3}$ cristalino, que aumentan con la edad del mortero.

A partir de los 28 días empieza a aparecer un pequeño "hombro" entorno a los $330^{\circ} \mathrm{C}$ sintomático de la presencia de $\mathrm{C}_{3} \mathrm{AH}_{6}$, que se presenta más claramente a 60 y 90 días, si bien la presencia de gibsita y katoita es de mucha menor cuantía en estos morteros que en los morteros de referencia. Este esquema puede representar un retraso en la conversión de los hidratos metaestables a los hidratos más estables, pero por ello no se debe asumir que un determinado grado de conversión, u otro, conduce inevitablemente a un mal producto (Bushnell-Watson y Sharp, 1992). Ya se ha comprobado en el apartado dedicado a resistencias mecánicas de los morteros que este comportamiento no implica una pérdida de resistencia.

A $573^{\circ} \mathrm{C}$ aparece un pequeño pico endotérmico sin pérdida de masa característico de la transformación polimórfica reversible de cuarzo-a a cuarzo- $\beta$.

Finalmente, el aporte de carbonato cálcico por la inclusión de las cenizas volantes inertizadas, intuido con anterioridad por la aparición del monocarboaluminato $\mathrm{C}_{4} \mathrm{AcH}_{11}$, se demuestra claramente por la aparición, entre $600^{\circ} \mathrm{C}$ y $800^{\circ} \mathrm{C}$, de una nítida reacción endotérmica visible en todos los termogramas. Esta fase corresponde a la descomposición de carbonatos, especialmente carbonato cálcico (Sepulcre-Aguilar y Hernández-Olivares, 2010; Rajamma et al., 2009). La relación directa entre la pérdida de peso y el tamaño del pico explica las cantidades de carbonato cálcico presentes, que en la mayoría de las edades estudiadas, duplican a las existentes en los morteros de referencia. 

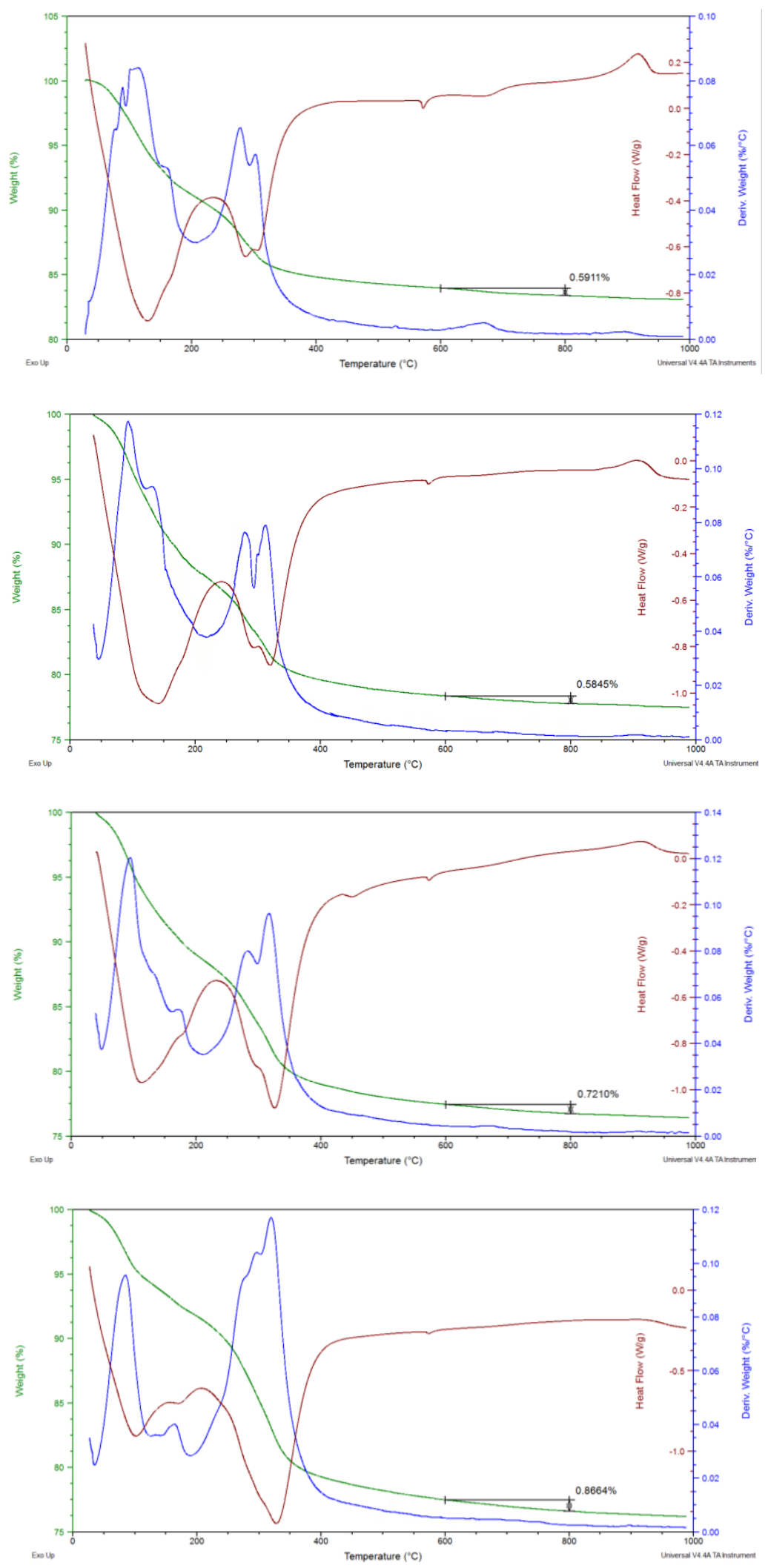

Ilustración 69. Termogramas del mortero de referencia de CAC $\cdot 1 / 1 \cdot 0 / 4$, a 7 días (parte superior), 28,60 y 90 . 

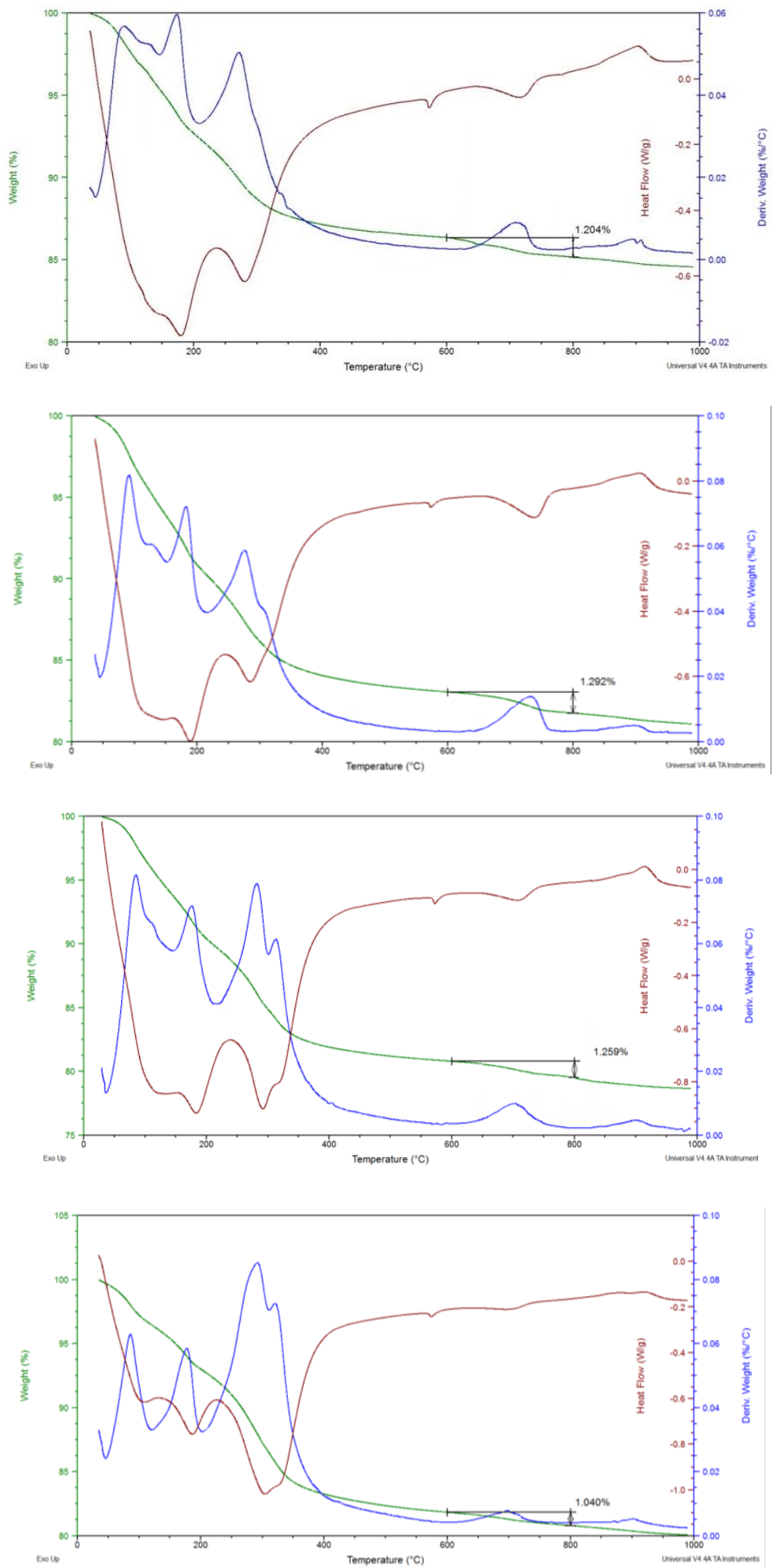

Ilustración 70. Termogramas del mortero de CAC $\cdot 1 / 1 \cdot 0 / 4$ con la incorporación de CVT, a 7 días (parte superior), 28, 60 y 90. 


\subsubsection{DIFRACCIÓN DE RAYOS X. ANÁLISIS DE MORTEROS DE CEMENTO} CAC.

Con la intención de analizar el excelente comportamiento mecánico de los morteros elaborados con CAC se llevaron a cabo análisis DRX de las distintas dosificaciones. En las tablas 60 a 67 se muestran las composiciones semicuantitativas de las distintas fases. En la comparación de estas tablas se observa la presencia de altas concentraciones de monocarboaluminato hidratado $\left(\mathrm{C}_{3} \mathrm{~A} \cdot \mathrm{CaCO}_{3} \cdot 11 \mathrm{H}_{2} \mathrm{O}\right.$ ó $\left.\mathrm{C}_{4} \mathrm{AcH}_{11}\right)$ en los morteros con CVT, aunque con especial relevancia en los de dosificación $1 / 1$. Por el contrario, la presencia de hemicarboaluminato hidratado $\left(3 \mathrm{CaO} \cdot \mathrm{Al}_{2} \mathrm{O}_{3} \cdot 0.5 \mathrm{Ca}(\mathrm{OH})_{2} \cdot 0.5 \mathrm{CaCO}_{3} \cdot 11,5 \mathrm{H}_{2} \mathrm{O}\right)$, sólo se aprecia en los morteros con CVT y dosificaciones 1/3. La formación de estos carboluminatos está directamente relacionada con la mejora en las resistencias mecánicas de determinadas mezclas ternarias de cementos, sobre todo a 7 y 28 días (Antoni, 2013). Si bien en este caso, por los valores contrastados, sólo se puede atribuir esta mejora en el comportamiento a la aparición de monocarbonato.

La actividad del $\mathrm{CaCO}_{3}$, puede inducir a la formación de nuevos productos como el hemicarboluminato cálcico o el monocarboaluminato cálcico (Xiao et al., 2010), los cuales pueden inhibir la formación de fases de la hidratación como $\mathrm{C}_{2} \mathrm{AH}_{8}$, $\mathrm{O}$ hacer que se retrase la formación en edades tempranas de otras, como $\mathrm{C}_{3} \mathrm{AH}_{6}$. De igual forma, la presencia de ciertas cantidades de $\mathrm{CaCO}_{3}$, en combinación con determinadas temperaturas y proporciones agua/cemento afectan directamente la velocidad de transformación de los aluminatos cálcicos metaestables de la hidratación del cemento CAC, incidiendo positivamente en la porosidad y las resistencias de los hormigones y morteros. Este efecto se relaciona directamente con la aparición de monocarboaluminato hidratado $\left(\mathrm{C}_{3} \mathrm{~A} \cdot \mathrm{CaCO}_{3} \cdot 11 \mathrm{H}_{2} \mathrm{O}\right)$.

En el estudio de los difractogramas relativos a los morteros de dosificación $1 / 1$ y con tamaño de árido $0 / 4$, no se distinguen trazas de 
hemicarboaluminato hidratado. Por el contrario, en el grado de estabilidad encontramos monocarboaluminato y solamente uno de los tres polimorfos del $\mathrm{CaCO}_{3}$ : la calcita. La ausencia de vaterita y aragonito, en la mayoría de los casos, implica un grado de carbonatación más avanzado de los morteros (Chinchón Yepes y Sanjuán Barbudo, 2008).

Queda demostrado, el proceso de carbonatación en los morteros de CAC se relaciona directamente con la aparición de monocarboaluminato y calcita. Todas estas fases se detectan perfectamente en el difractograma de la ilustración 71. En él están reflejadas las fases resultantes de la carbonatación de los aluminatos de muestras de morteros CAC·0/4·1/1 con un $10 \%$ de CVT en su dosificación, a 7, 28, 60 y 90 días. Estos análisis DRX poseen la dificultad de no poder diferenciar las reflexiones de la calcita proveniente de los áridos, de aquella resultante de los procesos de carbonatación.

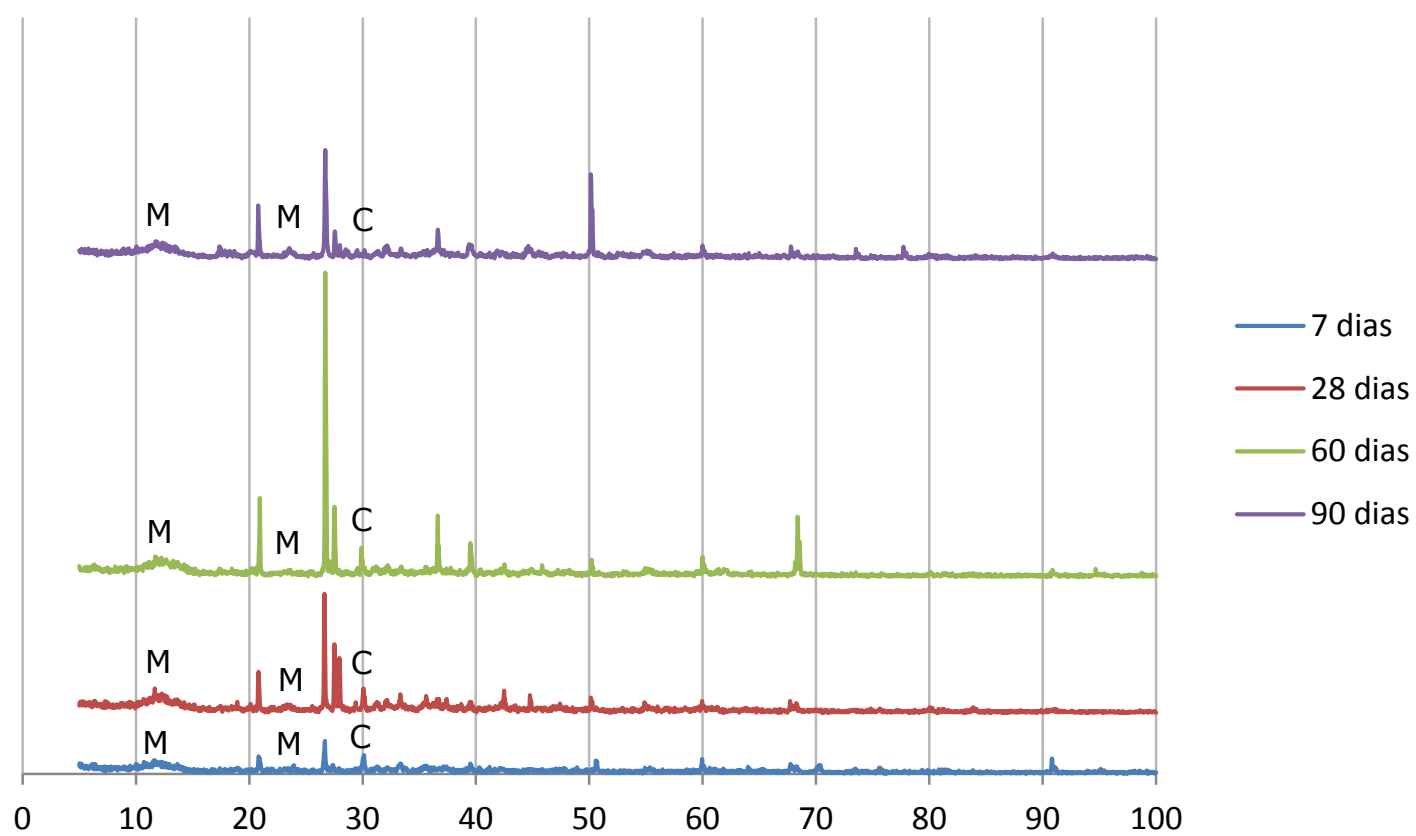

Ilustración 71. Difractogramas de los morteros CAC·0/4·1/1 con CVT a 7, 28, 60 y 90 días. Reflexiones más intensas de M: Monocarbonato C: Calcita 
Tabla 60. Composición semicuantitativa de la fase (analizada por DRX) de los morteros de referencia de CAC $\cdot 0 / 2 \cdot 1 / 1$.

Periodo de curado del mortero (días)

\begin{tabular}{|c|c|c|c|c|}
\hline Fase mineralógica & 7 días & 28 días & 60 días & 90 días \\
\hline $\mathrm{SiO}_{2}$ (Cuarzo) & ++++ & ++++ & +++ & ++++ \\
\hline $\mathrm{CAH}_{10}$ & + & ++ & ++ & ++ \\
\hline $\mathrm{C}_{2} \mathrm{AH}_{8}$ & + & & & \\
\hline $\mathrm{C}_{3} \mathrm{AH}_{6}$ (Katoita) & & ++ & & \\
\hline $\mathrm{AH}_{3}$ (Gibbsita) & + & + & + & + \\
\hline $\mathrm{AH}_{3}$ (Norstrandita) & $\mathbf{0}$ & & + & + \\
\hline \multicolumn{5}{|l|}{$\mathrm{AH}_{3}$ (Bayerita) } \\
\hline $\mathrm{CaCO}_{3}$ (Calcita) & $\mathbf{0}$ & + & $\mathbf{0}$ & \\
\hline \multicolumn{5}{|l|}{$\mathrm{CaCO}_{3}$ (Vaterita) } \\
\hline \multicolumn{5}{|l|}{$\mathrm{CaCO}_{3}$ (Aragonito) } \\
\hline $\mathrm{C}_{4} \mathrm{AF}$ (Brownmillerita) & + & + & + & + \\
\hline $\mathrm{Ca}_{12} \mathrm{Al}_{14} \mathrm{O}_{33}$ (Mayenita) & & + & + & + \\
\hline \multicolumn{5}{|l|}{$\begin{array}{l}3 \mathrm{CaO} \cdot \mathrm{Al}_{2} \mathrm{O}_{3} \cdot 0.5 \mathrm{Ca}(\mathrm{OH})_{2} \cdot 0.5 \mathrm{CaCO}_{3} \cdot 11.5 \mathrm{H}_{2} \mathrm{O} \\
\text { (Hemicarboaluminato) }\end{array}$} \\
\hline $\begin{array}{l}\mathrm{C}_{4} \mathrm{AcH}_{11} \\
\text { (Monocarboaluminato) }\end{array}$ & $\mathbf{0}$ & + & $\mathbf{0}$ & \\
\hline
\end{tabular}

++++ Muy abundante; +++ Abundante; ++ Moderado; + Poco; o Trazas

Tabla 61. Composición semicuantitativa de la fase (analizada por DRX) de los morteros CAC $\cdot 0 / 2 \cdot 1 / 1$ con la incorporación de un $10 \%$ de CVT.

\begin{tabular}{|c|c|c|c|c|}
\hline \multirow[b]{2}{*}{ Fase mineralógica } & \multicolumn{4}{|c|}{ Periodo de curado del mortero (días) } \\
\hline & 7 días & 28 días & 60 días & 90 días \\
\hline $\mathrm{SiO}_{2}($ Cuarzo) & ++++ & ++++ & +++ & ++++ \\
\hline $\mathrm{CAH}_{10}$ & + & + & + & + \\
\hline \multicolumn{5}{|l|}{$\mathrm{C}_{2} \mathrm{AH}_{8}$} \\
\hline \multicolumn{5}{|l|}{$\mathrm{C}_{3} \mathrm{AH}_{6}$ (Katoita) } \\
\hline $\mathrm{AH}_{3}$ (Gibbsita) & $\mathbf{0}$ & + & + & $\mathbf{0}$ \\
\hline $\mathrm{AH}_{3}$ (Norstrandita) & & $\mathbf{0}$ & $\mathbf{0}$ & $\mathbf{0}$ \\
\hline \multicolumn{5}{|l|}{$\mathrm{AH}_{3}$ (Bayerita) } \\
\hline $\mathrm{CaCO}_{3}$ (Calcita) & + & $\mathbf{0}$ & + & $\mathbf{0}$ \\
\hline \multicolumn{5}{|l|}{$\mathrm{CaCO}_{3}$ (Vaterita) } \\
\hline $\mathrm{CaCO}_{3}$ (Aragonito) & & $\mathbf{0}$ & & \\
\hline $\mathrm{C}_{4} \mathrm{AF}$ (Brownmillerita) & + & ++ & + & + \\
\hline $\mathrm{Ca}_{12} \mathrm{Al}_{14} \mathrm{O}_{33}$ (Mayenita) & + & + & + & + \\
\hline $\begin{array}{l}3 \mathrm{CaO} \cdot \mathrm{Al}_{2} \mathrm{O}_{3} \cdot 0.5 \mathrm{Ca}(\mathrm{OH})_{2} \cdot 0.5 \mathrm{CaCO}_{3} \cdot 11.5 \mathrm{H}_{2} \mathrm{O} \\
\text { (Hemicarboaluminato) }\end{array}$ & + & & $\mathbf{0}$ & \\
\hline $\begin{array}{l}\mathrm{C}_{4} \mathrm{AcH}_{11} \\
\text { (Monocarboaluminato) }\end{array}$ & 0 & ++ & ++ & ++ \\
\hline
\end{tabular}

++++ Muy abundante; +++ Abundante; ++ Moderado; + Poco; o Trazas 
Tabla 62. Composición semicuantitativa de la fase (analizada por DRX) de los morteros de referencia de CAC $\cdot 0 / 2 \cdot 1 / 3$

Periodo de curado del mortero (días)

\begin{tabular}{|c|c|c|c|c|}
\hline Fase mineralógica & 7 días & 28 días & 60 días & 90 días \\
\hline $\mathrm{SiO}_{2}($ Cuarzo $)$ & ++++ & ++++ & ++++ & ++++ \\
\hline $\mathrm{CAH}_{10}$ & ++ & +++ & + & +++ \\
\hline $\mathrm{C}_{2} \mathrm{AH}_{8}$ & + & & & \\
\hline $\mathrm{C}_{3} \mathrm{AH}_{6}$ (Katoita) & & & ++++ & \\
\hline $\mathrm{AH}_{3}$ (Gibbsita) & + & + & +++ & + \\
\hline $\mathrm{AH}_{3}$ (Norstrandita) & & $\mathbf{0}$ & + & + \\
\hline \multicolumn{5}{|l|}{$\mathrm{AH}_{3}$ (Bayerita) } \\
\hline $\mathrm{CaCO}_{3}$ (Calcita) & $\mathbf{0}$ & $\mathbf{o}$ & $\mathbf{0}$ & $\mathbf{0}$ \\
\hline \multicolumn{5}{|l|}{$\mathrm{CaCO}_{3}$ (Vaterita) } \\
\hline $\mathrm{CaCO}_{3}$ (Aragonito) & $\mathbf{o}$ & & & $\mathbf{0}$ \\
\hline $\mathrm{C}_{4} \mathrm{AF}$ (Brownmillerita) & + & + & + & + \\
\hline $\mathrm{Ca}_{12} \mathrm{Al}_{14} \mathrm{O}_{33}$ (Mayenita) & & + & + & \\
\hline \multicolumn{5}{|l|}{$\begin{array}{l}3 \mathrm{CaO} \cdot \mathrm{Al}_{2} \mathrm{O}_{3} \cdot 0.5 \mathrm{Ca}(\mathrm{OH})_{2} \cdot 0.5 \mathrm{CaCO}_{3} \cdot 11.5 \mathrm{H}_{2} \mathrm{O} \\
\text { (Hemicarboaluminato) }\end{array}$} \\
\hline $\begin{array}{l}\mathrm{C}_{4} \mathrm{AcH}_{11} \\
\text { (Monocarboaluminato) }\end{array}$ & + & + & + & + \\
\hline
\end{tabular}

++++ Muy abundante; +++ Abundante; ++ Moderado; + Poco; o Trazas

Tabla 63. Composición semicuantitativa de la fase (analizada por DRX) de los morteros CAC - $0 / 2 \cdot 1 / 3$ con la incorporación de un $10 \%$ de CVT.

Periodo de curado del mortero (días)

\begin{tabular}{|c|c|c|c|c|}
\hline Fase mineralógica & 7 días & 28 días & 60 días & 90 días \\
\hline $\mathrm{SiO}_{2}$ (Cuarzo) & ++++ & ++++ & ++++ & ++++ \\
\hline $\mathrm{CAH}_{10}$ & + & + & & + \\
\hline \multicolumn{5}{|l|}{$\mathrm{C}_{2} \mathrm{AH}_{8}$} \\
\hline \multicolumn{5}{|l|}{$\mathrm{C}_{3} \mathrm{AH}_{6}$ (Katoita) } \\
\hline $\mathrm{AH}_{3}$ (Gibbsita) & + & $\mathbf{0}$ & $\mathbf{0}$ & $\mathbf{0}$ \\
\hline \multicolumn{5}{|l|}{$\mathrm{AH}_{3}$ (Norstrandita) } \\
\hline \multicolumn{5}{|l|}{$\mathrm{AH}_{3}$ (Bayerita) } \\
\hline $\mathrm{CaCO}_{3}$ (Calcita) & + & +++ & ++ & ++ \\
\hline \multicolumn{5}{|l|}{$\mathrm{CaCO}_{3}$ (Vaterita) } \\
\hline $\mathrm{CaCO}_{3}$ (Aragonito) & + & & & \\
\hline $\mathrm{C}_{4} \mathrm{AF}$ (Brownmillerita) & + & + & + & + \\
\hline $\mathrm{Ca}_{12} \mathrm{Al}_{14} \mathrm{O}_{33}$ (Mayenita) & ++ & + & ++ & + \\
\hline $\begin{array}{l}3 \mathrm{CaO} \cdot \mathrm{Al}_{2} \mathrm{O}_{3} \cdot 0.5 \mathrm{Ca}(\mathrm{OH})_{2} \cdot 0.5 \mathrm{CaCO}_{3} \cdot 11.5 \mathrm{H}_{2} \mathrm{O} \\
\text { (Hemicarboaluminato) }\end{array}$ & ++ & ++ & +++ & ++ \\
\hline $\begin{array}{l}\mathrm{C}_{4} \mathrm{AcH}_{11} \\
\text { (Monocarboaluminato) }\end{array}$ & + & + & ++ & ++ \\
\hline
\end{tabular}

++++ Muy abundante; +++ Abundante; ++ Moderado; + Poco; o Trazas 
Tabla 64. Composición semicuantitativa de la fase (analizada por DRX) de los morteros de referencia de CAC $\cdot 0 / 4 \cdot 1 / 1$

Periodo de curado del mortero (días)

\begin{tabular}{|c|c|c|c|c|}
\hline Fase mineralógica & 7 días & 28 días & 60 días & 90 días \\
\hline $\mathrm{SiO}_{2}$ (Cuarzo) & ++++ & ++++ & ++++ & ++++ \\
\hline $\mathrm{CAH}_{10}$ & + & + & + & \\
\hline $\mathrm{C}_{2} \mathrm{AH}_{8}$ & + & & & \\
\hline $\mathrm{C}_{3} \mathrm{AH}_{6}$ (Katoita) & & +++ & +++ & ++++ \\
\hline $\mathrm{AH}_{3}$ (Gibbsita) & $\mathbf{0}$ & + & ++ & +++ \\
\hline $\mathrm{AH}_{3}$ (Norstrandita) & $\mathbf{0}$ & $\mathbf{0}$ & $\mathbf{0}$ & + \\
\hline $\mathrm{AH}_{3}$ (Bayerita) & & & & + \\
\hline $\mathrm{CaCO}_{3}$ (Calcita) & $\mathbf{0}$ & $\mathbf{0}$ & $\mathbf{0}$ & $\mathbf{0}$ \\
\hline \multicolumn{5}{|l|}{$\mathrm{CaCO}_{3}$ (Vaterita) } \\
\hline $\mathrm{CaCO}_{3}$ (Aragonito) & & $\mathbf{0}$ & & \\
\hline $\mathrm{C}_{4} \mathrm{AF}$ (Brownmillerita) & ++ & & + & + \\
\hline $\mathrm{Ca}_{12} \mathrm{Al}_{14} \mathrm{O}_{33}$ (Mayenita) & + & & + & ++ \\
\hline \multicolumn{5}{|l|}{$\begin{array}{l}3 \mathrm{CaO} \cdot \mathrm{Al}_{2} \mathrm{O}_{3} \cdot 0.5 \mathrm{Ca}(\mathrm{OH})_{2} \cdot 0.5 \mathrm{CaCO}_{3} \cdot 11.5 \mathrm{H}_{2} \mathrm{O} \\
\text { (Hemicarboaluminato) }\end{array}$} \\
\hline $\begin{array}{l}\mathrm{C}_{4} \mathrm{AcH}_{11} \\
\text { (Monocarboaluminato) }\end{array}$ & & + & $\mathbf{0}$ & $\mathbf{0}$ \\
\hline
\end{tabular}

++++ Muy abundante; +++ Abundante; ++ Moderado; + Poco; o Trazas

Tabla 65. Composición semicuantitativa de la fase (analizada por DRX) de los morteros CAC $\cdot 0 / 4 \cdot 1 / 1$ con la incorporación de un $10 \%$ de CVT.

\begin{tabular}{|c|c|c|c|c|}
\hline \multirow[b]{2}{*}{ Fase mineralógica } & \multicolumn{4}{|c|}{ Periodo de curado del mortero (días) } \\
\hline & 7 días & 28 días & 60 días & 90 días \\
\hline $\mathrm{SiO}_{2}$ (Cuarzo) & +++ & ++++ & ++++ & ++++ \\
\hline $\mathrm{CAH}_{10}$ & & + & + & + \\
\hline \multicolumn{5}{|l|}{$\mathrm{C}_{2} \mathrm{AH}_{8}$} \\
\hline $\mathrm{C}_{3} \mathrm{AH}_{6}$ (Katoita) & & & & ++ \\
\hline $\mathrm{AH}_{3}$ (Gibbsita) & $\mathbf{0}$ & $\mathbf{0}$ & $\mathbf{0}$ & + \\
\hline $\mathrm{AH}_{3}$ (Norstrandita) & $\mathbf{0}$ & & & + \\
\hline \multicolumn{5}{|l|}{$\mathrm{AH}_{3}$ (Bayerita) } \\
\hline $\mathrm{CaCO}_{3}$ (Calcita) & $\mathbf{0}$ & $\mathbf{0}$ & $\mathbf{0}$ & ++ \\
\hline \multicolumn{5}{|l|}{$\mathrm{CaCO}_{3}$ (Vaterita) } \\
\hline \multicolumn{5}{|l|}{$\mathrm{CaCO}_{3}$ (Aragonito) } \\
\hline $\mathrm{C}_{4} \mathrm{AF}$ (Brownmillerita) & $\mathbf{0}$ & + & + & + \\
\hline $\mathrm{Ca}_{12} \mathrm{Al}_{14} \mathrm{O}_{33}$ (Mayenita) & $\mathbf{0}$ & + & + & + \\
\hline \multicolumn{5}{|l|}{$\begin{array}{l}3 \mathrm{CaO} \cdot \mathrm{Al}_{2} \mathrm{O}_{3} \cdot 0.5 \mathrm{Ca}(\mathrm{OH})_{2} \cdot 0.5 \mathrm{CaCO}_{3} \cdot 11.5 \mathrm{H}_{2} \mathrm{O} \\
\text { (Hemicarboaluminato) }\end{array}$} \\
\hline $\begin{array}{l}\mathrm{C}_{4} \mathrm{AcH}_{11} \\
\text { (Monocarboaluminato) }\end{array}$ & + & ++ & ++ & +++ \\
\hline
\end{tabular}

++++ Muy abundante; +++ Abundante; ++ Moderado; + Poco; o Trazas 
Tabla 66. Composición semicuantitativa de la fase (analizada por DRX) de los morteros de referencia de CAC $\cdot 0 / 4 \cdot 1 / 3$

Periodo de curado del mortero (días)

\begin{tabular}{|c|c|c|c|c|}
\hline Fase mineralógica & 7 días & 28 días & 60 días & 90 días \\
\hline $\mathrm{SiO}_{2}$ (Cuarzo) & ++++ & ++++ & +++ & ++++ \\
\hline $\mathrm{CAH}_{10}$ & ++ & ++ & + & \\
\hline $\mathrm{C}_{2} \mathrm{AH}_{8}$ & + & & & \\
\hline $\mathrm{C}_{3} \mathrm{AH}_{6}$ (Katoita) & & & +++ & +++ \\
\hline $\mathrm{AH}_{3}$ (Gibbsita) & + & $\mathbf{0}$ & + & +++ \\
\hline $\mathrm{AH}_{3}$ (Norstrandita) & & $\mathbf{0}$ & $\mathbf{o}$ & + \\
\hline \multicolumn{5}{|l|}{$\mathrm{AH}_{3}$ (Bayerita) } \\
\hline $\mathrm{CaCO}_{3}$ (Calcita) & $\mathbf{0}$ & $\mathbf{o}$ & $\mathbf{0}$ & $\mathbf{0}$ \\
\hline \multicolumn{5}{|l|}{$\mathrm{CaCO}_{3}$ (Vaterita) } \\
\hline $\mathrm{CaCO}_{3}$ (Aragonito) & & $\mathbf{0}$ & & \\
\hline $\mathrm{C}_{4} \mathrm{AF}$ (Brownmillerita) & + & + & + & + \\
\hline \multicolumn{5}{|l|}{$\mathrm{Ca}_{12} \mathrm{Al}_{14} \mathrm{O}_{33}$ (Mayenita) } \\
\hline \multicolumn{5}{|l|}{$\begin{array}{l}3 \mathrm{CaO} \cdot \mathrm{Al}_{2} \mathrm{O}_{3} \cdot 0.5 \mathrm{Ca}(\mathrm{OH})_{2} \cdot 0.5 \mathrm{CaCO}_{3} \cdot 11.5 \mathrm{H}_{2} \mathrm{O} \\
\text { (Hemicarboaluminato) }\end{array}$} \\
\hline $\begin{array}{l}\mathrm{C}_{4} \mathrm{AcH}_{11} \\
\text { (Monocarboaluminato) }\end{array}$ & + & + & + & + \\
\hline
\end{tabular}

++++ Muy abundante; +++ Abundante; ++ Moderado; + Poco; o Trazas

Tabla 67. Composición semicuantitativa de la fase (analizada por DRX) de los morteros CAC - 0/4 $\cdot 1 / 3$ con la incorporación de un $10 \%$ de CVT.

\begin{tabular}{|c|c|c|c|c|}
\hline \multirow[b]{2}{*}{ Fase mineralógica } & \multicolumn{4}{|c|}{ Periodo de curado del mortero (días) } \\
\hline & 7 días & 28 días & 60 días & 90 días \\
\hline $\mathrm{SiO}_{2}($ Cuarzo $)$ & +++ & ++++ & ++++ & ++++ \\
\hline $\mathrm{CAH}_{10}$ & + & ++ & + & + \\
\hline \multicolumn{5}{|l|}{$\mathrm{C}_{2} \mathrm{AH}_{8}$} \\
\hline \multicolumn{5}{|l|}{$\mathrm{C}_{3} \mathrm{AH}_{6}$ (Katoita) } \\
\hline $\mathrm{AH}_{3}$ (Gibbsita) & + & + & $\mathbf{0}$ & + \\
\hline $\mathrm{AH}_{3}$ (Norstrandita) & $\mathbf{0}$ & & & \\
\hline \multicolumn{5}{|l|}{$\mathrm{AH}_{3}$ (Bayerita) } \\
\hline $\mathrm{CaCO}_{3}$ (Calcita) & & ++ & + & + \\
\hline \multicolumn{5}{|l|}{$\mathrm{CaCO}_{3}$ (Vaterita) } \\
\hline $\mathrm{CaCO}_{3}$ (Aragonito) & + & & & \\
\hline $\mathrm{C}_{4} \mathrm{AF}$ (Brownmillerita) & $\mathbf{0}$ & + & + & + \\
\hline $\mathrm{Ca}_{12} \mathrm{Al}_{14} \mathrm{O}_{33}$ (Mayenita) & & + & & \\
\hline $\begin{array}{l}3 \mathrm{CaO} \cdot \mathrm{Al}_{2} \mathrm{O}_{3} \cdot 0.5 \mathrm{Ca}(\mathrm{OH})_{2} \cdot 0.5 \mathrm{CaCO}_{3} \cdot 11.5 \mathrm{H}_{2} \mathrm{O} \\
\text { (Hemicarboaluminato) }\end{array}$ & ++ & ++ & ++ & +++ \\
\hline $\begin{array}{l}\mathrm{C}_{4} \mathrm{AcH}_{11} \\
\text { (Monocarboaluminato) }\end{array}$ & + & ++ & ++ & ++ \\
\hline
\end{tabular}

++++ Muy abundante; +++ Abundante; ++ Moderado; + Poco; o Trazas 
En efecto, los Cementos de Aluminato de Calcio desarrollan una resistencia mecánica mucho más elevada en las etapas tempranas de los procesos de hidratación, que los Cementos Portland ordinarios. El mecanismo de hidratación de los CAC engloba una primera disolución de las fases anhídridas, a las que les sigue la precipitación de los hidratos. Tras estas transformaciones químicas, la formación de hidratos deriva en un proceso de interrelación y formación de nuevos vínculos entre las fases cristalinas, lo que desarrolla un aumento de la resistencia mecánica en edades tempranas de los conglomerados realizados con morteros CAC (Kopanda, 1987; Mohammad Reza y Nasrien, 2007).

Durante el proceso de conversión del cemento CAC, los hidratos hexagonales, $\mathrm{CAH}_{10}$ y $\mathrm{C}_{2} \mathrm{AH}_{8}$, se transforman en hidratos cúbicos, $\mathrm{CAH}_{6}$ (katoita) y $\mathrm{Al}(\mathrm{OH})_{3}$ (gibsita), más estables, pero con el inconveniente de que durante este proceso se produce un incremente en la porosidad del material (hidratos con menor densidad dan lugar a otros con mayor densidad) lo que produce una reducción en las propiedades mecánicas de los productos elaborados con CAC. Por lo tanto, y con la intención de poder obtener un mejor comportamiento de estos cementos y sus morteros, la conversión de los hidratos metaestables debería ser evitada o, cuando menos, minimizada.

Diversos autores (Kuzel y Baier, 1996; Fentiman, 1985; Rivas-Mercury et al., 2003), han investigado los efectos producidos por adiciones de carbonato cálcico en compuestos derivados de cementos CAC con la intención de contrarrestar el proceso de conversión mediante la formación de un hidrato de forma laminar (Tetracalcio Monoaluminato Hidratado, $\left.\mathrm{C}_{3} \mathrm{~A} \cdot \mathrm{CaCO}_{3} \cdot 11 \mathrm{H}\right)$ también denominado "monocarbonato" o "carboaluminato cálcico" ( $\mathrm{C}_{4} \mathrm{AcH}_{11}$ en notación química del cemento).

En 1980 Cussino y Negro (1980) explicaron que la pérdida de resistencia mecánica en morteros ejecutados con cementos CAC podría ser prevenida bien con la utilización de áridos calcáreos, o bien mediante la adición de calcita granular al cemento, previa a la ejecución del mortero. En esta investigación se demostró la aparición del monocarbonato $\mathrm{C}_{4} \mathrm{AcH}_{11}, \mathrm{y}$ 
concluyeron que estaba directamente relacionado con la desaparición o disminución del proceso de conversión, inherente a las pastas y morteros ejecutados con CAC.

Fentiman (1985) confirmó la formación del monocarbonato $\mathrm{C}_{4} \mathrm{AcH}_{11}$, pero descubrió que tanto a $25^{\circ} \mathrm{C}$, como por debajo de esta temperatura, los hidratos hexagonales $\mathrm{CAH}_{10}$ eran todavía los principales productos de hidratación con lo que el proceso de conversión no se detenía, sino que simplemente se retrasaba. Fentiman elaboró toda una teoría sobre cómo la tempertura afectaba a la formación de hidratos y a su inestabilidad, sobre todo por encima de los $60^{\circ} \mathrm{C}$. Otros autores (Barret et al., 1983 y 1986), confirmaron la aparición del monocarbonato $\mathrm{C}_{4} \mathrm{AcH}_{11}$, mediante la disolución de carbonato cálcico pero sólo por encima de unas determinadas condiciones de presión de $\mathrm{CO}_{2}$.

En esta misma línea de investigación, Puertas et al. (1996), concluyeron que el depósito elevado de productos carbonatados en el fraguado de morteros, implicaba en todos los casos estudiados, una disminución en la porosidad de los mismos, lo cual relacionaron con un incremento de las resistencias mecánicas ensayadas.

Darweesh (2004) estudia las cantidades parciales de $\mathrm{CaCO}_{3}$ necesarias para conseguir el equilibrio de compuestos y la mejora en las condiciones mecánicas. Según estos estudios, la incorporación de carbonato cálcico debería ser llevada como máximo hasta un $15 \%$ de porcentaje en peso del total de cemento usado. Dosificaciones más elevadas podrían conllevar un impacto negativo en las resistencias del cemento debido, en gran manera, a la disminución de los principales productos de la hidratación, los cuales son los desencadenantes de las fuerzas de adherencia interna de este tipo de conglomerados.

Por otro lado, determinados autores (Kuzel y Baier, 1996; Fentiman, 1985; Luz y Pandolfelli, 2012) han señalado en sus investigaciones que, dependiendo de las condiciones de curado de los distintos compuestos a base de CAC, la carbonatación de este tipo de cementos no implicaría una 
completa desaparición de las reacciones comunes al proceso de conversión. En estos trabajos no se consigue establecer una concordancia clara que relacione la estabilidad de las reacciones que dan lugar al monocarbonato y las temperaturas a las que se produce su descomposición. De hecho, Luz y Pandolfelli (2012), señalan que la descomposición térmica del monocarbonato $\mathrm{C}_{4} \mathrm{AcH}_{11}$, podría ocurrir por encima de los $40^{\circ} \mathrm{C}$, mientras que Kuzel y Baier (1996), concluyen que este tipo de hidrato empieza a ser inestable por encima de $10 \mathrm{~s} 90^{\circ} \mathrm{C}$.

A pesar de las aparentes contradicciones de estas investigaciones, se puede concluir que el aporte de carbonato cálcico, independientemente del tipo de adición propuesta, aunque en cantidades que no deberían superar el $15 \%$ en peso de la cantidad de CAC utilizada, genera la aparición del monocarbonato $\mathrm{C}_{4} \mathrm{AcH}_{11}$ y que éste, está íntimamente relacionado con un aumento de las capacidades mecánicas de los compuestos formados con CAC. 


\subsubsection{ENSAYOS DE LIXIVIADO DE MORTEROS CAC.}

Los análisis de lixiviación de iones de metales pesados han sido realizados tanto a los morteros de referencia, como a los morteros con la incorporación de cenizas volantes inertizadas en forma de carbonatos insolubles. Los ensayos fueron efectuados sobre probetas monolíticas de los morteros de cemento de aluminato de calcio con mejores comportamientos físico/mecánicos (estabilidad dimensional y resistencia mecánica). Dichas probetas fueron curadas en cámara húmeda durante 28 días, de acuerdo a lo establecido en el ensayo francés NF P X31-211 sobre lixiviado de metales pesados en morteros monolíticos. Este ensayo, es específico para probetas de mortero monolíticas, de sencilla ejecución en el laboratorio e inmediata obtención de resultados (Aubert et al., 2006 y 2007; Barbosa et al., 2011; Filippov et al., 2009).

Para una sola extracción, el ensayo consiste en un ciclo de lixiviación de 24 horas de las probetas sumergidas en agua desionizada y removida constantemente por medios mecánicos. La relación agua/sólido fue establecida, a priori, en una proporción de 10 (ilustración 72). Para la realización del ensayo se procedió a efectuar una variación del mismo ya que las probetas de mortero analizadas fueron cortadas en prismas de $4 \times 4 \times 4 \mathrm{~cm}^{3}$ con la intención de mantener, aproximadamente, el volumen de probeta del ensayo original.

Dado que los morteros son y generan medios alcalinos en disolución, se han analizado las cantidades de $\mathrm{Zn}, \mathrm{Cd}, \mathrm{Pb}$ y $\mathrm{Cu}$. Especialmente significativa es la determinación de los valores de $\mathrm{Zn} \mathrm{y} \mathrm{Pb}$ ya que, en medios ácidos se solubilizan, y en medios muy alcalinos se transforman en cincatos y plumbitos. De aquí el evitar pH inferiores a 6 o superiores a 12 .

Las cantidades de estos metales pesados fueron determinadas mediante una voltamperometría de redisolución anódica realizada sobre el fluido obtenido tras el filtrado a través de filtros de $0,45 \mu \mathrm{m}$ del líquido resultante del proceso de lixiviado. 


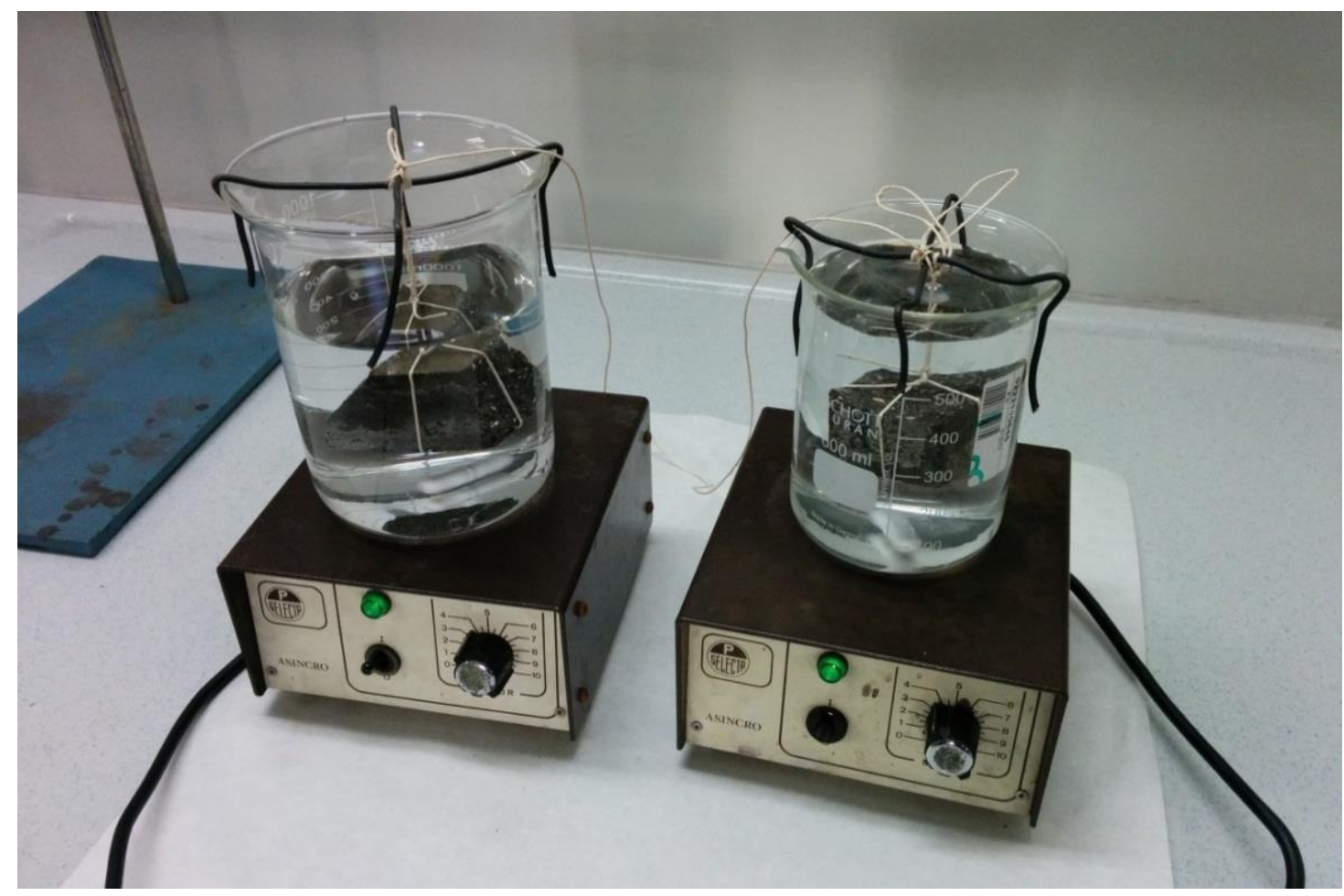

Ilustración 72. Ensayo de lixiviación de probetas monolíticas (NF P X31-211). Mortero de cemento CAC de referencia (izda.). Mortero de CAC con cenizas volantes inertizadas (dcha.)

La tabla 68 muestra los resultados de dichos ensayos de lixiviado. En ellos, los referidos a $\mathrm{Zn}$ y $\mathrm{Pb}$ son los verdaderamente significativos dada su capacidad de formar aniones (zincato y plumbito). Por el contrario, las cantidades de $\mathrm{Cd}$ y $\mathrm{Cu}$ son medidas prácticamente como contraste. De acuerdo a estos resultados, los iones de $\mathrm{Pb}$ son los que ligeramente se solubilizan en el lixiviado, mientras que el resto de los iones metálicos analizados, incluidos los de $\mathrm{Zn}$, permanecen en valores muy bajos, siendo prácticamente cero en algunos de los casos.

El resultado experimental muestra que el esperado efecto pantalla generado por la matriz del mortero, consigue encapsular completamente los iones de $\mathrm{Zn}$ y mitigar el lixiviado de los de $\mathrm{Pb}$. Estos resultados se encuentran en concordancia con las concusiones expuesta por (NavarroBlasco et al., 2013), según las que los morteros elaborados con cementos de aluminato de calcio son adecuados para la encapsulación de metales pesados e idóneos para la gestión de residuos sólidos urbanos. 
Tabla 68. Valores de lixiviación en $\eta \mathrm{g} / \mathrm{L}$ de los morteros de CAC analizados. (R) Morteros de referencia. (CVT) Morteros con cenizas volantes inertizadas en forma de carbonatos.

\begin{tabular}{ccc}
\hline \multirow{2}{*}{ Elemento } & \multicolumn{2}{c}{ Tipo de mortero } \\
\cline { 2 - 3 } & $\mathbf{R}$ & CVT \\
\hline \multirow{2}{*}{$\mathbf{Z n}$} & 0,000 & 0.000 \\
\cline { 2 - 3 } & 5,0094 & 355,99 \\
\cline { 2 - 3 } & 388.52 & 1,356 \\
\hline \multirow{2}{*}{$\mathbf{C d}$} & 164,11 & 618,56 \\
\cline { 2 - 3 } & 539,95 & 79,63 \\
\cline { 2 - 3 } & 129,65 & 45,78 \\
\hline \multirow{2}{*}{$\mathbf{P b}$} & 110,19 & 605,36 \\
\cline { 2 - 3 } & 372,92 & 650,1 \\
\cline { 2 - 3 } & 591,42 & 345,45 \\
\hline \multirow{2}{*}{ Cu } & 9,1667 & 0,0000 \\
\cline { 2 - 3 } & 0,0000 & 13,732 \\
\hline & 0,0000 & 0,0000 \\
\hline
\end{tabular}




\section{CONCLUSIONES}

- $\quad$ El promedio de datos obtenido sobre un espacio muestral de 22 semanas indica que las cenizas de RSU superan los valores límite al menos en lo relativo a $\mathrm{Zn}, \mathrm{Pb}$, cloruros y sulfatos, lo que hace que deban tratarse como residuos especiales.

- Se ha estimado que el reactivo que mejor estabiliza los metales pesados de las cenizas volantes de RSU es el anión carbonato. Por lo tanto, tanto para la estabilización de metales pesados presentes en las cenizas, como para la eliminación de cloruros, se ha utilizado un método de lavado con la combinación adecuada de $\mathrm{NaHCO}_{3}$. Los resultados presentan una reducción de casi un $99 \%$ de cloruros solubles aunque, a pesar de ello, su uso no resulta recomendable con armaduras de acero (Ministerio de Fomento. Secretaría General Técnica. 2010). Por otro lado, la adición del catión $\mathrm{Na}^{+}$favorece la eliminación de estos cloruros en forma de Cloruro Sódico. La solución indicada, de igual forma, ejercerá la función de tampón, por lo que mantendrá el pH entorno a los valores óptimos para que la concentración de los metales pesados en el lixiviado sea la mínima posible.

- La elaboración de morteros de albañilería con la incorporación de cenizas volantes inertizadas en forma de carbonatos, en una proporción de un $10 \%$ en peso de los áridos, es teóricamente posible. Por lo tanto, se trata de un método viable para conseguir la estabilización/solidificación de los metales pesados presentes en ellas.

- Los resultados muestran que el periodo de trabajabilidad de los morteros elaborados con cementos CAC y CSA y con la inclusión de cenizas volantes inertizadas (CVT) son mucho más cortos que los ofrecidos por los dos tipos de cemento Portland ordinario ensayados. 
- Los morteros de CSA, en ambas dosificaciones analizadas, y los de CAC, en la dosificación $1 / 1$, confeccionados con cenizas volantes inertizadas (CVT) presentan los mejores valores de estabilidad dimensional en lo relativo a pérdida de longitud específica por encima, incluso, de los valores ofrecidos por los morteros de referencia en cada uno de los casos. De igual forma, los morteros de CAC y dosificación $1 / 1$, son los únicos ensayados que presentan una menor disminución de masa específica. Por el contrario, se trata del único tipo de mortero que aumenta su densidad con la incorporación de las cenizas volantes inertizadas.

- Tanto en el caso de los morteros de CAC, como los de CSA, se ha comprobado que son los que sufren unos mayores índices de carbonatación. Los áridos junto a la evaporación del agua de amasado inducen el desarrollo de un sistema de poros que favorece la difusión del $\mathrm{CO}_{2}$. Este hecho, lejos de ser negativo, reduce la retracción y las fisuraciones de las muestras durante su secado y pueden dar lugar a posteriores reacciones puzolánicas que favorecen el aumento de las resistencias a compresión.

- La incorporación de cenizas volantes inertizadas, en una proporción de un $10 \%$ en peso de los áridos, afecta negativamente a los valores medios de tensión de rotura tanto a compresión, como a flexión, de los morteros realizados con CEM-I y CEM-II. Si bien esta reducción generalizada de las propiedades mecánicas en relación con los morteros de referencia, no impide que los valores obtenidos sean admitidos por norma.

- Los morteros de Cemento de Sulfoaluminato de Calcio con cenizas volantes inertizadas en forma de carbonatos en su composición y con dosificaciones árido/cemento $1 / 3$, muestran resistencias a compresión finales superiores a los morteros de referencia. Un 8,01\% mejores, en el caso de morteros elaborados con áridos de granulometría $0 / 2$; y un $11,89 \%$ superiores, para los de granulometría 0/3. Igualmente, sus 
resistencias a flexión son análogas a las de sus morteros de referencia. Por lo que la incorporación de cenizas volantes inertizadas en este tipo de cementos belíticos resulta más favorable, desde el punto de vista de las resistencias mecánicas, que su utilización en cementos tradicionales con base de alita, con el consiguiente beneficio ambiental que ello conlleva.

- Los morteros de Cemento de Aluminato de Calcio con la incorporación de cenizas volantes inertizadas en forma de carbonatos insolubles, en una proporción de un $10 \%$ en peso de los áridos, presentan los mejores datos de resistencias mecánicas de todos los morteros estudiados, superando tanto a flexión, como a compresión, las resistencias mecánicas finales de los morteros de referencia. De todos ellos, los mejores valores se obtienen en los morteros con cenizas volantes de dosificación $1 / 1$ y granulometría $0 / 4$ ya que las resistencias a compresión superan a los morteros de referencia en un $48,62 \%$; y las resistencias a flexión en un $67,02 \%$.

- Los estudios de difracción de Rayos X, justifican que las elevadas resistencias finales obtenidas en los morteros elaborados con CAC y cenizas volantes inertizadas, son debidas al aporte de carbonato cálcico de las cenizas volantes inertizadas, el cual genera la aparición de monocarbonato o carboaluminato cálcico $\mathrm{C}_{4} \mathrm{AcH}_{11}$.

- Se ha estimado que los morteros de Cemento de Aluminato de Calcio con dosificaciones $1 / 1$ y tamaño de árido $0 / 4$ son los que presentan un mejor comportamiento físico/mecánico. Sobre ellos se han realizado un ensayo de lixiviado. Los resultados obtenidos muestran que el efecto escudo que proporcionan las matrices de morteros realizados con cementos CAC y cenizas volantes inertizadas en forma de carbonatos insolubles, encapsulan completamente los iones de $\mathrm{Zn}$ y $\mathrm{Pb}$, los cuales son solubles con pH alto. 
- De lo anteriormente expuesto, se podría inferir que morteros confeccionados con Cementos de Aluminato de Calcio con la incorporación de cenizas volantes inertizadas en forma de carbonatos insolubles, con dosificaciones Cemento/Árido $=1 / 1$ y granulometría de los áridos $0 / 4$, podrían ser perfectamente validos en actuaciones en las que se necesitase un producto de fraguado rápido, altas resistencias iniciales y compensación de las retracciones con una elevada estabilidad dimensional. En base a esto, el material podría ser utilizado como mortero de reparación en viales y pavimentos que requiriesen altas prestaciones, tales como: soleras industriales, pistas de aterrizaje, aparcamientos, etc. O bien, dada su elevada resistencia a flexión, para la confección de elementos prefabricados sin armaduras estructurales debido a la existencia de $\mathrm{Cl}^{-}$residual. 


\section{FUTURAS LÍNEAS DE INVESTIGACIÓN}

- Dado su excelente comportamiento físico/mecánico, sería interesante aprovechar el sistema de baja alcalinidad formado por la matriz conjunta de los morteros de cemento de sulfoaluminato de calcio con las cenizas volantes inertizadas, el cual favorecería la posibilidad de utilizar cualquier tipo de refuerzo a base de fibras de vidrio de dichos morteros.

- Ampliar la investigación a la utilización de áridos calizos por tener éstos un mejor comportamiento físico-mecánico en productos derivados de cementos de aluminato de calcio.

- Estudiar la utilización de estas cenizas volantes inertizadas para reemplazar completamente las fracciones más finas de los áridos utilizados en la elaboración de morteros o de filler mineral en aglomerados asfálticos.

- Extender las investigaciones realizadas a la elaboración de morteros con cementos ternarios. 


\section{BIBLIOGRAFÍA}

Abe, S., Kambayashi, F., \& Okada, M. (1996). Ash melting treatment by rotating type surface melting furnace. Waste Management, 16, 431-443.

Alba, N., Gasso, S., Lacorte, T., \& Baldasano, J. M. (1997). Characterization of municipal solid waste incineration residues from facilities with different air pollution control. J. Air Waste Manage. Assoc., 47, 11701179.

Al-Rawas, A. A., Wahid Hago, A., Taha, R., \& Al-Kharousi, K. (2005). Use of incinerator ash as a replacement for cement and sand in cement mortars. Building and Environment, 40(9), 1261-1266.

Ampadu, K. O., \& Torii, K. (2001). Characterization of ecocement pastes and mortars produced from incinerated ashes. Cement and Concrete Research, 31(3), 431-436.

Antoni, M. (2013). Investigation of cement substitution by blends of calcined clays and limestone. Escuela Politécnica Federal de Lausana. Tesis No 6001

Applewhite-Ramsey, A., \& Sproull, J. F. (1993). Waste acceptance product specifications for vitrified high-level waste forms. American Ceramic Society, 39, 275-282.

Applewhite-Ramsey, A., Wolf, K. Z., \& Plodinec, M. J. (1993). EPA tests of simulated DWPF waste glass. Ceramic Transactions. Amer. Ceramic Society, 29

Asociación Española de Normalización y Certificación. (2003). UNEEN 998-1: Especificaciones de los morteros para albañilería. parte 1, morteros para revoco y enlucido 
Aubert, J. E., Husson, B., \& Sarramone, N. (2006). Utilization of municipal solid waste incineration (MSWI) fly ash in blended cement. Part 1: Processing and characterization of MSWI fly ash. Journal of Hazardous Materials, 136(3), 624-631.

Aubert, J. E., Husson, B., \& Sarramone, N. (2007). Utilization of municipal solid waste incineration (MSWI) fly ash in blended cement. Part 2. Mechanical strength of mortars and environmental impact. Journal of Hazardous Materials, 146(1-2), 12-19.

Aubert, J. E., Husson, B., \& Vaquier, A. (2004). Metallic aluminum in MSWI fly ash: Quantification and influence on the properties of cementbased products. Waste Management, 24(6), 589-596.

Auer, S., Kuzel, H. -., Pöllmann, H., \& Sorrentino, F. (1995). Investigation on MSW fly ash treatment by reactive calcium aluminates and phases formed. Cement and Concrete Research, 25(6), 1347-1359.

Bakolas, A., Biscontin, G., Moropoulou, A., \& Zendri, E. (1998). Characterization of structural byzantine mortars by thermogravimetric analysis. Thermochimica Acta, 321(1-2), 151-160.

Barna, R., Rethy, Z., Imyim, A., Perrodin, Y., Moszkowicz, P., \& Tiruta-Barna, L. (2000). Environmental behaviour of a construction made of a mixture of hydraulic binders and air pollution control residues from municipal solid waste incineration part 1 . Physico-chemical characterisation and modelling of the source term. Waste Management, 20(8), 741-750.

Barna, R., Rethy, Z., Perrodin, Y., Moszkowicz, P., \& Tiruta-Barna, L. (2000). Environmental behaviour of a construction made of a mixture of hydraulic binders and air pollution control residues from municipal solid waste incineration part 2. Simulation tests and validation of the source term modelling. Waste Management, 20(8), 751-759. 
Barret, P., Beau, D., \& Bertrandie, D. (1986). A discussion of the paper "stabilite thermodynamique des phases dans le systeme $\mathrm{CaO} \cdot \mathrm{Al}_{2} \mathrm{O}_{3} \cdot \mathrm{CO}_{2} \cdot \mathrm{H}_{2} \mathrm{O}$ " by $\mathrm{M}$. soustelle B. guilhot, A.A. fournier, M. Murat and A. Negro. Cement and Concrete Research, 16(5), 785-788.

Barret, P., Bertrandie, D., \& Beau, D. (1983). Calcium hydrocarboaluminate, carbonate alumina gel and hydrated aluminates solubility diagram calculated in equilibrium with $\mathrm{CO}_{2}(\mathrm{~g})$ and with $\mathrm{Na}^{+}(\mathrm{aq})$ ions. Cement and Concrete Research, 13(6), 789-800.

Battistoni, P., Cola, E., Fatone, F., Bolzonella, D., \& Eusebi, A. L. (2007). Micropollutants removal and operating strategies in ultrafiltration membrane systems for municipal wastewater treatment: Preliminary results. Industrial and Engineering Chemistry Research, 46(21), 6716-6723.

Beretka, J., de Vito, B., Santoro, L., Sherman, N., \& Valenti, G. L. (1993). Hydraulic behaviour of calcium sulfoaluminate-based cements derived from industrial process wastes. Cement and Concrete Research, 23(5), 1205-1214.

Biernacki, J. J., Vazrala, A. K., \& Wayne Leimer, H. (2008). Sintering of a class F fly ash. Fuel, 87(6), 782-792.

Bizzozero, J., Gosselin, C., \& Scrivener, K. L. (2012). Dimensional stability of calcium aluminate and sulfoaluminate systems. 31st Cement and Concrete Science Conference. 12-13 septiembre 2011. Imperial College, London, U.K.

Bizzozero, J., Gosselin, C., \& Scrivener, K. L. (2014). Expansion mechanisms in calcium aluminate and sulfoaluminate systems with calcium sulfate. Cement and Concrete Research, 56(0), 190-202.

Boccaccini, A. R., Kopf, M., \& Stumpfe, W. (1997). Glass-ceramics from filter dusts from waste incinerators. Ceram Int, 21, 231-235. 
Bushnell-Watson, S. M., \& Sharp, J. H. (1992). The application of thermal analysis to the hydration and conversión reactions of calcium aluminate cements. Materiales De Construcción, 42(228), 13-32.

Chan, C. C. Y., Kirk, D. W., \& Marsh, H. (2000). The behaviour of al in MSW incinerator fly ash during thermal treatment. Journal of Hazardous Materials, 76(1), 103-111.

Chang, J. C. (1990). Solubility product constants. CRC handbook of chemistry and physics. (71st Edition, ed.). Boca Raton, FL.:

Chinchón Yepes, S., \& Sanjuán Barbudo, M. A. (2008). El Cemento de Aluminato de Calcio y sus prefabricados. San Vicente del Raspeig: Publicaciones de la Universidad de Alicante, 2008. ISBN 978-84-9717-306$3,104 \mathrm{p}$.

Chrysochoou, M., Dermatas, D (2006). Evaluation of ettringite and hydrocalumite formation for heavy metal immobilization: literature review and experimental study. Journal of Hazardous Materials, 136 (1), 20-33.

Cinquepalmi, M. A., Mangialardi, T., Panei, L., Paolini, A. E., \& Piga, L. (2008). Reuse of cement-solidified municipal incinerator fly ash in cement mortars: Physico-mechanical and leaching characteristics. Journal of Hazardous Materials, 151(2-3), 585-593.

Collivignarelli, C., \& Sorlini, S. (2002). Reuse of municipal solid wastes incineration fly ashes in concrete mixtures. Waste Management, 22(8), 909912.

Commission Decision on the European List of Waste (COM 2000/532/EC) and Annex III to Directive 2008/98/EC, Commission Decision 2000/532/EC (2008).

Council Decision 2003/33/EC Establishing Criteria and Procedures for the Acceptance of Waste at Landfills Pursuant to Article 16 of and Annex II to Directive 1999/31/EC. LegislationU.S.C. (16 January 2003). 
Council Directive 1999/31/EC on the Landfill of Waste, LegislationU.S.C. (16 July 1999). Cussino, L., \& Negro, A. (1980). Hydration of aluminous cement in the presence of silicic and calcareous aggregates. (Proc. 7th Int. Cong. on Chemistry of Cement, Paris.) pp. 62-67.

Darweesh, H. H. M. (2004). Limestone as an accelerator and filler in limestone-substituted alumina cement. Ceramics International, 30(2), 145150.

De Casa, G., Mangialardi, T., Paolini, A. E., \& Piga, L. (2007). Physical-mechanical and environmental properties of sintered municipal incinerator fly ash. Waste Management, 27(2), 238-247.

De Casa, G., Mangialardi, T., \& Piga, L. (2004). Production of artificial aggregates from ceramic processing of municipal incinerator fly ash. Waste Management and the Environment II, pp. 45-54.

Delgado Quiñones, A., Talero Morales, R., \& Fátima Rahhal, V. (2006). Influencia de la naturaleza del árido sobre la evolución de la elasticidad dinámica de morteros y otras propiedades físicas y mecánicas. $I$ Congreso Nacional de Áridos. Los áridos un reto para el siglo XXI. Zaragoza. 115-120.

Elliot, D., Reading, M., \& Hill, V. L. (1993). A new approach to the calorimetric investigation of physical and chemical transitions. Journal of Thermal Analysis, 40(3), 949-955.

España. Ministerio de la Presidencia. EHE-08 (2008). Instrucción Española del Hormigón Estructural. [REAL DECRETO 1247/2008, de 18 de julio, por el que se aprueba la instrucción de hormigón estructural (EHE08)]. BOE 22 de agosto de 2008. Serie Normativa. (2010).

España. Ministerio de Fomento (2008). RC-08 Instrucción para la recepción de cementos: Texto oficial [Real Decreto 956/2008, de 6 de junio, 
por el que se aprueba la instrucción para la recepción de cementos (RC08)]. Madrid.

Fan, Y., Yin, S., Wen, Z., \& Zhong, J. (1999). Activation of fly ash and its effects on cement properties. Cement and Concrete Research, 29(4), 467-472.

Fentiman, C. H. (1985). Hydration of carbo-aluminous cement at different temperatures. Cement and Concrete Research, 15(4), 622-630.

Fernández, E., Macías, A., Guerrero, A., Lorenzo, M. P., \& Goñi, S. (2000). Influence of the cement type on the stabilisation of fly ashes from municipal solid waste incineration. Waste management series (pp. 169-177) Elsevier.

Fernández-Carrasco, L., Puertas, F., Blanco-Varela, M. T., \& Vazquez, T. (2001). Carbonatacion de pastas de cemento de aluminato de calcio. Materiales De Construcción, 5(263-264), 127-136.

Fernández-Carrasco, L., Rius, J., \& Miravitlles, C. (2008). Supercritical carbonation of calcium aluminate cement. Cement and Concrete Research, 38(8-9), 1033-1037.

Ferreira, C., Ribeiro, A., \& Ottosen, L. (2003). Heavy metals in MSW incineration fly ashes. Journal De Physique. IV : JP, , 107. (I) pp. 463-466.

Ferreira, C., Ribeiro, A., \& Ottosen, L. (2003). Possible applications for municipal solid waste fly ash. Journal of Hazardous Materials, 96(2-3), 201216.

Ferreira, C. D., Jensen, P., Ottosen, L., \& Ribeiro, A. (2008). Preliminary treatment of MSW fly ash as a way of improving electrodialytic remediation. Journal of Environmental Science and Health - Part A Toxic/Hazardous Substances and Environmental Engineering, 43(8), 837843. 
Fuoco, R., Ceccarini, A., Tassone, P., Wei, Y., Brongo, A., \& Francesconi, S. (2005). Innovative stabilization/solidification processes of fly ash from an incinerator plant of urban solid waste. Microchemical Journal, 79(1-2), 29-35.

Gao, X. (2008). Utilization of washed MSWI fly ash as partial cement substitute with the addition of dithiocarbamic chelate. Journal of Environmental Management, 88(2), 293-299.

Garcés, P., Zornoza, E., Alcocel, E. G., Galao, Ó., \& Andión, L. G. (2012). Mechanical properties and corrosion of CAC mortars with carbon fibers. Construction and Building Materials, 34(0), 91-96.

García-Maté, M., De la Torre, A. G., León-Reina, L., Aranda, M. A. G., \& Santacruz, I. (2013). Hydration studies of calcium sulfoaluminate cements blended with fly ash. Cement and Concrete Research, 54(0), 1220.

Garea, A., Ortiz, M. I., Viguri, J. R., Renedo, M. J., Fernandez, J., \& Irabien, J. A. (1996). Desulfurization yield of calcium hydroxide/fly-ash mixtures. Thermogravimetric determination. Thermochimica Acta, 286(1), 173-185.

Gazulla, M. F., Gómez, M. P., Orduña, M., \& Silva, G. (2005). Caracterización química, mineralógica y térmica de boratos naturales y sintéticos Boletín De La Sociedad Española De Cerámica y Vidrio, 44(1), 2131.

Ginés, O. (2009). Combined use of MSWI bottom ash and fly ash as aggregate in concrete formulation: Environmental and mechanical considerations. Journal of Hazardous Materials, 169(1-3), 643-650.

Glasser, F. P., \& Zhang, L. (2001). High-performance cement matrices based on calcium sulfoaluminate-belite compositions. Cement and Concrete Research, 31(12), 1881-1886. 
Goh, A. T. C., \& Tay, J. H. (1993). Municipal solid-waste incinerator fly ash for geotechnical applications. J. Geotech. Eng., 119(5), 811-825.

Goh, C. C., Show, K. Y., \& Cheong, H. K. (2003). Municipal solid waste fly ash as a blended cement material. Journal of Materials in Civil Engeniering, Nov/Dec, 513-523.

Goñi, S., Guerrero, A., Macías, A., \& Lorenzo, M. P. (2011). Materias primas alternativas para la fabricación de cementos más ecoeficientes de baja energía. Revista ALCONPAT, 1(1), 17-29.

Guerrero, A., Fernández, E., Macías, A., \& Goñi, S. (2000). Hydrothermal treatment of fly ash from municipal solid waste incineration. Waste management series (pp. 178-185) Elsevier.

Gunasekaran, S., \& Anbalagan, G. (2008). Spectroscopic study of phase transitions in natural calcite mineral. Spectrochimica Acta Part A: Molecular and Biomolecular Spectroscopy, 69(4), 1246-1251.

Guo, X., Shi, H., Hu, W., \& Wu, K. (2014). Durability and microstructure of CSA cement-based materials from MSWI fly ash. Cement and Concrete Composites, 46(0), 26-31.

Gupta, V. K. (2005). Removal of dyes from wastewater using bottom ash. Industrial Engineering Chemistry Research, 44(10), 3655-3664.

Haiying, Z., Youcai, Z., \& Jingyu, Q. (2007). Study on use of MSWI fly ash in ceramic tile. J. Hazard. Mater., 141, 106-114.

Hamernik, J. D., \& Frantz, G. C. (1991). Physical and chemical properties of municipal solid waste fly ash. ACI Mater. J., 88(3), 294-301.

Hjelmar, O. (1996). Disposal strategies for municipal solid waste incineration residues. Journal of Hazardous Materials, 47(1-3), 345-368. 
Ho, Y. S., \& McKay, G. (1999). Comparative sorption kinetic studies of dye and aromatic compounds onto fly ash. J. Environ. Sci. Health Part A: Toxic/Hazard. Subst. Environ. Eng., 34, 1179-1204.

Hollman, G. G., Steenbruggen, G., \& Janssen-Jurkovičová, M. (1999). A two-step process for the synthesis of zeolites from coal fly ash. Fuel, 78(10), 1225-1230.

Huang, W. J., \& Chu, S. C. (2003). A study on the cementlike properties of municipal waste incineration ashes. Cem. Concr. Res., 33, 1795-1799.

Hwa, T. J., \& Jeyaseelan, S. (1997). Conditioning of oily sludges with municipal solid wastes incinerator fly ash. Water Science and Technology, 35(8), 231-238.

Iacovidou, E., Ohandja, D., Gronow, J., \& Voulvoulis, N. (2012). The household use of food waste disposal units as a waste management option: A review. Critical Reviews in Environmental Science and Technology, 42(14), 1485-1508.

Irico, S., Gastaldi, D., Canonico, F., \& Magnacca, G. (2013). Investigation of the microstructural evolution of calcium sulfoaluminate cements by thermoporometry. Cement and Concrete Research, 53(0), 239247.

Isaia, G. C. (2000). High-performance concrete for sustainable constructions. Waste Management Series, 1(C), 344-354.

Jae-Myung, K., \& Hyung-Sun, K. (2004). Glass-ceramic produced from a municipal waste incinerator fly ash with high cl content. J Eur Ceram Soc, $24,2373-2382$.

Jin, M., Huang, C., Chen, L., Sun, X., \& Wang, L. (2011). Immobilization of MSWI fly ash with geopolymers. Advanced Materials Research.150-151: 1564-1569. 
Jin, M. T., Huang, C. J., \& Jin, Z. F. (2011). The physical and chemical properties of fly ash fom municipal solid wastes incineration. Advanced Materials Research. 194/196: 2065-2071

John, V. M., \& Zordan, S. E. (2000). Research development methodology for recycling residues as building materials-A proposal. Waste Management Series, , 513-524.

Juenger, M. C. G., Winnefeld, F., Provis, J. L., \& Ideker, J. H. (2011). Advances in alternative cementitious binders. Cement and Concrete Research, 41(12), 1232-1243.

K.E. Haugsten, B. G. (2000). Environmental properties of vitrified fly ash from hazardous and municipal waste incineration. Waste Management, 20, 167-176.

Kai, W., Huisheng, S., De Schutter, G., Xiaolu, G., \& Guang, Y. (2012). Experimental study on alinite ecocement clinker preparation from municipal solid waste incineration fly ash. Materials and Structures, 45, 1145-1153.

Kessler, B., Rollet, M., \& Sorrentino, F. (1992). Microstructure of cement pastes as incinerator ash host. Proceedings of the First International Symposium on Cement Industry Solution to Waste Management. Calgary. pp. 235-251.

Khare, S. K., Panday K.K., Srivastava, R. M., \& Singh, V. N. (1987). Removal of victoria blue from aqueous solution by fly ash. J. Chem. Tech. Biotech., 38, 99-104.

Klemm, W. A., \& Miller, F. M. (1997). Plausibility of delayed ettringite as a distress mechanism: Considerations at ambient and elevated temperatures. 10th. International Congress on Chemistry of Cement, Gotemburg, Sweden. , 10th. International Congress on Chemistry of Cement. 
Klemm, W., \& Siedel, H. (2002). Evaluation of the origin of sulphate compounds in building stone by sulphur isotope ratio

Kopanda, J. E., \& MacZura, G. (1987). Production process, properties, and applications for calcium aluminate cements. Calcium Aluminate Cements, Octubre, 171-183.

Kuzel, H. J., \& Baier, H. (1996). Hydration of calcium aluminate cements in the presence of calcium carbonate. Eur J Mineral, 8(Febrero), 129-141.

Lam, C. H. K. (2010). Use of incineration MSW ash: A review. Sustainability, 2(7), 1943-1968.

Lee, T., Chang, C. -., Rao, M. -., \& Su, X. -. (2011). Modified MSWI ashmix slag for use in cement concrete. Construction and Building Materials, 25(4), 1513-1520.

Lee, T., \& Li, Z. (2010). Conditioned MSWI ash-slag-mix as a replacement for cement in cement mortar. Construction and Building Materials, 24(6), 970-979.

Lima, A. T., Ottosen, L. M., \& Ribeiro, A. B. (2012). Assessing fly ash treatment: Remediation and stabilization of heavy metals. Journal of Environmental Management, 95(SUPPL.), S110-S115.

Lima, A. T., Rodrigues, P. C., \& Mexia, J. T. (2010). Heavy metal migration during electroremediation of fly ash from different wastesmodelling. Journal of Hazardous Materials, 175(1-3), 366-371.

Lin, C. F., \& Hsi, H. C. (1995). Resource recovery of waste fly ash: Synthesis of zeolite-like materials. Environ. Sci. Technol., 29, 1109-1117.

Lo, H. M., Liu, M. H., Pai, T. Y., Liu, W. F., Lin, C. Y., Wang, S. C., et al. (2009). Biostabilization assessment of MSW co-disposed with MSWI fly ash in anaerobic bioreactors. J. Hazard. Mater., 162, 1233-1242. 
Lombardi, F., Mangialardi, T., Piga, L., \& Sirini, P. (1998). Mechanical and leaching properties of cement solidified hospital solid waste incinerator fly ash. Waste Management, 18(2), 99-106.

\section{Luna Galiano, Y., Fernández Pereira, C., \& Vale, J. (2011).} Stabilization/solidification of a municipal solid waste incineration residue using fly ash-based geopolymers. Journal of Hazardous Materials, 185(1), 373-381.

Luz, A. P., \& Pandolfelli, V. C. (2012). $\mathrm{CaCO}_{3}$ addition effect on the hydration and mechanical strength evolution of calcium aluminate cement for endodontic applications. Ceramics International, 38(2), 1417-1425.

\section{Macías, A., Goñi, S., Guerrero, A., \& Fernández, E. (1999).} Immobilisation/solidification of hazardous toxic waste in cement matrices. Materiales De Contrucción, 49(254)

Mangialardi, T. (2001). Sintering of MSW fly ash for reuse as a concrete aggregate. Journal of Hazardous Materials, 87(1-3), 225-239.

Mangialardi, T. (2003). Disposal of MSWI fly ash through a combined washing-immobilisation process. Journal of Hazardous Materials, 98(1-3), 225-240.

Mangialardi, T. (2004). Effects of a washing pre-treatment of municipal solid waste incineration fly ash on the hydration behaviour and properties of ash-portland cement mixtures. Advances in Cement Research, 16(2), 4554.

Mangialardi, T., Panei, L., \& Piga, L. (2004). Cement-based immobilisation of municipal incinerator fly ash and reuse of solidified products as a construction material. Waste Management and the Environment II, pp. 35-44. 
Mangialardi, T., Paolini, A. E., Polettini, A., \& Sirini, P. (1999). Optimization of the solidification/stabilization process of MSW fly ash in cementitious matrices. Journal of Hazardous Materials, 70(1-2), 53-70.

Mata-Alvarez, J., Dosta, J., Macé, S., \& Astals, S. (2011). Codigestion of solid wastes: A review of its uses and perspectives including modeling. Critical Reviews in Biotechnology, 31(2), 99-111.

McCarthy, M. J., \& Dhir, R. K. (2005). Development of high volume fly ash cements for use in concrete construction. Fuel, 84(11), 1423-1432.

Miyake, M., Tamura, C., \& Matsuda, M. (2002). Resource recovery of waste incineration fly ash: Synthesis of zeolites A and P. J. Am. Ceram. Soc., 85, 1873-1875.

Morel, S. B., Clastres, P., \& Pellequer, A. (2001). Mineralogical, hydraulic and mechanical characterisation of solidified and stabilised MSWI fly ash: Contribution of blast furnace slag. Waste management series (pp. 260-268) Elsevier.

Mulder, E. (1996). Pre-treatment of mswi fly ash for useful application. Waste Management, 16(1-3), 181-184.

Navarro-Blasco, I., Duran, A., Sirera, R., Fernández, J. M., \& Alvarez, J. I. (2013). Solidification/stabilization of toxic metals in calcium aluminate cement matrices. Journal of Hazardous Materials, 260(0), 89-103.

Pan, J. R., Huang, C., Kuo, J. J., \& Lin, S. H. (2008). Recycling MSWI bottom and fly ash as raw materials for Portland cement. Waste Manag., 28, 1113-1118.

Pan, J. R. (2008). Recycling MSWI bottom and fly ash as raw materials for portland cement. Waste Management, 28(7), 1113-1118. 
Park, Y. J., \& Heo, J. (2002). Conversion to glass-ceramics from glasses made by MSW incinerator fly ash for recycling. Ceramics International, 28(6), 689-694.

Paul, A. (1990). Chemistry of glasses. Londres: Chapman and Hall.

Pecqueur, G., Crignon, C., \& Quénée, B. (2001). Behaviour of cementtreated MSWI bottom ash. Waste Management, Volume 1(21), 229-233.

Péra, J., \& Ambroise, J. (2004). New applications of calcium sulfoaluminate cement. Cement and Concrete Research, 34(4), 671-676.

Pera, J., Coutaz, L., Ambroise, J., \& Chababbet, M. (1997). Use of incinerator bottom ash in concrete. Cement and Concrete Research, 27(1), $1-5$.

Peysson, S., Péra, J., \& Chabannet, M. (2005). Immobilization of heavy metals by calcium sulfoaluminate cement. Cement and Concrete Research, $35(12), 2261-2270$.

Polettini, A., Pomi, R., Trinci, L., Muntoni, A., \& Lo Mastro, S. (2004). Engineering and environmental properties of thermally treated mixtures containing MSWI fly ash and low-cost additives. Chemosphere, 56(10), 901910.

Puertas, F., Fernández-Carrasco, L., Blanco-Varela, M. T., Vázquez, T., \& De La Fuente, A. (1996). Influence of $\mathrm{KOH}$ solution on the hydration and carbonation of high alumina cement mortars. Journal of Materials Science, 31(11), 2819-2827.

Qian, G. (2006). Utilization of MSWI fly ash for stabilization/solidification of industrial waste sludge. Journal of Hazardous Materials, 129(1-3), 274281.

Qian, G. R., Shi, J., Cao, Y. L., Xu, Y. F., \& Chui, P. C. (2008). Properties of MSW fly ash-calcium sulfoaluminate cement matrix and 
stabilization/solidification on heavy metals. Journal of Hazardous Materials, 152(1), 196-203.

Quenee, B., Li, G., Siwak, J. M., \& Basuyau, V. (2000). The use of MSWI (municipal solid waste incineration) bottom ash as aggregates in hydraulic concrete. Waste management series (pp. 422-437) Elsevier.

Queralt, I., Querol, X., López-Soler, A., \& Plana, F. (1997). Use of coal fly ash for ceramics: A case study for a large spanish power station. Fuel, 76(8), 787-791.

Quest, J. A., Hamernik, K. L., Engler, R., Burnam, W. L., \& FennerCrisp, P. A. (1991). Evaluation of the carcinogenic potential of pesticides: 3. aliette. Regulatory Toxicology and Pharmacology, 14(1), 3-11.

Rajamma, R., Ball, R. J., Tarelho, L. A. C., Allen, G. C., Labrincha, J. A., \& Ferreira, V. M. (2009). Characterisation and use of biomass fly ash in cement-based materials. Journal of Hazardous Materials, 172(2-3), 1049-1060.

Rashid, R. A., \& Frantz, G. C. (1992). MSW incinerator ash as aggregate in concrete and masonry. J. Mater. Civ. Eng., 4, 353-368.

Rémond, S., Bentz, D. P., \& Pimienta, P. (2002). Effects of the incorporation of municipal solid waste incineration fly ash in cement pastes and mortars - II: Modeling. Cement and Concrete Research, 32(4), 565576.

Rémond, S., Pimienta, P., \& Bentz, D. P. (2002). Effects of the incorporation of municipal solid waste incineration fly ash in cement pastes and mortars: I. experimental study. Cement and Concrete Research, 32(2), 303-311.

Ribeiro, A., Mateus, E., Lima, A. T., García Rubio, A., Vereda Alonso, C., Gómez Lahoz, C., et al. (2008). Flying ash from solid urban waste incinerators: Treatment and applications. [Cenizas volantes de 
incineradoras de residuos sólidos urbanos] Ingenieria Quimica, 40(460), 110-122.

Rincon, J. M., Romero, M., \& Boccaccini, A. R. (1999). Microstructural characterisation of a glass and a glass-ceramic obtained from municipal incinerator fly ash. J Mater Sci, 18, 4413-4423.

Rivas-Mercury, J. M., Aza Moya, Antonio H. de, Turrillas, X., \& Peña, P. (2003). Cementos de aluminatos de calcio, hidratación. Boletín De La Sociedad Española De Cerámica y Vidrio., 42(5) (Septiembre), 269-276.

Rogbeck, J., \& Knutz, A. (1996). Coal bottom ash as light fill material in construction. Waste Management, 16(1-3), 125-128.

Rokhvarger, A. E., \& Chigirinsky, L. A. (2009). In Rokhvarger A. E., Chigirinsky L. A.(Eds.), Sintered ceramic composite lead with superconductive nano-architecture (US7632784 B2 ed.)

Rosen, C. J., Bierman, P. M., \& Olson, D. (1994). Swiss chard and alfalfa responses to soils amended with municipal solid waste incinerator ash: Growth and elemental composition. J. Agric. Food Chem., 42, 13611368.

Sabbas, T., Polettini, A., Pomi, R., Astrup, T., Hjelmar, O., Mostbauer, P., et al. (2003). Management of municipal solid waste incineration residues. Waste Management, 23(1), 61-88.

Saikia, N., Kato, S., \& Kojima, T. (2007). Production of cement clinkers from municipal solid waste incineration (MSWI) fly ash. Waste Management, 27(9), 1178-1189.

Sakai, S., Sawell, S. E., Chandler, A. J., Eighmy, T. T., Kosson, D. S., Vehlow, J., et al. (1996). World trends in municipal solid waste management. Waste Manag., 16, 341-350. 
Sepulcre-Aguilar, A., \& Hernández-Olivares, F. (2010). Assessment of phase formation in lime-based mortars with added metakaolin, portland cement and sepiolite, for grouting of historic masonry. Cement and Concrete Research, 40(1), 66-76.

Shi, H., Deng, K., Yuan, F., \& Wu, K. (2009). Preparation of the savingenergy sulphoaluminate cements using MSWI fly ash. Journal of Hazardous Materials, 169(1-3), 551-555.

Shim, Y. (2003). The adsorption characteristics of heavy metals by various particle sizes of MSWI bottom ash. Waste Management, 23(9), 851-857.

Siddique, R. (2010). Utilization of municipal solid waste (MSW) ash in cement and mortar. Resources, Conservation and Recycling, 54(12), 10371047.

Singh, M., Kapur, P. C., \& Pradip. (2008). Preparation of calcium sulphoaluminate cement using fertiliser plant wastes. Journal of Hazardous Materials, 157(1), 106-113.

Sørensen, M. A., Stackpoole, M., Bender-Koch, C., Bordia, R., Benjamin, M. M., \& Christensen, T. H. (2001). Thermal treatment of iron oxide stabilized APC residues from waste incineration and the effect on heavy metal binding. Waste management series (pp. 281-286) Elsevier.

Sugrañez, R., Álvarez, J.I., Cruz-Yusta, M., Mármol, I., Morales, J. \& Sánchez, L. (2013). Controlling microstructure in cement based mortars by adjusting the particle size distribution of the raw materials. Construction and Building Materials 41, (pp. 139-145) Elsevier.

Sun, Y., Zheng, J., Zou, L., Liu, Q., Zhu, P., \& Qian, G. (2011). Reducing volatilization of heavy metals in phosphate-pretreated municipal solid waste incineration fly ash by forming pyromorphite-like minerals. Waste Management, 31(2), 325-330. 
Suryavanshi, A. K., Scantlebury, J. D., \& Lyon, S. B. (1996). Mechanism of friedel's salt formation in cements rich in tri-calcium aluminate. Cement and Concrete Research, 26(5), 717-727.

Swamy, R. N. (1994). Concrete technology: Past, present and future: Cement and Concrete Composites, 16(3), 227.

Tay, J. H. (1991). Leachate of fly ash derived from refuse incineration. Environ. Monit. Assess., 19, 157-164.

Taylor, H. F. W. (1997). In Thomas Telford L. (Ed.), Cement chemistry

Triano, J. R., \& Frantz, G. C. (1992). Durability of MSW fly-ash concrete. J. Mater. Civ. Eng., 4, 369-384.

Ukrainczyk, N., Matusinovic, T., Kurajica, S., Zimmermann, B., \& Sipusic, J. (2007). Dehydration of a layered double hydroxide $-\mathrm{C}_{2} \mathrm{AH}_{8}$. Thermochimica Acta, 464(1-2), 7-15.

Van der Sloot, H. A. (1991). Systematic leaching behaviour of trace elements from construction materials and waste materials. Studies in environmental science (pp. 19-36) Elsevier.

Van der Sloot, H. A., Kosson, D. S., \& Hjelmar, O. (2001). Characteristics, treatment and utilization of residues from municipal waste incineration. Waste Management, 21(8), 753-765.

van der Sloot, H. A. (2002). Developments in testing for environmental impact assessment. Waste Management, 22(7), 693-694.

Vedalakshmi, R., Sundara Raj, A., Srinivasan, S., \& Ganesh Babu, K. (2003). Quantification of hydrated cement products of blended cements in low and medium strength concrete using TG and DTA technique. Thermochimica Acta, 407(1-2), 49-60. 
Wang, K. -. (2002). The thermotreatment of MSW incinerator fly ash for use as an aggregate: A study of the characteristics of size-fractioning. Resources, Conservation, and Recycling, 35(3), 177-190.

Wang, L., Jin, Y., \& Nie, Y. (2010). Investigation of accelerated and natural carbonation of MSWI fly ash with a high content of ca. Journal of Hazardous Materials, 174(1-3), 334-343.

Wei, G., Liu, H. \& Zhang, S. (2011). Using of different type cement in solidification/stabilization of MSWI fly ash

Wesche, K. (1991). Fly ash in concrete: Properties and performance (Technical Committee No. 67). FAB: Use of fly ash in building: Chapman \& Hall, London.

Wu, K., Shi, H., \& Guo, X. (2011). Utilization of municipal solid waste incineration fly ash for sulfoaluminate cements clinker production. Waste Management, 31(9-10), 2001-2008.

Wu, K., Shi, H., Schutter, G. D., Guo, X., \& Ye, G. (2012). Preparation of alinite cement from municipal solid waste incineration fly ash. Cement and Concrete Composites, 34(3), 322-327.

Xiao, J., Gou, C., Jin, Y., \& Wang, Y. (2010). Effect of $\mathrm{CaCO}_{3}$ on hydration characteristics of $\mathrm{C}_{3} \mathrm{~A}$. J. Cent. South Univ. Technol., 17, 918923.

Xue, Y., Hou, H., Zhu, S., \& Zha, J. (2009). Utilization of municipal solid waste incineration ash in stone mastic asphalt mixture: Pavement performance and environmental impact. Construction and Building Materials, 23(2), 989-996.

Yang, G. C. C., \& Yang, T. Y. (1998). Synthesis of zeolites from municipal incinerator fly ash. J. Hazard. Mater., 62, 75-89. 
Yang, J., Xiao, B., \& Boccaccini, A. R. (2009). Preparation of low melting temperature glass-ceramics from municipal waste incineration fly ash. Fuel, 88, 1275-1280.

Yu, Q., Nagataki, S., Lin, J., Saeki, T., \& Hisada, M. (2005). The leachability of heavy metals in hardened fly ash cement and cementsolidified fly ash. Cement and Concrete Research, 35(6), 1056-1063.

Yvon, J., Antenucci, D., Jdid, E., Lorenzi, G., Dutre, V., Leclerq, D., et al. (2006). Long-term stability in landfills of municipal solid waste incineration fly ashes solidified/stabilized by hydraulic binders. Journal of Geochemical Exploration, 90(1-2), 143-155.

Zhang, W. (2006). Study on properties of incinerator ash as a cement admixture Journal of the Chinese Ceramic Society 34(2), 229-232.

Zornoza, E., Payá, J., \& Garcés, P. (2008). Chloride-induced corrosion of steel embedded in mortars containing fly ash and spent cracking catalyst. Corrosion Science, 50(6), 1567-1575. 